Nara Miranda Guimarães

\title{
ANÁLISE CRÍTICA DA MODELAGEM MATEMÁTICA DO PRIMEIRO ESTÁGIO DA SINTERIZAÇÃO
}

Tese apresentada à Escola Politécnica da Universidade de São Paulo para obtenção do título de Doutora em Ciências.

São Paulo

2019 


\section{NARA MIRANDA GUIMARÃES}

\section{ANÁLISE CRÍTICA DA MODELAGEM MATEMÁTICA DO PRIMEIRO ESTÁGIO DA SINTERIZAÇÃO}

Tese apresentada à Escola Politécnica da Universidade de São Paulo para obtenção do título de Doutora em Ciências.

Área de Concentração:

Engenharia de Materiais

Orientador:

Marcelo de Aquino Martorano 
Autorizo a reprodução e divulgação total ou parcial deste trabalho, por qualquer meio convencional ou eletrônico, para fins de estudo e pesquisa, desde que citada a fonte.

Este exemplar foi revisado e corrigido em relação à versão original, sob responsabilidade única do autor e com a anuência de seu orientador.

São Paulo, de de

Assinatura do autor:

Assinatura do orientador:

\section{Catalogação-na-publicação}

Guimarães, Nara Miranda

Análise crítica da modelagem matemática do primeiro estágio da sinterização / N. M. Guimarães -- versão corr. -- São Paulo, 2019.

$235 \mathrm{p}$.

Tese (Doutorado) - Escola Politécnica da Universidade de São Paulo. Departamento de Engenharia Metalúrgica e de Materiais.

1.modelagem matemática 2.sinterização 3.método do campo de fases (phase field method) 4.cobre puro I.Universidade de São Paulo. Escola Politécnica. Departamento de Engenharia Metalúrgica e de Materiais II.t. 


\section{Dedicatória}

Aos meus amados pais, Luíz Carlos Santos Guimarães e Raquel Maria Miranda Guimarães, pelo incentivo, força, paciência e dedicação que sempre tiveram comigo mesmo nos piores momentos.

À minha queridíssima avó, in memoriam, Zilda Maria Miranda Guimarães, que sempre foi um exemplo de garra, determinação, amor e fé. Devo muito a você, meu exemplo de vida.

À minha irmã, Leda Miranda Guimarães, que se mostrou um porto seguro nos momentos mais difíceis e que nunca desistiu de mim.

Ao meu orientador, Marcelo de Aquino Martorano, pela oportunidade de trabalhar com um tema tão interessante e complexo quanto a sinterização e a modelagem computacional. O senhor foi incrível do início ao fim dessa tese, agradeço muito a sua paciência, apoio, além da extrema e incansável dedicação, meu eterno obrigada. 
"Há uma força motriz mais poderosa que o vapor, a eletricidade e a energia atômica:

a vontade."

A. Einstein 


\section{AGRADECIMENTOS}

Agradeço ao meu orientador, Marcelo de Aquino Martorano por ter aceitado me orientar e por todo ensinamento e aprendizado ao longo destes anos. À você serei eternamente grata.

Agradeço à instituição de fomento à pesquisa FAPESP pela concessão da bolsa de doutorado (processo $n^{\circ}$ 2013/11421-7).

Agradeço aos meus colegas de grupo Juan Marcelo, Pierre, Allan, Hermes e Denir por compartilharem tanto conhecimento e me auxiliarem sempre que tinha dúvidas.

Em especial gostaria de agradecer aos colegas de grupo Rodrigo Ramalho Maciel que ajudou muito na paralelização do modelo do campo de fases, e Ygor Amadeo Sartori Regados pelas dicas, sugestões e ensinamentos ao longo desses anos.

Agradeço à equipe da secretaria do Departamento de Engenharia Metalúrgica e de Materiais, Vera Lúcia dos Santos, Patrícia dos Santos, Suellen Cristhine Cardozo Alves Nappi e Ivo de Macedo Gomes, pelas orientações e auxilio prestado.

Agradeço muito aos funcionários da biblioteca Departamento de Engenharia Metalúrgica e de Materiais, Clélia de Lourdes Lara Meguerditchian e Gilberto Martins, pela presteza em localizar os artigos e livros que solicitei.

Agradeço também à todos os demais colegas de Pós-Graduação do Departamento de Engenharia Metalúrgica e de Materiais pela amizade e companheirismo.

Agradeço finalmente à todos que estiveram direta ou indiretamente envolvidos nesta etapa tão importante da minha qualificação profissional. 


\section{RESUMO}

A sinterização do cobre ocorre através do transporte difusivo de matéria de regiões de alto para as de baixo potencial químico. Esse processo tem como força motriz a minimização da energia associada às interfaces. Na tentativa de quantificar o processo de sinterizaçao, diversos modelos analíticos foram desenvolvidos desde 1945.

O presente trabalho teve como intuito implementar e validar um modelo matemático baseado no modelo de campo de fases ("phase field method") para simular o primeiro estágio do processo de sinterização. Para isso, um estudo termodinâmico detalhado foi realizado de modo a definir as equações a serem empregadas no modelo. Foi feita uma análise quantitativa (análise estatística) e qualitativamente (análise gráfica e pelo expoente do tempo) dos modelos analíticos teóricos comparando-os com os valores experimentais publicados em cinco artigos de grande relevância na área.

A partir dos resultados estatísticos observou-se que o melhor mecanismo para descrever o processo de sinterização do cobre é o modelo combinado entre quatro dos seis principais modelos individuais. Os mecanismos de transporte de fase fictícia via evaporação-condensação e via difusão gasosa contribuem de maneira irrisória na sinterização do cobre, sendo por muitos autores desconsiderados.

Foi verificado que a configuração inicial do metal, se na forma de esferas ou cilindros, modifica o processo de difusão dominante. Sendo que o efeito da difusão superficial é mais predominante nas esferas do que nos cilindros, consequentemente, o mecanismo combinado para a esferas inclui a difusão superficial, enquanto que o dos cilindros não.

$\mathrm{Na}$ simulação em condições unidimensionais, o modelo foi capaz de impor as condições de equilíbrio termodinâmico local e de movimentar a interface no sentido contrário ao fluxo de lacunas. Sob condições bidimensionais, o mesmo impôs automaticamente a fração de lacunas de equilíbrio sob o efeito do raio de curvatura, responsável pela expansão ou retração do sólido/poro cilíndrico.

Na simulação da formação do pescoço entre dois cilindros de cobre puro, observou-se um comportamento qualitativo consistente com o comportamento físico. A principal dificuldade encontrada na modelagem foi o tamanho da malha e o tempo de processamento computacional necessário. Para resolução destes dois aspectos, usou-se uma malha adaptativa e foi feita a paralelização em placa de vídeo do código computacional. 


\section{ABSTRACT}

Copper sintering occurs through a diffusive transport of matter from regions with high chemical potential to regions of low chemical potential. The driving force of this process is the minimization of the energy associated with the interfaces of the system. In an attempt to quantify the sintering process, several analytical models have been developed since 1945.

The aim of the present work was to implement and validate a mathematical model based on the phase field model to simulate the first stage of sintering. A very detailed thermodynamic study was done in order to define which equations should me used in the computational model. As well as, the use of a quantitative (statistical analysis) and a qualitative analysis (graphical analysis and by the exponent of time) to compare the theoretical models with the experimental values published in five articles of great relevance in the area.

From the statistical results it was observed that the best mechanism to describe the copper sintering is the combined model between the main individual models (lattice diffusion from surface, lattice diffusion from grain boundary, surface diffusion and grain boundary diffusion). The mechanisms of gas-phase transport via evaporation-condensation and gas diffusion contribute in a negligible way in copper sintering, considered irrelevant by many authors .

It has been found that the initial configuration of the metal, whether in the form of spheres or cylinders, modifies the dominant diffusion mechanism. Since the effect of surface diffusion is more predominant in the spheres than in the cylinders, therefore the combined mechanism for the spheres includes surface diffusion, while the cylinders do not.

With the computational modeling, some important mechanisms that occur during stage I of sintering were simulated. Simulations performed under unidimensional conditions indicated that the model is able to impose local thermodynamic equilibrium conditions and to move the interface in the opposite direction of the vacancies flow. When used to simulate the transport of vacancies under two-dimensional conditions, the model automatically imposed the fraction of equilibrium vacancies under the effect of the radius of curvature. This fraction results in a flow that causes the expansion or retraction of the solid / cylindrical pore, which was reproduced by the implemented model.

The main difficulties found in the computational modeling were the size of the mesh and the computational processing time required. To solve these two aspects, an adaptive mesh was used and the parallelization of the computational code was done, which resulted in a significant reduction in the simulation time. 
Sumário

RESUMO

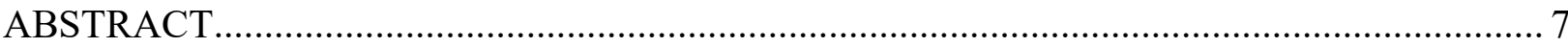

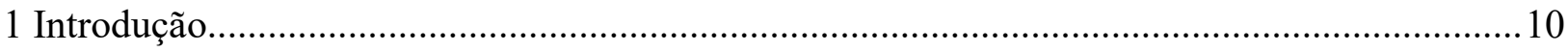

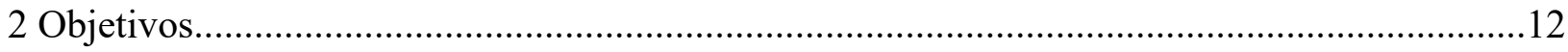

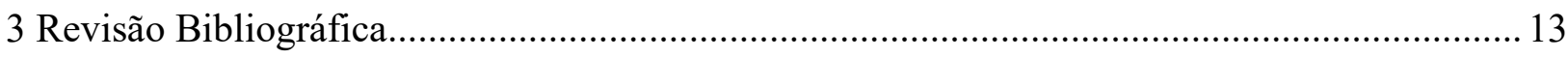

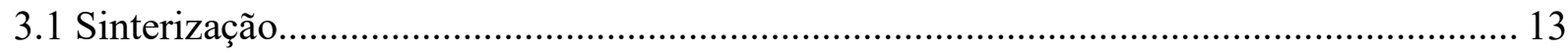

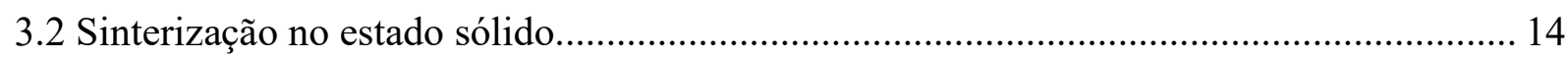

3.3 Energia de Contorno de Grão e de Superfície.................................................................. 19

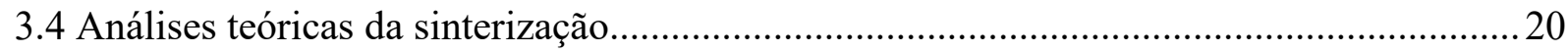

3.5 Modelos Matemáticos Analíticos do Processo de Sinterização......................................... 21

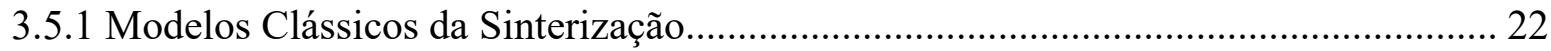

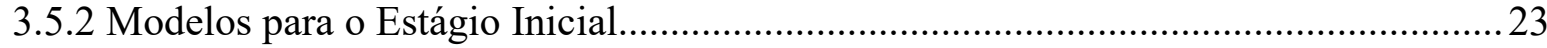

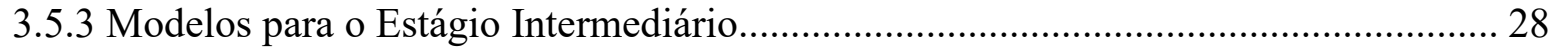

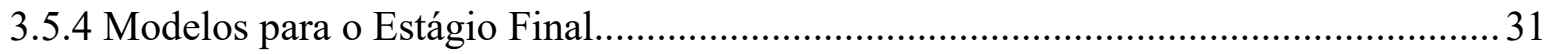

3.6 Histórico dos estudos e experimentos de sinterização para metais.................................... 34

3.7 Modelos Matemáticos Numéricos do Processo de Sinterização........................................ 41

3.8 Método do Campo de Fases ("phase-field method") na sinterização.................................43

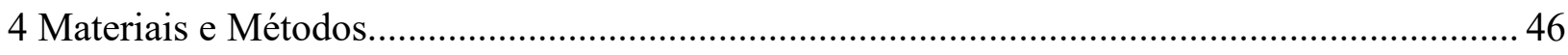

4.1 Desenvolvimento dos Modelos Analíticos do Estágio I da Sinterização........................... 46

4.1.1 Difusão pelo contorno de grão a partir do contorno de grão em esferas.......................48

4.1.2 Difusão superficial a partir da superfície das partículas em esferas...........................50

4.1.3 Difusão volumétrica a partir da superfície das partículas em esferas......................... 51

4.1.4 Difusão volumétrica a partir do contorno de grão em esferas.....................................52

4.1.5 Evaporação e condensação em esferas......................................................................53

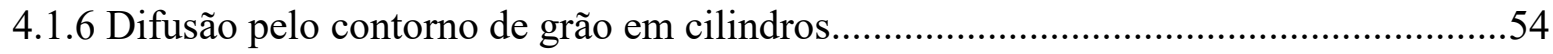

4.1.7 Difusão superficial a partir da superfície das partículas em cilindros.........................56 
4.1.8 Difusão volumétrica a partir da superfície das partícula em cilindros........................57

4.1.9 Difusão volumétrica a partir do contorno de grão em cilindros...................................58

4.1.10 Mecanismos Combinados - Equação Geral.............................................................59

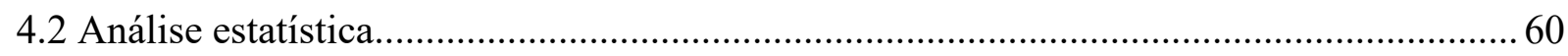

4.3 Proposta de um Modelo de Campo de Fases para a Sinterização....................................... 62

4.3.1 Aspectos Gerais e Hipóteses do Modelo de Campo de Fases....................................62

4.3.2 Descrição Termodinâmica do Sistema Modelado......................................................64

4.3.3 Desenvolvimento das equações diferenciais do modelo de campo de fases................ 72

4.3.4 Domínio de cálculo, condições de contorno e resumo das equações..........................81

4.3.5 Resolução numérica das equações do modelo de campo de fases.............................. 85

4.4 Propriedades utilizadas nos modelos analíticos e no modelo de campo de fases............. 104

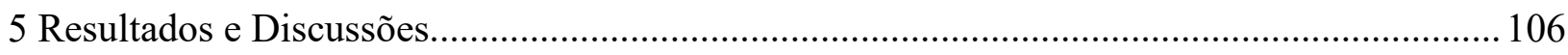

5.1 Dados experimentais da Sinterização do Cobre Puro.......................................................106

5.2 Análise Crítica dos Modelos Analíticos para a Sinterização............................................113

5.3 Aplicação do Modelo de Campo de Fases para Simular os Mecanismos do Estágio I da

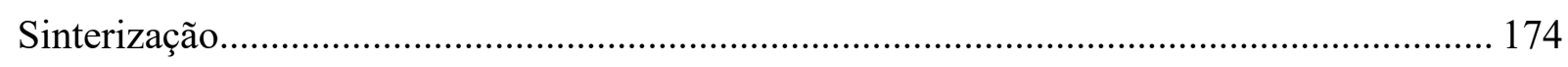

5.3.1 Efeito da Curvatura na Fração Molar de Lacunas em Equilíbrio............................... 175

5.3.2 Movimentação Unidimensional da Superfície (Interface Sólido-Fase Fictícia)........ 177

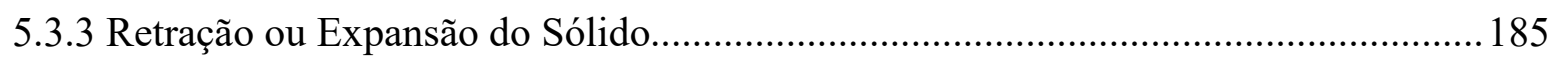

5.3.4 Crescimento ou Eliminação de Poro....................................................................... 202

5.3.5 Formação do Pescoço na Sinterização...................................................................... 211

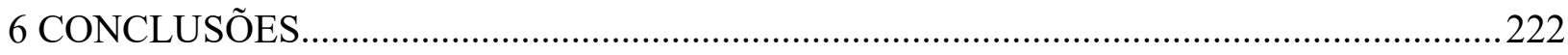

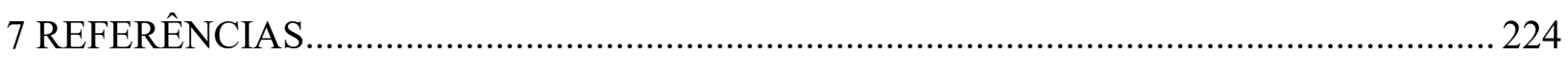




\section{Introdução}

O uso da sinterização se iniciou há aproximadamente 26.000 anos, data da descoberta dos mais antigos objetos cerâmicos em expedições arqueológicas em diferentes partes do mundo. Esse processo era denominado simplesmente de queima, com o termo sinterização empregado a partir de 1900 [GERMAN, 2013]. Os primeiros estudos dos conceitos teóricos envolvidos na sinterização foram feitos a partir de 1940 com os trabalhos publicados por Frenkel [FRENKEL, 1945]. A partir de então, muitos estudos e modelos foram apresentados para descrever o processo, nos quais se destacam os trabalhos de Kuczynski [KUCZYNSKI, 1949], Kingery e Berg [KINGERY, BERG, 1955], Coble [COBLE, 1958] e, Johnson e Cutler [JOHNSON, CUTLER, 1963].

A principal desvantagem destes modelos clássicos analíticos é que os mesmos tiveram como base o modelo geométrico idealizado de duas esferas de mesmo tamanho [RAHAMAN, 2007], além de considerarem que apenas um mecanismo responsável pela sinterização estivesse ativo, não havendo a possibilidade da operação simultânea entre mais de um mecanismo [KANG, 2005; RAHAMAN, 2007; KUMAR, 2011]. Em sistemas reais as partículas apresentam tamanhos variados, o que motivou a proposta de outros modelos, como os de Coble [COBLE, 1973] e Lange e Kellet [KELLET, LANGE, 1989]. Contudo, estes modelos ainda apresentam limitações e não descrevem simultaneamente alguns processos envolvidos na sinterização, como o surgimento e crescimento do pescoço, o crescimento dos grãos e a rápida movimentação e migração dos contornos dos grãos [KUMAR, 2011].

Para tentar solucionar os problemas identificados nos modelos analíticos, modelos numéricos foram propostos com o objetivo de simular mais mecanismos e descrever o processo de sinterização de forma mais realista [RAHAMAN, 2007]. Um dos métodos promissores para a simulação do processo de sinterização é o método do campo de fases ("phase field method"). Apesar de existirem algumas poucas propostas de modelos para sinterização baseados neste método [KRILL III, CHEN, 2002; MOELANS, et. al., 2005; ASP, AGREN, 2006; WANG, 2006; KUMAR, et. al., 2010; LIU, et. al., 2011; SUWA, 2013], os dados de entrada do modelo foram muitas vezes arbitrários e imprecisos, sem relação como algum sistema real. Como exemplo de dados de entrada importantes, pode-se citar a geometria dos grãos, propriedades de transporte dos elementos envolvidos como: o coeficiente de difusão de lacunas e as propriedades termodinâmicas do sistema. Até o momento, não há simulações numéricas que correlacionem 
propriedades termodinâmicas e cinéticas com sistemas reais, que permitam compreender, identificar, avaliar e mensurar o efeito dos mecanismos de sinterização ao longo do processo. 


\section{Objetivos}

O primeiro objetivo específico do presente trabalho é analisar criticamente, por meio de ferramentas estatísticas, os modelos matemáticos analíticos propostos para o estágio I da sinterização a partir da comparação com resultados experimentais confiáveis obtidos de cinco trabalhos distintos. Um segundo objetivo é desenvolver, implementar e analisar um modelo matemático, baseado no método de campo de fases ("phase-field method") e nas equações termodinâmicas de energia livre das fases presentes, de modo a simular os diversos mecanismos importantes que ocorrem no estágio I da sinterização. 


\section{Revisão Bibliográfica}

\subsection{Sinterização}

A sinterização é um processo termicamente ativado para consolidação de um corpo conformado a partir de um pó [JONGHE, RAHAMAN, 2003]. O pó, que pode ser cristalino ou amorfo, metálico, cerâmico ou polimérico, será transformado em um sólido coeso, com redução e/ou eliminação dos poros presentes entre as partículas iniciais, acompanhado de uma retração volumétrica e intensa aproximação entre as partículas, seguido pelo crescimento dos grãos [SHAW, 1989a; GERMAN, 1991; KANG, 2005].

O mecanismo de sinterização foi historicamente definido com base nos modelos cujos conceitos de organização abordavam a dimensão discreta das partículas, ou seja, o produto da sinterização é resultado do processo de adesão entre as partículas sendo seu crescimento promovido pelo contato e coalêscencia entre as mesmas, apresentando, apenas, interações cinéticas locais [OLEVSKY, 1998].

Para que o fenômeno ocorra, é necessário que haja a redução na energia livre superficial e interfacial do sistema. A força motriz para esta diminuição é a redução na curvatura das superfícies livres, substituindo as interfaces sólido-vapor por interfaces sólido-sólido. [SHI, 1999; JONGHE, RAHAMAN, 2003; RAHAMAN, 2007].

O processo de sinterização pode ser dividido em diferentes tipos, como sinterização no estado sólido, sinterização por fase líquida, sinterização via liquido transiente ou sinterização por fluxo viscoso. A principal diferença entre esses tipos é quanto ao estado físico do material na temperatura de sinterização [KANG, 2005].

Existem algumas variáveis muito importantes que determinam a eficiência da sinterização, assim como a microestrutura final. Essas dividem-se em variáveis relacionadas ao material, tais como composição química, tamanho, formato e distribuição das partículas, e seu grau de compactação; e ao processo, como temperatura, tempo, pressão, composição atmosférica e taxa de aquecimento ou resfriamento [KANG, 2005; RAHAMAN, 2007]. O entendimento e controle do processo permite a obtenção de propriedades desejadas para a estrutura final a partir de determinadas matérias-primas e condições de processamento.

Devido as inúmeras variáveis associadas ao processo de sinterização, este processo complexo intriga muitos pesquisadores da área. 


\subsection{Sinterização no estado sólido}

A sinterização de materiais, policristalinos ou não, ocorre através do transporte difusivo de matéria de regiões com elevado potencial químico para regiões de baixo potencial químico [RAHAMAN, 2007]. Esse processo tem como força motriz a minimização da energia associada às interfaces presentes no sistema, que pode acontecer através do crescimento de grão, que resulta na redução da área superficial, caracterizada por interfaces sólido-fase fictícia, e dos contornos de grão, com interfaces sólido-sólido; ou através da densificação, que resulta na substituição da área superficial pela área de contorno de grão, como apresentado na Figura 1. Quando corretamente controlados, estes processos podem resultar em materiais com a densidade e porosidade desejadas [GOUVÊA; CASTRO, 2003].

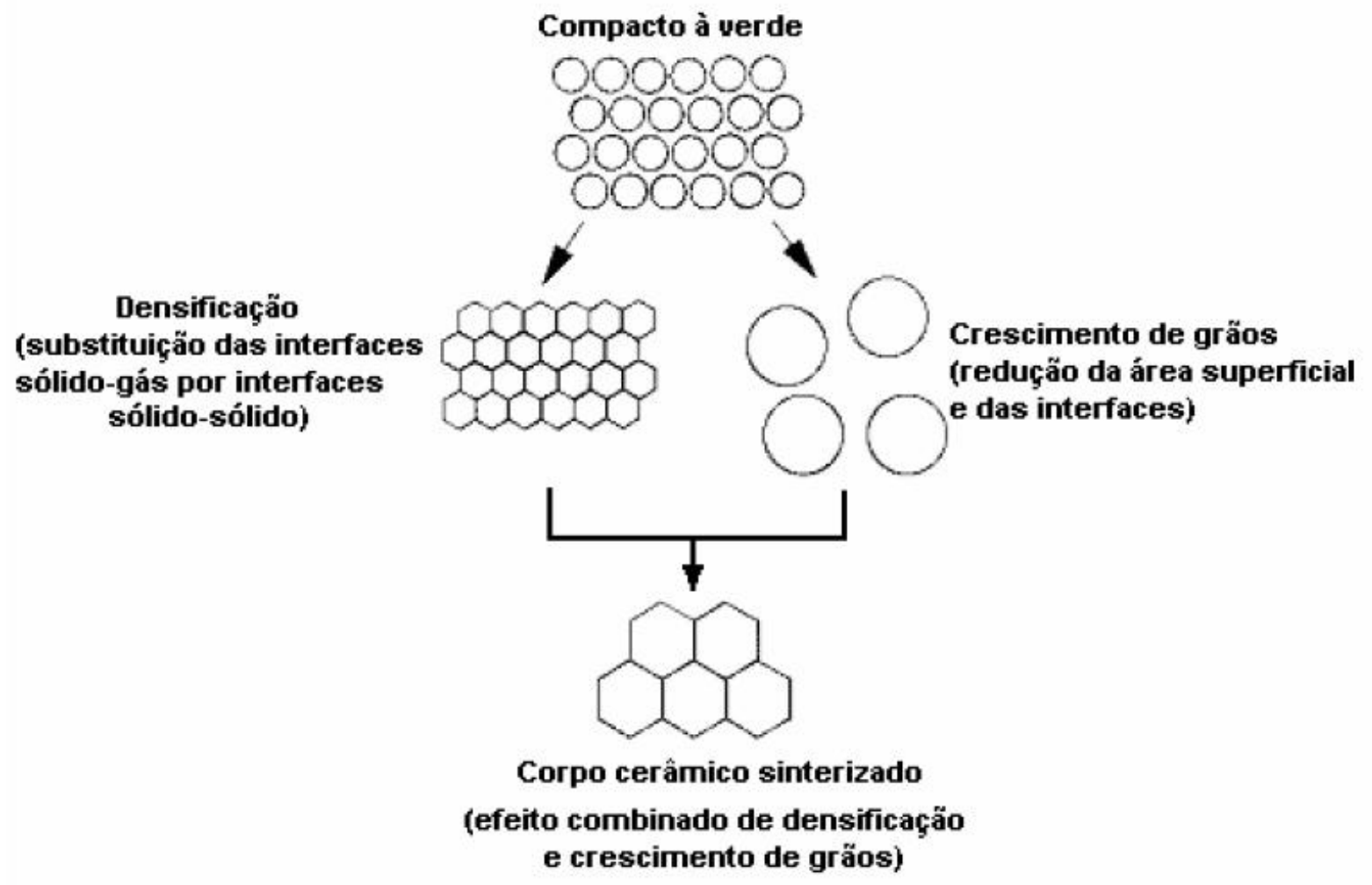

Figura 1: Desenho esquemático dos fenômenos de densificação e crescimento observados durante um processo de sinterização [SHAW, 1989a].

A maioria dos trabalhos da literatura, como os de Achari (1987), Silva (1998), Shimosaka et.al. (2003) e Silva (2009) abordam o processo de sinterização através dos conceitos simplificados propostos por Coble (1961). Segundo estes conceitos, a sinterização está relacionada apenas ao processo de eliminação das interfaces sólido-fase fictícia para minimizar a energia livre total do sistema. Neste caso, o mecanismo proposto para explicar o processo de eliminação da área interfacial é a migração de matéria sólida das regiões de interface com maior 
curvatura para as regiões de menor curvatura, desprezando-se o efeito da energia associada aos contornos de grão que se formam durante o processo. Esta teoria, entretanto, é incapaz de explicar diversos resultados experimentais, como a possibilidade de haver crescimento de grão sem densificação [GOUVÊA; CASTRO, 2003].

A teoria tradicional de sinterização de duas esferas em contato ou de uma esfera e uma superfície do mesmo material ajusta-se muito bem para metais, que apresentam ligações químicas não-direcionais, ausência de cargas elétricas e sistemas cristalinos simples, resultando em energias de contorno de grão por unidade de área relativamente baixas e, portanto, sem efeito significativo no processo de sinterização.

Durante a sinterização, um sistema de partículas adquire uma estrutura sólida coesa através da redução da área superficial, com surgimento de contornos de grão e formação dos pescoços. Pelas teorias aceitas, considera-se que a sinterização ocorre através de um fluxo de difusão de átomos e lacunas induzido por diferenças de concentração e pressão entre as regiões da interface com diferentes curvaturas. Há uma transferência de material das regiões convexas para as regiões côncavas, com maiores concentrações de lacunas, resultando assim na formação do pescoço entre as partículas e no preenchimento das regiões interpartículas (poros), como mostra a Figura 2 [LEE; RAINFORTH, 1994].
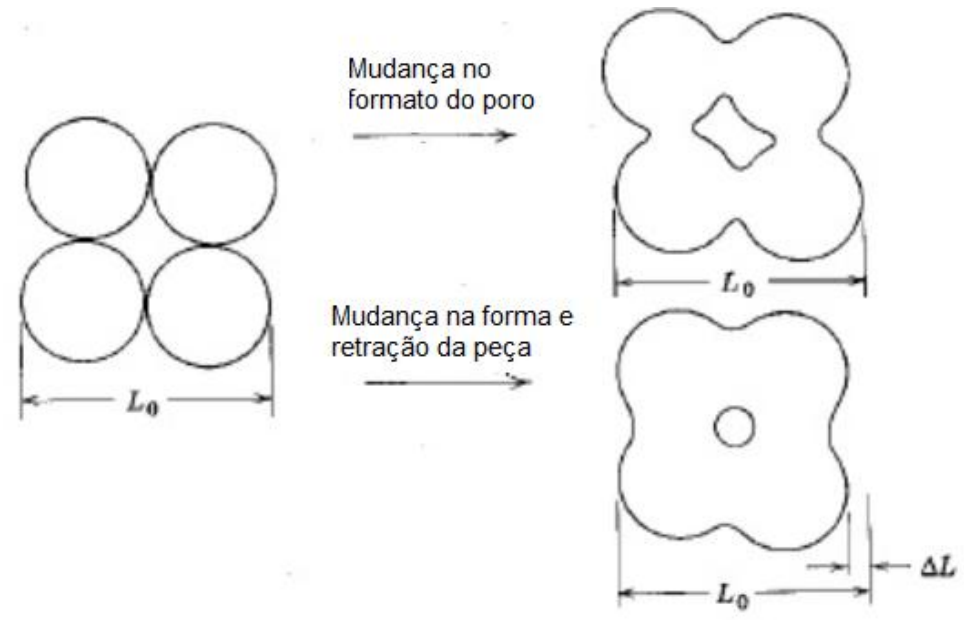

Figura 2: Representação esquemática dos processos que ocorrem ao longo da sinterização [LEE; RAINFORTH, $1994]$.

O processo de sinterização é tradicionalmente dividido em três estágios que podem ser identificados tanto no modelo de duas esferas proposto por Coble [COBLE, 1961] apresentado na Figura 3, como também em um conjunto de partículas, Figura 4. No estágio inicial, as partículas se atraem por forças interatômicas e, com aumento da temperatura, há a ativação dos mecanismos de transporte de massa por difusão no sólido, transporte de vapor, fluxos plásticos e 
viscosos [RAHAMAN, 2007], com o rearranjo das partículas dado pelo estabelecimento do pescoço nos pontos de contato. Neste estágio, os mecanismos da sinterização que conduzem à densificação são aqueles onde a fonte de matéria transferida para a região de pescoço não tem origem na superfície, como difusão pelo contorno de grão e difusão volumétrica a partir do contorno de grão, porém a densificação limita-se a 3-5\% da densificação total do material.

No estágio intermediário, os poros atingem suas formas de equilíbrio pelas tensões superficial e interfacial, com alongamento do pescoço estabelecido entre as partículas e formação de poros esféricos e desconectados. Há aumento no tamanho dos contatos entre as partículas, com eliminação da maior parte da porosidade, com retração da peça e densificação de aproximadamente $90 \%$ do valor teórico.

O estágio final se inicia quando os poros se tornam desconectados. Nesta etapa, os contornos de grão migram para o interior do grão, minimizando a energia total associada aos mesmos. Com isso, há o crescimento dos grãos e os poros remanescentes ficam aprisionados no interior dos grãos, o que ocasiona uma redução da densificação final devido a lenta e difícil eliminação dos desses poros.

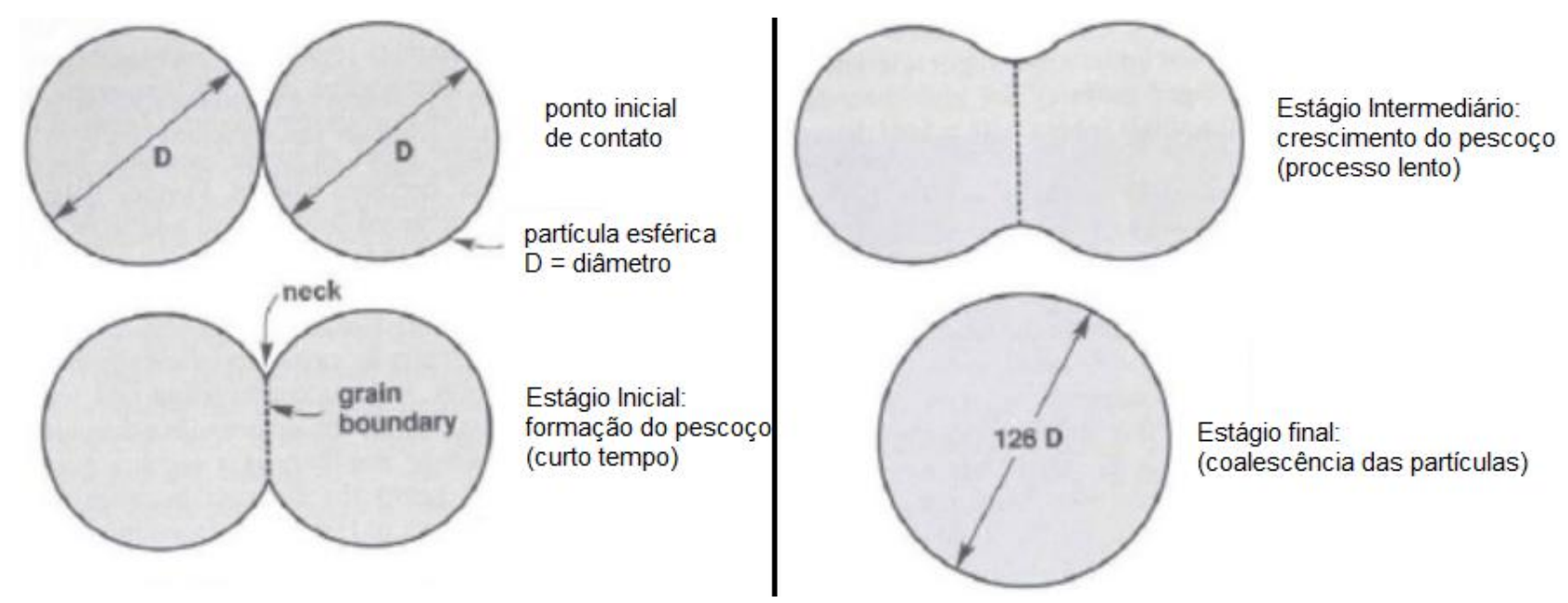

Figura 3: Representação esquemática do modelo de sinterização para duas esferas identificando seus principais estágios. [LEE; RAINFORTH, 1994] 

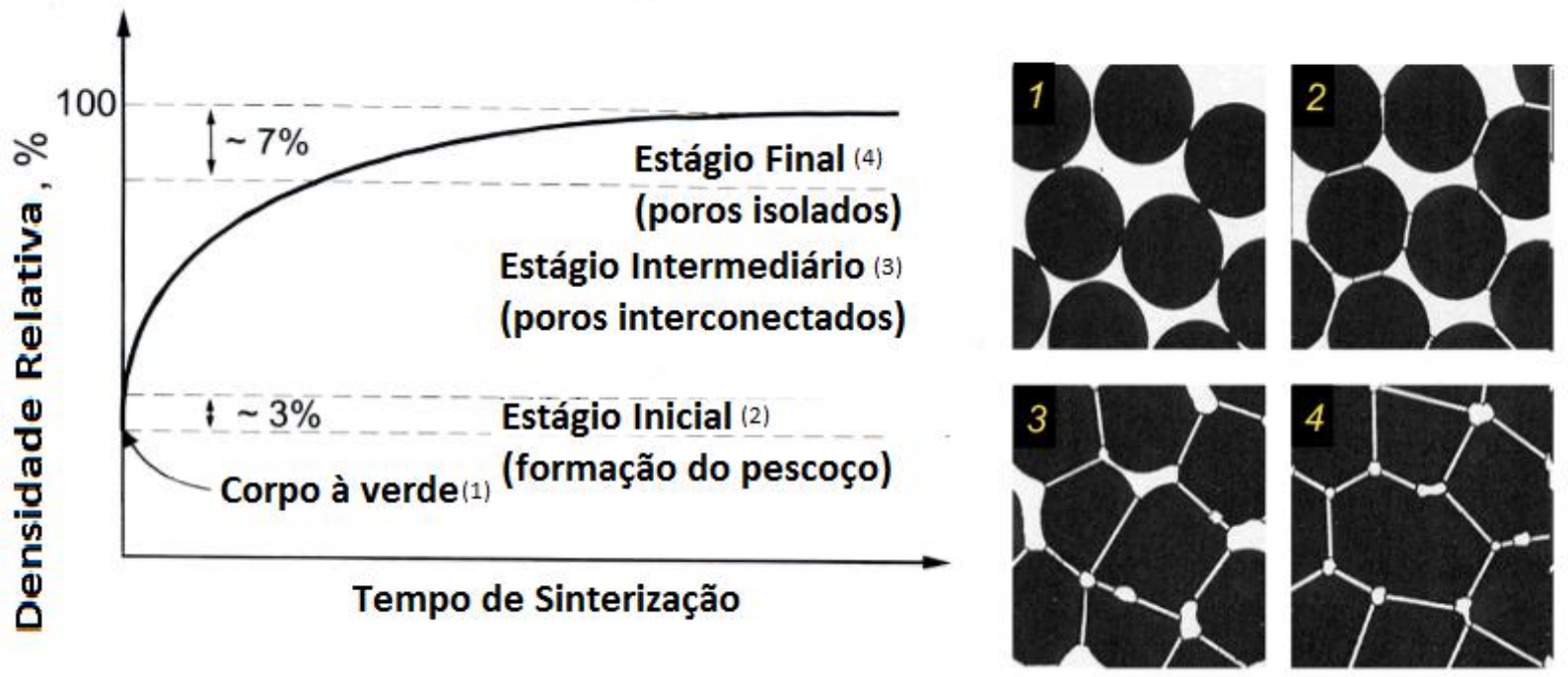

Figura 4: Gráfico representativo da evolução na densificação do material com o tempo de sinterização, identificando os estágios envolvidos desse processo. As microestruturas correspondentes podem ser identificadas ao lado, adaptado de Kang [KANG, 2005].

Os mecanismos de transporte de matéria são aqueles pelos quais ocorrem fluxo de átomos em resposta ao potencial termodinâmico de sinterização, ou seja, a redução de energia livre do sistema associada às superfícies das esferas [GERMAN, 1996]. Existem pelo menos seis mecanismos de transporte de massa envolvidos durante o processo de sinterização, ilustrados na Tabela 1 e na Figura 5. Todos os mecanismos levam à aproximação e ao crescimento do pescoço entre as partículas, alterando as propriedades mecânicas do compacto ao longo do processo de sinterização. Os mecanismos são classificados como densificantes, como difusão pelo contorno de grão e difusão volumétrica a partir do contorno de grão, e os não-densificantes, como difusão superficial, difusão volumétrica a partir da superfície e transporte da fase fictícia [RAHAMAN, 2007]. Apesar dos mecanismos não-densificantes promoverem apenas o crescimento do pescoço, eles são responsáveis pela redução na curvatura superficial do pescoço, consequentemente à redução na taxa de densificação [RAHAMAN, 2003; RAHAMAN, 2007].

A quantidade de material transportada ao longo de cada um dos seis percursos propostos na Figura 5 influi na taxa de crescimento do pescoço durante o estágio inicial. Esta quantidade depende do coeficiente de difusão e da extensão de área correspondente a cada percurso, podendo variar ao longo da sinterização, alterando a contribuição de cada mecanismo para o crescimento do pescoço ao longo do tempo. Como o coeficiente de difusão aumenta com a temperatura, um acréscimo na velocidade de aquecimento aumenta o transporte de material. Quando o transporte de matéria ocorre por difusão através do interior do grão e dos contornos de 
grãos, o material é retirado do interior das partículas e depositado no pescoço, causando a aproximação dos centros das partículas e a consequente contração do sistema.

Tabela 1: Mecanismos de transporte de massa e a forças motrizes associadas [LEE; RAINFORTH, 1994]

\begin{tabular}{|c|c|c|c|c|}
\hline & Transporte & Origem & Destino & Densificação \\
\hline (1) & Difusão superficial & Superfície & Pescoço & Não \\
\hline (2) & Difusão volumétrica & Superfície & Pescoço & Não \\
\hline (3) & $\begin{array}{l}\text { Transporte da fase fictícia via evaporação- } \\
\text { condensação ou difusão gasosa }\end{array}$ & Superfície & Pescoço & Não \\
\hline (4) & Difusão pelo contorno de grão & $\begin{array}{l}\text { Contorno de } \\
\text { grão }\end{array}$ & Pescoço & Sim \\
\hline$(5)$ & Difusão volumétrica & $\begin{array}{l}\text { Contorno de } \\
\text { grão }\end{array}$ & Pescoço & Sim \\
\hline (6) & Fluxo viscoso & Discordância & Pescoço & $\operatorname{Sim}$ \\
\hline
\end{tabular}

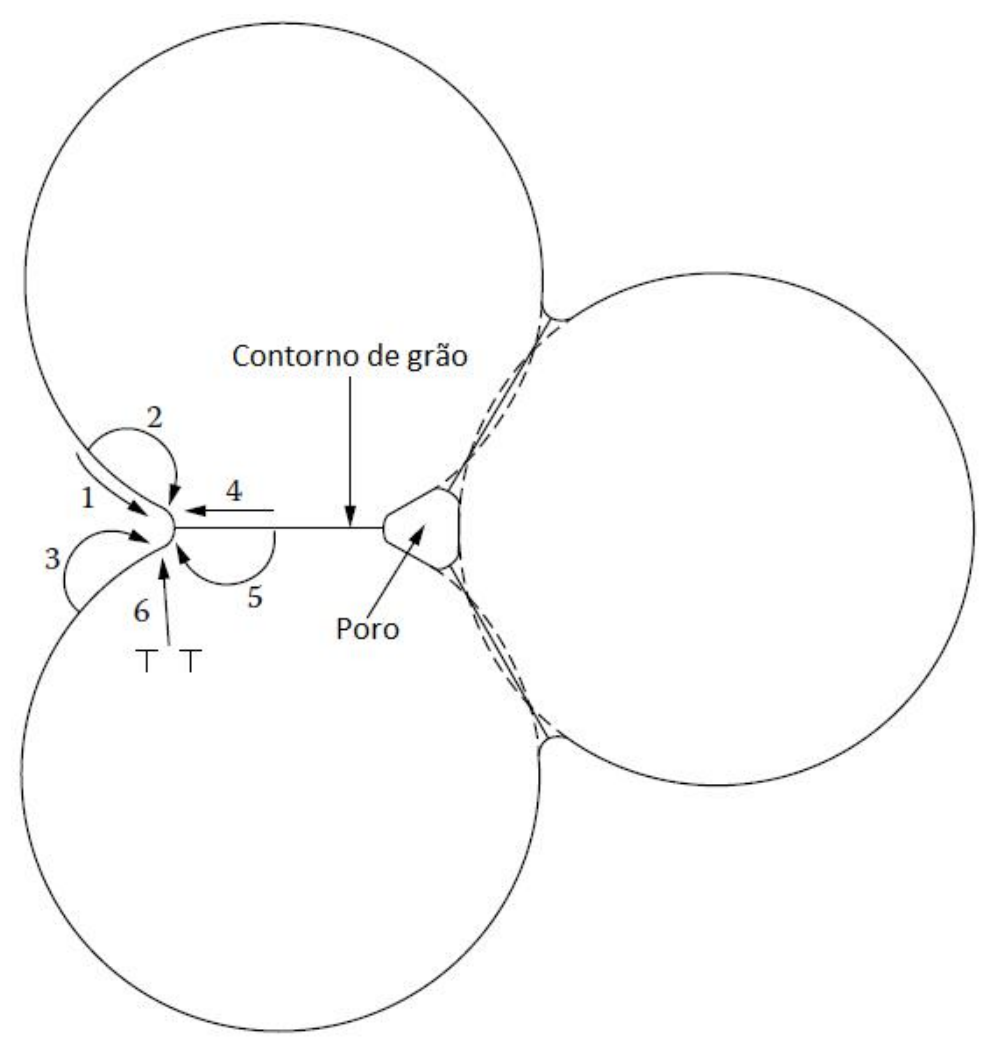

Figura 5: Mecanismos de transporte de massa durante a sinterização. Apenas os mecanismos (4)-(6) promovem a densificação, mas todos os mecanismos influenciam o crescimento do pescoço, ligado diretamente com a taxa de densificação. [KANG, 2005; RAHAMAN, 2008] 


\subsection{Energia de Contorno de Grão e de Superfície}

Os contornos de grão podem ser definidos como interfaces que separam dois cristais com diferentes orientações em um agregado policristalino. Alguns modelos, como o de Rosenhain e Ewen [ROSENHAIN, EWEN, 1912] e de Fisher [FISHER, 1951], tentam descrever os contornos de grão, mas o conhecimento desta estrutura da fronteira entre grãos ainda é bastante limitado, principalmente para materiais iônico-covalentes. O excesso de energia nesta interface decorre de fatores como a existência de diferentes orientações cristalográficas entre os grãos, presença das cargas elétricas, presença de defeitos cristalinos, composição química, segregação de contaminantes, coordenação de íons e o tipo de ligação química. A Tabela 2 apresenta algumas energias de contorno de grão associadas a diferentes materiais.

Tabela 2: Energia de contorno de grão e energia de superfície por unidade de área em materiais de engenharia

\begin{tabular}{|c|c|c|}
\hline Material & $\begin{array}{c}\text { Energia de Contorno de } \\
\text { Grão }\left(\mathrm{mJ} / \mathrm{m}^{2}\right)\end{array}$ & $\begin{array}{c}\text { Energia de Superfície } \\
\qquad\left(\mathrm{mJ} / \mathbf{m}^{2}\right)\end{array}$ \\
\hline Cobre & 530 & 1720 \\
\hline Alumínio & 600 & 1100 \\
\hline Ouro & 400 & 1400 \\
\hline Ferro (CCC) & 800 & 2100 \\
\hline Ferro (CFC) & 790 & 2200 \\
\hline Platina & 780 & 2100 \\
\hline Tungstênio & 1070 & 2800 \\
\hline Alumina $\left(\mathrm{Al}_{2} \mathrm{O}_{3}\right)$ & 1900 & 2500 a 3000 \\
\hline 8YSZ & $1108\left(25^{\circ} \mathrm{C}\right)$ & $1800\left(25^{\circ} \mathrm{C}\right)$ \\
\hline $\mathrm{ZrO}_{2}$ cúbica & $380\left(1220^{\circ} \mathrm{C}\right)$ & $1300\left(25^{\circ} \mathrm{C}\right)$ \\
\hline
\end{tabular}

A energia dos contornos de grão e a energia da superfície dos grãos compõem a chamada energia interfacial total [CASTRO, 2013]. Nas superfícies livres dos grãos, os processos de adsorção de gases e as ligações rompidas ou incompletas geralmente resultam em uma energia da superfície maior do que a energia do contorno de grão, como mostrado na Tabela 2. A energia média de contorno de grão é cerca de 45 a $75 \%$ da energia de superfície do material. Apesar dessa diferença de valores, as energias de contorno de grão não podem ser desprezadas, uma vez que influenciam na somatória da energia total e na estabilidade termodinâmica do sistema. 
[KELLETT; LANGE, 1989; GOUVÊA, 2004; LANGE, 2008; WAKAI; BRAKKE, 2011; CASTRO, 2013]

\subsection{Análises teóricas da sinterização}

O desenvolvimento dos modelos analíticos foi a primeira tentativa real de quantificação do processo de sinterização, iniciado por Frenkel em 1945 e por Kuczynski em 1949 [FRENKEL, 1945; KUCZYNSKI, 1949]. Mesmo assumindo uma geometria simples e ideal, exclusiva a um único mecanismo de sinterização por equação, estes modelos foram os responsáveis por fundamentar as bases para compreensão atual do processo de sinterização [RAHAMAN, 2007].

Uma outra maneira de avaliar o mecanismo operante é através da lei de escala (scaling law), formulada por Herring [HERRING, 1950], a qual relaciona a dependência do tamanho da partícula com o mecanismo de sinterização dominante e sua taxa.

As simulações numéricas oferecem um método poderoso para elucidar muitas das complexidades da sinterização. Estas simulações requerem métodos numéricos avançados e permitem uma visão do transporte de matéria pelo sistema, assim como analisam a variação de geometria com o tempo e podem identificar os mecanismos presentes [RAHAMAN, 2007].

Um outro modelo também disponível, limitado quanto a cinética de sinterização e mais adequado para compreensão da evolução da microestrutura, denomina-se modelo topológico ou topological model, o qual analisa as variações morfológicas com o tempo.

Os modelos estatísticos têm recebido pouca atenção desde sua origem com Kuczynski em 1976 [KUCZYNSKI, 1976].

Equações fenomenológicas são empregadas para ajustar os dados de sinterização sem, porém, acrescentar qualquer esclarecimento ao processo em si [RHINES, DEHOFF, 1984].

Os mapas de sinterização mostram as variações no comportamento e no mecanismo da sinterização sob diferentes condições de temperatura e tamanho de partícula. Como os mapas são baseados em previsões dos modelos analíticos, eles possuem algumas limitações.

A Tabela 3 apresenta um resumo das principais abordagens empregadas na análise teórica da sinterização. 
Tabela 3: Principais abordagens empregadas na análise teórica da sinterização [RAHAMAN, 2007].

\begin{tabular}{|c|c|c|}
\hline Abordagem & Característica & Referencias \\
\hline Lei de Escala & $\begin{array}{c}\text { Independente da geometria. Efeito da } \\
\text { variação da escala sobre a taxa de um único } \\
\text { mecanismo }\end{array}$ & Herring, 1950 \\
\hline Modelos Analíticos & $\begin{array}{l}\text { Geometria simplificada. Equações } \\
\text { descrevem a dependência da taxa de } \\
\text { sinterização para cada mecanismo } \\
\text { separadamente. }\end{array}$ & $\begin{array}{l}\text { Frenkel, 1945; } \\
\text { Kuczynski, 1949; } \\
\text { Kingery, Berg, 1955; } \\
\text { Coble, 1958; } \\
\text { Coble, 1961; } \\
\text { Johnson, Cutler, } 1963\end{array}$ \\
\hline Simulações Numéricas & $\begin{array}{c}\text { Equações para transporte de massa } \\
\text { solucionadas numericamente. Geometria } \\
\text { complexa e análise dos mecanismos } \\
\text { concorrentes. }\end{array}$ & $\begin{array}{l}\text { Chen, et al., 1990; } \\
\text { Fan, Chen, 1997; } \\
\text { Kazaryan, et al, 1999; } \\
\text { Longinova, 2003; } \\
\text { Wang, 2006; } \\
\text { Kumar, et al., 2010; } \\
\text { Nikolic, 2012 }\end{array}$ \\
\hline $\begin{array}{l}\text { Modelos Topológicos ou } \\
\text { Topological Models }\end{array}$ & $\begin{array}{c}\text { Análise de variações morfológicas. Previsões } \\
\text { de limites cinéticos. Mais adequado para } \\
\text { evolução microestrutural. }\end{array}$ & Rhines, DeHoff, 1984 \\
\hline Modelos Estatísticos & $\begin{array}{l}\text { Geometria simplificada. Análise semi- } \\
\text { empírica. }\end{array}$ & Kuczynski, 1976 \\
\hline Equações Fenomenológicas & $\begin{array}{l}\text { Derivação empírica ou fenomenológica das } \\
\text { equações para descrição dos dados da } \\
\text { sinterização. Sem base física razoável. }\end{array}$ & $\begin{array}{c}\text { Tikkanen, Makipirtti, } \\
1965\end{array}$ \\
\hline
\end{tabular}

\subsection{Modelos Matemáticos Analíticos do Processo de Sinterização}

Vários modelos analíticos foram propostos para estudar e descrever a cinética de sinterização, mas esses consideram microestruturas simplificadas e idealizadas para cada um dos estágios existentes. Para o estágio inicial emprega-se o modelo de duas esferas em contato, no estágio intermediário, estruturas tetradodecaédricas, e para o estágio final, grãos tetradodecaédricos com poros isolados nos contornos de grão [RAHAMAN, 2007; KUMAR, 2011]. Como as geometrias das partículas e dos poros variam durante a sinterização, não se pode formular uma única geometria, o que dificulta encontrar um modelo geral capaz de descrever com precisão o processo como um todo, sendo necessário dividi-lo em etapas ou estágios, os quais serão caracterizados por diferentes geometrias que representem o sistema real. Desta forma, o processo 
de sinterização foi conceitualmente dividido em três estágios de modo a evitar problemas de geometrias idealizadas [RAHMAN, 2007]. Uma revisão sobre os principais modelos matemáticos analíticos para cada um destes estágios é apresentada a seguir.

\subsubsection{Modelos Clássicos da Sinterização}

O primeiro modelo físico para o processo de sinterização foi proposto por Frenkel em 1945 [RISTIC, MILOSEVIC, 2006], no qual ele mostrava que, sob a influência de tensões superficiais, materiais cristalinos podiam apresentar fluxo viscoso newtoniano da mesma forma que materiais amorfos. Estabeleceu-se que este fluxo ocorria pela existência de um mecanismo de difusão representado pelo transporte direto de um número relativamente baixo de lacunas localizadas ao longo das posições atômicas da rede cristalina, este número porém, aumenta com a temperatura.

Frenkel postulou que a sinterização ocorre em duas etapas: na primeira, representada pela aproximação de duas partículas, compactação das mesmas, aumento da superfície de contato e formação dos poros. No segundo estágio, representado pela área de encontro entre as partículas ao longo do círculo de raio $Y(t)$, visto na Figura 6, os poros têm seu volume total reduzido devido à difusão do sólido ao longo das regiões do contorno de grão.

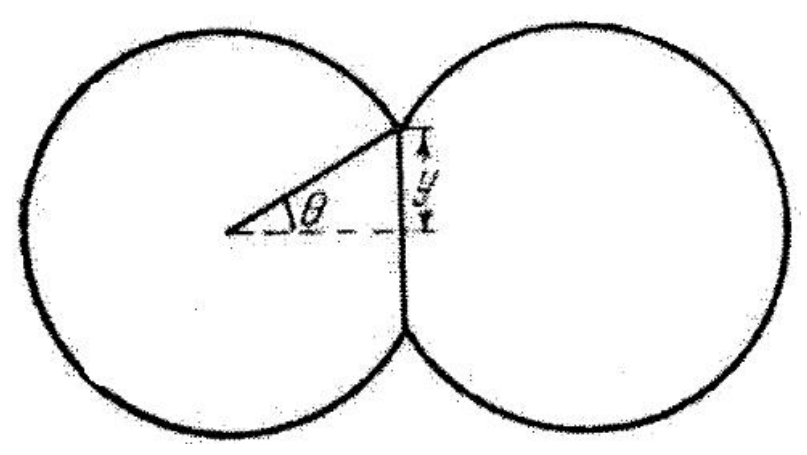

Figura 6: Modelo de Frenkel.

onde $\theta$ é o ângulo formato entre o centro da partícula e o ponto de formação do pescoço, e $y$ é o raio do pescoço.

Frenkel estabeleceu uma fórmula para o raio do pescoço, assumindo que as partículas mantenham a forma esférica com o tempo:

$$
Y(t)=a \cdot \operatorname{sen} \theta
$$

sendo $a$ o raio da partícula esférica, determinado pela condição do volume constante dada por:

$$
\frac{\pi}{3} a^{3}\left(2+\cos \theta-\cos ^{3} \theta\right)=\frac{(4 \pi)}{3} a_{0}^{3}
$$


onde $a_{0}$ é o valor do raio inicial. O decréscimo da área superficial das partículas é igual à:

$$
S_{0}=S+8 \pi a^{2}(1+\cos \theta)
$$

onde $S_{0}$ é a área superficial inicial da partícula e $S$ é a área superficial final.

Limitando o ângulo $\theta$ a valores pequenos, pode-se aproximar a Equação 3 para:

$$
S_{0}=S+2 \pi a^{2} \theta^{2}
$$

As teorias de Frenkel [FRENKEL, 1945] para a sinterização se basearam em sua compreensão sobre transferência de massa no estado sólido. A partir desta teoria, muitos outros modelos foram propostos com base no transporte de massa para materiais cristalinos baseados em arranjos geométricos do tipo esferas adjacentes. Estes modelos ficaram conhecidos como "modelos clássicos da sinterização".

Ao desenvolver a ideia do modelo de Frenkel, Pines [PINES, 1946; RISTIC, MILOSEVIC, 2006; RISTIC, NIKOLIC, 2006] concluiu que a cinética do processo poderia ser definida pela relação:

$$
\frac{d a}{d t}=-\frac{2 \sigma}{a^{2}} \cdot \frac{\varphi^{2}}{k T} D
$$

sendo $\varphi$ uma constante da rede cristalina; $D$ a constante de autodifusão do material; e $k$ a constante de Boltzmann.

A principal diferença entre as teorias de Pines e Frenkel, é que Pines visualizava a sinterização como sendo o preenchimento dos vazios por átomos, enquanto Frenkel previu que o preenchimento destes espaços era dado pelo lento fluxo viscoso de matéria no cristal. As conclusões chegadas por Pines são de natureza exclusivamente qualitativa, não apresentando comprovações experimentais [KUCZYNSKI, 1949].

\subsubsection{Modelos para o Estágio Inicial}

Desde os primeiros estudos publicados por Frenkel, o estágio inicial da sinterização tem sido o foco para compreensão e formulação de teorias e equações matemáticas analíticas representativas da cinética do transporte de material pelo tempo. Neste estágio, pode ocorrer tanto a formação do pescoço quanto a aproximação dos centros das partículas, ou ambos. A formação do pescoço nos metais é puramente elástica, e sua deformação é dependente da energia superficial das partículas metálicas, do módulo de elasticidade e da geometria de contato. Com 
isso, não somente fatores geométricos influenciam na formulação dos modelos, mas também os aspectos termodinâmicos do sistema são essenciais e determinantes nos cálculos.

A partir das teorias formuladas por Frenkel e Pines, outros estudos sobre a sinterização foram desenvolvidos, aprimorando a compreensão deste processo. Com isso, o conceito de fluxo viscoso, inicialmente estabelecido, foi desconsiderado, uma vez que materiais sólidos seguem a teoria da plasticidade [EXNER, ARZT, 1990].

Os modelos para o estágio inicial foram propostos primeiramente por Kingery e Berg [KINGERY, BERG, 1955]. Eles partiram de uma microestrutura ideal de duas partículas esféricas em contato, denominado modelo de duas esferas, para descrever a formação do pescoço durante este estágio [KUMAR, 2011].

O pescoço se forma logo no início da sinterização e se prolonga até aproximadamente 40$50 \%$ do tamanho da partícula [RAHMAN, 2007]. No entanto, Kang [KANG, 2005] afirma que o tamanho máximo alcançado pelo pescoço é de $20 \%$ do tamanho da partícula. Neste estágio, há uma contração linear de 3-5\%, definida como uma redução percentual do tamanho da partícula influenciando na área e volume finais, e os poros permanecem interconectados entre si ao longo da estrutura do material [KUMAR, 2011].

Este primeiro estágio pode apresentar duas distintas configurações de arranjo dos grãos cristalinos dependendo o mecanismo dominante, o qual pode ser não densificante ou densificante, com consequente aproximação dos centros esféricos, conforme a Figura 7. Considerando que o ângulo diedro, definido em função das tensões interfaciais localizadas na região de interseção entre os dois grãos independentemente da pressão interior ou exterior dos grãos [KANG, 2005], seja igual à $180^{\circ}$, que o tamanho do pescoço seja bem inferior ao da particula $\left(\frac{x}{a}<\sim 0.2-0.3\right)$ [ASHBY, 1974] e que não haja variação no tamanho dos grãos durante a sinterização, mantendo seu formato esférico. O raio de curvatura do pescoço $(r)$, a área da superfície do pescoço $(A)$ e o volume do pescoço $(V)$ estão apresentados na Figura 7, abaixo dos seus respectivos mecanismos. 


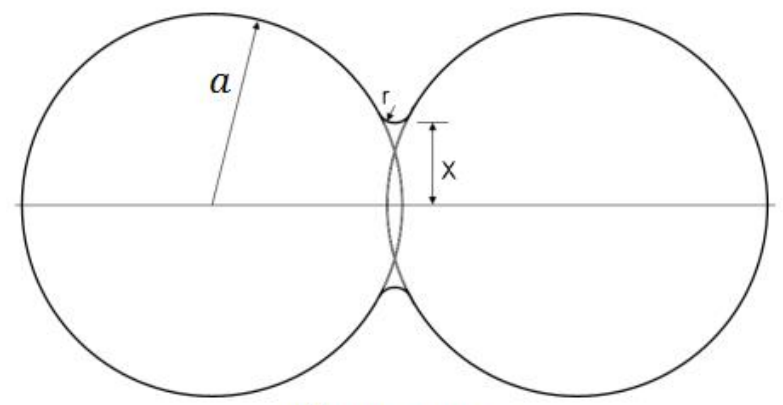

(a) com contração

$$
\begin{gathered}
r=\frac{X^{2}}{4 a} \\
A=\frac{\pi X^{3}}{a} \\
V=\frac{\pi X^{4}}{4 a}
\end{gathered}
$$

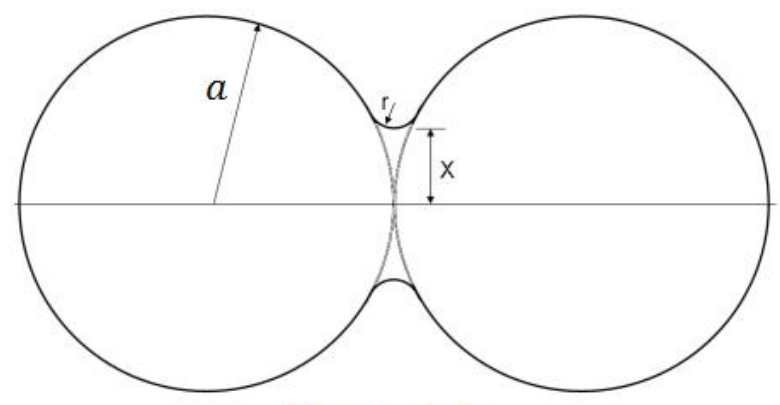

(b) sem contração

$$
\begin{gathered}
r=\frac{X^{2}}{2 a} \\
A=\frac{2 \pi X^{3}}{a} \\
V=\frac{\pi X^{4}}{2 a}
\end{gathered}
$$

Figura 7: Parâmetros geométricos empregados para o modelo de duas esferas referentes ao estágio inicial da sinterização [KANG, 2005].

Para o cálculo da área e do volume do pescoço, adota-se como aproximação um toróide cilíndrico tanto para os casos com mecanismos que promovem a contração como para aqueles que não a promovem. Esta simplificação permite com que os cálculos sejam realizados de forma mais concisa e menos complicada.

As equações para a cinética do estágio inicial para os diferentes mecanismos são apresentadas na Tabela 4 [KANG, 2004; RAHMAN, 2007; KUMAR, 2011]. Nesta Tabela, $D_{l}$ é o coeficiente de difusão da rede, $D_{g b}$ é o coeficiente de difusão do contorno de grão, $D_{s}$ é coeficiente de difusão superficial, $\gamma_{s}$ é a energia superficial, $\delta_{s}$ é a espessura de difusão para o mecanismo de difusão superficial, $\delta_{g b}$ é a espessura do contorno de grão, $\Omega$ é o volume molar, $k$ é a constante de Boltzmann, $T$ é a temperatura absoluta de sinterização, $d$ é a densidade do material, $D_{g}$ é a difusividade dos átomos gasosos, $p_{0}$ pressão de vapor de equilíbrio sobre uma superfície plana, $\eta$ é a viscosidade, e $M$ é o peso molecular. 
Tabela 4: Expressões para a cinética de sinterização no estágio inicial [KANG, 2004; RAHMAN, 2007; KUMAR, 2011

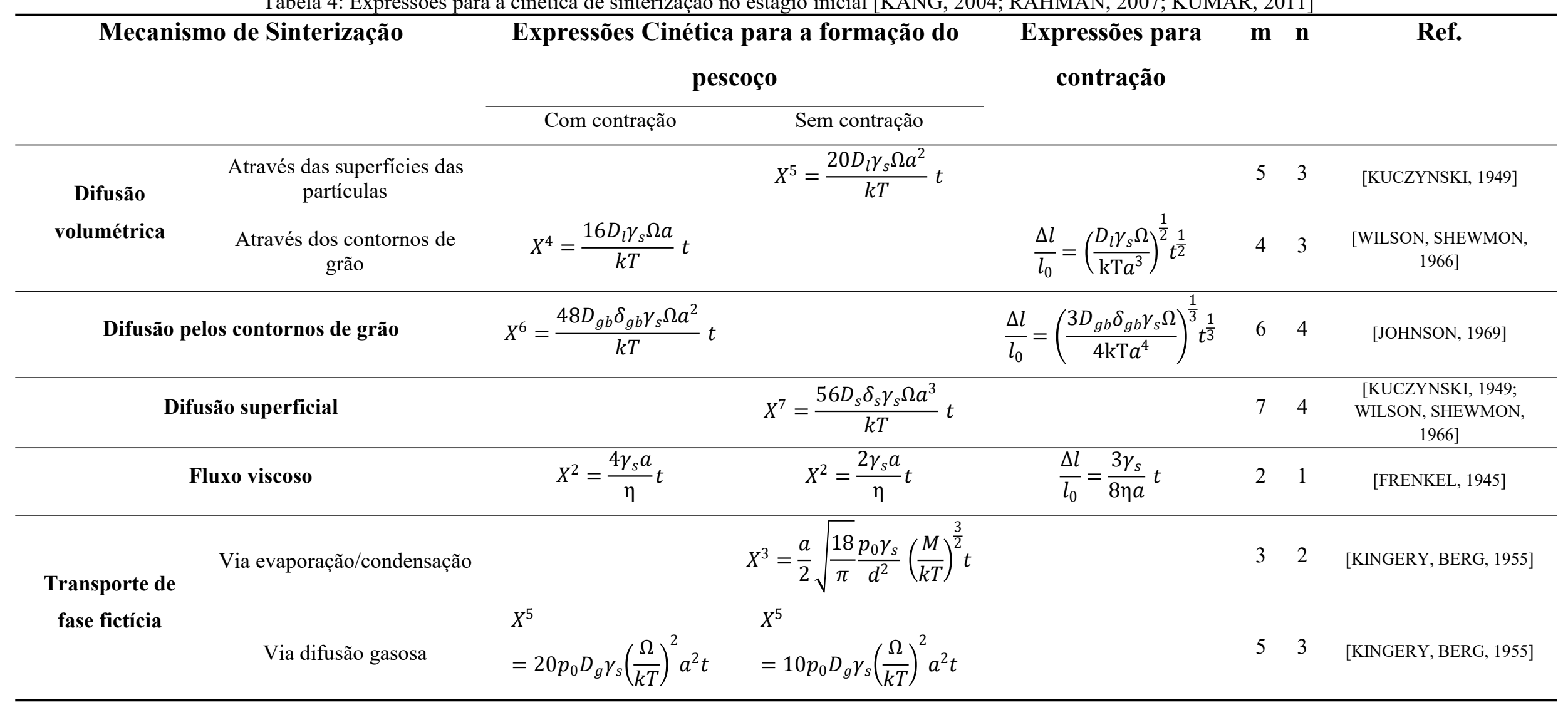


Observa-se que a relação entre os expoentes do tamanho do pescoço $(x)$, representado pela letra $m$ na Tabela 4, e a diferença entre os expoentes referentes ao tamanho do pescoço $(x)$ e da partícula (a), representado por $n$, define o mecanismo da sinterização dominante. Assim, estipulou-se uma expressão geral para escrever as equações da sinterização, sendo esta válida tanto para os modelos com e sem contração (densificação) das partículas, dada por:

$$
\left(\frac{X}{a}\right)^{m}=\frac{B(T)}{a^{n}} t
$$

onde $B(T)$ é um termo dependente da temperatura que inclui propriedades do material como coeficientes de difusão e constantes geométricas; $x$ é o raio do pescoço; $a$ é o raio da partícula esférica; $t$ é o tempo e os expoentes $m, n$ definem, respectivamente, o mecanismo característico e dependência do tamanho da partícula [KANG, 2005]. O valor do expoente $m$ pode ser obtido graficamente a partir da razão entre o tamanho do pescoço e tamanho da partícula $\left(\frac{X}{a}\right)$ em função do tempo de sinterização $(t)$, enquanto o expoente $n$ pode ser determinado pelo gráfico de $\left(\frac{x}{a}\right)$ em função do tamanho da partícula $(a)$, sendo que ambos os gráficos e eixos devem estar em escala logarítmica. Dados os expoentes, pode-se determinar qual o mecanismo de sinterização envolvido. Assume-se como hipótese ideal que somente um mecanismo é ativado por vez.

Kuczynski foi um dos primeiros a realizar experimentos práticos para estudar e compreender o mecanismo dominante na sinterização dos metais, bem como a relação entre o tempo e a temperatura na formação do raio do pescoço. Até então muita teoria havia sido desenvolvida por Frenkel (1945), Pines (1946) e, Shaler e Wulff (1948), mas nenhuma validação experimental efetiva havia sido conduzida para de fato comprovar suas teorias. Os resultados obtidos eram apenas qualitativos [KUCZYNSKI, 1949].

Kingery e Berg [KINGERY, BERG, 1955], em seu trabalho com partículas de cobre, mostraram que a difusão volumétrica é o mecanismo predominante para o crescimento do pescoço deste sistema. Estudos mais recentes mostraram, no entanto, que o mecanismo predominante é a difusão superficial, com contribuição significativa da difusão volumétrica e da difusão pelo contorno de grão [WILSON, SHEWMON, 1966; NICHOL, 1968; JOHNSON, 1969], enquanto que o mecanismo de evaporação-condensação deve também ser considerado em sinterizações à vácuo [ALEXANDER, BALUFFI, 1957]. Para os vidros, o mecanismo predominante é o fluxo viscoso [KUCZYNSKI, 1949]. 
É importante destacar que, a partir dos modelos iniciais, outros modelos cinéticos mais sofisticados como os de Johnson [JOHNSON, 1969], Young-Cutler [YOUNG, CUTLER, 1970], Woolfrey-Bannister [WOOLFREY, BANNISTER, 1972], Wang-Raj [WANG, RAJ, 1990] e Chu-Rahaman-Jonghe-Brook [CHU, RAHAMAN, JONGHE, BROOK, 1991], para sinterização sob taxa constante de aquecimento, foram desenvolvidos. Estes modelos apresentaram tentativas de descrever os três estágios do processo de sinterização em uma mesma equação [GERMAN, 1996], porém mantendo a consideração de haver apenas um mecanismo de transporte operante por vez. Os mesmos não serão abordados no presente trabalho.

\subsubsection{Modelos para o Estágio Intermediário}

O estágio intermediário inicia-se quando todos os poros presentes tenham adquirido sua forma de equilíbrio dada pelo balanço entre as tensões superficiais e interfaciais [COBLE, 1961]. Objetiva-se nesta etapa remover os poros abertos, densificando o material pelos métodos de difusão no volume e no contorno de grão [COBLE, 1961]. O modelo adotado por Coble [COBLE, 1961] assume que neste estágio as partículas sólidas do material apresentam um formato de um tetradodecaedro ou octaedro truncado, visto na Figura 8, onde os poros estão localizados nas arestas deste poliedro e estes apresentam forma cilíndrica, como apresentado na Figura 9. A força motriz nesta etapa é a redução na área superficial do poro, ou seja, seu raio.

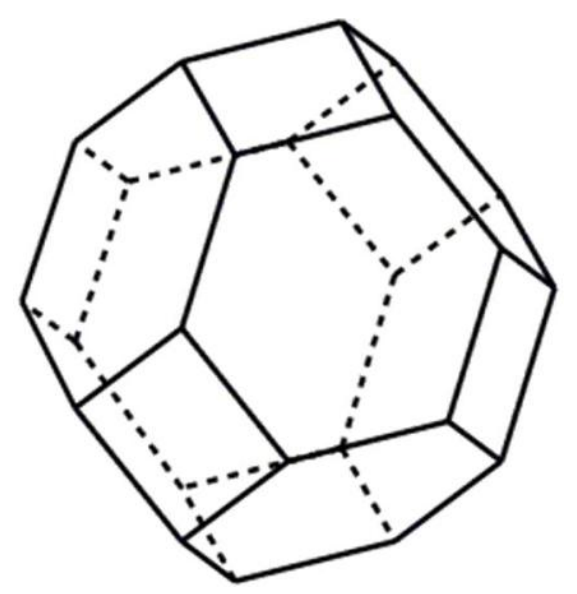

Figura 8: Tetradodecaedro ou octaedro truncado [KUMAR, 2010]. 

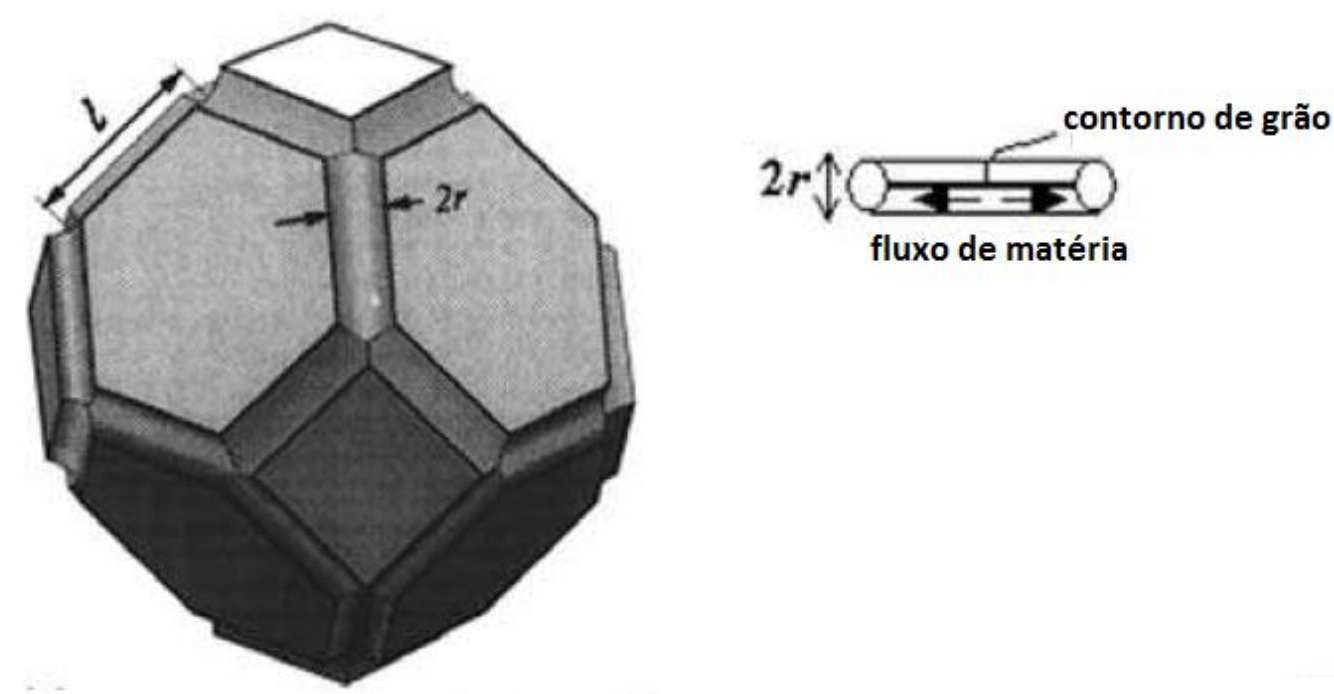

Figura 9: Modelo geométrico de Coble para o estágio intermediário [KANG, 2005].

O tetradodecaedro possui 36 arestas, 24 vértices e 14 faces conforme a Figura 8 . O volume deste poliedro é dado por:

$$
V_{t}=8 \sqrt{2} l_{p}^{3}
$$

onde $l_{p}$ é o comprimento das arestas do poliedro. Assumindo um empacotamento ideal, onde uma mesma aresta é compartilhada por três tetradodecaedro, o volume da porosidade é dado por:

$$
V_{P}=\frac{1}{3} 36 \pi r^{2} l_{p}
$$

com $r$ representando o raio do poro.

O fluxo atômico neste estágio ocorre através de dois mecanismos possíveis: difusão volumétrica ou difusão pelo contorno de grão. As equações que regem cada um destes mecanismos serão detalhadas a seguir.

\subsubsection{Difusão Volumétrica:}

A contração acontece ao longo de todas as 14 faces do tetradodecaedro, assim, Coble [COBLE, 1961] assumiu a difusão como sendo radial para um poro circular e negligenciou os efeitos da forma dos vértices do tetradodecaedro, definindo a taxa de variação do volume do poro $\frac{d V_{p}}{d t}$ como sendo: 


$$
\frac{d V_{p}}{d t}=-\frac{14}{2} 2 r J_{\text {atom }} V_{m}
$$

onde $J_{\text {atom }}$ é o fluxo atômico por unidade de comprimento, que vale $J_{\text {atom }}=4 \pi\left(\frac{D}{R T}\right) \Delta \sigma$. Assim, substituindo o valor de $J_{\text {atom }}$, tem-se:

$$
\frac{d V_{p}}{d t}=-14 r 4 \pi \frac{D_{l}}{R T}\left(\frac{\gamma_{s}}{r}\right) V_{m}
$$

Consequentemente, a taxa de variação da porosidade $\frac{d P_{v}}{d t}$ será:

$$
\frac{d P_{v}}{d t}=\frac{\frac{d V_{p}}{d t}}{8 \sqrt{2} l^{3}}=-\frac{d \rho}{d t}
$$

onde $l$ é o comprimento da aresta do grão e $\rho$ é a densidade relativa.

Substituindo o valor de $\frac{d V_{p}}{d t}$ (Equação (6)) na Equação (7)), tem-se que:

$$
\frac{d \rho}{d t}=\frac{14 \pi D_{l} \gamma_{s} V_{m}}{\sqrt{2} l^{3} R T}=\frac{336 D_{l} \gamma_{s} V_{m}}{R T G^{3}}
$$

onde $G$ é o diâmetro do grão que satisfaz a relação $\frac{\pi}{6} G^{3}=8 \sqrt{2} l^{3}$. Para o caso em que não há crescimento de grão durante a sinterização, o valor de $G$ é constante.

\subsubsection{Difusão através do contorno de grão}

Semelhante à difusão volumétrica, a Equação que relaciona a taxa de variação do volume do poro com o tempo é:

$$
\frac{d V_{p}}{d t}=-\frac{14}{2} 4 \pi \frac{D_{b}}{R T} \frac{\gamma_{s}}{r} \delta_{b} V_{m}
$$

onde $\delta_{b}$ é a espessura de difusão pelo mecanismo de difusão através do contorno de grão. Desta forma:

$$
\frac{d P_{v}}{d t}=\frac{\frac{d V_{p}}{d t}}{8 \sqrt{2} l^{3}}=-d \rho / d t
$$


Substituindo o valor de $\frac{d V_{p}}{d t}$, tem-se:

$$
\begin{gathered}
\frac{d P_{v}}{d t}=28 \pi \frac{D_{b} \delta_{b} \gamma_{s} V_{m}}{R T} \frac{1}{8 \sqrt{2} l^{3}} \frac{1}{\sqrt{P_{v}}} \sqrt{\frac{12 \pi}{8 \sqrt{2} l^{2}}} \\
\frac{d P_{v}}{d t}=854 \frac{D_{b} \delta_{b} \gamma_{s} V_{m}}{R T G^{4}}\left(\frac{1}{P_{v}}\right)^{\frac{1}{2}}
\end{gathered}
$$

Assim como no estágio inicial, a difusão pelo contorno de grão é, no estágio intermediário da sinterização, responsável por promover a densificação do material. A microestrutura final neste estágio é constituída de grãos com poros isolados. Modelos mais refinados e sofisticados foram desenvolvidos por Johnson [JOHNSON, 1970] e Beeré [BEERÉ, 1975].

\subsubsection{Modelos para o Estágio Final}

O estágio final inicia-se quando os poros passam a assumir a forma esférica e tornam-se isolados uns dos outros nos vértices dos grãos. Os modelos do estágio final da sinterização foram desenvolvidos também por Coble [COBLE, 1961] e por Coleman e Beeré [COLEMAN, BEERÉ, 1975]. Estes modelos adotam como geometria grãos tetradodecaédricos de mesmo tamanho com poros esféricos isolados nos vértices, conforme representação na Figura 10 [COBLE, 1961]. 


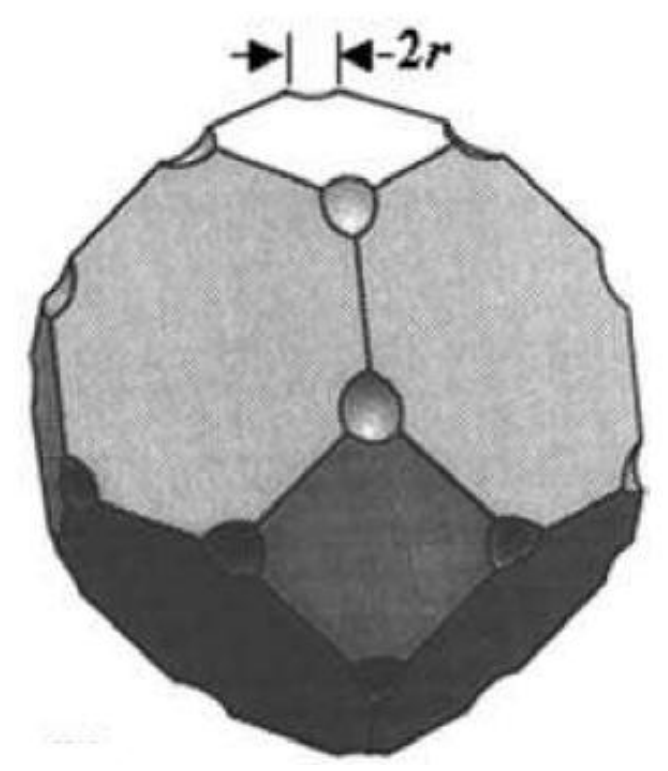

Figura 10: Modelo geométrico de Coble para o estágio final da sinterização [COBLE, 1961].

Com o tetradodecaedro possuindo 24 vértices, cada poro localizado nestes vértices é compartilhado por mais quatro grãos com arranjo cúbico de corpo centrado. Assim o volume dos poros para cada grão será:

$$
V_{p}=\frac{24}{4}\left(\frac{4 \pi}{3}\right) r^{3}=8 \pi r^{3}
$$

onde $r$ é o raio do poro. Assim, a porosidade associada a um único tetradodecaedro será:

$$
P_{s}=\frac{8 \pi r^{3}}{8 \sqrt{2} l^{3}}=\frac{\pi}{\sqrt{2}}\left(\frac{r^{3}}{l^{3}}\right)
$$

onde $l$ é o tamanho da aresta e $r$ é o raio do poro.

O fluxo difusivo para geometria esférica ainda não foi determinado, porém o cálculo da cinética de sinterização pode ser efetuado utilizando equações do fluxo entre duas concêntricas camadas de uma esfera. Desta forma, a equação do fluxo é dada por:

$$
J=\text { constante }=-4 \pi r^{2} \frac{D_{l}}{R T} \frac{d \sigma}{d r}
$$

Após integração, obtêm-se:

$$
J=4 \pi \frac{D_{l}}{R T} \Delta \sigma \frac{r_{1} r_{2}}{r_{2}-r_{1}}
$$


onde $J$ é o fluxo difusivo entre duas camadas concêntricas de uma esfera, $r_{1}$ é o raio interno e $r_{2}$ é o raio externo da esfera, $\Delta \sigma$ é a diferença na concentração de vacâncias entre a superfície do poro (fonte) e o contorno de grão (sumidouro), e $D_{l}$ é o coeficiente de difusão das vacâncias com fluxo partindo dos poros para os contornos de grão [RAHAMAN, 2007; KUMAR, 2011].

Considerando que $r_{1} \ll r_{2}$ :

$$
J=4 \pi \frac{D_{l}}{R T} \Delta \sigma r
$$

A taxa de densificação é calculada como:

$$
\frac{d \rho}{d t}=-\frac{\frac{24}{4} J V_{m}}{\frac{1}{6} \pi G^{3}}
$$

Substituindo o valor do fluxo na Equação (22), e adotando $\Delta \sigma=\frac{2 \gamma_{s}}{r}$, uma vez que a forma geométrica dos poros é esférica.

$$
\frac{d \rho}{d t}=\frac{288 D_{l} \gamma_{s} V_{m}}{R T G^{3}}
$$

Observa-se que a taxa de densificação é inversamente proporcional ao cubo do tamanho do grão; resultado este também observado em relação a dependência entre crescimento do pescoço e contração com o tamanho da partícula no estágio inicial [KANG, 2005].

O modelo de Coble [COBLE, 1961] é considerado um padrão para interpretação e determinação da densificação no estágio final da sinterização. Todavia, este modelo não considera o contorno de grão como uma fonte para a densificação e adota um fluxo de material constante do contorno de grão para a superfície do poro independente do tamanho deste poro [KANG, 2005].

Um outro modelo analítico utilizado para prever a cinética de sinterização no estágio final é a lei de escala de Herring [ZHAO, HARMER, 1991; KANG, JUNG, 2004], o qual considera o efeito da área superficial do poro no cálculo do fluxo de material a partir do contorno de grão para o poro. Partindo deste conceito, Kang e Jung [KANG, JUNG, 2004] 
derivaram a taxa de densificação não somente para a difusão volumétrica, mas também para a difusão através do contorno de grão, obtendo:

$$
\frac{d \rho}{d t}=\frac{441 D_{l} \gamma_{s} V_{m}}{R T G^{3}}(1-\rho)^{\frac{1}{3}}
$$

para a difusão volumétrica, e

$$
\frac{d \rho}{d t}=\frac{735 D_{b} \delta_{b} \gamma_{s} V_{m}}{R T G^{4}}
$$

para a difusão pelo contorno de grão.

Resumindo, os modelos geométricos adotados para os diferentes estágios da sinterização estão listados na Tabela 5 .

Tabela 5: Resumo das características e do modelo analítico clássico empregado para cada estágio do processo de sinterização.

\begin{tabular}{ccc}
\hline Estágio & Característica & Modelo Empregado \\
\hline Inicial & Formação do Pescoço & Duas esferas em contato \\
& & Tetradodecaedro com poros \\
Intermediário & Porosidade contínua & cilíndricos ao longo das \\
& & arestas \\
Final & Porosidade isolada & Tetradodecaedro com poros \\
& & esféricos nos vértices \\
\hline
\end{tabular}

\subsection{Histórico dos estudos e experimentos de sinterização para metais}

A Tabela 6 apresenta a evolução histórica dos principais estudos de sinterização para o cobre puro. 
Tabela 6- Históricos dos estudos e experimentos realizados para a sinterização do cobre.

\begin{tabular}{|c|c|}
\hline AUTOR(ES) & ESTUDO REALIZADO \\
\hline KUCZYNSKI (1949) & $\begin{array}{c}\text { Esfera de cobre sobre uma placa de mesmo } \\
\text { material. }\end{array}$ \\
\hline ALEXANDER e BALLUFFI (1957) & $\begin{array}{c}\text { Sinterização de fios de cobre em torno de um } \\
\text { carretel de cobre. }\end{array}$ \\
\hline PRANATIS e SEIGLE (1960) & $\begin{array}{c}\text { Estudo do crescimento do pescoço entre um } \\
\text { compacto de fios de cobre. }\end{array}$ \\
\hline RHINES et al. (1962) & $\begin{array}{c}\text { Medida da densificação das partículas esféricas } \\
\text { de cobre. }\end{array}$ \\
\hline WILSON e SHEWMON (1966) & $\begin{array}{c}\text { Medição do crescimento do pescoço para uma } \\
\text { sequência de esferas de cobre. }\end{array}$ \\
\hline
\end{tabular}

Em 1949, Kuczynski [KUCZYINSKI, 1949] publicou o primeiro artigo com o objetivo de estudar o processo da sinterização e os mecanismos nele envolvidos para o cobre e a prata, e estabelecer a relação entre as variáveis externas e o raio do pescoço final. O trabalho estudou a influência do tempo e da temperatura no raio do pescoço para o sistema composto entre uma partícula esférica e um placa do mesmo metal. A metodologia empregada para esta medição consistiu na dispersão das partículas de diferente diâmetros (maiores que $35 \mu \mathrm{m}$, de 15 - 35 $\mu m$, e menores que $15 \mu \mathrm{m}$ ) sobre a placa metálica, as partículas por sua vez não tocavam umas nas outras; o aquecimento do conjunto foi feito em uma atmosfera controlada de hidrogênio para diferentes temperaturas e tempos; após aquecimento, os blocos contendo as partículas sinterizadas foram seccionados, polidos e examinados por microscopia. A leitura do raio dos pescoços foi feita utilizando um micrômetro acoplado ao microscópio, sendo que pelo menos dez conjuntos foram analisados para cada tempo e temperatura, e o tamanho do pescoço final associado a cada condição foi adotado como sendo a média aritmética dos valores obtidos.

$\mathrm{O}$ autor plotou os gráficos entre $\log \left(\frac{x}{a}\right)$ pelo $\log t$; para o cobre, o coeficiente angular obtido foi 5 , indicando que o mecanismo de sinterização dominante neste processo foi a difusão volumétrica. Calculou-se o coeficiente de difusão volumétrica associado para cada temperatura utilizando como valor de tensão superficial do sólido o mesmo dado atribuído ao correspondente metal no estado fundido, sendo para o cobre igual a $1200 \mathrm{ergs} / \mathrm{cm}^{2}\left(1,2 \mathrm{~J} / \mathrm{m}^{2}\right)$. O gráfico entre o coeficiente de difusão volumétrica $\left(D_{v}\right)$ e a razão $\frac{1000}{T}$, onde $T$ é a temperatura absoluta de sinterização, permitiu o cálculo do calor de ativação e da difusividade para partículas grandes (com diâmetros superiores a $40 \mu \mathrm{m}$ ). Para partículas pequenas (com 
diâmetros inferiores a $30 \mu \mathrm{m}$ ), concluiu-se que em baixas temperaturas o mecanismo predominante é a difusão superficial, sendo o coeficiente de difusão neste caso também obtido graficamente.

Um outro objetivo de Kuczynski era demonstrar que a sinterização pode ser considerada uma técnica alternativa aos marcadores radioativos na obtenção do coeficiente de difusão. Porém, conforme publicado por Butrymowicz, et. al.[BUTRYMOWICZ, et.al., 1973], estes valores precisam ser cuidadosamente avaliados, uma vez que o mecanismo operante da sinterização pode não ser o mais correto, e os cálculos para determinação deste coeficiente não serem assim os mais apropriados e adequados. $\mathrm{O}$ uso das equações da sinterização para determinar o coeficiente de difusão é questionável, uma vez que estes valores serão obtidos de modo a se ajustarem aos valores de entrada. Como o trabalho experimental de Kuczynski consistiu no uso de uma placa plana e esferas sinterizadas sobre a mesma, não foi possível uma compreensão real da contração, apenas da formação do pescoço; assim, sua metodologia apresenta-se muito fora do objetivo desta tese de comparar as equações analíticas com os dados experimentais, todavia, uma vez disponíveis, estes serão utilizados a título de análise.

O trabalho publicado por Kingery e Berg [KINGERY, BERG, 1955] buscou esclarecer o mecanismo de transporte dominante durante a sinterização do vidro, cloreto de sódio e cobre, a partir das observações diretas das taxas de crescimento das áreas de contato, isto é, das interfaces, e pela aproximação dos centros entre as partículas esféricas (contração e densificação).

Eles verificaram que para as esferas de cobre, com diâmetros iniciais médios de $100 \mu \mathrm{m}$, sinterizadas entre 950 e $1050^{\circ} \mathrm{C}$, o mecanismo dominante na sinterização é a difusão volumétrica a partir dos contornos de grão com paralela ação dos defeitos de linha como sumidouros das vacâncias ou vazios existentes na estrutura.

Foram calculados os coeficientes de difusão por meio da Equação analítica, adotando a tensão superficial como 1670 dyne/cm $\left(1,67 \mathrm{~J} / \mathrm{m}^{2}\right)$, e estes foram comparados com outras técnicas tradicionais. Houve boa coerência com os resultados obtidos, porém há uma ressalva de que a fonte de material para difusão não pode ser proveniente da superfície, o que indica o contorno de grão como região energeticamente favorável à eliminação das vacâncias. Os autores ainda apontaram que estas condições complexas para a fronteira dos dados de sinterização tornam os valores quantitativos das constantes de difusão, energia de ativação e tensão superficial pouco confiáveis e muito susceptíveis a erros.

Todo estudo realizado pelos autores focou exclusivamente no primeiro estágio da sinterização com objetivo de identificar as taxas de crescimento do pescoço e o efeito da 
contração, para isso eles identificaram que o uso de esferas pequenas sinterizadas com o uso de um arco voltaico facilitaria tal análise [KINGERY, BERG, 1955].

Os autores reconhecem que a identificação do mecanismo de sinterização dominante é uma tarefa árdua, pois os efeitos podem ser resultados de uma combinação de mecanismos, ou quando um único apresenta-se mais acentuado há dificuldade por conta dos valores dos coeficiente do tempo se apresentarem muito próximos. Para casos em que há aproximação dos centros das esferas, os autores propuseram equações referentes à taxa de preenchimento do volume da região do pescoço para contrações de até $2 \%$, estas foram comparadas com os dados experimentais e dados publicados na literatura, apontando que tal modelo apresenta-se confiável para tais cálculos.

Em 1966, Wilson e Shewmon [WILSON, SHEWMON, 1966] publicaram um artigo no qual estudaram: o crescimento do pescoço e a contração de esferas de cobre em uma atmosfera de hidrogênio (dry hydrogen). O experimento utilizou uma fileira de esferas de cobre divididas em cinco grupos independentes entre si, os quais se distinguiam pelos diâmetros das esferas presentes (variando de 100 a $310 \mu \mathrm{m}$ ). Para o estudo do crescimento do pescoço foram empregadas as temperaturas de 950 e $1020^{\circ} \mathrm{C}$; enquanto que o estudo da contração foi feito para esferas com diâmetro de $145 \mu \mathrm{m}$ nas temperaturas de 650, 750, $850 \mathrm{e}$ $950^{\circ} \mathrm{C}$.

Os autores queriam inicialmente confrontar os estudos publicados até então referentes a sinterização do cobre, pois os mesmos indicavam a difusão volumétrica como mecanismo dominante. Após as análises, eles concluíram que o mecanismo dominante é a difusão superficial para o crescimento do pescoço, com significativa contribuição do mecanismo de difusão pelo contorno de grão para contração em baixas temperaturas (até $70 \%$ da temperatura absoluta de fusão do metal). Utilizando a lei de Herring (scaling law) eles concluíram que 95\% do fluxo de material para o pescoço é proveniente da superfície entre sólido e vapor, observaram também que apesar do expoente do tempo estar entre $\frac{1}{5}$ e $\frac{1}{5,5}$, correspondente aos mecanismos de difusão volumétrica a partir da superfície e difusão pelo contorno de grão a partir do contorno, o mecanismo da difusão superficial é predominante. Vale ainda ressaltar que para temperaturas de sinterização superiores a $950^{\circ} \mathrm{C}$, as esferas de cobre com diâmetros entre 100 e $300 \mu \mathrm{m}$ possuem como mecanismo dominante a difusão superficial exclusivamente no intervalo entre $0,20 \leqq \frac{x}{a} \leqq 0,40$. Essa conclusão foi obtida a partir do emprego da relação proposta por Nichols e Mullins [NICHOLS; MULLINS, 1965] referente a 
equação que governa o mecanismo de difusão superficial obtida a partir de integração numérica.

No artigo de Alexander e Balluffi [ALEXANDER, BALLUFFI, 1957], o estudo da sinterização foi conduzido utilizando fios com diâmetros de 0,0128 e $0,00526 \mathrm{~cm}$, os quais foram enrolados em múltiplas camadas ao redor de uma bobina também de cobre. Tal conFiguração foi adotada pois os autores objetivaram investigar a aproximação das partículas, formação dos pescoços e contração, além das variações na forma e tamanho dos vazios existentes entre os fios em função do tempo e da temperatura de sinterização.

Os autores reforçam que os artigos publicados por Kuczynski [KUCZYINSKI, 1949] e Kingery e Berg [KINGERY, BERG, 1955] são os responsáveis pelos principais avanços na determinação do mecanismo de sinterização dominante de modo experimental. Eles criticaram o método utilizado por Kuczynski [KUCZYINSKI, 1949] em concluir que o mecanismo de difusão volumétrica é o predominante, uma vez que o emprego de uma placa plana com esferas e fios depositadas sobre a mesma não permite a compreensão da contração, apenas da formação do pescoço.

Eles comprovaram experimentalmente que a contração, ou seja, aproximação dos centros das esferas possui sua maior taxa de ocorrência no início da sinterização, decrescendo com o tempo e cessando com a eliminação dos contornos de grão ao longo da estrutura. Essa evidência reforça a teoria de que o mecanismo dominante para que haja a contração é a difusão dos átomos a partir dos contornos de grão em direção aos vazios. Durante o estágio inicial, como a taxa de contração é maior, além do fluxo originado nos contornos de grão, tem-se também fluxos provenientes das superfícies convexas em direção aos vazios, como as energias superficiais são elevadas, elas favorecem termodinamicamente a minimização da energia interna e a suavização geométrica (tendendo a um formato esférico/cilíndrico) desses vazios. Foi, todavia, comprovado, que tanto as difusões superficiais como as por difusão gasosa via evaporação-condensação contribuem de maneira muito pequena frente a difusão volumétrica nos estágios iniciais, mas essas estão presentes e não devem ser descartadas. Essas conclusões só foram possíveis após uma série de análises realizada pelos autores, dentre as quais cita-se:

- análise da estrutura metalográfica dos vazios durante a sinterização isotérmica constatando que há uma evolução com o tempo e que a contração acontece quando os vazios atingem o formato de menor energia livre (pequenos tubos cilíndricos), com cessamento do crescimento do pescoço e início da contração; 
- os fluxos atômicos da difusão são característicos dos estágios da sinterização presentes, para o estágio inicial há fluxos originados nos contornos de grão e nas superfícies livre, enquanto que no estágio final o fluxo presente é originado exclusivamente nos contornos de grão;

- a análise do expoente do tempo para determinação do mecanismo dominante é muito limitante pois muitas simplificações são feitas de maneira a permitir um tratamento analítico nas equações dos diferentes mecanismos de sinterização existentes. Os autores sugerem que a análise mais adequada é dada pela relação do logaritmo do tempo pelo inverso da temperatura;

- as taxas de contração durante a sinterização são especificas dos diferentes estágios, sendo que no estágio final a contração ocorre exclusivamente devido a difusão volumétrica a partir dos contornos de grão, enquanto que nos estágios iniciais essa difusão existe em paralelo à formação do pescoço causada pela difusão volumétrica a partir da superfície;

- com a variação na escala da taxa de sinterização pôde-se concluir o mecanismo dominante, sendo dado pela relação linear das dimensões entre os fios e a razão entre os tempos necessários para atingir os mesmos estágios da sinterização.

Com essas análises, pode-se concluir que tanto a contração quanto a formação do pescoço são dadas pela difusão volumétrica, com operação concomitante dos contornos de grão e das superfícies livres, respectivamente. Os defeitos de linha ou unidimensionais não são eficientes nos processos da sinterização, uma vez que a movimentação das discordâncias por climbing é dificultada pelos pequenos potenciais existente, resultando em uma lenta movimentação, e o número de vazios ou vacâncias nas discordâncias é muito menor comparada a mesma quantidade presente nos contornos de grão.

Os autores também tiveram o cuidado de analisar as barreiras físicas impostas e existentes quanto a configuração do experimento. Eles mostraram graficamente que existe a restrição devido a natureza cilíndrica da bobina na qual os cilindros são enrolados, porém estas podem ser desprezadas quando a espessura da camada de fios é muito menor do que o diâmetro total do conjunto. A contração não fica restrita exclusivamente as regiões radiais, mas também ocorre longitudinalmente, o que permite extrapolar os resultados para uma configuração com cilindros paralelos retos.

As conclusões dos autores foram portanto que a sinterização por si só não garante eliminação completa da porosidade, e o aumento na taxa de sinterização produz maior área dos contornos de grão devido a recristalização. A contração é devido a difusão volumétrica dos átomos a partir dos contornos de grão, sendo cessada quando não existirem mais esses contornos; no estágio inicial, a difusão volumétrica a partir das superfícies livres garante a 
aproximação entre os fios e formação dos pescoços, conforme descrito por Kuczynski [KUCZYINSKI, 1949], sendo também responsável pela suavização no formato geométrico dos vazios existentes, os quais ao final do processo de sinterização adquirem uma geometria de pequenos tubos cilíndricos. É importante ressaltar que o mecanismo de sinterização dominante é muito susceptível as condições experimentais adotadas, quando, por exemplo, são sinterizadas partículas de diâmetros pequenos em baixas temperatura, a difusão superficial apresenta-se como o mecanismo dominante, enquanto que na sinterização à vácuo, a difusão gasosa via evaporação-condensação torna-se a mais relevante frente aos demais mecanismos; por isso é tão complexa e complicada a compreensão do processo de sinterização.

Um outro estudo realizado com fios foi o de Pranatis e Seigle [PRANATIS, SEIGLE, 1960]. Os autores queriam compreender a influência dos contornos de grão nas taxas de sinterização do níquel, cobre e ferro compactamente enrolados em uma bobina de 6,35 $\mathrm{mm}$ de diâmetro do mesmo material, pois essas regiões são consideradas sumidouros das vacâncias /vazios existentes de acordo com a teoria de Herring-Nabarro [HERRING, 1950] e reportadas por Alexander e Balluffi [ALEXANDER, BALLUFFI, 1957] como responsáveis pelo término da sinterização.

Como metodologia adotada para o estudo da influência dos contornos de grão nas taxas de sinterização, os autores dividiram os compactados de fios de cobre com 101,6 $\mu \mathrm{m}(0,004$ in) de diâmetro cada em dois conjuntos, sendo que um deles foi intencionalmente submetido a uma pré-sinterização a $895{ }^{\circ} \mathrm{C}$ para eliminação de $50-75 \%$ dos contornos por meio da recristalização. A sinterização desses conjuntos foi realizada na temperatura de $1060{ }^{\circ} \mathrm{C}$. Eles também quiseram entender como a variação na geometria dos fios afeta a taxa de sinterização, e para isso foi feita a sinterização de tubos e fios sólidos de cobre com 203,2 $\mu \mathrm{m}(0,008$ in) de diâmetro sob as mesmas condições. As medidas do comprimento do pescoço foram feitas a partir de fotomicrografias e as áreas dos vazios medidas planimétricamente.

Após as análises, os autores verificaram que não havia diferença na taxa de sinterização entre os fios com ou sem a presença dos contornos de grão nem entre tubos e fios sólidos, com a difusão volumétrica como mecanismo dominante em todas as situações analisadas, confirmando as conclusões de Kuczynski [KUCZYNSKI, 1949], Kingery e Berg [KINGERY, BERG,1955] e Alexander e Balluffi [ALEXANDER, BALLUFFI, 1957].

O resultados da contração apresentaram muitas incertezas, porque a sinterização quando realizada em curtos períodos de tempo apresentou falha no encaixe dos fios devido aos erros iniciais nas áreas dos vazios, e para longos períodos de tempo não houve uma contração uniforme entre os poros. Não foi verificada alteração na taxa de contração para os conjuntos 
com ou sem pré-sinterização, assim, a presença dos contornos de grão não limitam, nem retardam este processo. A contração por sua vez é maior para longos períodos da sinterização em fios com maiores diâmetros. No presente trabalho não serão analisados os dados de contração publicados por Pranatis e Seigle [PRANATIS, SEIGLE, 1960] devido a ampla as incertezas destes.

Eles concluíram que a sinterização do cobre próximo a temperatura de fusão ocorre pela difusão volumétrica com influência dos contornos de grão, por sua vez, o crescimento do pescoço não é influenciado pela presença ou não dos contornos de grão.

\subsection{Modelos Matemáticos Numéricos do Processo de Sinterização}

Com o avanço nas pesquisas e nas tecnologias, a formulação de modelos numéricos, mais ou menos sofisticados, tornou-se disponível para os principais mecanismos de sinterização e/ou para a combinação deles, contudo todos os modelos existentes apresentam erros decorrentes principalmente das aproximações consideradas para a geometria do pescoço e das partículas, dificultando assim uma comparação quantitativa entre a teoria e os resultados experimentais.

Infelizmente, processos reais de sinterização não podem ser reproduzidos nem explicados pelo modelo de duas esferas. Assim, modelos mais sofisticados e complexos passaram a ser formulados para reproduzir mais fielmente os resultados experimentais. Hwang e German [HWANG, GERMAN, 1984] ressaltam que a precisão das simulações depende não somente das equações selecionadas, mas também das propriedades dos materiais envolvidos, como por exemplo: tensão superficial, energia de ativação e difusividade. Por isso é tão importante que os dados de entrada sejam confiáveis e seguros, evitando resultados e interpretações errôneas.

Os modelos numéricos são classificados em três categorias dependendo da escala de comprimento em que a simulação é realizada. Suas denominações são: modelo de escala atômica, modelo de partícula ou modelo contínuo [PAN, 2003].

A modelagem realizada a nível atômico consiste no sistema composto por um determinado número de átomos ou moléculas cuja simulação avaliará o movimento individual de cada partícula que compõe um aglomerado de partículas sinterizadas. Essas simulações requerem dados como o potencial inter-atômico. Emprega-se simulações com dinâmica molecular (DM) que são ideais para o estudo de sistemas nanoparticulados, como apresentado por Nichols e Mullins [NICHOLS, MULLINS, 1965], Exner e Bross [EXNER, BROSS, 1979], Zeng [ZENG et. al., 1998] e Ding [DING et. al., 2009]. 
Com o objetivo de compreender melhor a difusão superficial, Nichols e Mullins (1965) utilizaram o método das diferenças finitas explícito para resolver a Equação do fluxo de átomos na superfície em duas situações específicas: sinterização de várias esferas alinhadas e sinterização de uma esfera sobre um plano (baseado no experimento conduzido por Kuczynski (1949)). Como condição inicial o tamanho de pescoço mínimo adotado foi igual a $1 \%$ do raio da partícula. Eles concluíram que na sinterização de várias esferas, a curvatura do pescoço é menor do que a prevista pelas soluções analíticas em ordem de magnitude e o expoente do tempo é susceptível a razão entre o tamanho do pescoço e o raio da partícula $\left(\frac{x}{a}\right)$; esta conclusão também foi verificada na sinterização de esferas sobre um plano. Ficou comprovado que a determinação do mecanismo de sinterização preponderante utilizando apenas a análise do expoente do tempo é muito questionável pelas incertezas associadas a este método. A partir das simulações realizadas, foram obtidas duas equações para o mecanismo de difusão superficial. A título de comparação com os resultados previamente publicados por Kuczynski, os autores recalcularam os coeficientes de difusão superficial, admitindo este como mecanismo dominante. Concluiu-se que para esferas com raios inferiores a $10 \mu \mathrm{m}$, os valores referentes às constantes de difusividade e energia de ativação estavam de acordo com os valores publicados; essas constantes não puderam ser obtidas para esferas com raios maiores pela influência principalmente do mecanismo da difusão volumétrica.

Hwang e German [HWANG, GERMAN, 1984] também simularam, empregando o método de Newton-Raphson, a sinterização de partículas esféricas alinhadas, porém, as aproximações provenientes dos efeitos geométricos foram excluídas, uma vez que os erros inerentes a estas aproximações podem chegar a $50 \%$ quando $\frac{x}{a}=0.3$ e $100 \%$ quando $\frac{d V}{d x}=0.2$. Nas simulações isotérmicas à $1050{ }^{\circ} \mathrm{C}$ de esferas de cobre em que os mecanismos de sinterização atuavam individualmente, os autores verificaram que nos gráficos entre o tamanho do pescoço pelo tempo, o mecanismo da difusão superficial apresentava maior taxa de crescimento, enquanto que o mecanismo de difusão gasosa via evaporação-condensação possuía a menor taxa comparativamente. Quanto ao expoente do tempo, foi verificado que os mesmos não são constantes, mas susceptíveis ao tempo de sinterização, podendo, assim, assumir uma faixa de valores possíveis. Como a presença de mais de um mecanismo operante é um cenário mais provável de ser verificado, o valor do expoente do tempo será susceptível a importância relativa dos mecanismos individuais, sendo que até 100 minutos, o mecanismo da difusão superficial é o mais atuante, e a partir deste tempo, a ação do mecanismo da difusão volumétrica se torna mais relevante. 
A taxa de aquecimento e a temperatura de sinterização também influenciam tanto no tamanho final do pescoço quanto no expoente do tempo. Para o tamanho do pescoço, somente após 30 minutos do início da sinterização é que seu valor passa a ser independente da taxa de aquecimento adotada e quanto maior a temperatura de sinterização, maior será o tamanho do pescoço; todavia, a precisão no expoente do tempo é inversamente proporcional a taxa de aquecimento adotada, e seu valor será menor para maiores temperaturas, haja visto que o mecanismo de difusão superficial tem sua importância reduzida frente aos demais mecanismos nestas circunstâncias.

Nos diagramas de sinterização propostos por Ashby (1974), alguns materiais, como por exemplo, o cobre, apresentam diferentes mecanismos de sinterização dominantes de acordo com a temperatura de sinterização adotada. Assim, o uso da classificação baseada no expoente do tempo deve ser feito preferencialmente com taxas de aquecimento elevadas, de modo a evitar a influência de outros mecanismos durante o período de aquecimento.

Moriyoshi e Komatsu [MORIYOSHI, KOMATSU, 1971] desenvolveram equações cinéticas para as difusões superficial e volumétrica a partir do contorno de grão, além de combinarem ambas as equações da difusão superficial e volumétrica, e das difusões superficial e a partir do contorno de grão em uma única. Eles verificaram que a taxa de difusão volumétrica para o pescoço é decrescente com o tempo, e que na temperatura de $950^{\circ} \mathrm{C}$ o desaparecimento dos contornos de grão ocorre após 28 horas do processo de sinterização.

A modelagem a nível das partículas é a mais estruturada e estudada dentre as três escalas, usando como dados de entrada o tamanho da partícula, energias específicas e coeficiente de difusão. Os modelos desta classe apresentam equações tipicamente na forma de taxa para o crescimento do pescoço e a aproximação dos grãos. A principal técnica utilizada para esta modelagem é o modelo do campo de fases [CHNG, PAN, 2007; PAN et. al., 2009].

$\mathrm{Na}$ modelagem a nível contínuo, o pó compactado é tratado como um sólido cujo comportamento macroscópico é avaliado através da simulação. É possível obter resultados de densidade, tamanho de grão, campo de tensão e deformação do compacto durante o processo de sinterização. A técnica de resolução numérica mais empregada é a dos elementos finitos, como visto nos trabalhos de Olevsky et al. [OLEVSKY et al., 2006], e Pan [PAN, 2003].

\subsection{Método do Campo de Fases ("phase-field method") na sinterização}

Um dos métodos mais promissores para a modelagem de fenômenos complexos envolvendo termodinâmica e cinética de transformações de fase é o método do campo de 
fases ("phase-field method"). A idéia central deste método surgiu nos trabalhos de Van der Waals [ROWLINSON, 1979] para interfaces líquido-gás e de Cahn e Hilliard [CAHN; HILLIARD, 1958] para decomposição espinodal. Segundo este método, associa-se uma variável chamada de "variável de fase" $(\phi)$, que é um tipo de parâmetro de ordem, a cada ponto das diferentes fases do sistema, permitindo assim, uma direta compreensão das alterações na microestrutura final.

Além disso, considera-se que $\phi$ varia suavemente (classe $\mathrm{C}^{1}$ ) através das interfaces ou contornos de grão. A Figura 11 mostra uma comparação da variável de fase $\phi$ para o modelo do campo de fase (a) e para o modelo clássico (b). Nota-se que $\phi$ varia abruptamente no modelo clássico, pois a interface é assumida como um plano ideal sem espessura não diferenciável.

a
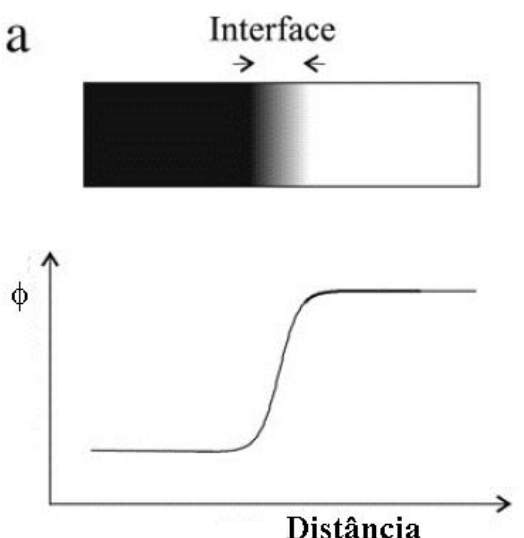

b
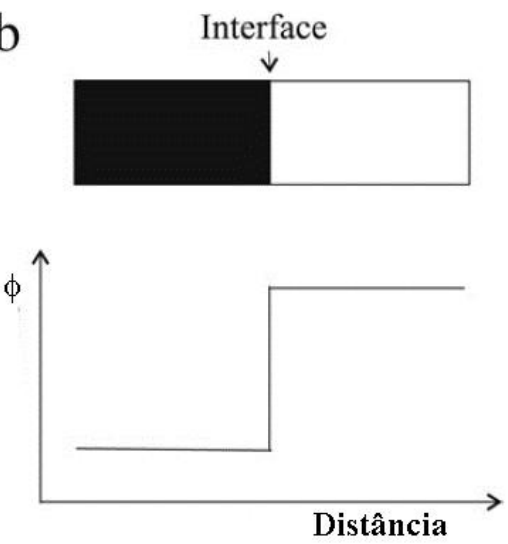

Figura 11: Variável de fase em função da distância através de uma interface segundo: (a) o modelo do campo de fase e (b) o modelo clássico [MOELANS et al.,2008].

Na simulação do modelo do campo de fases, variáveis como concentração, orientação cristalográfica e temperatura são representadas como campos e podem ser utilizadas para indicar a localização das fases do sistema, ou seja, podem ser utilizadas como uma variável de fase [KUMAR, et.al., 2010]. A partir destes campos é possível obter a densidade de energia livre em cada ponto do sistema, permitindo o cálculo da energia livre total a partir de uma integral de volume. Neste método, as equações para o cálculo da evolução no tempo de todos estes campos são obtidas para garantir que a energia livre total do sistema, calculada pela integral do volume, sempre diminua com o tempo [BOETTINGER, et al., 2002; JANSSENS, et al., 2007]. Estas equações são derivadas com base nos princípios gerais da termodinâmica [MOELANS et.al., 2008].

Uma das grandes vantagens na utilização do método do campo de fases é que não se faz necessário acompanhar explicitamente a interface ou o contorno de grão [LOGINOVA, 2003]. Nos modelos mais tradicionais, acompanhar o lugar geométrico do contorno ou da interface é 
uma tarefa computacional difícil, principalmente em sistemas tridimensionais. No método do campo de fases, utiliza-se a adaptação de uma Equação postulada por Landau para prever a evolução do campo da variável de fase, $\phi(\vec{r}, t)$. A partir deste campo, obtido pela solução desta Equação, pode-se prever onde as interfaces e os contornos estão localizados.

O método do campo de fases tem sido aplicado em variados problemas de transformação de fases, como o da solidificação de ligas metálicas e o da formação de precipitados em matrizes sólidas [BOETTINGER; WARREN, 1996; CHEN, 2002; STEINBACH, 2009]. Mais recentemente, este método foi aplicado ao problema da sinterização [KAZARYAN, et al., 1999; KRILL; CHEN, 2002].

Wang [WANG, 2006] ]foi o primeiro a propor um modelo empregando o método do campo de fases para compreender os mecanismos envolvidos no processo de sinterização, propondo também o uso da teoria de movimento de corpos rígidos para simular um compactado de pós durante a sinterização. Kumar et al [KUMAR, et al.,2010] usou também a mesma abordagem para estudar os diferentes estágios da sinterização para um compacto de partículas com diferentes tamanhos. Shinagawa [SHINAGAWA, 2014] combinou o método do campo de fases com o método dos elementos finitos para estudar o movimento do contorno de grão e a contração. Todos esses autores propuseram as formas para selecionar os coeficientes de energia livre e os parâmetros de mobilidade para as simulações, baseados na condição de que os materiais tem propriedades isotrópicas.

Desde então, modelos mais complexos e detalhados tem sido objeto de estudo procurando representar e descrever de forma mais fidedigna sistemas reais. Aspectos relevantes como a anisotropia do material [BISWAS et al, 2018], relação entre a direção da difusão na interface [DENG, 2012], sistemas multifásicos [ASP, AGREN, 2006], a mobilidade das partículas durante o crescimento de grão [AHMED et. al., 2017] são alguns dos temas das recentes pesquisas. 


\section{Materiais e Métodos}

Neste item será descrita a metodologia utilizada para obtenção dos resultados. Inicialmente serão apresentados os desenvolvimentos das equações dos modelos analíticos do estágio I da sinterização propostos na literatura para esferas e para cilindros. Posteriormente será explicada a análise estatística utilizada para a avaliação dos modelos analíticos frente a dados experimentais escolhidos. Esta análise estatística foi baseada no teste estatístico $\mathrm{t}$ de Student para quantificar e qualificar os mecanismos da sinterização em comparação aos experimentos realizados para o cobre puro, trazendo significância às conclusões obtidas a partir das análises gráficas e do cálculo do expoente do tempo.

$\mathrm{Na}$ segunda parte da metodologia será descrito um modelo matemático numérico baseado no método do campo de fases. Serão apresentados os aspectos gerais do modelo, sua descrição termodinâmica, o desenvolvimento e a resolução das equações envolvidas.

\subsection{Desenvolvimento dos Modelos Analíticos do Estágio I da Sinterização}

Neste sub-item serão desenvolvidas as equações dos modelos analíticos da sinterização para geometrias esféricas, a qual é majoritariamente empregada e descrita na literatura, e geometrias cilíndricas, cujas equações serão apresentadas de modo inédito, uma vez que nunca esta geometria foi minuciosamente estudada e avaliada dentre os trabalhos e artigos publicados.

A base desta modelagem foi desenvolvida admitindo que a massa do sistema entre duas esferas ou dois cilindros permanece constante ao longo do processo de sinterização [KANG, 2005; RAHAMAN, 2008]. Para os metais, os processos de difusão atômica são os únicos responsáveis pelo transporte de matéria das regiões de maior potencial químico (fonte, superfície ou contorno de grão) para as regiões de menor potencial químico (sumidouro, correspondente a região do pescoço entre as partículas) durante a sinterização [KINGERY, BERG, 1955; KUCZYNSKI, 1949].

Assim, a cinética do estágio inicial pode ser obtida igualando a massa do pescoço com a massa transportada para o volume do pescoço através do fluxo difusivo conforme Equação (26):

$$
J_{a}=\frac{D_{v}}{\Omega} \frac{d C_{v}}{d L}
$$


onde $J_{a}$ é o fluxo difusivo de átomos, $D_{v}$ é o coeficiente de difusão das lacunas, $\Omega$ é o volume molar de átomos ou lacunas, $\frac{d C_{v}}{d L}$ é o gradiente de concentração das lacunas na fonte , $C_{v}$ é a fração volumétrica de sítios na rede ocupados por lacunas, e $L$ é a menor distância de difusão pelo qual os átomos percorrerem até chegar ao pescoço. $\mathrm{O}$ valor de $L$ será igual a $x$, raio do pescoço, para as difusões pelo contorno de grão e volumétrica a partir do contorno de grão; enquanto que para as difusões superficial e volumétrica a partir da superfície terá valor igual a $r$, raio de curvatura do pescoço.

. Assim, a taxa de transferência com o tempo do volume de matéria para o pescoço será:

$$
\frac{d V}{d t}=J_{a} A_{a} \Omega
$$

onde $A_{a}$ é a área da seção transversal da fonte através da qual a difusão ocorre.

A variação do volume com o tempo pode ser reescrita em função da área do pescoço pela variação do tamanho do pescoço com o tempo. Com isso, a Equação (28) torna-se:

$$
\frac{d V}{d t}=A_{0} \frac{d x}{d t}=J_{a} A_{a} \Omega
$$

onde $A_{0}$ é a área do pescoço dada em função do tipo de mecanismo predominante.

O valor do fluxo difusivo de átomos é considerado igual ao oposto do fluxo das lacunas:

$$
J_{a}=-J_{V}
$$

onde $J_{v}=-\frac{D_{v} C_{v}}{\Omega R T} \frac{d \mu_{v}}{d L}=\frac{D_{v}}{\Omega} \frac{d C_{v}}{d L} ; C_{V}$ é a fração de sítios ocupados pelas lacunas, $D_{V}$ é o coeficiente de difusão das lacunas, e $\mu_{V}$ é o potencial químico da lacunas. Adotando que o potencial químico da lacuna seja independente da sua posição no material e que não haja movimentação de lacunas, tem-se que $\mu_{V}=0$. Desta forma, o fluxo atômico equivale à Equação (26) com $D_{v}=D_{a}$, sendo que o índice $a$ será substituído pelas nomenclaturas associadas com os correspondentes mecanismos governantes.

Assim, a Equação (30) é considerada a Equação geral para todos os mecanismos da sinterização.

$$
A_{0} \frac{d x}{d t}=\left(\frac{D_{a}}{R T} \nabla C_{V}\right) A_{a} \Omega
$$


Considerando duas esferas em contato, Figura 12, o efeito resultante dependerá do tipo de mecanismo atuante, havendo ou não aproximação dos centros das esferas, os valores da área, do volume e do raio de curvatura do pescoço são dados conforme as relações:

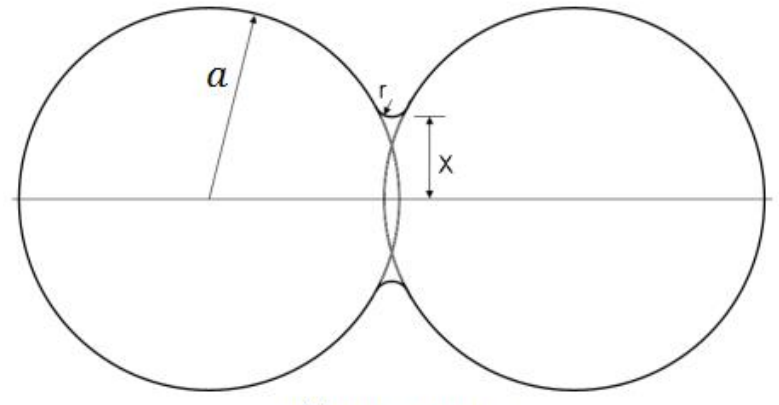

(a) com contração

$$
\begin{gathered}
r=\frac{X^{2}}{4 a} \\
A=\frac{\pi X^{3}}{a} \\
V=\frac{\pi X^{4}}{4 a}
\end{gathered}
$$

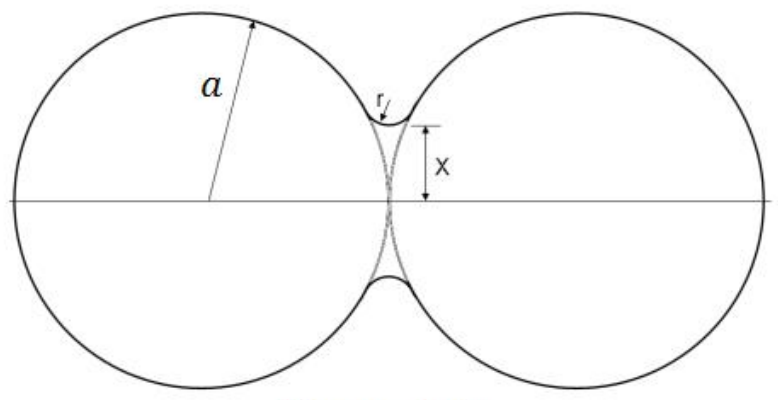

(b) sem contração

$$
\begin{gathered}
r=\frac{X^{2}}{2 a} \\
A=\frac{2 \pi X^{3}}{a} \\
V=\frac{\pi X^{4}}{2 a}
\end{gathered}
$$

Figura 12: Parâmetros geométricos empregados para o modelo de duas esferas [KANG, 2005].

A seguir serão detalhadas as equações específicas para cada mecanismo.

\subsubsection{Difusão pelo contorno de grão a partir do contorno de grão em esferas}

Para o contorno assume-se uma espessura $\delta_{g b}$ associada (Figura 13), $A_{g b}$ é igual a $2 \pi x \delta_{g b}$, $\operatorname{com} x$ sendo o raio do pescoço. Modificando a Equação (30), tem-se:

$$
\frac{d V}{d t}=D_{v} 2 \pi x \delta_{g b} \frac{d C_{v}}{d L}
$$




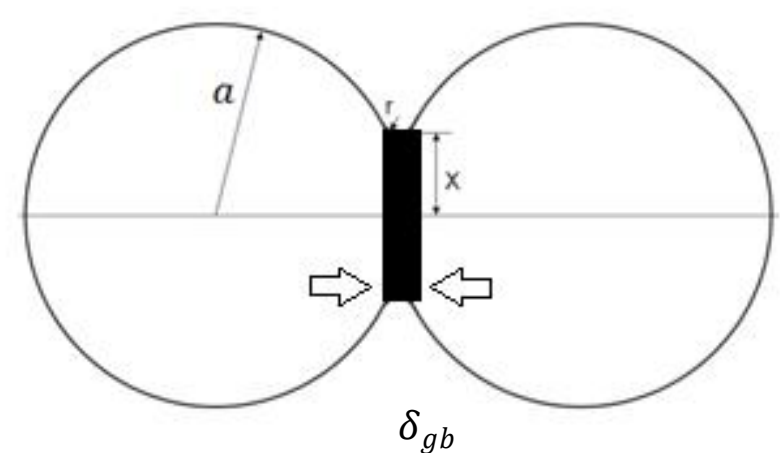

Figura 13: Representação esquemática do mecanismo de difusão pelo contorno de grão.

Desde que o raio do pescoço aumente radialmente, na direção ortogonal à linha de união dos centros das esferas, esta solução unidimensional é adequada. Considerando que a concentração das vacâncias entre a superfície do pescoço e o centro apresente uma variação linear, a razão $\frac{d C_{v}}{d L}$ pode ser reescrita como $\frac{\Delta C_{v}}{L}$, onde $\Delta C_{v}$ é a diferença entre a concentração de vacâncias entre a superfície e o centro do pescoço, e $L$ é a distância de difusão que será igual ao raio do pescoço, $x$. Adotando a concentração no centro do pescoço, $C_{v o}$, como sendo igual àquela de uma superfície plana e ausente de tensão, pode-se calcular a diferença de concentrações, $\Delta C_{v}$, como:

$$
\Delta C_{v}=C_{v}-C_{v o}=\frac{C_{v o} \gamma_{s} \Omega}{k T}\left(\frac{1}{r_{1}}+\frac{1}{r_{2}}\right)
$$

onde $r_{1}$ e $r_{2}$ são os chamados raios de curvatura principais na superfície do pescoço. Pela Figura $13 r_{1}=r$ e $r_{2}=-x$, e considerando $x>>$, simplifica-se a Equação (32) para:

$$
\frac{d V}{d t}=\frac{2 \pi x D_{v} \delta_{g b} C_{v 0} \gamma_{s} \Omega}{k T} \frac{1}{r} \frac{1}{x}
$$

A multiplicação de $D_{v} C_{v o}$ pode ser substituída pelo coeficiente de difusão do contorno de grão, $D_{g b}$. Como o mecanismo de difusão por contorno de grão promove a aproximação dos centros das esferas, há contração dos grãos, a Equação (33) pode ser reescrita como:

$$
\frac{\pi x^{3}}{a} \frac{d x}{d t}=\frac{2 \pi x D_{g b} \delta_{g b} \gamma_{s} \Omega}{k T}\left(\frac{4 a}{x^{2}}\right) \frac{1}{x}
$$

Integrando a Equação (34) com as condições de iniciais iguais a $x=0 \mathrm{et}=0$, tem-se: 


$$
\frac{x}{a}=\left(\frac{48 D_{g b} \delta_{g b} \gamma_{s v} \Omega}{k T a^{4}}\right)^{\frac{1}{6}} t^{\frac{1}{6}}
$$

Com este mecanismo há tanto a formação e crescimento do pescoço como também a aproximação dos centros das partículas, isto é, ocorre a contração com remoção de material da área de contato entre as partículas. A dedução da equação para contração considera que a diferença entre o tamanho inicial e final da partícula é igual ao raio de curvatura do pescoço, assim:

$$
\frac{\Delta l}{l_{0}}=\frac{r}{a}=\frac{x^{2}}{4 a^{2}}
$$

Substituindo o valor do raio do pescoço, $x$, tem-se:

$$
\frac{\Delta l}{l_{0}}=\left(\frac{3 D_{g b} \delta_{g b} \gamma_{s} \Omega}{4 k T a^{2}}\right)^{\frac{1}{3}} t^{\frac{1}{3}}
$$

\subsubsection{Difusão superficial a partir da superfície das partículas em esferas}

A difusão a partir da superfície é dada por uma região com espessura $\delta_{s}$ associada, Figura 14 , e área $A_{s}=2 \pi x 2 \delta_{s}$. Substituindo-se na Equação (30), tem-se:

$$
\frac{d V}{d t}=D_{v} 2 \pi \times 2 \delta_{s} \frac{d C_{v}}{d L}
$$

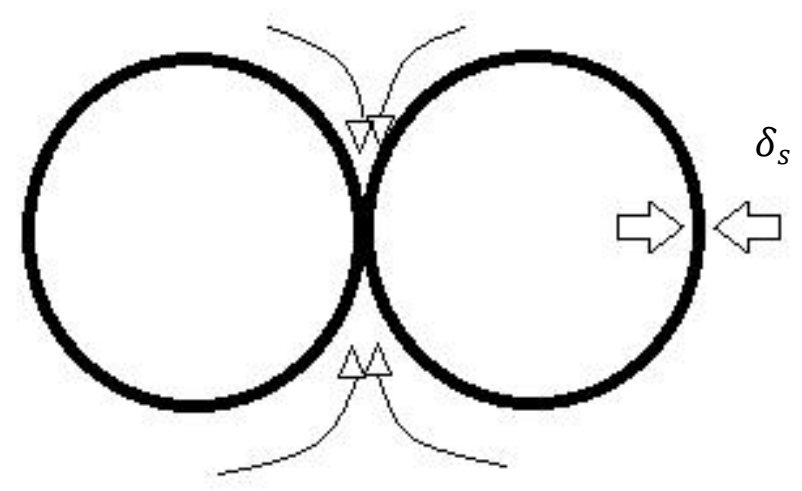

Figura 14: Representação esquemática do mecanismo de sinterização por difusão superficial. 
Assumindo que a concentração das vacâncias entre a superfície do pescoço e o centro tenham uma variação linear, a razão $\frac{d C_{v}}{d L}$ pode ser reescrita como $\frac{\Delta C_{v}}{L}$. A diferença de concentrações, $\Delta C_{v}$, será:

$$
\Delta C_{v}=C_{v}-C_{v 0}=\frac{C_{v 0} \gamma_{s} \Omega}{k T} \frac{1}{r}
$$

E o valor de $L$ será igual ao raio de curvatura do pescoço, $r$. Substituindo na Equação (38) o valor da diferença de concentração, tem-se:

$$
\frac{d V}{d t}=\frac{\left(2 \pi x 2 \delta_{s}\right) D_{v} C_{v o} \gamma_{s} \Omega}{k T r^{2}}
$$

Substitui-se a multiplicação de $D_{v} C_{v o}$ pelo coeficiente de difusão superficial, $D_{s}$. Este mecanismo, diferentemente da difusão pelo contorno de grão, não promove a aproximação dos centros das esferas. Substitui-se os valores do raio de curvatura do pescoço e da área do pescoço conforme equações da Figura 14, tem-se:

$$
\frac{2 \pi x^{3}}{a} \frac{d x}{d t}=\frac{\left(2 \pi x 2 \delta_{s}\right) D_{s} \gamma_{s} \Omega}{k T r}\left(\frac{2 a}{X^{2}}\right)^{2}
$$

Integrando a Equação (41) com as condições iniciais de $X=0$ e t $=0$, tem-se:

$$
\frac{x}{a}=\left(\frac{56 D_{s} \delta_{s} \gamma_{s} \Omega}{k T a^{4}}\right)^{\frac{1}{7}} t^{\frac{1}{7}}
$$

\subsubsection{Difusão volumétrica a partir da superfície das partículas em esferas}

A diferença de concentrações, $\Delta C_{v}$, quando o mecanismo for a difusão volumétrica é dada de acordo pela relação:

$$
\Delta C_{v}=C_{v}-C_{v 0}=\frac{C_{v 0} \gamma_{s} \Omega}{k T} \frac{1}{r}
$$

E o valor de $L$ será igual ao raio de curvatura do pescoço, $r$. Substituindo na Equação (30) o valor da diferença de concentração, tem-se:

$$
\frac{d V}{d t}=\frac{D_{v} C_{v o} \gamma_{s} \Omega}{k T r^{2}}
$$


O coeficiente de difusão volumétrica, $D_{l}$, substitui a multiplicação entre $D_{v} C_{v o}$. Como o mecanismo da difusão superficial, a difusão volumétrica a partir da superfície não promove a aproximação dos centros das esferas, desta forma:

$$
\frac{2 \pi x^{3}}{a} \frac{d x}{d t}=\frac{D_{l} \gamma_{s} \Omega}{k T r}\left(\frac{2 a}{X^{2}}\right)^{2}
$$

Integrando a Equação (45) com as condições iniciais de $X=0$ e t $=0$, tem-se:

$$
\frac{x}{a}=\left(\frac{20 D_{l} \delta_{s} \gamma_{s} \Omega}{k T a^{3}}\right)^{\frac{1}{5}} t^{\frac{1}{5}}
$$

\subsubsection{Difusão volumétrica a partir do contorno de grão em esferas}

Um segundo mecanismo que também utiliza da difusão volumétrica para transporte de matéria ao longo do volume tem o contorno de grão como região de maior potencial químico.

A diferença de concentrações, $\Delta C_{v}$, é dada pela relação:

$$
\Delta C_{v}=C_{v}-C_{v 0}=\frac{C_{v 0} \gamma_{s} \Omega}{k T} \frac{1}{r}
$$

E o valor de $L$ será igual ao rai do pescoço, $x$. Substituindo na Equação (30) o valor da diferença de concentração, tem-se:

$$
\frac{d V}{d t}=\frac{D_{v} C_{v o} \gamma_{s} \Omega}{k \operatorname{Tr} x}
$$

O coeficiente de difusão volumétrica, $D_{l}$, substitui a multiplicação entre $D_{v} C_{v o}$. Assim como o mecanismo da difusão pelo contorno de grão, este mecanismo promove não somente o crescimento do pescoço mas também a aproximação dos centros das esferas, assim:

$$
\frac{\pi x^{3}}{a} \frac{d x}{d t}=\frac{D_{l} \gamma_{s} \Omega}{k T r}\left(\frac{4 a}{X^{2}}\right) \frac{1}{x}
$$

Integrando a Equação (49) nas condições iniciais de $x=0$ e $t=0$, tem-se:

$$
\frac{x}{a}=\left(\frac{16 D_{l} \delta_{s} \gamma_{s} \Omega}{k T a^{3}}\right)^{\frac{1}{4}} t^{\frac{1}{4}}
$$

Assim como o mecanismo de sinterização via difusão pelo contorno de grão, na difusão volumétrica a partir do contorno de grão há contração das esferas durante o processo, desta forma a equação matemática que quantifica esta contração é dada por: 


$$
\frac{\Delta l}{l_{0}}=\frac{r}{a}=\frac{x^{2}}{4 a^{2}}
$$

Substituindo o valor do raio do pescoço, $x$, tem-se:

$$
\frac{\Delta l}{l_{0}}=\left(\frac{D_{l} \gamma_{s} \Omega}{k T a^{3}}\right)^{\frac{1}{2}} t^{\frac{1}{2}}
$$

\subsubsection{Evaporação e condensação em esferas}

Neste mecanismo os átomos se evaporam da superfície esférica e condensam-se na região do pescoço. Quando a distância entre a região de evaporação e condensação é menor do que o caminho livre médio dos átomos gasosos (inversamente proporcional a pressão total do gás no sistema), o mecanismo de evaporação/ condensação é o responsável pelo transporte da fase fictícia, porém se esta distância for maior, o mecanismo predominante será a difusão gasosa.

A cinética de crescimento do pescoço por este mecanismo foi derivada a partir da Equação de Langmuir [LEE, KANG, 2001], pela qual a quantidade de material depositado por unidade de área e tempo é dado por:

$$
m=\alpha \Delta P\left(\frac{M}{2 \pi R T}\right)^{\frac{1}{2}}
$$

onde $\alpha$ é um coeficiente de atrito, que assumirá valor unitário porque não há evaporação, $M$ é o peso molar. Assim:

$$
\frac{d x}{d t}=\frac{m}{d}=\frac{\left(p_{\infty} \frac{\gamma_{s}}{r} \frac{V_{m}}{R T}\right)\left(\frac{M}{2 \pi R T}\right)^{\frac{1}{2}}}{d}
$$

onde $d$ é a densidade do material $\left(d=\frac{M}{V_{m}}\right)$. Integrando a Equação (54) com as condições iniciais de $x=0$ e $\mathrm{t}=0$, tem-se:

$$
x^{3}=\sqrt{\frac{18}{\pi}} \frac{p_{\infty} \gamma_{s}}{d^{2}}\left(\frac{M}{R T}\right)^{\frac{3}{2}} a t
$$


Os mesmos equacionamentos realizados para o sistema constituído por duas esferas em contato foi desenvolvido para dois cilindros, uma vez que a análise pela modelagem com o phase field será estabelecida para um sistema de duas dimensões e a geometria mais adequada é a cilindrica.

Na Figura 15 há uma representação esquemática dos mecanismos densificantes e não densificantes, com as respectivas equações para o raio de curvatura do pescoço, área do pescoço e volume dos cilindros. Estas equações foram inicialmente apresentadas por Uskokovic e Exner [Uskokovic, Exner, 1977] e revisadas para este trabalho.

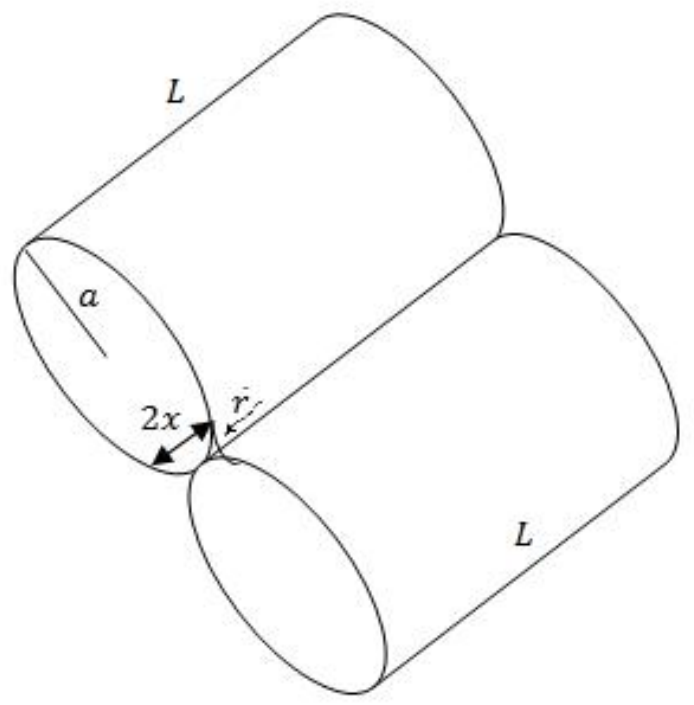

sem contração

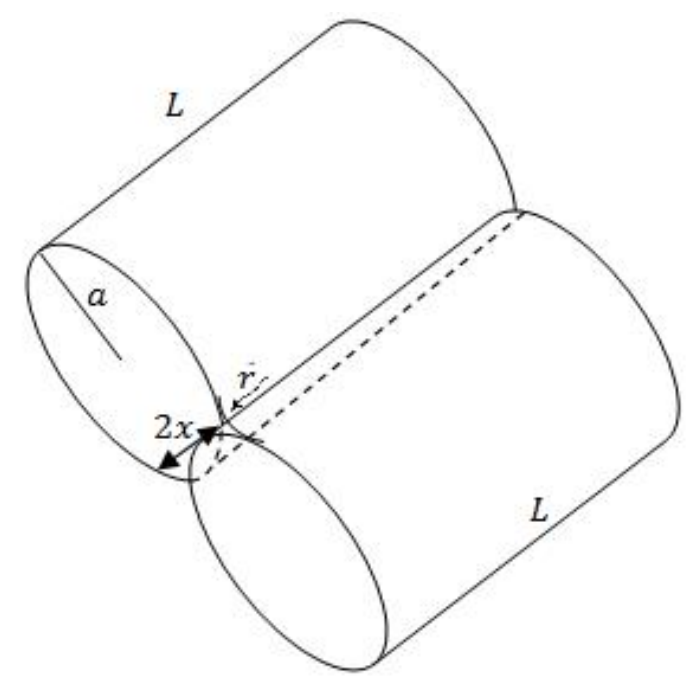

\begin{tabular}{l|r}
$r=\frac{x^{2}}{2 a}$ & $r=\frac{x^{2}}{4 a}$ \\
$A=\frac{2 x^{2} L}{a}$ & $A=\frac{x^{2} L}{a}$ \\
$V=\frac{x^{3} L}{a}$ & $V=\frac{x^{3} L}{2 a}$
\end{tabular}

Figura 15: Parâmetros geométricos empregados para o modelo de dois cilindros [USKOKOVIC, EXNER, 1977].

A seguir serão detalhadas as equações específicas para cada mecanismo.

\subsubsection{Difusão pelo contorno de grão em cilindros}

Para o contorno assume-se uma espessura $\delta_{g b}$ associada ao longo de todo perímetro da região central (Figura 16), substituindo $A_{g b}$ pelo produto entre $\delta_{g b} L$, sendo $l$ o comprimento 
do cilindro, $x$ o raio do pescoço e $L$ a distância de difusão. Fazendo as devidas substituições na Equação (30), tem-se:

$$
\frac{d V}{d t}=D_{v} l \delta_{g b} \frac{d C_{v}}{d L}
$$

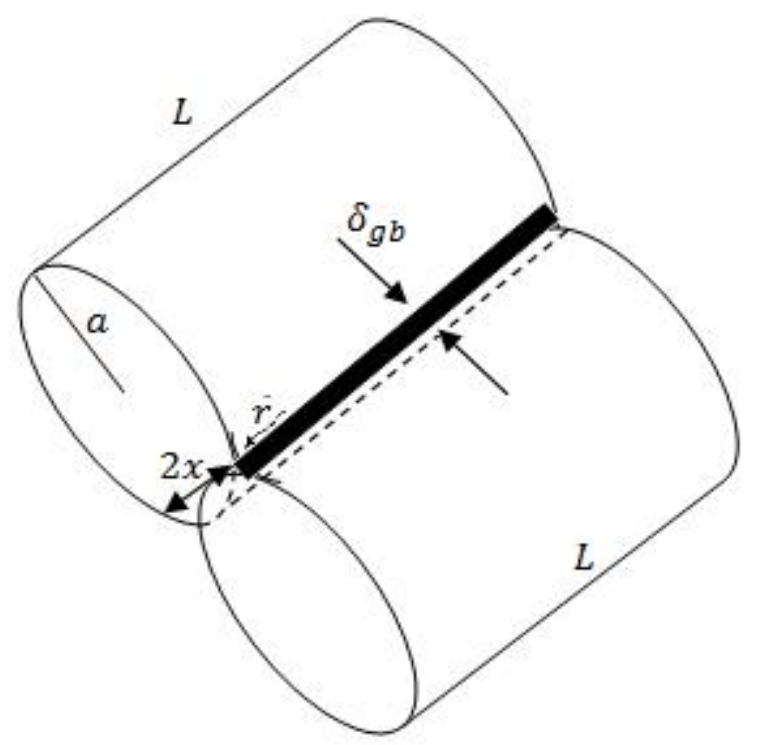

Figura 16: Representação esquemática do mecanismo de difusão pelo contorno de grão.

A diferença entre concentração de vacâncias na superfície e no centro do pescoço $\left(\Delta C_{v}\right)$, será calculada considerando que a concentração no centro do pescoço, $C_{v o}$, igual aquela verificada em uma superfície plana e ausente de tensão, assim:

$$
\Delta C_{v}=C_{v}-C_{v o}=\frac{C_{v o} \gamma_{s} \Omega}{k T}\left(\frac{1}{r_{1}}+\frac{1}{r_{2}}\right)
$$

onde $r_{1}$ e $r_{2}$ são os chamados raios de curvatura principais da superfície do pescoço. Pela Figura 16, $r_{1}=r$ e $r_{2}=-x$ e considerando $x>>r$, a Equação (56) pode ser simplificada para:

$$
\frac{d V}{d t}=\frac{D_{v} l \delta_{g b} C_{v 0} \gamma_{s} \Omega}{k T r L}
$$

A multiplicação entre $D_{v} C_{v o}$ pode ser substituída pelo coeficiente de difusão do contorno de grão, $D_{g b}$, e $L$ será igual ao raio do pescoço $(x)$. Como o mecanismo de difusão por contorno de grão promove a aproximação dos centros das esferas, com contração dos grãos, a Equação (58) pode ser reescrita como:

$$
\frac{x^{2} L}{a} \frac{d X}{d t}=\frac{D_{g b} L \delta_{g b} \gamma_{s} \Omega}{k T}\left(\frac{4 a}{x^{2}}\right)
$$


Integrando a Equação (59) com as condições iniciais d $X=0$ e t $=0$, tem-se:

$$
\frac{x}{a}=\left(\frac{24 D_{g b} \delta_{g b} \gamma_{s} \Omega}{k T a^{4}}\right)^{\frac{1}{6}} t^{\frac{1}{6}}
$$

O resultado para os cilindros (Equação (60)) é metade da mesma relação obtida para duas esferas (Equação (35)). Isto deve-se a variação na área superficial em que o fluxo é originado.

\subsubsection{Difusão superficial a partir da superfície das partículas em cilindros}

A difusão a partir da superfície é dada por uma região com espessura $\delta_{s}$ (Figura 17), e área $A_{s}$ igual à $2 \delta_{s} L$. Fazendo as devidas substituições na Equação (30), tem-se:

$$
\frac{d V}{d t}=D_{v} 2 \delta_{s} l \frac{d C_{v}}{d L}
$$

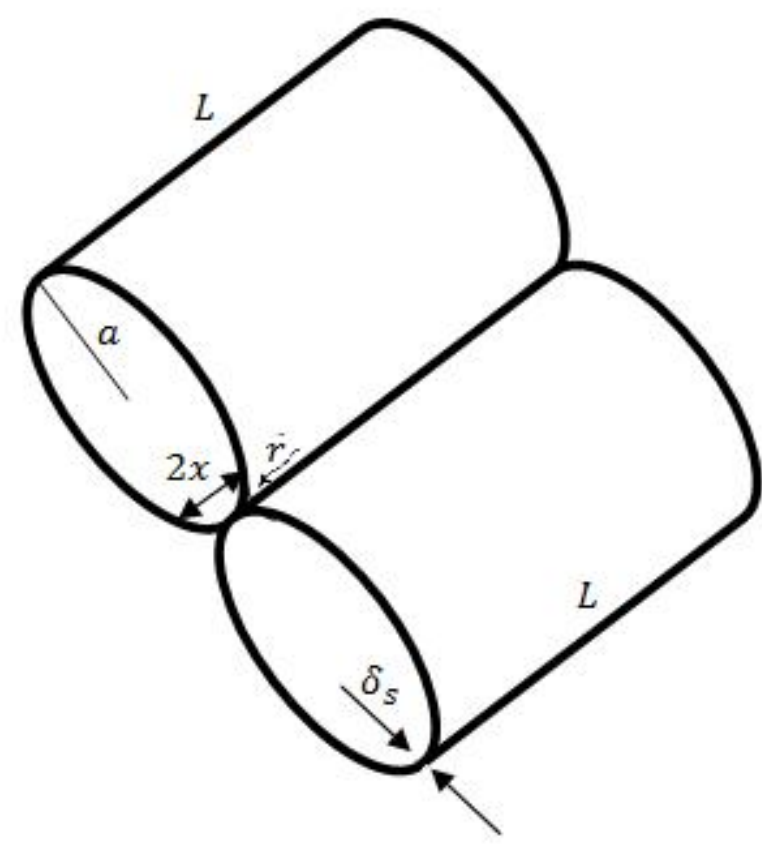

Figura 17: Representação esquemática do mecanismo de sinterização por difusão superficial.

Assumindo que a concentração das vacâncias entre a superfície do pescoço e o centro varie linearmente, a razão $\frac{d C_{v}}{d L}$ pode ser reescrita como $\frac{\Delta C_{v}}{L}$. A diferença de concentrações, $\Delta C_{v}$, será: 


$$
\Delta C_{v}=C_{v}-C_{v 0}=\frac{C_{v 0} \gamma_{s} \Omega}{k T} \frac{1}{r}
$$

E $L$ será igual ao raio de curvatura do pescoço (r). Substituindo na Equação (61) o valor da diferença de concentração, tem-se:

$$
\frac{d V}{d t}=\frac{D_{v}\left(2 \delta_{s} l\right) C_{v 0} \gamma_{s} \Omega}{k T r^{2}}
$$

Substitui-se a multiplicação de $D_{v} C_{v o}$ pelo coeficiente de difusão superficial, $D_{s}$. Este mecanismo não promove a aproximação dos centros das esferas apenas o crescimento do pescoço. Substituindo o valor do raio de curvatura do pescoço e a área do pescoço conforme equações da Figura 15, tem-se:

$$
\frac{x^{2}}{a} \frac{d x}{d t}=\frac{D_{s}\left(2 \delta_{s} l\right) \gamma_{s} \Omega}{k T r}\left(\frac{2 a}{x^{2}}\right)
$$

Integrando a Equação (64) com as condições iniciais de $X=0$ e t $=0$, tem-se:

$$
\frac{x}{a}=\left(\frac{56 D_{s} \delta_{s} \gamma_{s} \Omega}{k T a^{4}}\right)^{\frac{1}{7}} t^{\frac{1}{7}}
$$

Observa-se que o resultado final é o mesmo obtido para a conFiguração de duas esferas em contato.

\subsubsection{Difusão volumétrica a partir da superfície das partícula em cilindros}

A diferença de concentrações pela distância de difusão, $\frac{\Delta C_{v}}{L}$, associada a difusão volumétrica é dada pela relação:

$$
\frac{\Delta C_{v}}{L}=\frac{C_{v}-C_{v 0}}{L}=\frac{C_{v 0} \gamma_{s} \Omega}{k T} \frac{1}{r} \frac{1}{r}
$$

Substituindo na Equação (30) o valor da diferença de concentração, tem-se:

$$
\frac{d V}{d t}=\frac{D_{v} C_{v o} \gamma_{s} \Omega}{k T r^{2}}
$$


O coeficiente de difusão volumétrica, $D_{l}$, substitui a multiplicação entre $D_{v} C_{v o}$. Como o mecanismo da difusão superficial, a difusão volumétrica a partir da superfície da partícula não promove a aproximação dos centros das esferas. Desta forma:

$$
\frac{x^{2} L}{a} \frac{d x}{d t}=\frac{D_{l} \gamma_{s} \Omega}{k T}\left(\frac{2 a}{x^{2}}\right)^{2} \frac{x^{2} L}{a}
$$

Integrando a Equação (68) para as condições iniciais iguais a $X=0$ e t $=0$, tem-se:

$$
\frac{x}{a}=\left(\frac{20 D_{l} \delta_{s} \gamma_{s} \Omega}{k T a^{3}}\right)^{\frac{1}{5}} \frac{1}{t^{5}}
$$

Como as áreas do pescoço e superficial da região fonte de material para a difusão são equivalentes entre cilindros e esferas, o resultado da Equação final será o mesmo.

\subsubsection{Difusão volumétrica a partir do contorno de grão em cilindros}

Este é o segundo mecanismo que possui a difusão volumétrica como mecanismo de transporte de matéria, e que apresenta o contorno de grão como região com maior potencial químico.

A diferença de concentrações pela distância de difusão, $\frac{\Delta C_{v}}{L}$, é dada pela relação:

$$
\frac{\Delta C_{v}}{L}=\frac{C_{v}-C_{v 0}}{L}=\frac{C_{v 0} \gamma_{s} \Omega}{k T} \frac{1}{r} \frac{1}{x}
$$

Substituindo na Equação (30) o valor da diferença de concentração, tem-se:

$$
\frac{d V}{d t}=\frac{D_{v} C_{v o} \gamma_{s} \Omega}{k \operatorname{Tr} x}
$$

O coeficiente de difusão volumétrica, $D_{l}$, substitui a multiplicação ente $D_{v} C_{v o}$. Como o mecanismo da difusão pelo contorno de grão, este mecanismo promove não somente o crescimento do pescoço mas também a aproximação dos centros das esferas, assim:

$$
\frac{x^{2} l}{a} \frac{d x}{d t}=\frac{D_{l} \gamma_{s} \Omega}{k T}\left(\frac{4 a}{x^{2}}\right) \frac{1}{x} \frac{x^{2} l}{a}
$$

Integrando a Equação (72) para as condições iniciais de $X=0$ e t $=0$, tem-se:

$$
\frac{x}{a}=\left(\frac{16 D_{l} \delta_{s} \gamma_{s} \Omega}{k T a^{3}}\right)^{\frac{1}{4}} t^{\frac{1}{4}}
$$


Assim como na difusão volumétrica a partir da superfície, neste mecanismo há coincidência entre os resultados obtidos para as geometrias esféricas e cilíndricas, uma vez que as área são equivalentes.

\subsubsection{Mecanismos Combinados - Equação Geral}

O desenvolvimento da equação geral incluindo os quatro principais mecanismos dominantes da sinterização de metais (difusão volumétrica a partir da superfície, difusão volumétrica a partir do contorno de grão, difusão superficial e difusão pelo contorno de grão) foi formulado a partir do somatório dos fluxos individuais desses mecanismos.

Como nem todos os mecanismos são densificantes, mas todos são não densificantes, utilizou-se como raio de curvatura do pescoço a razão: $r=\frac{x^{2}}{2 a}$.

A combinação dos principais mecanismos é dada pela Equação (74):

$$
\frac{d V}{d t}=(J A \Omega)_{V S}+(J A \Omega)_{V B}+(J A \Omega)_{S S}+(J A \Omega)_{B B}
$$

Os índices indicam o mecanismo atuante, sendo: $V S$ - difusão volumétrica a partir da superfície, $V B$ - difusão volumétrica a partir do contorno de grão, $S S$ - difusão superficial a partir da superfície, $B B$ - difusão do contorno de grão a partir do contorno de grão.

Substituindo cada fluxo atômico pelas equações gerais de cada mecanismo correspondente, tem-se a Equação (75):

$$
A_{0} \frac{d x}{d t}=\frac{D_{v} \gamma_{s} \Omega A_{0}}{k \operatorname{Tr}^{2}}+\frac{D_{v} \gamma_{s} \Omega A_{0}}{k \operatorname{Tr} x}+\frac{2 \pi x 2 \delta_{s} D_{s} \gamma_{s} \Omega}{k \operatorname{Tr}^{2}}+\frac{2 \pi x D_{g b} \delta_{g b} \gamma_{s} \Omega}{k \operatorname{Tr} x}
$$

Sendo que a área do pescoço, $A_{0}$, é igual a $\frac{2 \pi x^{3}}{a}$. Esta área é a mesma para as duas difusões volumétricas, pois como o próprio nome indica, elas ocorrem no interior do volume do átomo.

Substituindo $A_{0}$ e $r$ na Equação (75), e fazendo as devidas simplificações obtém-se a Equação (76): 


$$
\frac{d x}{d t}=\frac{4 a^{2} D_{v} \gamma_{s} \Omega}{k T}+\frac{2 a}{x^{4}} \frac{D_{v} \gamma_{s} \Omega}{k T}+\frac{8 a^{3}}{x^{6}} \frac{D_{s} \delta_{s} \gamma_{s} \Omega}{k T}+\frac{2 a^{2}}{x^{5}} \frac{D_{g b} \delta_{g b} \gamma_{s} \Omega}{k T}
$$

$\mathrm{Na}$ Equação (76) é possível observar que cada mecanismo contribui individualmente para a sinterização. A predominância de um determinando mecanismo será dada pela relevância que o mesmo terá frente aos demais, o coeficiente da difusão e o tamanho do raio do pescoço (x) são os responsáveis por impor tal distinção, a qual pode variar ao longo do processo.

A resolução numérica da Equação (76) foi feita empregando o método de Euler implícito, com o raio da esfera/cilindro (a) dado pela média dos raios experimentais, o passo de tempo e o número de nós da malha foram ajustados individualmente para cada artigo dependendo da duração de tempo dos respectivos processos de sinterização.

\subsection{Análise estatística}

Uma análise estatística foi adotada a fim de permitir uma interpretação mais detalhada dos resultados, ao invés de usar apenas os gráficos (qualitativa) e os expoentes do tempo. Para isso utilizou-se das seguintes equações:

$$
\begin{gathered}
\text { Erro relativo (\%) }=\sum_{i=1}^{N}\left\{\frac{\left|E X P_{i}-A N_{i}\right|}{N \cdot E X P_{i}}\right\} \\
\qquad \text { Erro }=\frac{\sum_{i=1}^{N}\left(E X P_{i}-A N_{i}\right)}{N} \\
\text { Desvio Padrão (SD) }=\sqrt{\frac{\sum_{i=1}^{N}\left[\left(E X P_{i}-A N_{i}\right)-e r r o\right]^{2}}{N-1}}
\end{gathered}
$$




$$
\text { Intervalo crítico }(\mathrm{CI})= \pm t \underset{\frac{0.05}{2}, N-1}{\frac{S D}{\sqrt{N}}}
$$

onde $E X P_{i}$ e $A N_{i}$ correspondem, respectivamente, aos valores medidos experimentalmente (dados da literatura) e calculados a partir da equações analíticas das razões entre tamanho do pescoço pelo tamanho da partícula $\left(\frac{x}{a}\right)$ e variação do comprimento pelo comprimento inicial $\left(\frac{\Delta L}{L_{0}}\right)$ nas amostras $i$ de um conjunto de $N$ amostras.

Adotando a hipótese de que a média do valor do erro é igual a zero, define-se o erro como sendo a média entre os erros sistemáticos do modelo e os erros aleatórios do experimento. Quando há uma grande quantidade de pontos para análise $(N)$, os erros aleatórios se cancelam entre si pela hipótese adotada inicialmente, e o erro para a ser exclusivamente o erro do modelo. O erro relativo é a média dos erros relativos que combinam os efeitos dos erros sistemáticos do modelo e randômicos/ aleatórios do experimento; $S D$ é o desvio padrão dos erros, é a medida da dispersão em torno da média da variável aleatória; $C I$ é o intervalo crítico o qual considera, com nível de significância de 5\%, que o erro médio seja proveniente de uma população com uma média de erros igual a zero; $t_{\frac{0.05}{2}, N-1}$ é o valor da distribuição bicaudal de $t$-Student com $N-1$ graus de liberdade e área contida nas duas caudas igual a 0,025 .

Com esses parâmetros, três tipos de erros são analisados para cada um dos mecanismos de sinterização:

1. A combinação dos erros sistemáticos e randômicos, dados pelo erro relativo absoluto (Equação (77)), revelam a qualidade geral do método;

2. Erros sistemáticos estão relacionados com a existência de viés (bias) e são calculados com a equação do erro (Equação (78)), lembrando que os erros aleatórios positivos e negativos de mesmo módulo se cancelam;

3. Erros randômicos ou aleatórios, os quais mostram a dispersão nos cálculos, dado pelo SD (Equação (79)). O método é considerado errado quando o valor médio do erro (Equação (78)) estiver fora do intervalo crítico - CI (Equação (80)). 
Para a análise estatística, assumiu a hipótese de que os dados experimentais não possuíam erros sistemáticos, apenas erros de medida.

\subsection{Proposta de um Modelo de Campo de Fases para a Sinterização}

\subsubsection{Aspectos Gerais e Hipóteses do Modelo de Campo de Fases}

Um modelo matemático bidimensional baseado no método do campo de fases foi implementado para prever a evolução com o tempo da sinterização isotérmica de cilindros sólidos imersos em um meio gasoso inerte. Apesar das equações principais do modelo serem gerais, elas serão aplicadas para prever a sinterização pelo mecanismo de difusão de lacunas no interior de cilindros de cobre puro imersos em um gás inerte mantido à pressão atmosférica. Todos os outros mecanismos de transporte de massa, como a difusão na fase fíctícia, serão desprezados. A fase sólida será considerada como uma solução binária $\mathrm{Cu}$-lacuna, a fase fictícia será desconsiderada e o espaço que ela ocupa no sistema real será substituído por uma fase fictícia também do sistema $\mathrm{Cu}$-lacuna. As justificativas para estas hipóteses estão apresentadas no item 4.3.2. A concentração de lacunas no sólido junto à interface sólido-fase fictícia será definida pelo equilíbrio termodinâmico local, incluindo os efeitos da curvatura e da energia interfacial. O equilíbrio local é empregado de forma geral para o tratamento das transformações de fase e em particular nos modelos analíticos de sinterização. Este equilíbrio pode ser assumido quando a cinética de transferência de átomos através da interface sólidofase fictícia for muito mais rápida do que a transferência no interior dos meios adjacentes [PORTER; EASTERLING, 1992]. Esta hipótese poderia, por exemplo, ser violada nos instantes iniciais do estágio I da sinterização, quando a velocidade de movimentação do pescoço é relativamente elevada e a cinética de movimentação através da interface poderia limitar o transporte de massa.

No presente trabalho, os aspectos termodinâmicos, como os efeitos das curvaturas nas concentrações de lacunas em equilíbrio, serão modelados e verificados cuidadosamente, por se entender que são fundamentais para simulações quantitativas da sinterização. Como o transporte de massa na fase fictícia é desprezível durante a sinterização do $\mathrm{Cu}$, esta fase não será considerada no modelo de campo de fases, porém o seu efeito na região da interface sólido-fase fictícia será garantido no modelo.

Apesar do método do campo de fases já ter sido utilizado para desenvolver alguns modelos para sinterização [ASP, AGREN, 2006; WANG, 2006; LIU, GAO, HU, 2010; KUMAR, 2011; DENG, 2012; SHINAGAWA, 2014; ZHANG et al, 2014], os modelos 
resultantes são incapazes de apresentar resultados quantitativos corretos. Estes modelos foram baseados em uma variação de um método do campo de fases conhecido como modelo WBM [Wheeler-Boettinger-McFadden], proposto por Wheeler et al. [WHEELER et al., 1992], para simular a solidificação de ligas binárias. O modelo WBM apresenta sérias limitações para se impor o valor correto da energia da interface sólido-fase fictícia, que é essencial para simular a sinterização. Kim et al. [KIM et al., 1998] e Echebarria et al. [ECHEBARRIA et al., 2004] mostraram que valores de energia interfacial cada vez menores exigem a definição de interfaces difusas com espessuras cada vez menores, ou seja, a energia interfacial e a espessura da interface difusa adotada nas simulações não são independentes. Em alguns testes preliminares conduzidos no presente trabalho com o modelo WBM, notou-se que a espessura da interface difusa deveria ser da ordem de $10^{-10} \mathrm{~m}$ para ser possível introduzir uma interface sólido-fase fictícia com a energia interfacial específica do cobre puro $\left(1,2 \mathrm{~mJ} / \mathrm{m}^{2}\right)$. Uma espessura de interface difusa de $10^{-10} \mathrm{~m}$ exigiria uma malha numérica com um número inviável de elementos, pois esta malha densa deve estender-se por todo o grão que está sofrendo sinterização. Com o intuito de evitar este problema, o modelo de campo de fases proposto por Kim et al. [KIM et al., 1999] foi adotado no presente trabalho. Os autores Kim et al. [KIM et al., 1999] mostraram que este modelo não apresenta as limitações do modelo WBM e pode ser utilizado para soluções diluídas ou concentradas, ao contrário do modelo de Echebarria et al. [ECHEBARRIA et al., 2004], que apesar de ser uma extensão natural do modelo WBM e, portanto, ser mais conveniente, só pode ser aplicado para soluções diluídas.

O modelo de campo de fases proposto por Kim et al. [KIM et al., 1999], que foi aplicado para simular a solidificação de ligas binárias, foi adaptado no presente trabalho para simular a sinterização. Apesar da possibilidade de se definir o valor da energia interfacial e a espessura da interface difusa independentemente neste modelo, a espessura da interface difusa sólido-fase fictícia deve ser aproximadamente uma ordem de grandeza menor do que o tamanho do aspecto microestrutural que se deseja simular. No caso da sinterização, o raio de curvatura do pescoço é o menor tamanho microestrutural importante. Entretanto, teoricamente este raio tende a zero no início do processo, o que acarretaria novamente na necessidade de se adotar uma espessura excessivamente reduzida para a interface gás-sólido, acarretando em uma malha numérica com um número de elementos suficientemente grande para inviabilizar as simulações em um tempo possível. Com o objetivo de diminuir o número de elementos necessários e mesmo assim manter uma malha numérica suficientemente refinada na região da interface sólido-fase fictícia, foi adotada a técnica da malha adaptativa proposta por Lan et al. (2002a, 2002b), baseada em uma estrutura de malha chamada de quadtree (SAMET, 1984; 
1990). Apesar desta técnica ter causado uma redução significativa no tempo de processamento, a simulação do estágio I da sinterização ainda envolveria tempos de simulação proibitivos. Portanto, o código computacional foi convertido para ser processado pelos núcleos da placa de vídeo (GPU - "Graphics Processing Unit”), reduzindo significativamente o tempo total de processamento.

Inicialmente o domínio de simulação, as equações diferenciais do modelo de campo de fases e suas condições de contorno serão apresentadas. Posteriormente, serão descritas as funções termodinâmicas que descrevem a energia livre das fases sólida e gasosa. Finalmente as técnicas empregadas para a solução numérica das equações diferenciais serão mostradas.

\subsubsection{Descrição Termodinâmica do Sistema Modelado}

\subsubsection{Hipóteses e Considerações do Modelo Termodinâmico}

A sinterização de $\mathrm{Cu}$ puro sólido imerso em um gás inerte consiste idealmente da fase fictícia contendo átomos de $\mathrm{Cu}$ e de, por exemplo, argônio, e da fase sólida $\alpha-\mathrm{Cu}$ contendo átomos de $\mathrm{Cu}$, lacunas e átomos de Ar. Em termos práticos, as frações molares de lacunas na fase $\alpha-\mathrm{Cu}$ e de $\mathrm{Cu}$ na fase fictícia são relativamente reduzidas nas condições mais comuns de sinterização, enquanto a fração molar de Ar na fase $\alpha-\mathrm{Cu}$ é praticamente nula. Uma descrição deste sistema deve considerar uma fase fictícia binária $\mathrm{Cu}-\mathrm{Ar}$ e uma fase sólida ternária $\mathrm{Cu}$ lacunas-Ar, tratando as lacunas também como uma espécie química. Inicialmente será apresentada uma análise de equilíbrio termodinâmico deste sistema, indicando o seu

comportamento e as variáveis importantes e permitindo comparações e validações dos resultados do modelo de campo de fases.

Quando as duas fases estão a mesma temperatura (condições isotérmicas), possuem composição uniforme, estão em contato por meio de uma interface sólido-fase fictícia com curvatura local $\mathrm{K}$ uniforme sobre a superfície e estão em equilíbrio termodinâmico, as seguintes condições devem existir [DEHOFF, 2006]

$$
\begin{gathered}
\mu_{C u}^{s}\left(T, P^{s}, X_{C u}^{s}, X_{v}^{s}\right)=\mu_{C u}^{g}\left(T, P^{g}, X_{C u}^{g}\right) \\
\mu_{A r}^{s}\left(T, P^{s}, X_{C u}^{s}, X_{v}^{s}\right)=\mu_{A r}^{g}\left(T, P^{g}, X_{C u}^{g}\right) \\
\mu_{v}^{s}\left(T, P^{s}, X_{C u}^{s}, X_{v}^{s}\right)=0 \\
P^{s}=P^{g}+2 \gamma_{s} \mathrm{~K}
\end{gathered}
$$

além de

$$
\begin{gathered}
X_{v}^{s}+X_{C u}^{s}+X_{A r}^{s}=1 \\
X_{C u}^{g}+X_{A r}^{g}=1
\end{gathered}
$$


onde $\mathrm{K}=\frac{1}{2}\left(\frac{1}{r_{1}}+\frac{1}{r_{1}}\right) ; \mu_{C u}^{S}$, $\mu_{A r}^{S}$ e $\mu_{v}^{S}$ são os potenciais químicos do $\mathrm{Cu}$, do Ar e das lacunas na fase sólida; $\mu_{C u}^{g}$ e $\mu_{A r}^{g}$ são os potenciais químicos do $\mathrm{Cu}$ e do Ar no gás; $X_{C u}^{g}$ é a fração molar de $\mathrm{Cu}$ no gás; $X_{C u}^{S}$ é a fração molar sítios do reticulado do sólido ocupados por átomos de $\mathrm{Cu}$, ou seja, a fração molar de $\mathrm{Cu}$ na mistura Cu-lacunas-Ar; $X_{A r}^{S}$ e $X_{A r}^{g}$ são as frações molares de átomos de Ar no reticulado do sólido e no gás, respectivamente; $P^{s}$ e $P^{g}$ são as pressões da fase sólida e gasosa, respectivamente, sendo que $P^{g}$ será mantido igual à pressão atmosférica no presente trabalho. Não há lacunas na fase fictícia, portanto não é possível existir transferência de lacunas desta fase para o sólido. Porém, as lacunas podem ser criadas no interior do sólido ou na interface sólido-fase fictícia a partir do rearranjo dos átomos de $\mathrm{Cu}$ na região da interface [USKOKOVIC, EXNER, 1977; WAKAI, 2006; McDONALD et al, 2017]. Esta particularidade implica no potencial químico nulo das lacunas no sólido, ou seja, na Equação (33) [DEHOFF, 2006]. No presente modelo, será assumido que as lacunas serão criadas apenas na interface sólido-fase fictícia, sendo conservadas no interior do sólido. Está é uma hipótese frequentemente utilizada nos modelos analíticos descritos no item 4.1.

As Equações (83) a (86) permitem o cálculo de $X_{v}^{s}, X_{C u}^{s}, X_{A r}^{s}, X_{C u}^{g}, X_{A r}^{g}$ e $P^{s}$ no equilíbrio termodinâmico entre as fases quando os valores de $T, P^{g}$ e $\mathrm{K}$ são fornecidos. Quando não há equilíbrio termodinâmico, como é o caso de um sistema que está sofrendo sinterização, estes valores ainda estão presentes na fase sólida e gasosa junto à sua interface devido ao equilíbrio termodinâmico local, que é uma hipótese muito assumida na sinterização. Desta forma, as Equações (83) a (86)permitem o cálculo da composição do sólido e do gás adjacentes à interface (incluindo o efeito de curvatura da interface e energia interfacial) durante o processo de sinterização, informações que são necessárias para qualquer tipo de modelo matemático de sinterização.

Segundo a descrição termodinâmica apresentada, a fase sólida é um sistema ternário (Cu-lacunas-Ar), enquanto a fase fíctícia é um sistema binário ( $\mathrm{Cu}-\mathrm{Ar})$. No entanto, os modelos de campo de fases validados e aceitos atualmente foram desenvolvidos considerando que todas as fases têm o mesmo número de componentes ou espécies. Logo, para a modelagem com o método do campo de fases, a fase sólida e a fase fictícia deveriam ser assumidas ternárias, ou seja, seria necessário considerar a presença de lacunas também na fase fictícia, complicando a descrição termodinâmica.

É possível, entretanto, realizar simplificações reconhecendo que o objetivo do presente modelo de campo de fases é considerar apenas o mecanismo de difusão de lacunas na fase sólida, desprezando o transporte de massa na fase fictícia. O transporte de lacunas no 
contorno entre dois grãos do sólido ou na interface sólido-fase fictícia também ocorrerá no modelo proposto, porém, o coeficiente de difusão de lacunas nestas duas regiões será assumido igual ao do interior do sólido. Os modelos analíticos apresentados no item 4.1 mostram que a sinterização resultante apenas do mecanismo de difusão de lacunas na fase sólida é corretamente modelada, independentemente da consideração ou não da fase fictícia, quando: (1) calcula-se a difusão das lacunas no interior do sólido assumindo que a quantidade de lacunas é conservada, ou seja, não há fontes ou sorvedouros no interior do sólido; (2) calcula-se a concentração de lacunas no sólido junto à interface de acordo com o equilíbrio termodinâmico local, incluindo o efeito da curvatura local da interface e da energia interfacial; e (3) considera-se que as lacunas são criadas ou eliminadas apenas na interface sólido-fase fictícia e que este processo determina o deslocamento da interface, desprezando o efeito da reduzida concentração de átomos de $\mathrm{Cu}$ na fase fictícia junto a esta interface.

Um modelo de campo de fases binário $\mathrm{Cu}$-lacunas está sendo proposto no presente trabalho onde existe apenas a fase sólida, ou seja, a fase fictícia não é considerada, mas os três requisitos apresentados acima são garantidos de forma precisa ou aproximada para que a sinterização dada pela difusão de lacunas na fase sólida seja corretamente modelada. O cálculo da difusão das lacunas com conservação no interior da fase sólida (requisito 1) será automaticamente imposto ao se utilizar a Equação (127), baseada no princípio de conservação das espécies químicas e desenvolvida no item 4.3.3.2, para prever a evolução da fração molar de lacunas no interior do sólido.

O requisito (2), relacionado ao equilíbrio local dado pelas equações (83) a (86), será garantido de forma aproximada após uma simplificação destas equações para tentar eliminar o componente Ar, tornando binária a fase sólida, e para eliminar a fase fictícia, que tem transporte de massa nulo no seu interior. Estas duas eliminações facilitam a construção de um modelo binário de campo de fases. A fração molar de átomos de Ar na fase sólida $\left(X_{A r}^{S}\right)$ é praticamente nula e, portanto, o potencial químico das lacunas no sólido $\left(\mu_{v}^{s}\right)$ pode ser assumido independente desta concentração, permitindo considerar a fase sólida como binária. Neste caso, a fração de lacunas de equilíbrio no sólido $\left(X_{v}^{S}\right)$, incluindo o efeito da curvatura da interface e da energia interfacial, pode ser calculada por

$$
\begin{gathered}
\mu_{v}^{s}\left(T, P^{s}, X_{v}^{s}\right)=0 \\
P^{s}=P^{g}+2 \gamma_{s} \mathrm{~K} \\
X_{v}^{s}+X_{C u}^{s}=1
\end{gathered}
$$


Estas equações mostram que, ao se considerar o equilíbrio termodinâmico local, o efeito da fase fictícia sobre a concentração de lacunas no sólido $\left(X_{v}^{S}\right)$ junto à interface ocorre apenas pela definição da pressão total do gás $\left(P^{g}\right)$, que altera a pressão no sólido $\left(P^{s}\right)$ e, consequentemente, o potencial químico das lacunas no sólido $\left(\mu_{v}^{S}\right)$. Como mencionado, $P^{g}$ será mantida constante, igual à pressão atmosférica. A partir destas equações, $X_{v}^{s}$ junto à interface e $P^{s}$ podem ser determinados se $T, P^{g}$ e $\mathrm{K}$ forem conhecidos. A fase sólida será considerada como uma solução binária $\mathrm{Cu}$-lacunas e, no espaço onde estaria o gás, será assumida a existência de uma fase fictícia $\left(g^{\prime}\right)$ binária $\mathrm{Cu}$-lacunas que tem o objetivo de auxiliar o cumprimento dos requisitos (2) e (3) sem a presença da fase fictícia. Este sistema binário simplificado pode ser modelado pelo método do campo de fases.

A garantia do requisito (2) equivale a garantir o resultado dado pelas Equações (87) a (89) nas duas fases junto à interface. Análises assintóticas mostram que os modelos de campo de fases garantem que as composições das fases que nele são consideradas $\left(X_{v}^{s}\right.$ e $X_{v}^{g^{\prime}}$ no presente modelo) junto à interface são dadas pela tangente comum das curvas de energia livre molar do sólido, $F^{s}\left(T, P^{s}\left(P^{g}, \mathrm{~K}\right), X_{v}^{s}\right)$, e da energia molar da fase fictícia, $F^{g^{\prime}}\left(X_{v}^{g^{\prime}}\right)$, incluindo o efeito de curvatura da interface e da energia interfacial (equilíbrio local). Para isto deve-se introduzir nas equações do modelo de campo de fases as duas funções de energia livre molar $\left(F^{s}\right.$ e $\left.F^{g^{\prime}}\right)$ obtidas para curvatura nula $(\mathrm{K}=0)$, ou seja, para $P^{s}=P^{g}$, e garantir que a cinética de transferência de átomos através da interface não seja limitante [BOETTINGER; WARREN, 1996; WHEELER et al., 1992; KIM et al., 1992], o que pode ser imposto ajustando-se o valor da mobilidade da variável de fase, $M_{\phi}$ (parâmetro da Equação (117), deduzida no item 4.3.3.1). A imposição das Equações (87) e (88) no modelo do campo de fases implica em definir $F^{g^{\prime}}$ de forma que a sua tangente comum com a curva $F^{s}$ passe pelo ponto $F^{g^{\prime}}=0$ em $X_{v}^{g^{\prime}}=1$ da função $F^{g^{\prime}}\left(X_{v}^{g^{\prime}}\right)$.

A primeira parte do requisito (3), ou seja, a criação/eliminação de lacunas na interface sólido-fase fictícia, está garantida pela existência da fase fictícia contendo átomos de $\mathrm{Cu}$ e lacunas. Esta fase, no interior da qual não há transporte e que está ao lado da interface, pode fornecer as lacunas necessárias para a região da interface ou acomodar as lacunas que nela foram eliminadas. As equações do modelo de campo de fases tentam automaticamente manter o valor de $X_{v}^{s}$ dado pelo equilíbrio local no sólido junto à interface a partir da coleta ou depósito de lacunas na fase fictícia junto à interface, que funciona como uma fonte/sorvedouro de lacunas. A segunda parte do requisito (3) é o cálculo correto da 
velocidade de deslocamento da interface sólido-fase fictícia, causada pela criação/eliminação das lacunas. No sistema completo, onde a fase sólida é composta de átomos de $\mathrm{Cu}$ e lacunas e a fase fictícia de átomos de $\mathrm{Cu}$ e $\mathrm{Ar}$, a quantidade de átomos de $\mathrm{Cu}$ deve ser conservada independente de um sistema ser binário e outro ternário. Esta conservação permite escrever uma Equação que mostra a correta dependência da velocidade local da interface sólido-fase fictícia $\left(\vec{V}_{i}\right)$ em relação aos fluxos de átomos de $\mathrm{Cu}$ junto à interface. Esta Equação, dada a seguir para o sistema real completo, é sempre válida em interfaces, sendo conhecida como “condição de salto" (“jump condition”) para o balanço de espécies químicas [SLATTERY, 1999]

$$
\left(\rho_{m}^{s} X_{C u}^{s}-\rho_{m}^{g} X_{C u}^{g}\right) \vec{V}_{i} \cdot \vec{n}=\left(\vec{J}_{C u}^{s}-\vec{J}_{C u}^{g}\right) \cdot \vec{n}
$$

onde $X_{C u}^{s}$ e $X_{C u}^{g}$ são frações molares nas fases sólida e gasosa, junto à interface; $\rho_{m}^{s}$ e $\rho_{m}^{g}$ são as densidades molares respectivamente da fase sólida e da fase fictícia (mols de lacunas e átomos de $\mathrm{Cu}$ na fase sólida e mols de átomos de $\mathrm{Ar}$ e de $\mathrm{Cu}$ na fase fictícia, ambos por unidade de volume); $\vec{n}$ é um vetor normal e unitário definido no ponto da interface onde se está aplicando a Equação (39); $\vec{J}_{C u}^{s}$ e $\vec{J}_{C u}^{g}$ são os vetores de fluxo de átomos de Cu no sólido e no gás, respectivamente, junto à interface. A Equação (90) pode ser simplificada considerando que $\vec{J}_{C u}^{g}=0$ devido ao transporte ser assumido nulo no gás, $X_{C u}^{s}=1-X_{v}^{s}$ e $\vec{J}_{C u}^{s}=-\vec{J}_{v}^{s}$, Equação válida no sólido para um referencial fixo no reticulado cristalino [SHEWMON, 1989] transformando a Equação (90) em

$$
\left[\rho_{m}^{s} X_{v}^{s}-\rho_{m}^{s}\left(1-\frac{\rho_{m}^{g}}{\rho_{m}^{s}} X_{C u}^{g}\right)\right] \vec{V}_{i} \cdot \vec{n}=\vec{J}_{v}^{s} \cdot \vec{n}
$$

Para o modelo de campo de fases assumido no presente trabalho, consistindo de uma fase sólida $(s)$ e uma fictícia $\left(g^{\prime}\right)$ binária Cu-lacunas, a análise assintótica [BOETTINGER; WARREN, 1996; WHEELER et al., 1992; KIM et al., 1992] garante que a seguinte condição de salto é satisfeita na interface entre estas fases quando o transporte é nulo na fase fictícia e quando a densidade molar da fase fictícia é igual à do sólido $\left(\rho_{m}^{s}\right)$

$$
\left(\rho_{m}^{s} X_{v}^{s}-\rho_{m}^{s} X_{v}^{g^{\prime}}\right) \vec{V}_{i} \cdot \vec{n}=\vec{J}_{v}^{s} \cdot \vec{n}
$$

Pode-se notar que as Equações (91) e (92) se tornam iguais, garantindo o correto cálculo da velocidade da interface pelo presente modelo de campo de fases, quando $X_{v}^{g^{\prime}}=1-\frac{\rho_{m}^{g}}{\rho_{m}^{s}} X_{C u}^{g}$, ou seja, $X_{C u}^{g^{\prime}}=\frac{\rho_{m}^{g}}{\rho_{m}^{s}} X_{C u}^{g}$, onde $X_{C u}^{g}$ deve ser a fração molar de átomos de Cu no gás inerte dada pelo equilíbrio local. Em consequência, a definição de $F^{g^{\prime}}\left(X_{v}^{g^{\prime}}\right)$ deve satisfazer duas restrições, a 
saber, $F^{g^{\prime}}=0$ em $X_{v}^{g^{\prime}}=1$, e $X_{v}^{g^{\prime}}=1-\frac{\rho_{m}^{g}}{\rho_{m}^{s}} X_{C u}^{g}$, que são obviamente incompatíveis. Porém, como $1-\frac{\rho_{m}^{g}}{\rho_{m}^{s}} X_{C u}^{g} \approx 1$, elas podem ser satisfeitas aproximadamente adotando-se um valor para $X_{v}^{g^{\prime}}$ o mais próximo de 1 possível sem prejudicar a estabilidade da solução numérica das equações. As funções $F^{s}\left(T, P^{s}, X_{v}^{s}\right)$ e $F^{g^{\prime}}\left(X_{v}^{g^{\prime}}\right)$ serão apresentadas no próximo item.

\subsubsection{Definição das Energias Livres Molares das Fases}

Neste item serão definidas as funções matemáticas para $F^{s}\left(T, P^{s}, X_{v}^{s}\right)$ e $F^{g^{\prime}}\left(X_{v}^{g^{\prime}}\right)$, que são as energias livres molares do $\mathrm{Cu}$ sólido e da fase fictícia $\left(g^{\prime}\right)$ assumidas no presente modelo de campo de fases. Estas funções são introduzidas diretamente nas equações diferenciais principais do modelo de fases, desenvolvidas no item 4.3.3. Neste modelo, $F^{s}$ deve ser escrito para a mesma pressão do gás, ou seja, $P^{s}=P^{g}$, que foi adotada igual à atmosférica, sendo que o modelo de campo de fases introduz automaticamente o efeito de aumento/diminuição de $P^{s}$ causado pela curvatura local da interface. A função $F^{s}\left(T, P^{s}, X_{v}^{s}\right)$ é construída baseada na hipótese de que a fase sólida é uma solução diluída de átomos de $\mathrm{Cu}$ e lacunas [DEHOFF, 2006], resultando em [GUAN; LIU, 2017]

$$
\begin{aligned}
F^{s}\left(T, P^{s}, X_{v}^{s}\right)= & X_{v}^{s} G^{v}+\left(1-X_{v}^{s}\right) G^{s}\left(T, P^{s}\right)+R T\left[X_{v}^{s} \ln X_{v}^{s}+\left(1-X_{v}^{s}\right) \ln \left(1-X_{v}^{s}\right)\right] \\
& +X_{v}^{s}\left(1-X_{v}^{s}\right) L_{C u, v}^{0}
\end{aligned}
$$

onde $G^{s}$ é a energia livre de Gibbs molar do $\mathrm{Cu}$ sólido puro; $G^{v}$ é a energia livre molar de um mol de lacunas isoladas, ou seja, fora do reticulado do sólido; $L_{C u, v}^{0}$ é o parâmetro de interação de ordem 0 entre os átomos de $\mathrm{Cu}$ e as lacunas, adotado no formalismo termodinâmico CALPHAD [REDLICH, KISTER, 1948; HELANDER, 1999; KATTNER, CAMPBELL, 2009; LIU, 2009; KATTNER, 2016], sendo um valor constante não-nulo para soluções regulares e igual a 0 para soluções ideais. A partir da Equação (93) é possível calcular o potencial químico para das lacunas na fase sólida como

$$
\mu_{v}^{s}=F^{s}+\left(\frac{\partial F^{s}}{\partial X_{v}^{s}}\right)_{T, P^{s}}\left(1-X_{v}^{s}\right)=G^{v}+R T \ln X_{v}^{s}+\left(1-X_{v}^{s}\right)^{2} L_{C u, v}^{0}
$$

onde o último termo à direita representa o desvio em relação a uma solução ideal.

Guan e Liu [GUAN; LIU, 2017] discutem sobre o significado da energia livre molar das lacunas no estado "puro", $G^{v}$. Existem diversas possibilidades, como a de que $G^{v}=0$, pois lacunas isoladas são um "vazio", e neste caso os desvios da idealidade causados pelas lacunas 
são introduzidos no termo $\left(1-2 X_{v}^{S}\right) L_{C u, v}^{0}$. Outra possibilidade, somo sugerido por Dehoff [DEHOFF, 2006] sobre a Equação (94) seria considerar

$$
G^{v}+\left(1-X_{v}^{s}\right)^{2} L_{C u, v}^{0}=H^{v}-T S^{v, x s}
$$

onde $H^{v}$ poderia representar a entalpia de formação de uma lacuna no reticulado do sólido enquanto $S^{v, x s}$ representaria a entropia de excesso, que é um desvio da idealidade, relacionada com a alteração dos modos de vibração dos átomos de $\mathrm{Cu}$ no reticulado causada pela presença da lacuna. Esta foi a abordagem escolhida, que possibilita calcular a fração molar de lacunas em equilíbrio a uma dada temperatura consistente com medidas experimentais.

A função $G^{s}\left(T, P^{s}\right)$ foi obtida a partir da compilação de Dinsdale [DINSDALE, 1991] considerando $P^{s}$ igual à pressão atmosférica, que é a pressão de referência, $P_{r e f}$, utilizada nesta compilação. A função está apresentada abaixo

$$
\begin{aligned}
G^{s}\left(T, P_{r e f}\right)= & -7770.458+130.485235 * \mathrm{~T}-24.112392 * \mathrm{~T} * \ln (T)+ \\
& -2.65684 .10^{-3} * \mathrm{~T}^{2}+0.129223 .10^{-6} * \mathrm{~T}^{3}+\frac{52478}{\mathrm{~T}}
\end{aligned}
$$

Considerando ainda que $1-X_{v}^{S} \approx 1$, já que a fração de lacunas é relativamente baixa na fase sólida, a seguinte expressão final foi adotada

$F^{s}=X_{v}^{s}\left(H^{v}-T S^{v, x s}\right)+\left(1-X_{v}^{s}\right) G^{s}\left(T, P_{r e f}\right)+R T\left[X_{v}^{s} \ln X_{v}^{s}+\left(1-X_{v}^{s}\right) \ln \left(1-X_{v}^{s}\right)\right]$ onde $H^{v}=112,8 \frac{\mathrm{kJ}}{\mathrm{mol}}$ e $S^{v, x s}=12,5 \frac{\mathrm{J}}{\mathrm{mol} \mathrm{K}}$ [FREDRIKSSON; EMI, 1998].

Como discutido no item 4.3.2.1, a energia livre molar da fase fictícia, $F^{g^{\prime}}\left(X_{v}^{g^{\prime}}\right)$, deve ser definida em um formato em que a sua tangente comum com a função $F^{s}\left(T, P^{s}, X_{v}^{s}\right)$, incluindo o efeito de curvatura, passe pelo ponto $F^{g^{\prime}}=0 \mathrm{em} X_{v}^{g^{\prime}} \approx 1$. Esta função foi então definida como um polinômio de $2^{\circ}$ grau do tipo

$$
F^{g^{\prime}}=a_{v}\left(X_{v}^{g^{\prime}}-b_{v}\right)^{2}
$$

ou seja, uma parábola com concavidade positiva. Os valores de $a_{v}=5 \cdot 10^{7} \frac{\mathrm{J}}{\mathrm{mol}}$ e $b_{v}=0,99$ foram adotados após diversos testes onde um sistema contendo um cilindro sólido de $\mathrm{Cu}$ imerso na fase fictícia atingia equilíbrio e resultava no correto valor de fração molar de lacunas do sólido $\left(X_{v}^{s}\right)$ afetado pela curvatura do cilindro e, na fase fictícia, $X_{v}^{g^{\prime}} \approx 1$ e sempre $<1$. Estes resultados serão apresentados no item 0. As Equações (96), (97) e (98) são introduzidas no modelo de campo de fases e representam as energias livres molares da fase sólida e da fase fictícia, consideradas como soluções Cu-lacuna. Estas curvas estão apresentadas na Figura 18 para a temperatura de $1000^{\circ} \mathrm{C}$. 


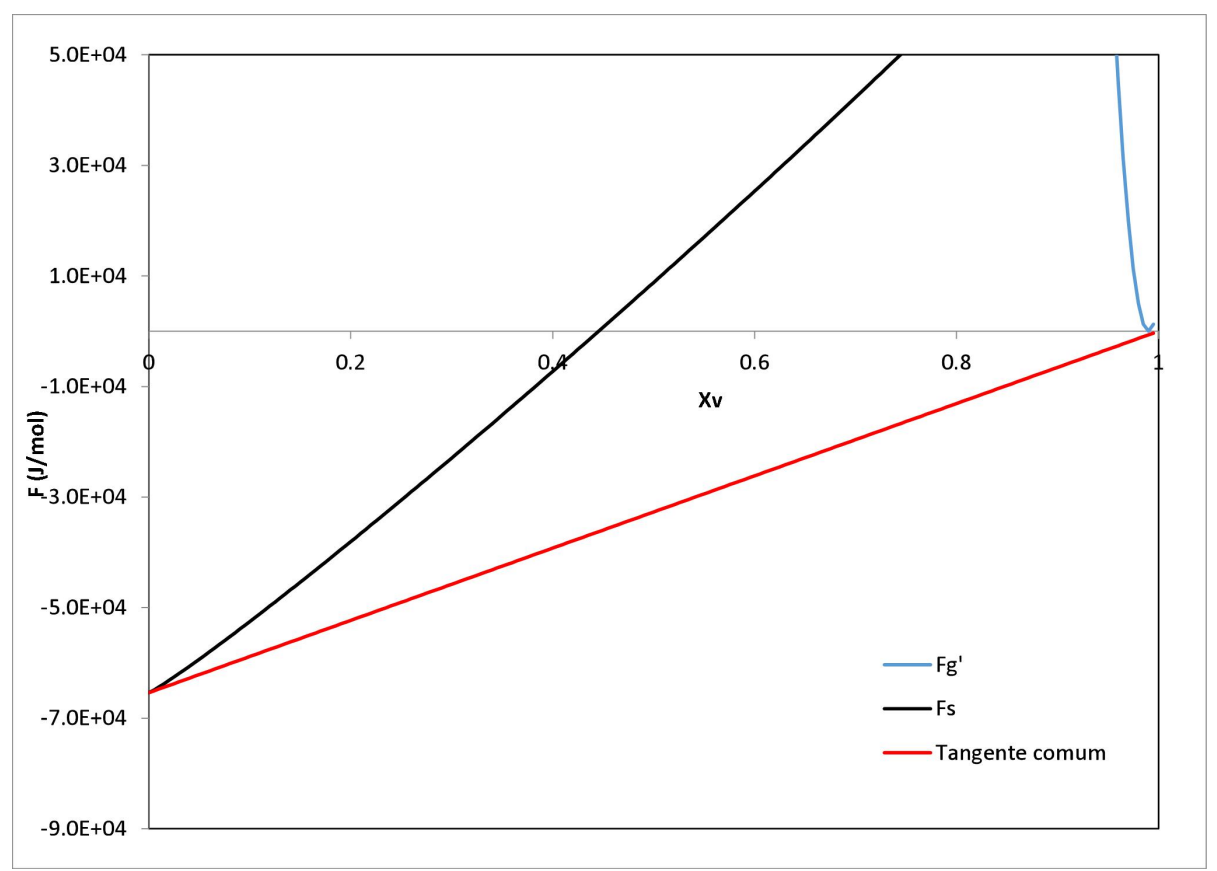

Figura 18: Curvas de energia livre molar da fase sólida $\left(F^{s}\right)$ e fase fictícia $\left(F^{g^{\prime}}\right)$, ambas consideradas uma solução de átomos de $\mathrm{Cu}$ e de lacunas, em função da fração molar de lacunas $\left(X_{v}\right)$ na temperatura de $1000^{\circ} \mathrm{C}$. A tangente comum, que fornece os valores de equilíbrio, também está apresentada.

Além de serem introduzidas no modelo de campo de fase, as Equações (96), (97) e (98) também podem ser utilizadas para calcular a fração de lacunas de equilíbrio na fase sólida $\left(X_{v, e q}^{s}\right)$ que satisfaz exatamente os requisitos termodinâmicos (Equações (87) a (89)) e o valor dado pelo modelo aproximado, proposto pelas Equações (96) a (98) envolvendo a fase fíctícia, além da fração de lacunas na fase fictícia $\left(X_{v, e q}^{g^{\prime}}\right)$, todos sob efeito da curvatura da interface e da tensão interfacial. Para realização destes cálculos, será necessário um ajuste da Equação (97) para incluir o efeito da curvatura local da interface, K. As Equações (87) e (88) mostram que a curvatura introduz um aumento na pressão da fase sólida $\left(P^{S}\right)$ e que esta pressão afeta o potencial químico das lacunas nesta fase, $\mu_{v}^{s}$. A curvatura também altera a energia livre molar da fase sólida $\left(F^{S}\right)$ calculada na pressão de referência, dada pela Equação (97). Esta alteração pode ser escrita como

$$
F^{s}\left(T, P^{s}, X_{v}^{s}\right)=F^{s}\left(T, P_{r e f}, X_{v}^{s}\right)+\int_{P_{\text {ref }}}^{P^{s}}\left(\frac{\partial F^{s}}{\partial P}\right)_{T, X_{v}^{S}} d P
$$

sendo que $\left(\frac{\partial F^{s}}{\partial P}\right)_{T, X_{v}^{s}}=\frac{1}{\rho_{m}^{s}}$, que é o volume molar da fase sólida. Lembrando que $P^{s}=P_{r e f}+$ $2 \gamma_{S} \mathrm{~K}$ (Equação (88)), pode-se escreve finalmente

$$
\begin{aligned}
F^{s}\left(T, \mathrm{~K}, X_{v}^{s}\right)= & X_{v}^{s}\left(H^{v}-T S^{v, x s}\right)+\left(1-X_{v}^{s}\right) G^{s}\left(T, P_{r e f}\right) \\
& +R T\left[X_{v}^{s} \ln X_{v}^{s}+\left(1-X_{v}^{s}\right) \ln \left(1-X_{v}^{s}\right)\right]+\frac{2 \gamma_{s} \mathrm{~K}}{\rho_{m}^{s}}
\end{aligned}
$$


Esta Equação pode ser finalmente utilizada para os cálculos das frações molares de lacunas em equilíbrio. Um primeiro cálculo, que é dado pela análise termodinâmica, é aquele que satisfaz as Equações (87) a (89). Adicionando o termo de curvatura $\left(\frac{2 \gamma_{s} \mathrm{~K}}{\rho_{m}^{s}}\right)$ ao lado direito da Equação (94) e fazendo $\mu_{v}^{s}=0$ (Equação (87)), obtém-se

$$
X_{v, e q}^{s}=e^{\frac{-\left(H^{v}-T S^{v, x s}\right)}{R T}} e^{\frac{-2 \gamma_{s} \mathrm{~K} / \rho_{m}^{s}}{R T}}
$$

Note que quando $\mathrm{K}=0$, obtém-se a expressão frequentemente utilizada para calcular a fração de lacunas de equilíbrio em um sólido [DEHOFF, 2006], que desconsidera a presença de curvatura. O efeito da curvatura é dado pelo segundo termo exponencial ao lado direito da Equação. Por outro lado, o cálculo de $X_{v, e q}^{s}$ segundo o modelo termodinâmico aproximado introduzido no modelo de campo de fases (Equações (86), (87) e (88)) pode ser realizado a partir da tangente comum às curvas de energia livre, como indicado abaixo

$$
\left(\frac{\partial F^{s}}{\partial X_{v}^{s}}\right)_{X_{v, e q}^{s}}=\left(\frac{\partial F^{g^{\prime}}}{\partial X_{v}^{g^{\prime}}}\right)_{X_{v, e q}^{g^{\prime}}}=\frac{F^{g^{\prime}}\left(X_{v, e q}^{g^{\prime}}\right)-F^{s}\left(T, \mathrm{~K}, X_{v, e q}^{s}\right)}{X_{v, e q}^{g^{\prime}}-X_{v, e q}^{s}}
$$

resultando após substituição das Equações (97) e (98) no sistema de equações a seguir

$$
\begin{gathered}
X_{v, e q}^{s}=1-e^{\frac{a_{v}\left(b_{v}^{2}-X_{v, e q}^{g^{\prime 2}}\right)-2 \gamma_{s} \mathrm{~K} / \rho_{m}^{s}-G^{s}\left(T, P_{r e f}\right)}{R T}} \\
\frac{X_{v, e q}^{s}}{1-X_{v, e q}^{s}}=e^{\frac{-\left(H^{v}-T S^{v, x s}\right)}{R T}} e^{\frac{2 a_{v}\left(X_{v, e q}^{g^{\prime}}-b_{v}\right)}{R T}}
\end{gathered}
$$

utilizado para calcular numericamente $X_{v, e q}^{s}$ e $X_{v, e q}^{g^{\prime}}$ pelo método de Newton-Rapson (GERALD; WHEATLEY, 2004). Considerando uma interface plana $(\mathrm{K}=0)$ e temperatura de $1000{ }^{\circ} \mathrm{C}$, estas equações fornecem $X_{v, e q}^{g^{\prime}}=0,9907$ e $X_{v, e q}^{s}=1,039 \cdot 10^{-4}$, que é muito próximo do valor obtido pelo modelo termodinâmico exato (Equação (107)), igual a $X_{v, e q}^{s}=$ $1,058 \cdot 10^{-4}$. Além disso, $X_{v, e q}^{g^{\prime}}$ é próximo da unidade, como requerido para satisfazer os requisitos discutidos no item 4.3.2.1, mostrando que o modelo aproximado tem o comportamento necessário para modelar a sinterização pelo mecanismo de difusão de lacunas no sólido. As Equações (101), (103) e (104) serão utilizadas para aferir diversos resultados a serem apresentados do modelo de campo de fases.

\subsubsection{Desenvolvimento das equações diferenciais do modelo de campo de fases}

O presente modelo baseado na técnica do método do campo de fases propõe uma variável de campo denominada de variável de fase, $\phi$, que tem valor 1 na fase sólida, valor 0 na fase fictícia e um valor entre 0 e 1 na região da interface sólido-fase fictícia, que é considerada 
difusa, ou seja, apresenta uma espessura finita. Logo, se o campo da variável de fase for conhecido, é possível saber a localização da interface sólido-fase fictícia e acompanhar a sua evolução, representando um dos principais objetivos do modelo. O modelo a ser apresentado consiste basicamente de duas equações diferenciais principais, uma para o cálculo da variável de fase, $\phi$, e outra para o cálculo da fração molar de lacunas, $X_{v}$. Como o sistema será assumido isotérmico com temperatura conhecida, não há necessidade de uma Equação para determinação do campo de temperaturas.

O desenvolvimento das duas equações diferenciais principais do modelo tem início na definição de um funcional que representa a energia livre total do volume do sistema, que engloba tanto a fase sólida como a gasosa. Este funcional foi definido por

$$
\left.F^{\prime}=\int_{\Omega} f\left(\phi, X_{v}\right) d V=\int_{\Omega}\left[f_{0}\left(\phi, X_{v}\right)+\frac{K_{\phi}}{2}|\vec{\nabla} \phi|^{2}\right)\right] d V
$$

onde $F^{\prime}$ é a energia livre total do sistema; $\Omega$ representa o volume do domínio a ser modelado; $f$ é a densidade de energia livre (energia livre por unidade de volume), definida em cada ponto no interior do domínio, em função da temperatura, $T$, da variável de fase, $\phi$, e da fração molar de lacunas $X_{v}$ em cada ponto do domínio; $f_{0}$ é a densidade de energia livre para um sistema que possui $T, \phi$, e $X_{v}$ uniformes no domínio, ou seja, sem gradientes e $K_{\phi}$ é denominado coeficiente da energia gradiente, representada pelo último termo do funcional. $\mathrm{O}$ desenvolvimento das duas equações principais, uma para o cálculo do campo de $\phi$ e outra para o campo de $X_{v}$, está apresentado nos próximos itens.

A definição da densidade de energia livre para sistemas uniformes, $f_{0}$, é uma etapa importante na construção de um modelo de campo de fases. Esta densidade é sempre definida com base nas densidades da fase sólida, $f^{S}\left(X_{v}^{s}\right)$, e da fase fictícia, $f^{g}\left(X_{v}^{g}\right)$, sendo que $X_{v}^{s}$ e $X_{v}^{g}$ são as frações em molar de lacuna nas fases sólida e gasosa, respectivamente. Na região da interface difusa, não há uma diretriz clara de como esta função deve ser definida, surgindo diversas propostas. Porém, todas as definições propõem algum tipo de interpolação baseada no valor da variável de fase, $\phi$, e adotam uma elevação da densidade de energia na região interna da interface. Esta elevação permite a criação de uma energia extra na região da interface, que é forçada ser igual à energia interfacial [CAHN; HILLIARD, 1958]. No modelo WBM a seguinte função foi adotada [WHEELER et al., 1992]:

$$
f_{0}\left(\phi, X_{v}\right)=h(\phi) f^{s}\left(X_{v}\right)+[1-h(\phi)] f^{g}\left(X_{v}\right)+W g(\phi)
$$

sendo que $h(\phi)$ é uma função de interpolação que assume $h(\phi=0)=0$ e $h(\phi=1)=1$; $g(\phi)$ é uma função que introduz uma elevação no valor de $f_{0}$ na região da interface $(0<$ 
$\phi<1$ ), com um formato de poço duplo (“double well”), com valor $g=0$ para ambos $\phi=0$ e $\phi=1$ e um máximo em $\phi=0,5$ e $W$ representa a amplitude desta elevação e, portanto, possibilita introduzir o valor desejado para a energia interfacial. Note que na região interfacial, onde $0<\phi<1$, no modelo WBM o mesmo valor de fração em molar de lacunas, $X_{v}$, é utilizado para o cálculo das densidades de energia do sólido $\left(f^{s}\right)$ e do gás $\left(f^{g}\right)$. Esta representação corresponde a assumir que na região da interface existe uma mistura das fases sólida e gasosa com a mesma composição. Esta hipótese implícita do modelo WBM introduz a dependência mencionada anteriormente entre a energia interfacial e a espessura da interface e, portanto, não foi adotada no presente trabalho.

No presente modelo, adotou-se a função densidade de energia livre proposto por Kim et al. [KIM et al., 1999], apresentada abaixo

$$
f_{0}\left(\phi, X_{v}\right)=h(\phi) f^{s}\left(X_{v}^{s}\right)+[1-h(\phi)] f^{g}\left(X_{v}^{g}\right)+W g(\phi)
$$

onde as funções $f^{s}\left(X_{v}^{s}\right)$ e $f^{g}\left(X_{v}^{g}\right)$ estão apresentadas no item 4.3.2.2. Foram adotadas as funções de interpolação propostas por Boettinger et al., muito utilizadas nos problemas de solidificação, definidas como [BOETTINGER et al., 2002]

$$
\begin{gathered}
h(\phi)=\phi^{3}\left(6 \phi^{2}-15 \phi+10\right) \\
g(\phi)=\phi^{2}(1-\phi)^{2}
\end{gathered}
$$

Adotando-se a Equação (107), está-se assumindo que a região da interface é formada por uma mistura da fase sólida e gasosa, cada uma com composição diferente. O interior de cada fase também é considerado como uma mistura destas duas fases, porém a fração da fase que não está presente tende a zero. A composição local em cada ponto na região da interface ou no interior das fases é definida como

$$
X_{v}(\phi)=h(\phi) X_{v}^{s}+[1-h(\phi)] X_{v}^{g}
$$

A função $f_{0}\left(\phi, X_{v}\right)$ dada pela Equação (107) indica que $f_{0}$ pode ser calculado quando $\phi$ e $X_{v}$ são conhecidos. No entanto, há 5 incógnitas $\left(f_{0}, \phi, X_{v}, X_{v}^{s}\right.$ e $\left.X_{v}^{g}\right)$ e apenas 2 equações (Equações (107) e (110)), sendo que duas incógnitas ( $\phi$ e $X_{v}$ ) são fornecidas, ou seja, mais uma Equação será necessária. Kim et al. [KIM et al., 1999] adotaram a igualdade dos potenciais químicos na suposta fase sólida e fase fictícia misturadas na região da interface, escrevendo:

$$
\frac{\partial f^{s}}{\partial X_{v}^{s}}\left(X_{v}^{s}\right)=\frac{\partial f^{g}}{\partial X_{v}^{g}}\left(X_{v}^{g}\right)
$$


Logo, a partir das equações (107), (110) e (111) é possível calcular $f_{0}$ e também $X_{v}^{s}$ e $X_{v}^{g}$, quando os valores de $\phi$ e $X_{v}$ são dados. Desta forma a Equação (107) (56) pode ser escrita como

$$
f_{0}\left(\phi, X_{v}\right)=h(\phi) f^{s}\left(X_{v}^{s}\left(\phi, X_{v}\right)\right)+[1-h(\phi)] f^{g}\left(X_{v}^{g}\left(\phi, X_{v}\right)\right)+W g(\phi)
$$

Nos próximos dois itens serão desenvolvidas as duas equações diferenciais principais para o cálculo da variável de fase, $\phi$, e da fração em molar de lacunas na fase sólida, $X_{v}^{s}$.

\subsubsection{Equação para o cálculo da variável de fase}

A equação para previsão da evolução no tempo do campo da variável de fase foi desenvolvida a partir da Equação postulada por Allen e Cahn [ALLEN, CAHN, 1979], apresentada abaixo

$$
\frac{\partial \phi}{\partial t}=-M_{\phi} \frac{\delta F^{\prime}}{\delta \phi}
$$

onde $M_{\phi}$ é denominado mobilidade da variável de fase e $\frac{\delta F^{\prime}}{\delta \phi}$ é a derivada variacional da energia livre total em relação à variável de fase. O cálculo desta derivada variacional resulta em

$$
\frac{\delta F^{\prime}}{\delta \phi}=\frac{\partial f_{0}}{\partial \phi}-K_{\phi} \nabla^{2} \phi
$$

Substituindo a Equação (114) na Equação (105), obtém-se a equação abaixo, muitas vezes denominada de Equação de Allen-Cahn:

$$
\frac{1}{M_{\phi}} \frac{\partial \phi}{\partial t}=K_{\phi} \nabla^{2} \phi-\frac{\partial f_{0}}{\partial \phi}
$$

A expressão da derivada $\frac{\partial f_{0}}{\partial \phi}$ foi calculada a partir da Equação (112), utilizando a regra da cadeia e a Equação (111), possibilitando a obtenção da forma final da Equação (115), apresentada abaixo [KIM et al., 1999] em coordenadas cartesianas retangulares em um domínio bidimensional:

$$
\frac{1}{M_{\phi}} \frac{\partial \phi}{\partial t}=\frac{\partial}{\partial x}\left(K_{\phi} \frac{\partial \phi}{\partial x}\right)+\frac{\partial}{\partial y}\left(K_{\phi} \frac{\partial \phi}{\partial y}\right)+\frac{d h}{\partial \phi}\left[\left(f^{g}-f^{s}\right)+\frac{d f^{s}}{d X_{v}^{s}}\left(X_{v}^{s}-X_{v}^{g}\right)\right]-W \frac{d g}{\partial \phi}
$$

Apesar do coeficiente da energia gradiente, $K_{\phi}$, ser um valor constante, o termo $K_{\phi} \nabla^{2} \phi$ da Equação (115) foi escrito no formato conservativo pois esta Equação foi solucionada pelo método dos volumes finitos [PATANKAR, 1980], que requer este formato. A Equação (116) foi também escrita abaixo utilizando as energias livres molares do sólido ou gás (energia por unidade de mols de átomos do sólido ou de lacunas, respectivamente), pois são mais 
comumente definidas do que as densidades de energia livre (energia livre por unidade de volume), e assumindo volume molar $\left(V_{m}\right)$ constante:

$$
\frac{1}{M_{\phi}} \frac{\partial \phi}{\partial t}=\frac{\partial}{\partial x}\left(K_{\phi} \frac{\partial \phi}{\partial x}\right)+\frac{\partial}{\partial y}\left(K_{\phi} \frac{\partial \phi}{\partial y}\right)+\rho_{m} \frac{d h}{\partial \phi}\left[\left(F^{g}-F^{s}\right)+\frac{d F^{s}}{d X_{v}^{s}}\left(X_{v}^{s}-X_{v}^{g}\right)\right]-W \frac{d g}{\partial \phi}
$$

onde $F^{s}=\frac{f^{s}}{\rho_{m}}$ e $F^{g}=\frac{f^{g}}{\rho_{m}}$ são as energias livres molares do sólido e da fase fictícia e $\rho_{m}=1$ / $V_{m}$ é a densidade molar da mistura de átomos do sólido e lacunas, que no caso da fase sólida $\left(\rho_{m}^{s}\right)$ representa a densidade de número de sítios do reticulado cristalino (número de mols de sítios por unidade de volume). Como as lacunas foram consideradas como um tipo de espécie química, $V_{m}$ representa o volume ocupado por um mol da mistura de átomos do sólido e lacunas, que no caso da fase sólida representa praticamente o volume molar do sólido, já que a quantidade de lacunas é sempre muito reduzida. No caso da fase fictícia, a definição de $V_{m}$ não tem significado físico e, portanto, será adotado o mesmo valor da fase sólida.

\subsubsection{Equação da conservação de lacunas}

Considerando que as lacunas podem ser tratadas como uma espécie química e que, portanto, obedecem ao princípio de conservação das espécies químicas, a equação abaixo pode ser escrita [BIRD et al., 2002]

$$
\frac{\partial\left(\rho_{m} X_{v}\right)}{\partial t}=-\vec{\nabla} \cdot \vec{J}_{v}
$$

onde $\vec{J}_{v}$ é o fluxo molar de lacunas. Quando a Equação (118) é utilizada, está se assumindo implicitamente que não há nem fontes nem sorvedouros de lacunas em todo o domínio (sólido, interface e fase fictícia), uma hipótese também empregada nos modelos analíticos descritos no item 4.1. Esta abordagem já foi empregada para a sinterização utilizando o modelo WBM [ASP; AGREN, 2006] e também em modelos para o cálculo da evolução da concentração de lacunas em metais expostos à radiação [MILLETT et al., 2009; MILLETT et al., 20011a, 2011b].

A termodinâmica de processos irreversíveis apresenta uma proposta para o cálculo do fluxo de espécies químicas, incluindo lacunas, como sendo proporcional ao gradiente de potencial químico daquela espécie no meio [SHEWMON, 1989]. Cahn e Hilliard [CAHN; HILLIARD, 1971] estenderam este conceito para possibilitar o cálculo do fluxo inclusive na região da interface difusa e, portanto, incluindo os efeitos da energia gradiente, que são significativos nesta região. O fluxo foi então postulado ser proporcional ao gradiente da 
derivada variacional da energia livre total do sistema, $F^{\prime}$, em relação ao campo de concentração da espécie envolvida. No presente caso, esta Equação pode ser escrita como

$$
\vec{J}_{v}=-\rho_{m} M_{c} \vec{\nabla}\left(\frac{\delta F^{\prime}}{\delta X_{v}}\right)
$$

onde $M_{c}$ é a mobilidade das lacunas. Utilizando a definição de derivada variacional e a definição de $F^{\prime}$ adotada na Equação (105), tem-se $\frac{\delta F^{\prime}}{\delta X_{v}}=\frac{\partial f_{0}}{\partial X_{v}}$. Derivando as equações (110) e (111), é possível mostrar que $\frac{\partial f_{0}}{\partial X_{v}}=\frac{d f^{s}}{d X_{v}^{s}}=\frac{d f^{g}}{d X_{v}^{g}}$ [KIM et al., 1999]. Diferentemente de Kim et al. [KIM et al., 1999], Kim [2007] considerou que a mobilidade das lacunas depende da fase em que o fluxo é calculado, ou seja, $M_{c}=M_{c}(\phi)$ e utilizou a seguinte Equação para o cálculo do fluxo

$$
\vec{J}_{v}=-\rho_{m} M_{c}(\phi) \vec{\nabla}\left(\frac{\partial f_{0}}{\partial X_{v}}\right)=-\rho_{m} M_{c}(\phi) \vec{\nabla}\left(\frac{d f^{s}}{d X_{v}^{s}}\right)=-\rho_{m} M_{c}(\phi) \vec{\nabla}\left(\frac{d f^{g}}{d X_{v}^{g}}\right)
$$

onde $M_{c}(\phi)=h(\phi) M_{c}^{s}+[1-h(\phi)] M_{c}^{g}$, sendo que $M_{c}^{s}$ e $M_{c}^{g}$ são as mobilidades das lacunas na fase sólida e gasosa, respectivamente. Neste caso, a Equação (120) pode ser rearranjada na forma abaixo

$$
\vec{J}_{v}=-\rho_{m}\left\{h(\phi) M_{c}^{s} \vec{\nabla}\left(\frac{d f^{s}}{d X_{v}^{s}}\right)+[1-h(\phi)] M_{c}^{g} \vec{\nabla}\left(\frac{d f^{g}}{d X_{v}^{g}}\right)\right\}
$$

que pode ser modificada aplicando a regra da cadeia nos dois termos gradientes, lembrando que $f^{s}\left(X_{v}^{s}\right)$ e $f^{g}\left(X_{v}^{g}\right)$ e que $X_{v}^{s}$ e $X_{v}^{g}$ variam com a coordenada espacial, resultando em

$$
\vec{J}_{v}=-\rho_{m}\left\{h(\phi) M_{c}^{s} \frac{d^{2} f^{s}}{d X_{v}^{s 2}} \vec{\nabla} X_{v}^{s}+[1-h(\phi)] M_{c}^{g} \frac{d^{2} f^{g}}{d X_{v}^{g 2}} \vec{\nabla} X_{v}^{g}\right\}
$$

Usualmente, a mobilidade é definida a partir desta Equação considerando que no interior tanto da fase sólida $(h(\phi)=1)$ como gasosa $(h(\phi)=0)$ ela deve igualar-se a $1^{\mathrm{a}}$ Lei de Fick Cahn e Hilliard [CAHN; HILLIARD, 1971], escrita abaixo para as duas fases, respectivamente [BIRD et al., 2002]

$$
\begin{aligned}
& \vec{J}_{v}=-\rho_{m} D_{v}^{s} \vec{\nabla} X_{v}^{s} \\
& \vec{J}_{v}=-\rho_{m} D_{v}^{g} \vec{\nabla} X_{v}^{g}
\end{aligned}
$$

onde $D_{v}^{s}$ e $D_{v}^{g}$ são os coeficientes de difusão de lacunas na fase sólida e fíctícia, respectivamente, resultando na seguinte Equação final para o cálculo do fluxo de lacunas [KIM, 2007]

$$
\vec{J}_{v}=-\rho_{m}\left\{h(\phi) D_{v}^{s} \vec{\nabla} X_{v}^{s}+[1-h(\phi)] D_{v}^{g} \vec{\nabla} X_{v}^{g}\right\}
$$

No presente trabalho, o transporte de massa na fase fictícia foi desprezado, ou seja, $D_{v}^{g}$, portanto o fluxo foi definido como 


$$
\vec{J}_{v}=-\rho_{m} h(\phi) D_{v}^{s} \vec{\nabla} X_{v}^{s}
$$

que quando substituído na Equação de conservação (118), escrita em coordenadas cartesianas retangulares em um domínio bidimensional resulta em

$$
\frac{\partial X_{v}}{\partial t}=\frac{\partial}{\partial x}\left(h(\phi) D_{v}^{s} \frac{\partial X_{v}^{s}}{\partial x}\right)+\frac{\partial}{\partial y}\left(h(\phi) D_{v}^{s} \frac{\partial X_{v}^{S}}{\partial y}\right)
$$

assumindo $\rho_{m}$ constante. Na fase sólida, $\phi=1, h=1$ e $X_{v}=X_{v}^{s}$ (Equação (127)), reduzindo esta Equação à $2^{\mathrm{a}}$ Lei de Fick, como esperado. Na fase fictícia, $\phi=0, h=0$, logo tem-se $\frac{\partial X_{v}}{\partial t}=0$, indicando que a fração molar de lacunas $\left(X_{v}\right)$ ou de átomos do sólido $\left(1-X_{v}\right)$ permanecerá inalterada, como esperado devido à hipótese de transporte de massa nulo nesta fase.

\subsubsection{Tensão interfacial, espessura e raio de curvatura local da interface difusa}

Nos parâmetros de entrada das equações do modelo de campo de fases (Equações (117) e (127)) não estão presentes a tensão interfacial e a espessura da interface difusa, mas elas estão implicitamente definidas. A análise abaixo apresenta o desenvolvimento que relaciona os parâmetros de entrada com a tensão interfacial, além de mostrar como a tensão interfacial pode ser obtida numericamente a partir do campo da variável de fase, $\phi$. Tanto as interfaces reais como as obtidas no modelo de campo de fases são interfaces difusas. Portanto, as propriedades de excesso de superfície introduzidas por Gibbs [GIBBS, 1948] para relacionar as propriedades de uma região de transição e as de uma interface matemática, que não tem espessura, podem ser utilizadas diretamente no modelo de campo de fases. A partir destes conceitos, no sistema binário $\mathrm{Cu}$-lacunas contendo a fase sólida e a fase hipotética assumida no presente modelo e uma interface entre estas duas fases, pode-se escrever [DEVEREUX, 1983; DEHOFF, 2006]

$$
\gamma_{s}=\frac{F^{\prime x s}}{A}-\Gamma_{C u} \mu_{C u}^{x s}-\Gamma_{v} \mu_{v}^{x s}
$$

onde $\frac{F^{\prime x s}}{A}$ é a energia livre (de Gibbs ou Hemholtz) de excesso de superfície por unidade de área, ou simplesmente energia livre de superfície, sendo $A$ a área da interface entre as fases; $\mu_{C u}^{x s}$ e $\mu_{v}^{x s}$ são os potenciais químicos dos átomos de $C u$ e das lacunas na região da interface, lembrando que no equilíbrio termodinâmico $\mu_{C u}^{x s}=\mu_{C u}^{s}=\mu_{C u}^{g^{\prime}}=\mu_{C u, e q}$ e $\mu_{v}^{x s}=\mu_{v}^{s}=\mu_{v}^{g^{\prime}}=$ $\mu_{v, e q} ;$ e $\Gamma_{C u}=\frac{n_{C u}^{x s}}{A}$ e $\Gamma_{v}=\frac{n_{v}^{x s}}{A}$ são os excessos na interface do número de mols de átomos de $C u$ 
e de lacunas ( $n_{C u}^{x s}$ e $n_{v}^{x s}$, respectivamente), por unidade de área. Wheeler et al. [WHEELER et al., 1993] mostraram que, em um sistema binário com densidade molar $\left(\rho_{m}^{s}\right)$ constante, tem-se $\Gamma_{C u}=\Gamma_{v}$. A energia livre de interface é usualmente definida em condições de equilíbrio, permitindo simplificar a Equação (128) para o sistema do presente modelo como

$$
\gamma_{s}=\frac{F_{e q}^{\prime x s}}{A}-\Gamma_{v, e q}\left(\mu_{v, e q}-\mu_{C u, e q}\right)
$$

A energia livre da interface, $\frac{F_{e q}^{x s}}{A}$, e o excesso de lacunas, $\Gamma_{v, e q}$, podem ser calculados a partir dos campos de variável de fase $(\phi)$ e de fração molar de lacunas $\left(X_{v}\right)$ calculados pelas Equações (117) e (127)em uma condição de equilíbrio termodinâmico, permitindo então determinar qual a tensão interfacial, $\gamma_{s}$, introduzida. Neste sistema, a partir da definição da energia livre de excesso de superfície pode-se escrever [DEHOFF, 2006]

$$
F_{e q}^{\prime x s}=F_{e q}^{\prime}-F_{e q}^{\prime s}-F_{e q}^{\prime g^{\prime}}
$$

onde $F_{e q}^{\prime}$ é a energia livre total do sistema, $F_{e q}^{\prime s}$ e $F_{e q}^{\prime g^{\prime}}$ são as energias livres das fases sólida e hipotética, assumidas homogêneas até a posição da interface matemática (sem espessura).

Com este objetivo, considera-se um sistema unidimensional contendo a fase sólida e a fase fictícia separadas por uma interface em equilíbrio termodinâmico. Considerando este sistema e lembrando que $\vec{\nabla} \phi=0$ no interior das fases homogêneas, a Equação (130) pode ser escrita no seguinte formato com o auxílio da Equação (105)

$$
\begin{aligned}
\frac{F_{e q}^{\prime x s}}{A}=\int_{-\infty}^{0}\left[f_{0}(\right. & \left.\left.\phi_{e q}, X_{v, e q}\right)-f_{0}\left(\phi_{e q}^{-\infty}, X_{v, e q}^{-\infty}\right)+\frac{K_{\phi}}{2}\left(\frac{d \phi_{e q}}{d x}\right)^{2}\right] d x \\
& +\int_{0}^{+\infty}\left[f_{0}\left(\phi_{e q}, X_{v, e q}\right)-f_{0}\left(\phi_{e q}^{+\infty}, X_{v, e q}^{+\infty}\right)+\frac{K_{\phi}}{2}\left(\frac{d \phi_{e q}}{d x}\right)^{2}\right] d x
\end{aligned}
$$

onde $x$ é a coordenada ao longo do eixo de referência do sistema unidirecional, sendo $x=0 \mathrm{a}$ posição definida para a interface matemática; $\phi_{e q}^{-\infty}, \phi_{e q}^{+\infty}$ representam os valores de equilíbrio da variável de fase no interior das fases, suficientemente longe da interface e $X_{v, e q}^{-\infty}$ e $X_{v, e q}^{+\infty}$ são as frações de lacunas correspondentes.

Quando os sistema está em equilíbrio termodinâmico, é possível escrever $\frac{\partial f_{0}}{\partial \phi_{e q}}=K_{\phi} \frac{d^{2} \phi_{e q}}{d x^{2}}$ (Equação (115)) e $\vec{J}_{v}=0$ (Equação (119)), ou seja, $\frac{\partial f_{0}}{\partial X_{v, e q}}=\left(\frac{\partial f_{0}}{\partial X_{v, e q}}\right)_{x \rightarrow+\infty}=\left(\frac{\partial f_{0}}{\partial X_{v, e q}}\right)_{x \rightarrow-\infty}=$ $\rho_{m}^{s}\left(\mu_{v, e q}-\mu_{C u, e q}\right)$, que é um valor constante para todo o sistema [WHEELER et al., 1993]. Utilizando estas relações, é possível mostrar que [WHEELER et al., 1993] 


$$
\begin{aligned}
& f_{0}\left(\phi_{e q}, X_{v, e q}\right)-f_{0}\left(\phi_{e q}^{-\infty}, X_{v, e q}^{-\infty}\right)=\frac{K_{\phi}}{2}\left(\frac{d \phi_{e q}}{d x}\right)^{2}+\rho_{m}^{s}\left(\mu_{v, e q}-\mu_{C u, e q}\right)\left(X_{v, e q}-X_{v, e q}^{-\infty}\right) \\
& f_{0}\left(\phi_{e q}, X_{v, e q}\right)-f_{0}\left(\phi_{e q}^{+\infty}, X_{v, e q}^{+\infty}\right)=\frac{K_{\phi}}{2}\left(\frac{d \phi_{e q}}{d x}\right)^{2}+\rho_{m}^{s}\left(\mu_{v, e q}-\mu_{C u, e q}\right)\left(X_{v, e q}-X_{v, e q}^{+\infty}\right)
\end{aligned}
$$

que, quando substituídas na Equação (131) resulta em

$$
\frac{F_{e q}^{\prime x s}}{A}=\int_{-\infty}^{+\infty} K_{\phi}\left(\frac{d \phi_{e q}}{d x}\right)^{2} d x+\Gamma_{v, e q}\left(\mu_{v, e q}-\mu_{C u, e q}\right)
$$

lembrando que

$$
\Gamma_{v, e q}=\rho_{m}^{s}\left[\int_{-\infty}^{+\infty} X_{v, e q} d x-\int_{-\infty}^{0} X_{v, e q}^{-\infty} d x-\int_{0}^{+\infty} X_{v, e q}^{+\infty} d x\right]
$$

Substituindo a Equação (133) na Equação (129), obtém-se a relação final permitindo o cálculo da tensão interfacial implícita no modelo a partir do campo da variável de fase em um estado de equilíbrio $\left(\phi_{e q}\right)$

$$
\gamma_{s}=\int_{-\infty}^{+\infty} K_{\phi}\left(\frac{d \phi_{e q}}{d x}\right)^{2} d x
$$

Quando os dados de $\phi_{e q}$ foram obtidos a partir de uma solução numérica, a Equação (135) deve ser escrita na forma discretizada como

$$
\gamma_{s}=\int_{-\infty}^{+\infty} K_{\phi}\left(\frac{\phi_{e q, i+1}-\phi_{e q, i-1}}{2 \Delta \mathrm{x}}\right)^{2} d x
$$

onde $\phi_{e q, i+1}$ e $\phi_{e q, i-1}$ são valores obtidos nos nós de uma malha numérica de nós espaçados por $\Delta \mathrm{x}$ e indexados por números inteiros consecutivos colocada sobre o domínio.

Note que no caso de uma solução numérica, para se verificar o valor de $\gamma_{S}$ introduzido, deve-se ter o campo de $\phi_{e q}$ calculado pelo modelo. Logo, quando se deseja um valor específico de $\gamma_{s}$, deve-se recorrer a um processo de tentativa-e-erro. No entanto, no caso unidimensional existe uma solução analítica dada por [KIM et al., 1999]

$$
\phi_{e q}=\frac{1}{2}\left[1-\tanh \left(\sqrt{\frac{W}{2 K_{\phi}} x}\right)\right]=\frac{1}{1+\exp \left(\sqrt{\frac{2 W}{K_{\phi}} x}\right)}
$$

que quando substituída na Equação (136) resulta em

$$
\gamma_{s}=\frac{\sqrt{K_{\phi} W}}{3 \sqrt{2}}
$$


possibilitando introduzir o valor de $\gamma_{s}$ desejado a partir dos parâmetros $K_{\phi}$ e $W$, introduzidos na Equação (117).

O perfil de $\phi_{e q}$ dado pela Equação (137) também possibilita o cálculo da espessura aproximada da interface difusa como

$$
\delta=\alpha \sqrt{2} \sqrt{\frac{K_{\phi}}{W}}
$$

sendo que $\alpha=2,2$ quando se considera que a interface difusa está dentro da região $0,1<$ $\phi_{e q}<0,9$ e $\alpha=2,94$ quando está na região $0,05<\phi_{e q}<0,95$.

Uma combinação das Equações (138) e (139) permite o cálculo direto dos parâmetros $K_{\phi}$ e $W$ do modelo de campo de fases a partir da definição da tensão interfacial $\left(\gamma_{s}\right)$ e da espessura da interface difusa $(\delta)$, como dado abaixo

$$
\begin{aligned}
& K_{\phi}=\frac{3}{\alpha} \gamma_{s} \delta \\
& W=6 \alpha \frac{\gamma_{s}}{\delta}
\end{aligned}
$$

A curvatura local na região da interface $(\kappa)$ pode ser calculada a partir do campo da variável de fase $(\phi)$ a partir da expressão [GOLDMAN, 2005]:

$$
\kappa=-\frac{1}{2} \frac{\frac{\partial^{2} \phi}{\partial x^{2}}\left(\frac{\partial \phi}{\partial y}\right)^{2}+\frac{\partial^{2} \phi}{\partial y^{2}}\left(\frac{\partial \phi}{\partial x}\right)^{2}-2 \frac{\partial \phi}{\partial x} \frac{\partial \phi}{\partial y} \frac{\partial^{2} \phi}{\partial x \partial y}}{\left[\left(\frac{\partial \phi}{\partial x}\right)^{2}+\left(\frac{\partial \phi}{\partial y}\right)^{2}\right]^{3 / 2}}
$$

e finalmente o raio de curvatura local foi obtido a partir de

$$
r=\frac{1}{2 \kappa}
$$

\subsubsection{Domínio de cálculo, condições de contorno e resumo das equações}

O modelo de campo de fases bidimensional proposto no presente trabalho foi utilizado para simular a sinterização por difusão de lacunas na fase sólida de cilindros de cobre imersos em um gás inerte. Os cilindros foram considerados suficientemente longos (cilindros “infinitos") para que o transporte de massa nas suas pontas pudesse ser desprezado. O modelo físico teórico do sistema real que foi utilizado nas simulações está apresentado na Figura 19 (a) e consiste de um arranjo de diversos cilindros de cobre de raio a enfileirados, mantendo um ponto de contato com cada cilindro vizinho. Neste modelo, o gás inerte foi substituído por uma fase fictícia, onde o transporte de massa é nulo, mas cujo efeito sobre a fase sólida é 
equivalente ao efeito da fase fictícia do sistema real. Como os cilindros têm tamanhos iguais, o transporte de massa no sólido é simétrico, permitindo que apenas uma parte do domínio seja analisada, já que o restante é apenas uma simples repetição desta parte. O domínio de cálculo, que tem formato retangular, está apresentado na Figura 19(b). Como a massa é transportada gradativamente através da seção do cilindro, o domínio de cálculo foi dividido em subdomínios (Figura 19(c)) cada vez maiores conforme o tempo avançou para reduzir o tempo total de simulação.

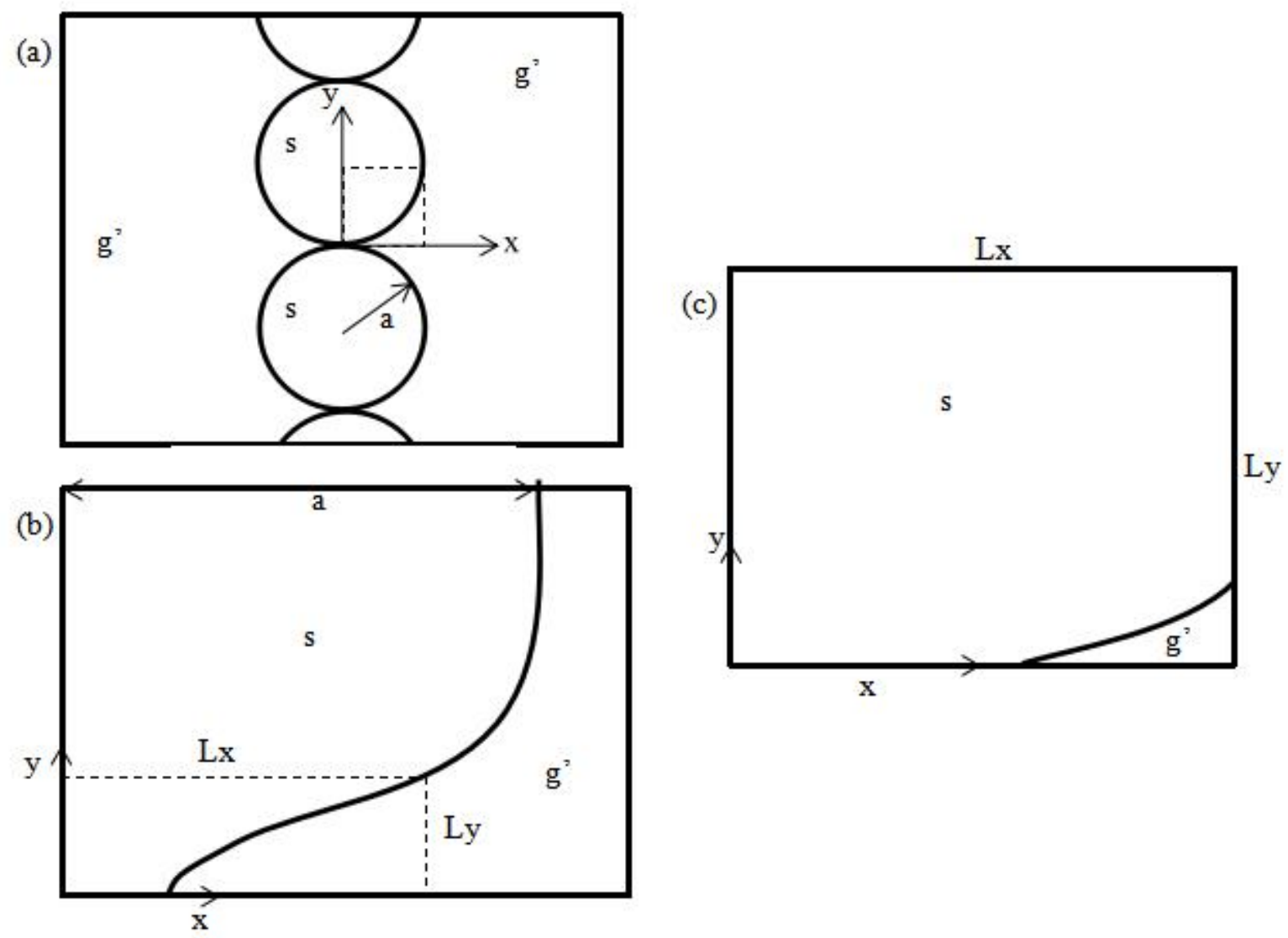

Figura 19: Sinterização de cilindros de $\mathrm{Cu}$ sólido (s) de raio a posicionados lado-a-lado e imersos em uma fase fictícia ( $\mathrm{g}^{\prime}$ ) que simula o efeito de um gás inerte: (a) modelo físico teórico do sistema real; (b) domínio de cálculo e (c) subdomínio parcial de cálculo utilizado nas simulações.

Na Tabela 6 está apresentado o conjunto completo das equações do presente modelo de campo de fases desenvolvido para simular a sinterização. As condições de contorno utilizadas para resolução das equações diferenciais foram do $2^{\circ}$ tipo para todas variáveis de campo $\phi, X_{v}^{s}$ e $X_{v}^{g^{\prime}}$, impondo a simetria mencionada. Nos dois contornos do domínio retangular paralelos ao eixo $y$, adotou-se 


$$
\frac{\partial \phi}{\partial x}=\frac{\partial X_{v}^{s}}{\partial x}=\frac{\partial X_{v}^{g^{\prime}}}{\partial x}=0
$$

enquanto nos dois contornos paralelos ao eixo $x$ adotou-se

$$
\frac{\partial \phi}{\partial y}=\frac{\partial X_{v}^{s}}{\partial y}=\frac{\partial X_{v}^{g^{\prime}}}{\partial y}=0
$$

As equações e condições de contorno apresentadas foram utilizadas em todas as simulações do presente trabalho. Porém, o modelo foi aplicado a outros problemas além do problema principal, apresentado na Figura 19. Como exemplo, um dos problemas solucionados foi o do crescimento de um cilindro isolado, imerso em um gás inerte. Estes problemas foram utilizados tanto para aferição do modelo como para observação do seu comportamento. Como a diferença entre cada problema solucionado está apenas na definição da condição inicial, esta condição será apresentada em conjunto com os resultados específicos a cada problema no item 5.4. No próximo item, o método numérico de resolução das equações apresentadas na Tabela 6, submetidas às condições de contorno dadas pelas Equações (144) e (145), será descrito. As propriedades utilizadas nas simulações com o modelo do campo de fases estão apresentadas no item 4.4. 


\begin{tabular}{|c|c|}
\hline Equação & \\
\hline $\begin{array}{c}\frac{1}{M_{\phi}} \frac{\partial \phi}{\partial t}=\frac{\partial}{\partial x}\left(K_{\phi} \frac{\partial \phi}{\partial x}\right)+\frac{\partial}{\partial y}\left(K_{\phi} \frac{\partial \phi}{\partial y}\right)+\rho_{m}^{s} \frac{d h}{\partial \phi}\left[\left(F^{g}-F^{s}\right)+\frac{d F^{s}}{d X_{v}^{s}}\left(X_{v}^{s}-X_{v}^{g}\right)\right]-W \frac{d g}{\partial \phi} \\
\frac{\partial X_{v}}{\partial t}=\frac{\partial}{\partial x}\left(h D_{v}^{s} \frac{\partial X_{v}^{s}}{\partial x}\right)+\frac{\partial}{\partial y}\left(h D_{v}^{s} \frac{\partial X_{v}^{s}}{\partial y}\right)\end{array}$ & $\begin{array}{r}(117) \\
(127)\end{array}$ \\
\hline $\begin{array}{c}\frac{\partial F^{s}}{\partial X_{v}^{s}}\left(X_{v}^{s}\right)=\frac{\partial F^{g^{\prime}}}{\partial X_{v}^{g^{\prime}}}\left(X_{v}^{g^{\prime}}\right) \\
X_{v}(\phi)=h(\phi) X_{v}^{s}+[1-h(\phi)] X_{v}^{g^{\prime}}\end{array}$ & $\begin{array}{l}(111) \\
(110)\end{array}$ \\
\hline $\begin{array}{c}h(\phi)=\phi^{3}\left(6 \phi^{2}-15 \phi+10\right) \\
\frac{d h}{d \phi}=30 g(\phi) \\
g(\phi)=\phi^{2}(1-\phi)^{2} \\
\frac{d g}{d \phi}=2 \phi(1-\phi)(1-2 \phi)\end{array}$ & $(108)$ \\
\hline $\begin{array}{c}G^{s}\left(T, P_{r e f}\right)=-7770.458+130.485235 * \mathrm{~T}-24.112392 * \mathrm{~T} * \ln (T)+ \\
-2.65684 .10^{-3} * \mathrm{~T}^{2}+0.129223 .10^{-6} * \mathrm{~T}^{3}+\frac{52478}{\mathrm{~T}} \\
F^{s}=X_{v}^{s}\left(H^{v}-T S^{v, x s}\right)+\left(1-X_{v}^{s}\right) G^{s}\left(T, P_{r e f}\right)+R T\left[X_{v}^{s} \ln X_{v}^{s}+\left(1-X_{v}^{s}\right) \ln \left(1-X_{v}^{s}\right)\right] \\
F^{g^{\prime}}=a_{v}\left(X_{v}^{g^{\prime}}-b_{v}\right)^{2}\end{array}$ & $\begin{array}{l}(96) \\
(97) \\
(98)\end{array}$ \\
\hline$K_{\phi}=\frac{3}{\alpha} \gamma_{s} \delta$ & $(140)$ \\
\hline$W=6 \alpha \frac{\gamma_{s}}{\delta}$ & (141) \\
\hline
\end{tabular}




\subsubsection{Resolução numérica das equações do modelo de campo de fases}

As equações apresentadas na Tabela 6, submetidas às condições de contorno dadas pelas Equações (142) e (143), foram solucionadas a partir do método dos volumes finitos, na sua formulação implícita [PATANKAR, 1980; FERZIGER; PERIC, 2002]. No item 4.3.5.1 será apresentado o processo de discretização do domínio de cálculo ilustrado na Figura 19(c) utilizando uma malha numérica adaptativa de volumes quadrados com um nó central. No item 4.3.5.2 será apresentada a discretização das equações diferenciais principais (Equações (117) e (127) da Tabela 6), originando dois sistemas de equações algébricas. Algumas particularidades da implementação do algoritmo de resolução das equações algébricas utilizando o processamento paralelo serão apresentadas no item 4.3.5.3.

\subsubsection{Discretização do domínio modelado - implementação da malha adaptativa}

O domínio de cálculo apresentado na Figura 19(c) foi discretizado por volumes finitos quadrados utilizando a técnica de malha adaptativa proposta por Lan et al. (2002a, 2002b), baseada em uma estrutura chamada de quadtree (SAMET, 1984; 1990). A malha é refinada na região da interface, como ilustrado no exemplo da Figura 20, a partir da subdivisão de um volume quadrado em quatro volumes "filhos", originando o nome "quadtree". Esta estrutura de malha é gerada facilmente, pois o refino é conduzido a partir da aplicação de um mesmo procedimento de divisão de um volume qualquer da malha, que neste caso torna-se um volume "pai", mas que também pode ser um volume "filho", caso seja o resultado de uma subdivisão. A estrutura de quadtree permite ainda a rápida determinação da localização de volumes vizinhos $(n b i)$ no momento de solucionar as equações diferenciais discretizadas. Nos próximos parágrafos serão descritos os detalhes da construção da malha. 


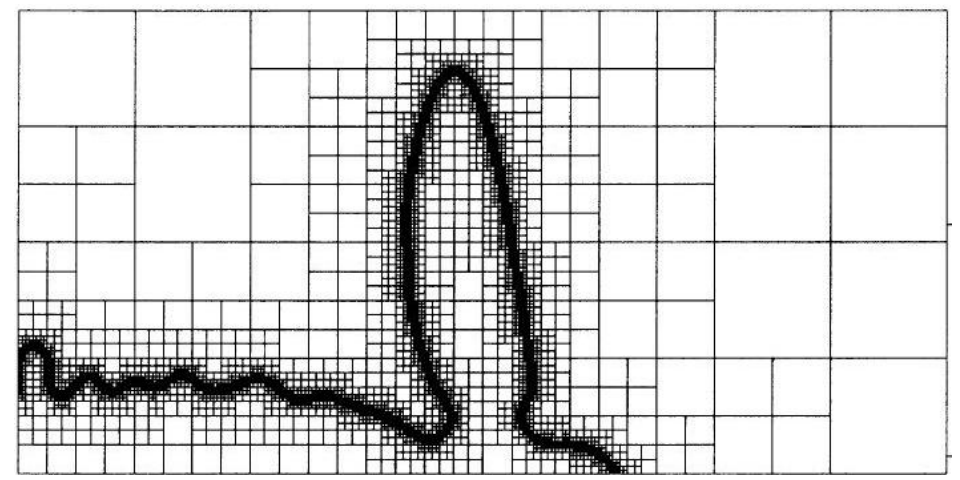

Figura 20: Malha adaptativa utilizando 18 níveis de subdivisão na região da interface [Lan et al., 2002a].

No início da simulação, o domínio retangular dado na Figura 19(c) foi subdividido (discretizado) por uma malha raiz. Cada volume da malha raiz pode ser subdividido diversas vezes de acordo com algum critério, mas nunca eliminado, ou seja, combinado com os volumes vizinhos para formar um único volume, processo denominado de coalescimento de volumes. Portanto, o mínimo número possível de volumes da malha numérica é aquele da malha raiz e ocorre quando não existem volumes subdivididos. A Figura 21 mostra uma malha com estrutura de quadtree onde o quadrado externo equivale a um único volume raiz (quadrado externo) definido no presente trabalho. Este volume raiz foi subdividido com uma estrutura de quadtree até o nível 4. Logo, uma estrutura deste tipo existe para cada volume da malha raiz. 


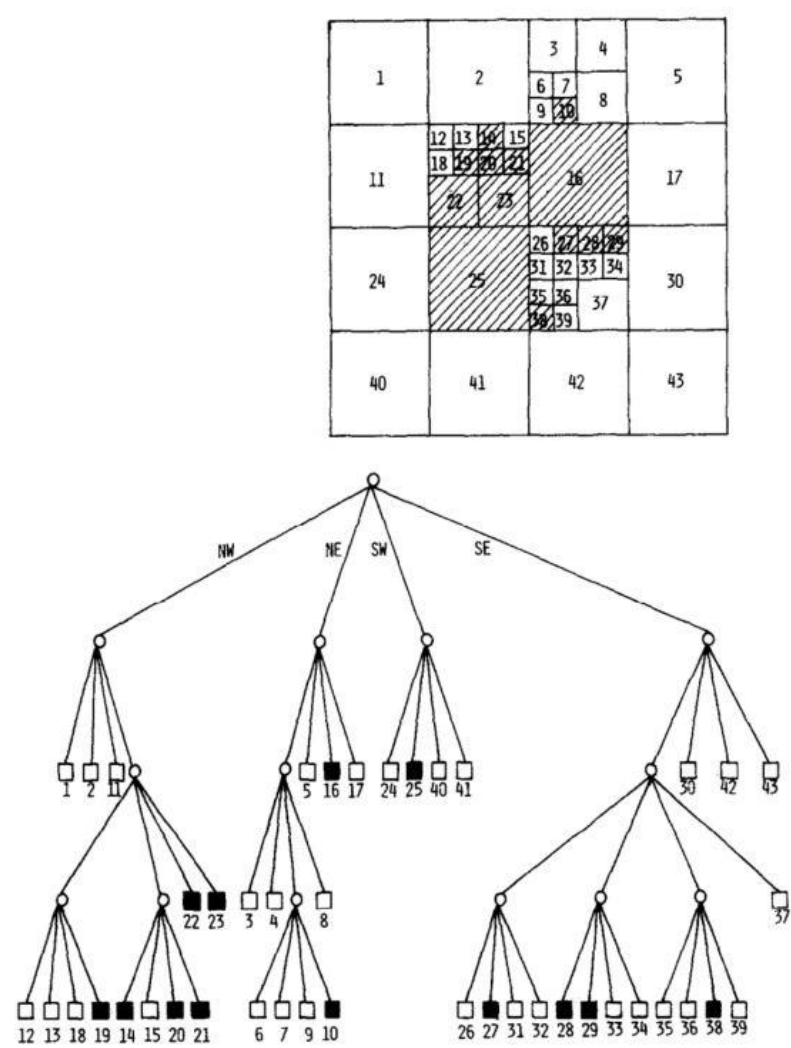

Figura 21: Malha refinada localmente com estrutura de quadtree (acima) e sua representação na forma de quadtree (abaixo). O estado do símbolo como aberto ou fechado (preto) é uma informação armazenada em cada volume/bloco da malha [SAMET, 1982]. O quadrado externo que abrange todos os blocos é equivalente a um volume da malha raiz construída no presente trabalho.

No instante inicial da simulação $(t=0)$, tem-se um cilindro com o centro de sua seção circular posicionada em $x=0$ e $y=a$, onde $a$ representa o raio da seção, sem a existência de um pescoço. A malha raiz foi subdividida (refinada) em uma sequência de 11 passos. Em cada passo, um conjunto de volumes próximos à interface entre as fases $s$ e $g^{\prime}$ era subdividido em quatro volumes "filho", implicando em uma árvore subdividida até o nível 11, ou seja, o lado do menor volume finito é dado por $\frac{1}{2^{11}} \frac{L_{x}}{N_{x}}=\frac{1}{2^{11}} \frac{L_{y}}{N_{y}}$ onde $N_{x}$ e $N_{y}$ são os números de volumes da malha raiz ao longo das direções $x$ e $y$, respectivamente. Em cada passo de refino todos os volumes da malha serão examinados e um determinado volume será subdividido quando as coordenadas de seu nó central, definidas por $x_{P}$ e $y_{P}$, obedecerem à inequação abaixo

$$
\left(a-C \delta_{i}\right)^{2}<x_{P}^{2}+\left(y_{P}-a\right)^{2}<\left(a+C \delta_{i}\right)^{2}
$$

onde $\delta_{i}$ é a espessura definida inicialmente para a interface difusa e $C$ é uma constante que determina a espessura de um "anel" ao redor da interface cilíndrica matemática (sem espessura) no qual os volumes serão subdivididos por quatro uma vez no passo atual. Os valores de $C$ nos passos 1 a 11 foram, respectivamente: $20 ; 18 ; 15 ; 12 ; 10 ; 9 ; 7 ; 5 ; 3 ; 1,5 ; 1$. Após os 11 passos de refino, os menores volumes estarão localizados em um anel de 
espessura $\delta_{i}$ envolvendo a interface matemática ideal (sem espessura), que é um segmento de uma circunferência de raio $a$.

Após definição do posicionamento de todos os volumes da malha, valores de $\phi$ e $X_{v}^{s}$ foram atribuídos aos nós de cada volume, sendo definidos respectivamente por $\phi_{P}^{t=0}$ e $X_{v, P}^{s, t=0}$. Estes valores foram definidos utilizando-se o perfil dado pela Equação (137) para impor uma transição difusa (não-abrupta) da fase $s$ para a fase $g^{\prime}$ através da região da interface difusa de espessura $\delta_{i}$ definida inicialmente. Os valores da variável de fase para cada nó foram calculados por

$$
\phi_{P}^{t=0}=1-\frac{1}{1+\exp \left(\frac{a-r_{P}}{0,1 \delta_{i}}\right)}
$$

onde

$$
r_{P}=\sqrt{x_{P}^{2}+\left(a-y_{P}\right)^{2}}
$$

sendo que $r_{P}$ representa a distância entre o nó do volume em questão $(P)$ e o centro da seção do cilindro sólido de $\mathrm{Cu}$. A Equação (147) impõe uma transição difusa através da interface entre $\phi=1$ no interior de $s$ e $\phi=0$ no interior de $g^{\prime}$. O primeiro passo para se obter $X_{v, P}^{s, t=0}$ é o cálculo de $X_{v, P}^{t=0}$ a partir da Equação abaixo

$$
X_{v, P}^{t=0}=X_{v}^{s, 0}+\frac{\left(X_{v}^{g^{\prime}, 0}-X_{v}^{s, 0}\right)}{1+\exp \left(\frac{a-r_{P}}{0,1 \delta_{i}}\right)}
$$

onde $X_{v}^{s, 0}$ e $X_{v}^{g^{\prime}, 0}$ são as frações molares de lacunas no interior da fase sólida e gasosa no instante inicial, que foram consideradas como sendo os valores de equilíbrio incluindo o efeito do raio de curvatura $a$ do cilindro inicial. $\mathrm{O}$ valor $X_{v, P}^{t=0}$ foi utilizado para se calcular $X_{v, P}^{s, t=0}$ a partir da combinação das Equações (97), (98), (99) e (111). Substituindo as Equações (97) e (98) na Equação (110), obtém-se

$$
X_{v}^{g^{\prime}}=\frac{\left(H^{v}-T S^{v, x s}\right)-G^{s}\left(T, P_{r e f}\right)+R T\left[\ln X_{v}^{s}-\ln \left(1-X_{v}^{s}\right)\right]}{2 a_{v}}+b_{v}
$$

que quando substituída na Equação (111) e aplicando-se ao valor do nó do volume resulta na Equação final para o cálculo de $X_{v, P}^{s, t}$ 


$$
\begin{gathered}
X_{v, P}^{t=0}=h\left(\phi_{P}^{t=0}\right) X_{v, P}^{s, t=0}+ \\
+\frac{\left[1-h\left(\phi_{P}^{t=0}\right)\right]}{2 a_{v}}\left\{\left(H^{v}-T S^{v, x s}\right)-G^{s}\left(T, P_{r e f}\right)+R T\left[\ln X_{v, P}^{s, t=0}-\ln \left(1-X_{v, P}^{s, t=0}\right)\right]\right\} \\
+\left[1-h\left(\phi_{P}^{t=0}\right)\right] b_{v}
\end{gathered}
$$

Esta Equação permite o cálculo de $X_{v, P}^{s, t=0}$ a partir do valor de $X_{v, P}^{t=0}$, calculado pela Equação (149). Porém, como não é possível isolar $X_{v, P}^{s, t=0}$, a solução foi obtida utilizando-se o método de Newton-Rapson (GERALD; WHEATLEY, 2004). Logo, os campos iniciais de $\phi$ e $X_{v}^{s}$ na (a) posição dos nós dos volumes da malha foram calculados pelas Equações (147), (148), (149) e (151). A Figura 22 mostra um exemplo de malha e campo da variável $\phi$ obtidos como condição inicial para um domínio dado pela Figura 18(c) onde $a=1 \mathrm{~mm}$ e $L_{x}=L_{y}=2 \mu \mathrm{m}$. 

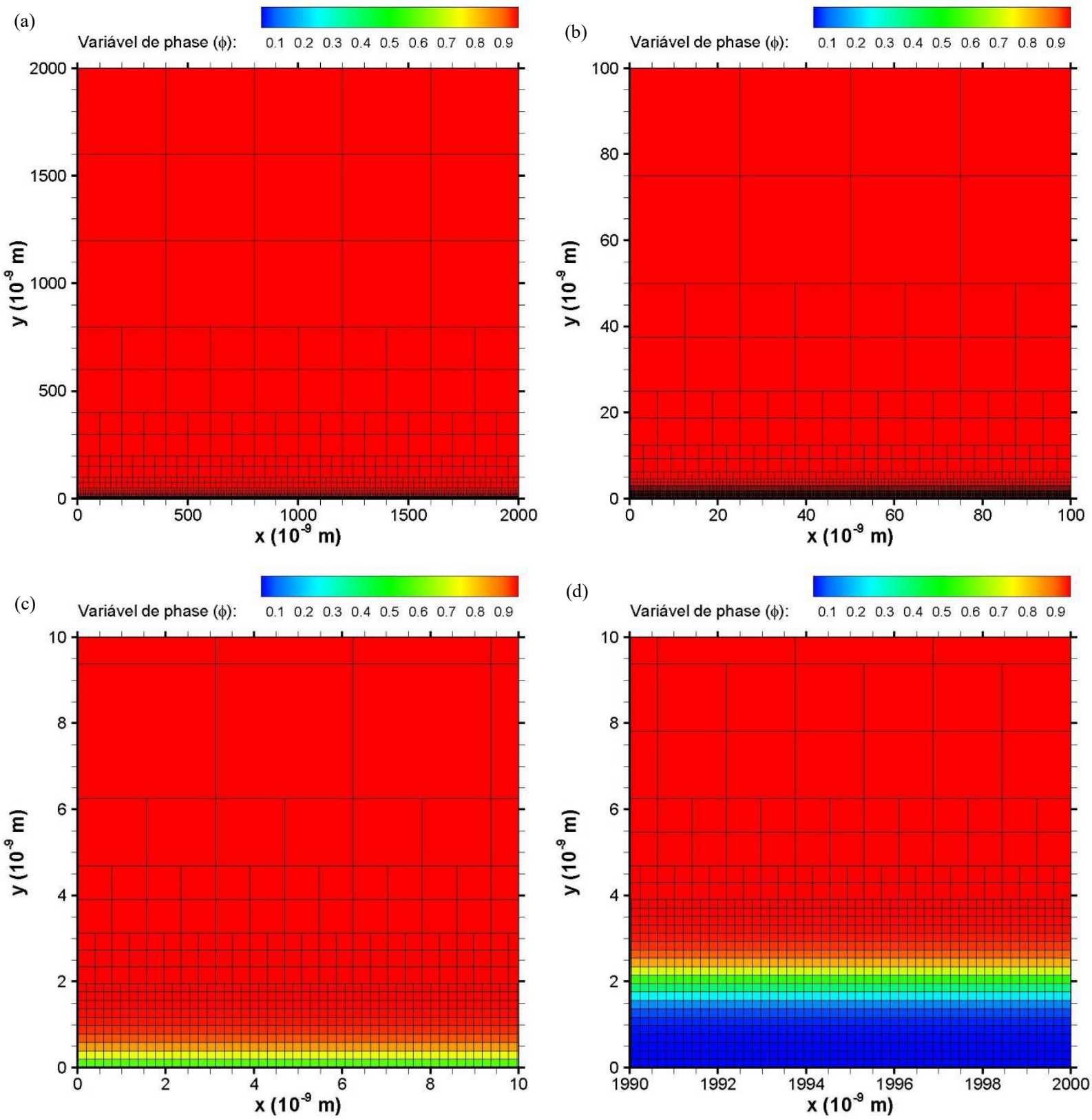

Figura 22: Malha e campo da variável de fase gerada como condição inicial para simulação onde $a=1 \mathrm{~mm}$ e $L_{x}=L_{y}=2 \mu \mathrm{m}$ : (a) domínio discretizado completo; (b) aumento de 20x do domínio na região onde o pescoço se forma; (c) aumento de 200x do domínio na região onde o pescoço se forma e (d) aumento de 200x do domínio na região mais distante de onde o pescoço deve-se formar.

Os procedimentos descritos nos parágrafos anteriores permitem a definição do tamanho e posição do nó de todos os volumes da malha numérica no início da simulação, além da definição dos valores de $\phi$ e $X_{v}^{S}$ (condição inicial) na posição de cada nó. Estas informações são suficientes para iniciar o processo de solução numérica das equações diferenciais, que permite a previsão da evolução no tempo dos valores de $\phi$ e $X_{v}^{s}$ a partir das Equações (159) e (167), desenvolvidas no item 4.3.5.2. Como o campo de $\phi$ define a região da interface, ou seja, a região que está aproximadamente no intervalo $0,1<\phi<0,9$, e como 
este campo evolui após cada passo de tempo $\Delta t$, a região da interface pode-se movimentar, exigindo uma reestruturação da malha adaptativa. $\mathrm{O}$ objetivo é que a região da interface seja sempre discretizada pelos menores volumes, ou seja, aqueles com os maiores níveis de subdivisão.

A reestruturação da malha consistiu basicamente em examinar cada volume da malha e, de acordo com um critério a ser explicado adiante, subdividir este volume em quatro volumesfilhos ou eliminar (coalescer) quatro volumes-filhos de um mesmo volume. O critério para subdivisão ou coalescimento de volumes foi definido com base no seu nível de subdivisão e no valor de $\phi$ associado ao nó deste volume. O nível de subdivisão de um volume foi definido como o número de vezes que um volume da malha raiz foi subdividido para chegar neste volume. O nível 1, por exemplo, corresponde a um volume obtido após uma única subdivisão de um volume da malha raiz em quatro volumes-filhos. Quando o nível de subdivisão de um volume é menor do que aquele definido para o valor de $\phi$ que ele contém, este volume é subdividido em quatro volumes-filho e a cada um deles atribui-se o mesmo valor de $\phi$ e $X_{v}^{s}$ do volume-pai. Quando os quatro volumes-filhos de um determinado volume não estão subdivididos e quando seus quatro valores de $\phi$ exigem um menor nível de divisão, estes volumes são eliminados e atribui-se a média dos quatro valores de $\phi$ e $X_{v}^{s}$ ao volume-pai. Este volume-pai agora não tem subdivisão e as Equações (91) e (99) serão utilizadas para calcular os valores de $\phi$ e $X_{v}^{s}$ no próximo instante de tempo. Os níveis de subdivisão de um dado volume e a faixa de valores de $\phi$ correspondentes, adotadas nas simulações deste trabalho, estão apresentadas abaixo:

- nível 0 (sem subdivisão - malha raiz): $0 \leq \phi \leq 10^{-14}$ ou $\left(1-10^{-14}\right) \leq \phi \leq 1$;

- nível 1: $10^{-14}<\phi \leq 10^{-12}$ ou $\left(1-10^{-12}\right) \leq \phi<\left(1-10^{-14}\right)$;

- nível 2: $10^{-12}<\phi \leq 10^{-11}$ ou $\left(1-10^{-11}\right) \leq \phi<\left(1-10^{-12}\right)$;

- nível 3: $10^{-11}<\phi \leq 10^{-10}$ ou $\left(1-10^{-10}\right) \leq \phi<\left(1-10^{-11}\right)$;

- nível 4: $10^{-10}<\phi \leq 10^{-9}$ ou $\left(1-10^{-9}\right) \leq \phi<\left(1-10^{-10}\right)$;

- nível 5: $10^{-9}<\phi \leq 10^{-8}$ ou $\left(1-10^{-8}\right) \leq \phi<\left(1-10^{-9}\right)$;

- nível 6: $10^{-8}<\phi \leq 10^{-7}$ ou $\left(1-10^{-7}\right) \leq \phi<\left(1-10^{-8}\right)$;

- nível 7: $10^{-7}<\phi \leq 10^{-6}$ ou $\left(1-10^{-6}\right) \leq \phi<\left(1-10^{-7}\right)$;

- nível 8: $10^{-6}<\phi \leq 10^{-5}$ ou $\left(1-10^{-5}\right) \leq \phi<\left(1-10^{-6}\right)$;

- nível 9: $10^{-5}<\phi \leq 10^{-4}$ ou $\left(1-10^{-4}\right) \leq \phi<\left(1-10^{-5}\right)$;

- nível 10: $10^{-4}<\phi \leq 10^{-3}$ ou $\left(1-10^{-3}\right) \leq \phi<\left(1-10^{-4}\right)$;

- nível 11: $10^{-3}<\phi<\left(1-10^{-3}\right)$. 
Estes níveis e suas faixas correspondentes foram escolhidos em um processo de tentativae-erro com avaliação visual da malha. Durante avaliação de cada tentativa, foi definido como condição que deveria existir uma variação suave no nível de subdivisão dos volumes através da região da interface e também que deveria ocorrer uma reestruturação adequada da malha para acompanhar a região da interface durante sua movimentação. Provavelmente existem outras combinações de níveis de subdivisão e faixas de valores de $\phi$ que funcionam tão bem ou melhor do que a combinação adotada.

O exame de todos os volumes da malha para em seguida reestruturá-la foi realizado após cada passo de tempo. Após sua reestruturação da malha a partir da subdivisão ou coalescimento foi realizado um último procedimento antes de aplicar as Equações (159) e (167) a cada volume não-subdividido da malha. Com o objetivo de evitar grandes diferenças de nível de subdivisão entre dois volumes vizinhos, o que poderia aumentar erros numéricos relacionados aos cálculos dos fluxos entre um volume e outro, um procedimento de nivelamento foi realizado. Este procedimento consistiu em examinar cada volume da malha e verificar o nível de subdivisão entre o volume examinado e todos os seus vizinhos. Se algum volume vizinho apresentasse um nível de subdivisão duas ou mais vezes maior que o volume examinado, este era subdividido. Este processo foi realizado por toda a malha até que nenhuma subdivisão ou coalescimento eram necessários. Este procedimento forneceu uma malha com refino gradual entre a região da interface e as regiões do interior das fases.

O código computacional utilizado para construção da malha e resolução numérica das equações diferenciais foi escrito em linguagem C padrão (ANSI). No código, cada volume finito da malha numérica foi representado por uma variável do tipo "struct" [KERNIGHAM, 1978], denominada "struct volume", construída especificamente para a solução das equações do presente modelo. A variável do tipo "struct volume" está apresentada na Figura 23, sendo que cada volume finito da malha numérica está associado a uma variável deste tipo, que contém todas as informações importantes do volume. 


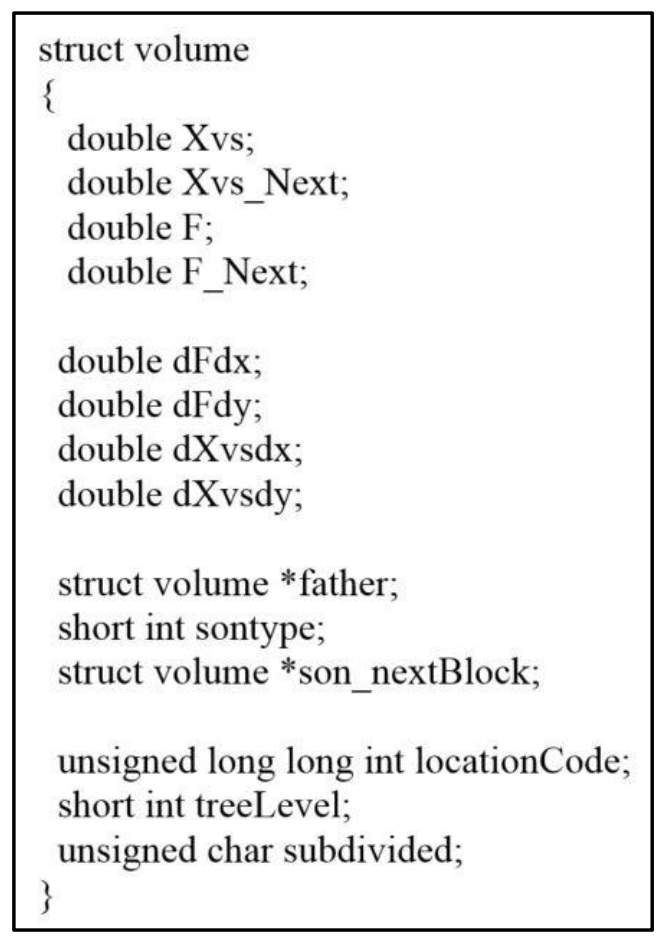

Figura 23: Definição da variável do tipo "struct volume" projetada para construção do código computacional que definiu a malha adaptativa com estrutura quadtree e solucionou numericamente as equações diferenciais pelo método dos volumes finitos.

Considere um volume finito da malha denominado $P$. As variáveis Xvs e $\mathrm{F}$ da struct volume correspondem, respectivamente, às variáveis $\phi_{p}^{t}$ e $X_{v, P}^{s, t}$ associadas a este volume, enquanto Xvs_Next e F_Next correspondem a $\phi_{p}^{t+\Delta t}$ e $X_{v, P}^{s, t+\Delta t}$. As variáveis $\mathrm{dFdx}, \mathrm{dFdy}$, dXvsdx e dXvsdy correspondem, respectivamente, a $\frac{\partial \phi}{\partial x}, \frac{\partial \phi}{\partial y}, \frac{\partial X_{v}^{s}}{\partial x} \mathrm{e} \frac{\partial X_{v}^{s}}{\partial y}$. As outras variáveis pertencentes ao tipo "struct volume" são melhores explicadas a partir da malha exemplificada na Figura 24. Na Figura 24(a) está apresentada uma malha raiz bidimensional com 4 x 3 volumes raízes onde cada volume pode apresentar uma estrutura de quadtree semelhante à da Figura 21. No presente trabalho, cada pequeno símbolo (bolinha, quadradinho) indicado na representação de quadtree mostrada na Figura 21 indica a criação de uma variável do tipo "struct volume", com um endereço de memória específico. A cada volume da malha raiz da Figura 24(a) foi atribuído um índice que variou de forma linear de 0 até 11, possibilitando encontrar o volume raiz desejado e sua posição relativa. O volume 5 desta malha foi subdividido, gerando 4 volumes-filhos que são identificados pela variável sontype (1, 2, 3 e 4$)$ de acordo com a sua posição relativa no interior do volume-pai. O volume-filho com sontype 1 foi ainda subdividido, gerando 4 novos volumes-filhos.

Na Figura 24(b) está a representação da malha raiz utilizada no código, bem como a quadtree associada ao volume raiz 5 . Os valores atribuídos a algumas das variáveis internas da 
"struct volume" associada a cada volume da malha também estão apresentados. Por exemplo, estão apresentadas a variável sontype e a variável subdivided, que indica se o volume está subdividido (subdivided $=1$ ) ou não (subdivided $=0$ ). A variável treeLevel armazena o nível de subdivisão correspondente a cada volume da malha. A malha da Figura 24(a) tem um nível de subdivisão 2 (treeLevel = 2), mas nas simulações conduzidas no presente trabalho, o valor máximo de treeLevel foi 11 . Como as variáveis father e son_nextBlock são ponteiros e armazenam o endereço de memória de um determinado volume, uma seta foi colocada ao lado da variável para mostrar para qual volume elas estão apontando (Figura 24(b)). Os volumes da malha raiz não têm volume-pai (father = NULL), mas a variável father de qualquer volumefilho aponta para o seu-volume-pai, que tem um nível de subdivisão a menos, como pode ser visto nos volumes-filhos do volume raiz 5 e nos volumes-filhos do volume-filho com sontype $=1$, com nível de subdivisão 2 (treeLevel $=2$ ). O volume para o qual a variável son_nextBlock aponta depende de algumas condições. Se o volume que contém a variável son_nextBlock é um volume raiz e não está subdividido, esta variável apontará para um volume com endereço adjacente, como por exemplo, os volumes-raízes de índices 3, 4 e 6. Qualquer volume que esteja subdividido, seja ele raiz ou não, a sua variável son_nextBlock apontará para o seu volume-filho com sontype $=0$, como é o caso do volume-raiz 5 e de seu volume-filho com sontype $=1$. A variável son_nextBlock de um volume-filho que não está subdividido e não tem sontype $=3$, aponta para o volume-filho com endereço adjacente, como alguns volumes com treeLevel $=1$, definidos na Figura 24(b). No entanto, caso o volumefilho tenha sontype $=3$ (não tem volume adjacente) e não esteja subdividido, a variável son_nextBlock apontará para o volume com endereço adjacente de seu volume-pai. Se o volume-pai também for um volume-filho com sontype $=3$ e, portanto, sem volume adjacente, son_nextBlock apontará para o volume adjacente do volume-pai deste volume-pai. Este processo pode continuar até a malha raiz. Esta estrutura de ponteiros, que foi desenvolvida especificamente no presente trabalho, funcionou perfeitamente sem qual quer problema na sua lógica de funcionamento. 
(a)

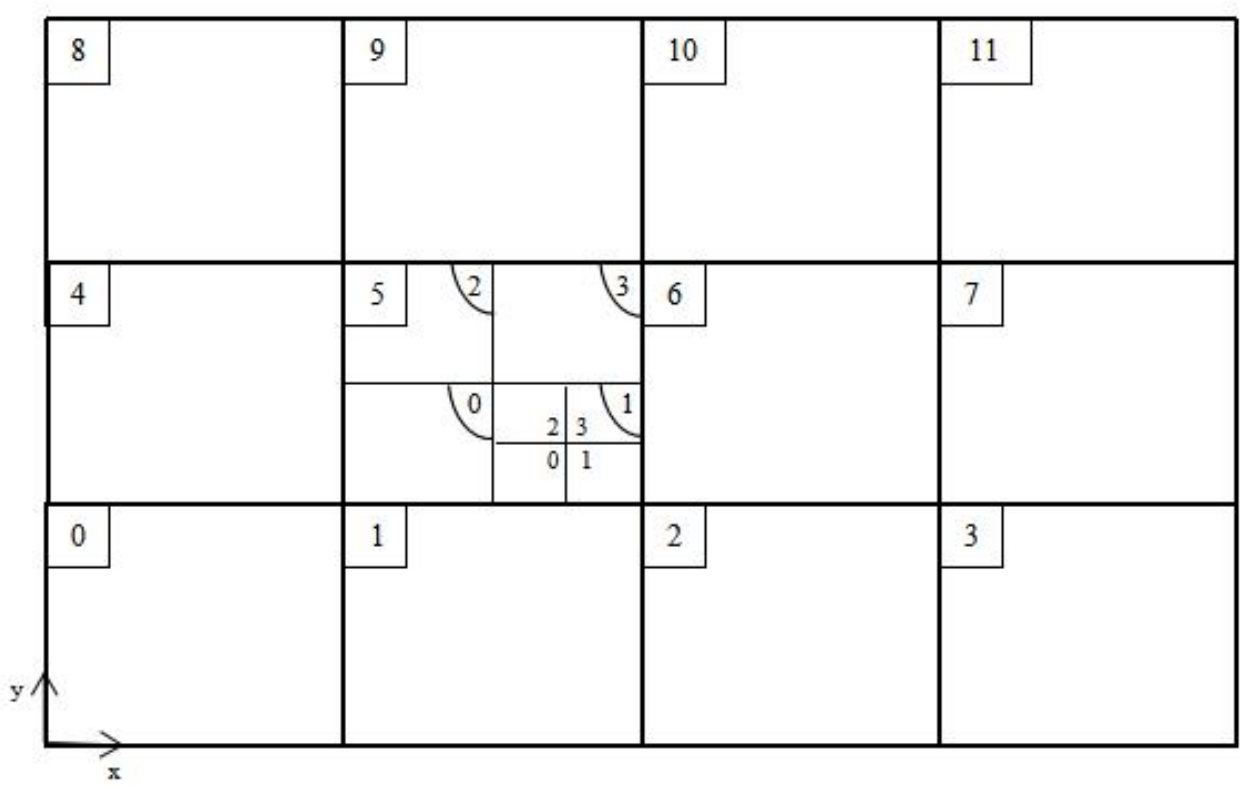

(b)

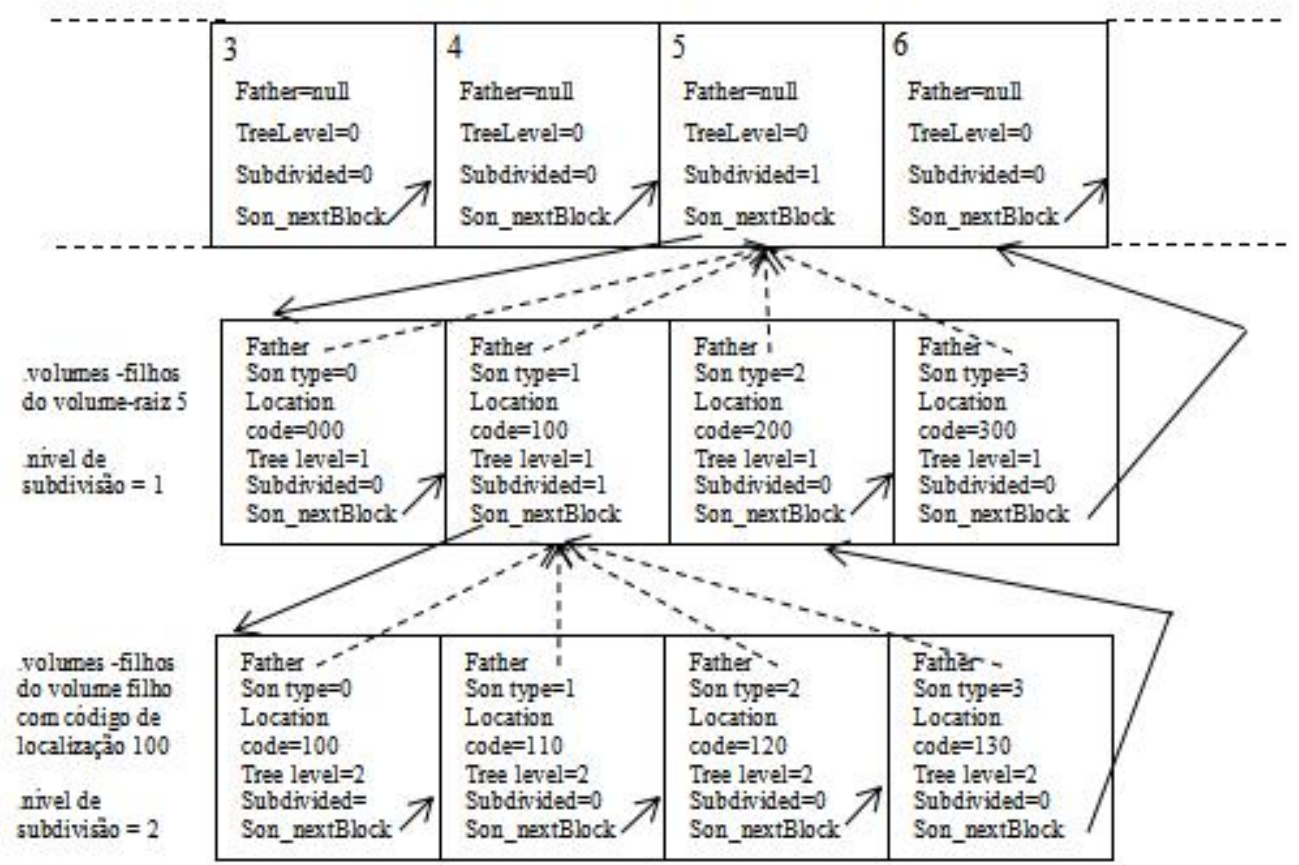

Figura 24: Exemplo de malha refinada localmente segundo uma estrutura do tipo quadtree: (a) malha raiz bidimensional com $4 \times 3$ volumes finitos (índices no canto superior esquerdo), sendo o volume 5 subdividido e volume-filho (sontype $=1$ ) subdividido; $(b)$ estrutura do código computacional - setas indicam para qual volume as variáveis do tipo ponteiro estão apontando. 
A variável locationCode, que tem tipo integer e também faz parte da "struct volume" (Figura 23), armazena um código de localização que permite o cálculo das coordenadas $x$ e $y$ do vértice inferior esquerdo de seu volume em relação a um sistema de coordenadas posicionado no vértice inferior esquerdo do volume raiz ao qual ele pertence. Este código, que é um número inteiro, ocupa um espaço de memória RAM menor do que a alternativa de se armazenar diretamente as coordenadas $x$ e $y$ utilizando duas variáveis do tipo double, ou seja, a utilização de códigos do tipo interior para localização apresenta potencial para economia de espaço de memória [SAMET, 1990]. Além disso, os erros de arredondamento no cálculo das coordenadas de qualquer volume de malha, seja ele o menor ou maior, são minimizados, pois o código armazenado é um número inteiro.

O código é utilizado para se obter as coordenadas de qualquer volume-filho em relação a um sistema de coordenadas posicionado no volume-raiz que contém este volume filho, qualquer seja o nível de subdivisão deste volume-raiz. O número de dígitos do código deve ser igual ao máximo nível de subdivisão definido inicialmente para a malha a ser construída. No presente trabalho, como o máximo nível de subdivisão foi 11, este código apresentou 11 dígitos. Já a malha apresentada na Figura 24 foi subdividida até o nível 2, mas acomodaria uma subdivisão até o nível 3 pois o código de localização apresenta 3 dígitos. De forma geral, cada dígito contém uma informação do nível de subdivisão correspondente à sua posição no código - por exemplo, o segundo dígito da esquerda para a direita contém informação do nível de subdivisão 2. Se um determinado volume tem nível de subdivisão 2, somente os dois primeiros dígitos contém informações e podem ser diferentes de zero. Todos os outros dígitos à direita são iguais a zero e não carregam informações. Considere como exemplo os volumes-filhos com nível de subdivisão 2 (treeLevel $=2$ ) apresentados na Figura 24(b), em particular o volume com sontype $=2$. Seu código de localização é 120 e apenas o 12 tem informações. Cada dígito com informação é igual ao sontype do volume que contém o volume de código 120 no nível de subdivisão correspondente. Por exemplo, o primeiro dígito (1) é igual ao sontype do volume no nível de subdivisão 1 que contém o volume de código 120, enquanto que o segundo (2) é o sontype do próprio volume, já que está na posição do nível de subdivisão deste volume, que também é 2 . Pode-se concluir então que o maior dígito é 3, pois é o maior valor de sontype possível.

Os passos para o cálculo das coordenadas do vértice inferior esquerdo de um determinado volume-filho a partir de seu código de localização serão descritos a seguir, exemplificando para o volume de código 110 da Figura 24(b): 
a) cada dígito com informação é convertido para um número binário de dois dígitos $(0=00$; $1=01 ; 2=10$ e $3=11$ ) - para o código 110 , de um volume com nível de subdivisão 2 , tem-se 01 e 01 ;

b) forma-se um novo número binário utilizando todos os primeiros dígitos da forma binária de cada dígito com informação do código de localização e este novo número binário será convertido para um número inteiro que será usado para calcular a coordenada y - no exemplo do código 110 tem-se o binário 00 , que convertido para inteiro resulta em 0 ;

c) forma-se um segundo número binário utilizando todos os segundos dígitos da forma binária de cada dígito do código de localização e este número será também convertido para um número inteiro que será usado para calcular a coordenada $\mathrm{x}$ - no exemplo do código 110 tem-se o binário 11, que convertido para inteiro resulta em 3;

d) os números inteiros obtidos, correspondentes as coordenadas $x$ e $y$, devem ser multiplicados pelo tamanho do lado do volume (que é sempre quadrado) para finalmente encontrar as coordenadas do seu vértice inferior esquerdo - no exemplo do código 110 tem-se $y=0$ e $x=3 \Delta x$, sendo $\Delta x$ o lado do volume.

As coordenadas $x=3 \Delta x$ e $y=0$ em relação ao vértice do volume-raiz podem ser verificadas na malha da Figura 24(a). Outros detalhes sobre este código de localização podem ser encontrados na literatura [AIZAWA et al., 2008].

Uma tarefa comum durante a resolução numérica de equações diferenciais a partir de uma malha de volumes é a identificação dos vizinhos adjacentes às faces de um determinado volume e o cálculo dos fluxos de calor e/ou massa com estes vizinhos. Em uma malha estruturada, o índice do volume no código computacional indica diretamente quem são estes vizinhos. Em uma malha não-estruturada, como a adotada no presente trabalho, a tarefa de localizar os vizinhos não é simples e torna-se mais complexa quando esta malha varia ao longo do tempo. Quando se tem uma estrutura de quadtree, esta tarefa é simplificada. Samet [SAMET, 1982] apresentou alguns algoritmos simples para a localização de vizinhos adjacentes às faces (arestas) e aos vértices de um determinado volume. $\mathrm{O}$ algoritmo apresentado pelo autor [SAMET, 1982] que localiza o vizinho de mesmo nível de subdivisão, ou seja, mesmo tamanho, ou maior (menor nível de subdivisão) caso um de mesmo tamanho não exista, foi utilizado na construção do código computacional do presente trabalho. 


\subsubsection{Discretização das equações diferenciais}

As Equações (117) e (127) da Tabela 6 foram discretizadas pelo método dos volumes finitos, formulação implícita [PATANKAR, 1980; MALISKA, 1995; FERZIGER; PERIC, 2002]. Estas equações serão discretizadas para um volume finito de nó denominado $P$ e localizado no interior da malha, apresentado na Figura 25 em conjunto os volumes finitos vizinhos. Todos os volumes da malha são quadrados e cada um contêm um nó posicionado no seu centro (centroide). O processo de discretização é realizado a partir da integral de volume no interior do volume $P$ em um período de tempo que se inicia em $t$ e termina em $t+\Delta t$, sendo que $\Delta t$ é o passo de tempo.

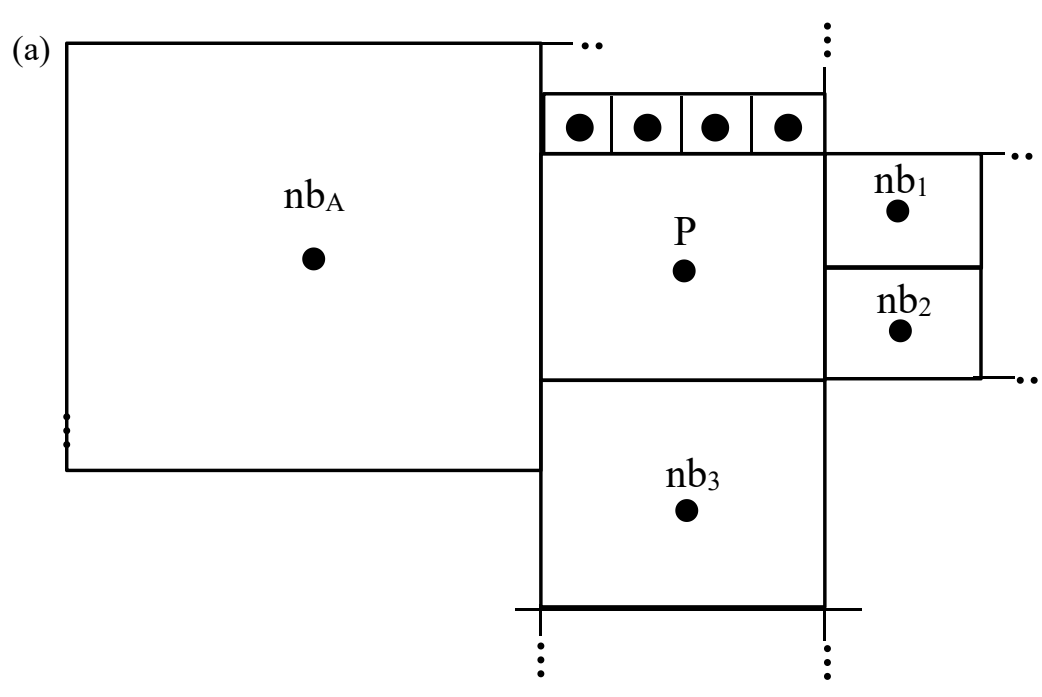

(b)

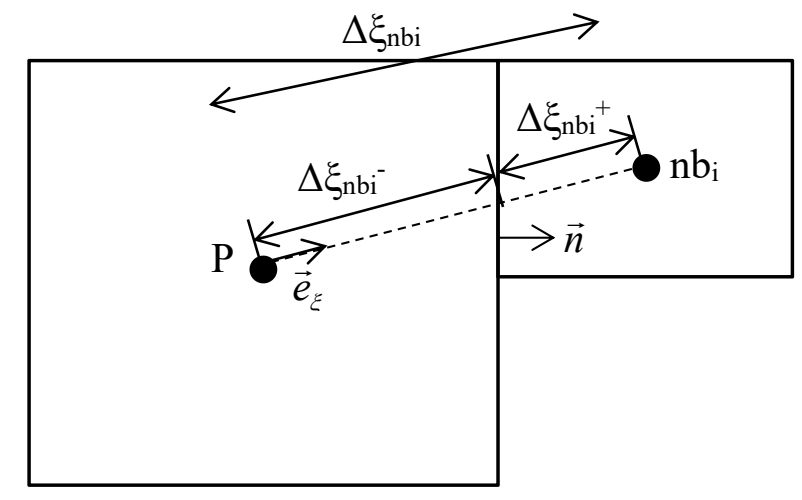

Figura 25: Volume finito e seus vizinhos extraídos de uma malha não estruturada de quadrados: (a) exemplo de parte da malha e (b) detalhes geométricos relativos a um dos vizinhos do volume central.

A Equação (117) escrita em notação simbólica, foi discretizada segundo a Equação abaixo 


$$
\int_{t}^{t+\Delta t} \int_{V_{P}}\left[\frac{1}{M_{\phi}} \frac{\partial \phi}{\partial t}=\vec{\nabla} \cdot\left(K_{\phi} \vec{\nabla} \phi\right)-\frac{\partial f_{0}}{\partial \phi}\right] d V d t
$$

onde $M_{\phi}$ e $K_{\phi}$ são assumidos constantes e

$$
\frac{\partial f_{0}}{\partial \phi}=\rho_{m}^{s} \frac{d h}{\partial \phi}\left[\left(F^{g}-F^{s}\right)+\frac{d F^{s}}{d X_{v}^{s}}\left(X_{v}^{s}-X_{v}^{g}\right)\right]-W \frac{d g}{\partial \phi}
$$

sendo $V_{P}$ o volume do volume finito $P$. O cálculo da integral de volume em uma malha nãoestruturada do primeiro termo à direita na Equação (152) exige um procedimento diferente daquele adotada nas malhas estruturadas. Inicialmente deve-se reescrever este termo utilizando o teorema do divergente, como indicado abaixo

$$
\int_{V_{P}}\left[\vec{\nabla} \cdot\left(K_{\phi} \vec{\nabla} \phi\right)\right] d V=K_{\phi} \sum_{i=1}^{N}\left[\int_{A_{n b_{i}}} \vec{\nabla} \phi \cdot \vec{n} d A\right]
$$

onde $A_{n b_{i}}$ é a área da face de contato entre o volume $P$ e o volume vizinho $n b_{i} ; \vec{n}$ é um vetor unitário e normal a esta face de contato, apontando para fora do volume $P$ e $N$ é o número total de vizinhos deste volume. Na integral à direita da Equação (154) o termo $\vec{\nabla} \phi$ deve ser integrado na face de contato de área $A_{n b_{i}}$. No método dos volumes finitos, assume-se que o perfil de $\phi$ é linear, permitindo escrever

$$
\int_{V_{P}}\left[\vec{\nabla} \cdot\left(K_{\phi} \vec{\nabla} \phi\right)\right] d V=K_{\phi} \sum_{i=1}^{N}\left[(\vec{\nabla} \phi)_{f n b_{i}} \cdot \vec{n} A_{n b_{i}}\right]
$$

onde $(\vec{\nabla} \phi)_{f n b_{i}}$ é o vetor $\vec{\nabla} \phi$ no centro da face de contato de área $A_{n b_{i}}$. Em uma malha estruturada, nesta Equação utiliza-se a aproximação $(\vec{\nabla} \phi)_{f n b_{i}} \cdot \vec{n} \approx \frac{\phi_{n b i}-\phi_{P}}{\Delta \xi_{n b_{i}}}$, onde $\Delta \xi$ é a distância entre os nós $P$ e $n b_{i}, \phi_{P}$ e $\phi_{n b i}$ são os valores de $\phi$ nestes nós, respectivamente. No entanto, esta aproximação não é aceitável em uma malha não-estruturada, como aquela ilustrada na Figura 25(a), pois ela agora representa $(\vec{\nabla} \phi)_{f n b_{i}} \cdot \vec{e}_{\xi}$ e não mais $(\vec{\nabla} \phi)_{f n b_{i}} \cdot \vec{n}$. Logo, será necessário uma correção. Jasak [JASAK, 1996] e Demirdžić [DEMIRDŽIĆ, 2015] concluíram que entre os diversos esquemas de correção examinado para discretização em malhas não-estruturadas, o esquema sobre-relaxado ("overrelaxed”) é mais robusto e eficiente. Este esquema foi adotado no presente trabalho e mantém o termo apresentado $\left((\vec{\nabla} \phi)_{f n b_{i}}\right.$. $\left.\vec{e}_{\xi} \approx \frac{\phi_{n b i}-\phi_{P}}{\Delta \xi_{n b_{i}}}\right)$, porém introduzindo um coeficiente de ajuste $(C)$ e adicionando um vetor ortogonal a $\vec{n}$, denominado $\vec{K}$, onde $\vec{n}=C \vec{e}_{\xi}+\vec{K}$ e $\vec{n} \cdot \vec{K}=0$. Estas duas relações mostram que $C=1 /\left(\vec{e}_{\xi} \cdot \vec{n}\right)$ e, obviamente, $\vec{K}=\vec{n}-\frac{\vec{e}_{\xi}}{\vec{e}_{\xi} \cdot \vec{n}}$, resultando em 


$$
(\vec{\nabla} \phi)_{f n b_{i}} \cdot \vec{n}=\frac{1}{\vec{e}_{\xi} \cdot \vec{n}}(\vec{\nabla} \phi)_{f n b_{i}} \cdot \vec{e}_{\xi}+\left[(\vec{\nabla} \phi)_{f n b_{i}} \cdot \vec{n}-(\vec{\nabla} \phi)_{f n b_{i}} \cdot \frac{\vec{e}_{\xi}}{\vec{e}_{\xi} \cdot \vec{n}}\right]
$$

onde o primeiro termo $(\vec{\nabla} \phi)_{f n b_{i}}$ entre colchetes ao lado direito é calculado por $\frac{\Delta \xi_{b_{i}^{+}}}{\Delta \xi_{n b_{i}}}(\vec{\nabla} \phi)_{P}+$ $\frac{\Delta \xi_{n b_{i}^{-}}^{-}}{\Delta \xi_{n b_{i}}}(\vec{\nabla} \phi)_{n b_{i}}$ e o segundo por $\frac{(\vec{\nabla} \phi)_{P}+(\nabla \phi)_{n b_{i}}}{2}$. O cálculo final dado pela Equação (155) torna-se

$$
\begin{aligned}
\int_{V_{P}}\left[\vec{\nabla} \cdot\left(K_{\phi} \vec{\nabla} \phi\right)\right] d V= \\
=K_{\phi} \sum_{i=1}^{N} A_{n b_{i}}\left\{\frac{1}{\overrightarrow{\vec{e}}_{\xi} \cdot \vec{n}} \frac{\left(\phi_{n b i}-\phi_{P}\right)}{\Delta \xi_{n b_{i}}}+\left(\frac{\Delta \xi_{n b_{i}^{+}}}{\Delta \xi_{n b_{i}}}(\vec{\nabla} \phi)_{P}+\frac{\Delta \xi_{n b_{i}^{-}}}{\Delta \xi_{n b_{i}}}(\vec{\nabla} \phi)_{n b_{i}}\right) \cdot \vec{n}\right. \\
\left.\quad-\left(\frac{(\vec{\nabla} \phi)_{P}+(\vec{\nabla} \phi)_{n b_{i}}}{2}\right) \cdot \frac{\vec{e}_{\xi}}{\vec{e}_{\xi} \cdot \vec{n}}\right\}
\end{aligned}
$$

onde $(\vec{\nabla} \phi)_{P}$ e $(\vec{\nabla} \phi)_{n b_{i}}$ são os valores de $\vec{\nabla} \phi$ estimados nos nós $P$ e $n b_{i}$ a partir dos valores de $\phi$ dos volumes vizinhos. Note que em uma malha estruturada, $\vec{e}_{\xi}=\vec{n}, \operatorname{logo} \vec{e}_{\xi} \cdot \vec{n}=1 \mathrm{e}$ $\frac{\Delta \xi_{n b_{i}^{+}}}{\Delta \xi_{n b_{i}}}=\frac{\Delta \xi_{n b_{i}^{-}}}{\Delta \xi_{n b_{i}}}=0,5$, resultando na aproximação tradicional.

Substituindo a Equação (157) na Equação (152), após assumir que na integral de volume do termo à esquerda da Equação (152) a variável de fase $\phi$ é uniforme no interior do volume e que, na integral de volume à direita, o termo $\frac{\partial f_{0}}{\partial \phi}$ também é uniforme no interior do volume, como usualmente considerado no método dos volumes finitos, obtém-se

$$
\begin{aligned}
\frac{V_{P}}{M_{\phi}}\left(\phi_{P}^{t+\Delta t}-\phi_{P}^{t}\right) & \\
& =K_{\phi} \sum_{i=1}^{N} A_{n b_{i}}\left\{\frac{1}{\vec{e}_{\xi} \cdot \vec{n}} \int_{t}^{t+\Delta t} \frac{\left(\phi_{n b i}-\phi_{P}\right)}{\Delta \xi_{n b_{i}}} d t\right. \\
& +\int_{t}^{t+\Delta t}\left(\frac{\Delta \xi_{n b_{i}^{+}}}{\Delta \xi_{n b_{i}}}(\vec{\nabla} \phi)_{P}+\frac{\Delta \xi_{n b_{i}^{-}}}{\Delta \xi_{n b_{i}}}(\vec{\nabla} \phi)_{n b_{i}}\right) \cdot \vec{n} d t \\
& \left.-\int_{t}^{t+\Delta t} \frac{\left[(\vec{\nabla} \phi)_{P}+(\vec{\nabla} \phi)_{n b_{i}}\right]}{2} \cdot \frac{\vec{e}_{\xi}}{\vec{e}_{\xi} \cdot \vec{n}} d t\right\}-\int_{t}^{t+\Delta t}\left(\frac{\partial f_{0}}{\partial \phi}\right)_{P} d t
\end{aligned}
$$

onde $\phi_{P}^{t}$ e $\phi_{P}^{t+\Delta t}$ são os valores de $\phi$ calculados no nó $P$ e nos instantes de tempo $t$ e $t+\Delta t$ respectivamente. Ao lado direito desta Equação existem quatro integrais no intervalo de tempo $\Delta t$ que precisam ser calculadas. A primeira foi calculada a partir do método explícito enquanto as outras pelo método explícito. A equação final discretizada, que resulta no sistema 
de equações algébricas a ser solucionado para obtenção do campo da variável de fase, $\phi$, está apresentada abaixo

$$
\begin{gathered}
{\left[1+\frac{K_{\phi} M_{\phi} \Delta t}{V_{P}} \sum_{i=1}^{N}\left(\frac{A_{n b_{i}}}{\overrightarrow{\vec{d}}_{n b_{i}} \cdot \vec{n}}\right)\right] \phi_{P}^{t+\Delta t}=\phi_{P}^{t}-M_{\phi} \Delta t\left(\frac{\partial f_{0}}{\partial \phi}\right)_{P}^{t}} \\
+\frac{K_{\phi} M_{\phi} \Delta t}{V_{P}} \sum_{i=1}^{N} A_{n b_{i}}\left\{\frac{\phi_{n b_{i}}^{t+\Delta t}}{\overrightarrow{\vec{d}}_{n b_{i}} \cdot \vec{n}}+\left[\frac{\Delta \xi_{n b_{i}^{+}}}{\Delta \xi_{n b_{i}}}(\vec{\nabla} \phi)_{P}^{t}+\frac{\Delta \xi_{n b_{i}^{-}}}{\Delta \xi_{n b_{i}}}(\vec{\nabla} \phi)_{n b_{i}}^{t}\right] \cdot \vec{n}\right. \\
\left.-\left[(\vec{\nabla} \phi)_{P}^{t}+(\vec{\nabla} \phi)_{n b_{i}}^{t}\right] \cdot \frac{\vec{d}_{n b_{i}}}{2\left(\vec{d}_{n b_{i}} \cdot \vec{n}\right)}\right\}
\end{gathered}
$$

onde $(\vec{\nabla} \phi)_{P}^{t}$ e $(\vec{\nabla} \phi)_{n b_{i}}^{t}$ são os valores de $(\vec{\nabla} \phi)_{P}$ e $(\vec{\nabla} \phi)_{n b_{i}}$ calculados no instante $t ; \vec{d}_{n b_{i}}=$ $\Delta \xi_{n b_{i}} \vec{e}_{\xi}$ e $\left(\frac{\partial f_{0}}{\partial \phi}\right)_{P}^{t}=\frac{\partial f_{0}}{\partial \phi}\left(\phi_{P}^{t}, X_{v, P}^{s, t}, X_{v, P}^{g^{\prime}, t}\right)$, sendo $X_{v, P}^{s, t}$ e $X_{v, P}^{g^{\prime}, t}$ os valores de $X_{v}^{s}$ e $X_{v}^{g^{\prime}}$ calculados no nó $P$ e no instante de tempo $t$. Aplicando-se a Equação (159) a cada um dos volumes da malha, considerando as pequenas modificações necessárias nos volumes que estão nos contornos, obtém-se um sistema de equações acopladas que quando solucionadas fornecem os valores de $\phi_{P}^{t+\Delta t}$ para cada volume da malha, ou seja, obtém-se o campo de $\phi$ no instante $t+$ $\Delta t$.

Analogamente a Equação (127) escrita em notação simbólica foi discretizada segundo a integral abaixo

$$
\int_{t}^{t+\Delta t} \int_{V_{P}}\left[\frac{\partial X_{v}}{\partial t}=\vec{\nabla} \cdot\left(h(\phi) D_{v}^{s} \vec{\nabla} X_{v}^{s}\right)\right] d V d t
$$

onde $D_{v}^{s}$ foi assumido constante. Seguindo um procedimento análogo àquele utilizado para calcular as integrais da Equação (152) e considerando o método implícito para o cálculo da integral do tempo do termo à direita da Equação (160), obtém-se a equação abaixo

$$
\begin{gathered}
X_{v, P}^{t+\Delta t}-X_{v, P}^{t}= \\
=\frac{D_{v}^{s} \Delta t}{V_{P}} \sum_{i=1}^{N} A_{n b_{i}} h^{t+\Delta t}\left\{\frac{X_{v, n b_{i}}^{s, t}-X_{v, P}^{s, t+\Delta t}}{\vec{d}_{n b_{i}} \cdot \vec{n}}+\left[\frac{\Delta \xi_{n b_{i}^{+}}}{\Delta \xi_{n b_{i}}}\left(\vec{\nabla} X_{v}^{s}\right)_{P}^{t}+\frac{\Delta \xi_{n b_{i}^{-}}}{\Delta \xi_{n b_{i}}}\left(\vec{\nabla} X_{v}^{s}\right)_{n b_{i}}^{t}\right] \cdot \vec{n}\right. \\
\left.-\left[\left(\vec{\nabla} X_{v}^{s}\right)_{P}^{t}+\left(\vec{\nabla} X_{v}^{s}\right)_{n b_{i}}^{t}\right] \cdot \frac{\vec{d}_{n b_{i}}}{2\left(\vec{d}_{n b_{i}} \cdot \vec{n}\right)}\right\}
\end{gathered}
$$

onde $h^{t+\Delta t}=2 h\left(\phi_{P}^{t+\Delta t}\right) h\left(\phi_{n b_{i}}^{t+\Delta t}\right) /\left[h\left(\phi_{P}^{t+\Delta t}\right)+h\left(\phi_{n b_{i}}^{t+\Delta t}\right)\right]$. Utilizando a Equação (110), o lado esquerdo pode ser escrito como 


$$
\begin{aligned}
X_{v, P}^{t+\Delta t}-X_{v, P}^{t}= & h\left(\phi_{P}^{t+\Delta t}\right) X_{v, P}^{s, t+\Delta t}-h\left(\phi_{P}^{t}\right) X_{v, P}^{s, t}+\left[1-h\left(\phi_{P}^{t+\Delta t}\right)\right] X_{v, P}^{g^{\prime}, t+\Delta t} \\
& -\left[1-h\left(\phi_{P}^{t}\right)\right] X_{v, P}^{g^{\prime}, t}
\end{aligned}
$$

Com o objetivo de obter uma Equação para eliminar $X_{v, P}^{g^{\prime}, t+\Delta t}$, a Equação (111) foi reescrita abaixo novamente, mas agora mostrando explicitamente a dependência de $X_{v}^{S}$ e $X_{v}^{g^{\prime}}$ no tempo e nas coordenadas espaciais, $\vec{r}$, e lembrando que $F^{s}=\frac{f^{s}}{\rho_{m}^{s}}$ e $F^{g^{\prime}}=\frac{f^{g^{\prime}}}{\rho_{m}^{s}}$ :

$$
\frac{\partial F^{s}}{\partial X_{v}^{s}}\left(X_{v}^{s}(t, \vec{r})\right)=\frac{\partial F^{g^{\prime}}}{\partial X_{v}^{g^{\prime}}}\left(X_{v}^{g^{\prime}}(t, \vec{r})\right)
$$

Derivando esta Equação em relação ao tempo a partir da regra da cadeia, obtém-se

$$
\frac{d^{2} F^{s}}{d X_{v}^{s 2}} \frac{\partial X_{v}^{s}}{\partial t}=\frac{d^{2} F^{g^{\prime}}}{d X_{v}^{g^{2} 2}} \frac{\partial X_{v}^{g^{\prime}}}{\partial t}
$$

que na forma discretizada pode ser escrita como

$$
\frac{d^{2} F^{s}}{d X_{v}^{s 2}}\left(X_{v, P}^{s, t+\Delta t}-X_{v, P}^{s, t}\right)=\frac{d^{2} F^{g}}{d X_{v}^{g 2}}\left(X_{v, P}^{g^{\prime}, t+\Delta t}-X_{v, P}^{g^{\prime}, t}\right)
$$

Isolando $X_{v, P}^{g^{\prime}, t+\Delta t}$ e substituindo na Equação (94), tem-se

$$
\begin{aligned}
X_{v, P}^{t+\Delta t}-X_{v, P}^{t}= & {\left[h\left(\phi_{P}^{t+\Delta t}\right)+\alpha\left(1-h\left(\phi_{P}^{t+\Delta t}\right)\right)\right] X_{v, P}^{s, t+\Delta t} } \\
& -\left[h\left(\phi_{P}^{t}\right)+\alpha\left(1-h\left(\phi_{P}^{t+\Delta t}\right)\right)\right] X_{v, P}^{s, t}-\left[h\left(\phi_{P}^{t+\Delta t}\right)-h\left(\phi_{P}^{t}\right)\right] X_{v, P}^{g^{\prime}, t}
\end{aligned}
$$

onde

$$
\alpha=\frac{\frac{d^{2} F^{s}}{d X_{v}^{s 2}}}{\frac{d^{2} F^{g^{\prime}}}{d X_{v}^{g^{\prime 2}}}}=\frac{R T}{2 a_{v} X_{v, P}^{s, t}\left(1-X_{v, P}^{s, t}\right)}
$$

após utilização das equações (97) e (98). Substituindo a Equação (165) na Equação (161), chega-se à equação discretizada final para o cálculo do campo $X_{v}^{s}$ no instante,$t+\Delta t$, dada abaixo

$$
\begin{aligned}
{\left[h\left(\phi_{P}^{t+\Delta t}\right)+\alpha\right.} & \left.\left(1-h\left(\phi_{P}^{t+\Delta t}\right)\right)+\frac{D_{v}^{s} \Delta t}{V_{P}} \sum_{i=1}^{N}\left(\frac{A_{n b_{i}} h^{t+\Delta t}}{\vec{d}_{n b_{i}} \cdot \vec{n}}\right)\right] X_{v, P}^{s, t+\Delta t}= \\
= & {\left[h\left(\phi_{P}^{t}\right)+\alpha\left(1-h\left(\phi_{P}^{t+\Delta t}\right)\right)\right] X_{v, P}^{s, t}+\left[h\left(\phi_{P}^{t+\Delta t}\right)-h\left(\phi_{P}^{t}\right)\right] X_{v, P}^{g, t} } \\
& +\frac{D_{v}^{s} \Delta t}{V_{P}} \sum_{i=1}^{N} A_{n b_{i}} h^{t+\Delta t}\left\{\frac{X_{v, n b_{i}}^{s, t+\Delta t}}{\overrightarrow{\vec{d}}_{n b_{i}} \cdot \vec{n}}+\left[\frac{\Delta \xi_{n b_{i}^{+}}}{\Delta \xi_{n b_{i}}}\left(\vec{\nabla} X_{v}^{s}\right)_{P}^{t}+\frac{\Delta \xi_{n b_{i}^{-}}}{\Delta \xi_{n b_{i}}}\left(\vec{\nabla} X_{v}^{s}\right)_{n b_{i}}^{t}\right] \cdot \vec{n}\right. \\
& \left.-\left[\left(\vec{\nabla} X_{v}^{s}\right)_{P}^{t}+\left(\vec{\nabla} X_{v}^{s}\right)_{n b_{i}}^{t}\right] \cdot \frac{\vec{d}_{n b_{i}}}{2\left(\vec{d}_{n b_{i}} \cdot \vec{n}\right)}\right\}
\end{aligned}
$$


Após obtenção de $X_{v, P}^{s, t+\Delta t}$, a Equação (111) permite o cálculo de $X_{v, P}^{g^{\prime}, t+\Delta t}$ e a Equação (110) permite o cálculo de $X_{v, P}^{t+\Delta t}$. Aplicando-se a Equação (167) a todos os volumes da malha, obtém-se novamente um sistema de equações algébricas onde os valores de $X_{v, P}^{s, t+\Delta t}$ em cada volume são as incógnitas. Os sistemas gerados pelas Equações (159) e (167) foram então solucionados iterativamente após cada passo de tempo pelo método de Gauss-Seidel.

\subsubsection{Resolução numérica das equações diferenciais por computação paralela}

Foi construído um código computacional para resolução das equações algébricas discretizadas, apresentadas no item anterior. Este código computacional foi executado em um computador pessoal com processador Intel Core i7 de $8^{\mathrm{a}}$ geração, com 16GB de memória RAM e placa de vídeo da NVIDIA, modelo GFORCE GTX 1080 TI. O código foi escrito em linguagem $\mathrm{C}^{++}$e utilizou-se um compilador Microsoft Visual Studio 2015 para depurar e compilar o código. A este compilador foi incorporada a biblioteca CUDA de rotinas de paralelização nos processadores e memória RAM da placa de vídeo (GPU).

Para que o código seja executado em paralelo nos processadores da placa de vídeo, é necessário que seja escrito com uma lógica diferente da computação serial tradicional. Todas as variáveis que são utilizadas nas rotinas executadas nos processadores da placa de vídeo devem ser definidas na memória RAM da placa e não se tem acesso direto facilmente aos valores destas variáveis. O salvamento de dados calculados em arquivos necessita que estes dados estejam na memória RAM da CPU e, portanto, devem ser transferidos de uma memória RAM para outra. Além disso, quando uma rotina é enviada para a placa de vídeo utilizando-se o chamado "kernel", ela é executada paralelamente em todos os processadores da placa, requerendo que a lógica de programação seja cuidadosamente projetada. Uma estratégia utilizada foi a de extrair os endereços de memória dos volumes ativos da malha adaptativa e coloca-los em série em um vetor que era percorrido sequencialmente durante a execução do código. Desta forma, a divisão das posições do vetor entre os processadores da placa de vídeo tornou-se uma tarefa relativamente fácil. A transferência de dados da memória da placa de vídeo para a memória da CPU é um processo relativamente lento, portanto esta transferência era realizada somente no momento de salvar os dados no disco rígido para posterior análise.

Em testes iniciais durante a construção do código computacional, a sua paralelização resultou em uma redução de pelo menos 10 vezes nos tempos de processamento para a 
resolução do mesmo problema. Algumas das simulações mais longas duraram cerca de 2 dias e possivelmente exigiriam mais de 20 dias caso o código não estivesse paralelizado.

\subsection{Propriedades utilizadas nos modelos analíticos e no modelo de campo de fases}

As propriedades do cobre sólido puro utilizadas nos cálculos dos modelos analíticos e do modelo de campo de fases estão apresentadas na Tabela 7. Quando disponíveis, foram escolhidos valores de propriedades determinadas por métodos que não envolveram a sinterização para permitir uma análise mais imparcial da qualidade e aderência dos modelos a dados experimentais. A tensão superficial do cobre $(\gamma)$ foi obtida pela técnica de "zero creep" [JONES, 1971], enquanto a distância interatômica foi medida por difração de raios-X [WELLS, 1984; LIDE, 2005].

O coeficiente de difusão superficial não pode ser obtido de maneira direta, sendo assim faz-se uso de relações matemáticas teóricas para se obter tal valor. Dentre as técnicas mais conhecidas e utilizadas cita-se: "grain boundry grooving" [MULLINS, 1957; MULLINS, SHEWMON, 1959] e "scratch smoothing" [KING, MULLINS, 1962; BLAKELY, MYKURA, 1962].

O coeficiente de difusão volumétrica também é obtido a partir de análises gráficas e relações teóricas. A técnica experimental adotada consiste no fino revestimento superficial do metal com uma camada de isótopos ou marcadores radioativos (no caso do cobre, emprega-se ${ }^{64} \mathrm{Cu}$ e ${ }^{67} \mathrm{Cu}$ ), após o recozimento do conjunto, mede-se a concentração do isótopo ao longo da espessura do material. Com a segunda lei de Fick calcula-se o coeficiente de difusão volumétrica [SHEWMON, 1963]. 
Tabela 7: Propriedades do cobre sólido puro.

\begin{tabular}{|c|c|c|c|}
\hline Propriedade & Símbolo & Valor & Referência \\
\hline Tensão superficial & $\gamma_{s}$ & $1720 \frac{\mathrm{ergs}}{\mathrm{cm}^{2}}=1.72 \frac{\mathrm{J}}{\mathrm{m}^{2}}$ & $\begin{array}{c}\text { Udin et. al., } 1949 \\
\text { Jones, } 1971 \\
\text { Utigard, } 1993\end{array}$ \\
\hline Volume atômico & $\Omega$ & $1,18.10^{-23} \mathrm{~cm}^{3}$ & Ashby, 1974 \\
\hline Densidade mássica & $\rho_{m}$ & $8,96 \frac{\mathrm{g}}{\mathrm{cm}^{3}}$ & $\begin{array}{c}\text { Chase, 1998. Ashby, } \\
1974\end{array}$ \\
\hline Volume molar & $V_{m}$ & $7,11 \frac{\mathrm{cm}^{3}}{\mathrm{~mol}}$ & Weast, 1975 \\
\hline Raio atômico & $\mathrm{r}$ & $128 \mathrm{pm}$ & $\begin{array}{l}\text { Wells, } 1984 \\
\text { Lide, } 2005\end{array}$ \\
\hline $\begin{array}{c}\text { Distância } \\
\text { interatômica }\end{array}$ & $\mathrm{d}$ & $255,6 \mathrm{pm}$ & $\begin{array}{l}\text { Wells, } 1984 \\
\text { Lide, } 2005\end{array}$ \\
\hline $\begin{array}{l}\text { Coeficiente de } \\
\text { difusão } \\
\text { volumétrica de } \\
\text { lacunas }\end{array}$ & $D_{v}^{v}$ & $\begin{array}{c}0.78 \exp \left(\frac{-50.5 \mathrm{kcal} \mathrm{mol}^{-1}}{R T}\right) \frac{\mathrm{cm}^{2}}{\mathrm{~s}} \\
\text { para } 700^{\circ} \mathrm{C}<T<1060^{\circ} \mathrm{C}\end{array}$ & $\begin{array}{c}\text { [ROTHMAN, } \\
\text { PETERSON, 1969] }\end{array}$ \\
\hline $\begin{array}{c}\text { Coeficiente de } \\
\text { difusão superficial } \\
\text { de lacunas }\end{array}$ & $D_{v}^{s}$ & $\begin{array}{c}0.26 \exp \left(\frac{-20.7 \mathrm{kcal} \mathrm{mol}^{-1}}{R T}\right) \frac{\mathrm{cm}^{2}}{\mathrm{~s}} \\
\text { para } 500^{\circ} \mathrm{C}<T<960^{\circ} \mathrm{C}\end{array}$ & [BONZEL, 1972] \\
\hline $\begin{array}{l}\text { Entalpia de } \\
\text { formação de } \\
\text { lacunas }\end{array}$ & $H^{v}$ & $112,8 \frac{\mathrm{kJ}}{\mathrm{mol}}$ & $\begin{array}{l}\text { [FREDRIKSSON; } \\
\text { EMI, 1998] }\end{array}$ \\
\hline $\begin{array}{l}\text { Entropia de } \\
\text { excesso de } \\
\text { formação de } \\
\text { lacunas }\end{array}$ & $S^{v, x S}$ & $12,5 \frac{\mathrm{J}}{\mathrm{mol} \mathrm{K}}$ & $\begin{array}{l}\text { [FREDRIKSSON; } \\
\text { EMI, 1998] }\end{array}$ \\
\hline
\end{tabular}




\section{Resultados e Discussões}

\subsection{Dados experimentais da Sinterização do Cobre Puro}

A seguir serão apresentados os principais dados experimentais para sinterização do cobre, bem como as condições nas quais os mesmos foram obtidos em detalhes. Kuczynski [KUCZYNSKI, 1949] dispersou partículas do cobre, com diâmetros iniciais na faixa de 4 a $100 \mu \mathrm{m}$, sobre uma superfície plana do mesmo material e aqueceu o conjunto em uma atmosfera controlada de hidrogênio em diferentes temperaturas e tempos. Após a sinterização, o conjunto foi embutido em baquelite e cortado para análise microscópica da seção transversal do pescoço formado. A leitura do raio dos pescoços foi feita utilizando um micrômetro acoplado ao microscópio, sendo que pelo menos dez conjuntos foram averiguados para cada tempo e temperatura, e o tamanho do pescoço final associado a cada condição foi adotado como sendo a média aritmética dos valores obtidos. A Tabela 8 apresenta os resultados obtidos.

Tabela 8: Dados experimentais publicados por Kuczynski [KUCZYNSKI, 1949].

\begin{tabular}{|c|c|c|c|c|}
\hline $\begin{array}{c}\text { Temperatura } \\
\left({ }^{\circ} \mathrm{C}\right)\end{array}$ & $\begin{array}{c}\text { Tempo } \\
\text { (hr) }\end{array}$ & $\begin{array}{l}\text { Raio da } \\
\text { partícula } \\
\text { a.10-4 cm }\end{array}$ & $\begin{array}{c}\text { Raio do pescoço } \\
x \cdot 10^{-4} \mathrm{~cm}\end{array}$ & $\begin{array}{l}\text { Coeficiente da } \\
\text { difusão } \\
\text { volumétrica } \\
\text { calculado } \\
D_{\mathrm{v}}\left(\frac{\boldsymbol{c m}^{2}}{\mathrm{sec}}\right)\end{array}$ \\
\hline 400 & 6,0 & $\begin{array}{c}20,0 \\
13,0 \\
3,2\end{array}$ & $\begin{array}{l}0,5 \\
1,0 \\
0,8\end{array}$ & $\begin{array}{l}4,2.10^{-16} \\
3,2.10^{-14} \\
3,0.10^{-13}\end{array}$ \\
\hline & 1,0 & $\begin{array}{c}10,0 \\
4,0\end{array}$ & $\begin{array}{l}1,0 \\
1,0\end{array}$ & $\begin{array}{l}3,8 \cdot 10^{-13} \\
2,3 \cdot 10^{-12}\end{array}$ \\
\hline 500 & 65,0 & $\begin{array}{l}47,5 \\
41,5 \\
30,0\end{array}$ & $\begin{array}{l}2,0 \\
1,9 \\
2,0\end{array}$ & $\begin{array}{l}8,2.10^{-15} \\
8,3 \cdot 10^{-15} \\
2,1.10^{-14}\end{array}$ \\
\hline \multirow{3}{*}{600} & $\begin{array}{l}0,5 \\
1,0\end{array}$ & $\begin{array}{c}4,5 \\
15,5 \\
3,8 \\
\end{array}$ & $\begin{array}{l}1,8 \\
1,7 \\
1,7 \\
\end{array}$ & $\begin{array}{l}8,0 \cdot 10^{-11} \\
3,5 \cdot 10^{-12} \\
4,5 \cdot 10^{-11}\end{array}$ \\
\hline & 3,0 & $\begin{array}{c}10,0 \\
4,2\end{array}$ & $\begin{array}{l}1,7 \\
2,3\end{array}$ & $\begin{array}{l}2,0.10^{-12} \\
5,1.10^{-11}\end{array}$ \\
\hline & 16,0 & $\begin{array}{l}40,5 \\
28,0\end{array}$ & $\begin{array}{l}4,1 \\
3,4\end{array}$ & $\begin{array}{l}1,9.10^{-12} \\
1,6.10^{-12}\end{array}$ \\
\hline \multirow{4}{*}{700} & 0,5 & 4,5 & 2,0 & $1,5.10^{-10}$ \\
\hline & 1,0 & 3,5 & 1,7 & $5,5.10^{-11}$ \\
\hline & 2,0 & 40,2 & 4,0 & $1,5.10^{-11}$ \\
\hline & 4,0 & 47,7 & 6,0 & $4,1.10^{-11}$ \\
\hline
\end{tabular}




\begin{tabular}{c|c|c|c|c}
\hline & & 41,0 & 5,1 & $2,5.10^{-11}$ \\
& & 33,0 & 4,8 & $2,8.10^{-11}$ \\
& & 26,2 & 3,1 & $5,0.10^{-11}$ \\
& & 16,0 & 3,2 & $1,6.10^{-11}$ \\
\cline { 2 - 5 } & 8,0 & 43,0 & 7,2 & $6,3.10^{-11}$ \\
\cline { 2 - 5 } & 41,0 & 39,0 & 14,0 & $4,0.10^{-10}$ \\
\hline \multirow{4}{*}{$\mathbf{8 0 0}$} & 0,5 & 47,0 & 8,0 & $1,6.10^{-9}$ \\
& & 39,8 & 7,0 & $1,1.10^{-9}$ \\
& & 35,3 & 6,0 & $6,6.10^{-10}$ \\
\cline { 2 - 5 } & 2,0 & 11,0 & 3,6 & $5,3.10^{-10}$ \\
\cline { 2 - 5 } & 4,0 & 53,0 & 10,0 & $9,4.10^{-10}$ \\
\cline { 2 - 5 } & 16,5 & 40,1 & 9,0 & $4,9.10^{-10}$ \\
\cline { 2 - 5 } & 0,5 & 45,0 & 13,6 & $1,3.10^{-10}$ \\
\hline \multirow{3}{*}{$\mathbf{1 0 0 0}$} & 1,0 & 41,0 & 12,1 & $1,6.10^{-8}$ \\
& & 43,2 & 14,0 & $9,8.10^{-9}$ \\
\hline & 0,5 & 30,5 & 11,0 & $4,3.10^{-8}$ \\
& & 47,0 & 15,0 & $4,2.10^{-8}$ \\
& & 40,0 & 14,0 & $4,7.10^{-8}$ \\
\hline
\end{tabular}

Kingery e Berg [KINGERY, BERG, 1955] estudaram o comportamento da sinterização em esferas de cobre com aproximadamente $100 \mu \mathrm{m}$ de diâmetro entre 950 e $1050^{\circ} \mathrm{C}$ em uma atmosfera de hidrogênio e hélio. Os resultados obtidos estão reproduzidos na Figura 26, gráfico entre o logarítmico da razão $\left(\frac{x}{a}\right)$ e o logaritmo do tempo, e na Figura 27, gráfico da contração linear pelo tempo.

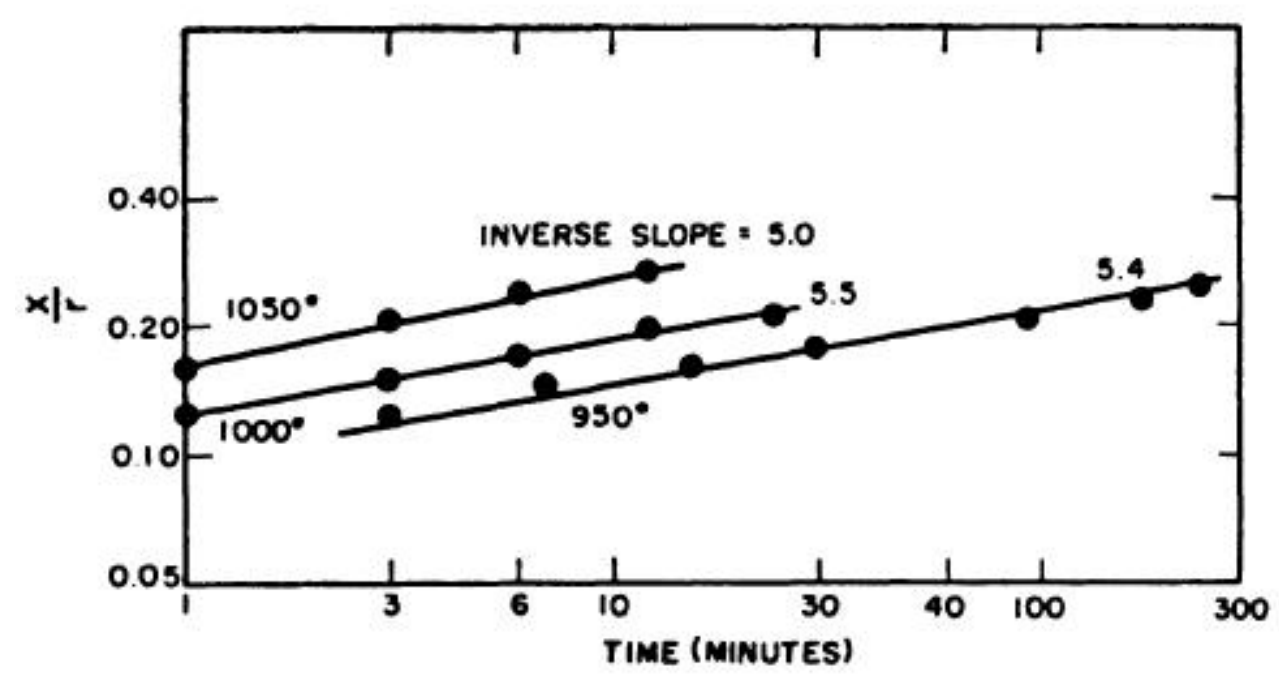

Figura 26: Gráfico da taxa de crescimento da interface entre esferas de cobre publicado por Kingery e Berg [KINGERY, BERG, 1955]. 


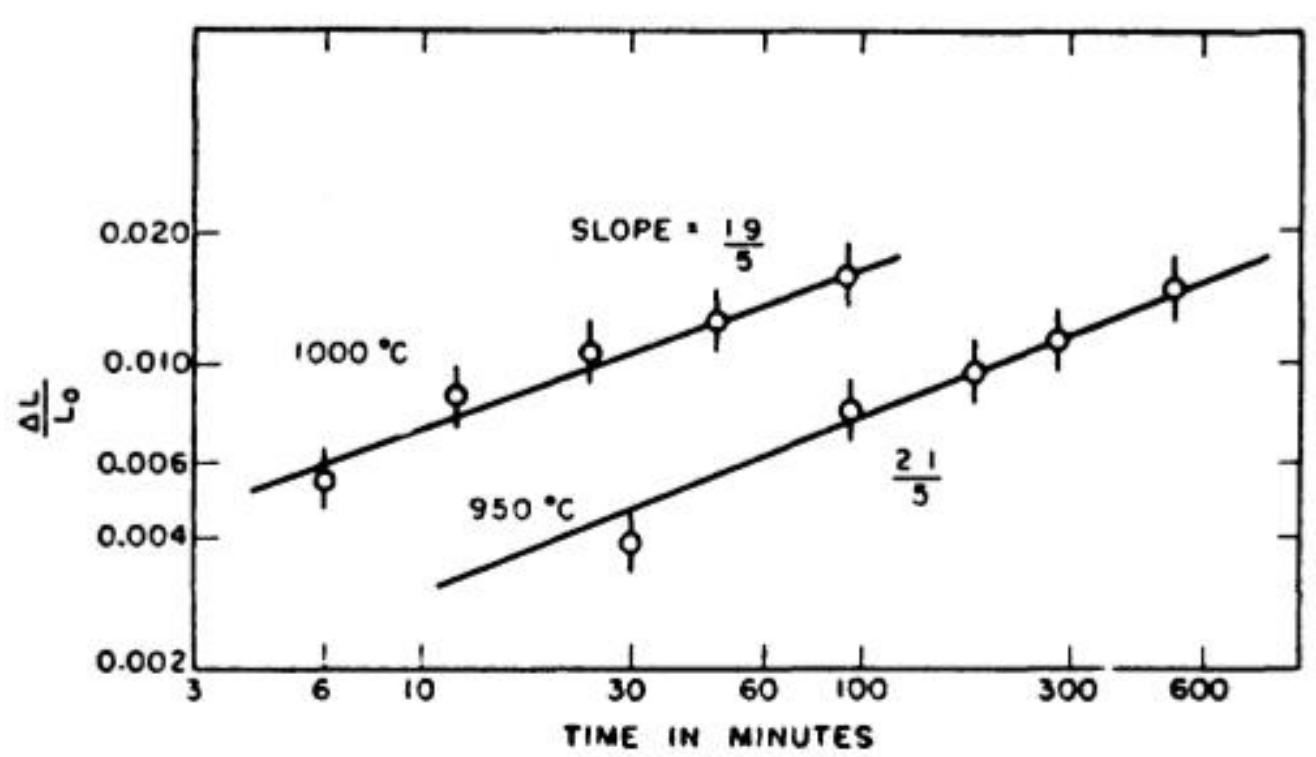

Figura 27: Gráfico da taxa de crescimento da interface entre esferas de cobre publicado por Kingery e Berg [KINGERY, BERG, 1955].

Alexander e Balluffi [ALEXANDER, BALLUFFI, 1957] estudaram a sinterização de fios de cobre de $0,0128 \mathrm{~cm}$ de diâmetro, os quais foram enrolados em uma bobina também de cobre com 1,9 cm de diâmetro, formando uma camada de doze a vinte fios sobre a bobina. $\mathrm{O}$ conjunto foi aquecido em diferentes temperaturas em uma atmosfera de hidrogênio. Após a sinterização, os conjuntos foram imersos em metil metacrilato e seccinados de modo a expor suas seções transversais. As medidas do tamanho dos pescoços foram realizadas via micrografias com auxílio de um micrômetro.

Os valores encontrados estão reproduzidos na Tabela 9.

Tabela 9: Dados publicados por Alexander e Balluffi para fios de cobre com diâmetro de 0,0128 cm

\begin{tabular}{|c|c|c|}
\hline $\begin{array}{c}\text { Temperatura } \\
\left({ }^{\circ} \mathrm{C}\right)\end{array}$ & $\begin{array}{c}\text { Tempo } \\
\text { (hr) }\end{array}$ & $\begin{array}{r}\text { Tamanho } \\
\text { do pescoço } \\
\left(\mathrm{cm} x 10^{3}\right)\end{array}$ \\
\hline \multirow{6}{*}{900} & 0 & 0,00 \\
\hline & 25 & 2,64 \\
\hline & 50 & 2,12 \\
\hline & 100 & 3,38 \\
\hline & 300 & 4,37 \\
\hline & 600 & 4,77 \\
\hline 1000 & 8 & 2,62 \\
\hline
\end{tabular}




\begin{tabular}{|c|c|c|}
\hline & 20 & 3,36 \\
\hline & 40 & 3,58 \\
\hline & 80 & 4,24 \\
\hline & 160 & 4,44 \\
\hline & 328 & 5,08 \\
\hline \multirow{8}{*}{1050} & 4 & 2,86 \\
\hline & 8 & 3,33 \\
\hline & 16 & 3,86 \\
\hline & 48 & 4,38 \\
\hline & 76 & 4,63 \\
\hline & 144 & - \\
\hline & 192 & 4,89 \\
\hline & 408 & 5,20 \\
\hline \multirow{8}{*}{1075} & 4 & 3,38 \\
\hline & 8 & 4,05 \\
\hline & 16 & 4,15 \\
\hline & 32 & 4,45 \\
\hline & 64 & 5,00 \\
\hline & 96 & 4,88 \\
\hline & 192 & 4,92 \\
\hline & 408 & 5,02 \\
\hline
\end{tabular}

Pranatis e Seigle [PRANATIS, SEIGLE, 1960] estudaram também a sinterização de fios de cobre enrolados ao redor de uma bobina também de cobre. Eles separaram as análises em duas.

A primeira foi composta por dois conjuntos de fios sólidos de cobre com 50,8 $\mu \mathrm{m}$ de diâmetro, sendo que um deles foi submetido a uma pré-sinterização de $895^{\circ} \mathrm{C}$ para eliminação parcial dos contornos de grão. A sinterização dos dois conjuntos foi realizada na temperatura de $1060{ }^{\circ} \mathrm{C}$. A Figura 28 reproduz o gráfico traçado entre o $\log \left(\frac{x}{a}\right)$ e o $\log \mathrm{t}$ com os dados experimentais. 


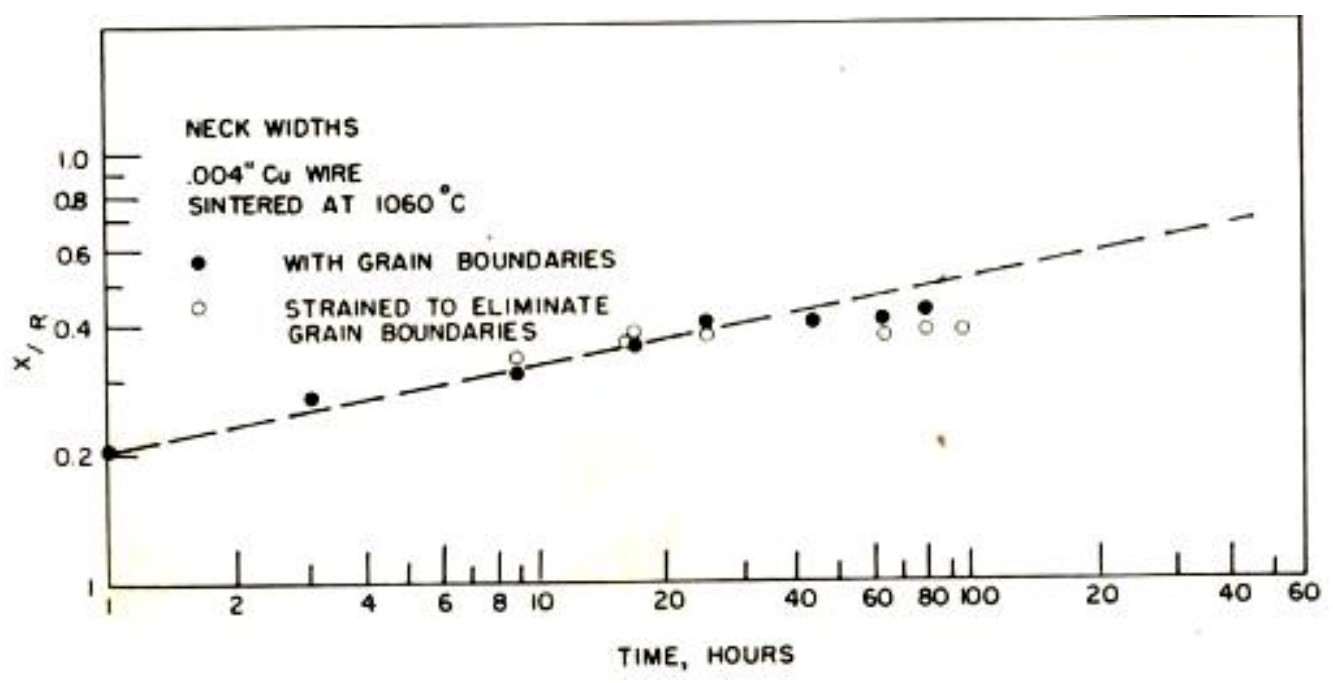

Figura 28: Gráfico entre $\log \left(\frac{x}{a}\right)$ e $\log \mathrm{t}$ [horas] para os fios de cobre com $50,8 \mu \mathrm{m}$ de diâmetro publicadoS por Pranatis e Seigle [PRANATIS, SEIGLE, 1960].

A segunda análise foi realizada entre tubos e fios sólidos de cobre com 101,6 $\mu \mathrm{m}$ de diâmetro (Figura 29).

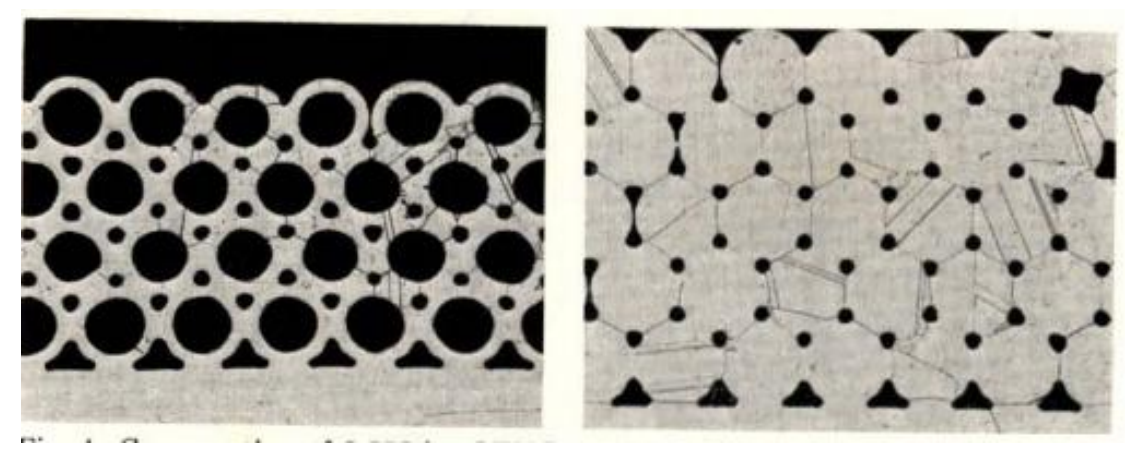

Figura 29: Seções transversais dos tubos e fios sólidos de cobre com 101,6 $\mu \mathrm{m}$ de diâmetro [PRANATIS, SEIGLE, 1960].

A sinterização dos tubos e fios sólidos também foi realizada na temperatura de $1060{ }^{\circ} \mathrm{C}$. A Figura 30 reproduz o gráfico entre $\log \left(\frac{x}{a}\right)$ e o $\log \mathrm{t}$ traçado com os dados experimentais. 


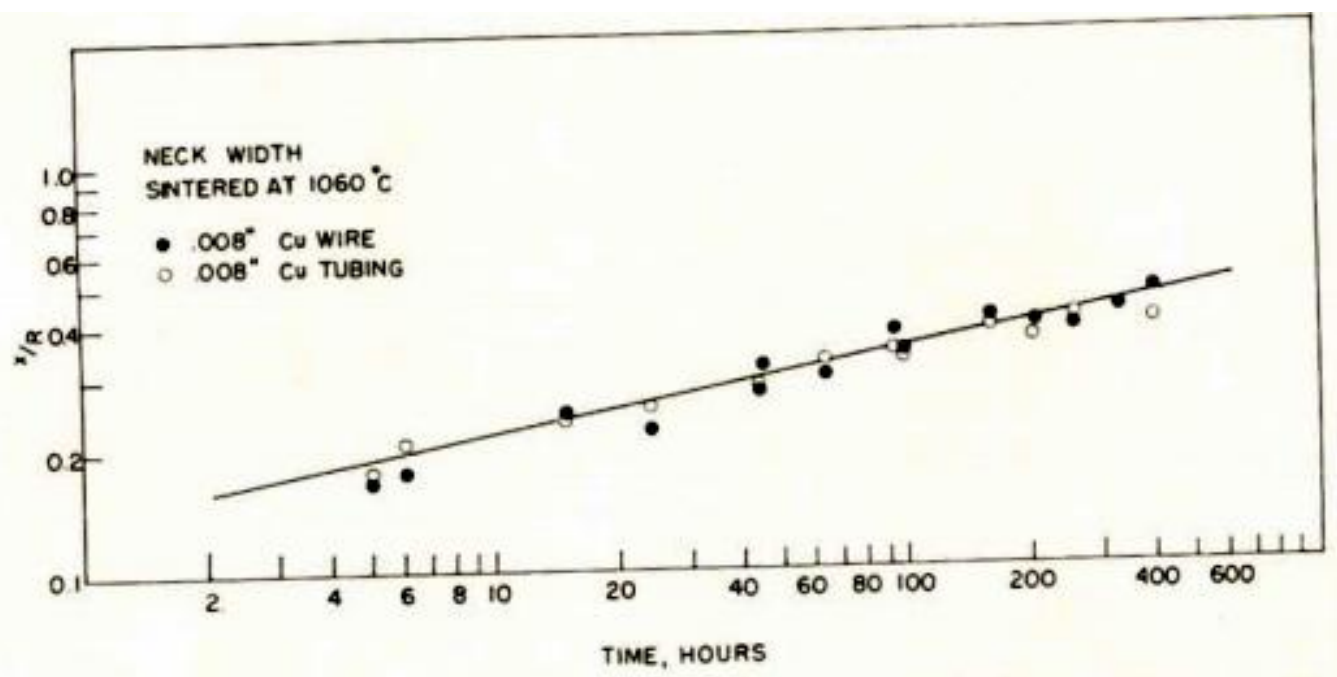

Figura 30: Gráfico entre $\log \left(\frac{x}{a}\right)$ e $\log \mathrm{t}$ [horas] para os fios de cobre com $50,8 \mu \mathrm{m}$ de diâmetro publicadoS por Pranatis e Seigle [PRANATIS, SEIGLE, 1960].

Os pontos na Figura 28 e na Figura 30 foram medidos a partir de foto micrografias e representam o valor médio de 30 a 60 medidas cada um.

Wilson e Shewmon [WILSON, SHEWMON, 1966] dividiram as esferas de cobre em dois lotes, conforme os fornecedores. O lote A, obtido de Mr. F. J. Bolda na IBM, foi sinterizado a $950{ }^{\circ} \mathrm{C}$ entre 8 e 12 horas em atmosfera de hidrogênio; enquanto que o lote $\mathrm{B}$ foi fornecido pelo Federal Mogul Bearing Co, e submetido a um aquecimento até $1020^{\circ} \mathrm{C}$ entre 60 e 120 horas em atmosfera de hidrogênio. Após estes períodos, os materiais foram analisados microscopicamente para medição dos raios do pescoço e dos raios das partículas.

A Figura 31 apresenta os resultados gráficos obtidos, e a Tabela 10 os tamanhos relativos das esferas para cada subconjunto avaliado. 

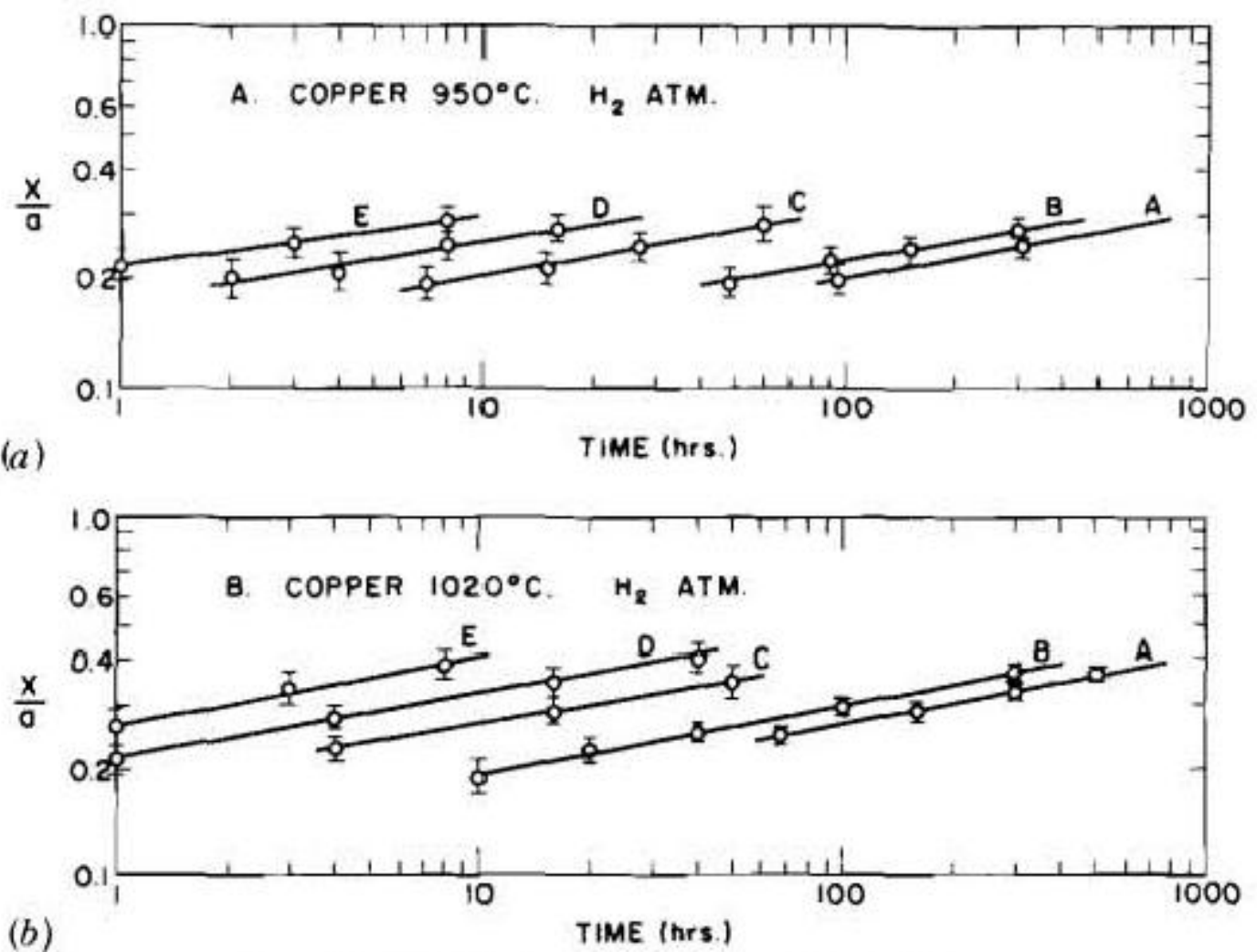

Figura 31: Gráficos logaritmos publicados por Wilson e Shewmon para os diferentes conjuntos das esferas de cobre [WILSON, SHEWMON, 1966].

Tabela 10: Tamanhos relativos das esferas para cada subconjunto estudado por Wilson e Shewmon [WILSON,

\begin{tabular}{|c|c|c|c|}
\hline \multicolumn{4}{|c|}{ SHEWMON, 1966] } \\
\hline Denominação & $\begin{array}{c}\text { Numero de esferas } \\
\text { medidas }\end{array}$ & $\begin{array}{c}\text { Diâmetro médio } \\
\qquad(\boldsymbol{\mu m})\end{array}$ & $\begin{array}{c}\text { Desvio padrão } \\
(\boldsymbol{\mu m})\end{array}$ \\
\hline \multicolumn{4}{|c|}{$950^{\circ} \mathrm{C}$} \\
\hline A & 18 & 310 & 12,9 \\
\hline B & 8 & 258 & 19,8 \\
\hline $\mathrm{C}$ & 13 & 177 & 9,5 \\
\hline $\mathrm{D}$ & 8 & 128 & 6,7 \\
\hline $\mathrm{E}$ & 26 & 101 & 7,2 \\
\hline \multicolumn{4}{|c|}{$1020^{\circ} \mathrm{C}$} \\
\hline A & 6 & 300 & 18,5 \\
\hline B & 10 & 254 & 10,0 \\
\hline $\mathrm{C}$ & 17 & 176 & 12,2 \\
\hline $\mathrm{D}$ & 17 & 127 & 9,1 \\
\hline$E$ & 19 & 96 & 4,3 \\
\hline
\end{tabular}


O estudo da contração foi feito utilizando esferas com diâmetros de $145 \mu \mathrm{m}$ em quatro temperaturas distintas $\left(650,750,850\right.$ e $\left.950^{\circ} \mathrm{C}\right)$. A Figura 32 reproduz os resultados obtidos.

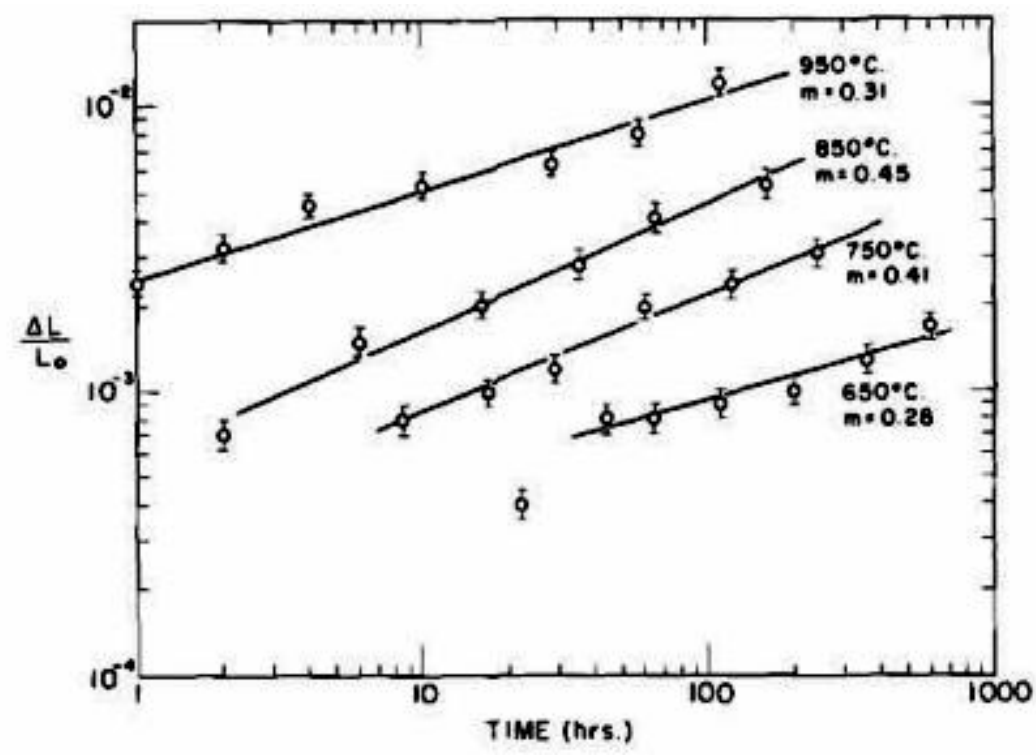

Figura 32: Conjuntos estudados por Wilson e Shewmon para estudo da contração em diferentes temperaturas. Gráfico em escala logarítmica de $\frac{\Delta L}{L_{0}}$ vs Tempo (horas) [WILSON, SHEWMON, 1966]. (Onde $L_{0}$ corresponde ao comprimento inicial da sequência de esferas, $\Delta L$ é a variação deste comprimento após a sinterização.

\subsection{Análise Crítica dos Modelos Analíticos para a Sinterização}

Os modelos analíticos da sinterização surgiram como interpretações matemáticas dos fenômenos decorrentes e recorrentes durante o processo de sinterização.

Todavia, devido à complexidade dos sistemas e as inúmeras variáveis existentes, não se pôde formular uma única Equação que contemplasse e abrangesse todos os mecanismos existentes da sinterização. Assim, estabeleceram-se várias equações individuais para os principais mecanismos, os quais a priori, atuariam de maneira independente entre si. Simplificações geométricas também foram adotadas e as equações finais estão apresentadas na Tabela 4.

A seguir serão avaliados alguns artigos considerados referência na área de sinterização de metais puros, evidenciando e diferenciando suas principais contribuições científicas nesta área [KUCZYNSKI, 1949; KINGERY, BERG, 1955; ALEXANDER, BALLUFFI, 1957; PRANATIS, SEIGLE, 1960; WILSON, SHEWMON, 1966]. O metal escolhido para análise dos dados da literatura foi o cobre, porque suas propriedades termodinâmicas e cinéticas são bem conhecidas e já foram amplamente estudadas e revisadas, além dele ser o material com a maior quantidade de estudos em sinterização existente dentre os metais. 
Para verificar a eficiência dos modelos analíticos, utilizou-se dados de entrada independentes da sinterização, conforme Tabela 8.

As comparações foram realizadas para cada um dos dados selecionados na literatura e apresentados no item 5.1 deste texto.

\section{a) Experimentos de Kuczynski com o cobre}

Inicialmente foi necessário corrigir o gráfico entre $\log \left(\frac{x}{a}\right) \times \log t$ publicado pelo autor, pois este apresenta um erro na divisão dos valores do tamanho do pescoço pelo raio da partícula $\left(\frac{x}{a}\right)$, alterando assim o coeficiente angular da reta final. A Figura 33 apresenta o gráfico publicado (a) e sua correção (b).

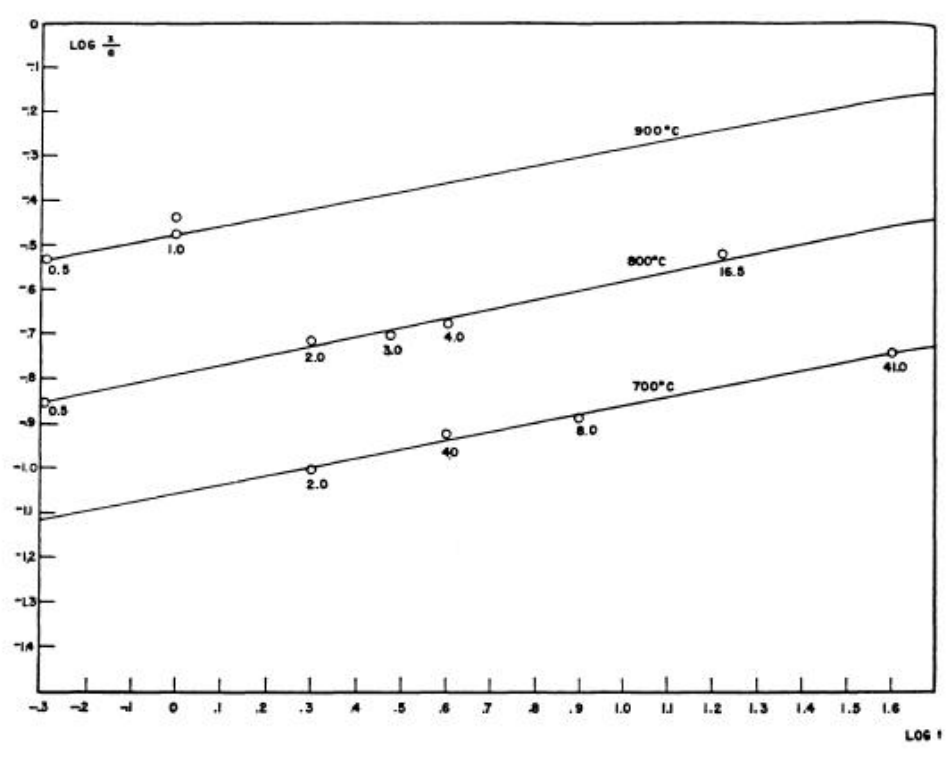

(a) 


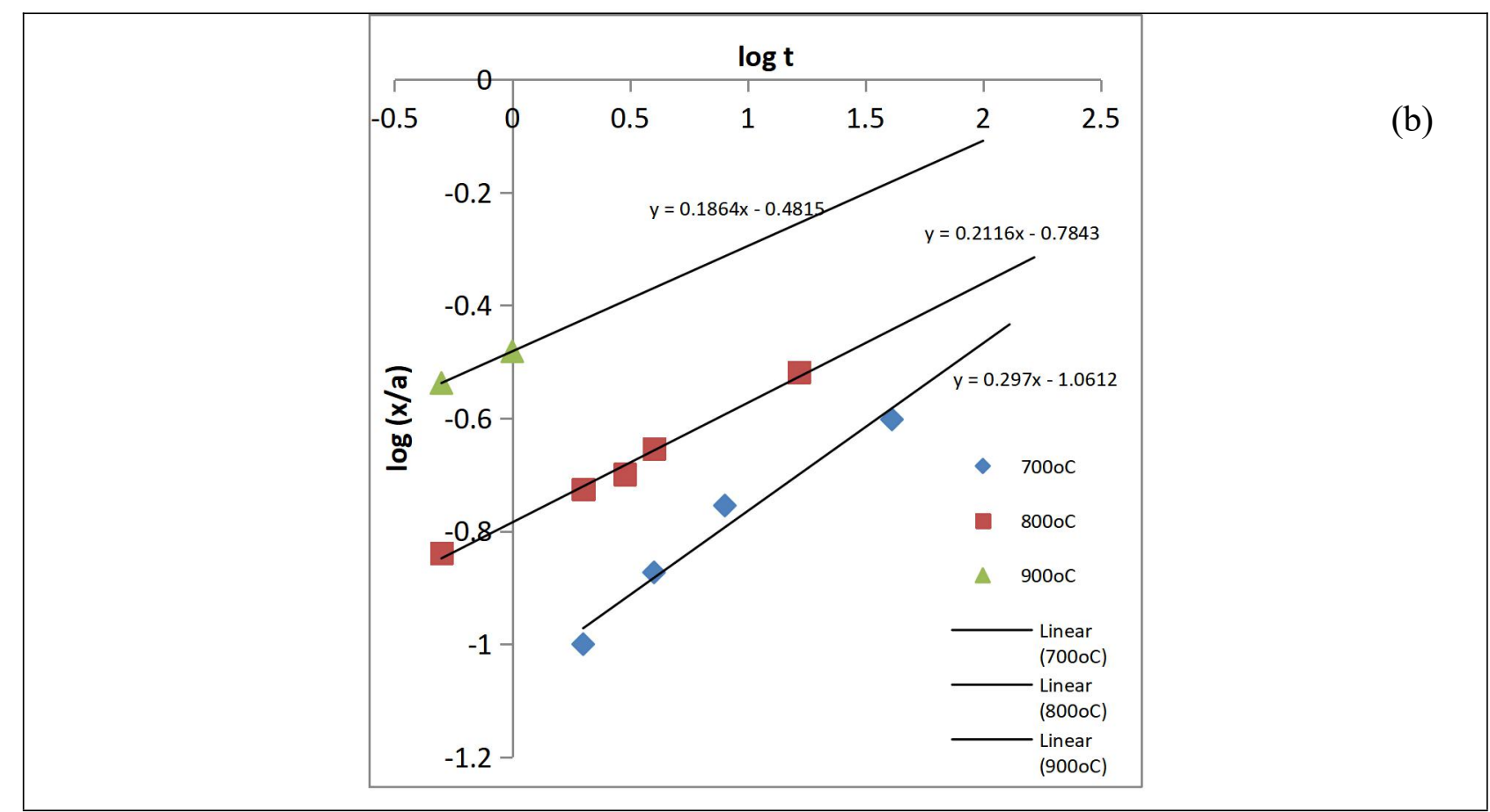

Figura 33: Gráficos logarítmicos entre a razão $\left(\frac{x}{a}\right)$ e o tempo (t): (a) publicados por Kuczynski [KUCZYNSKI, 1949] e (b) após correção entre a razão $\left(\frac{x}{a}\right)$.

A reta a $700{ }^{\circ} \mathrm{C}$ apresenta um coeficiente angular de 3,36, enquanto que o coeficiente da reta a $800{ }^{\circ} \mathrm{C}$ é 4,76 e a $900{ }^{\circ} \mathrm{C}$ o valor é de 5,36 , considerando apenas a classificação dos mecanismos pelo inverso do coeficiente angular da reta, observa-se uma alteração de mecanismo preponderante com a variação da temperatura de sinterização.

Os dados de entrada, como tensão superficial e espaçamento interatômico, utilizados por Kuczynski para os cálculos do coeficiente de difusão são questionáveis devido a ausência de referências e por não corresponderem exclusivamente ao material no estado sólido.

O valor adotado para o espaçamento interatômico não foi fornecido, assim calculando inversamente a partir dos dados fornecidos a fim de encontrá-lo, verificou-se que o mesmo variava entre 2,52 e $2,55.10^{-8} \mathrm{~cm}$, porém foram identificados também seis pontos nos quais estes valores eram diferentes, sendo estes muito abaixo da média $\left(1,17.10^{-8}\right.$ e 2,27.10-8 $\left.\mathrm{cm}\right)$.

Na Figura 34 estão os gráficos das razões entre o raio do pescoço pelo raio da partícula analítico e experimental na faixa de temperatura estudada por Kuczynski. As linhas em vermelho representam a região que limita o estágio inicial da sinterização, enquanto que a linha preta diagonal traçada apresenta coeficiente angular de $45^{\circ}$. 
(a)

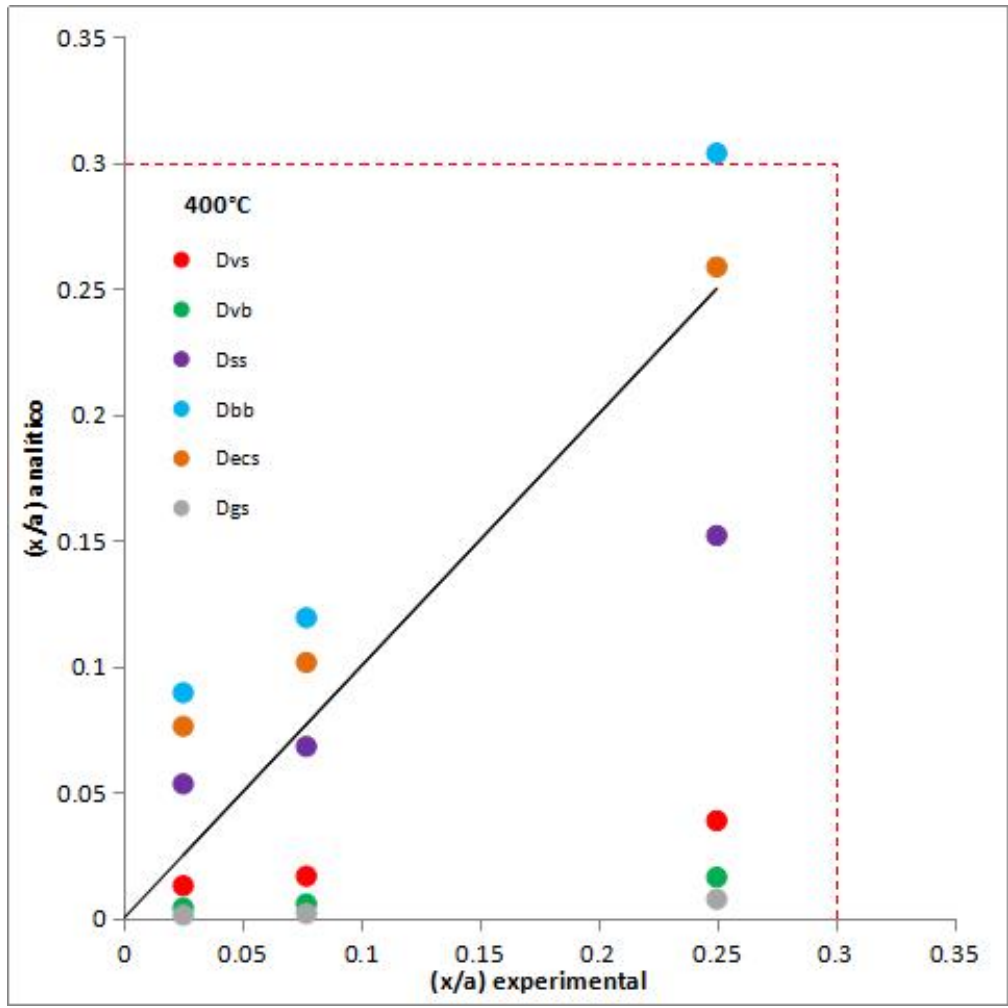

(b)

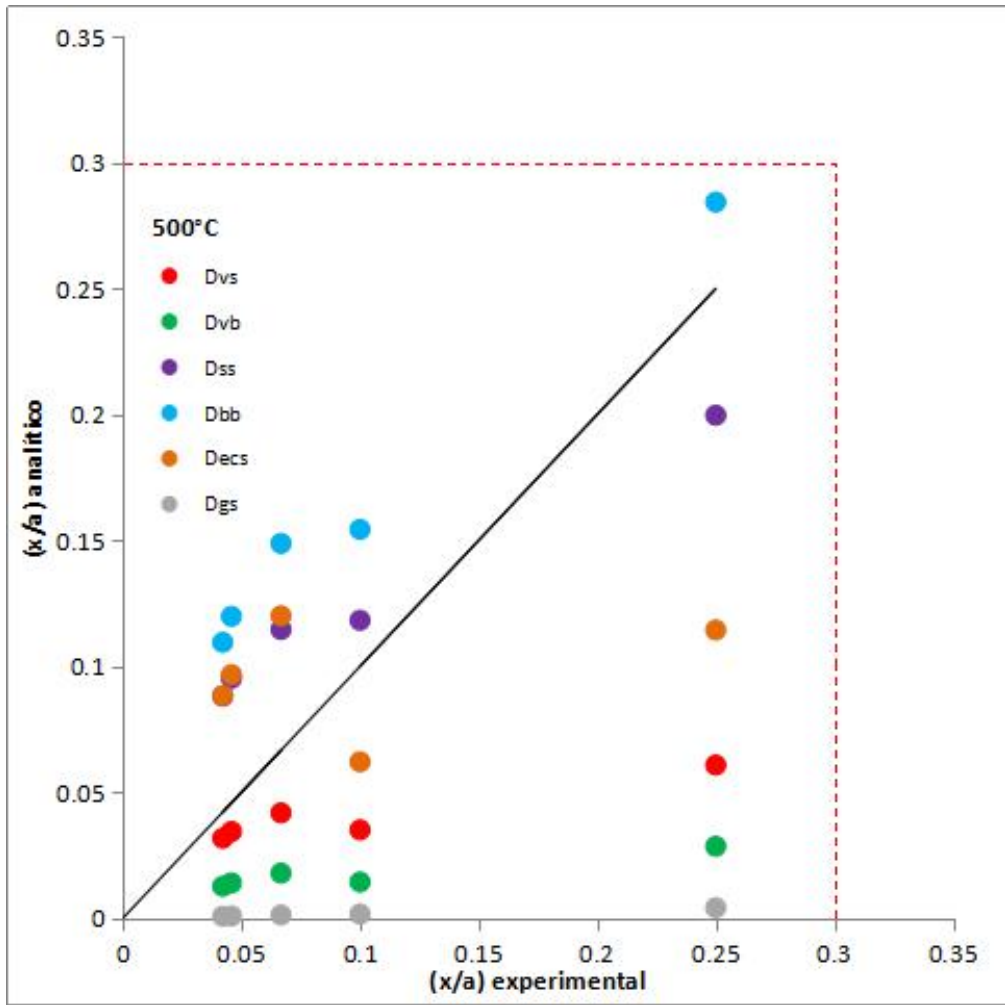


(c)

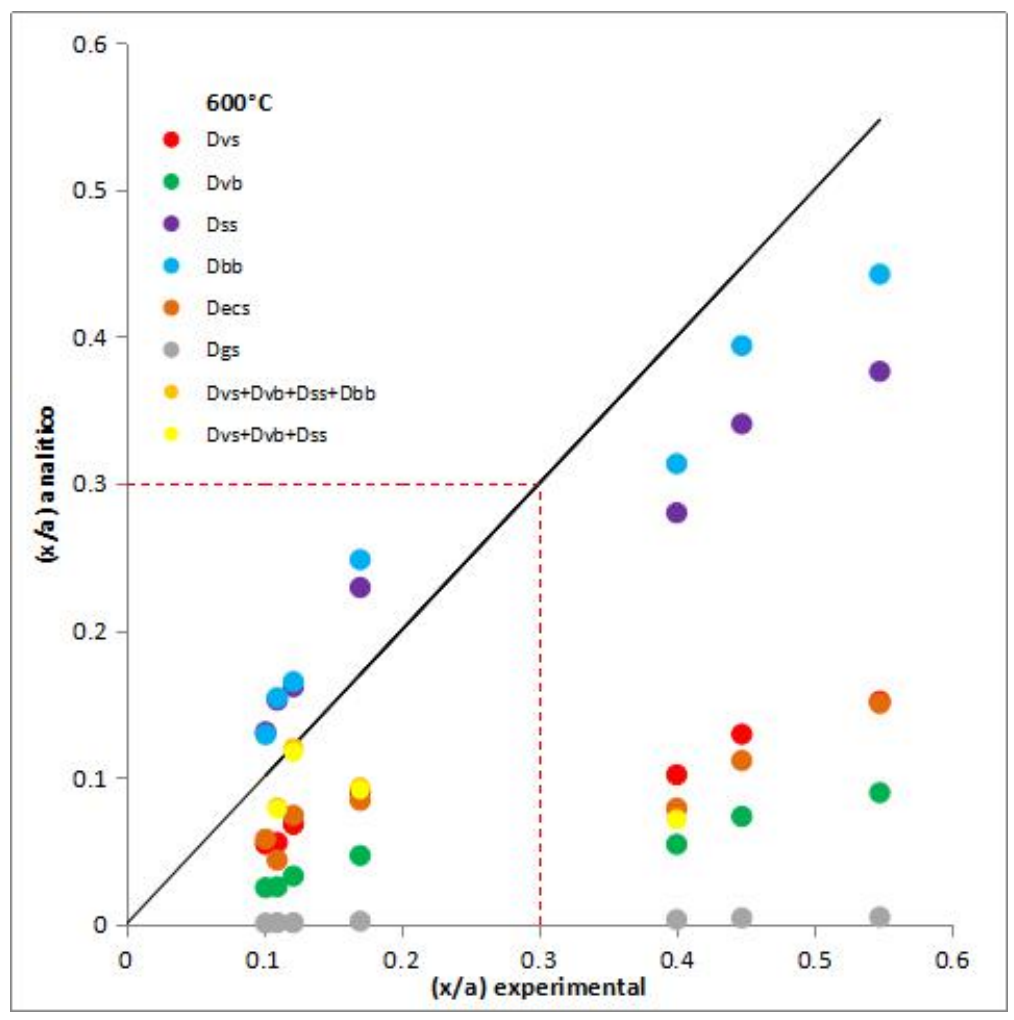

(d)

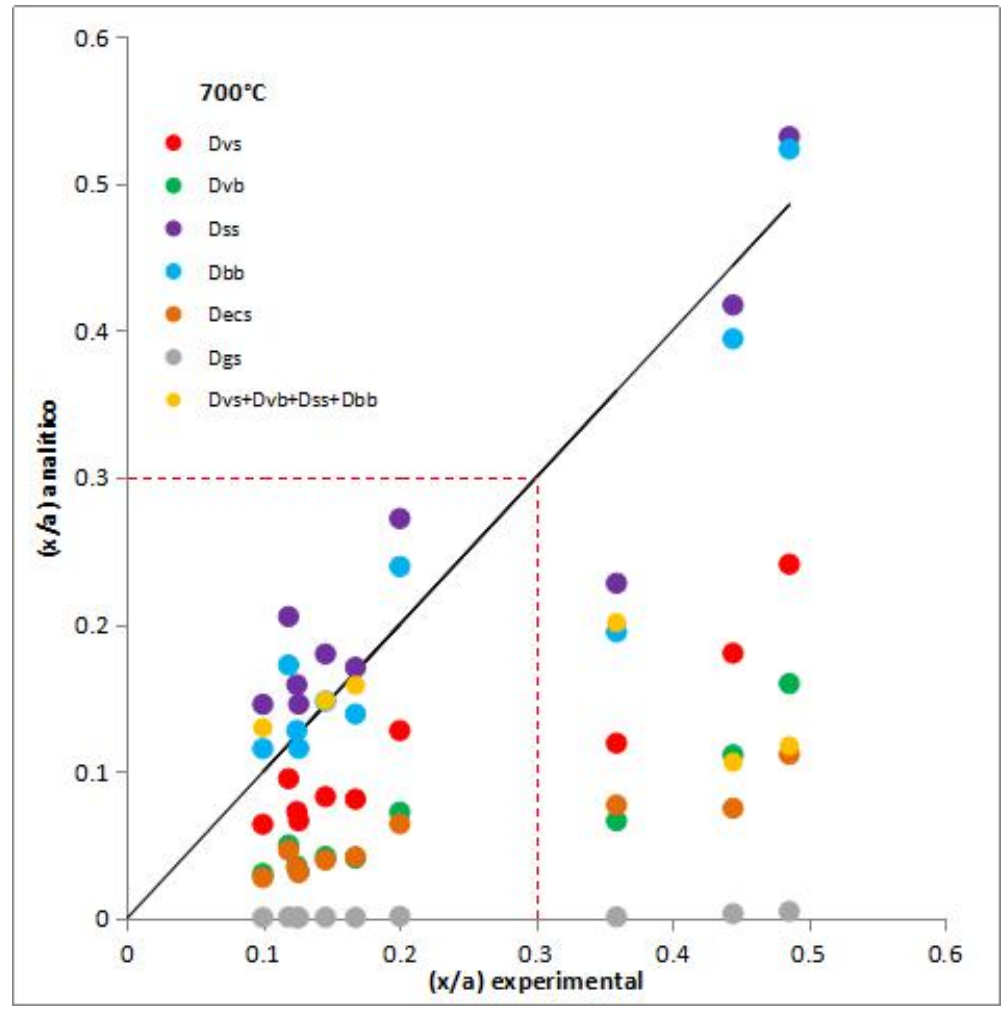


(e)

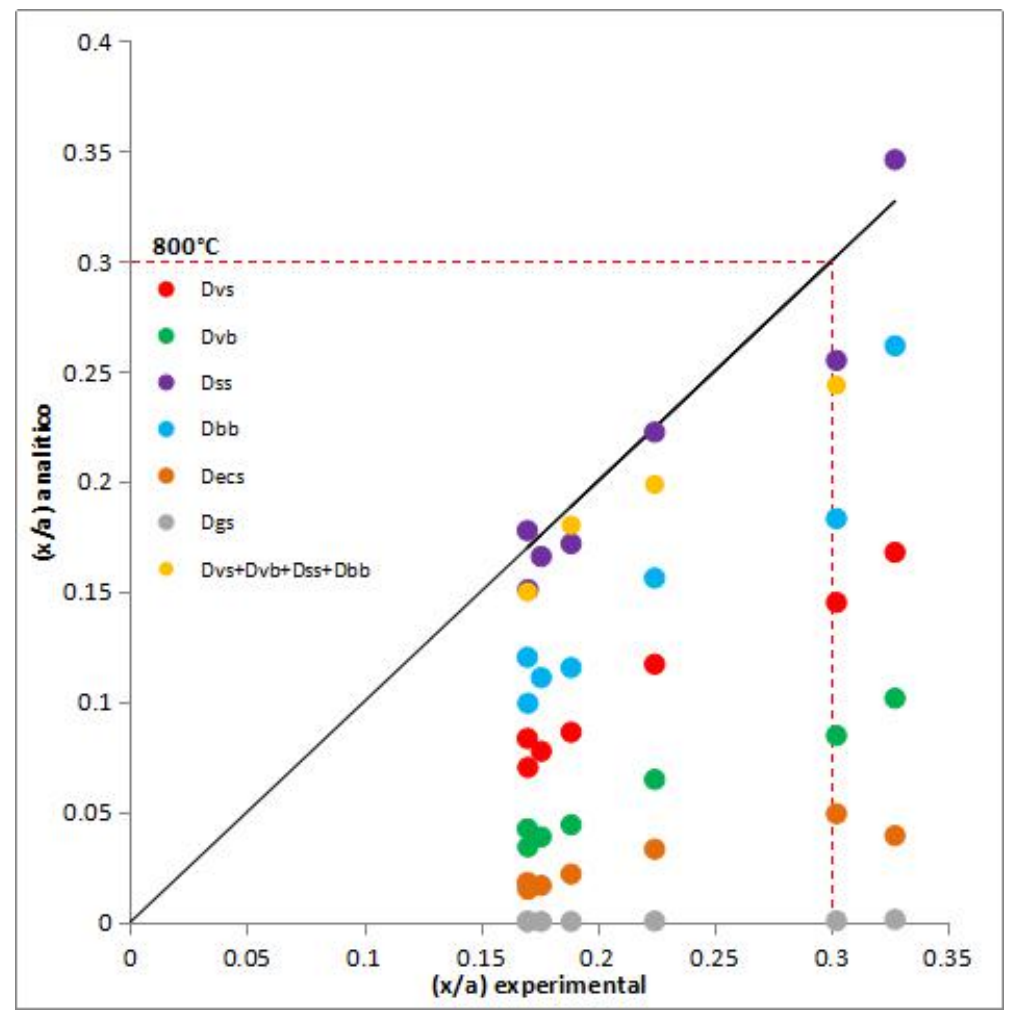

(f)

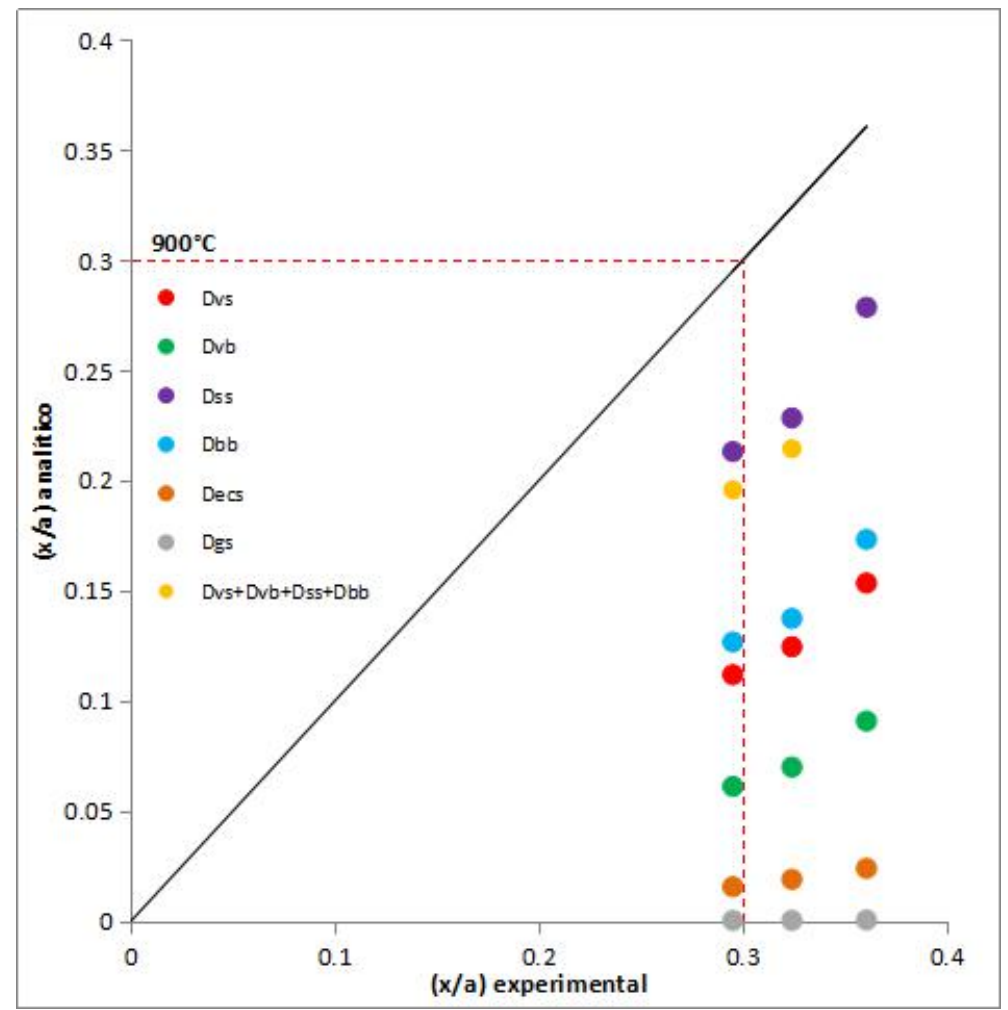


(g)

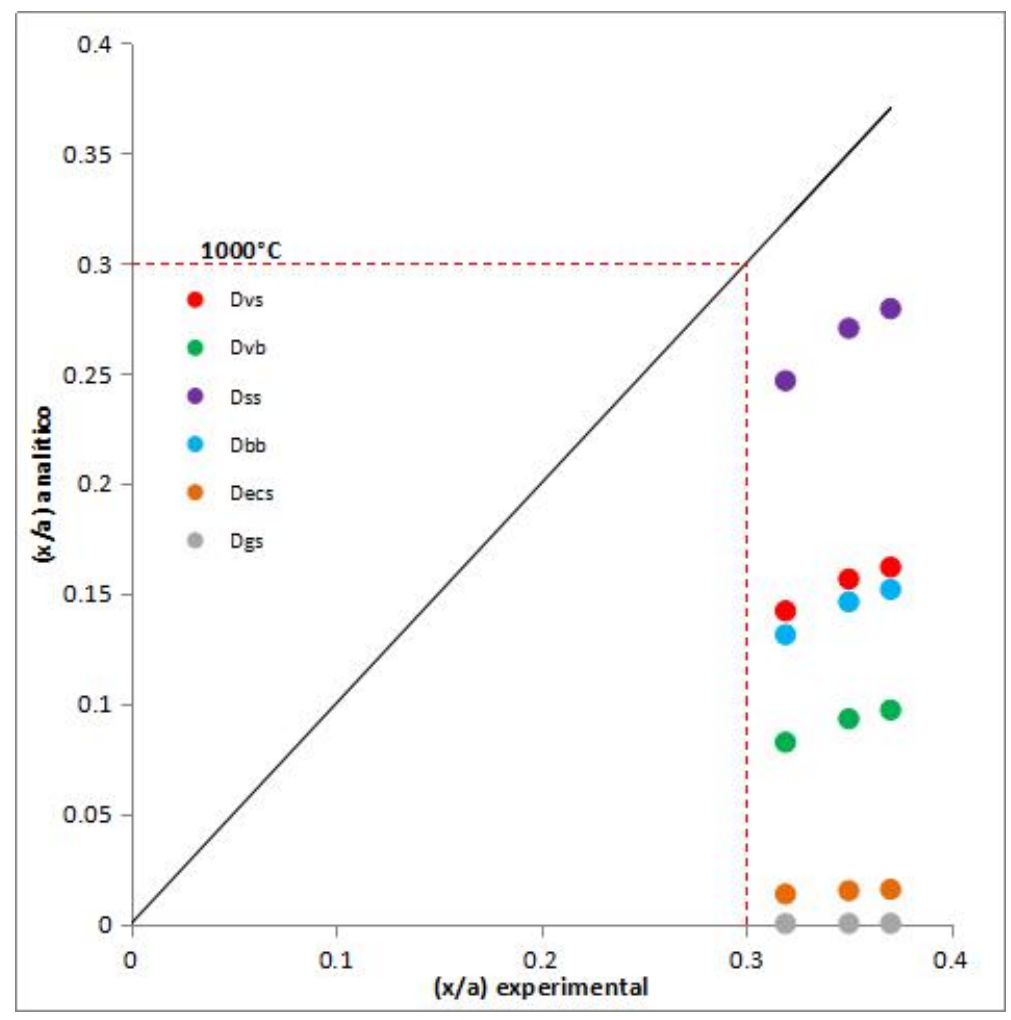

Figura 34: Gráficos comparativos entre (x/a) experimental e (x/a) analítico para as temperaturas de (a) $400^{\circ} \mathrm{C},(\mathrm{b})$ $500^{\circ} \mathrm{C}$, (c) $600^{\circ} \mathrm{C}$, (d) $700^{\circ} \mathrm{C}$, (e) $800^{\circ} \mathrm{C}$, (f) $900^{\circ} \mathrm{C}$ e (g) $1000^{\circ} \mathrm{C}$ com os dados extraídos do artigo de Kuczynski para o cobre [KUCZYNSKI, 1949]. ( $\mathrm{D}_{\mathrm{vs}}$ - difusão volumétrica a partir da superfície; $\mathrm{D}_{\mathrm{vb}}$ - difusão volumétrica a

partir do contorno de grão; $\mathrm{D}_{\mathrm{ss}}$ - difusão superficial a partir da superfície; Dbb- difusão do contorno de grão a partir do contorno de grão; $\mathrm{D}_{\text {ecs- }}$ difusão gasosa via evaporação-condensação a partir da superfície; e $\mathrm{D}_{\mathrm{gs}}$ - difusão gasosa a partir da superfície).

Kuczynski fez análises utilizando vários tamanhos de partícula, para uma mesma temperatura e nos mesmos tempo de sinterização, com isso não foi possível estabelecer um valor médio de raio da partícula que permitisse a comparação entre os mecanismos de sinterização combinados para todas as temperaturas; isso só foi possível nos casos em que a temperatura de sinterização foi de $600,700,800$ ou $900{ }^{\circ} \mathrm{C}$. Para a temperatura de $600{ }^{\circ} \mathrm{C}$, como os pontos referentes ao mecanismo de difusão do contorno de grão a partir do contorno de grão estavam posicionados acima da linha diagonal de $45^{\circ}$, fez-se duas simulações sendo uma incluindo a contribuição deste coeficiente e outra não. Ambos os valores resultantes da simulação foram bem próximos porque os tempos selecionados eram inferiores a três horas, o que nessa temperatura não resulta em um crescimento significativo do pescoço, tanto que todas as investigações referentes ao estudo da sinterização do cobre utilizam temperaturas superiores a $900{ }^{\circ} \mathrm{C}$, pois nesta condição o tempo necessário para que o processo ocorra é menor quando comparado as temperaturas inferiores [Alexander e Balluffi, 1957; Wilson e Shewmon, 1966; Kingery e Berg, 1955]. 
Dos dados publicados pode-se concluir também que quanto maior a temperatura de sinterização ou maior o tempo da sinterização, maior será o tamanho do pescoço final.

Entre as temperaturas de 400 e $600^{\circ} \mathrm{C}$, o tamanho do pescoço não é influenciado pelo tamanho inicial das partículas, apenas pelo tempo da sinterização. Porém em temperaturas acima de $700{ }^{\circ} \mathrm{C}$, o tamanho da partícula influencia diretamente o tamanho do pescoço final, ou seja, quanto maior o raio da partícula, maior será o tamanho do pescoço formado, porque maior será o fluxo de matéria para esta região.

Observa-se que em baixas temperaturas, maior é a quantidade de pontos experimentais contidos dentro da região correspondente ao estágio inicial da sinterização, o aumento gradual na temperatura ocasiona uma diminuição nessa quantidade pontos. Isso se deve ao curto espaço de tempo necessário para formação do pescoço, quanto maior temperatura, maior energia fornecida ao sistema e mais rápida será a sinterização. Infelizmente para altas temperaturas, como $900^{\circ}$ e $1000^{\circ} \mathrm{C}$, Kuczynski selecionou poucos tempos e fez poucas medições do tamanho do pescoço formado.

A $400{ }^{\circ} \mathrm{C}$, todos os pontos, exceto um pertencente ao conjunto de pontos referente a difusão pelo contorno de grão, encontram-se dentro do estágio inicial da sinterização. Nenhum ponto, porém, aderiu exatamente a linha diagonal de equivalência. Isso indica que os modelos analíticos utilizados ou superestimaram os valores do tamanho do pescoço, considerando que os dados de entrada do modelo são precisos e confiáveis ausentes de erros, como para os mecanismos de difusão gasosa via evaporação-condesação a partir da superfície e difusão pelo contorno de grão; ou subestimam estes valores como nos conjuntos da difusão volumétrica a partir do contorno de grão, difusão volumétrica a partir da superfície e difusão gasosa a partir da superfície. Apenas um ponto pertencente ao conjunto de resultados da difusão superficial a partir da superfície se aproxima mais da reta diagonal, sem aderência à mesma, no entanto.

A $500{ }^{\circ} \mathrm{C}$, todos os pontos também estão contidos dentro da região limitada pelo estágio inicial da sinterização. Os mecanismos da difusão pelo contorno de grão, difusão superficial a partir da superfície e difusão gasosa via evaporação-condensação a partir da superfície possuem todos ou a grande maioria dos pontos acima da reta diagonal, indicando que o modelo analítico superestima o raio do pescoço para estes mecanismos. Esta relação entre os dados analíticos e experimentais é crescente, todavia não linear, principalmente para os mecanismos de difusão superficial a partir da superfície e difusão gasosa via evaporaçãocondensação. A difusão pelo contorno de grão apresenta uma distribuição mais homogênea dos pontos, permitindo assim traçar uma reta com coeficiente angular diferente da reta 
diagonal. Os mecanismos de difusão volumétrica a partir da superfície, difusão volumétrica a partir do contorno de grão e a difusão gasosa a partir da superfície têm pontos somente abaixo da reta diagonal. Observa-se que os pontos destes três últimos mecanismos, quando ligados, aproximam-se a uma reta horizontal, isto indica que o método analítico não foi eficiente nesses casos, calculando de forma errônea os valores do tamanho do pescoço.

Kuczynski concluiu em seu estudo que o mecanismo dominante para o cobre é a difusão volumétrica, porém no início da sinterização a difusão superficial se faz operante. Este resultado foi questionado por diversos autores, dentre os quais podemos citar Ashby [ASHBY, 1974], que utilizou os dados de Kuczynski nos seus mapas e concluiu que o mecanismo dominante é a difusão superficial a partir da superfície. Nichols também fez uso dos dados experimentais de Kuczynski, o autor desenvolveu uma solução matemática de diferenças finitas para análise bidimensional da sinterização de uma sequência de fios sobre uma placa plana. Neste trabalho, Nichols concluiu que a lei baseada no expoente do tempo, time law, é valida apenas para uma faixa muito restrita de tamanhos de pescoço; e que o mecanismo dominante no caso de Kuczynski é a difusão superficial [Nichols, 1968].

Essas conclusões corroboram o conceito de que a utilização apenas do expoente do tempo para determinar o mecanismo dominante não é ideal, uma vez que o valor do expoente não é um número inteiro preciso, este pode variar dentro de uma faixa, que vir ou não a coincidir com valores de outros mecanismos.

Sabe-se também que o processo de sinterização é raramente dominado por único mecanismo, geralmente este é dado pela soma de vários mecanismos agindo concomitantemente e cujos percentuais de contribuição variam conforme a sinterização avança no tempo.

Kuczynski também utilizou das equações teóricas para determinar o valor da constante de energia de ativação do cobre. Apesar deste cálculo ser um método eficiente para identificar os mecanismos de sinterização, no caso do cobre este método não é recomendado uma vez que as energias de ativação para a difusão superficial e volumétrica são muito similares, 49,0 e 49,6 kcal/mol respectivamente [CHOI, SHEWMON, 1962; PETERSON, 1968].

Outro detalhe verificado no estudo de Kuczynski foi à inexistência das referências das quais ele obteve as constantes utilizadas nos seus cálculos, sendo que muitas das quais se diferem daquelas tradicionalmente aceitas e existentes nas literaturas e nos handbooks, como exemplo cita-se a tensão superficial por ele utilizada como sendo igual a $1200 \mathrm{ergs} / \mathrm{cm}^{2}$ enquanto que o valor aceito é de $1720 \mathrm{ergs} / \mathrm{cm}^{2}$. 
No desenvolvimento das equações para os mecanismos de sinterização, Kuczysnki não diferenciou o valor do raio do pescoço para as situações onde há ou não contração, além disso, a área da superfície do pescoço mencionada em seu artigo não condiz com a integral do volume do pescoço associado por ele. Assim, a constante para o mecanismo de difusão volumétrica que deveria ser 80 tornou-se 40 pelo autor devido as simplificações realizadas.

Para estabelecer quão representativos e precisos são os dados analíticos na reprodução do experimento de Kuczynski, foi feita uma análise estatística com nível de confiança de 5\%. A Tabela 11 e a Tabela 12 apresentam, respectivamente, as análises de todos os pontos mensurados e somente daqueles compreendidos dentro da região correspondente ao estágio 1 da sinterização.

Tabela 11: Análise estatística entre os dados experimentais e analíticos da razão (x/a) com nível de confiança igual a $5 \%$.

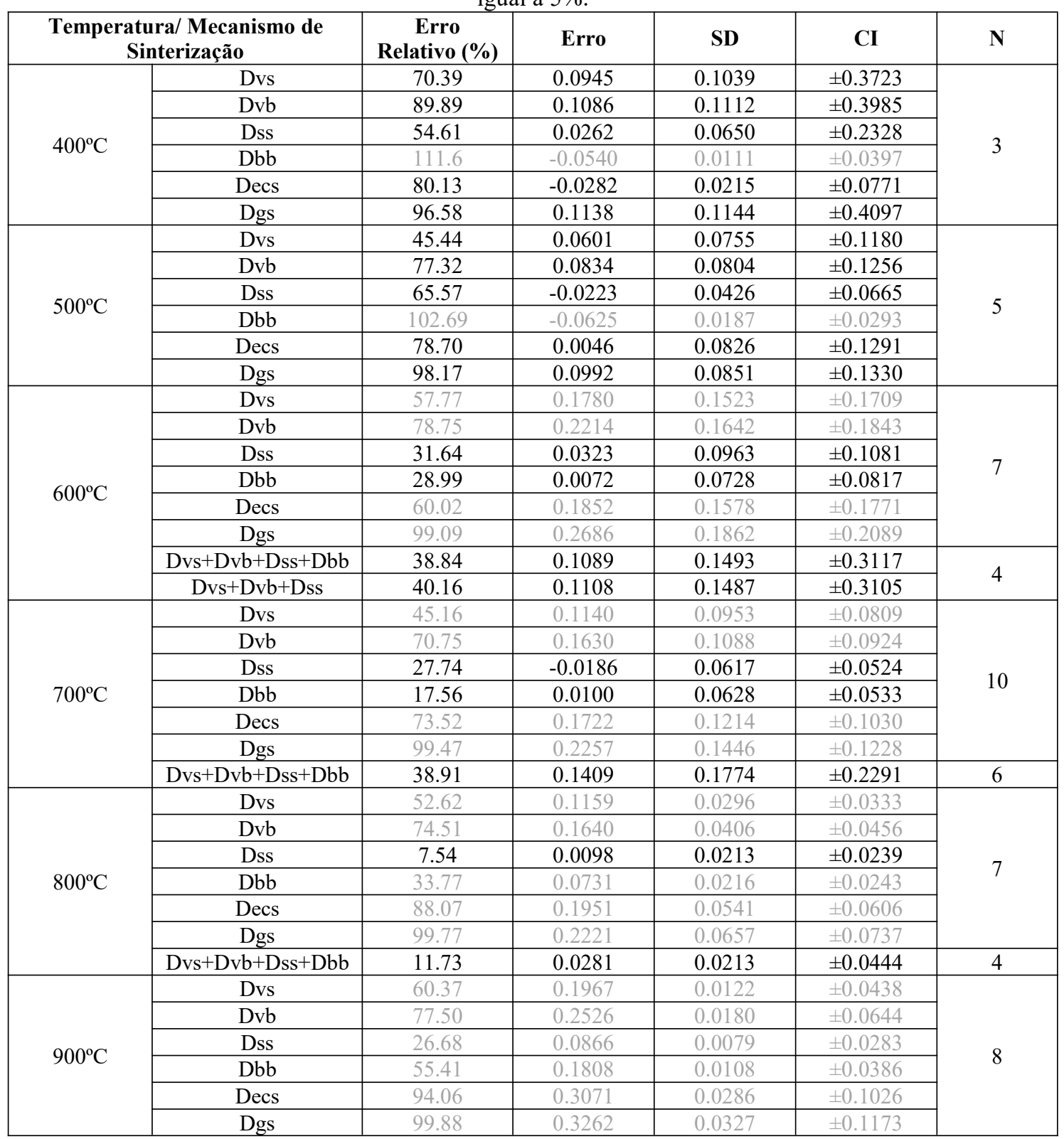




\begin{tabular}{|c|c|c|c|c|c|c|}
\hline & Dvs+Dvb+Dss+Dbb & 33.78 & 0.1046 & 0.0077 & \pm 0.1394 & 2 \\
\hline \multirow{3}{*}{$1000^{\circ} \mathrm{C}$} & Dvs & 55.65 & 0.1929 & 0.0157 & \pm 0.0562 & \\
\cline { 2 - 6 } & Dvb & 73.75 & 0.2555 & 0.0183 & \pm 0.0656 & \multirow{2}{*}{8} \\
\cline { 2 - 6 } & Dss & 23.34 & 0.0810 & 0.0094 & \pm 0.0335 & \\
\cline { 2 - 5 } & Dbb & 58.66 & 0.2033 & 0.0153 & \pm 0.0550 & \\
\cline { 2 - 5 } & Decs & 95.69 & 0.3316 & 0.0247 & \pm 0.0885 & \\
\cline { 2 - 5 } & Dgs & 99.90 & 0.3462 & 0.0258 & \pm 0.0923 & \\
\hline
\end{tabular}

Nas temperaturas de 400 e $500{ }^{\circ} \mathrm{C}$ todos os mecanismos, exceto a difusão do contorno de grão, são passíveis de serem os dominantes. Contudo observando o gráfico da Figura 115, para $400^{\circ} \mathrm{C}$ os mecanismos que mais se aderem a reta diagonal são a difusão gasosa via evaporação-condensação e a difusão superficial, enquanto que em $500{ }^{\circ} \mathrm{C}$ a maioria dos pontos encontram-se mais distantes da reta, exceto para razões de $\left(\frac{x}{a}\right)$ inferiores a 0.1 o mecanismo que melhor descreve os dados experimentais é a difusão volumétrica a partir da superfície.

Para as temperaturas de 600 e $700{ }^{\circ} \mathrm{C}$, apenas os mecanismos da difusão superficial, difusão do contorno de grão e os métodos combinados são estatisticamente aceitos como os que melhor reproduzem os dados experimentais. Observa-se que principalmente a $700{ }^{\circ} \mathrm{C}$ há um aglomerado de pontos muito próximos à reta diagonal, indicando o quanto que estas equações conseguem representar com precisão as medidas experimentais nestas condições.

A $800{ }^{\circ} \mathrm{C}$, apenas a difusão superficial e o método combinado descrevem com nível de significância de $5 \%$ os dados experimentais.

Apesar do mecanismo combinado a $900^{\circ} \mathrm{C}$ apresentar-se como estatisticamente possível, pela análise gráfica observa-se que este não pode ser considerado dominante. Como existem apenas dois pontos disponíveis para a análise, o tamanho do intervalo crítico aumenta consideravelmente e aumenta também a probabilidade do erro estar contido nesta faixa.

$\mathrm{Na}$ temperatura $1000{ }^{\circ} \mathrm{C}$, não houve qualquer mecanismo com a precisão estatística mínima necessária para representar os dados experimentais publicados. Vale ressaltar que os dados experimentais coletados a 900 e $1000{ }^{\circ} \mathrm{C}$ não estão contidos dentro da região limitada pelo estágio inicial da sinterização, com isso as equações analíticas empregadas não são mais validas pois existem modelos mais precisos dos estágios intermediário e final da sinterização que podem ser aplicados [Coble, 1961, Johnson, 1970; Beeré, 1975; Coleman, 1975].

Os mecanismos cujo modelo mais apresenta erros variam muito conforme a temperatura de sinterização empregada. Para 400 e $500{ }^{\circ} \mathrm{C}$, estes mecanismos são, em ordem decrescente: difusão gasosa a partir da superfície $\left(\mathrm{D}_{\mathrm{gs}}\right)$, difusão volumétrica a partir do contorno de grão $\left(\mathrm{D}_{\mathrm{vb}}\right)$, e difusão volumétrica a partir da superfície $\left(\mathrm{D}_{\mathrm{vs}}\right)$. Para $600{ }^{\circ} \mathrm{C}$ são: difusão gasosa a 
partir da superfície $\left(\mathrm{D}_{\mathrm{gs}}\right)$, difusão volumétrica a partir do contorno de grão $\left(\mathrm{D}_{\mathrm{vb}}\right)$, difusão gasosa via evaporação-condensação a partir da superfície $\left(\mathrm{D}_{\mathrm{ecs}}\right)$ e difusão volumétrica a partir da superfície $\left(\mathrm{D}_{\mathrm{vs}}\right)$. De 700 a $1000{ }^{\circ} \mathrm{C}$ a ordem dos mecanismos com mais erros foi mantida, sendo estes: difusão gasosa a partir da superfície $\left(\mathrm{D}_{\mathrm{gs}}\right)$, difusão gasosa via evaporaçãocondensação a partir da superfície $\left(\mathrm{D}_{\mathrm{ecs}}\right)$ e difusão volumétrica a partir do contorno de grão $\left(\mathrm{D}_{\mathrm{vb}}\right)$.

Tabela 12: Análise estatística nível de confiança igual a 5\% entre os dados experimentais e analíticos contidos exclusivamente na região delimitada pelo estágio 1 da sinterização.

\begin{tabular}{|c|c|c|c|c|c|c|}
\hline \multicolumn{2}{|c|}{$\begin{array}{l}\text { Temperatura/ Mecanismo de } \\
\text { Sinterização }\end{array}$} & $\begin{array}{c}\text { Erro } \\
\text { Relativo (\%) }\end{array}$ & Erro & SD & CI & $\mathbf{N}$ \\
\hline \multirow{6}{*}{$400^{\circ} \mathrm{C}$} & Dvs & 70.39 & 0.0945 & 0.1039 & \pm 0.3723 & \multirow{6}{*}{3} \\
\hline & Dvb & 89.89 & 0.1086 & 0.1112 & \pm 0.3985 & \\
\hline & Dss & 54.61 & 0.0261 & 0.0650 & \pm 0.2328 & \\
\hline & Dbb & 111.60 & -0.0536 & 0.0111 & \pm 0.0397 & \\
\hline & Decs & 80.13 & -0.0282 & 0.0215 & \pm 0.0771 & \\
\hline & Dgs & 96.58 & 0.1138 & 0.1144 & \pm 0.4097 & \\
\hline \multirow{6}{*}{$500^{\circ} \mathrm{C}$} & Dvs & 45.44 & 0.0601 & 0.0755 & \pm 0.1180 & \multirow{6}{*}{5} \\
\hline & Dvb & 77.32 & 0.0834 & 0.0804 & \pm 0.1256 & \\
\hline & Dss & 65.57 & -0.0223 & 0.0426 & \pm 0.0665 & \\
\hline & Dbb & 102.69 & -0.0625 & 0.0187 & \pm 0.0293 & \\
\hline & Decs & 78.70 & 0.0046 & 0.0826 & \pm 0.1291 & \\
\hline & Dgs & 98.17 & 0.0991 & 0.0851 & \pm 0.1330 & \\
\hline \multirow{8}{*}{$600^{\circ} \mathrm{C}$} & Dvs & 46.61 & 0.0585 & 0.0146 & \pm 0.0304 & \multirow{6}{*}{4} \\
\hline & Dvb & 74.40 & 0.0931 & 0.0207 & \pm 0.0433 & \\
\hline & Dss & 34.09 & -0.0430 & 0.0122 & \pm 0.0255 & \\
\hline & Dbb & 37.54 & -0.0486 & 0.0212 & \pm 0.0442 & \\
\hline & Decs & 48.06 & 0.0606 & 0.0195 & \pm 0.0407 & \\
\hline & Dgs & 99.07 & 0.1244 & 0.0302 & \pm 0.0630 & \\
\hline & Dvs+Dvb+Dss+Dbb & 24.45 & 0.0359 & 0.0378 & \pm 0.1356 & \\
\hline & Dvs+Dvb+Dss & 26.12 & 0.0381 & 0.0374 & \pm 0.1341 & 3 \\
\hline \multirow{7}{*}{$700^{\circ} \mathrm{C}$} & Dvs & 39.29 & 0.0559 & 0.0214 & \pm 0.0240 & \multirow{6}{*}{7} \\
\hline & Dvb & 69.12 & 0.0968 & 0.0243 & \pm 0.0272 & \\
\hline & Dss & 32.18 & -0.0425 & 0.0290 & \pm 0.0325 & \\
\hline & Dbb & 15.84 & -0.0110 & 0.0283 & \pm 0.0318 & \\
\hline & Decs & 70.93 & 0.0994 & 0.0247 & \pm 0.0277 & \\
\hline & Dgs & 99.52 & 0.1394 & 0.0338 & \pm 0.0379 & \\
\hline & Dvs+Dvb+Dss+Dbb & 12.46 & -0.0065 & 0.0210 & \pm 0.0751 & 3 \\
\hline \multirow{7}{*}{$800^{\circ} \mathrm{C}$} & Dvs & 9.56 & 0.0989 & 0.0077 & \pm 0.0120 & \multirow{6}{*}{5} \\
\hline & Dvb & 14.23 & 0.1410 & 0.0120 & \pm 0.0188 & \\
\hline & Dss & 0.18 & 0.0081 & 0.0111 & \pm 0.0174 & \\
\hline & Dbb & 6.08 & 0.0654 & 0.0093 & \pm 0.0145 & \\
\hline & Decs & 17.04 & 0.1649 & 0.0158 & \pm 0.0246 & \\
\hline & Dgs & 19.95 & 0.1855 & 0.0228 & \pm 0.0356 & \\
\hline & Dvs+Dvb+Dss+Dbb & 9.23 & 0.0180 & 0.0085 & \pm 0.0306 & 3 \\
\hline
\end{tabular}

Para a análise estatística da região limitada exclusivamente pelo estágio inicial da sinterização, alguns pontos experimentas precisaram ser excluídos nas temperaturas estudadas.

Para as temperaturas de 400 e $500{ }^{\circ} \mathrm{C}$ nenhum ponto experimental foi excluído da análise, sendo que as mesmas conclusões realizadas anteriormente continuam válidas.

A partir de $600{ }^{\circ} \mathrm{C}$ o cenário possível foi alterado. Para esta temperatura apenas os mecanismos combinados foram considerados estatisticamente possíveis de serem os 
dominantes. Na temperatura de $700{ }^{\circ} \mathrm{C}$, além do mecanismo combinado, a difusão do contorno de grão também pôde ser considerada como dominante. Em $800{ }^{\circ} \mathrm{C}$, a difusão superficial e o mecanismo combinado são os dominantes.

Para as temperaturas de 900 e $1000{ }^{\circ} \mathrm{C}$ nenhuma análise foi feita pelo fato de que todos os dados experimentais se encontravam fora da região delimitada pelo estágio inicial.

Nesta região do estágio inicial, os modelos que apresentaram maiores erros prevaleceram os mesmos verificados quando a análise englobou todos os pontos experimentais. Assim, para 400 e $500^{\circ} \mathrm{C}$, os mecanismos são: difusão gasosa a partir da superfície $\left(D_{\mathrm{gs}}\right)$, difusão volumétrica a partir do contorno de grão $\left(\mathrm{D}_{\mathrm{vb}}\right)$, e difusão volumétrica a partir da superfície $\left(\mathrm{D}_{\mathrm{vs}}\right)$. Para $600{ }^{\circ} \mathrm{C}$ são: difusão gasosa a partir da superfície $\left(\mathrm{D}_{\mathrm{gs}}\right)$, difusão volumétrica a partir do contorno de grão $\left(\mathrm{D}_{\mathrm{vb}}\right)$, difusão gasosa via evaporaçãocondensação a partir da superfície $\left(\mathrm{D}_{\mathrm{ecs}}\right)$ e difusão volumétrica a partir da superfície $\left(\mathrm{D}_{\mathrm{vs}}\right)$. Entre 700 e $800{ }^{\circ} \mathrm{C}$ a ordem foi: difusão gasosa a partir da superfície $\left(\mathrm{D}_{\mathrm{gs}}\right)$, difusão gasosa via evaporação-condensação a partir da superfície $\left(D_{\text {ecs }}\right)$ e difusão volumétrica a partir do contorno de grão $\left(\mathrm{D}_{\mathrm{vb}}\right)$.

b) Experimentos de Kingery e Berg para o cobre

Kingery e Berg chegaram a conclusão do mecanismo dominante para o cobre a partir da análise gráfica entre $\log \left(\frac{x}{a}\right)$ pelo $\log \mathrm{t}$, e do coeficiente do tempo associado a reta obtida pela regressão linear dos pontos experimentais.

Na Figura 35 estão reproduzidos os gráficos entre $\frac{x}{a}$ experimental e $\frac{x}{a}$ analítico para as temperaturas de 950,1000 e $1050^{\circ} \mathrm{C}$. 
(a)

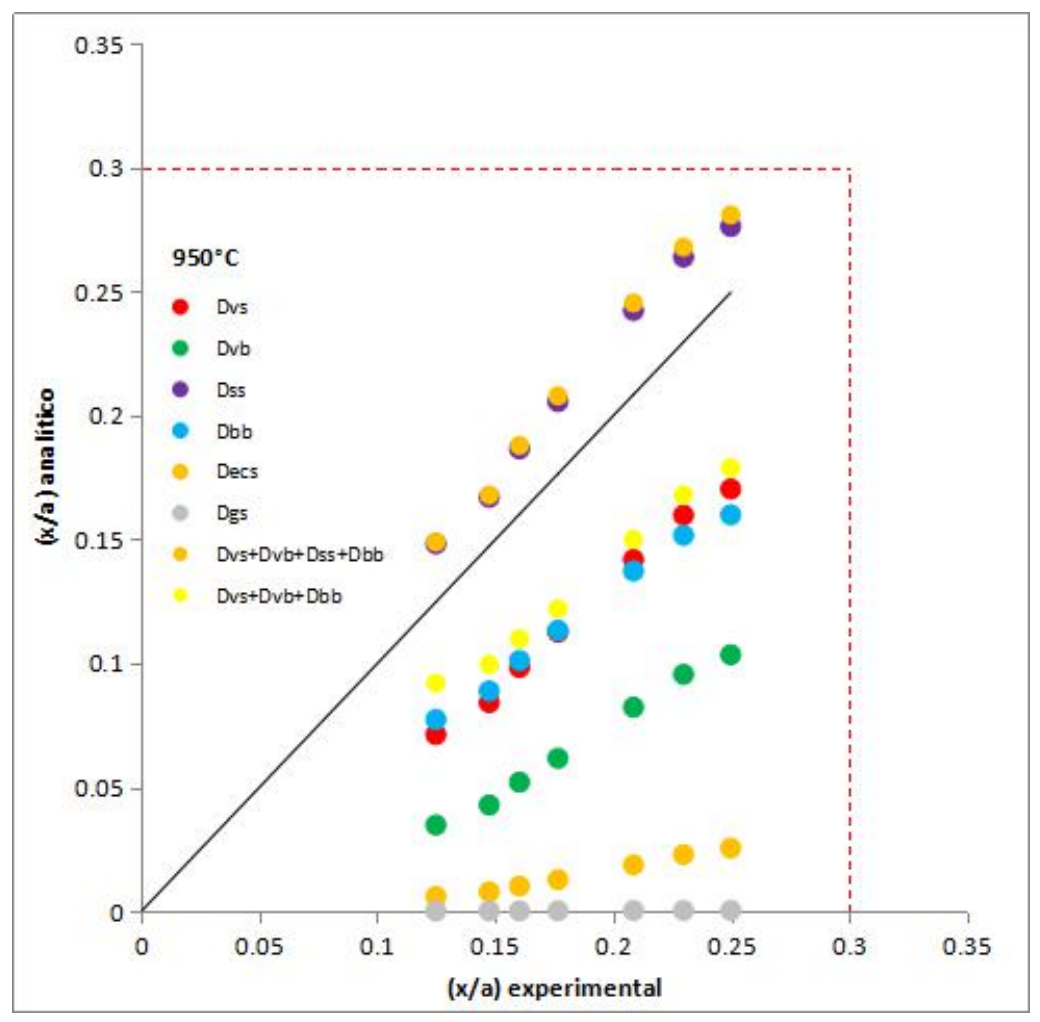

(b)

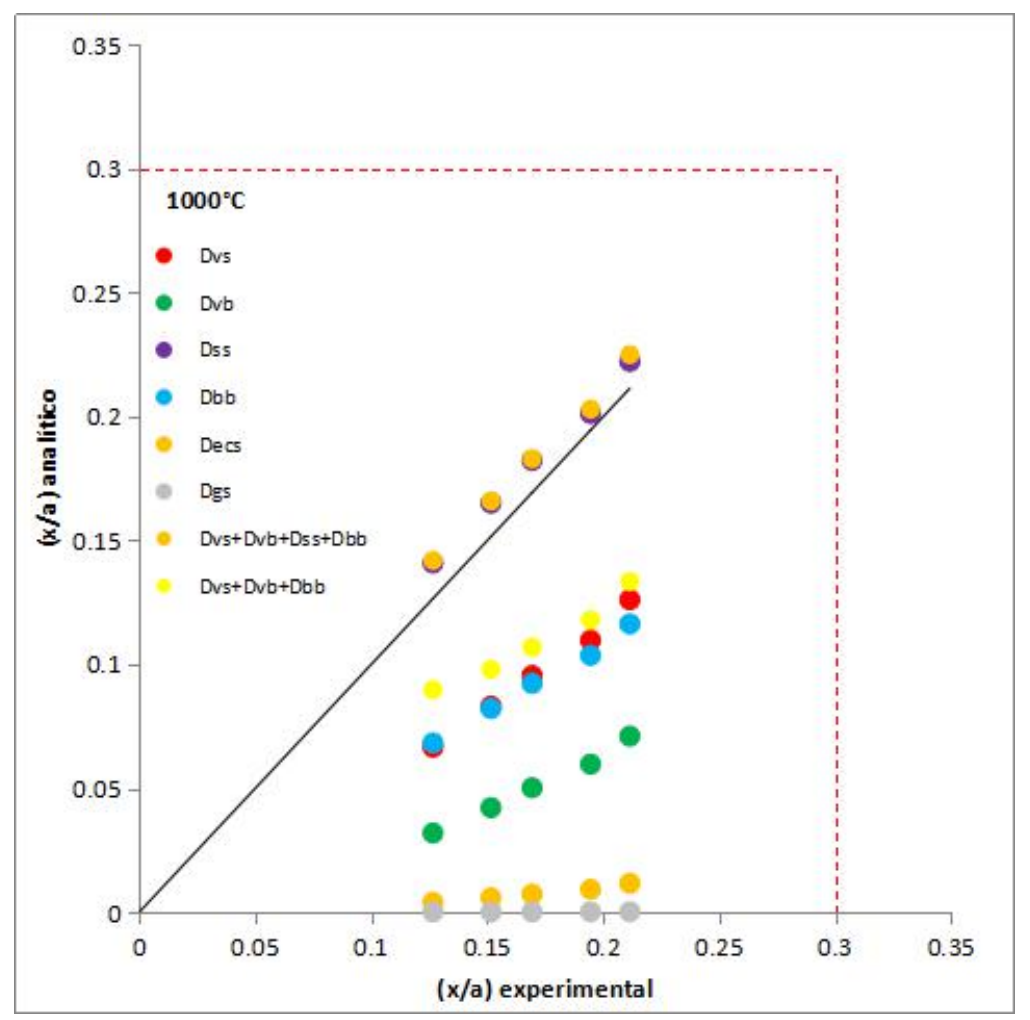


(c)

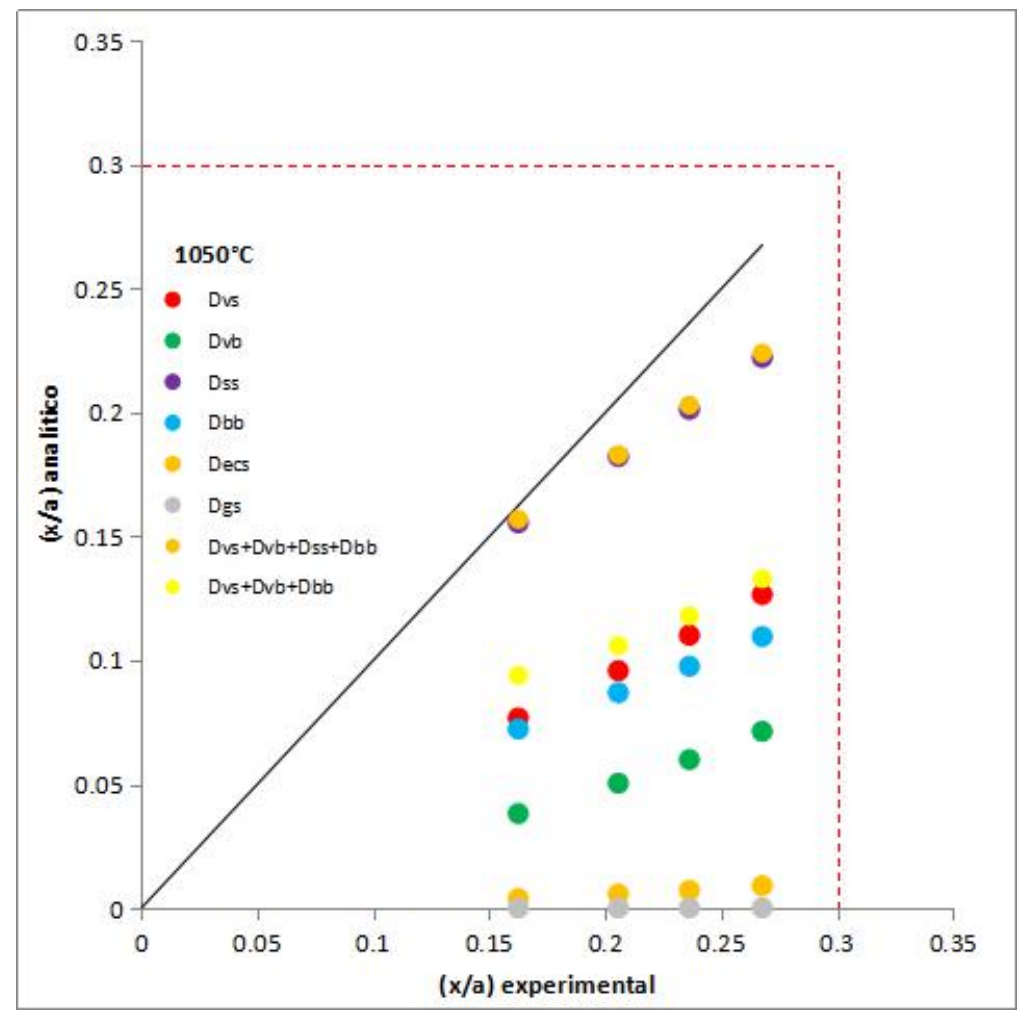

Figura 35: Gráficos para as temperaturas de (a) $950^{\circ} \mathrm{C}$, (b) $1000^{\circ} \mathrm{C}$ e (c) $1050^{\circ} \mathrm{C}$ entre $\left(\frac{x}{a}\right)$ experimental vs $\left(\frac{x}{a}\right)$ analítico baseado no artigo de Kingery e Berg [KINGERY, BERG, 1955]. ( $D_{v s-}$ difusão volumétrica a partir da superfície; $\mathrm{D}_{\mathrm{vb}}$ - difusão volumétrica a partir do contorno de grão; $\mathrm{D}_{\mathrm{ss}}$ - difusão superficial a partir da superfície; Dbb- difusão do contorno de grão a partir do contorno de grão; $D_{\text {ecs- }}$ difusão gasosa via evaporação-condensação a partir da superfície; e $\mathrm{D}_{\mathrm{gs}}$ - difusão gasosa a partir da superfície).

Em todas as três situações, os pontos encontram-se dentro da região limitada correspondente ao primeiro estágio da sinterização.

$\mathrm{Na}$ temperatura de $950{ }^{\circ} \mathrm{C}$, nenhum dos mecanismos avaliados apresenta uma perfeita aderência a reta de $45^{\circ}$, porém os que mais se aproximam, apesar de estarem acima da reta, são os mecanismos de difusão superficial a partir da superfície e o mecanismo combinado incluindo a difusão superficial $\left(\mathrm{D}_{\mathrm{vs}}+\mathrm{D}_{\mathrm{vb}}+\mathrm{D}_{\mathrm{ss}}+\mathrm{D}_{\mathrm{bb}}\right)$. Com o aumento da temperatura de sinterização, esses dois mecanismos passam a se aproximar cada vez mais da reta de $45^{\circ}$ (como pode ser observado para a temperatura de $1000^{\circ} \mathrm{C}$ ). Na temperatura de $1050{ }^{\circ} \mathrm{C}$, tem-se o efeito inverso da temperatura de $950^{\circ} \mathrm{C}$, os resultados dos modelos subestimam os dados analíticos se posicionando abaixo da reta diagonal. Os modelos também se afastam mais da reta a partir da razão $\frac{x}{a}$ igual a 0,15 , nem mesmo o modelo combinado conseguiu acompanhar o direcionamento da reta de $45^{\circ}$, houve um desvio que passou a ser mais acentuado quanto maior o tamanho do pescoço.

A Tabela 13 apresenta a análise estatística para estes dados. 
Tabela 13: Análise estatística entre as razões $\left(\frac{x}{a}\right)$ calculado versus $\left(\frac{x}{a}\right)$ experimental com os dados de Kingery

\begin{tabular}{|c|c|c|c|c|c|c|}
\hline \multicolumn{2}{|c|}{$\begin{array}{c}\text { Temperatura/ Mecanismo de } \\
\text { Sinterização }\end{array}$} & \multirow{2}{*}{$\begin{array}{c}\text { Erro } \\
\text { Relativo (\%) } \\
36.37 \\
\end{array}$} & \multirow{2}{*}{$\begin{array}{l}\text { Erro } \\
0.0654\end{array}$} & \multirow{2}{*}{$\begin{array}{l}\text { SD } \\
0.0079\end{array}$} & \multirow{2}{*}{$\begin{array}{c}\mathbf{C I} \\
\pm 0.0089\end{array}$} & \multirow{2}{*}{$\begin{array}{l}\mathbf{N} \\
7\end{array}$} \\
\hline $950^{\circ} \mathrm{C}$ & Dvs & & & & & \\
\hline & Dvb & 64.70 & 0.1177 & 0.0191 & \pm 0.0215 & \\
\hline & Dss & 15.28 & -0.0276 & 0.0053 & \pm 0.0060 & \\
\hline & Dbb & 36.32 & 0.0667 & 0.0141 & \pm 0.0158 & \\
\hline & Decs & 92.43 & 0.1704 & 0.0380 & \pm 0.0426 & \\
\hline & Dgs & 99.85 & 0.1850 & 0.0455 & \pm 0.0510 & \\
\hline & $\mathrm{Dvs}+\mathrm{Dvb}+\mathrm{Dss}+\mathrm{Dbb}$ & 16.50 & -0.030 & 0.0064 & \pm 0.0072 & \\
\hline & Dvs+Dvb+Dbb & 29.15 & 0.0537 & 0.0120 & \pm 0.0135 & \\
\hline \multirow[t]{8}{*}{$1000^{\circ} \mathrm{C}$} & Dvs & 43.99 & 0.0744 & 0.0108 & \pm 0.0169 & \multirow[t]{8}{*}{5} \\
\hline & Dvb & 70.56 & 0.1196 & 0.0186 & \pm 0.0291 & \\
\hline & Dss & 7.30 & -0.0117 & 0.0030 & \pm 0.0047 & \\
\hline & Dbb & 45.76 & 0.0781 & 0.0152 & \pm 0.0237 & \\
\hline & Decs & 95.65 & 0.1630 & 0.0307 & \pm 0.0480 & \\
\hline & Dgs & 99.89 & 0.1705 & 0.0336 & \pm 0.0526 & \\
\hline & $\mathrm{Dvs}+\mathrm{Dvb}+\mathrm{Dss}+\mathrm{Dbb}$ & 8.11 & -0.0131 & 0.0027 & \pm 0.0042 & \\
\hline & Dvs+Dvb+Dbb & 35.48 & 0.0614 & 0.0171 & \pm 0.0267 & \\
\hline \multirow[t]{8}{*}{$1050^{\circ} \mathrm{C}$} & Dvs & 53.03 & 0.1156 & 0.0237 & \pm 0.0495 & \multirow[t]{8}{*}{4} \\
\hline & Dvb & 74.95 & 0.1629 & 0.0308 & \pm 0.0642 & \\
\hline & Dss & 11.83 & 0.0276 & 0.0165 & \pm 0.0344 & \\
\hline & Dbb & 57.71 & 0.1263 & 0.0290 & \pm 0.0605 & \\
\hline & Decs & 97.07 & 0.2115 & 0.0426 & \pm 0.0890 & \\
\hline & Dgs & 99.92 & 0.2178 & 0.0448 & \pm 0.0935 & \\
\hline & $\mathrm{Dvs}+\mathrm{Dvb}+\mathrm{Dss}+\mathrm{Dbb}$ & 11.18 & 0.0262 & 0.0163 & \pm 0.0340 & \\
\hline & $\mathrm{Dvs}+\mathrm{Dvb}+\mathrm{Dbb}$ & 47.73 & 0.1052 & 0.0284 & \pm 0.0592 & \\
\hline
\end{tabular}

Observa-se que nenhum dos mecanismos, para as temperaturas de 900 e $1000^{\circ} \mathrm{C}$, pode ser considerado dominante com significância de 5\%. Inclusive os mecanismos de difusão superficial e mecanismo combinado para $1000{ }^{\circ} \mathrm{C}$ foram reprovados na análise estatística. Apesar dos valores estarem bem próximos a reta de $45^{\circ}$, todos eles estão localizados acima da mesma. O cálculo do erro é dado pela soma dos erros individuais, como todos estão do mesmo lado, não há nenhuma compensação negativa de modo a equilibrar esta variação. Assim, a variável erro apresenta um valor fora do intervalo crítico calculado. Vale ressaltar que mesmo sendo reprovado estatisticamente, os mecanismos que melhor explicam a sinterização e o crescimento do pescoço a $1000^{\circ} \mathrm{C}$ são a difusão superficial e o mecanismo 
combinado. Nem a análise estatística nem a análise gráfica devem ser exclusivas, ela combinadas permitem uma análise mais sólida e consistente do processo como um todo.

$\mathrm{Na}$ temperatura de $1050{ }^{\circ} \mathrm{C}$ os possíveis mecanismos dominantes são: difusão superficial e mecanismos combinado $\left(D_{\mathrm{vs}}+\mathrm{D}_{\mathrm{vb}}+\mathrm{D}_{\mathrm{ss}}+\mathrm{D}_{\mathrm{bb}}\right)$. Apesar dos erros relativos desses mecanismos nesta temperatura serem maiores do que para a temperatura de $1000{ }^{\circ} \mathrm{C}$, o numero de pontos analisados foi menor, aumentando assim a faixa de valores do intervalo crítico estimado (CI).

Os mecanismos que apresentaram os maiores valores para o erro relativo foram os mesmos nas três temperaturas estudadas. Em ordem decrescente estes foram: difusão gasosa a partir da superfície $\left(\mathrm{D}_{\mathrm{gs}}\right)$, difusão gasosa via evaporação-condensação a partir da superfície $\left(D_{\text {ecs }}\right)$ e difusão volumétrica a partir do contorno de grão $\left(D_{\mathrm{vb}}\right)$.

A Figura 36 e a Figura 37 apresentam, respectivamente, os gráficos tanto na escala logarítmica quanto na linear da razão entre tamanho do pescoço pelo raio da partícula $\left(\frac{x}{a}\right)$ e o tempo $(\mathrm{t})$ para as três temperaturas analisadas.

(a)

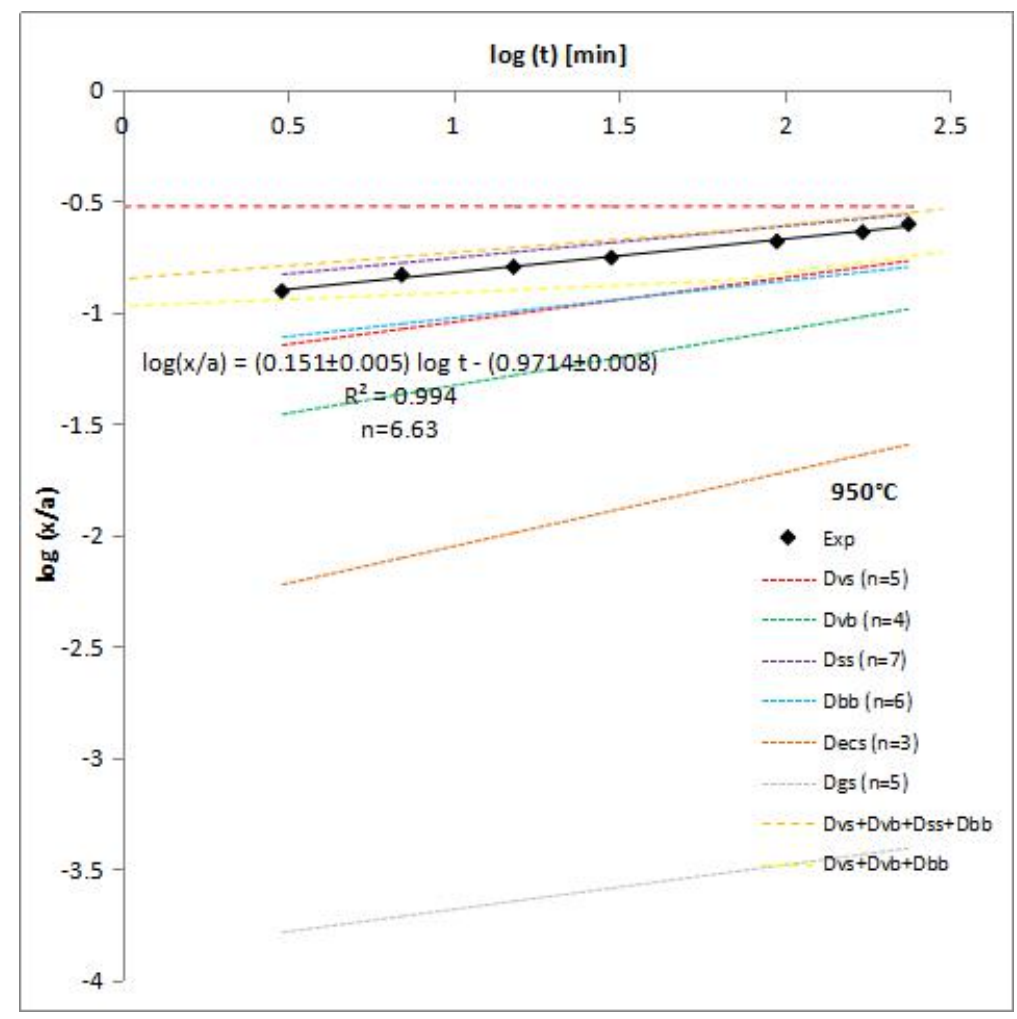


(b)

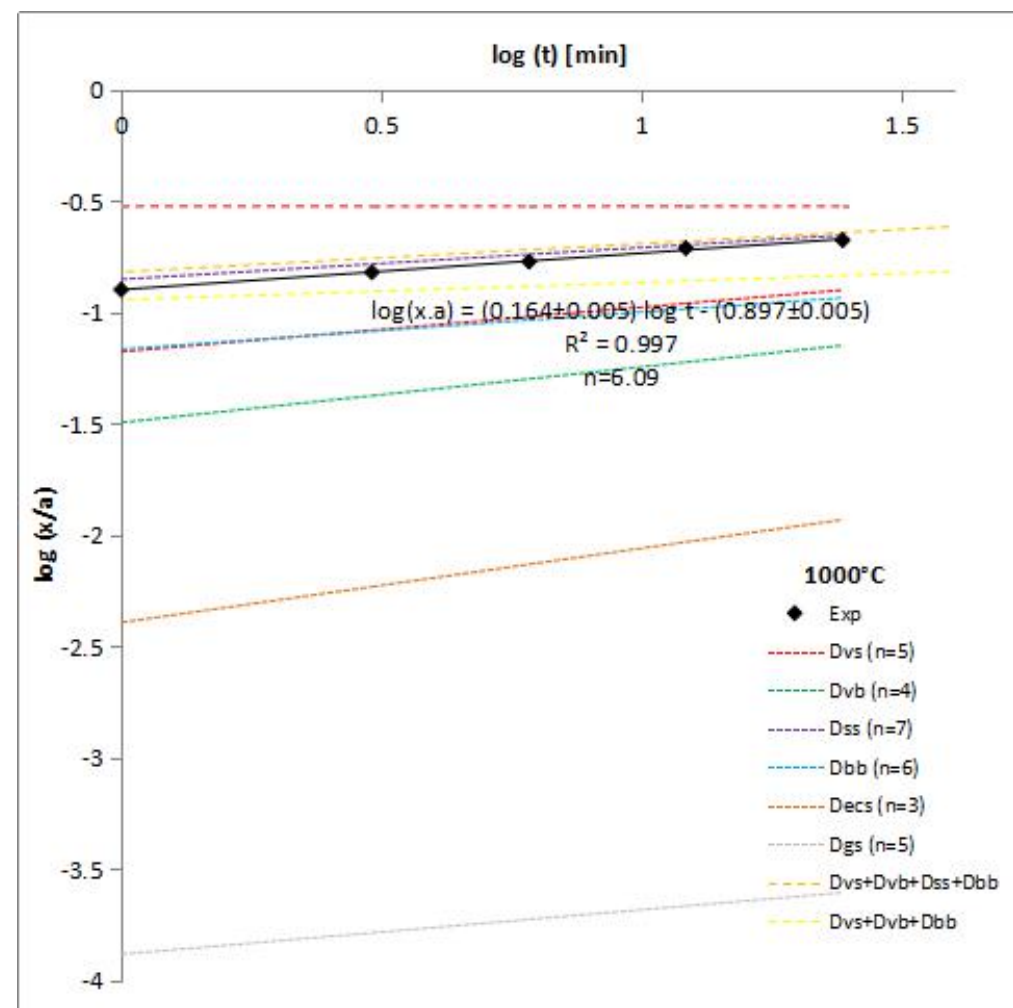

(c)

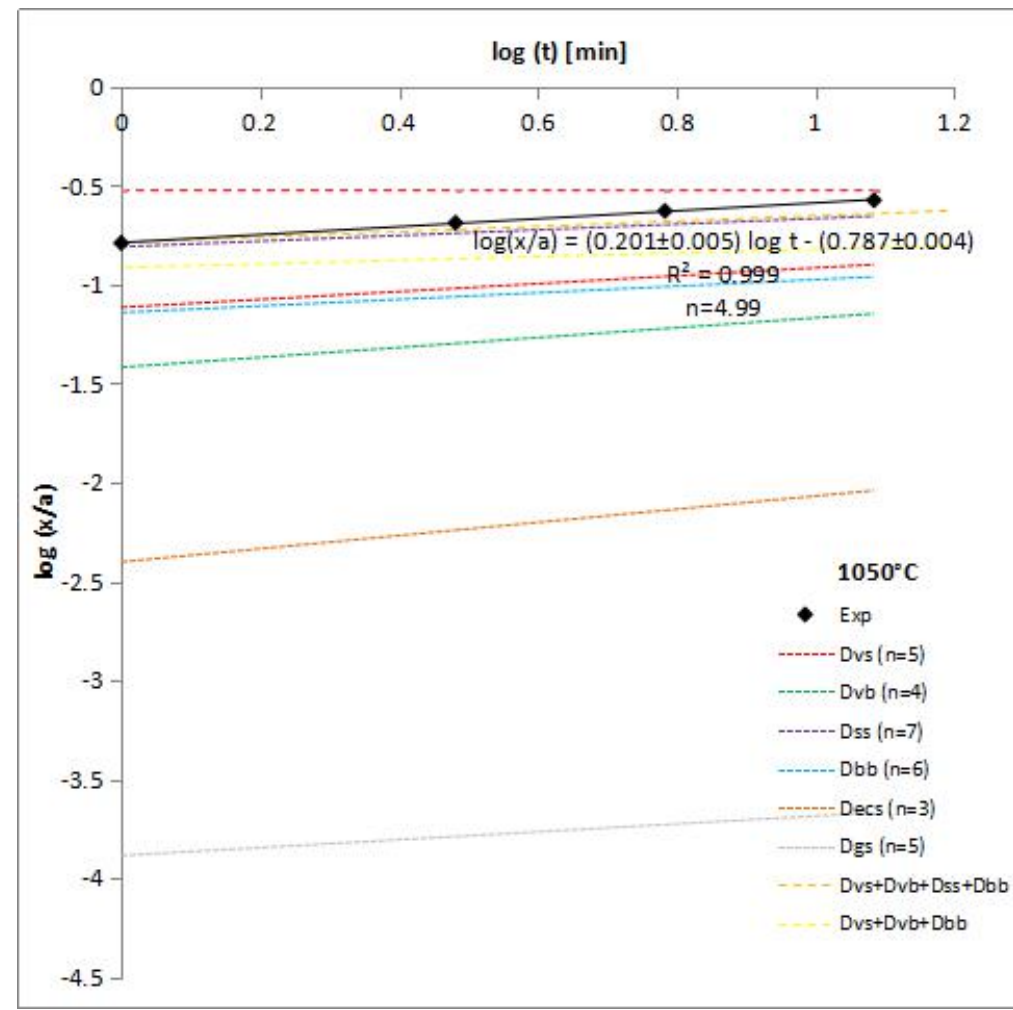

Figura 36: Gráficos para as temperaturas de (a) $950^{\circ} \mathrm{C}$, (b) $1000^{\circ} \mathrm{C}$ e (c) $1050^{\circ} \mathrm{C}$ entre $\log \left(\frac{x}{a}\right)$ vs $\log \mathrm{t}[\mathrm{min}]$ baseado no artigo de Kingery e Berg [KINGERY, BERG, 1955]. 
(a)

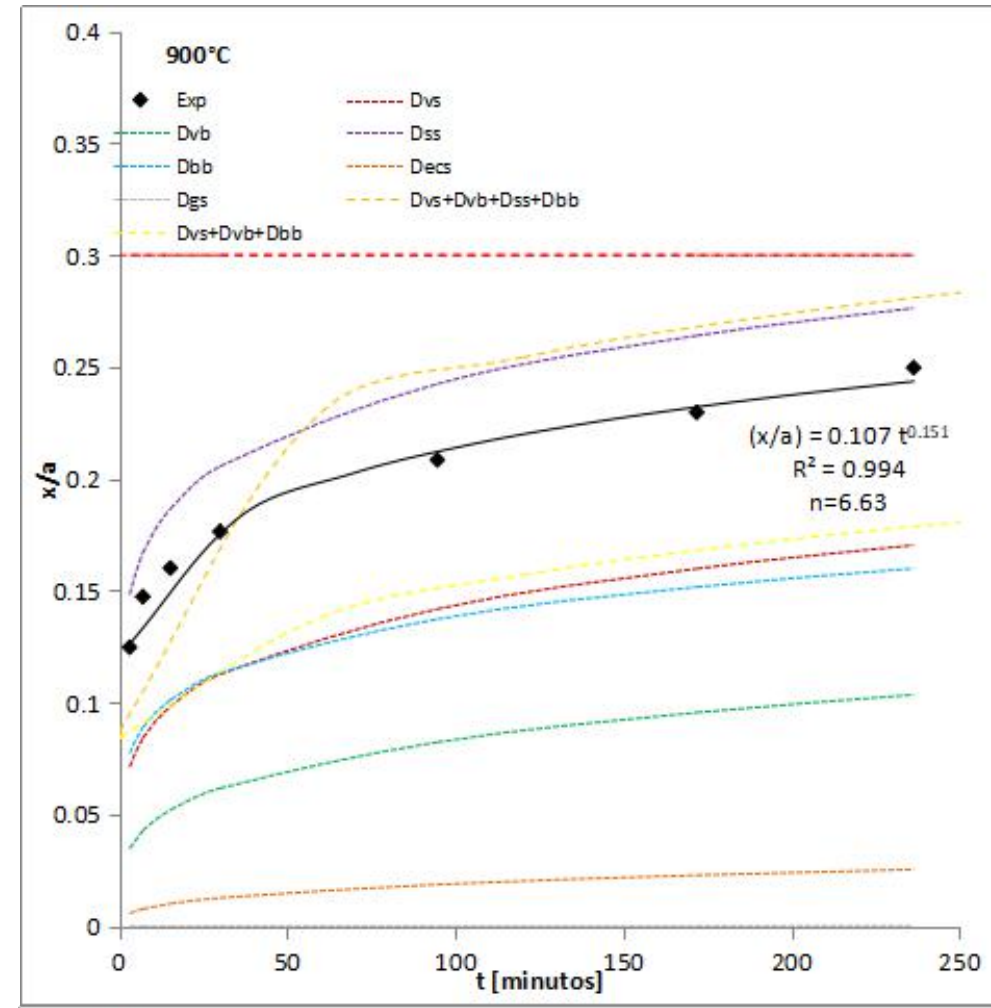

(b)

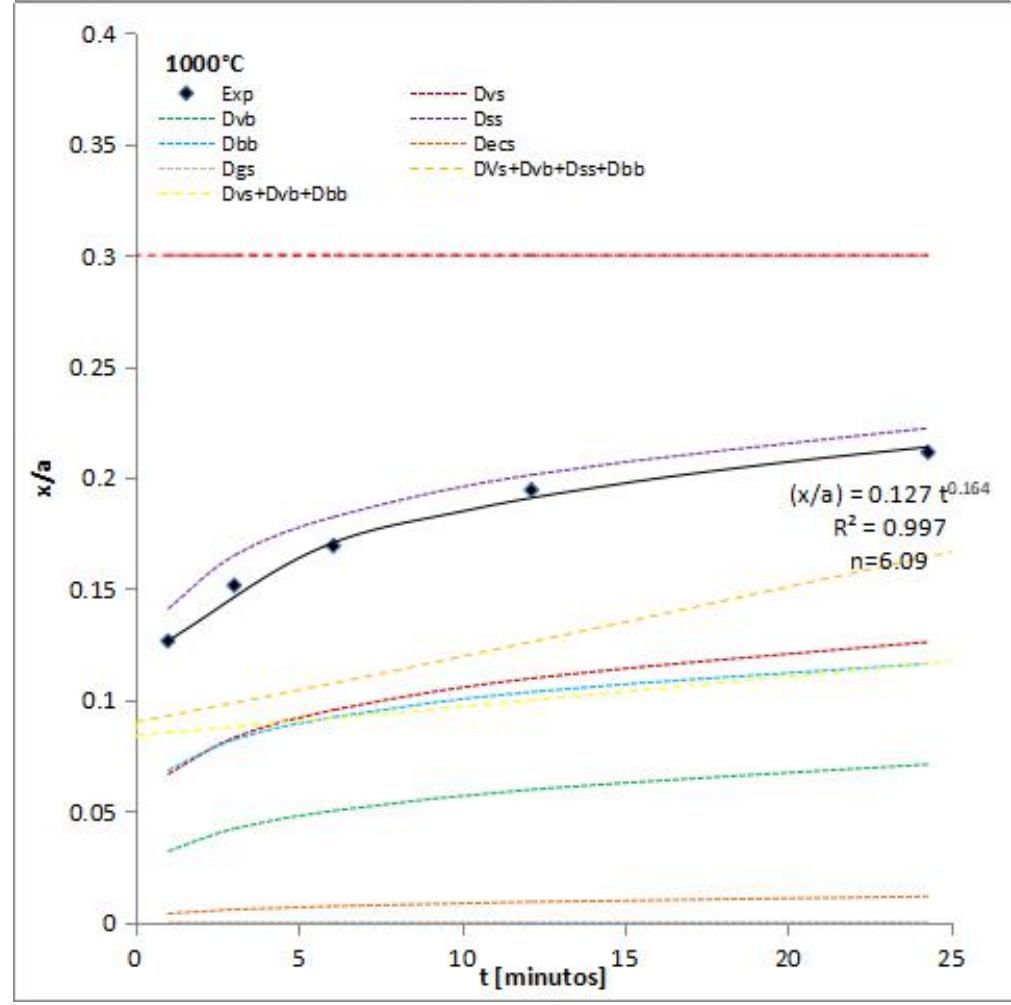


(c)

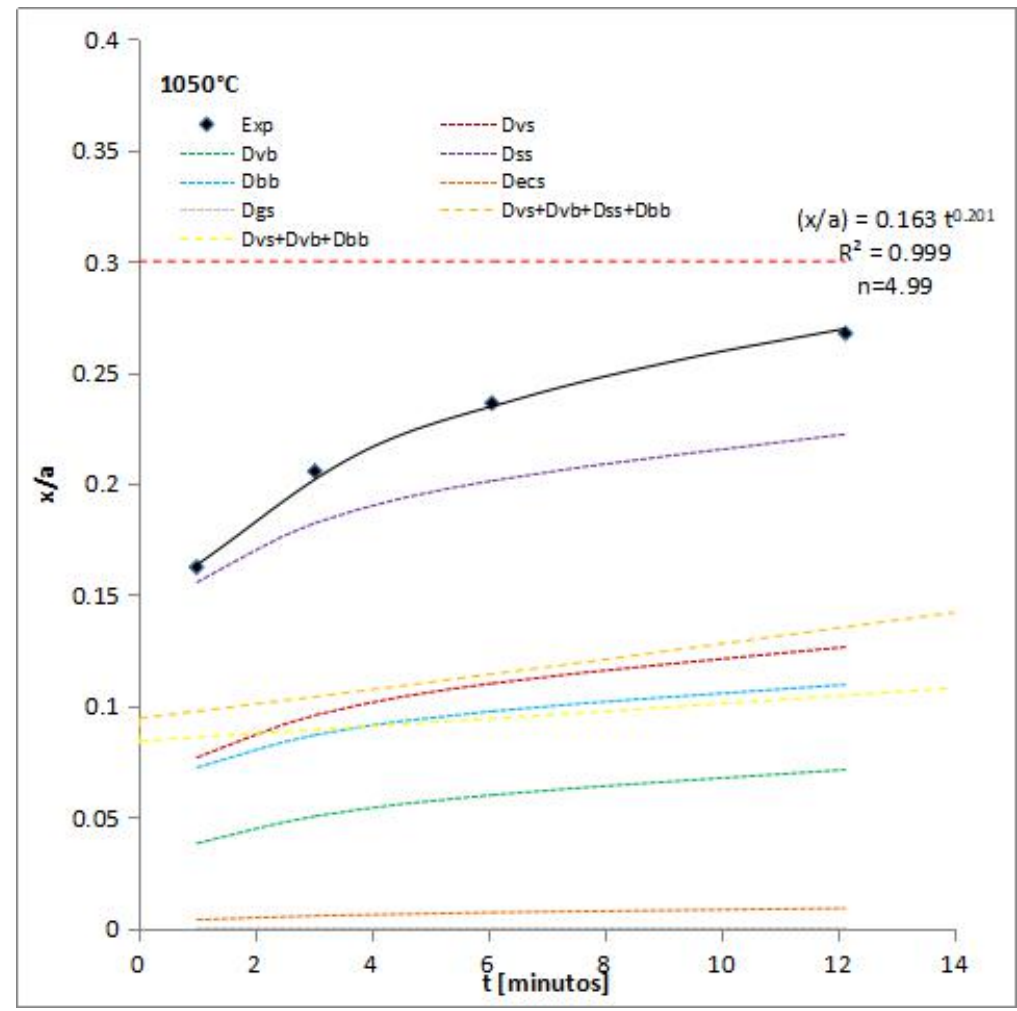

Figura 37: Gráficos comparativos entre $\left(\frac{x}{a}\right)$ vs tempo[minutos] em escala linear baseado no artigo de Kingery e Berg [KINGERY, BERG, 1955] nas temperaturas (a) $950^{\circ} \mathrm{C}$, (b) $1000^{\circ} \mathrm{C}$ e (c) $1050^{\circ} \mathrm{C}$.

A partir dos gráficos da Figura 36 e da Figura 37, pode-se calcular o expoente do tempo com a regressão linear dos pontos experimentais. Exceto para temperatura de $1050{ }^{\circ} \mathrm{C}$, nas temperaturas de 900 e $1000{ }^{\circ} \mathrm{C}$ os expoentes do tempo foram muito maiores do que aqueles encontrados pelos autores. Muito provavelmente isto deve-se as incertezas decorrentes das aproximações e arredondamentos no modo de obtenção dos dados experimentais a partir dos gráficos, uma vez que os autores não disponibilizaram os mesmos em Tabelas.

Os valores obtidos indicam que tanto para $900{ }^{\circ} \mathrm{C}$ quanto para $1000{ }^{\circ} \mathrm{C}$, os possíveis mecanismos são: difusão pelo contorno de grão $(n=7)$ e difusão superficial $(n=6)$, respectivamente.

Ashby [ASHBY, 1974] também analisou os resultados publicados por Kingery e Berg nos diagramas de sinterização por ele proposto. Ele concluiu que o mecanismo dominante para estes resultados é a difusão superficial com significativa contribuição da difusão volumétrica, a qual é responsável pela densificação das esferas.

Como as conclusões de Kingery e Berg pautaram-se exclusivamente no expoente do tempo, Ashby explica que este método apresenta baixa precisão devido a duas razões principais: 
1. A taxa de sinterização é raramente determinada por um único mecanismo, este é geralmente dado pela soma de diversas contribuições, cuja magnitude e importância variam ao longo do processo; ou seja, há alternância entre o(s) mecanismo(s) dominante(s) ao longo da sinterização;

2. Como as equações gerais dos mecanismos de sinterização foram deduzidas a partir de geometrias com baixa complexidade, contendo diversas aproximações e simplificações, estas não conseguem representar fidedignamente a grandiosidade desse processo. Assim, a representação dos mecanismos não deveria ser dada apenas por um número inteiro, mas por uma faixa de valores.

Ashby ainda ressalva que a teoria subestima o crescimento do pescoço em altas temperaturas, principalmente para aquelas próximas a temperatura de fusão. Ele sugere que a difusão superficial não é caracterizada apenas por uma única energia de ativação, porque próximo a temperatura de fusão sua taxa é maior do que o valor esperado pela extrapolação a baixas temperaturas [ASHBY, 1974].

Na Figura 38 estão apresentadas as análises para os dados de contração.

(a)

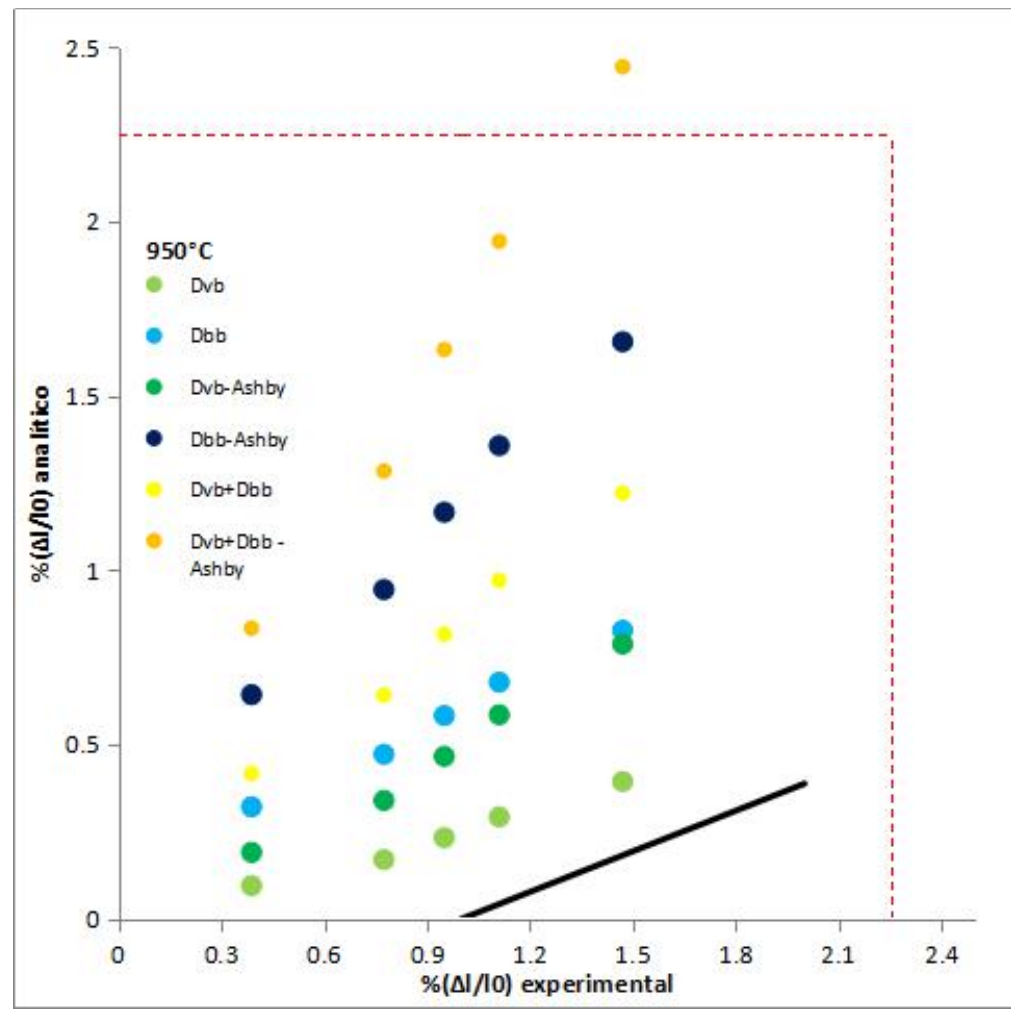


(b)

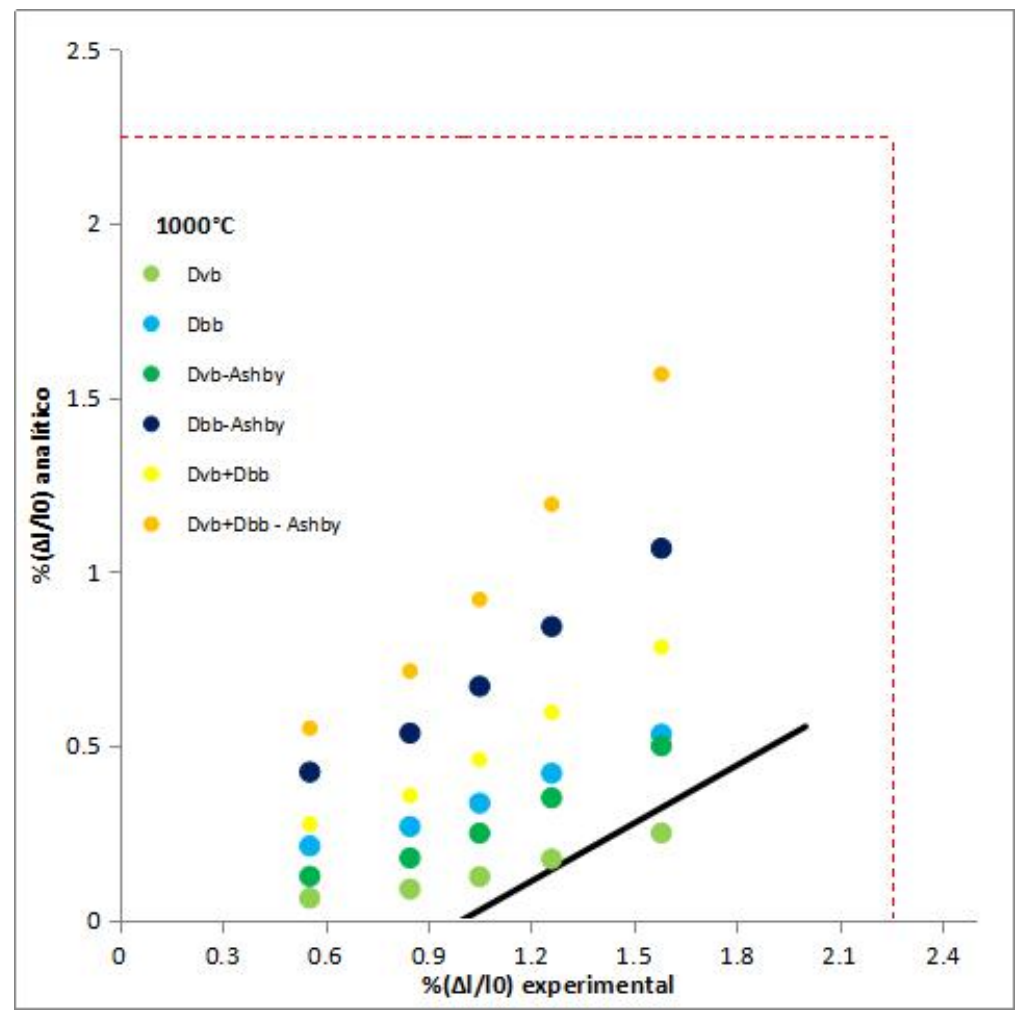

Figura 38: Gráficos entre $\frac{\Delta L}{L_{0}}$ experimental por $\frac{\Delta L}{L_{0}}$ analítico para as temperaturas de (a) $950^{\circ} \mathrm{C}$ e (b) $1000^{\circ} \mathrm{C}$, dados obtidos do artigo de Kingery e Berg [KINGERY, BERG, 1955]

Para a contração, Kingery e Berg analizaram apenas as temperaturas de 950 e $1000{ }^{\circ} \mathrm{C}$. Observa-se pelos gráficos da Figura 38 que a $950{ }^{\circ} \mathrm{C}$, o modelo combinado entre difusão volumétrica a partir do contorno de grão e a difusão pelo contorno de grão, assim como a difusão pelo contorno de grão usando o modelo de Ashby (no qual ele sugere usar o mesmo valor de raio do pescoço do modelo sem contração para o modelo com contração, ou seja, ao invés de usar $\rho=\frac{x^{2}}{4 a}$, ele adota $\rho=\frac{x^{2}}{2 a}$ ) [ASHBY, 1974], são os que mais se aproximam da reta de $45^{\circ}$. Enquanto que a $1000^{\circ} \mathrm{C}$ apenas o mecanismo combinado utilizando a teoria de Ashby melhor reproduz os valores obtidos experimentalmente.

Na Tabela 14 encontra-se a análise estatística realizada para esses dois cenários. 
Tabela 14: Análise estatística para os dados referentes a contração entre as razões $\left(\frac{\Delta L}{L_{0}}\right)$ calculado vs $\left(\frac{\Delta L}{L_{0}}\right)$ experimental.

\begin{tabular}{|c|c|c|c|c|c|c|}
\hline \multicolumn{2}{|c|}{$\begin{array}{c}\text { Temperatura/ Mecanismo de } \\
\text { Sinterização }\end{array}$} & \multirow{2}{*}{$\begin{array}{c}\text { Erro } \\
\text { Relativo (\%) } \\
75.14\end{array}$} & \multirow{2}{*}{$\begin{array}{c}\text { Erro } \\
0.0070\end{array}$} & \multirow{2}{*}{$\begin{array}{c}\text { SD } \\
0.0029\end{array}$} & \multirow{2}{*}{$\begin{array}{c}\text { CI } \\
\pm 0.0045\end{array}$} & \multirow[t]{2}{*}{$\mathbf{N}$} \\
\hline \multirow{6}{*}{$950^{\circ} \mathrm{C}$} & Dvb & & & & & \\
\hline & Dbb & 50.27 & 0.0046 & 0.0018 & \pm 0.0027 & \multirow{5}{*}{5} \\
\hline & Dvb - Ashby & 35.45 & 0.0036 & 0.0021 & \pm 0.0033 & \\
\hline & Dbb - Ashby & 29.10 & -0.0022 & 0.00037 & \pm 0.00058 & \\
\hline & $\mathrm{Dvb}+\mathrm{Dbb}$ & 13.58 & 0.0012 & 0.00099 & \pm 0.0015 & \\
\hline & Dvb+Dbb - Ashby & 78.83 & -0.0069 & 0.0022 & \pm 0.0034 & \\
\hline \multirow{6}{*}{$1000^{\circ} \mathrm{C}$} & Dvb & 87.31 & 0.0092 & 0.0032 & \pm 0.0050 & \multirow{6}{*}{5} \\
\hline & Dbb & 74.62 & 0.0078 & 0.0025 & \pm 0.0038 & \\
\hline & Dvb - Ashby & 66.18 & 0.0070 & 0.0027 & \pm 0.0041 & \\
\hline & Dbb - Ashby & 32.36 & 0.0035 & 0.0014 & \pm 0.0022 & \\
\hline & $\mathrm{Dvb}+\mathrm{Dbb}$ & 53.49 & 0.0056 & 0.0019 & \pm 0.0030 & \\
\hline & Dvb+Dbb - Ashby & 6.98 & 0.00069 & 0.00061 & \pm 0.00096 & \\
\hline
\end{tabular}

Estatisticamente, com 5\% de significância, o mecanismo combinado $\left(\mathrm{D}_{\mathrm{vb}}+\mathrm{D}_{\mathrm{bb}}\right)$ é o dominante nas duas temperaturas $\left(950\right.$ e $\left.1000^{\circ} \mathrm{C}\right)$, a diferença está que em $1000^{\circ} \mathrm{C}$ utilizou-se a teoria de Ashby para este cálculo.

Johnson [JOHNSON, 1969] também analisou os dados de Kingery e Berg a partir de um modelo combinado desenvolvido por ele para sistemas que apresentassem contração. Sua conclusão foi que um único mecanismo não atua sozinho durante a contração, há contudo uma simultaneidade entre os mesmos. Assim, em 950 e $1000^{\circ} \mathrm{C}$, o modelo combinado, dado pelos mecanismos de difusão volumétrica a partir do contorno de grão e difusão pelo contorno de grão, representou satisfatoriamente os dados experimentais e foi considerado o mecanismo dominante.

Na Figura 39 e na Figura 40 estão representadas as curvas em escalas logarítmica e linear entre a razão $\left(\frac{\Delta L}{L_{0}}\right)$ pelo tempo. 
(a)

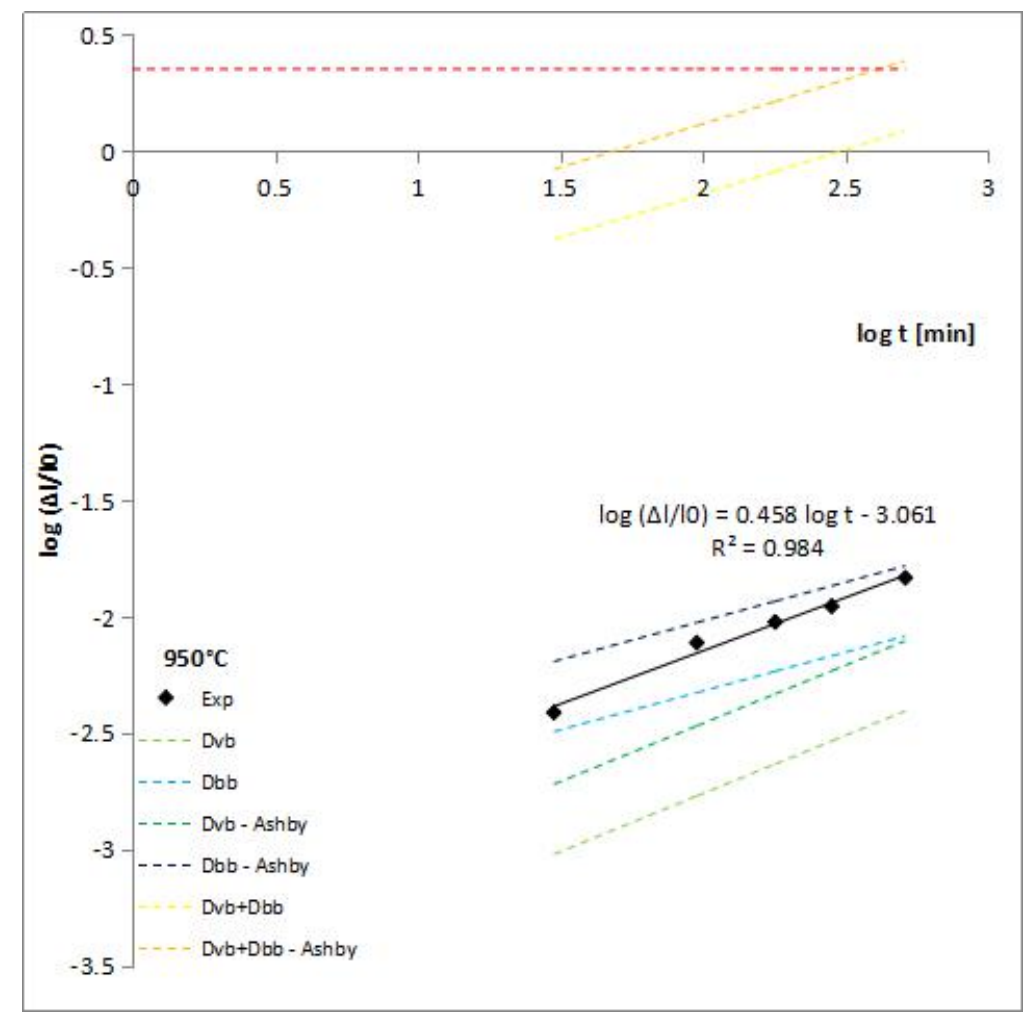

(b)

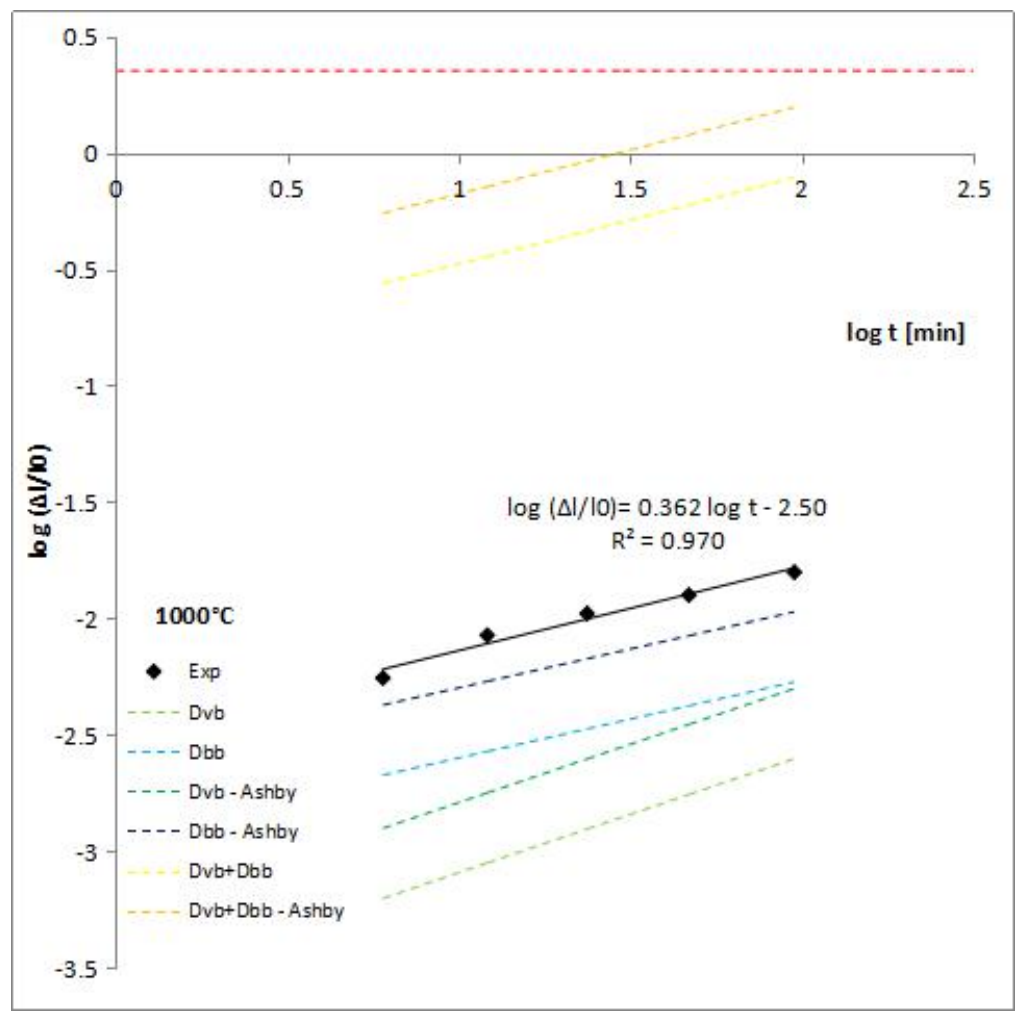

Figura 39: Gráficos para as temperaturas de (a) $950^{\circ} \mathrm{C} \mathrm{e} \mathrm{(b)} 1000^{\circ} \mathrm{C}$ entre $\log \left(\frac{\Delta L}{L_{0}}\right)$ pelo $\log \mathrm{t}[\mathrm{min}]$ para as temperaturas de 950 e $1000^{\circ} \mathrm{C}$ baseado nos dados de Kingery e Berg [KINGERY, BERG, 1955] 
(a)

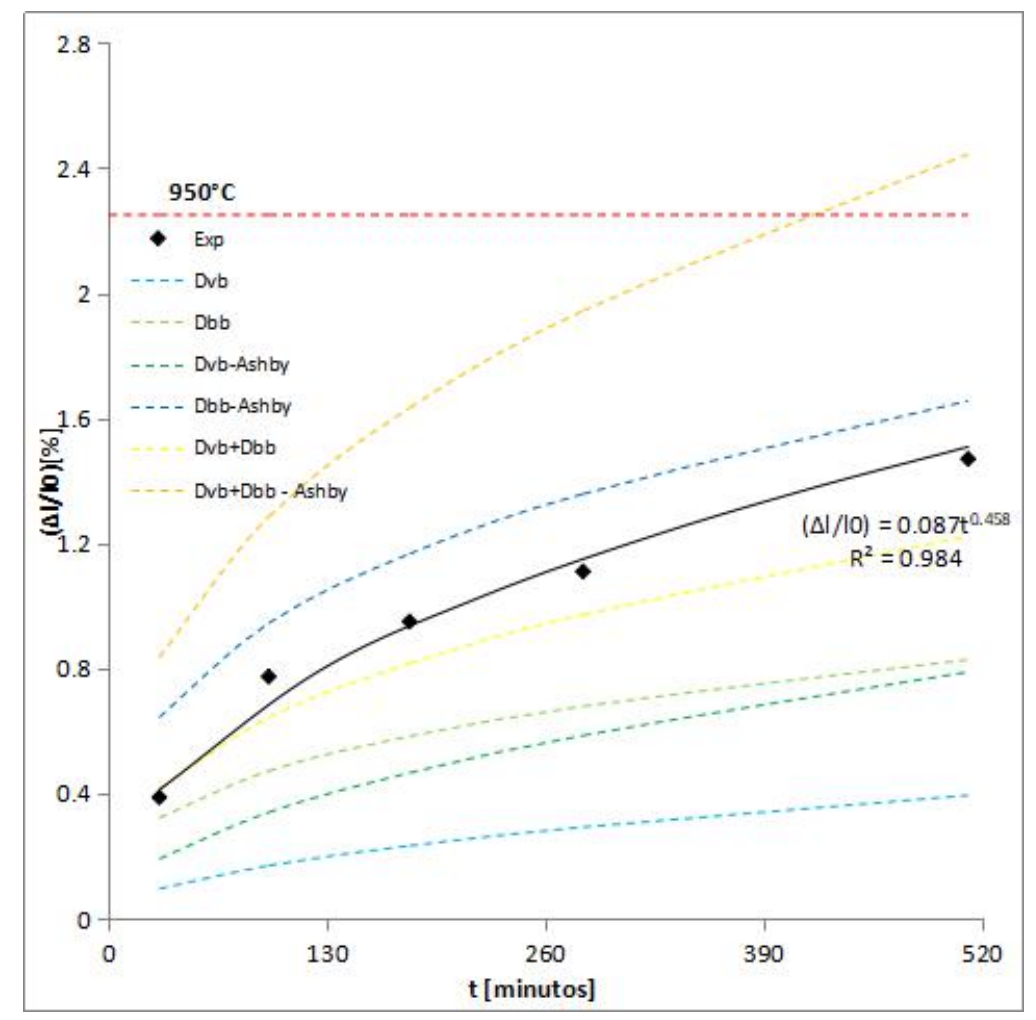

(b)

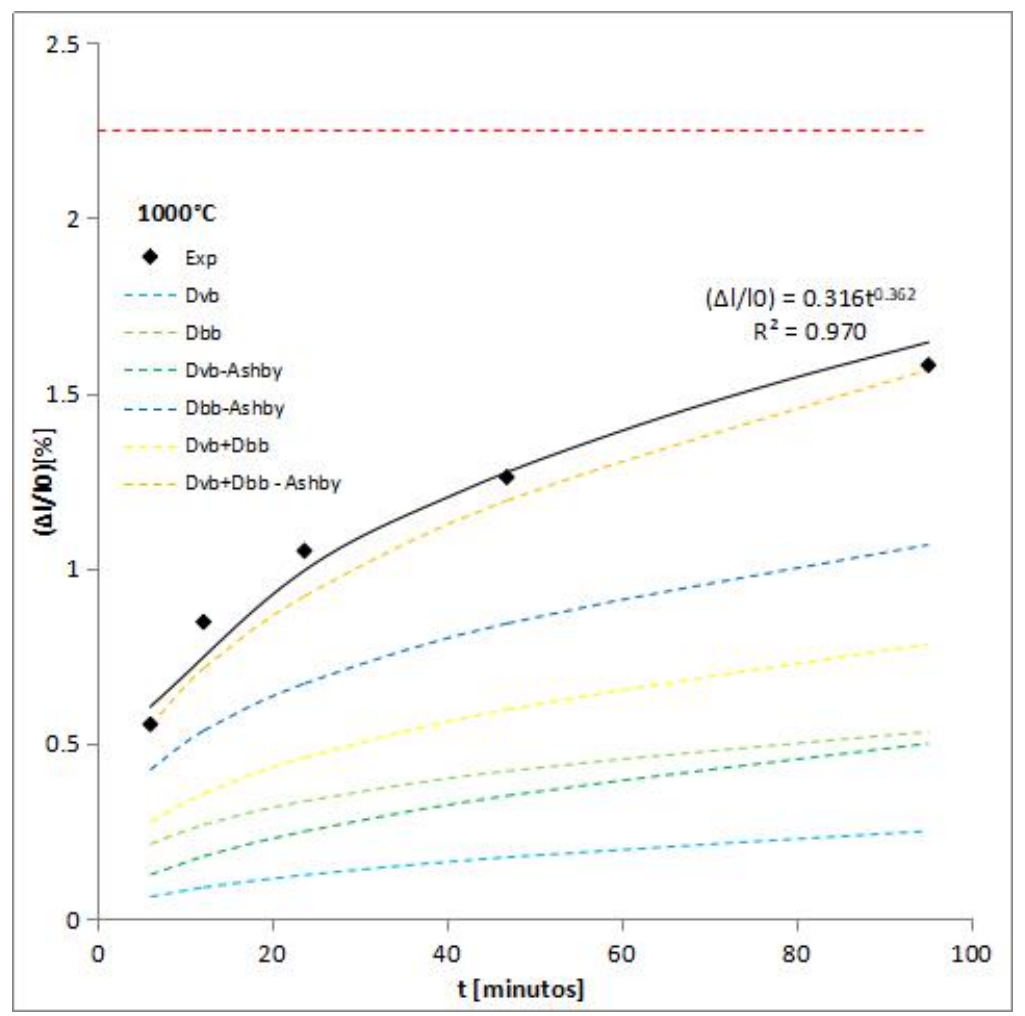

Figura 40: Gráficos para as temperaturas de (a) $950^{\circ} \mathrm{C}$ e (b) $1000^{\circ} \mathrm{C}$ entre $\left(\frac{\Delta L}{L_{0}}\right)$ pelo tempo [min] para as temperaturas de 950 e $1000^{\circ} \mathrm{C}$ baseado nos dados de Kingery e Berg [KINGERY, BERG, 1955]

Analisando apenas o coeficiente do tempo, temos que para $950{ }^{\circ} \mathrm{C}, \mathrm{n}=2.18$, e para 1000 ${ }^{\circ} \mathrm{C}, \mathrm{n}=2.76$. Os coeficientes estariam na faixa entre 2 e 3 correspondentes aos mecanismos de 
difusão volumétrica a partir do contorno de grão e difusão pelo contorno de grão, respectivamente.

c) Experimento de Alexander e Balluffi para o cobre

O artigo de Alexander e Balluffi [ALEXANDER, BALLUFFI, 1957] foi o primeiro a estudar a sinterização em cilindros de cobre e avaliar os resultados de modo a determinar o mecanismo atuante para quatro temperaturas de sinterização $\left(900,1000,1050\right.$ e $\left.1075^{\circ} \mathrm{C}\right)$.

Na Figura 41 estão os gráficos referentes à análise da formação do pescoço entre $\frac{x}{a}$ experimental e $\frac{x}{a}$ analítico. A região delimitada pelas linhas em vermelho indica a área correspondente ao estágio inicial da sinterização.

(a)

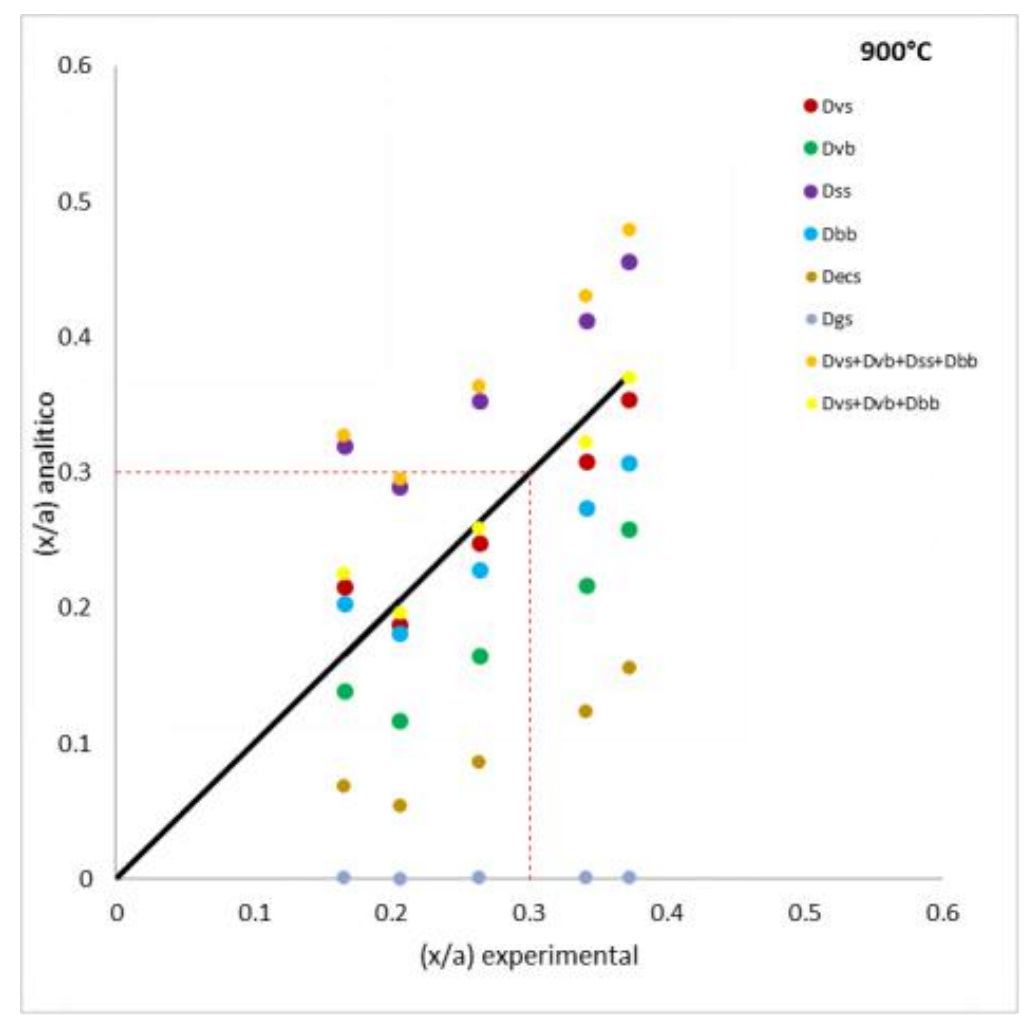


(b)

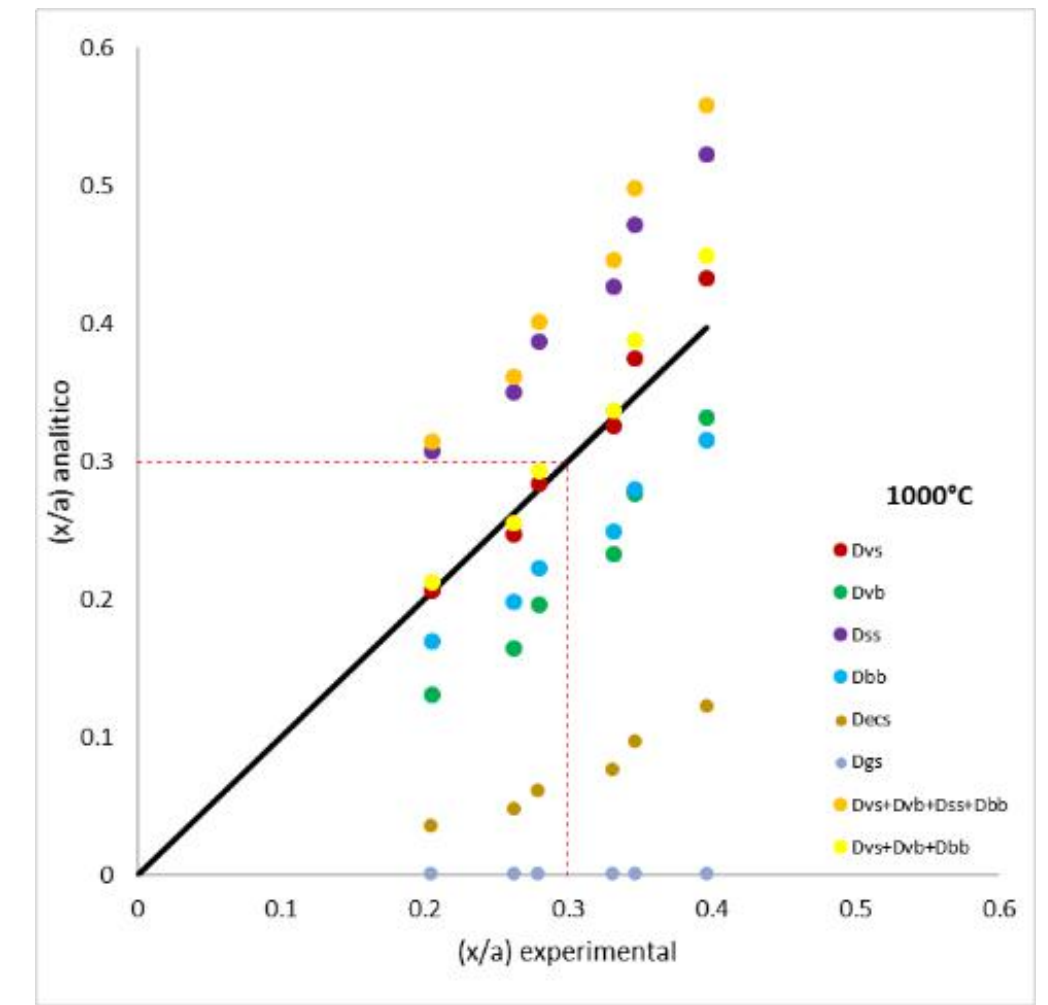

(c)

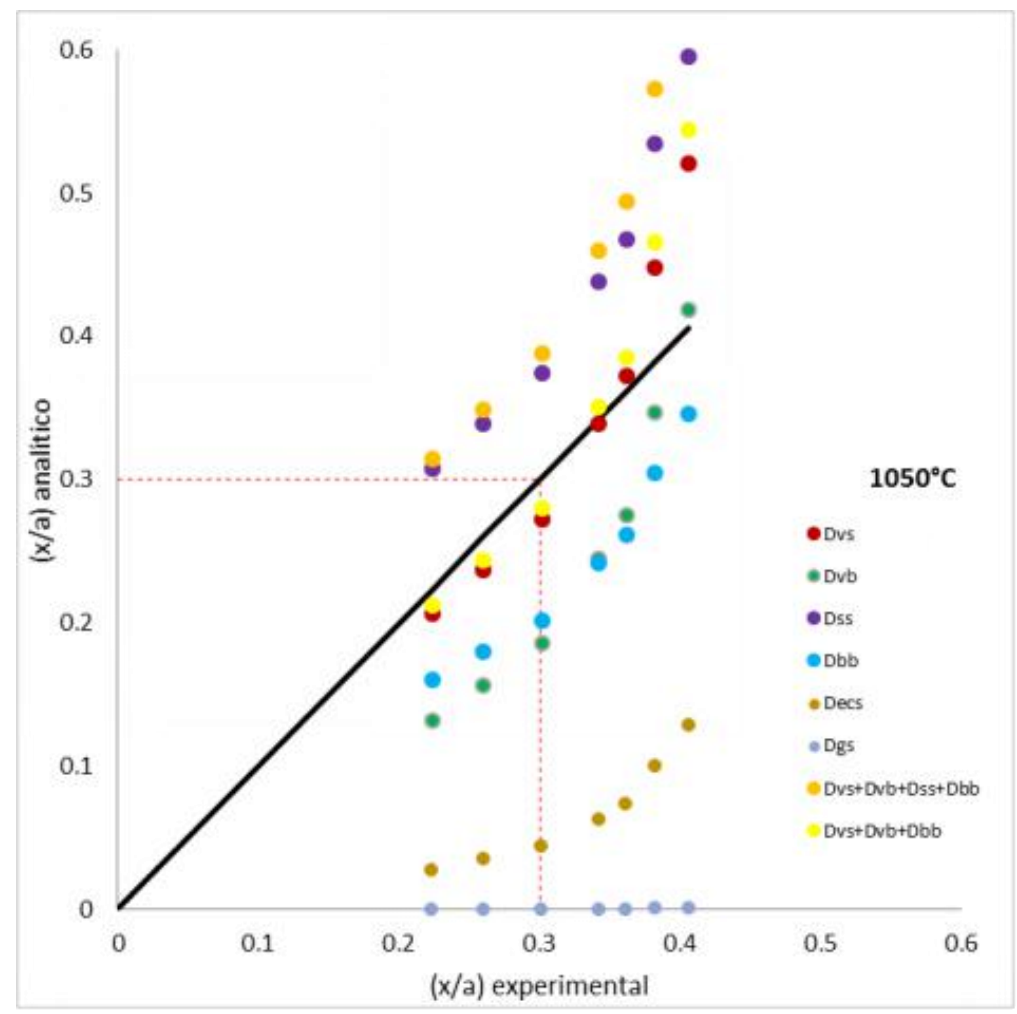


(d)

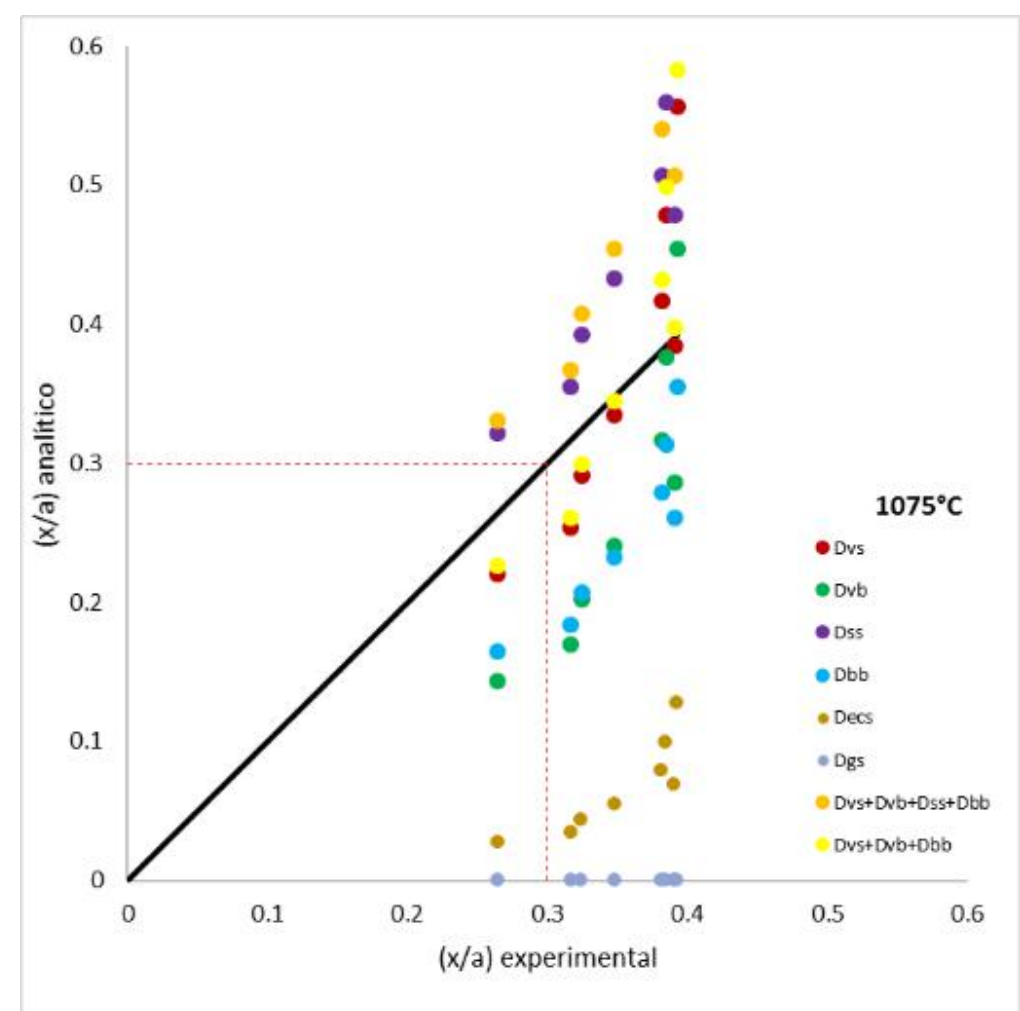

Figura 41: Gráficos comparativos entre (x/a) experimental e (x/a) analítico para as temperaturas de (a) $900^{\circ} \mathrm{C}$, (b) $1000^{\circ} \mathrm{C}$, (c) $1050^{\circ} \mathrm{C}$ e (d) $1075^{\circ} \mathrm{C}$ com os dados extraídos do artigo de Alexander e Balluffi para o cobre [ALEXANDER, BALLUFFI, 1957]. ( $D_{v s-}$ difusão volumétrica a partir da superfície; $D_{v b-}$ difusão volumétrica a partir do contorno de grão; $\mathrm{D}_{\mathrm{ss}}$ - difusão superficial a partir da superfície; $\mathrm{D}_{\mathrm{bb}}$ - difusão do contorno de grão a partir do contorno de grão; $D_{\text {ecs- }}$ difusão gasosa via evaporação-condensação a partir da superfície; e $\mathrm{D}_{\mathrm{gs}}$ - difusão gasosa a partir da superfície).

Observa-se inicialmente que quanto maior a temperatura, menor a quantidade de pontos dentro da região correspondente ao estágio inicial, isso se deve a elevada energia fornecida ao sistema, acelerando o processo de sinterização. Para conseguir mais pontos dentro desta região em elevadas temperaturas é preciso reduzir o tempo das medições e coleta de dados. A linha diagonal preta é uma referência que norteia quando os dados analíticos e os dados experimentais são equivalentes. Exceto para a temperatura de $1075{ }^{\circ} \mathrm{C}$, que contém apenas um ponto dentro do limite do estágio inicial impossibilitando, assim, qualquer conclusão plausível do mecanismo dominante, nas demais temperaturas pode-se analisar com maior precisão a atuação dos mecanismos de sinterização.

A $900{ }^{\circ} \mathrm{C}$, o mecanismo combinado entre difusão volumétrica a partir da superfície, difusão volumétrica a partir do contorno de grão e difusão pelo contorno de grão, é o que mais se aproxima da reta diagonal que corresponde à equivalência entre os dados analíticos e os experimentais. Caso o mecanismo combinado fosse excluído, o mecanismo da difusão volumétrica a partir da superfície é o que melhor representa o comportamento do cobre durante a sinterização principalmente no estágio inicial de crescimento do pescoço. Um 
terceiro mecanismo que também se aproxima dos valores experimentais é a difusão pelo contorno de grão.

A $1000{ }^{\circ} \mathrm{C}$, tanto o mecanismo combinado entre difusão volumétrica a partir da superfície, difusão volumétrica a partir do contorno de grão e difusão pelo contorno de grão, quanto o mecanismo da difusão volumétrica a partir da superfície conseguem reproduzir satisfatoriamente o comportamento experimental dos fios de cobre, principalmente dentro da região do estágio inicial.

$\mathrm{Na}$ temperatura de $1050{ }^{\circ} \mathrm{C}$ não há uma aderência à reta diagonal tão boa quanto nas temperaturas anteriores dentro da região que limita o estágio inicial da sinterização, porém fora desta região observa melhor precisão entre os valores do mecanismo combinado $\left(\mathrm{D}_{\mathrm{vs}}, \mathrm{D}_{\mathrm{vb}}\right.$ e $\left.D_{b b}\right)$ e da difusão volumétrica a partir da superfície $\left(D_{v s}\right)$.

A seguir estão as Tabelas com as análises estatísticas referentes aos dados apresentados nos gráficos da Figura 41. Foram feitas análise com todos os pontos (Tabela 15) e somente com aqueles contidos na região delimitada pelo estágio 1 (Tabela 16).

Tabela 15: Análise estatística com todos os dados do artigo de Alexander e Balluffi [ALEXANDER, BALLUFFI, 1957]. (SD - desvio padrão; CI - intervalo de erro crítico; N - número de pontos avaliados)

\begin{tabular}{|c|c|c|c|c|c|c|}
\hline Temper & $\begin{array}{l}\text { ra/ Mecanismo de } \\
\text { terização }\end{array}$ & $\begin{array}{c}\text { Erro } \\
\text { Relativo (\%) }\end{array}$ & Erro & SD & CI & $\mathbf{N}$ \\
\hline \multirow{8}{*}{$900^{\circ} \mathrm{C}$} & Dvs & 12.09 & 0.0078 & 0.0327 & \pm 0.0512 & \multirow{8}{*}{5} \\
\hline & Dvb & 32.95 & 0.0911 & 0.0382 & \pm 0.0598 & \\
\hline & Dss & 41.79 & -0.0955 & 0.0330 & \pm 0.0516 & \\
\hline & Dbb & 17.22 & 0.0316 & 0.0427 & \pm 0.0667 & \\
\hline & Decs & 64.52 & 0.1727 & 0.0503 & \pm 0.0786 & \\
\hline & Dgs & 99.87 & 0.2697 & 0.0874 & \pm 0.1367 & \\
\hline & $\mathrm{Dvs}+\mathrm{Dvb}+\mathrm{Dss}+\mathrm{Dbb}$ & 46.48 & -0.1087 & 0.0304 & \pm 0.0476 & \\
\hline & $\mathrm{Dvs}+\mathrm{Dvb}+\mathrm{Dbb}$ & 9.86 & -0.0044 & 0.0315 & \pm 0.0493 & \\
\hline \multirow{8}{*}{$1000^{\circ} \mathrm{C}$} & Dvs & 4.39 & -0.0079 & 0.0196 & \pm 0.0253 & \multirow{8}{*}{6} \\
\hline & Dvb & 28.24 & 0.0814 & 0.0142 & \pm 0.0184 & \\
\hline & Dss & 36.36 & -0.1071 & 0.0153 & \pm 0.0197 & \\
\hline & Dbb & 21.16 & 0.0647 & 0.0175 & \pm 0.0226 & \\
\hline & Decs & 76.88 & 0.2306 & 0.0377 & \pm 0.0487 & \\
\hline & Dgs & 70.50 & 0.3034 & 0.0683 & \pm 0.0882 & \\
\hline & Dvs+Dvb+Dss+Dbb & 42.20 & -0.1261 & 0.0246 & \pm 0.0318 & \\
\hline & $\mathrm{Dvs}+\mathrm{Dvb}+\mathrm{Dbb}$ & 6.36 & -0.0187 & 0.0232 & \pm 0.0300 & \\
\hline \multirow{4}{*}{$1050^{\circ} \mathrm{C}$} & Dvs & 10.74 & -0.0169 & 0.0535 & \pm 0.0601 & \multirow{4}{*}{7} \\
\hline & Dvb & 26.28 & 0.0741 & 0.0456 & \pm 0.0512 & \\
\hline & Dss & 33.69 & -0.1113 & 0.0432 & \pm 0.0484 & \\
\hline & Dbb & 26.37 & 0.0831 & 0.0174 & \pm 0.0195 & \\
\hline
\end{tabular}




\begin{tabular}{|c|c|c|c|c|c|c|}
\hline & Decs & 80.45 & 0.2580 & 0.0347 & \pm 0.0389 & \\
\hline & Dgs & 99.92 & 0.3251 & 0.0665 & \pm 0.0746 & \\
\hline & Dvs+Dvb+Dss+Dbb & 40.57 & -0.1356 & 0.0598 & \pm 0.0671 & \\
\hline & Dvs+DvbDbb & 11.87 & -0.0290 & 0.0598 & \pm 0.0671 & \\
\hline \multirow{8}{*}{$1075^{\circ} \mathrm{C}$} & Dvs & 15.95 & -0.0171 & 0.0775 & \pm 0.0779 & \multirow{8}{*}{8} \\
\hline & Dvb & 27.74 & 0.0762 & 0.0705 & \pm 0.0709 & \\
\hline & Dss & 29.99 & -0.1089 & 0.0652 & \pm 0.0655 & \\
\hline & Dbb & 29.61 & 0.1006 & 0.0322 & \pm 0.0323 & \\
\hline & Decs & 81.64 & 0.2834 & 0.0253 & \pm 0.0254 & \\
\hline & Dgs & 99.92 & 0.3498 & 0.0459 & \pm 0.0461 & \\
\hline & Dvs+Dvb+Dss+Dbb & 37.65 & -0.1371 & 0.0834 & \pm 0.0838 & \\
\hline & Dvs+Dvb+Dbb & 16.71 & -0.0303 & 0.0843 & \pm 0.0847 & \\
\hline
\end{tabular}

A Tabela 15 retrata o mesmo resultado obtido pela análise gráfica referente aos possíveis mecanismos dominantes. Os mecanismos com maiores erros relativos são a difusão gasosa a partir da superfície $\left(\mathrm{D}_{\mathrm{gs}}\right)$, difusão gasosa via evaporação-condensação $\left(\mathrm{D}_{\mathrm{ecs}}\right)$, mecanismo combinado $\left(D_{\mathrm{ss}}+D_{\mathrm{vs}}+\mathrm{D}_{\mathrm{vb}}+\mathrm{D}_{\mathrm{bb}}\right)$ e a difusão superficial $\left(\mathrm{D}_{\mathrm{ss}}\right)$.

$\mathrm{O}$ erro relativo da difusão pelo contorno de grão $\left(\mathrm{D}_{\mathrm{bb}}\right)$ vai aumentando com a temperatura. A $900{ }^{\circ} \mathrm{C}$ era considerado um mecanismo estatisticamente possível, enquanto que a $1075{ }^{\circ} \mathrm{C}$, o valor do erro relativo para este mecanismo é aproximadamente $30 \%$, ultrapassando o erro relativo da difusão volumétrica a partir do contorno de grão $\left(\mathrm{D}_{\mathrm{vb}}\right)$.

Tabela 16: Análise estatística com os dados exclusivamente contidos na região delimitada pelo estágio inicial da sinterização [ALEXANDER, BALLUFFI, 1957]. (SD - desvio padrão; CI - intervalo de erro crítico; N -

\begin{tabular}{|c|c|c|c|c|c|c|}
\hline Temper & $\begin{array}{l}\text { ra/ Mecanismo de } \\
\text { terização }\end{array}$ & $\begin{array}{c}\text { Erro } \\
\text { Relativo (\%) }\end{array}$ & Erro & SD & CI & $\mathbf{N}$ \\
\hline \multirow{8}{*}{$900^{\circ} \mathrm{C}$} & Dvs & 15.17 & -0.0045 & 0.0390 & \pm 0.1396 & \multirow{8}{*}{3} \\
\hline & Dvb* & 32.49 & 0.0720 & 0.0392 & \pm 0.1406 & \\
\hline & Dss & - & - & - & - & \\
\hline & Dbb & 16.20 & 0.0082 & 0.0397 & \pm 0.1423 & \\
\hline & Decs* & 66.82 & 0.1428 & 0.0412 & \pm 0.1477 & \\
\hline & Dgs & 99.87 & 0.2117 & 0.0494 & \pm 0.1771 & \\
\hline & $\mathrm{Dvs}+\mathrm{Dvb}+\mathrm{Dss}+\mathrm{Dbb}$ & - & - & - & - & \\
\hline & $\mathrm{Dvs}+\mathrm{Dvb}+\mathrm{Dbb}$ & 14.28 & -0.0148 & 0.0389 & \pm 0.1395 & \\
\hline \multirow{7}{*}{$1000^{\circ} \mathrm{C}$} & Dvs & 2.62 & 0.0034 & 0.0105 & \pm 0.0376 & \multirow{7}{*}{3} \\
\hline & Dvb & 34.39 & 0.0851 & 0.0121 & \pm 0.0433 & \\
\hline & Dss & - & - & - & - & \\
\hline & Dbb** & 10.38 & 0.0524 & 0.0156 & \pm 0.0558 & \\
\hline & Decs & 80.92 & 0.2010 & 0.0275 & \pm 0.0987 & \\
\hline & Dgs & 99.91 & 0.2487 & 0.0393 & \pm 0.1406 & \\
\hline & Dvs+Dvb+Dss+Dbb & - & - & - & - & \\
\hline
\end{tabular}




\begin{tabular}{|c|c|c|c|c|c|c|}
\hline & Dvs+Dvb+Dbb & 3.74 & -0.0042 & 0.0108 & \pm 0.0388 & \\
\hline \multirow{8}{*}{$1050^{\circ} \mathrm{C}$} & Dvs & 8.70 & 0.0230 & 0.0061 & \pm 0.0218 & \multirow{8}{*}{3} \\
\hline & Dvb & 39.74 & 0.1036 & 0.0118 & \pm 0.0423 & \\
\hline & Dss & - & - & - & - & \\
\hline & Dbb & 30.84 & 0.0813 & 0.0183 & \pm 0.0655 & \\
\hline & Decs & 86.61 & 0.2264 & 0.0310 & \pm 0.1110 & \\
\hline & Dgs & 99.93 & 0.2615 & 0.0391 & \pm 0.1399 & \\
\hline & $\mathrm{Dvs}+\mathrm{Dvb}+\mathrm{Dss}+\mathrm{Dbb}$ & - & - & - & - & \\
\hline & $\mathrm{Dvs}+\mathrm{Dvb}+\mathrm{Dbb}$ & 6.18 & 0.0164 & 0.0048 & \pm 0.0174 & \\
\hline \multirow{8}{*}{$1075^{\circ} \mathrm{C}$} & Dvs & - & - & - & - & \multirow{8}{*}{1} \\
\hline & Dvb & - & - & - & - & \\
\hline & Dss & - & - & - & - & \\
\hline & Dbb & - & - & - & - & \\
\hline & Decs & - & - & - & - & \\
\hline & Dgs & - & - & - & - & \\
\hline & Dvs+Dvb+Dss+Dbb & - & - & - & - & \\
\hline & Dvs+Dvb+Dbb & - & - & - & - & \\
\hline
\end{tabular}

Quando se reduz a quantidade de pontos analisados, a variável associada a distribuição $t$ de Student $\left(t_{\frac{0.05}{2}, N-1}\right)$ aumenta e, consequentemente o intervalo crítico também. Com isso, alguns mecanismos que antes não eram rejeitados pelo teste estatístico podem vir a ser considerados possíveis mecanismos dominantes.

$\mathrm{Na}$ Tabela 16, os mecanismos com asterisco (*) indicam aqueles que foram aprovados pelo teste estatístico porém, a partir da análise gráfica e dos altos valores associados aos seus erros relativos (superiores a 30\%), estes mecanismos não devem ser efetivamente considerados possíveis. Enquanto que o mecanismo com duplo asterisco $(* *)$, apesar de apresentarem um erro relativo relativamente baixo (aproximadamente igual a 10\%), foram aprovados estatisticamente mas rejeitados pela análise gráfica. Em ambos os casos, a aprovação pela análise estatística deve-se a reduzida quantidade de valores analisados.

$\mathrm{Na}$ temperatura de $1000^{\circ} \mathrm{C}$, o mecanismo da difusão pelo contorno de grão apresenta-se como estatisticamente possível. Os valores do erro e do intervalo crítico para este mecanismo são muito próximos e, por isso, faz-se necessária a análise gráfica, a partir qual permite concluir que este não é um mecanismo que retrata satisfatoriamente os dados experimentais.

$\mathrm{Na}$ Tabela 16 foram utilizados três pontos para análise estatística na temperatura de $1050{ }^{\circ} \mathrm{C}$, porém, um desses pontos encontra-se no limite superior máximo entre os estágios inicial e intermediário. Com isso, uma nova estatística foi realizada utilizando-se apenas os dois pontos compreendidos dentro da região do estágio inicial (Tabela 17). 
Tabela 17: Análise estatística para os dois pontos delimitados pelo estágio inicial da sinterização na temperatura de $1050^{\circ} \mathrm{C}$ [ALEXANDER, BALLUFFI, 1957].

\begin{tabular}{|c|c|c|c|c|c|}
\hline \multicolumn{1}{|c|}{ de $1050^{\circ} \mathrm{C}$ [ALEXANDER, BALLUFFI, 1957]. } & \\
\hline Dvs & 8.22 & 0.0200 & 0.0043 & \pm 0.0766 & \\
\hline Dvb* & 40.47 & 0.0977 & 0.0084 & \pm 0.1504 & \\
\hline Dss & - & - & - & - & \\
\hline Dbb* & 27.80 & 0.0675 & 0.0117 & \pm 0.2112 & \\
\hline Decs* & 87.16 & 0.2107 & 0.0148 & \pm 0.2665 & \\
\hline Dgs* & 99.93 & 0.2416 & 0.0259 & \pm 0.4670 & \\
\hline Dvs+Dvb+Dss+Dbb & - & - & - & - \\
\hline Dvs+Dvb+Dbb & 5.75 & 0.0140 & 0.0049 & \pm 0.0098 & \\
\hline
\end{tabular}

Uma menor quantidade de pontos aumenta consideravelmente as possibilidades dos mecanismos analisados serem dominantes, isto porque a variável associada a distribuição de $t$ -

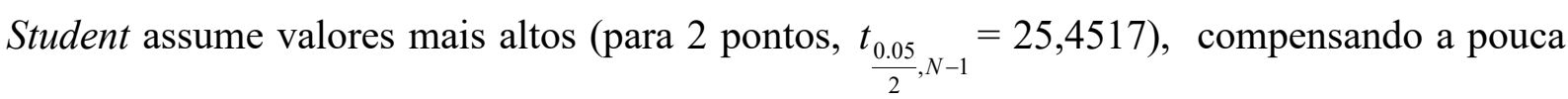
quantidade de pontos disponíveis para análise.

Enquanto que com três pontos analisados nenhum dos mecanismos foi considerado dominante com 5\% de significância, com dois pontos todos os mecanismos foram considerados possíveis. O mecanismo da difusão superficial e o mecanismo combinado $\left(\mathrm{D}_{\mathrm{ss}}+\right.$ $\mathrm{D}_{\mathrm{vb}}+\mathrm{D}_{\mathrm{vs}}+\mathrm{D}_{\mathrm{bb}}$ ) não foram analisados porque somente um ponto de cada estava contido dentro da região do estágio inicial.

É preciso analisar com cuidado este resultado, apesar de serem estatisticamente possíveis os mecanismos com asterisco $(*)$, a análise gráfica evidencia a diferença efetiva entre os pontos e a reta diagonal. Estes mecanismos apresentam valores de erro relativo superiores a $25 \%$. Assim, com apenas dois pontos contidos na região delimitada pelo estágio inicial da sinterização, não é possível afirmar qual o principal mecanismo da sinterização a $1050^{\circ} \mathrm{C}$.

Quanto aos modelos que apresentaram maiores erros, observa-se que o resultado para os pontos do estágio inicial é o mesmo daquele obtido com todos os pontos experimentais para todas as temperaturas, a difusão gasosa a partir da superfície $\left(\mathrm{D}_{\mathrm{gs}}\right)$ possui o maior erro, seguido pela difusão gasosa via evaporação-condensação a partir da superfície ( $\left.D_{\text {ecs}}\right)$.

A Figura 42 e a Figura 43 apresentam os gráficos entre a razão $\frac{x}{a}$ e o tempo nas escalas logarítmica e linear. 
(a)

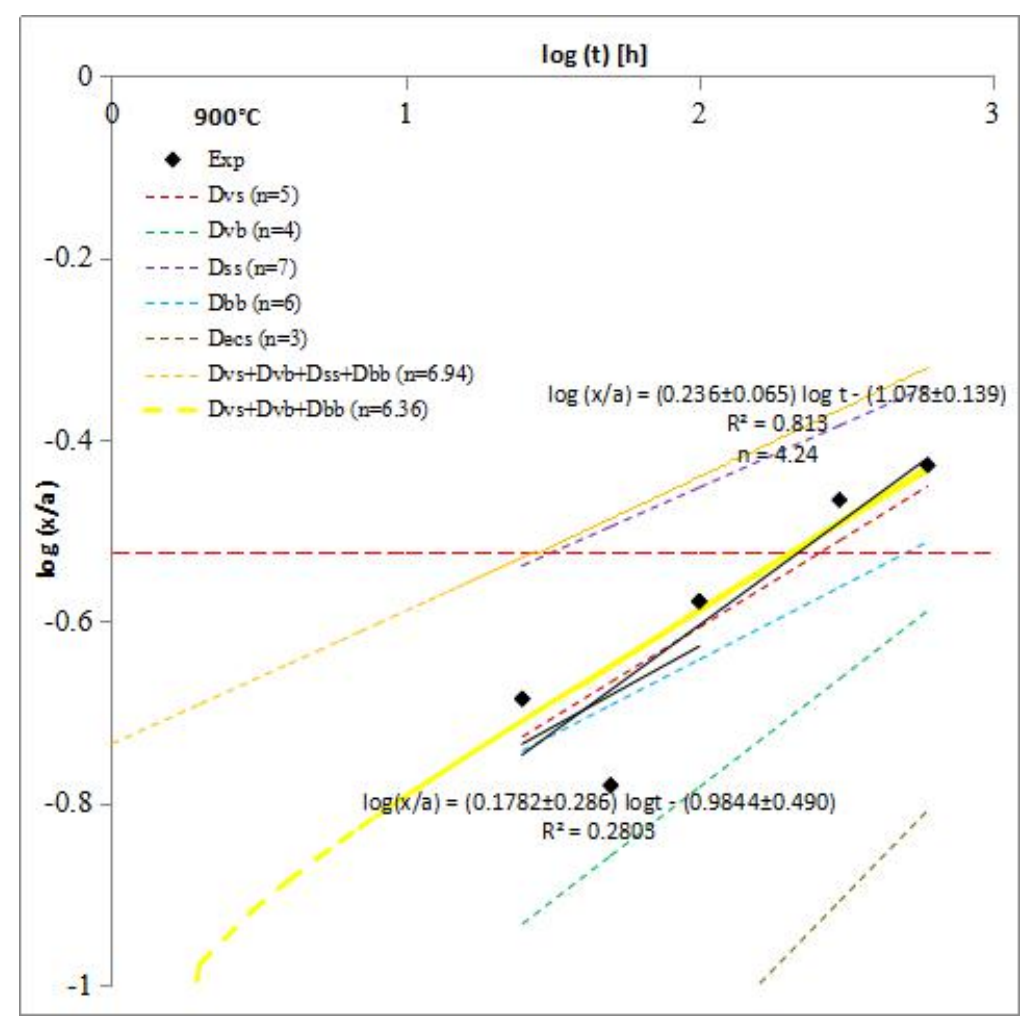

(b)

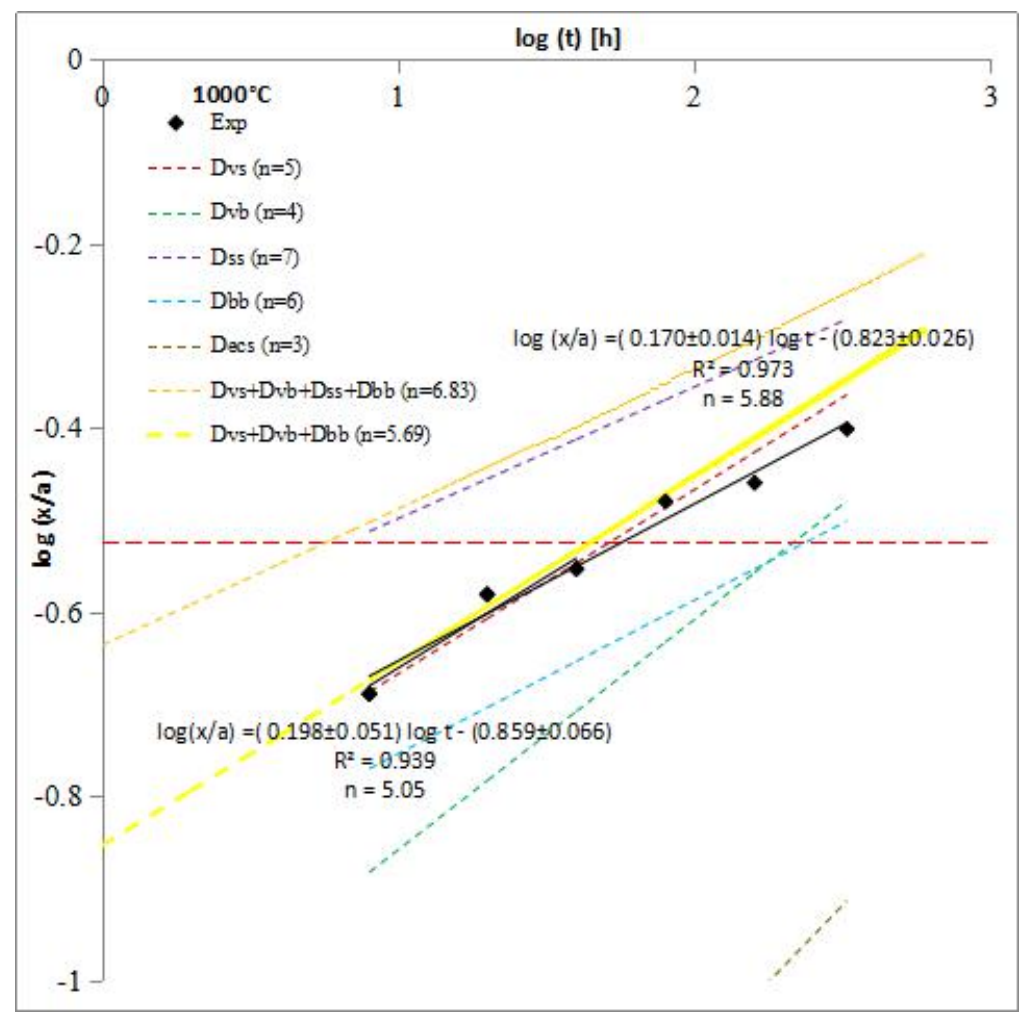


(c)

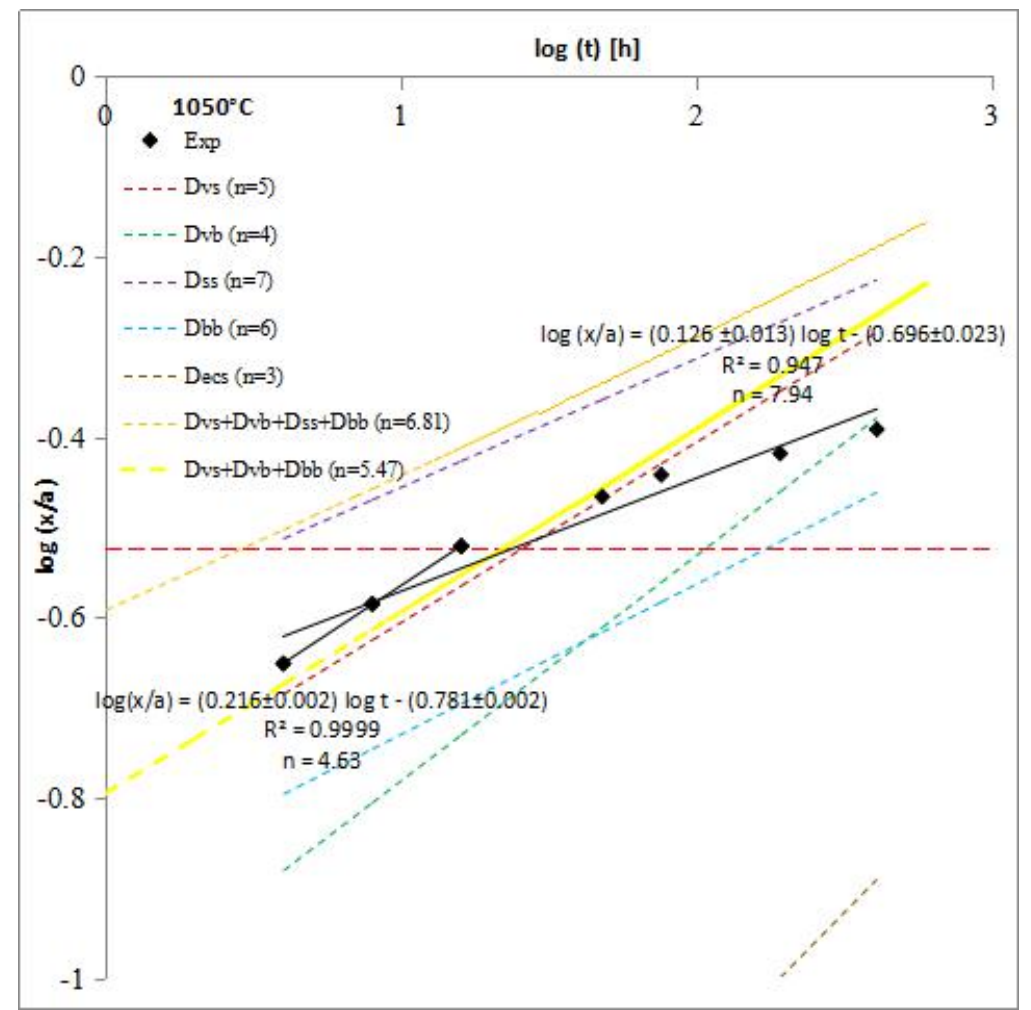

(d)
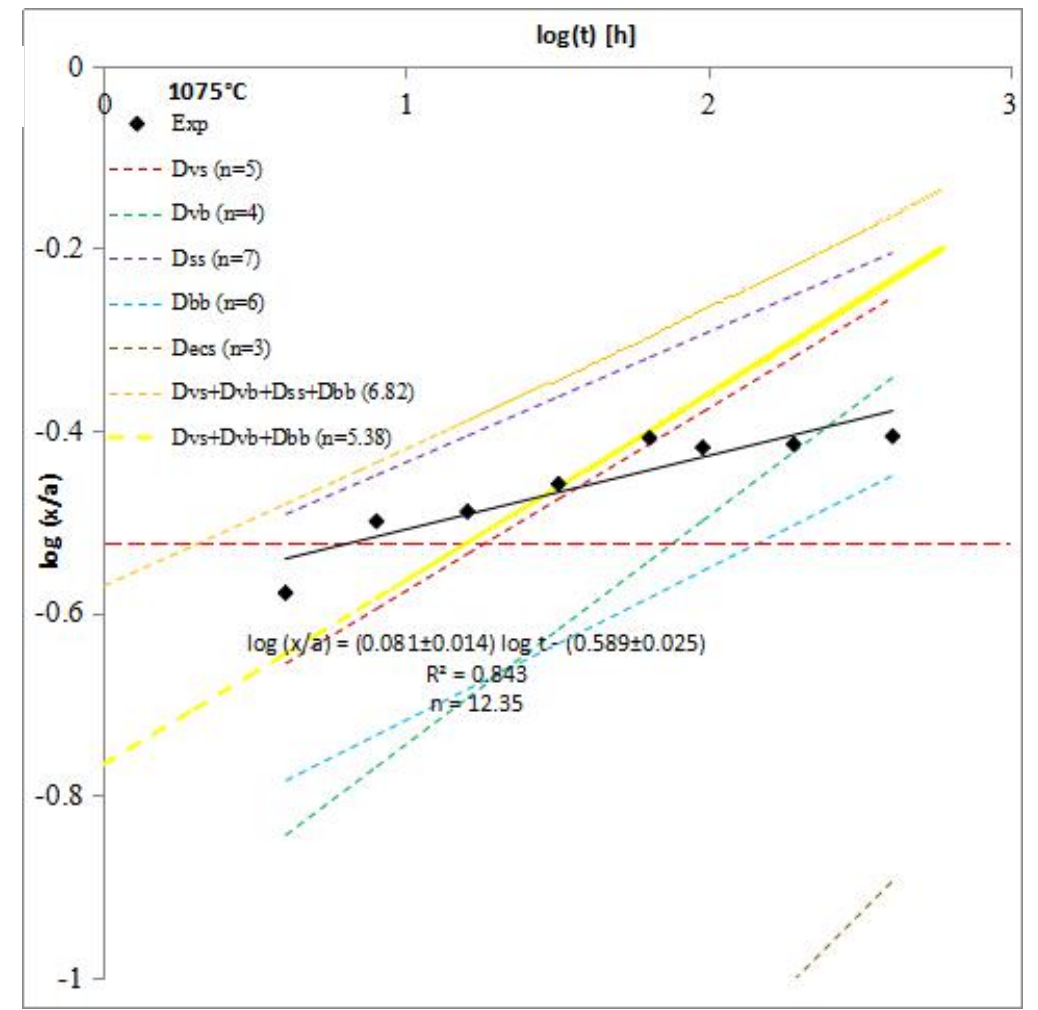

Figura 42: Gráficos de $\log (\mathrm{x} / \mathrm{a})$ vs $\log \mathrm{t}[\mathrm{h}]$ para as temperaturas de (a) $900^{\circ} \mathrm{C}$, (b) $1000^{\circ} \mathrm{C}$, (c) $1050^{\circ} \mathrm{C} \mathrm{e} \mathrm{(d)}$ $1075^{\circ} \mathrm{C}$. 
(a)

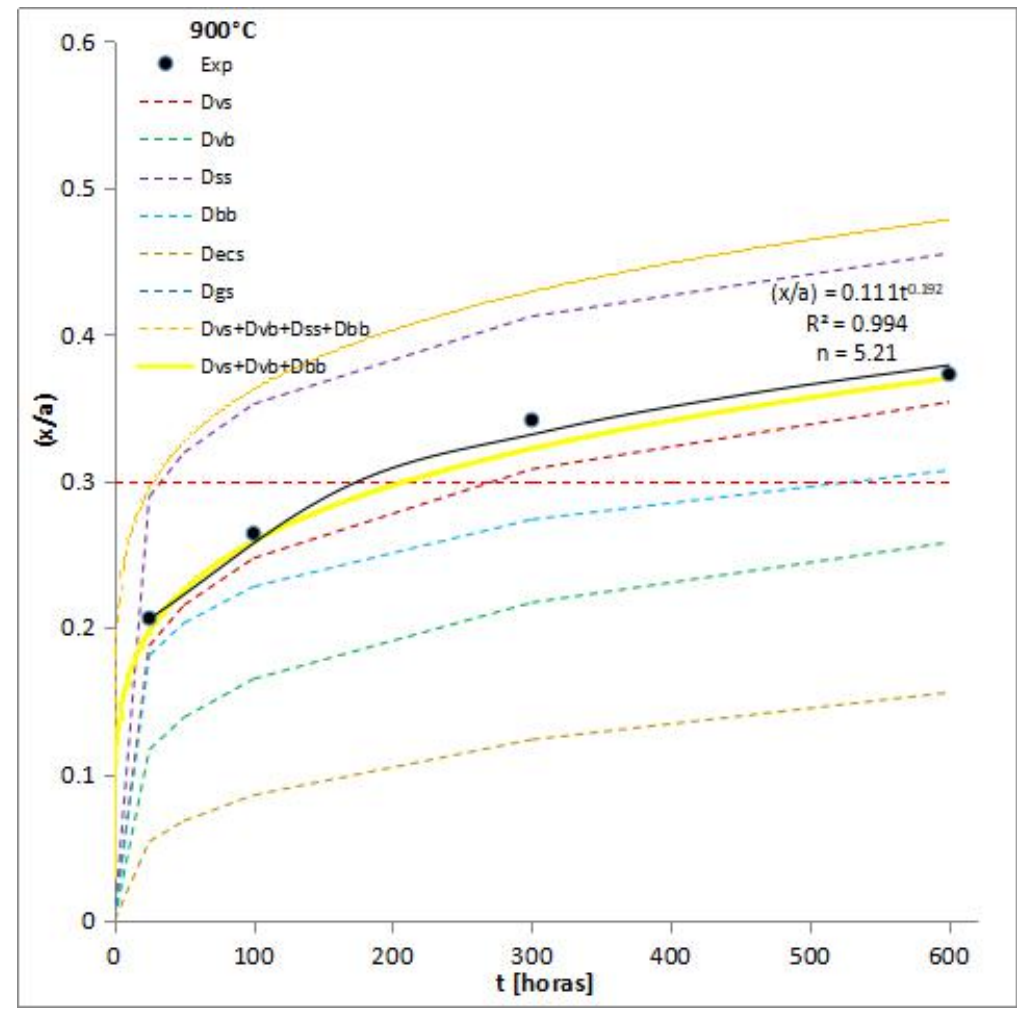

(b)

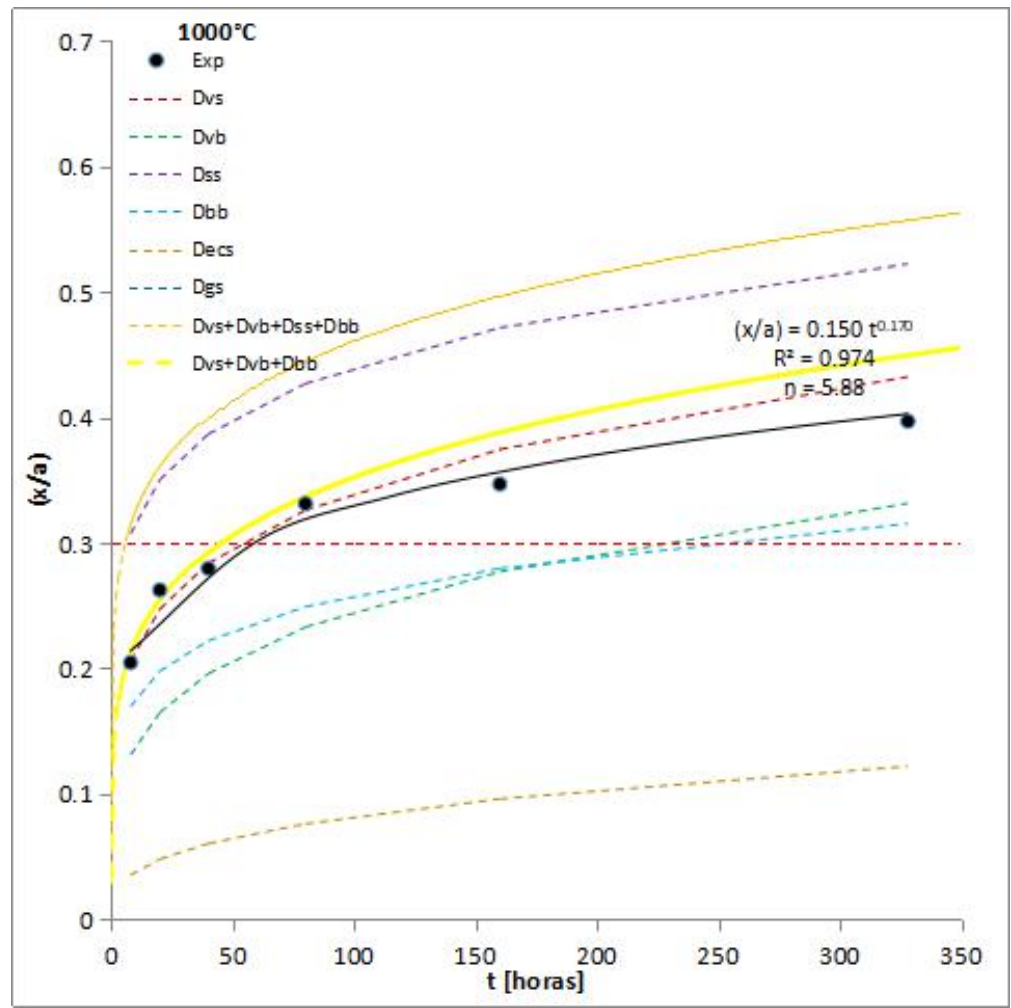


(c)

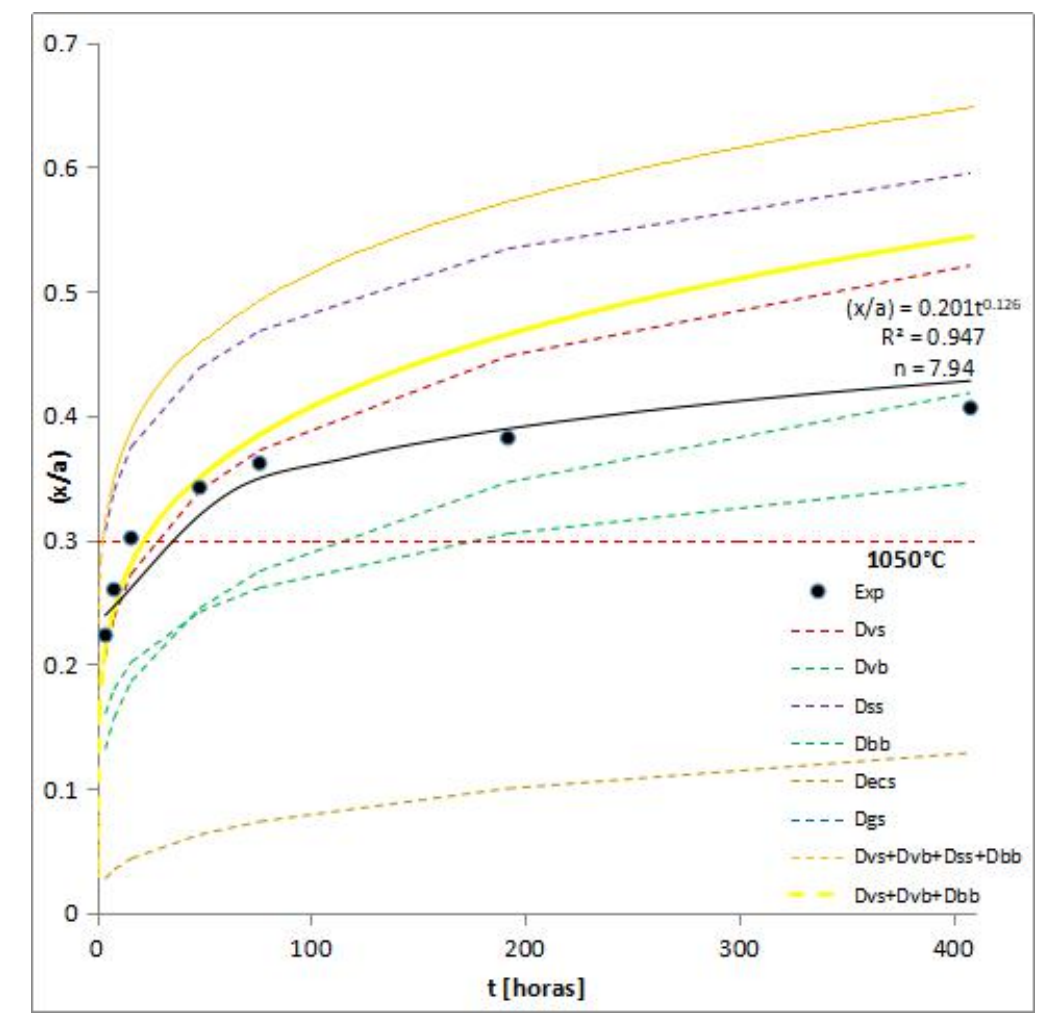

(d)

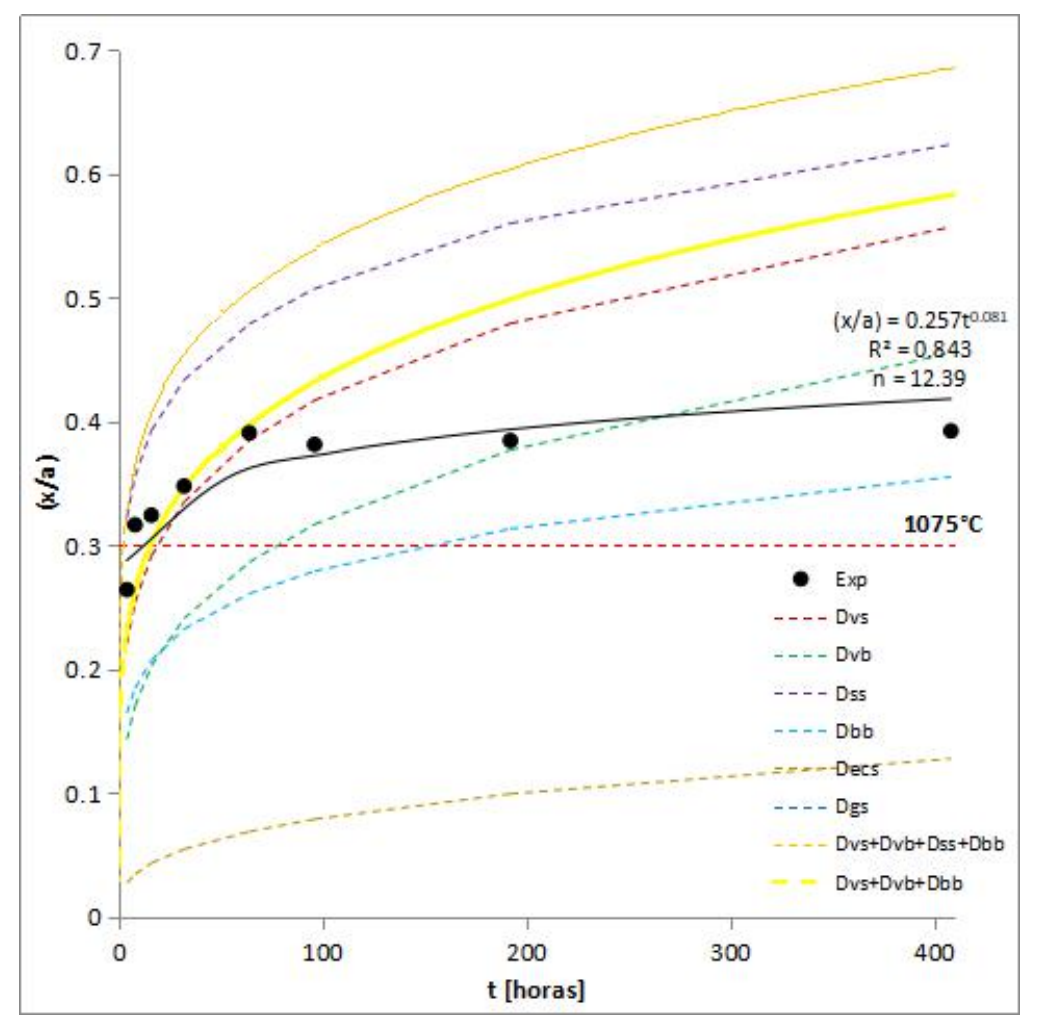

Figura 43: Gráficos de (x/a) vs t [h] para as temperaturas de (a) $900^{\circ} \mathrm{C}$, (b) $1000^{\circ} \mathrm{C}$, (c) $1050^{\circ} \mathrm{C}$ e (d) $1075^{\circ} \mathrm{C}$.

$\mathrm{Na}$ determinação do mecanismo dominante, os autores utilizaram para compreensão do crescimento do pescoço a análise via expoente do tempo e cálculo da energia de ativação; enquanto que para contração utilizaram os gráficos de taxa de contração em função da temperatura e do tempo, além da lei de Herring (Herring's scaling law). 
No artigo original, os autores concluíram que tanto o processo de contração quanto o de formação do pescoço em elevadas temperaturas de sinterização para o cobre ocorrem essencialmente pelo mecanismo da difusão volumétrica. Eles comentaram que tanto a difusão volumétrica a partir da superfície quanto à difusão volumétrica a partir dos contornos de grão contribuem de maneira efetiva neste processo, enquanto que a difusão pelas discordâncias é ineficaz devido ao baixo potencial químico associado ao movimento de escalada (climb) dessas discordâncias durante a sinterização, e das fontes operantes para difusão estarem presentes em maior quantidade nos contornos de grão do que nas discordâncias. Eles enfatizaram ainda que, por ser um processo complexo, a sinterização é diretamente afetada pelas condições experimentais adotadas.

Swinkels e Ashby [SWINKELS, ASHBY, 1981] analisaram os resultados publicados com os gráficos de sinterização de Ashby [ASHBY, 1974]. Eles concluíram que dois mecanismos contribuem para o crescimento do pescoço, porém até 10 horas de experimento o crescimento do pescoço é regido principalmente pelo mecanismo da difusão superficial; entre 10 e 50 horas os mecanismos da difusão superficial e volumétrica contribuem por igual; a partir de 50 horas de sinterização a difusão volumétrica a partir do contorno de grão se torna dominante.

d) Experimento de Pranatis e Seigle para o cobre

Pranatis e Seigle [PRANATIS, SEIGLE, 1960] também estudaram a sinterização em fios de cobre. Assim como na análise feita com os dados experimentais de Alexander e Balluffi [ALEXANDER, BALLUFFI, 1957], as equações analíticas utilizadas nos mecanismos de sinterização foram aquelas desenvolvidas no item 120 para a geometria cilíndrica.

O objetivo principal deste estudo foi verificar a influência e o efeito na taxa de sinterização caso os cilindros fossem submetidos a uma pré sinterização para remoção dos contornos de grão, e se ao invés de utilizar fios sólidos, a sinterização fosse feita em tubos qual seria o impacto no resultado final.

Nos dois cenários estudados, os autores não observaram qualquer alteração na taxa de sinterização, porém eles atentam para o fato de que os tubos precisam de um cuidado especial, principalmente de limpeza, pois por possuírem maior área superficial, eles podem absorver impurezas, as quais limitam tanto a temperatura como o tempo máximo de sinterização. Como não houve alteração nessas taxas, o presente trabalho não distinguiu as análises entre fios com ou sem os contornos de grão, nem entre tubos e fios sólidos; diferenciou-se apenas os diâmetros dos cilindros. 
Na Figura 44 está reproduzido o gráfico entre $\frac{x}{a}$ experimental e $\frac{x}{a}$ analítico para os cilindros de $101,6 \mu \mathrm{m}\left(0,004^{\prime \prime}\right)$ de diâmetro na temperatura de sinterização de $1060{ }^{\circ} \mathrm{C}$.

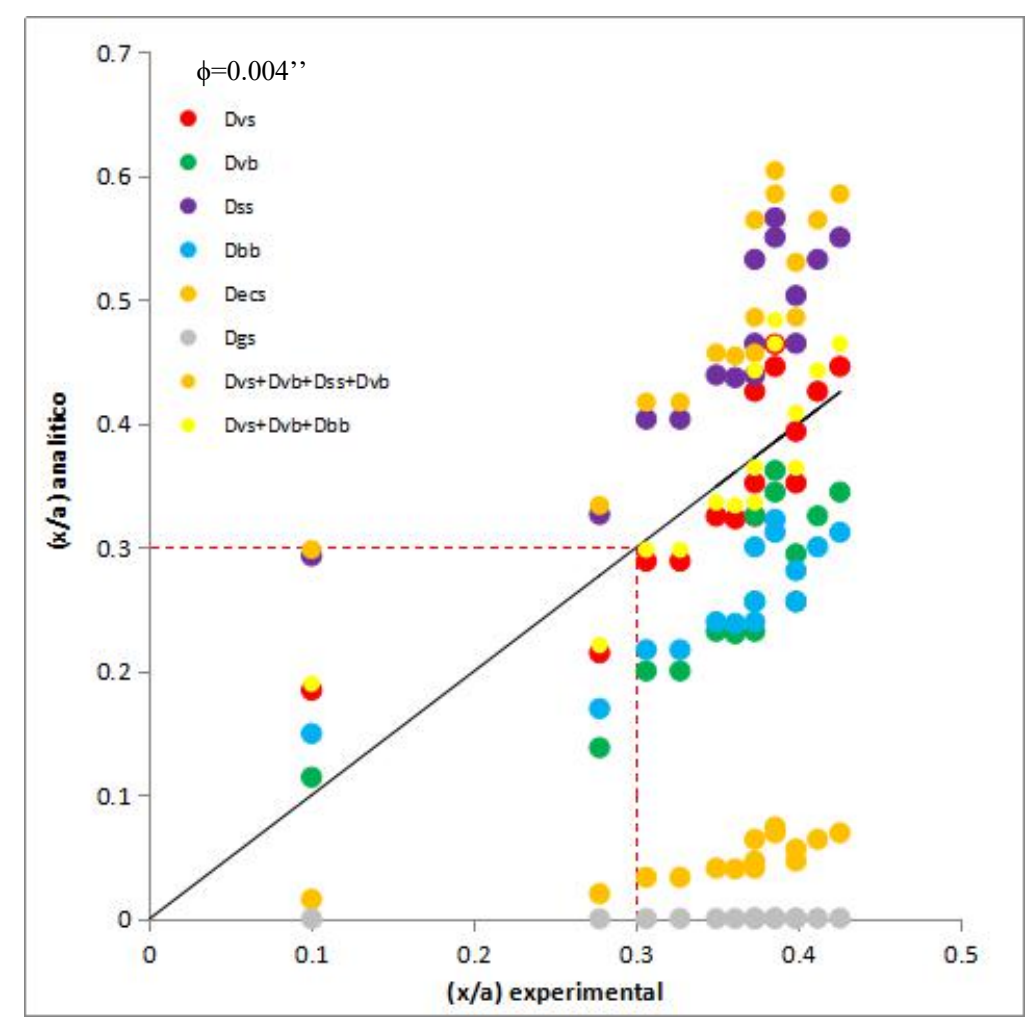

Figura 44: Gráfico comparativo entre $\left(\frac{x}{a}\right)$ experimental e $\left(\frac{x}{a}\right)$ analítico para as temperatura de $1060^{\circ} \mathrm{C}$ com os dados extraídos do artigo de Pranatis e Seigle para o cobre com 101,6 $\mu \mathrm{m}$ de diâmetro [PRANATIS, SEIGLE, 1960]. ( $D_{\mathrm{vs}}$ difusão volumétrica a partir da superfície; $\mathrm{D}_{\mathrm{vb}}$ - difusão volumétrica a partir do contorno de grão; $\mathrm{D}_{\mathrm{ss}}$ - difusão superficial a partir da superfície; $\mathrm{D}_{\mathrm{bb}}$ - difusão do contorno de grão a partir do contorno de grão; $\mathrm{D}_{\mathrm{ecs}}$ difusão gasosa via evaporação-condensação a partir da superfície; e $\mathrm{D}_{\mathrm{gs}}$ - difusão gasosa a partir da superfície).

Observa-se uma grande quantidade de pontos fora da região limitada pelo estágio inicial. Dentro desta região, apenas um ponto (do mecanismo de difusão volumétrica a partir do contorno de grão) mais se aproxima da reta diagonal de $45^{\circ}$, fora deste estágio, há um aglomerado de pontos do mecanismo da difusão volumétrica a partir da superfície e do mecanismo combinado $\left(D_{v s}+D_{v b}+D_{b b}\right)$ que mais se aproximam desta reta.

Na Tabela 18 encontra-se a análise estatística realizada para todos os pontos disponíveis. Esta mesma análise não foi feita para os pontos contidos na região do estágio inicial porque, conforme visto nos cálculos com os dados de Alexander e Balluffi, a variável associada a distribuição $t$ de Student assume um valor muito alto e não se pode assumir nada conclusivo quanto ao(s) mecanismo(s) dominante(s), porque a probabilidade deles ocorrerem aumenta consideravelmente mesmo que o erro relativo e o erro se apresentem com valores altos. 
Tabela 18: Análise estatística de todos os pontos para os fios com diâmetro de 101,6 $\mu \mathrm{m}$.

\begin{tabular}{|c|c|c|c|c|c|c|}
\hline \multicolumn{2}{|c|}{$\begin{array}{c}\text { Temperatura/ Mecanismo de } \\
\text { Sinterização }\end{array}$} & $\begin{array}{c}\text { Erro } \\
\text { Relativo (\%) }\end{array}$ & Erro & SD & CI & $\mathbf{N}$ \\
\hline \multirow{7}{*}{$\begin{array}{c}1060{ }^{\circ} \mathrm{C} \\
\text { Para fios } \\
\text { com } \\
101,6 \mu \mathrm{m} \\
\left(0,004^{\prime \prime}\right) \text { de } \\
\text { diâmetro }\end{array}$} & Dvs & 15.4396 & -0.0009 & 0.0485 & \pm 0.0314 & \multirow{8}{*}{15} \\
\hline & Dvb & 27.1426 & 0.0923 & 0.0479 & \pm 0.0310 & \\
\hline & Dss & 39.3323 & -0.1109 & 0.0450 & \pm 0.0292 & \\
\hline & Dbb & 30.4124 & 0.0952 & 0.0459 & \pm 0.0297 & \\
\hline & Decs & 86.3933 & 0.3014 & 0.0663 & \pm 0.0430 & \\
\hline & Dgs & 99.8260 & 0.3488 & 0.0794 & \pm 0.0514 & \\
\hline & Dvs+Dvb+Dss+Dbb & 45.4907 & -0.1332 & 0.0506 & \pm 0.0328 & \\
\hline & Dvs+Dvb+Dbb & 15.8296 & -0.0138 & 0.0508 & \pm 0.0329 & \\
\hline
\end{tabular}

Com 5\% de significância, o mecanismo da difusão volumétrica a partir da superfície e o mecanismo combinado $\left(\mathrm{D}_{\mathrm{vs}}+\mathrm{D}_{\mathrm{vb}}+\mathrm{D}_{\mathrm{bb}}\right)$ são os possíveis mecanismos dominantes. Estes apresentam erros relativos de aproximadamente 15\%, enquanto que para os demais mecanismos o erro relativo foi superior a 30\% atingindo valor máximo de 99,826\% para o mecanismo da difusão gasosa a partir da superfície.

Swinkles e Ashby [SWINKLES, ASHBY, 1981] utilizaram também os dados experimentais, sem distinção daqueles pré-sinterizados ou não, dos fios de cobre com 101,6 $\mu \mathrm{m}$ de diâmetro para análise com os diagramas de sinterização. A discrepância entre os valores esperados e os experimentais para o tamanho dos pescoços foi de $9 \%$.

Eles concluíram que a difusão superficial e a difusão volumétrica contribuem quase que igualmente para o crescimento do pescoço; nesta faixa de tempo eles verificaram que deve haver também a contração.

Apesar dos resultados obtidos terem reproduzido adequadamente as medidas de Pranatis e Seigle, Swinkles e Ashby atentam para o fato de que a escolha do coeficiente de difusão superficial pode vir a alterar significativamente os cálculos finais e as conclusões, por isso é muito importante que os dados de entrada dos modelos analíticos sejam confiáveis.

A análise via expoente do tempo foi realizada para os gráficos entre $\frac{x}{a}$ e o tempo nas escalas logarítmica (Figura 45) e linear (Figura 46). 


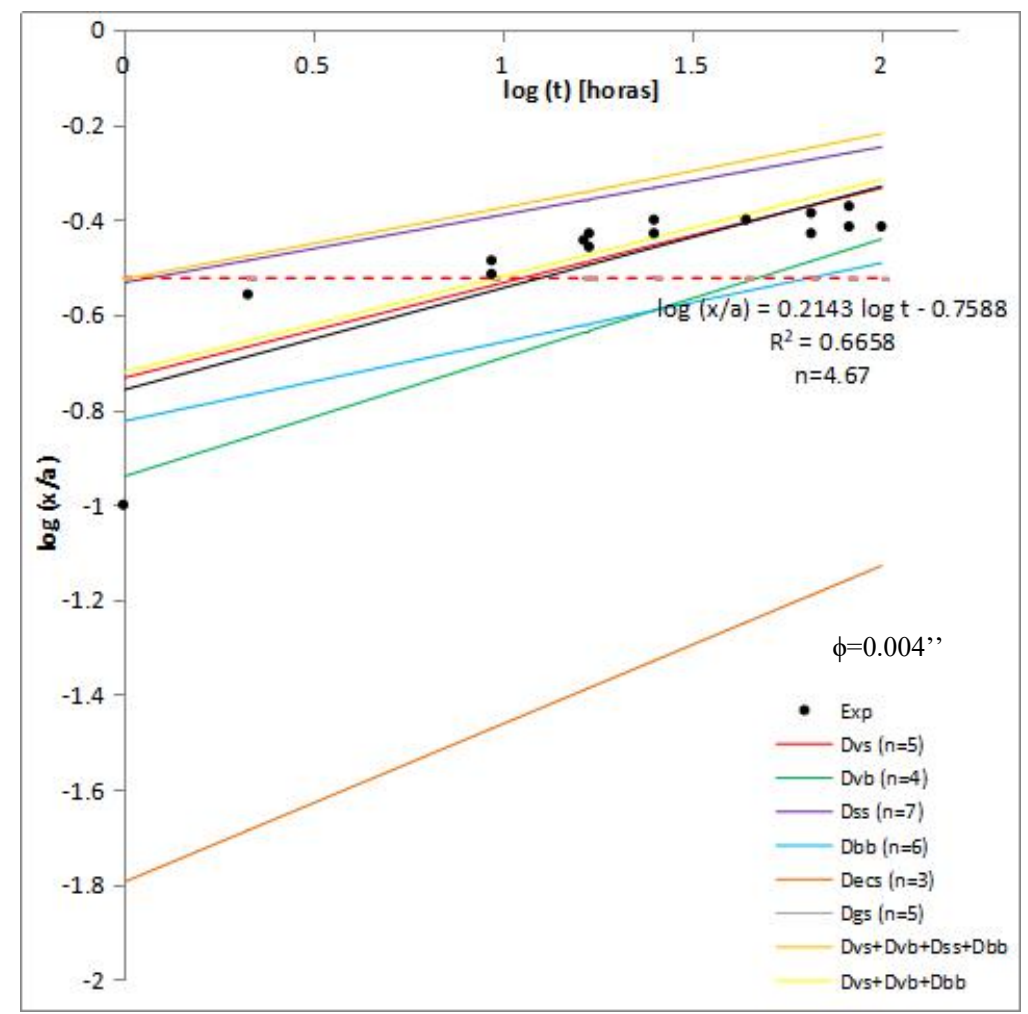

Figura 45: Gráficos entre $\log \left(\frac{x}{a}\right)$ vs $\log \mathrm{t}$ [horas] para fios com diâmetro de 101,6 $\mu \mathrm{m}$ na temperatura de 1060 ${ }^{\circ} \mathrm{C}$ baseado nos dados de Pranatis e SEIGLE [PRANATIS, SEIGLE, 1960]. 


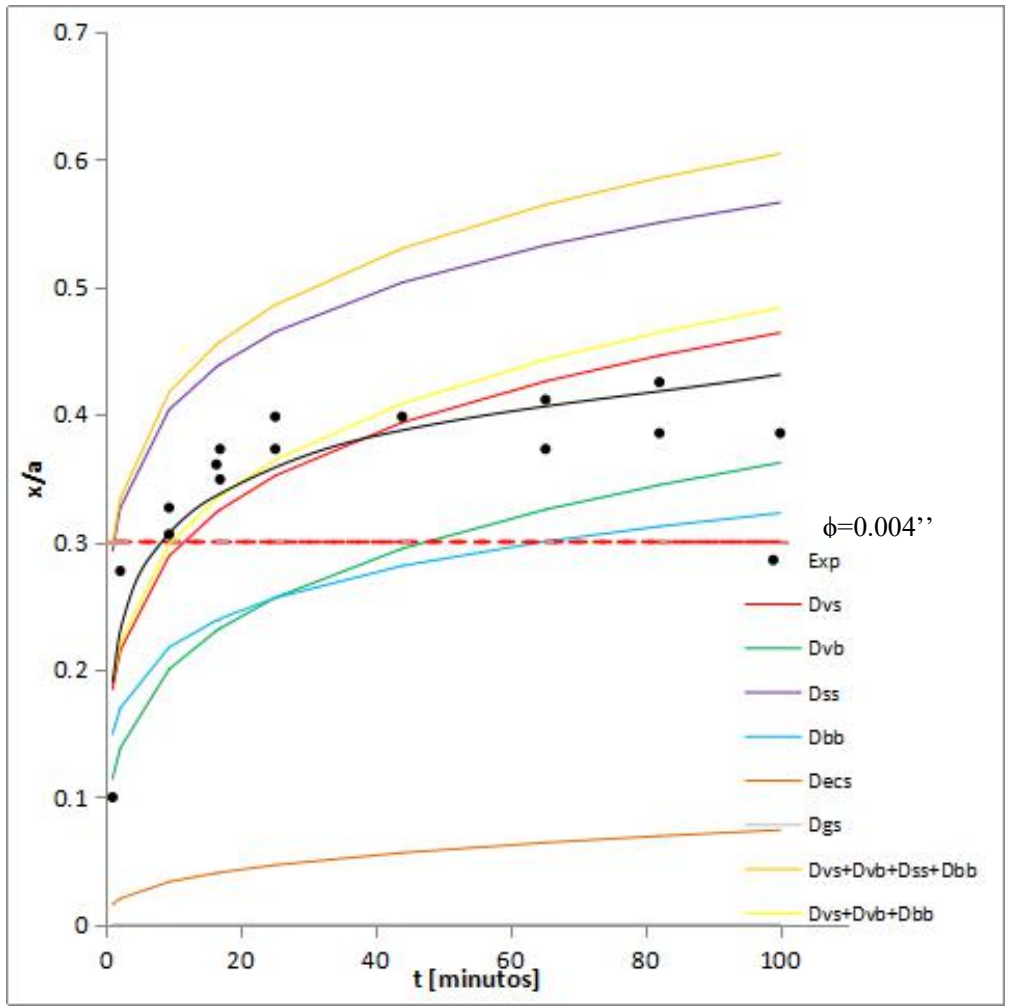

Figura 46: Gráfico de $\left(\frac{x}{a}\right)$ vs tempo [horas] para fios de $101,6 \mu \mathrm{m}$ e temperatura de $1060^{\circ} \mathrm{C}$ baseado nos dados de Pranatis e SEIGLE [PRANATIS, SEIGLE, 1960].

O expoente do tempo obtido com os dados experimentais foi de 4,67, este valor está entre os mecanismos de difusão volumétrica a partir do contorno de grão $(n=4)$ e difusão volumétrica a partir da superfície $(\mathrm{n}=5)$. Pela análise estatística apresentada na Tabela 123, a difusão volumétrica a partir da superfície tem a maior probabilidade de ser o mecanismo individual dominante.

Para os fios com diâmetro de 203,2 $\mu \mathrm{m}(0,008$ '), as mesmas análises foram realizadas. Na Figura 47 estão apresentadas as comparações entre $\frac{x}{a}$ experimental e analítico. 


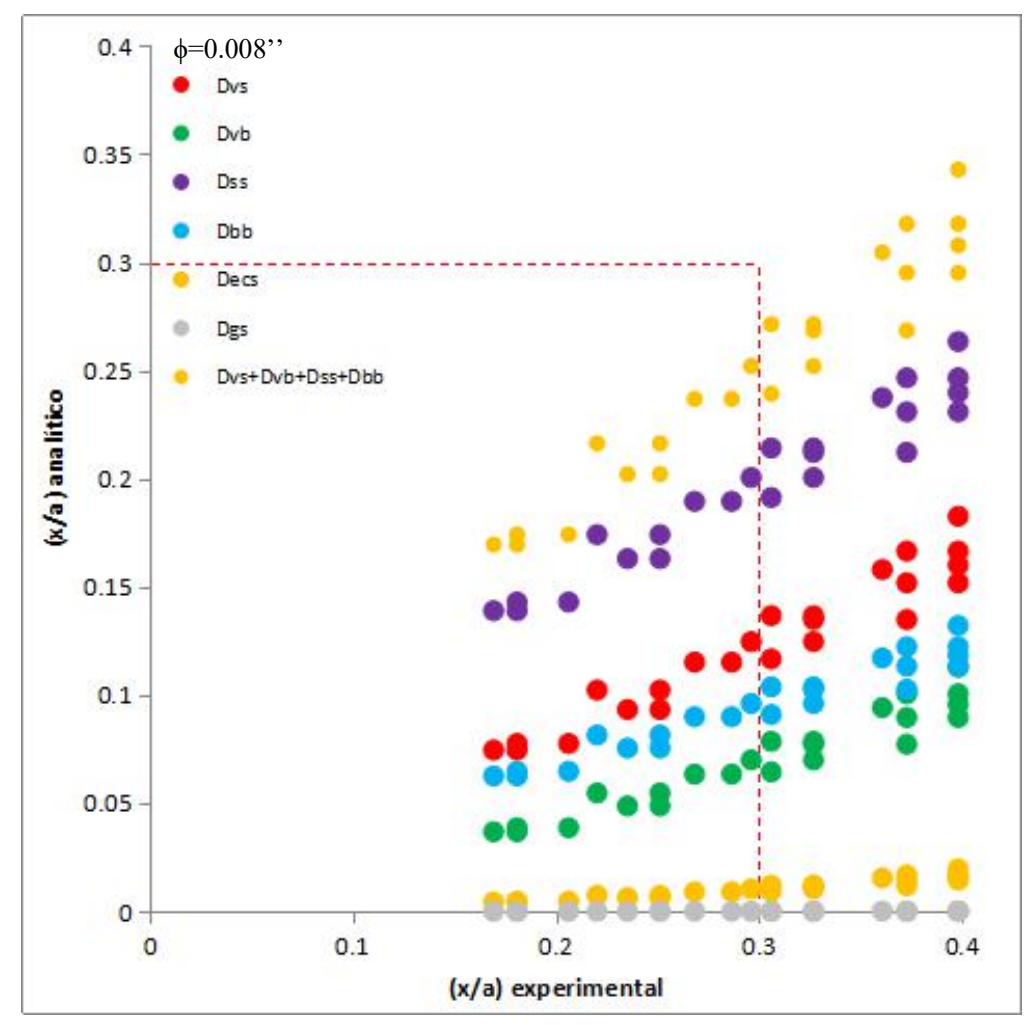

Figura 47: Gráfico comparativo entre $\left(\frac{x}{a}\right)$ experimental e $\left(\frac{x}{a}\right)$ analítico para as temperatura de $1060^{\circ} \mathrm{C}$ com os dados extraídos do artigo de Pranatis e Seigle para o cobre com 203,2 $\mu \mathrm{m}$ de diâmetro [PRANATIS, SEIGLE, 1960]. ( $D_{v s}$ - difusão volumétrica a partir da superfície; $D_{v b}$ - difusão volumétrica a partir do contorno de grão; $\mathrm{D}_{\mathrm{ss}}$ - difusão superficial a partir da superfície; $\mathrm{D}_{\mathrm{bb}}$ - difusão do contorno de grão a partir do contorno de grão; $\mathrm{D}_{\mathrm{ecs}}{ }^{-}$ difusão gasosa via evaporação-condensação a partir da superfície; e $\mathrm{D}_{\mathrm{gs}}$ - difusão gasosa a partir da superfície).

Diferentemente dos fios com diâmetro de 101,6 $\mu \mathrm{m}$, os fios com 203,2 $\mu \mathrm{m}$ de diâmetro tiveram mais pontos medidos dentro da região do estágio inicial, porém nenhum dos mecanismos se aproximou da reta diagonal de $45^{\circ}$. Como todos os mecanismos tem seus pontos posicionados abaixo da reta de equivalência, calculou-se apenas o método combinado composto pelos quatro principais mecanismos: difusão volumétrica pelo contorno de grão $\left(D_{v b}\right)$, difusão volumétrica pela superfície $\left(D_{v s}\right)$, difusão superficial $\left(D_{s}\right)$ e difusão pelo contorno de grão $\left(\mathrm{D}_{\mathrm{bb}}\right)$. Os valores correspondentes ao mecanismo combinado são os que mais se aproximam dos valores experimentais dentro da região do estágio inicial.

A Tabela 19 e a Tabela 20 apresentam as análises estatística para todos os pontos experimentais e aqueles contidos na região do estágio inicial, respectivamente. 
Tabela 19: Análise estatística de todos os pontos para os fios com diâmetro de 203,2 $\mu \mathrm{m}$.

\begin{tabular}{|c|c|c|c|c|c|c|}
\hline \multicolumn{2}{|c|}{$\begin{array}{c}\text { Temperatura/ Mecanismo de } \\
\text { Sinterização }\end{array}$} & $\begin{array}{c}\text { Erro } \\
\text { Relativo (\%) }\end{array}$ & Erro & SD & CI & $\mathbf{N}$ \\
\hline & Dvs & 58.75 & 0.1830 & 0.0493 & \pm 0.0231 & \multirow{7}{*}{26} \\
\hline & Dvb & 76.81 & 0.2378 & 0.0588 & \pm 0.0275 & \\
\hline \multirow{5}{*}{$\begin{array}{c}\text { Para fios } \\
\text { com } \\
203,2 \mu \mathrm{m} \\
\left(0,008^{\prime \prime}\right) \text { de } \\
\text { diâmetro }\end{array}$} & Dss & 33.29 & 0.1081 & 0.0444 & \pm 0.0208 & \\
\hline & Dbb & 68.11 & 0.2132 & 0.0606 & \pm 0.0284 & \\
\hline & Decs & 94.49 & 0.2997 & 0.0772 & \pm 0.0361 & \\
\hline & Dgs & 99.95 & 0.3109 & 0.0818 & \pm 0.0382 & \\
\hline & Dvs+Dvb+Dss+Dbb & 16.07 & 0.0543 & 0.0315 & \pm 0.0147 & \\
\hline
\end{tabular}

Tabela 20: Análise estatística dos pontos contidos na região do estágio inicial para os fios com diâmetro de 203,2

\begin{tabular}{|c|c|c|c|c|c|c|}
\hline \multicolumn{2}{|c|}{$\begin{array}{c}\text { Temperatura/ Mecanismo de } \\
\text { Sinterização }\end{array}$} & \multirow{2}{*}{$\begin{array}{c}\text { Erro } \\
\text { Relativo (\%) }\end{array}$} & \multirow{2}{*}{$\begin{array}{c}\text { Erro } \\
0.1359\end{array}$} & \multirow{2}{*}{$\begin{array}{c}\text { SD } \\
0.0274\end{array}$} & \multirow{2}{*}{$\begin{array}{c}\text { CI } \\
\pm 0.0218\end{array}$} & \multirow[t]{2}{*}{$\mathbf{N}$} \\
\hline \multirow{7}{*}{$\begin{array}{c}1060^{\circ} \mathrm{C} \\
\text { Para fios } \\
\text { com } \\
203,2 \mu \mathrm{m} \\
\left.\left(0,008^{\prime}\right)\right) \mathrm{de} \\
\text { diâmetro }\end{array}$} & Dvs & & & & & \\
\hline & Dvb & 78.29 & 0.1809 & 0.0328 & \pm 0.0261 & \multirow{6}{*}{11} \\
\hline & Dss & 27.76 & 0.0661 & 0.0239 & \pm 0.0190 & \\
\hline & Dbb & 66.53 & 0.1546 & 0.0326 & \pm 0.0259 & \\
\hline & Decs & 97.09 & 0.2246 & 0.0264 & \pm 0.0210 & \\
\hline & Dgs & 99.95 & 0.2313 & 0.0437 & \pm 0.0347 & \\
\hline & $\mathrm{Dvs}+\mathrm{Dvb}+\mathrm{Dss}+\mathrm{Dbb}$ & 10.79 & 0.0269 & 0.0184 & \pm 0.0146 & \\
\hline
\end{tabular}

Pela Tabela 19 e pela Tabela 20, observa-se que nenhum dos mecanismos pode ser considerado dominante com $5 \%$ de significância. Esta análise contou com uma grande quantidade de pontos, o que torna a distribuição t-Student mais próxima da distribuição Normal.

Dentre os mecanismos, aquele que apresenta menores erro e erro relativo é o mecanismo combinado $\left(\mathrm{D}_{\mathrm{vs}}+\mathrm{D}_{\mathrm{vb}}+\mathrm{D}_{\mathrm{ss}}+\mathrm{D}_{\mathrm{bb}}\right)$.

A análise via expoente do tempo foi realizada para os gráficos entre $\frac{x}{a}$ e o tempo nas escalas logarítmica (Figura 48) e linear (Figura 49). 


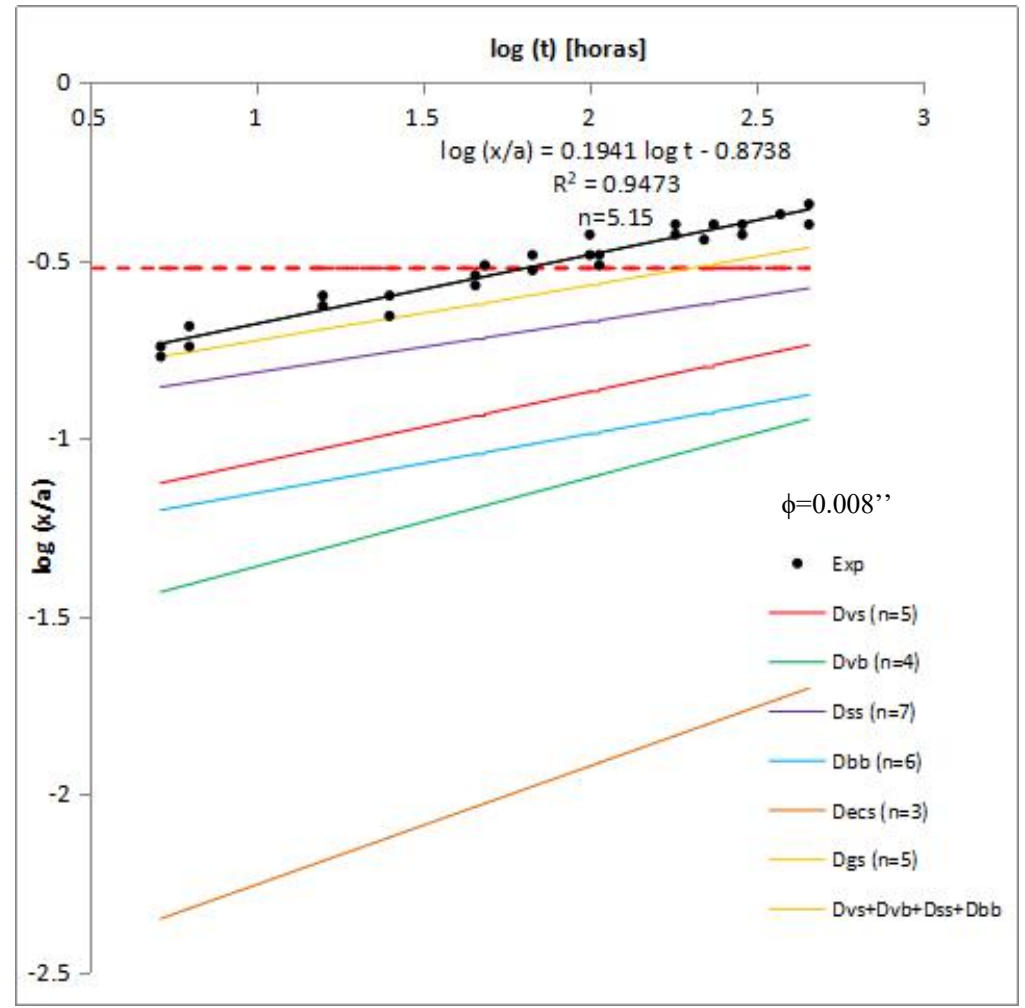

Figura 48: Gráfico de $\log \left(\frac{x}{a}\right)$ vs $\log \mathrm{t}$ [horas] para fios com diâmetro de $203,2 \mu \mathrm{m}$ e temperatura de $1060^{\circ} \mathrm{C}$ baseado nos dados de Pranatis e SEIGLE [PRANATIS, SEIGLE, 1960].

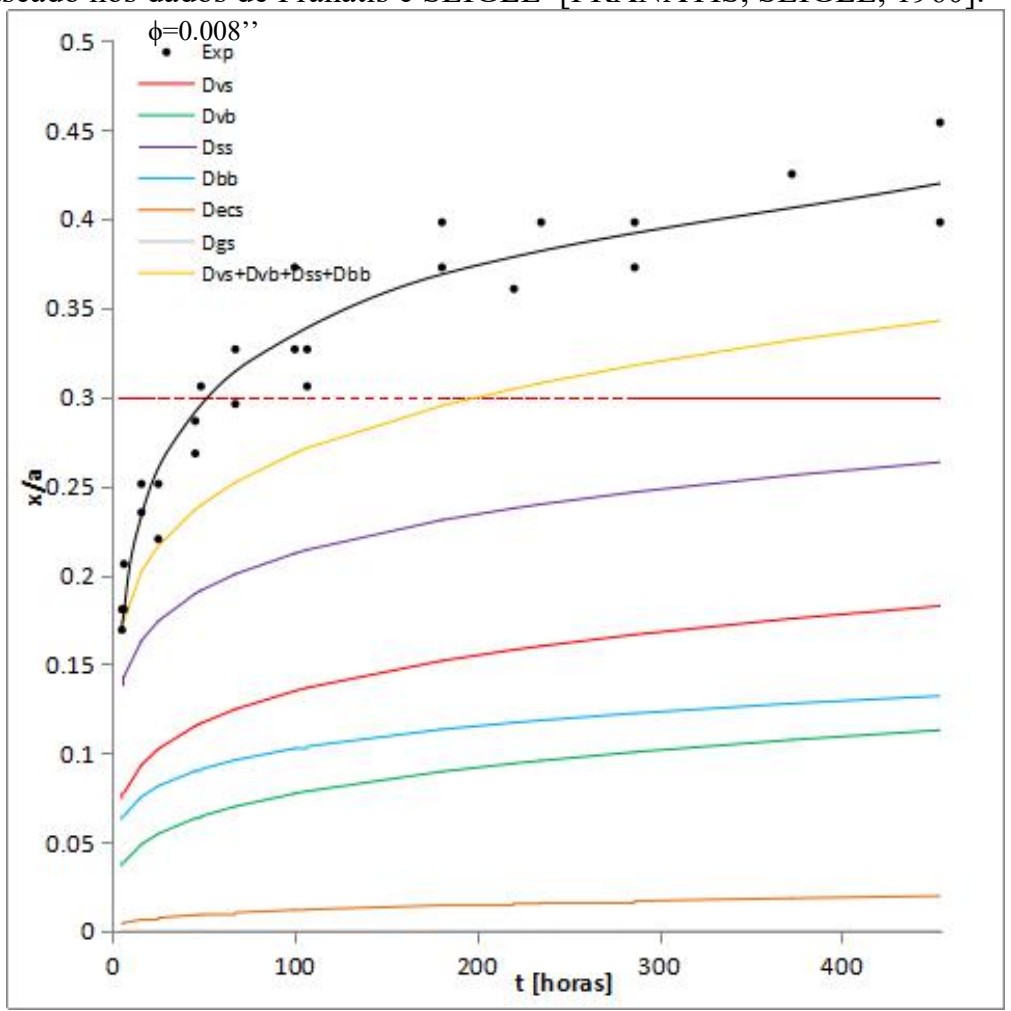

Figura 49: Gráfico de $\left(\frac{x}{a}\right)$ vs tempo [horas] para fios com diâmetro de $203,2 \mu \mathrm{m}$ e temperatura de $1060^{\circ} \mathrm{C}$ baseado nos dados de Pranatis e SEIGLE [PRANATIS, SEIGLE, 1960]. 
O valor do expoente do tempo é igual a 5,15, o mecanismo que mais se aproxima deste valor é a difusão volumétrica a partir da superfície $(\mathrm{n}=5)$.

Comparando os gráficos da Figura 44 e da Figura 47 é possível observar que para uma mesma razão de $\frac{x}{a}$, menor será o tempo necessário para obtê-lo quanto menor for o diâmetro do fio. Esta evidência só reforça a hipótese de que a superfície é o caminho favorável para o transporte de matéria até o pescoço, uma vez que esta é força motriz para a sinterização.

e) Experimento de Wilson e Shewmon para o cobre

Wilson e Shewmon [WILSON, SHEWMON, 1966] decidiram avaliar a sinterização para uma conFiguração até então não estudada, uma sequência de esferas de cobre. Kuczynski [KUCZYNSKI, 1949] e Kingery e Berg [KINGERY, BERG, 1955] avaliaram um sistema composto apenas por duas esferas. Neste artigo, os autores analisaram o crescimento do pescoço para duas temperaturas $\left(950\right.$ e $\left.1020^{\circ} \mathrm{C}\right)$ com cinco conjuntos de fileiras de esferas cada um.

A Figura 50 apresenta os gráficos entre $\frac{x}{a}$ experimental e $\frac{x}{a}$ analítico para as temperaturas de 900 e $1020^{\circ} \mathrm{C}$. 
(a)

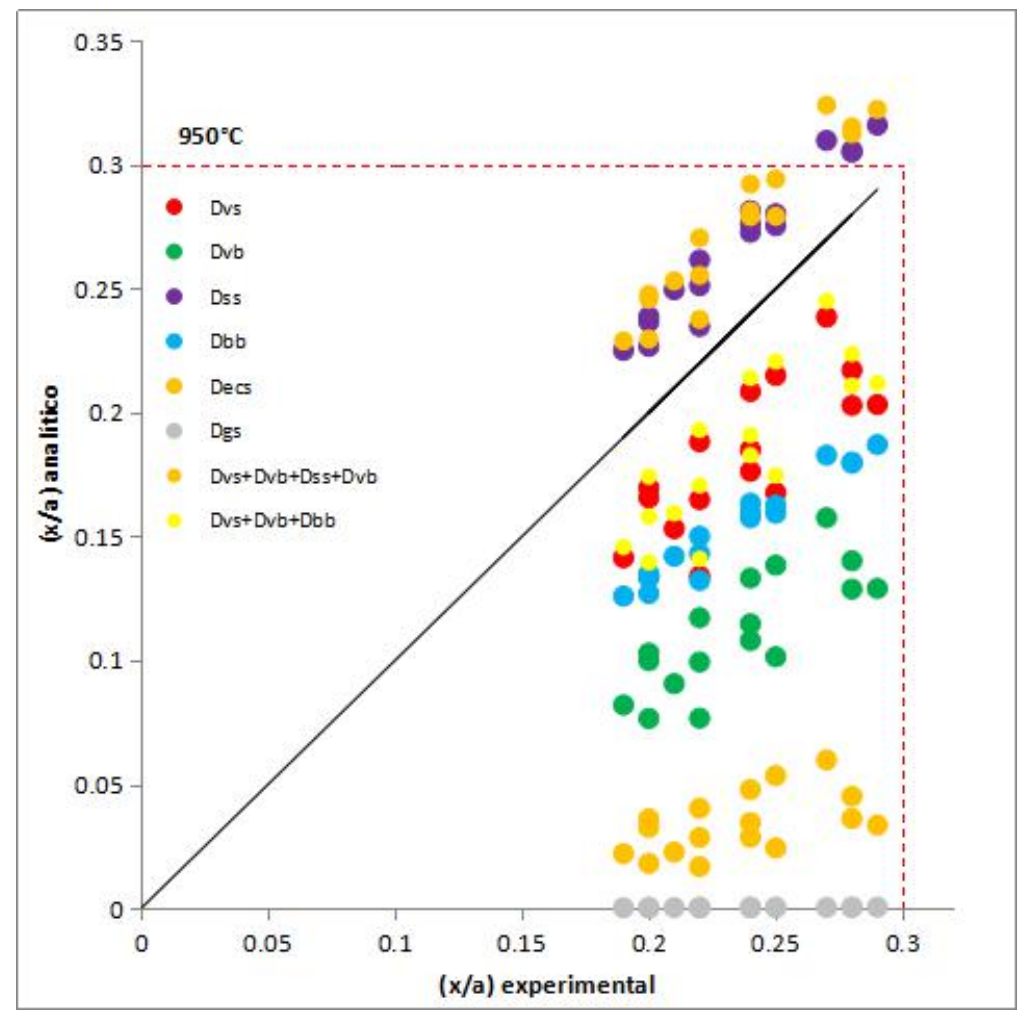

(b)

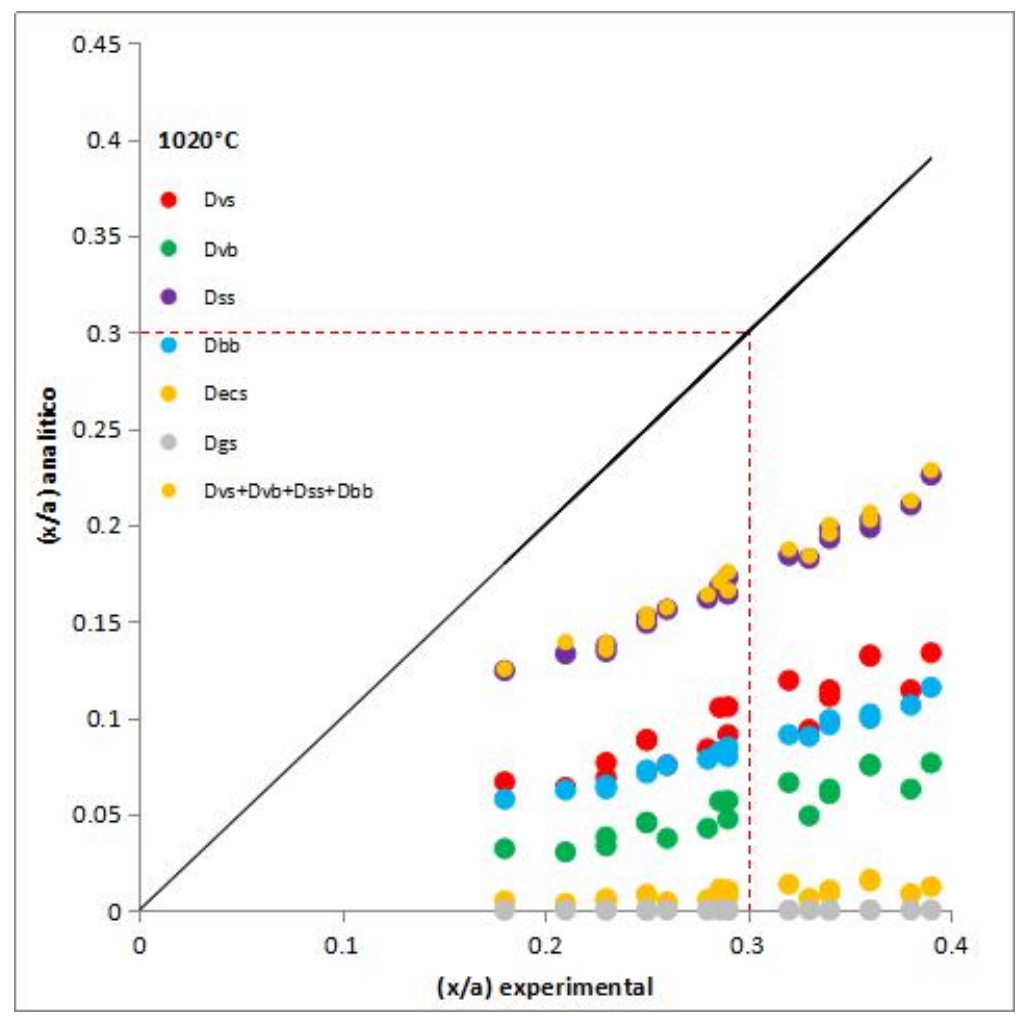

Figura 50: Gráficos comparativos entre $\left(\frac{x}{a}\right)$ experimental e $\left(\frac{x}{a}\right)$ analítico para as temperaturas de (a) $900^{\circ} \mathrm{C}$ e (b) $1020^{\circ} \mathrm{C}$ com os dados extraídos do artigo de Wilson e Shewmon para o cobre [WILSON, SHEWMON, 1964]. ( $\mathrm{D}_{\mathrm{vs}}$ - difusão volumétrica a partir da superfície; $\mathrm{D}_{\mathrm{vb}}$ - difusão volumétrica a partir do contorno de grão; $\mathrm{D}_{\mathrm{ss}}{ }^{-}$ difusão superficial a partir da superfície; $\mathrm{D}_{\mathrm{bb}}$ - difusão do contorno de grão a partir do contorno de grão; $\mathrm{D}_{\text {ecs- }}$ difusão gasosa via evaporação-condensação a partir da superfície; e $\mathrm{D}_{\mathrm{gs}}$ - difusão gasosa a partir da superfície). 
Nas duas temperaturas estudadas não há coincidência entre os valores obtidos com os modelos analíticos e os dados experimentais. Em $900{ }^{\circ} \mathrm{C}$, a difusão superficial e o modelo combinado, que inclui a difusão superficial, superestimam as medidas experimentais enquanto que os demais modelos as subestimam. Observa-se, contudo, que quatro mecanismos são os que mais se aproximam dos valores experimentais, sendo estes: difusão superficial, difusão volumétrica a partir da superfície, e mecanismos combinados com e sem o mecanismo da difusão superficial incluso. Todos estes quatro mecanismos têm como principal fonte de contribuição para fluxo de matéria na formação do pescoço a superfície, isso evidencia sua importância na sinterização a $900^{\circ} \mathrm{C}$.

Na temperatura de $1020^{\circ} \mathrm{C}$ todos os modelos subestimam os dados experimentais e estes se distanciam bastante da reta de $45^{\circ}$. Como todos os mecanismos estão posicionados abaixo da reta, calculou-se apenas um mecanismo combinado englobando os quatro principais mecanismos, sendo estes: difusão superficial, difusão volumétrica a partir da superfície, difusão volumétrica a partir do contorno de grão, e difusão pelo contorno de grão.

A Tabela 21 apresenta a análise estatística de todos os pontos experimentais e a Tabela 22 faz a mesma análise apenas para os pontos contidos na região correspondente ao estágio 1 da sinterização.

Tabela 21: Análise estatística para todos os pontos nas temperaturas de 900 e $1000{ }^{\circ} \mathrm{C}$.

\begin{tabular}{|c|c|c|c|c|c|c|}
\hline \multicolumn{2}{|c|}{$\begin{array}{c}\text { Temperatura/ Mecanismo de } \\
\text { Sinterização }\end{array}$} & $\begin{array}{c}\text { Erro } \\
\text { Relativo (\%) }\end{array}$ & Erro & SD & CI & $\mathbf{N}$ \\
\hline \multirow{8}{*}{$900^{\circ} \mathrm{C}$} & Dvs & 23.38 & 0.0550 & 0.0203 & \pm 0.0122 & \multirow{8}{*}{17} \\
\hline & Dvb & 52.78 & 0.1237 & 0.0194 & \pm 0.0116 & \\
\hline & Dss & 14.01 & -0.0322 & 0.0074 & \pm 0.0045 & \\
\hline & Dbb & 34.41 & 0.0811 & 0.0127 & \pm 0.0076 & \\
\hline & Decs & 85.58 & 0.2011 & 0.0270 & \pm 0.0162 & \\
\hline & Dgs & 99.86 & 0.2350 & 0.0314 & \pm 0.0188 & \\
\hline & Dvs+Dvb+Dss+Dbb & 17.04 & -0.0393 & 0.0095 & \pm 0.0057 & \\
\hline & Dvs+Dvb+Dbb & 21.18 & 0.0496 & 0.0188 & \pm 0.0113 & \\
\hline \multirow{7}{*}{$1020^{\circ} \mathrm{C}$} & Dvs & 66.60 & 0.1953 & 0.0404 & \pm 0.0226 & \multirow{7}{*}{19} \\
\hline & Dvb & 82.36 & 0.2411 & 0.0468 & \pm 0.0263 & \\
\hline & Dss & 41.26 & 0.1226 & 0.0318 & \pm 0.0178 & \\
\hline & Dbb & 71.35 & 0.2097 & 0.0439 & \pm 0.0246 & \\
\hline & Decs & 97.10 & 0.2848 & 0.0575 & \pm 0.0322 & \\
\hline & Dgs & 99.95 & 0.2933 & 0.0601 & \pm 0.0337 & \\
\hline & Dvs+Dvb+Dss+Dbb & 40.46 & 0.1202 & 0.0315 & \pm 0.0176 & \\
\hline
\end{tabular}

Como previsto pela análise gráfica, nenhum mecanismo pode ser considerado estatisticamente possível com 5\% de significância. 
Tabela 22: Análise estatística para os pontos contidos dentro da região do estágio inicial da sinterização nas

\begin{tabular}{|c|c|c|c|c|c|c|}
\hline \multicolumn{2}{|c|}{$\begin{array}{l}\text { Temperatura/ Mecanismo de } \\
\text { Sinterização }\end{array}$} & \multirow{2}{*}{$\begin{array}{c}\text { Erro } \\
\text { Relativo (\%) } \\
23.38 \\
\end{array}$} & \multirow{2}{*}{$\begin{array}{c}\text { Erro } \\
0.0550 \\
\end{array}$} & \multirow{2}{*}{$\begin{array}{c}\text { SD } \\
0.0203 \\
\end{array}$} & \multirow{2}{*}{$\begin{array}{c}\text { CI } \\
\pm 0.0104\end{array}$} & \multirow{3}{*}{$\begin{array}{l}\mathbf{N} \\
17\end{array}$} \\
\hline \multirow{8}{*}{$900^{\circ} \mathrm{C}$} & Dvs & & & & & \\
\hline & Dvb & 52.78 & 0.1237 & 0.0194 & \pm 0.0010 & \\
\hline & Dss & 15.11 & -0.0331 & 0.0076 & \pm 0.0054 & 13 \\
\hline & Dbb & 34.41 & 0.0811 & 0.0127 & \pm 0.0065 & \multirow{3}{*}{17} \\
\hline & Decs & 85.58 & 0.2011 & 0.0270 & \pm 0.0139 & \\
\hline & Dgs & 99.86 & 0.2350 & 0.0314 & \pm 0.0161 & \\
\hline & Dvs+Dvb+Dss+Dbb & 18.02 & -0.0396 & 0.0097 & \pm 0.0069 & 13 \\
\hline & Dvs+Dvb+Dbb & 21.18 & 0.0496 & 0.0188 & \pm 0.0097 & 17 \\
\hline \multirow{7}{*}{$1020^{\circ} \mathrm{C}$} & Dvs & 66.82 & 0.1675 & 0.0250 & \pm 0.0166 & \multirow{7}{*}{11} \\
\hline & Dvb & 83.17 & 0.2081 & 0.0286 & \pm 0.0190 & \\
\hline & Dss & 39.65 & 0.1003 & 0.0205 & \pm 0.0136 & \\
\hline & Dbb & 71.15 & 0.1785 & 0.0272 & \pm 0.0180 & \\
\hline & Decs & 97.36 & 0.2438 & 0.0342 & \pm 0.0227 & \\
\hline & Dgs & 99.95 & 0.2504 & 0.0357 & \pm 0.0237 & \\
\hline & Dvs+Dvb+Dss+Dbb & 38.85 & 0.0983 & 0.0207 & \pm 0.0137 & \\
\hline
\end{tabular}

Tanto na análise de todos os pontos experimentais quanto daqueles limitados pela região do estágio inicial, nenhum dos mecanismos foi considerado dominante pela análise estatística com 5\% de significância nas temperaturas estudadas. Os mecanismos cujos modelos apresentaram mais erros foram, em ordem decrescente: difusão gasosa a partir da superfície $\left(D_{g s}\right)$, difusão gasosa via evaporação-condensação a partir da superfície $\left(\mathrm{D}_{\mathrm{ecs}}\right)$, e difusão volumétrica a partir do contorno de grão $\left(\mathrm{D}_{\mathrm{vb}}\right)$.

A Figura 51 e a Figura 52 mostram os gráficos entre a razão $\frac{x}{a}$ pelo tempo nas escalas logarítmica e linear respectivamente. 
(a)

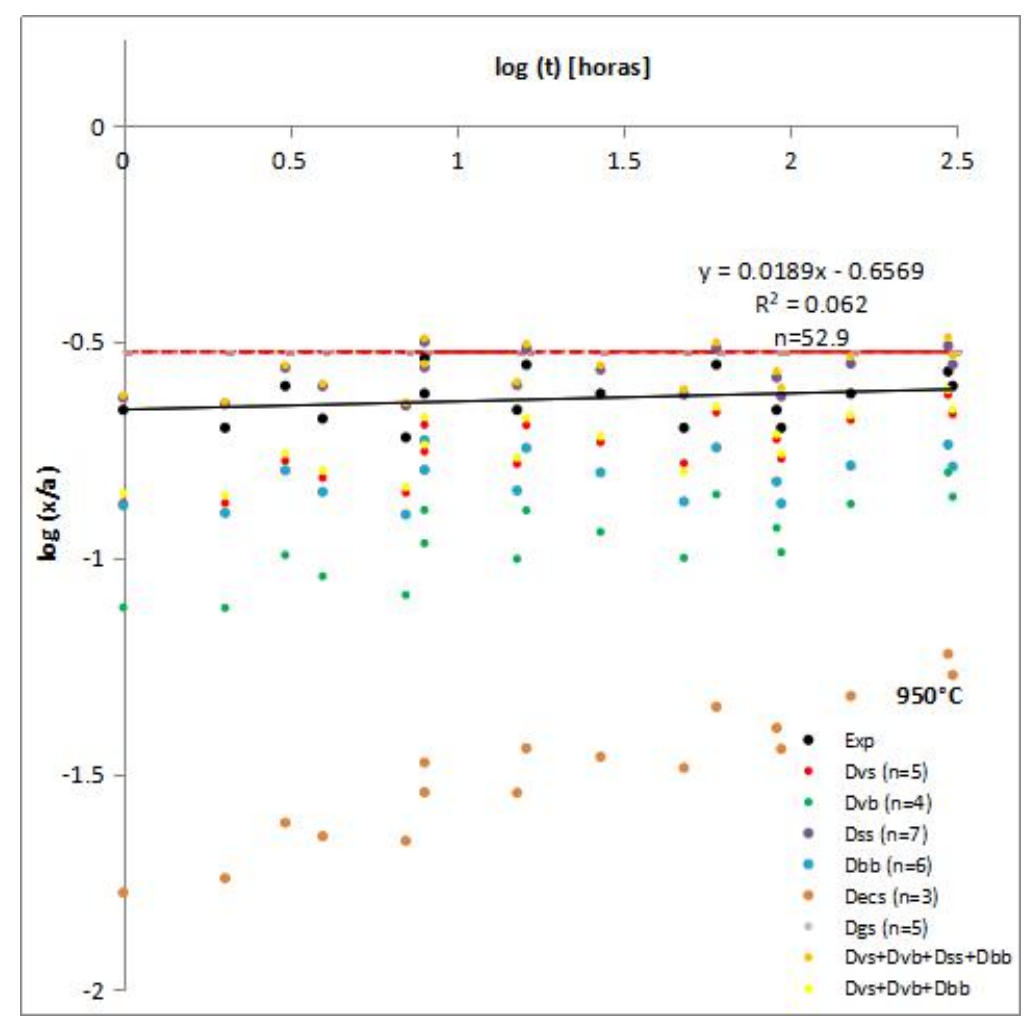

(b)

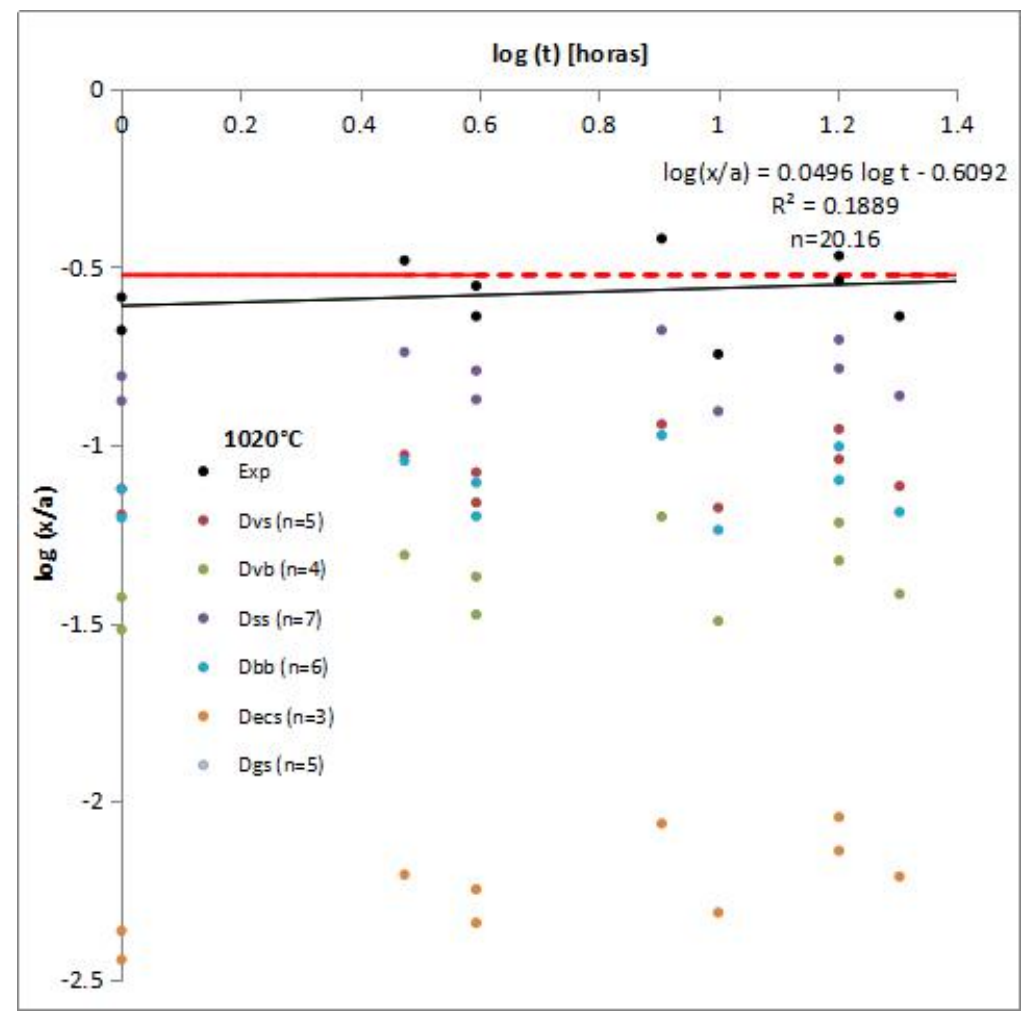

Figura 51: Gráficos entre $\log \left(\frac{x}{a}\right)$ vs $\log \mathrm{t}$ [horas] para as temperaturas de (a) $900^{\circ} \mathrm{C} \mathrm{e} \mathrm{(b)} 1000{ }^{\circ} \mathrm{C}$ baseado nos dados de Wilson e Shewmon [WILSON, SHEWMON, 1964]. 
(a)

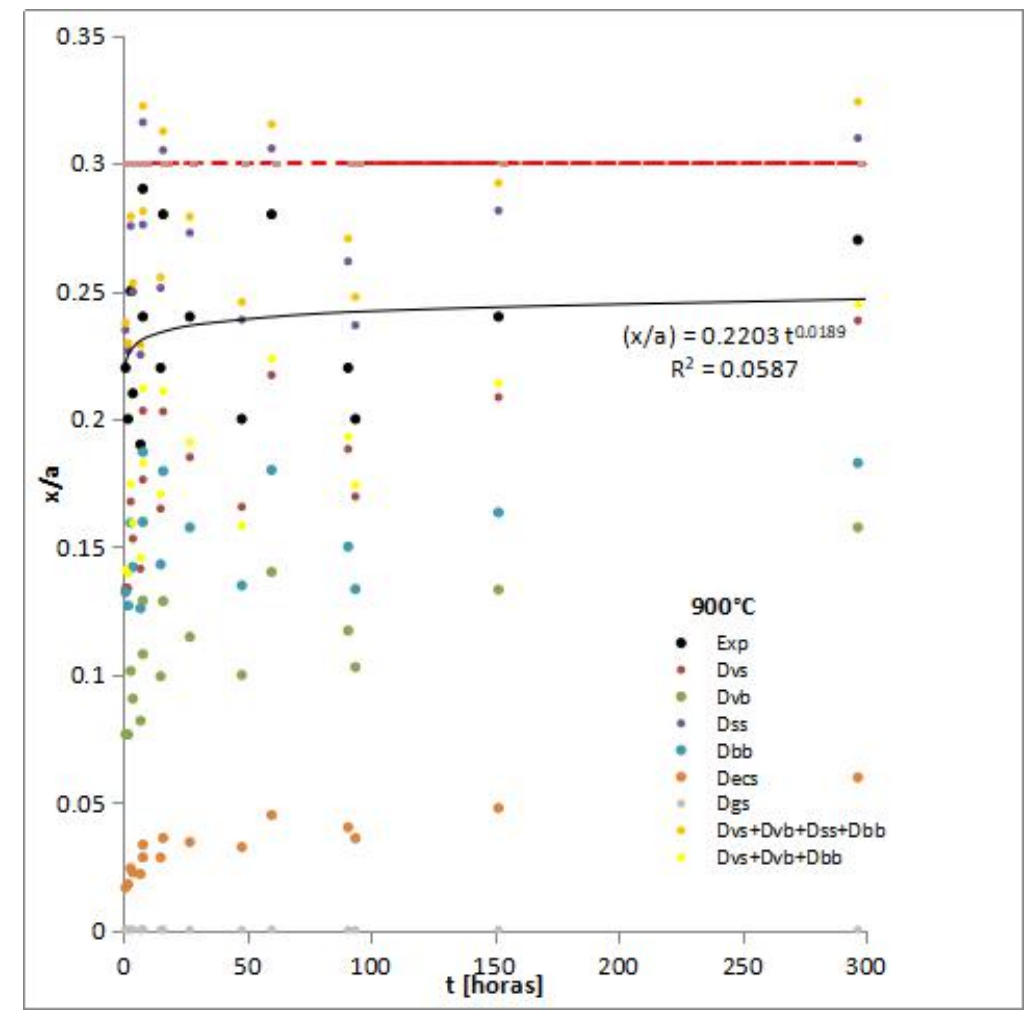

(b)

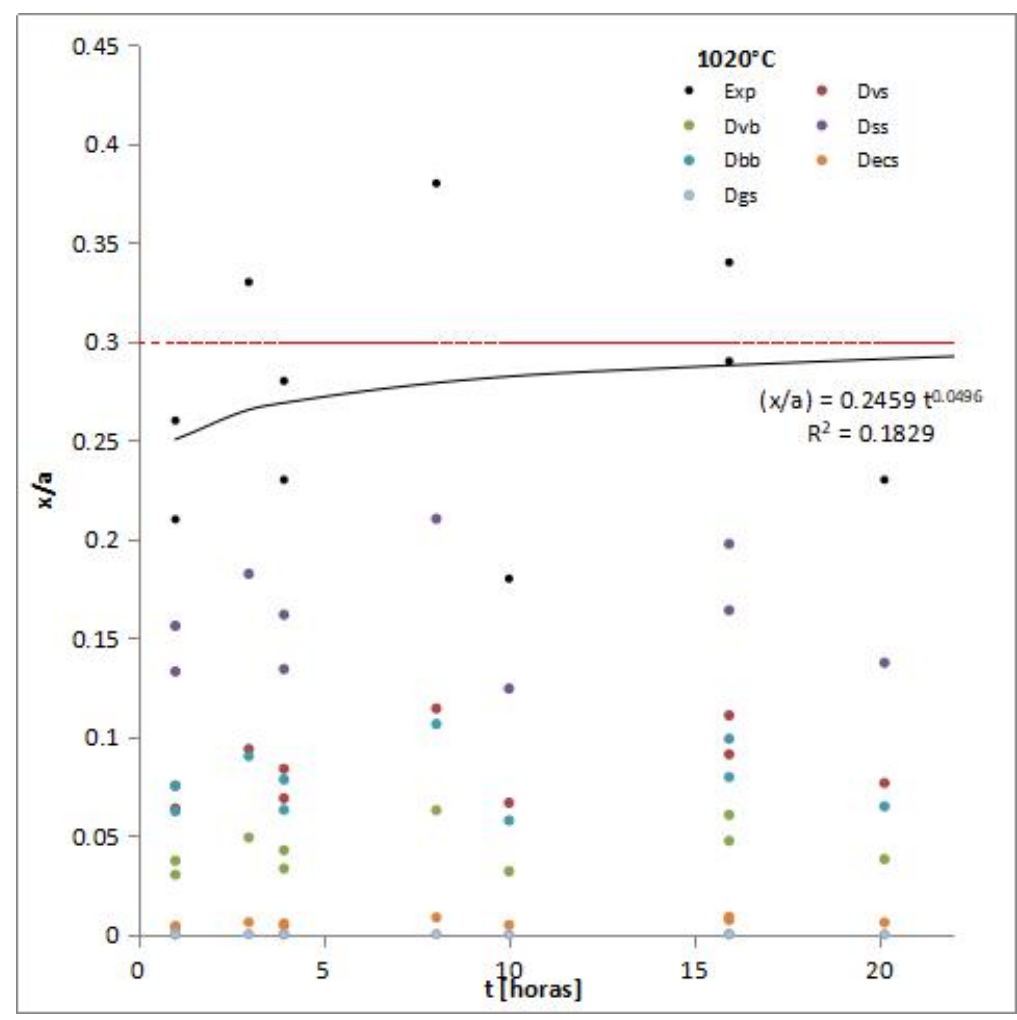

Figura 52: Gráficos entre $\left(\frac{x}{a}\right)$ vs tempo [horas] para as temperaturas de (a) $900^{\circ} \mathrm{C} \mathrm{e} \mathrm{(b)} 1000^{\circ} \mathrm{C}$ baseado nos dados de Wilson e Shewmon [WILSON, SHEWMON, 1964]. 
Nas duas análises gráficas é possível observar uma grande dispersão dos dados experimentais frente a reta e curva média calculada, por esta razão o expoente do tempo obtido foi muito elevado impossibilitando uma conclusão concreta por meio desta técnica.

Os autores, contudo, utilizaram o expoente do tempo para análise e conclusão do mecanismo dominante; para isso eles selecionaram um específico valor para a razão $\frac{x}{a}$, igual a 0,28 em ambas as temperaturas, e obtiveram os tempos correspondentes nas retas dos conjuntos analisados. O valor do expoente obtido correspondeu ao mecanismo da difusão superficial em ambos os casos, com uma considerável contribuição do mecanismo da difusão pelo contorno de grão.

Ashby [ASHBY, 1974] também analisou os resultados de Wilson e Shewmon com os diagramas de sinterização. A mesma conclusão publicada no artigo de que a difusão superficial é o mecanismo dominante foi obtida, além também de indícios da presença da difusão volumétrica, a qual se torna mais evidente e significativa para tamanhos de pescoço maiores. Ashby ainda salienta que a difusão superficial não é o mecanismo dominante ao longo de todo o processo da sinterização, quando $\frac{x}{a}=0,32$ a difusão volumétrica passa a ser o mecanismo dominante, e quando a temperatura estiver em torno de $55 \%$ da temperatura de fusão do cobre, a difusão pelo contorno de grão é a dominante. O erro relativo entre os valores esperados (calculado por Ashby) e os medidos (por Wilson e Shewmon) para os tamanhos de pescoço foi de $4 \%$.

Um detalhe muito interessante que Ashby comentou foi que a geometria utilizada por Wilson e Shewmon, uma fileira de esferas, caso fosse alterada para um compactado de esfera, resultaria em um novo mecanismo dominante. Ele ainda simulou os dados de Wilson e Shewmon para esta nova configuração e o resultado final foi que a difusão volumétrica a partir do contorno de grão torna-se o mecanismo dominante neste caso, isso deve-se ao fato de que em um compactado de esferas a força motriz da difusão superficial tende a zero para valores grandes de $\frac{x}{a}$ (quando os poros passam a ter geometria cilíndrica ou esférica), isto não significa que a sinterização cessa, apenas que outro mecanismo passa a atuar.

Wilson e Shewmon também avaliaram a contração das fileiras de esferas para as temperaturas de $650,750,850$ e $950{ }^{\circ} \mathrm{C}$. Na Figura 53, encontra-se a análise entre os dados experimentais e analíticos para a razão $\frac{\Delta L}{L_{0}}$. 
(a)

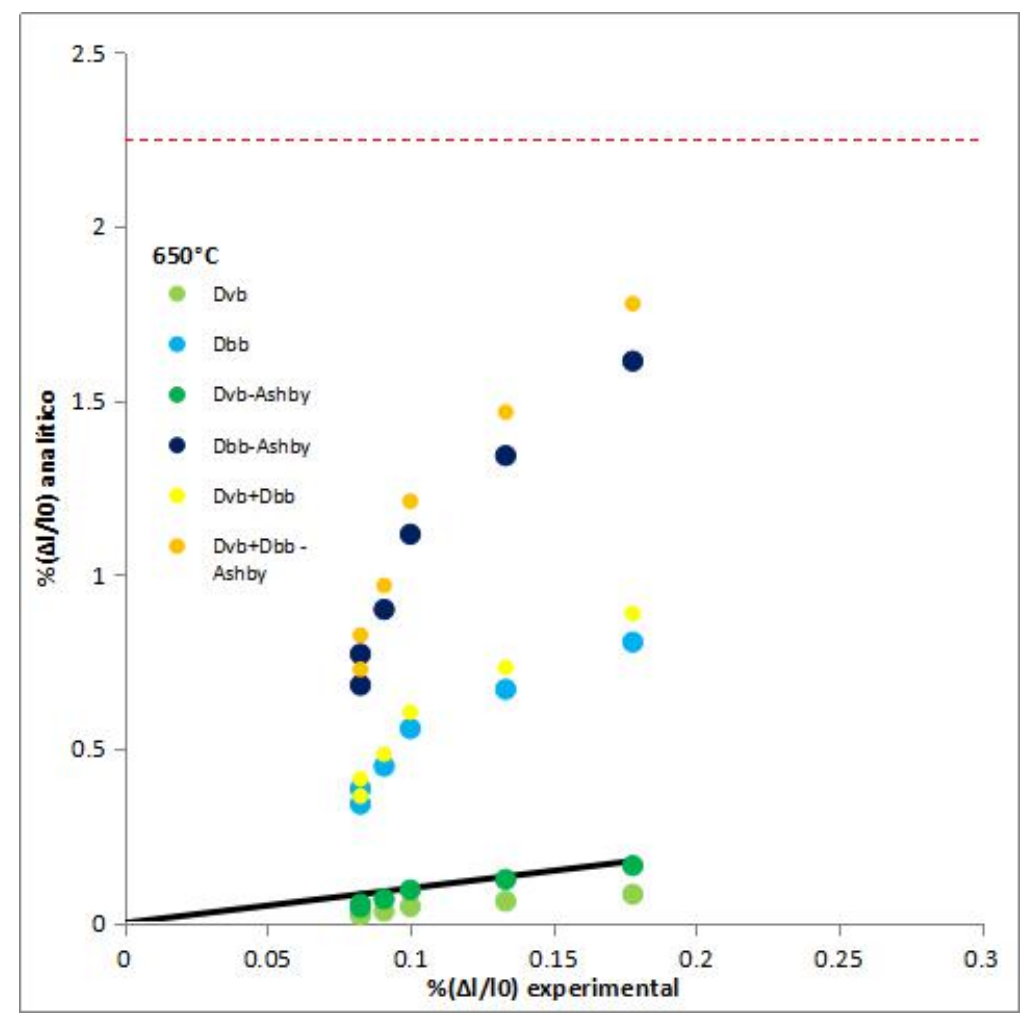

(b)

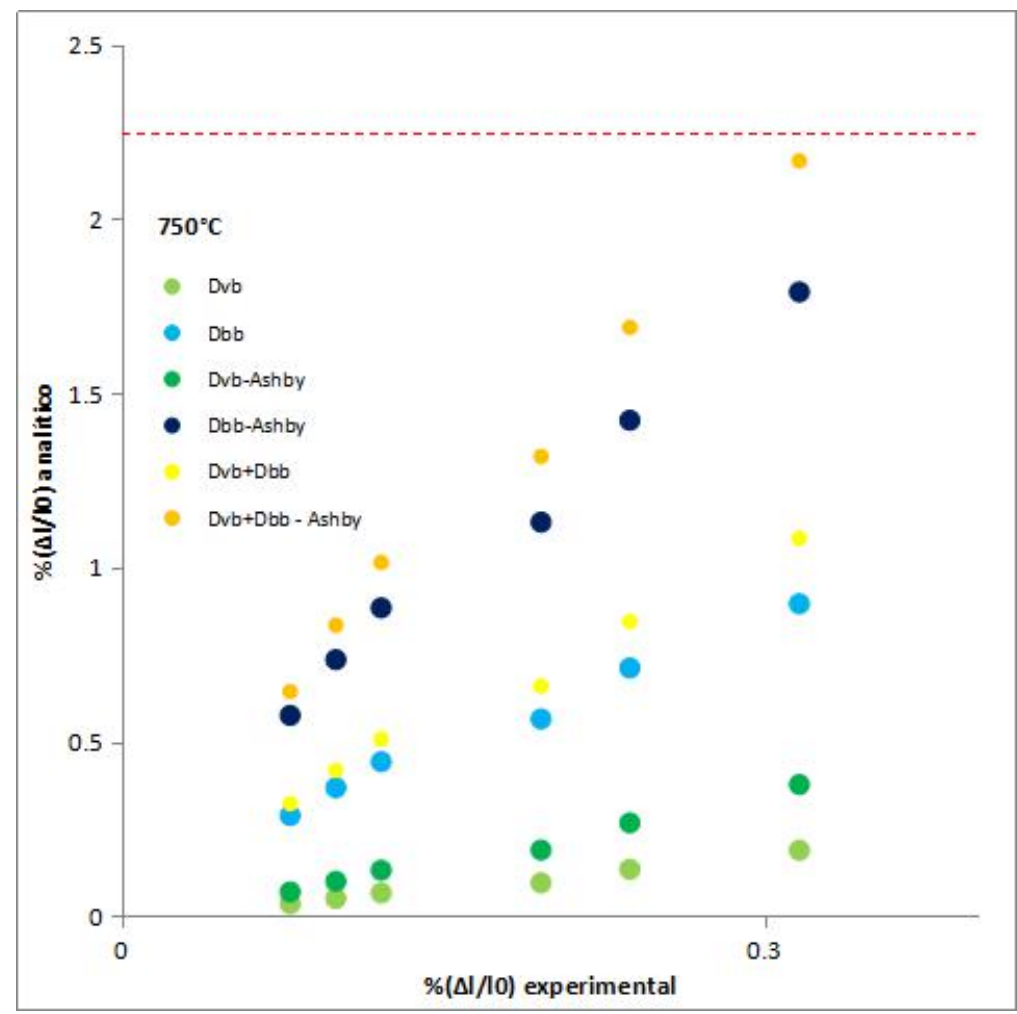


(c)

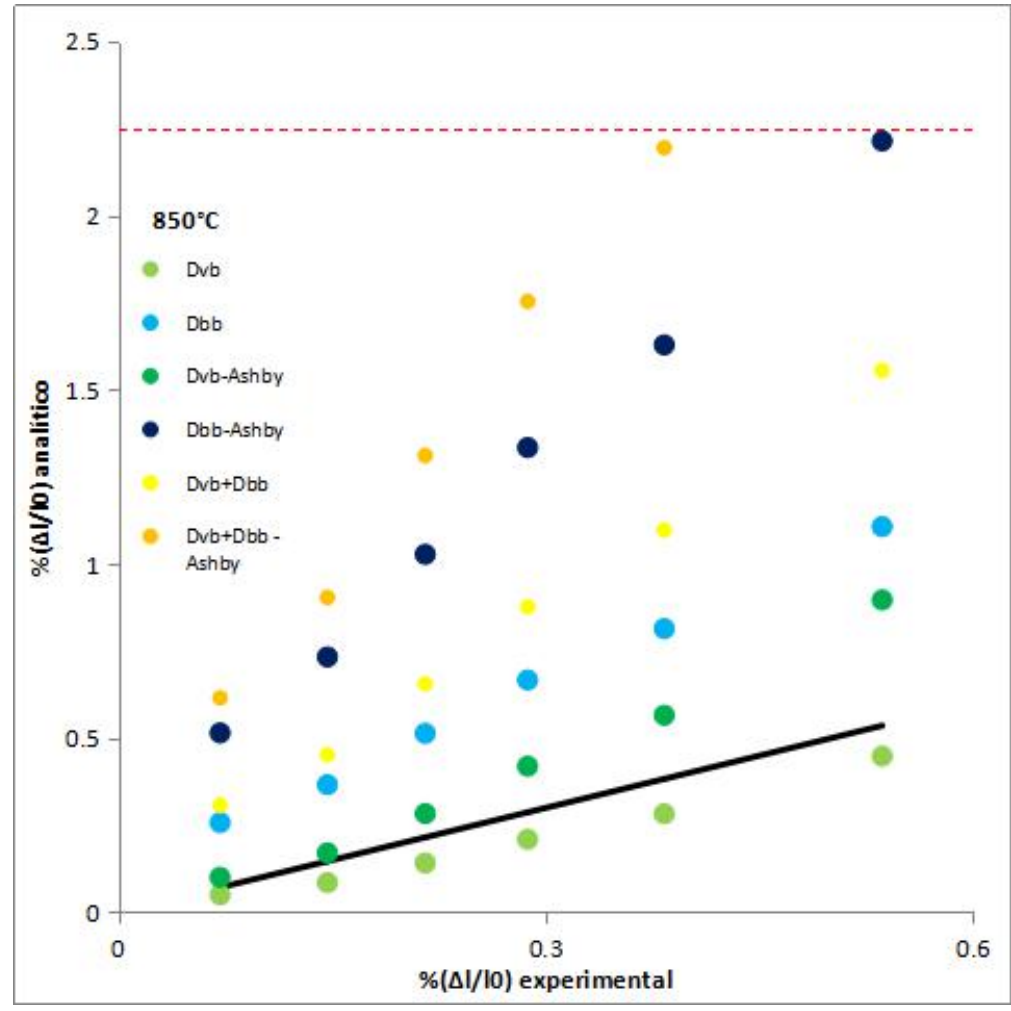

(d)

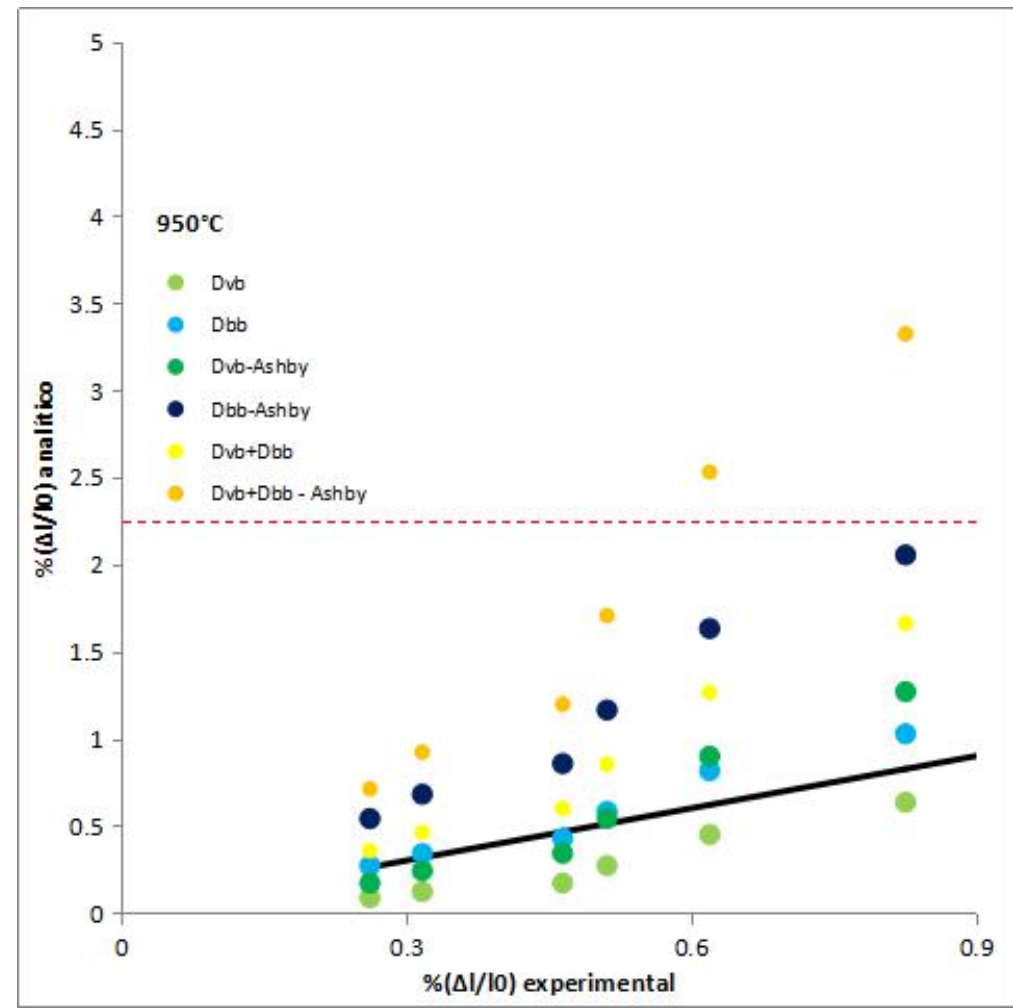

Figura 53: Gráficos comparativos entre $\frac{\Delta L}{L_{0}}$ experimental e $\frac{\Delta L}{L_{0}}$ analítico baseado nos dados de Wilson e Shewmon [WILSON, SHEWMON, 1964] para as temperaturas de (a) $650^{\circ} \mathrm{C}$, (b) $750^{\circ} \mathrm{C}$, (c) $850^{\circ} \mathrm{C}$ e (d) $950^{\circ} \mathrm{C}$.. 
A partir dos gráficos entre $\frac{\Delta L}{L_{0}}$ experimental e $\frac{\Delta L}{L_{0}}$ analítico, observa-se que o mecanismo dominante nas quatro temperaturas estudas é a difusão volumétrica a partir do contorno de grão, tanto aquele calculado considerando o raio do pescoço igual a $r=\frac{x^{2}}{4 a}$ (modelo para contração/ aproximação dos centros das partículas - Figura 7), quanto o que adota o raio do pescoço igual ao dos mecanismos não densificantes, sem aproximação dos centros das esferas, conforme proposto por Ashby $\left(r=\frac{x^{2}}{2 a}\right)$ [ASHBY, 1974].

Nas temperaturas mais baixas, 650 e $750{ }^{\circ} \mathrm{C}$, dentre os possíveis mecanismos que promovem a contração, o modelo da difusão volumétrica a partir do contorno de grão utilizando o mesmo raio de pescoço que os mecanismos sem contração, possui melhor aderência aos dados experimentais obtidos por Wilson e Shewmon [WILSON, SHEWMON, 1964]. O mesmo mecanismo nas temperaturas de 850 e $950{ }^{\circ} \mathrm{C}$, retrata bem os dados experimentais para $\frac{\Delta L}{L_{0}}$ pequeno, porém, quando esta razão aumenta, os valores analíticos distanciam-se consideravelmente dos experimentais. Em $950{ }^{\circ} \mathrm{C}$, além do mecanismo da difusão volumétrica a partir do contorno de grão, a difusão pelo contorno de grão também se aproxima dos dados experimentais, representados pela reta de equivalência de $45^{\circ}$.

A Tabela 23 apresenta a análise estatística realizada para os dados da contração.

Tabela 23: Análise estatística para os dados de contração.

\begin{tabular}{|c|c|c|c|c|c|c|}
\hline \multicolumn{2}{|c|}{$\begin{array}{c}\text { Temperatura/ Mecanismo de } \\
\text { Sinterização }\end{array}$} & $\begin{array}{c}\text { Erro } \\
\text { Relativo (\%) }\end{array}$ & Erro & SD & CI & $\mathbf{N}$ \\
\hline \multirow{6}{*}{$650^{\circ} \mathrm{C}$} & Dvb & 60.13 & 0.0650 & 0.0162 & \pm 0.0209 & \multirow{6}{*}{6} \\
\hline & Dvb - Ashby & 20.27 & 0.0189 & 0.0124 & \pm 0.0211 & \\
\hline & Dbb & 381.91 & -0.4243 & 0.1428 & \pm 0.1844 & \\
\hline & Dbb - Ashby & 863.81 & -0.9598 & 0.3212 & \pm 0.4149 & \\
\hline & Dvb+Dbb & 421.77 & -0.4705 & 0.1656 & \pm 0.2138 & \\
\hline & Dvb+Dbb - Ashby & 943.55 & -1.0521 & 0.3670 & \pm 0.4739 & \\
\hline \multirow{6}{*}{$750^{\circ} \mathrm{C}$} & $\overline{\text { Dvb }}$ & 48.19 & 0.0807 & 0.0348 & \pm 0.0449 & \multirow{6}{*}{6} \\
\hline & Dvb - Ashby & 9.45 & -0.0135 & 0.0270 & \pm 0.0349 & \\
\hline & Dbb & 228.23 & -0.3699 & 0.1367 & \pm 0.1766 & \\
\hline & Dbb - Ashby & 556.46 & -0.9146 & 0.3642 & \pm 0.4703 & \\
\hline & $\mathrm{Dvb}+\mathrm{Dbb}$ & 280.03 & -0.4641 & 0.1944 & \pm 0.2511 & \\
\hline & Dvb+Dbb - Ashby & 660.07 & -1.1029 & 0.4798 & \pm 0.6196 & \\
\hline \multirow{2}{*}{$850^{\circ} \mathrm{C}$} & Dvb & 29.17 & 0.0702 & 0.0274 & \pm 0.0354 & \multirow{2}{*}{6} \\
\hline & Dvb - Ashby & 41.66 & -0.1329 & 0.1275 & \pm 0.1274 & \\
\hline
\end{tabular}




\begin{tabular}{|c|c|c|c|c|c|c|}
\hline & Dbb & 150.02 & -0.3478 & 0.1435 & \pm 0.1853 & \\
\hline & Dbb - Ashby & 400.04 & -0.9690 & 0.4545 & \pm 0.5870 & \\
\hline & $\mathrm{Dvb}+\mathrm{Dbb}$ & 220.85 & -0.5510 & 0.2896 & \pm 0.3741 & \\
\hline & Dvb+Dbb - Ashby & 541.71 & -1.3753 & 0.7469 & \pm 0.9646 & \\
\hline \multirow{6}{*}{$950^{\circ} \mathrm{C}$} & Dvb & 45.35 & 0.2286 & 0.0640 & \pm 0.0719 & \multirow{6}{*}{7} \\
\hline & Dvb - Ashby* & 33.40 & -0.1429 & 0.2743 & \pm 0.3078 & \\
\hline & Dbb & 13.45 & -0.0756 & 0.0916 & \pm 0.1028 & \\
\hline & Dbb-Ashby & 122.47 & -0.7523 & 0.4376 & \pm 0.4910 & \\
\hline & $\mathrm{Dvb}+\mathrm{Dbb}$ & 65.89 & -0.4481 & 0.3550 & \pm 0.3983 & \\
\hline & Dvb+Dbb - Ashby & 231.77 & -1.4974 & 1.0219 & \pm 1.1466 & \\
\hline
\end{tabular}

Com 5\% de significância, o mecanismo da difusão volumétrica a partir do contorno de grão pelo método de Ashby apresenta-se como dominante para as temperaturas de 650 e 750 ${ }^{\circ} \mathrm{C}$. Este mecanismo apresenta os menores valores de erro e de erro relativo. Não se pode afirmar nada quanto a temperatura de $850^{\circ} \mathrm{C}$, porém analisando apenas o erro e o erro relativo, a difusão volumétrica a partir do contorno de grão possui os menores valores. Na temperatura de $950{ }^{\circ} \mathrm{C}$, a difusão volumétrica a partir do contorno de grão por Ashby e a difusão pelo contorno de grão apresentam-se como os possíveis mecanismos dominantes, porém a difusão volumétrica a partir do contorno de grão possui um erro relativo superior a $30 \%$ e, pela análise gráfica, este mecanismo não reproduz satisfatoriamente os dados experimentais.

Johnson [JOHNSON, 1969] também analisou os dados de Wilson e Shewmon com o modelo combinado dos mecanismos para a contração. O modelo por ele desenvolvido não foi capaz de reproduzir os dados experimentais. Uma possível justificativa para isso seria o fato de que para coleta dos dados referentes a formação e crescimento do pescoço, o conjunto das fileiras de esferas era removido do forno em determinados tempos e levados para análise em um microscópio eletrônico. Essa ação de retirada e retomada do conjunto ao forno pode ter provocado a recristalização bem como o desaparecimento dos contornos de grão entre as esferas. Essas perdas são responsáveis por encerrar a contração nessas regiões do pescoço, contudo elas não afetam o fluxo de material para as regiões do pescoço provenientes das superfícies das esferas.

A análise via expoente do tempo foi realizada ao traçar os gráficos entre $\frac{\Delta L}{L_{0}}$ e o tempo nas escalas logarítmica (Figura 54) e linear (Figura 55). 
(a)

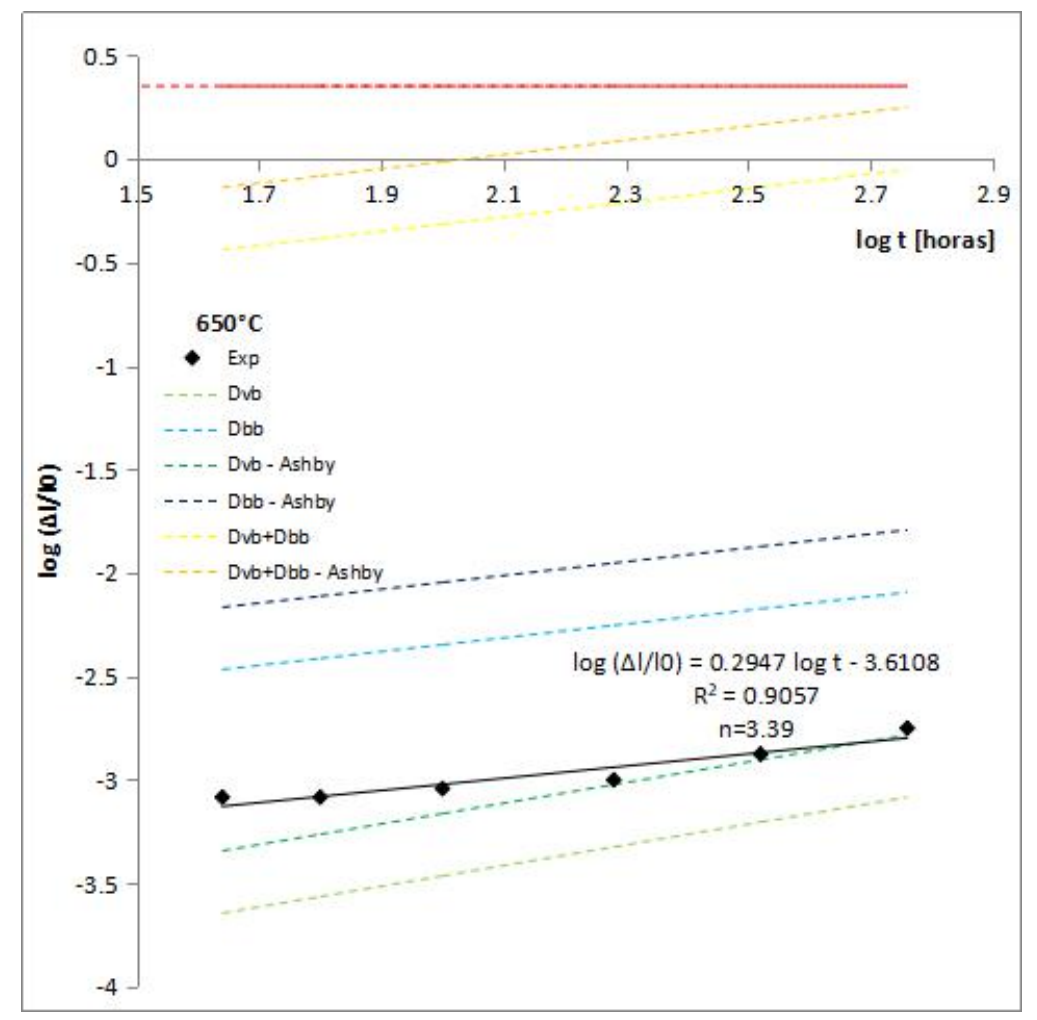

(b)

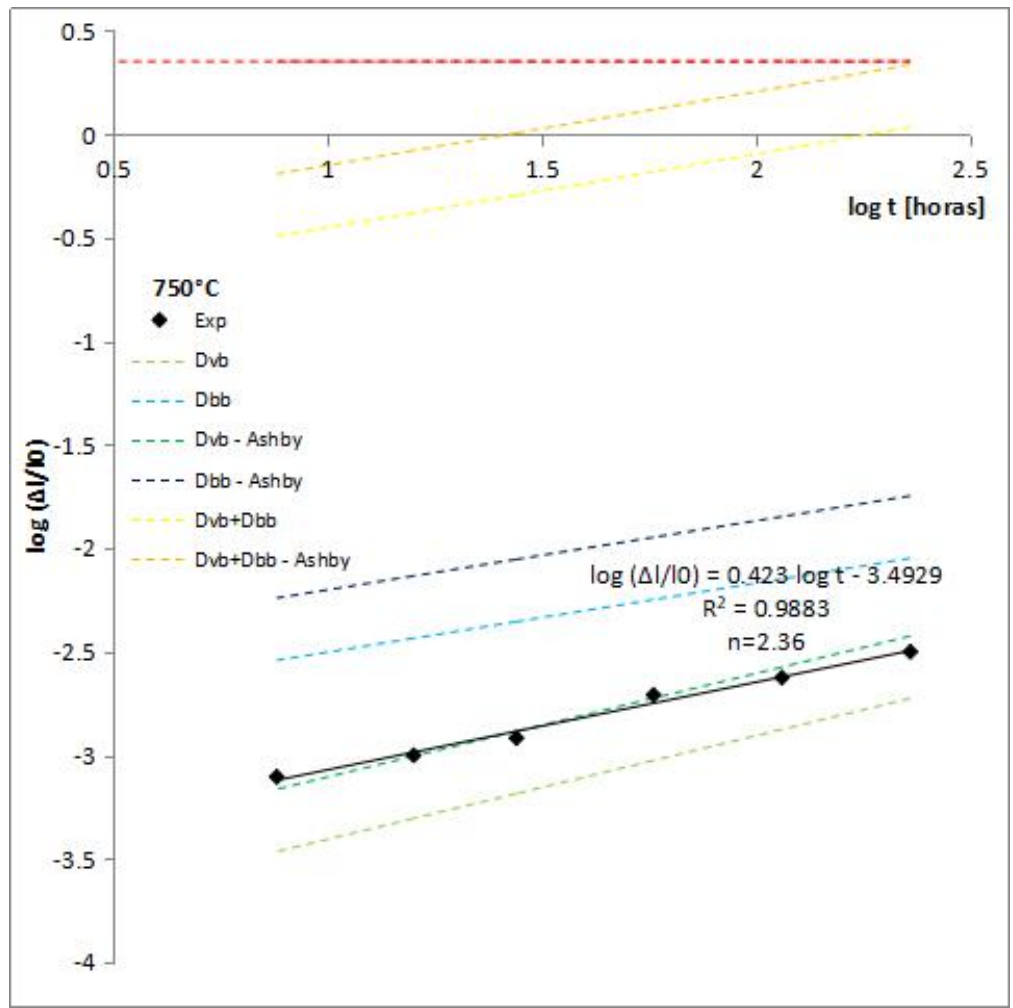


(c)

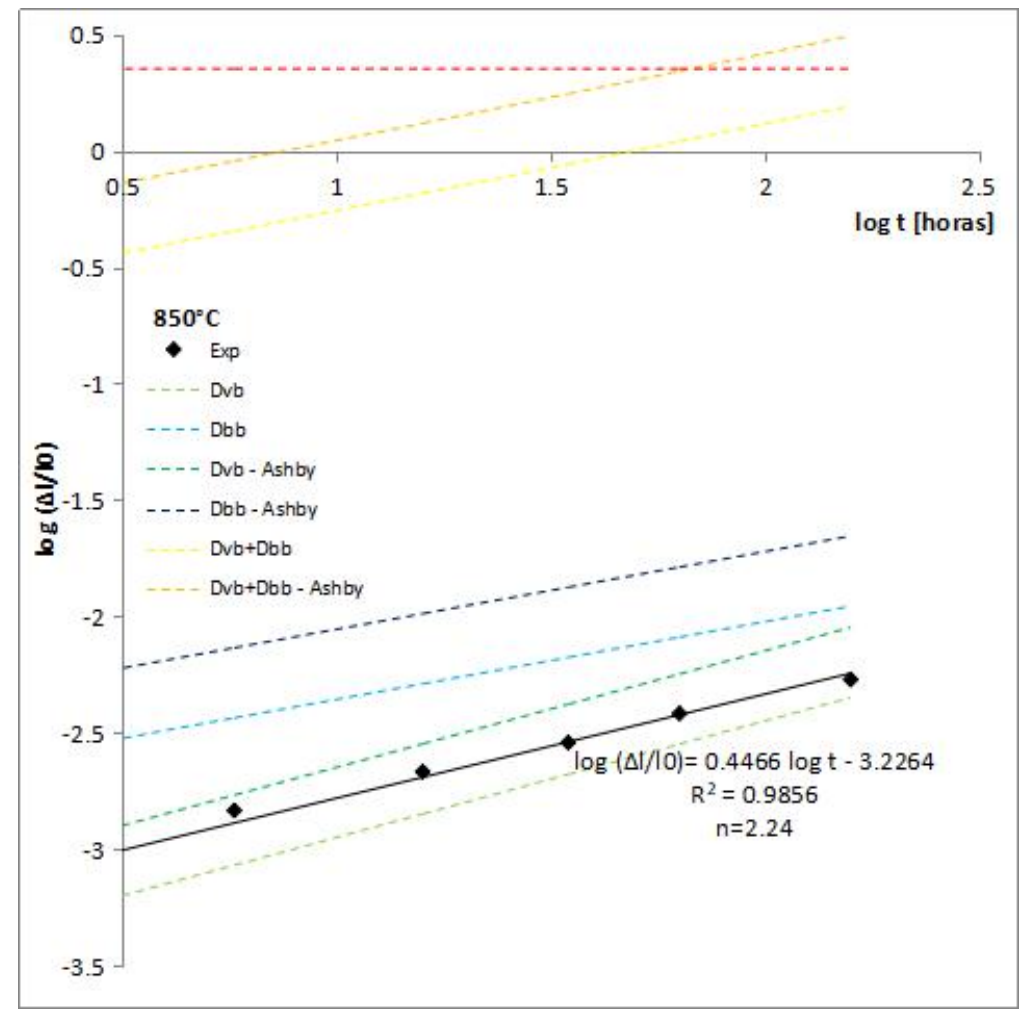

(d)

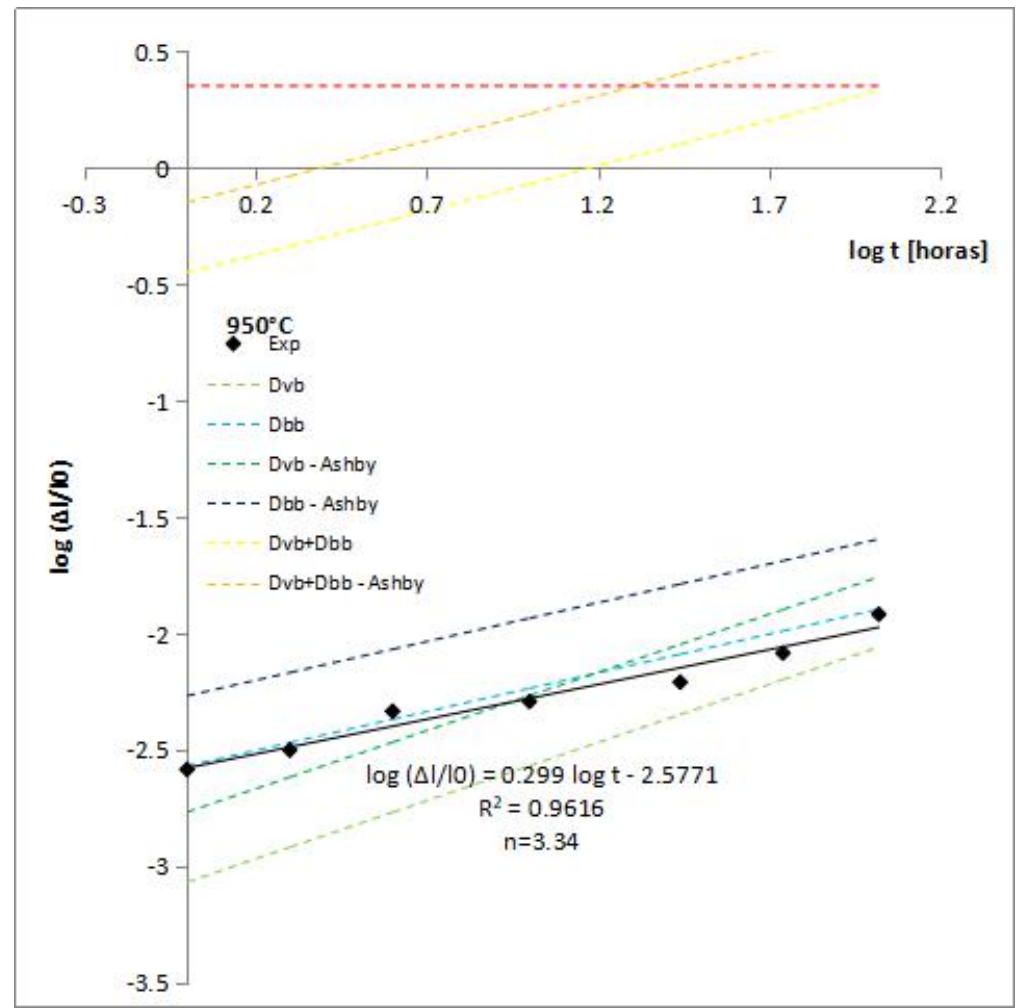

Figura 54: Gráficos entre $\log \left(\frac{\Delta L}{L_{0}}\right)$ vs $\log \mathrm{t}$ [horas] para as temperaturas de (a) $650^{\circ} \mathrm{C}$, (b) $750^{\circ} \mathrm{C}$, (c) $850^{\circ} \mathrm{C}$ e (d) $950{ }^{\circ} \mathrm{C}$ dos dados publicados por Wilson e Shewmon [WILSON, SHEWMON, 1964]. 
(a)

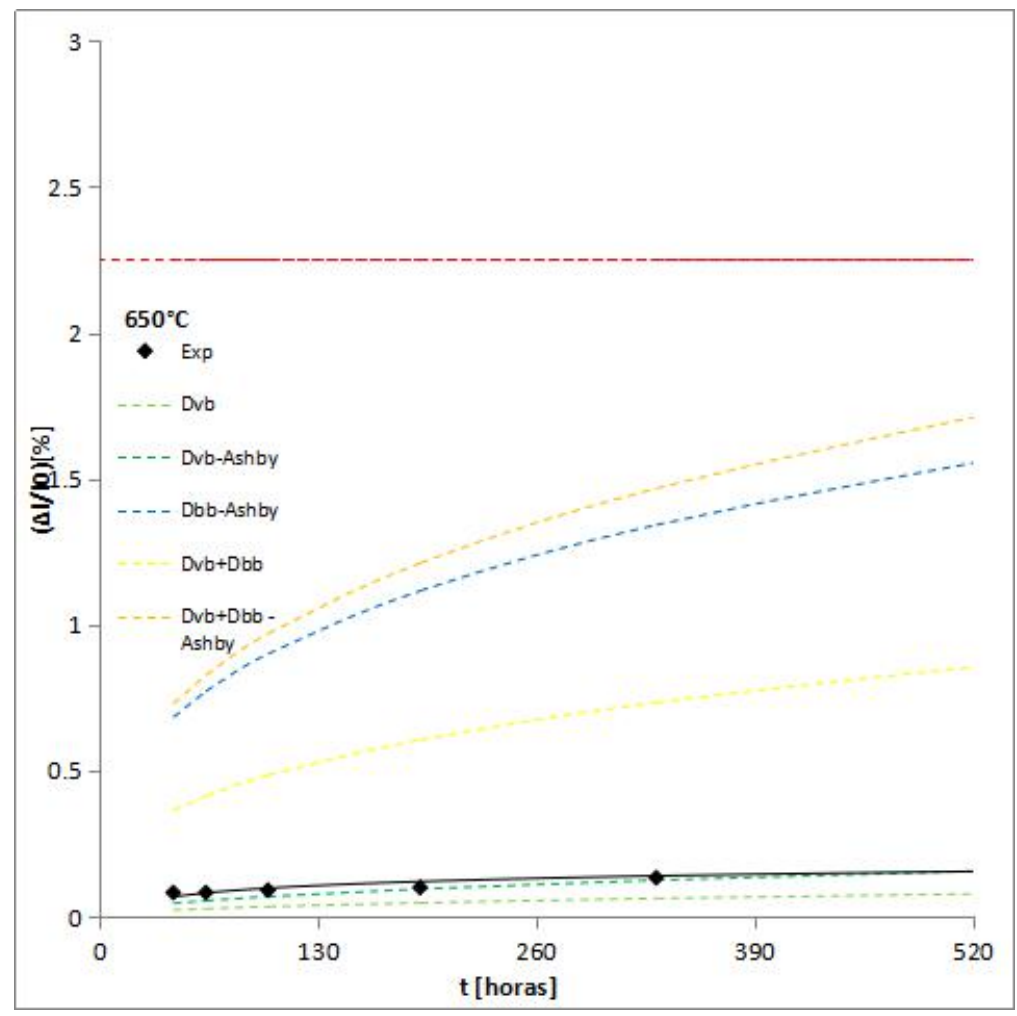

(b)

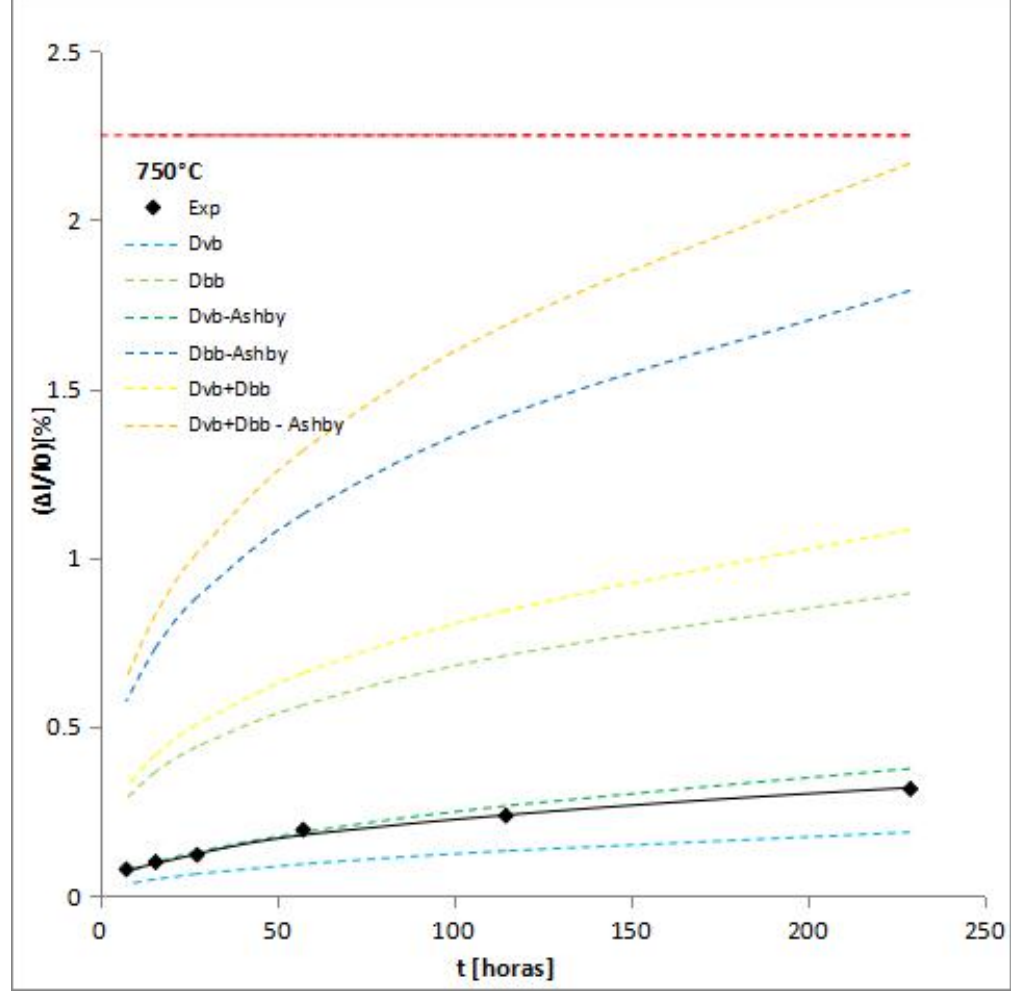


(c)

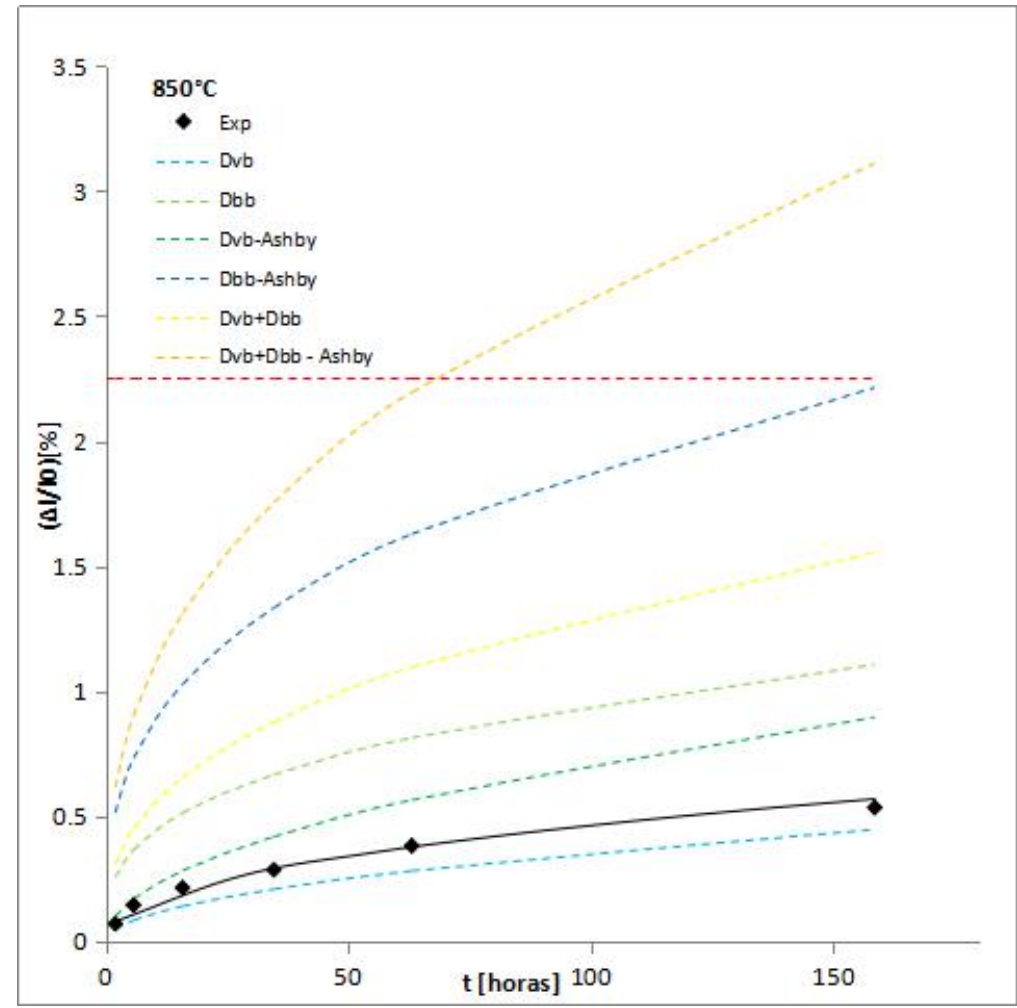

(d)

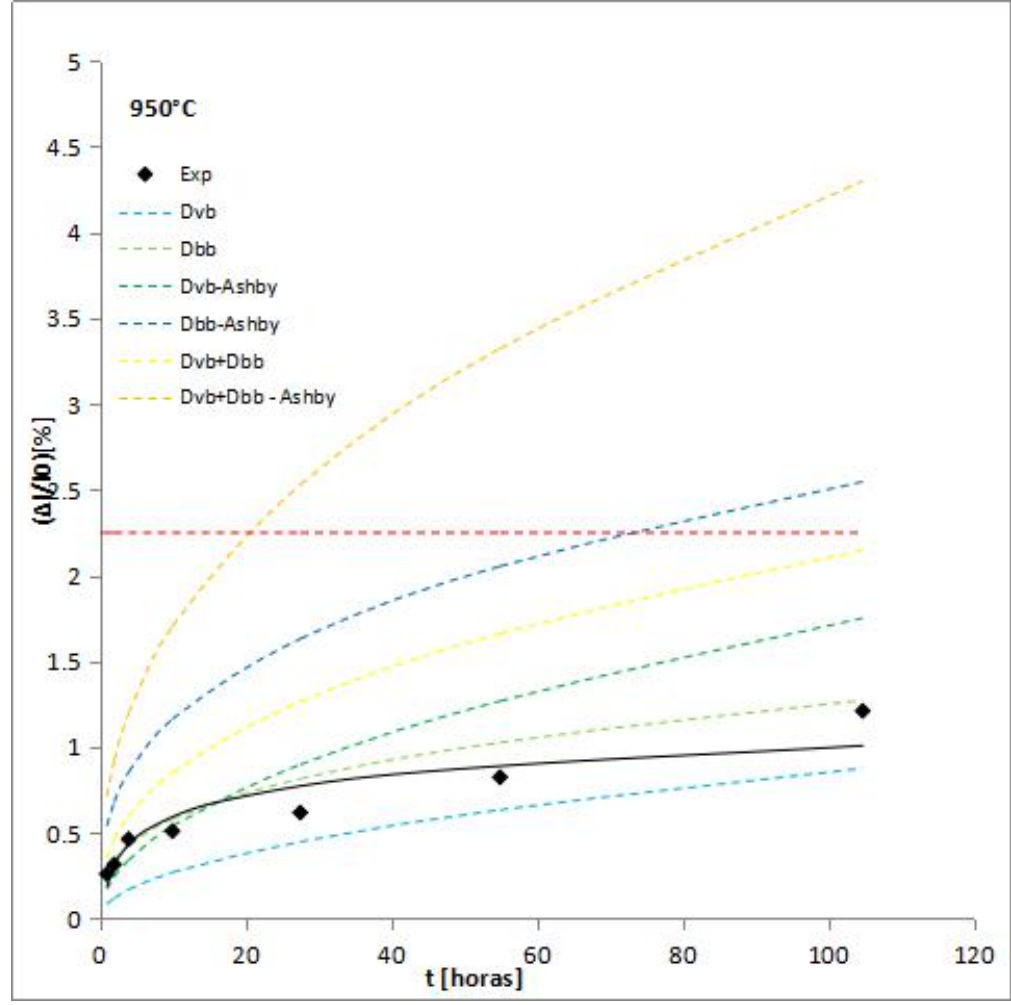

Figura 55: Gráficos entre $\frac{\Delta L}{L_{0}}$ vs $\mathrm{t}$ [horas] para as temperaturas de (a) $650^{\circ} \mathrm{C}$, (b) $750^{\circ} \mathrm{C}$, (c) $850^{\circ} \mathrm{C}$ e (d) $950^{\circ} \mathrm{C}$ dos dados publicados por Wilson e Shewmon [WILSON, SHEWMON, 1964]. 
Nos gráficos de $\frac{\Delta L}{L_{0}}$ pelo tempo (Figura 54 e Figura 55), observa-se o mesmo comportamento dos mecanismos comparados nos gráficos entre $\frac{\Delta L}{L_{0}}$ experimental pelo $\frac{\Delta L}{L_{0}}$ analítico. Os expoentes do tempo para as temperaturas analisadas ficaram entre 2 e 4, sendo que os possíveis mecanismos seriam: difusão volumétrica a partir do contorno de grão $(\mathrm{n}=2)$ ou difusão pelo contorno de grão (n=3).

A Tabela 24 apresenta um resumo dos artigos estudados bem como a conclusões originais, conclusões de outros autores para aquele estudo e conclusão do presente trabalho. 
Tabela 24: Resumo das conclusões obtidas originalmente nos artigos, de outros estudos relacionados a estes artigos e do presente trabalho.

\begin{tabular}{|c|c|c|c|c|}
\hline \multirow{2}{*}{ AUTOR(ES) } & \multicolumn{4}{|c|}{ CONCLUSÕES: MECANISMO DOMINANTE } \\
\hline & ORIGINAL & \multicolumn{2}{|c|}{ OUTROS TRABALHOS } & PRESENTE TRABALHO \\
\hline $\begin{array}{c}\text { KUCZYNSKI } \\
(1949)\end{array}$ & $\begin{array}{c}\text { Difusão } \\
\text { volumétrica }\end{array}$ & $\begin{array}{c}\text { Ashby, } \\
1974\end{array}$ & $\begin{array}{l}\text { Difusão superficial } \\
\text { Em baixas T: } \\
\text { difusão pelo } \\
\text { contorno de grão }+ \\
\text { difusão volumétrica }\end{array}$ & $\begin{array}{c}600^{\circ} \mathrm{C}: \text { mecanismos } \\
\text { combinados. } \\
700^{\circ} \mathrm{C} \text { e } 800^{\circ} \mathrm{C}: \mathrm{D}_{\mathrm{bb}}+ \\
\text { mecanismo combinado. }\end{array}$ \\
\hline \multirow[t]{2}{*}{$\begin{array}{l}\text { KINGERY e } \\
\text { BERG (1955) }\end{array}$} & \multirow{2}{*}{$\begin{array}{l}\text { Difusão } \\
\text { volumétrica a } \\
\text { partir dos } \\
\text { contornos de } \\
\text { grão }\end{array}$} & $\begin{array}{c}\text { Johnson, } \\
1969\end{array}$ & $\begin{array}{l}\text { Contração: Difusão } \\
\text { volumétrica a partir } \\
\text { do contorno de grão } \\
\text { e Difusão pelo } \\
\text { contorno de grão } \\
\text { (mecanismo } \\
\text { combinado) }\end{array}$ & \multirow{2}{*}{$\begin{array}{c}\text { Formação do pescoço: } \mathrm{D}_{\mathrm{ss}}+ \\
\text { mecanismo combinado } \\
\left(\mathrm{D}_{\mathrm{vb}}+\mathrm{D}_{\mathrm{vs}}+\mathrm{D}_{\mathrm{ss}}+\mathrm{D}_{\mathrm{bb}}\right) \\
\text { Contração: mecanismo } \\
\text { combinado }\left(\mathrm{D}_{\mathrm{vb}}+\mathrm{D}_{\mathrm{bb}}\right)\end{array}$} \\
\hline & & $\begin{array}{c}\text { Ashby, } \\
1974\end{array}$ & $\begin{array}{l}\text { Difusão superficial } \\
\text { com significativa } \\
\text { contribuição da } \\
\text { difusão volumétrica } \\
\text { (densificação). }\end{array}$ & \\
\hline $\begin{array}{c}\text { ALEXANDER } \\
\text { e BALLUFFI } \\
(1957)\end{array}$ & $\begin{array}{c}\text { Difusão } \\
\text { volumétrica a } \\
\text { partir do } \\
\text { contorno de } \\
\text { grão } \\
\text { (contração) e } \\
\text { Difusão } \\
\text { volumétrica a } \\
\text { partir da } \\
\text { superfície } \\
\text { (formação do } \\
\text { pescoço) }\end{array}$ & $\begin{array}{c}\text { Swinkles, } \\
\text { Ashby, } \\
1981\end{array}$ & $\begin{array}{c}t<10 h \text { - difusão } \\
\text { superficial. } \\
10 \leqq t \leqq 50 h- \\
\text { difusão superficial } \\
+ \text { difusão } \\
\text { volumétrica. } \\
t>50 h \text { - difusão } \\
\text { volumétrica a partir } \\
\text { do contorno de } \\
\text { grão. }\end{array}$ & $\begin{array}{c}900{ }^{\circ} \mathrm{C}: \mathrm{D}_{\mathrm{vs}}, \mathrm{D}_{\mathrm{bb}} \mathrm{e} \\
\text { mecanismo combinado } \\
\left(\mathrm{D}_{\mathrm{vs}}+\mathrm{D}_{\mathrm{vb}}+\mathrm{D}_{\mathrm{bb}}\right) \\
1000 \text { e } 1050{ }^{\circ} \mathrm{C}: \mathrm{D}_{\mathrm{vs}} \mathrm{e} \\
\text { mecanismo combinado } \\
\quad\left(\mathrm{D}_{\mathrm{vs}}+\mathrm{D}_{\mathrm{vb}}+\mathrm{D}_{\mathrm{bb}}\right) .\end{array}$ \\
\hline $\begin{array}{l}\text { PRANATIS e } \\
\text { SEIGLE (1960) }\end{array}$ & $\begin{array}{c}\text { Difusão } \\
\text { volumétrica }\end{array}$ & $\begin{array}{c}\text { Swinkles, } \\
\text { Ashby, } \\
1981\end{array}$ & $\begin{array}{l}\text { Difusão superficial } \\
\text { e difusão } \\
\text { volumétrica } \\
\text { igualmente. }\end{array}$ & $\begin{array}{c}\phi=0,004^{\prime \prime} \text { : Difusão } \\
\text { volumétrica a partir da } \\
\text { superfície }\left(\mathrm{D}_{\mathrm{vs}}\right) \text { e mecanismo } \\
\text { combinado }\left(\mathrm{D}_{\mathrm{vb}}+\mathrm{D}_{\mathrm{vs}}+\mathrm{D}_{\mathrm{bb}}\right) .\end{array}$ \\
\hline & & $\begin{array}{c}\text { Johnson, } \\
1969 \\
\end{array}$ & $\begin{array}{l}\text { Nenhuma } \\
\text { conclusão. }\end{array}$ & \\
\hline $\begin{array}{c}\text { WILSON e } \\
\text { SHEWMON } \\
(1966)\end{array}$ & $\begin{array}{c}\text { Difusão } \\
\text { superficial } \\
\text { com } \\
\text { contribuição } \\
\text { da difusão } \\
\text { pelo contorno } \\
\text { de grão para } \\
\text { a contração }\end{array}$ & $\begin{array}{c}\text { Ashby, } \\
1974\end{array}$ & $\begin{array}{c}\text { Difusão superficial } \\
\text { com significativa } \\
\text { contribuição da } \\
\text { difusão } \\
\text { volumétrica. } \\
\frac{x}{a}>0,32 \text { - difusão } \\
\text { volumétrica, } \\
0,55 T_{m} \text { - difusão } \\
\text { pelo contorno de } \\
\text { grão. }\end{array}$ & $\begin{array}{c}\text { Contração: } \\
650 \text { e } 750^{\circ} \mathrm{C}: \mathrm{D}_{\mathrm{vb}} \text { por } \\
\text { Ashby. } \\
950^{\circ} \mathrm{C}: \mathrm{D}_{\mathrm{bb}} .\end{array}$ \\
\hline
\end{tabular}




\subsection{Aplicação do Modelo de Campo de Fases para Simular os Mecanismos do Estágio I da Sinterização}

No item 4.3 foi apresentado em detalhes um modelo matemático bidimensional baseado na técnica do campo de fases para simular o estágio I da sinterização. O objetivo inicial do desenvolvimento deste modelo era o de simular a sinterização de cilindros enfileirados de cobre puro durante todo o período que caracteriza o estágio I. Um objetivo especifico do modelo desenvolvido foi o de escolher parâmetros numéricos que representassem corretamente as curvaturas das superfícies do pescoço e do grão e garantir a correta imposição da energia de superfície e do equilíbrio termodinâmico local próximo à interface sólido-fase fictícia, refletindo-se no cálculo correto pelo modelo das frações de lacunas junto à interface. Em outras palavras, objetivou-se o desenvolvimento de um modelo de campo de fases quantitativo para simular a sinterização.

Ao longo do desenvolvimento do trabalho, notou-se a existência de limitações numéricas muito severas para garantir todas estas características objetivadas. De forma geral, estas limitações se resumem à necessidade de uma malha numérica com um número de elementos que frequentemente ultrapassava a capacidade de memória RAM dos computadores pessoais atuais e à necessidade de passos de tempo numéricos excessivamente reduzidos para evitar instabilidades numéricas, o que reduzia significativamente o tempo de sinterização possível de simular viavelmente. Essas instabilidades numéricas foram exaustivamente estudadas na modelagem numérica, sem empregar o método do campo de fases "phase field method", de problemas de difusão de soluto sem ou com convecção (no caso de líquidos) e suas origens e métodos de eliminação são muito bem conhecidas atualmente. No entanto, a resolução e instabilidades numérica das equações acopladas dos modelos de campo de fases, particularmente do modelo utilizado no presente trabalho, foram muito pouco estudadas. Durante a execução do presente trabalho, os chamados termos-fonte $\left(\phi, X_{v}\right)$ da equação da variável de fase resultaram com muita frequência em instabilidades numéricas na maior parte dos problemas examinados. Desta forma, as condições numéricas de cada simulação conduzida serão sempre apresentadas, pois muitas vezes envolveram um longo processo de tentativa-e-erro.

Em trabalhos anteriores de modelagem da sinterização utilizando o método do campo de fases, como aquele apresentado por Asp e Agren [ASP, AGREN, 2006], não houve a preocupação ou cuidado de verificar se a malha numérica e a espessura da interface difusa 
utilizadas foram adequadas para representar geometricamente o raio de curvatura do pescoço, que inicialmente é nulo, para garantir o equilíbrio termodinâmico local (correta fração de lacunas) próximo à interface sólido-fase fictícia e finalmente para impor corretamente a energia de superfície. Por exemplo, a utilização por Asp e Agren [ASP, AGREN, 2006] do modelo WBM [WHEELER et al., 1992], não garante a imposição da correta energia de superfície, que também não foi verificada por estes autores pela Equação (138) em seus resultados numéricos. Não se observa uma atenção especial na escolha dos parâmetros numéricos, que muitas vezes são inclusive omitidos Estes trabalhos podem então ser considerados semi-quantitativos.

O modelo desenvolvido foi utilizado para simular diversas situações que envolvem fenômenos importantes da sinterização, como a difusão de lacunas pelo reticulado, o efeito da curvatura sobre a fração de lacunas em regiões próximas à interface sólido-fase fictícia (segundo o equilíbrio termodinâmico local) e a diminuição das curvaturas da superfície do sistema. No item 5.3.1, os resultados de cálculos termodinâmicos do efeito da curvatura na fração molar de lacunas no sólido serão apresentados para auxiliar no entendimento das condições adotadas para todas as simulações. No item 5.3.2, serão apresentados resultados de simulação para uma superfície (interface sólido-fase fictícia) plana, onde não há efeito de curvatura, mas que pode ser entendido como o caso de um raio de curvatura excessivamente grande. Posteriormente, os efeitos da curvatura da superfície serão observados em simulações do crescimento/encolhimento de grãos e poros (itens 5.3.3 e 5.3.4) para finalmente simular o processo de sinterização envolvendo o grão e o pescoço formado (item 5.3.5). Em todas as simulações foram utilizadas as propriedades do cobre puro, apresentadas no item 4.4. Em razão das limitações mencionadas, não foi possível simular completamente a sinterização de todo o estágio I, mas apenas de trechos deste estágio.

\subsubsection{Efeito da Curvatura na Fração Molar de Lacunas em Equilíbrio}

A fração molar de lacunas dada pelo equilíbrio termodinâmico na fase sólida $\left(X_{v, e q}^{s}\right)$, considerada como cobre puro à temperatura de $1000{ }^{\circ} \mathrm{C}$, foi calculada pela Equação (101), desenvolvida a partir da termodinâmica clássica, e pelas Equações (103) e (104), desenvolvidas no presente trabalho a partir das curvas de energia livre introduzidas no modelo de campo de fases para a fase sólida $(s)$ e fictícia $\left(g^{\prime}\right)$ dadas pelas Equações (96), (97) e (98). 
(a)
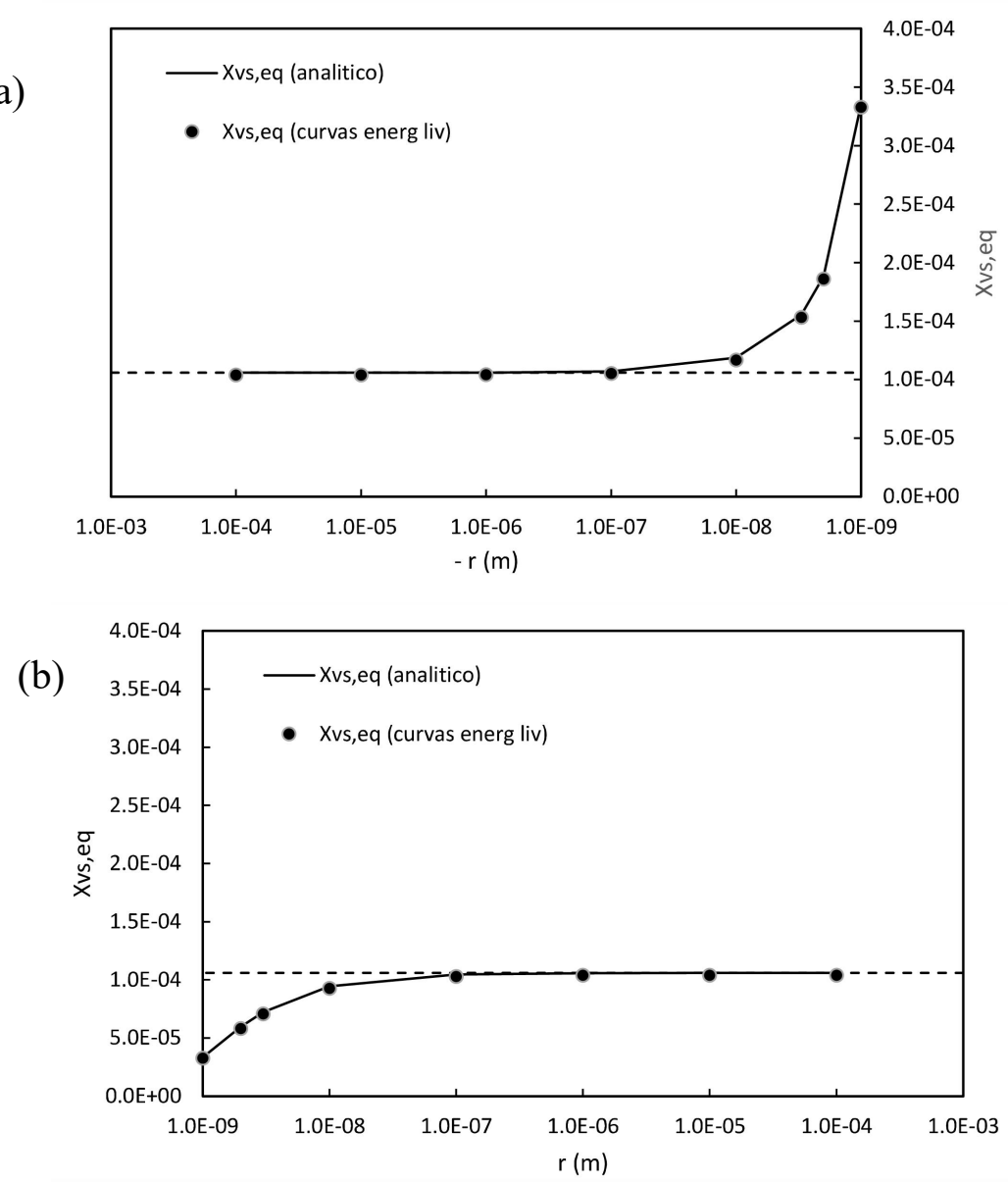

Figura 56: Fração molar de lacunas no cobre sólido puro em equilíbrio termodinâmico à temperatura de $1000^{\circ} \mathrm{C}$ em função do raio de curvatura: (a) raios de curvatura negativos (pescoço ou poro); (b) raios de curvatura positivos (grão).

A concordância entre os dois cálculos é excelente e mostra que o modelo termodinâmico adotado para descrever o equilíbrio local na interface sólido-fase fictícia fornece corretamente o efeito da curvatura sobre a fração de lacunas. No caso da interface plana ou de raio de curvatura relativamente elevado em módulo, a fração de lacunas de equilíbrio é de $X_{v, e q}^{s} \approx$ $1,039 \cdot 10^{-4}$. Nota-se que, no caso do pescoço ou de poros (raios de curvatura negativos), dado pela Figura 56(a) o efeito de curvatura passa a ser importante e aumentar a fração de lacunas para raios menores (em módulo) que $\approx 10^{-7} \mathrm{~m}$. Desta forma, no início da sinterização onde o raio de curvatura do pescoço tende a zero, a fração de lacunas tende ao infinito, o que em termos práticos representa uma fração muito elevada. Esta fração elevada resultará em um fluxo de átomos de cobre a partir do interior do grão e a partir da superfície (interface sólidofase fictícia) em direção à região do pescoço, como esperado. Por outro lado, nota-se que no caso dos grãos (raios de curvatura positivo) a Figura 56(b) mostra que a diminuição do seu raio de curvatura tem efeito significativo em valores também menores do que $\approx 10^{-7} \mathrm{~m}$. Os 
fios de cobre utilizados em um dos experimentos de Alexander e Balluffi [ALEXANDER, BALLUFFI, 1957], por exemplo, apresentavam diâmetro de $\approx 128 \mu \mathrm{m}$, indicando que a curvatura não tem qualquer efeito sobre a fração molar de lacunas e que esta fração é igual àquela em uma superfície plana. A elevação da temperatura aumenta todas as frações dadas na Figura 56, deslocando as curvas na direção ascendente, enquanto a diminuição da temperatura resulta em um deslocamento das curvas na direção descendente, diminuindo as frações de lacunas de equilíbrio.

\subsubsection{Movimentação Unidimensional da Superfície (Interface Sólido-Fase Fictícia)}

O modelo de campo de fases foi ajustado para simular a movimentação de um pequeno trecho de uma superfície (interface sólido-fase fictícia) em condições unidimensionais. A interface foi considerada plana, o que seria equivalente a um grão com raio de curvatura maior que $\approx 10^{-7} \mathrm{~m}$. O comprimento do domínio foi de $1,28 \cdot 10^{-7} \mathrm{~m}$ e a interface foi assumida inicialmente no centro. Como mencionado, o cobre sólido puro foi escolhido como material e a temperatura de simulação foi de $1000{ }^{\circ} \mathrm{C}$. Duas situações foram simuladas, uma onde a fração molar inicial de lacunas no sólido, $X_{v}=1,96 \cdot 10^{-4}$, maior do que a fração de equilíbrio na temperatura de $1000{ }^{\circ} \mathrm{C}\left(1,04 \cdot 10^{-4}\right)$ e outra onde $X_{v}=7,75 \cdot 10^{-7}$, menor do que a fração de equilíbrio. A primeira situação seria equivalente a expor o cobre sólido à temperatura de 1080 ${ }^{\circ} \mathrm{C}$, próximo à sua temperatura de fusão, esperar o equilíbrio de lacunas ser atingido e posteriormente resfriar o sólido abruptamente até $1000{ }^{\circ} \mathrm{C}$. A segunda situação seria semelhante à primeira, porém o cobre seria inicialmente mantido à temperatura de $600{ }^{\circ} \mathrm{C}$ até atingir a fração de equilíbrio de lacunas nesta temperatura e posteriormente aquecer o sólido até $1000{ }^{\circ} \mathrm{C}$. Os demais parâmetros utilizados nas simulações estão apresentados na Tabela 25 . A mobilidade da variável de fase, $M_{\phi}$, foi adotada como $0,137 \mathrm{~J}^{-1} \cdot \mathrm{s}^{-1}$. Quanto maior o valor de $M_{\phi}$, mais rapidamente o equilíbrio local é atingido nas fases junto à interface, porém valores relativamente elevados podem causar instabilidades numéricas ou requerer um passo de tempo numérico excessivamente reduzido, resultando em tempos de simulação inviáveis. Desta forma, o valor de $M_{\phi}$ foi determinado em um processo de tentativa-e-erro. 
Tabela 25: Parâmetros das simulações unidimensionais da movimentação da interface sólido-fase fictícia.

\begin{tabular}{|c|c|c|}
\hline Variável & Símbolo & Valor \\
\hline$\overline{\text { Tensão superficial }}$ & $\gamma_{s}$ & $1,72 \mathrm{~J} \cdot \mathrm{m}^{-2}$ \\
\hline Densidade molar de sítios & $\rho_{m}^{S}$ & $1,41 \cdot 10^{5} \mathrm{mols} \cdot \mathrm{m}^{-3}$ \\
\hline Coeficiente de difusão de lacunas no sólido & $D_{v}^{S}$ & $1,67 \cdot 10^{-9} \mathrm{~m}^{2} \cdot \mathrm{s}^{-1}$ \\
\hline Temperatura & $T$ & $1000^{\circ} \mathrm{C}$ \\
\hline Tamanho do domínio & $L_{x}$ & $1,28 \cdot 10^{-7} \mathrm{~m}$ \\
\hline Fração inicial de lacunas no sólido $(\boldsymbol{s})$ & $X_{v, t=0}^{S}$ & $1,96 \cdot 10^{-4}$ ou $7,75 \cdot 10^{-7}$ \\
\hline Fração inicial de lacunas na fase fictícia $\left(\boldsymbol{g}^{\prime}\right)$ & $X_{v, t=0}^{g^{\prime}}$ & 0,9906 \\
\hline Número de nós da malha raiz & $\mathrm{N}_{\mathrm{x}}$ & 3200 \\
\hline Nível máximo de subdivisão da malha & $\mathrm{N}$ & 0 \\
\hline Passo de tempo & $\Delta t$ & $4 \cdot 10^{-10} \mathrm{~s}$ \\
\hline Espessura da interface difusa & $\delta$ & $2 \cdot 10^{-9} \mathrm{~m}$ \\
\hline Mobilidade da variável de fase & $M_{\varnothing}$ & $0,137 \mathrm{~J}^{-1} \cdot \mathrm{s}^{-1}$ \\
\hline
\end{tabular}

Os resultados fornecidos pelo modelo de campo de fases para o primeiro caso estão apresentados na Figura 57, na Figura 58 e na Figura 59. Os perfis da variável de fase $(\phi)$ e da fração molar de lacunas $\left(X_{v}\right)$ no início da simulação estão apresentados na Figura 43(a), indicando que o sólido $(\phi=1)$ está à esquerda e a fase fictícia $(\phi=0)$ à direita. A região da interface difusa está mostrada em detalhes na Figura 43(b), onde os pontos indicam os nós da malha numérica utilizada. Nota-se uma transição rápida, mas contínua. Para fins práticos, a posição da interface é definida como o local onde $\phi=0,5$. Um detalhe da interface mostrando o sólido adjacente e a sua composição inicial $\left(X_{v}=1,96 \cdot 10^{-4}\right)$ está ilustrado na Figura 57(c).

(a)

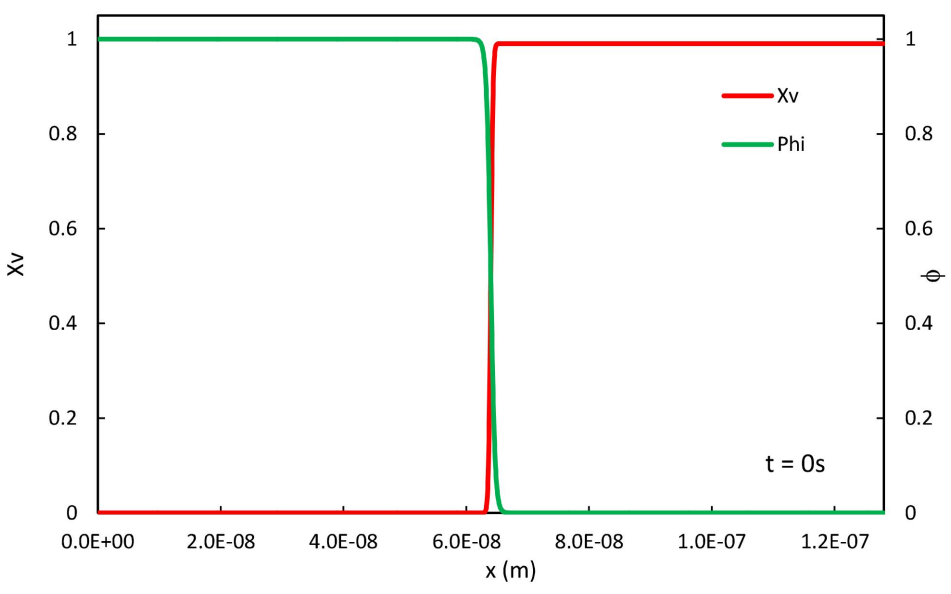


(b)

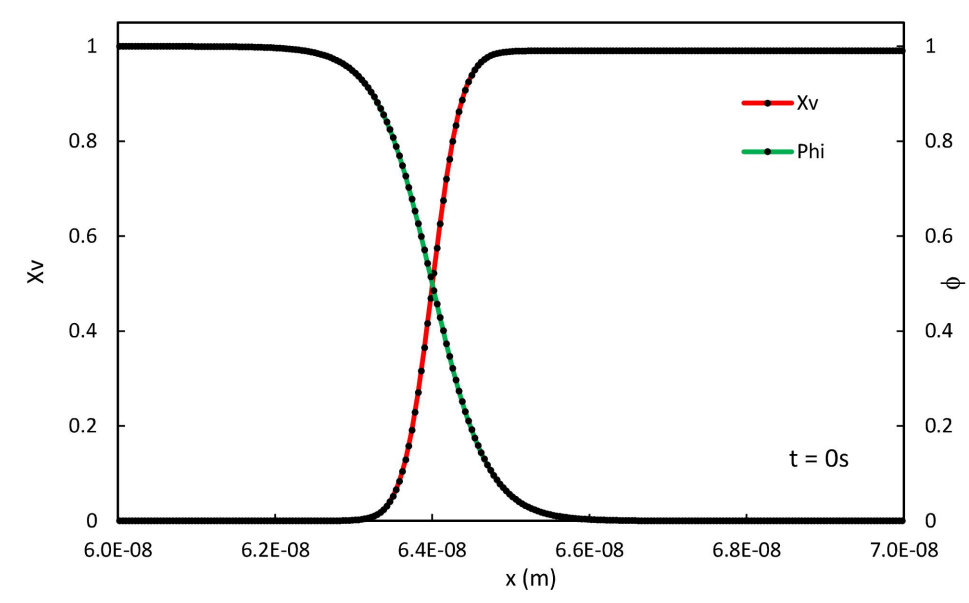

(c)

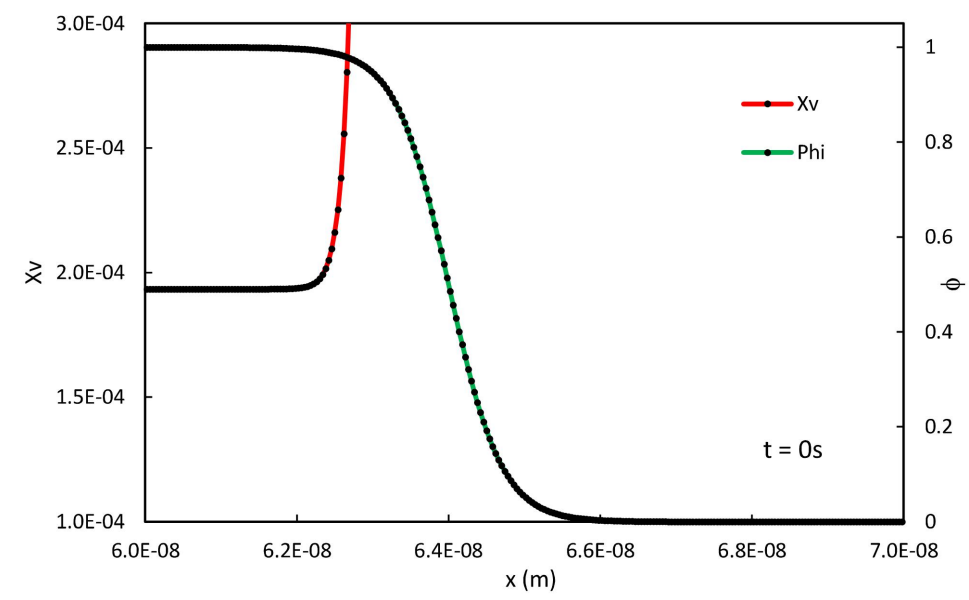

Figura 57: Perfil de fração molar de lacunas $\left(X_{v}\right)$ e da variável de fase $(\phi)$ em função da distância ao longo do sistema unidimensional sólido-fase fictícia no instante inicial $(t=0)$ : (a) perfil ao longo do sistema completo; (b) detalhe na região da interface sólido-fase fictícia mostrando os nós da malha numérica e (c) detalhe da região da interface indicando a fração de lacunas na região sólida $(\phi=1)$ à esquerda.

Durante um período de $6 \cdot 10^{-3} \mathrm{~s}$, a simulação mostra que a interface se movimentou em direção ao sólido, como mostra a Figura 58(a) e Figura 58(b), diminuindo o volume dessa fase e aumentando o da fase fictícia. Este comportamento era esperado fisicamente, pois inicialmente há um excesso de lacunas que é eliminado na superfície (interface sólido-fase fictícia), causando uma retração da fase sólida. Nota-se que a fração inicial de lacunas indicada na Figura 44(a), de $1,96 \cdot 10^{-4}$, foi reduzida para aproximadamente o valor de equilíbrio na temperatura de simulação, ou seja, 1,04 $10^{-4}$, como mostrado na Figura 58(b). Nota-se também que a fração no sólido junto à interface é um pouco menor que no interior da fase ("bulk") - esta diferença ocasionou o fluxo de lacunas do interior da fase em direção à superfície. A fração de lacunas junto à interface é aproximadamente $1,043 \cdot 10^{-4}$, que é o valor de equilíbrio termodinâmico, enquanto que na extremidade esquerda do domínio tem-se 
$1,082 \cdot 10^{-4}$. A tensão interfacial foi calculada a partir dos valores de $\phi$ para cada nó e inserindo estes valores na Equação (136), resultando em $1,714 \mathrm{~J} \cdot \mathrm{m}^{-2}$, em grande concordância com o valor objetivado de $\gamma_{s}=1,72 \mathrm{~J} \cdot \mathrm{m}^{-2}$, utilizado para os cálculos de $K_{\phi}$ e $W$ (Equações (140) e (141)), que são dois parâmetros da Equação da variável de fase (Equação (117)). Esta verificação é importante para garantir que os efeitos de curvatura que serão examinados em simulações posteriores estejam sendo modelados corretamente. A Figura 58(c) mostra ainda um detalhe dos perfis próximo a interface e indicam uma espessura de interface difusa de aproximadamente $\delta \approx 2 \cdot 10^{-9}$, como objetivado nos parâmetros de entrada (Tabela 25).

Um tempo maior de simulação resultaria em uma fração uniforme de lacunas em todo o sólido, igual ao valor de equilíbrio. Neste momento, a velocidade da interface seria nula. A Figura (a) mostra a evolução da posição da interface e a sua velocidade negativa, que inicialmente tem módulo relativamente elevado, mas sofre uma redução contínua, mostrando uma tendência a parar. A Figura (b) mostra a fração molar de lacunas no sólido junto à interface. Como a interface é difusa, a fração molar de lacunas na região já considerada sólida é aquela na posição onde $\phi=0,995$. Esta concentração é inicialmente $1,96 \cdot 10^{-4}$, mas decai a um valor muito próximo do equilíbrio termodinâmico nos instantes iniciais, como desejado.

(a)

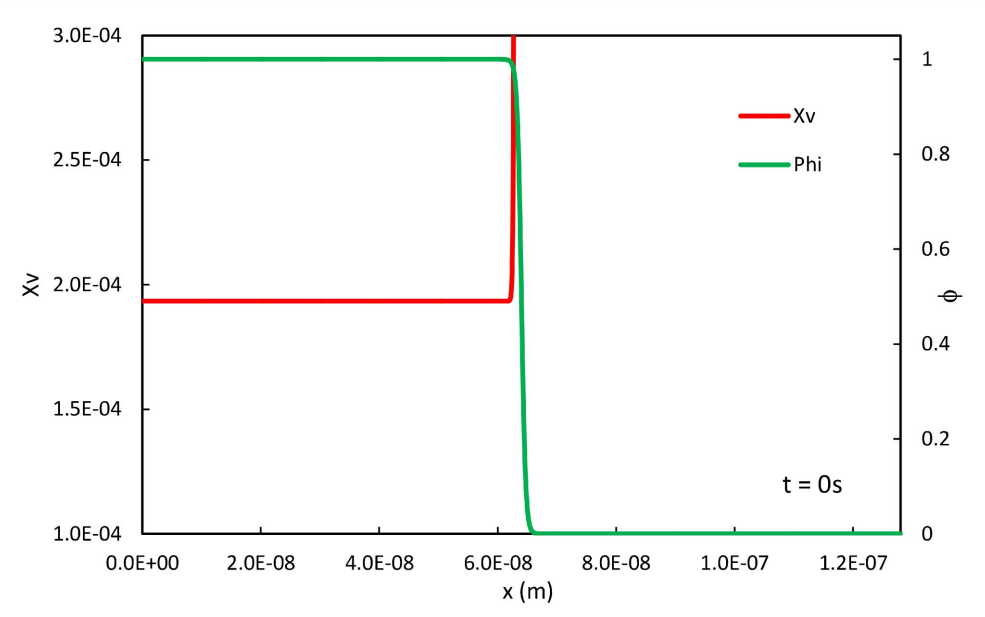


(b)

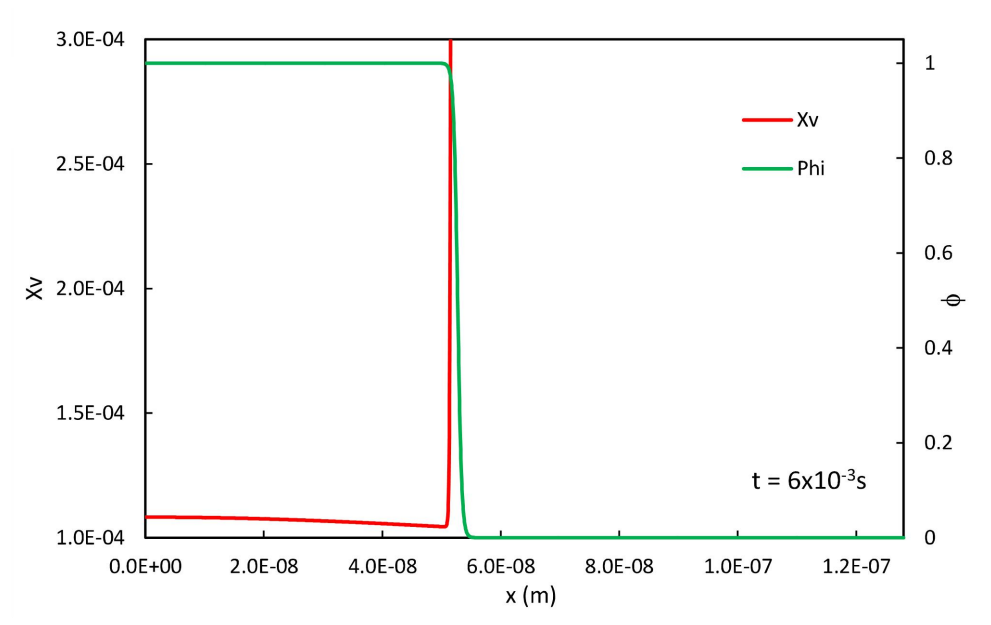

(c)

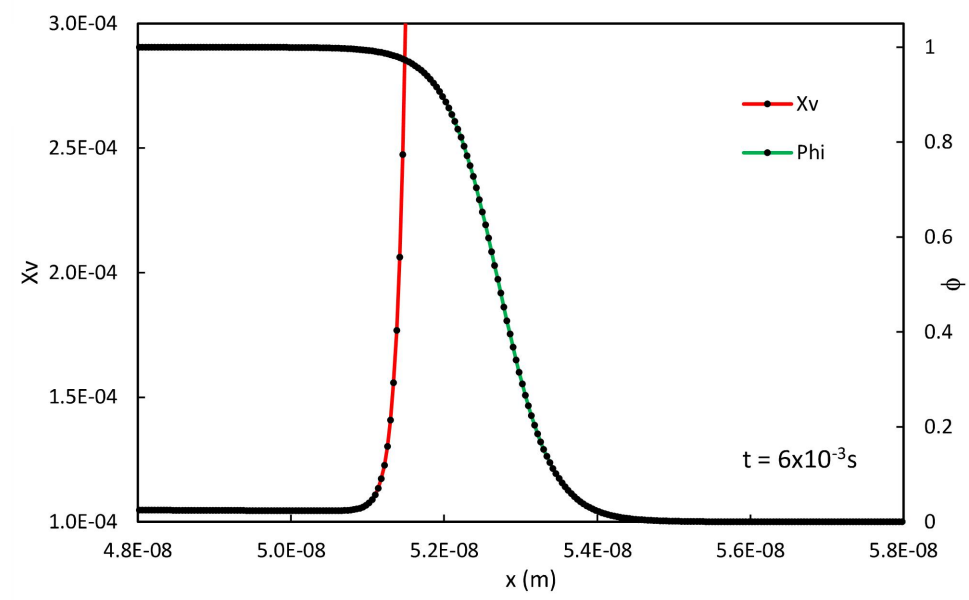

Figura 58: Perfil de fração molar de lacunas $\left(X_{v}\right)$, mostrando em detalhes a fração molar na fase sólida (à esquerda) e da variável de fase $(\phi)$ em função da distância ao longo do sistema unidimensional sólido-fase fictícia completo: (a) $t=0$; (b) $t=6 \cdot 10^{-3} \mathrm{~s}$ e (c) detalhe dos perfis para $t=6 \cdot 10^{-3} \mathrm{~s}$.

(a)

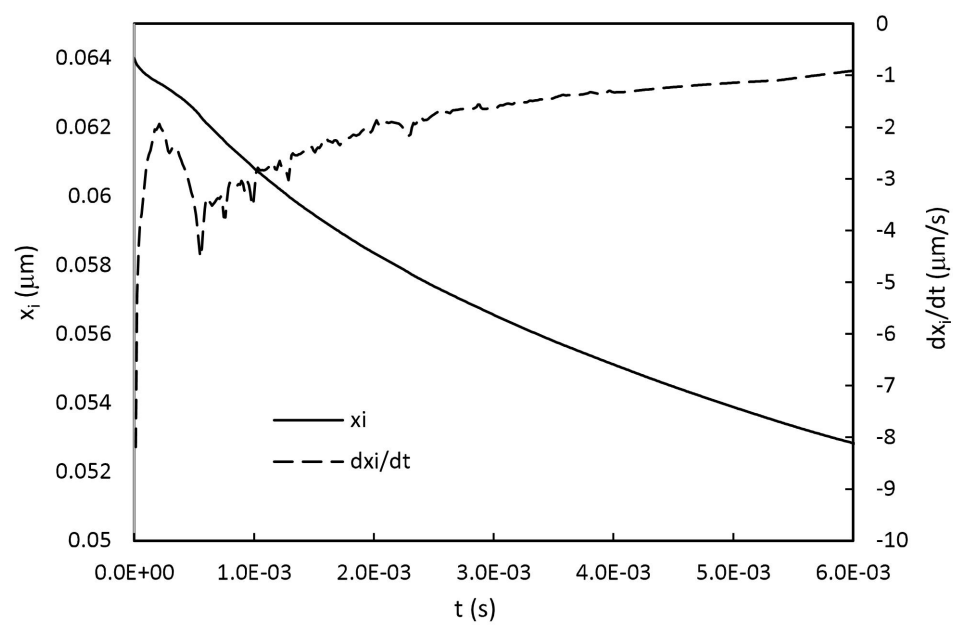




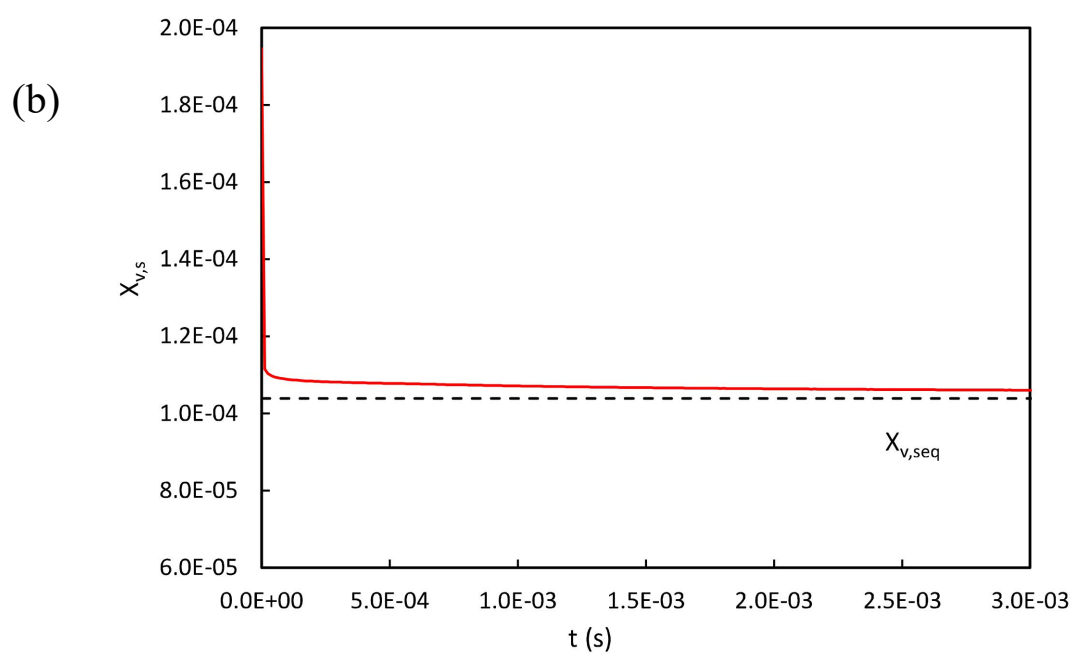

Figura 59: Parâmetros da superfície (interface sólido-fase fictícia) em função do tempo: (a) posição $\left(x_{i}\right) \mathrm{e}$ velocidade $\left(d x_{i} / d t\right)$ da interface; (b) fração de lacunas no sólido junto à interface $\left(X_{v, s}\right)$, onde $X_{v \text {,seq }}$ corresponde à fração no equilíbrio termodinâmico.

A Figura 60, Figura 61 e Figura 62 mostram os resultados para a simulação da segunda condição mencionada, onde a fração de lacunas inicial é menor $\left(X_{v}=7,75 \cdot 10^{-7}\right)$ do que a de equilíbrio $\left(1,04 \cdot 10^{-4}\right)$ e equivalente ao equilíbrio na temperatura de $600{ }^{\circ} \mathrm{C}$. A Figura 60 mostra a condição inicial, semelhante ao da simulação anterior, porém a Figura 60(c) mostra que a fração de lacunas no sólido está abaixo do valor utilizado no caso anterior.

(a)

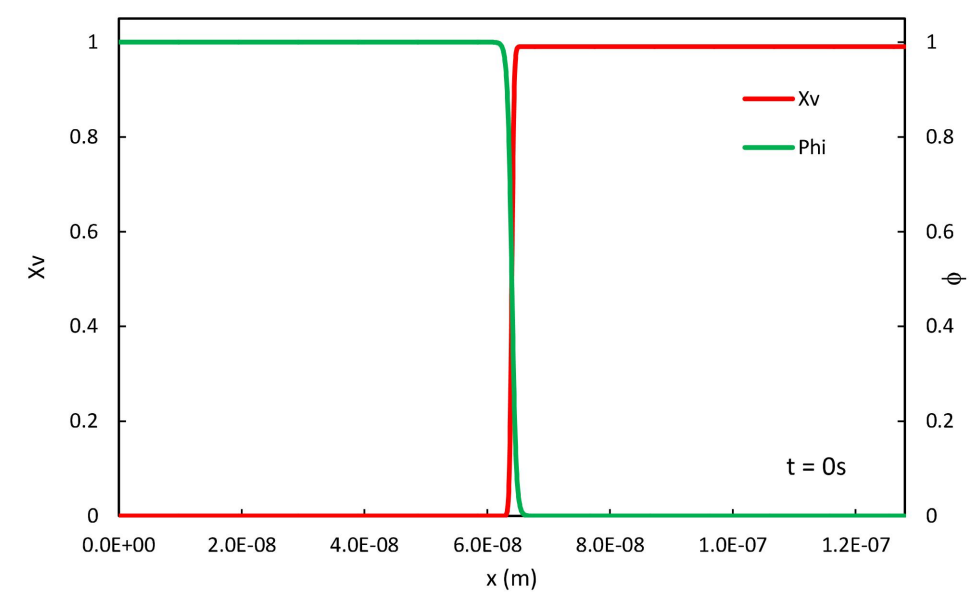


(b)

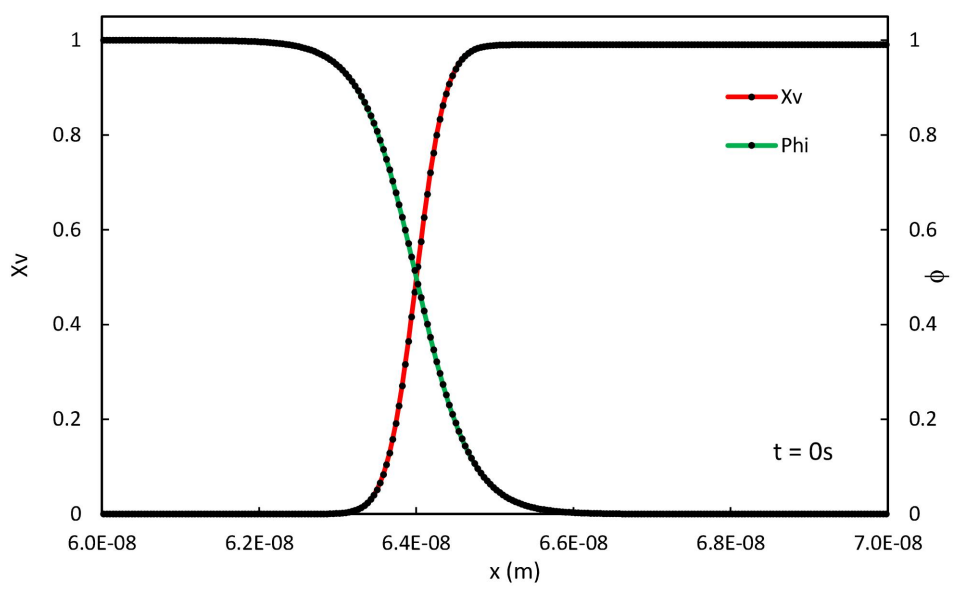

(c)

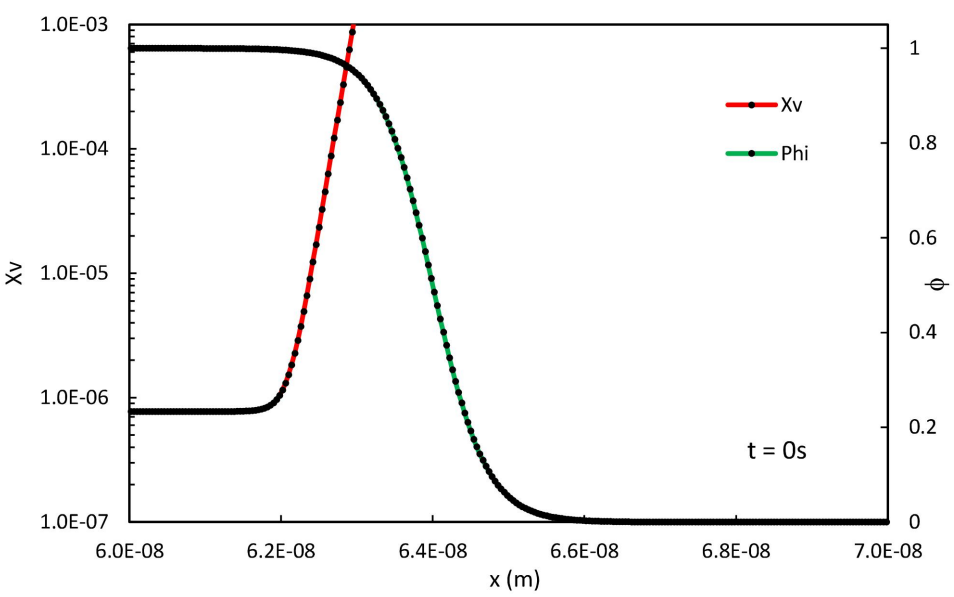

Figura 60: Perfil de fração molar de lacunas $\left(X_{v}\right)$ e da variável de fase $(\phi)$ em função da distância ao longo do sistema unidimensional sólido-fase fictícia no instante inicial $(t=0)$ : (a) perfil ao longo do sistema completo; (b) detalhe na região da interface sólido-fase fictícia mostrando os nós da malha numérica e (c) detalhe da região da interface indicando a fração de lacunas na região sólida $(\phi=1)$ à esquerda.

Neste caso, durante o período de tempo de $6 \cdot 10^{-3} \mathrm{~s}$, a interface movimenta-se para a direita, ou seja, ocorre uma expansão do sólido, como ilustra a Figura 61(a) e (b). Nota-se que o sólido sofreu uma absorção de lacunas a partir de um fluxo da interface em direção ao seu interior, movido pelo gradiente observado na Figura 60(b). Esta absorção resultou em um aumento de volume, como esperado, indicado pelo deslocamento da interface para a direita. Um aspecto importante é que a fração de lacunas no sólido aumentou até aproximadamente o valor de equilíbrio, como na simulação anterior. 
(a)

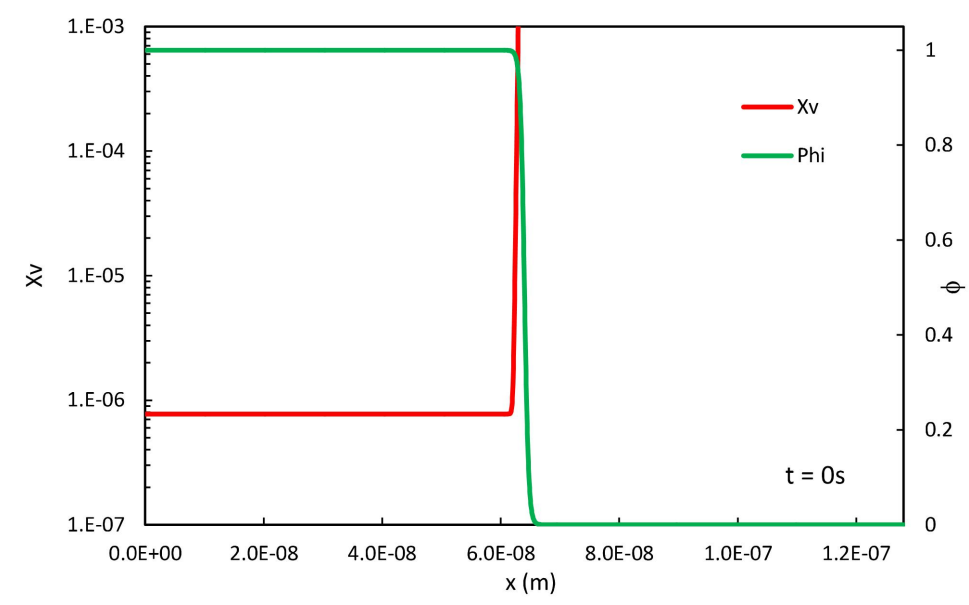

(b)

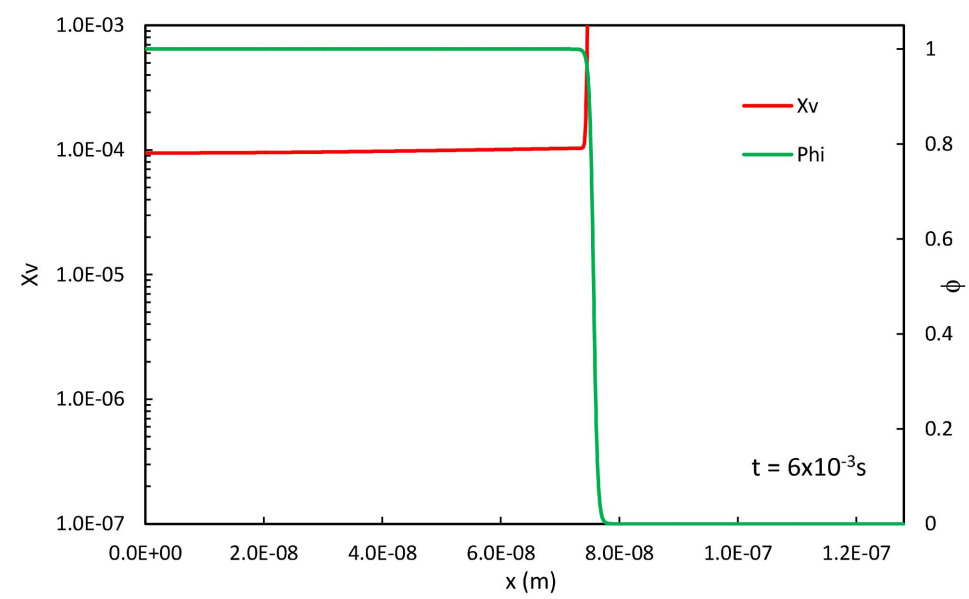

Figura 61: Perfil de fração molar de lacunas $\left(X_{v}\right)$, mostrando em detalhes a fração molar na fase sólida (à esquerda) e da variável de fase $(\phi)$ em função da distância ao longo do sistema unidimensional sólido-fase fictícia completo: (a) $t=0$ e (b) $t=6 \cdot 10^{-3} \mathrm{~s}$.

Finalmente, a Figura 62(a) mostra o deslocamento da interface e que a sua velocidade novamente era elevada no início, mas decresce e tende a zero, situação que corresponderia a condição de equilíbrio global. A Figura 62(b) mostra, como na simulação anterior, que a fração de lacunas no sólido adjacente à interface rapidamente atinge o valor de equilíbrio termodinâmico, indicando a ocorrência do equilíbrio local.

Pode-se concluir, a partir dos resultados destas simulações, que o modelo implementado e os parâmetros escolhidos são capazes de impor o equilíbrio termodinâmico local na interface sólido-fase fictícia e mostram o comportamento fisicamente correto de retração ou de expansão da fase sólida causados pela eliminação ou absorção de lacunas, respectivamente. 
(a)

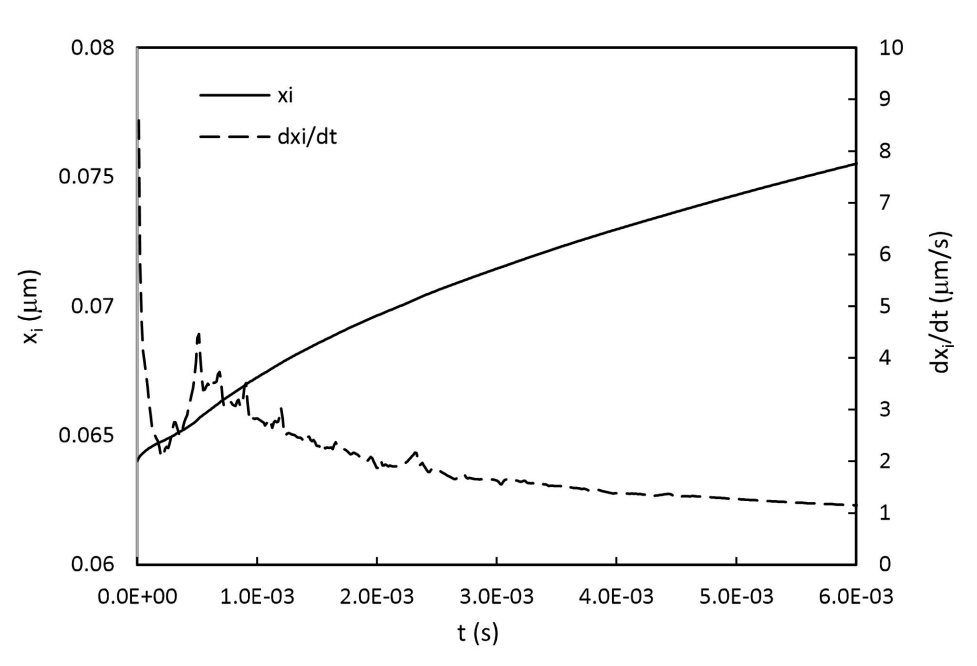

(b)

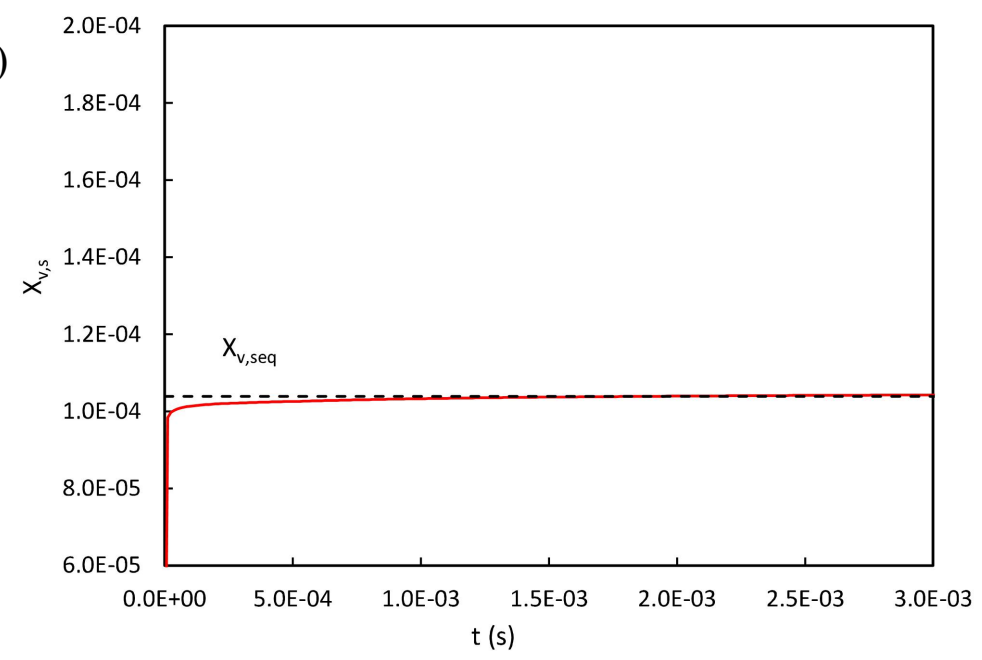

Figura 62: Parâmetros da superfície (interface sólido-fase fíctícia) em função do tempo: (a) posição $\left(x_{i}\right) \mathrm{e}$ velocidade $\left(d x_{i} / d t\right)$ da interface; (b) fração de lacunas no sólido junto à interface $\left(X_{v, s}\right)$, onde $X_{v, s e q}$ corresponde à fração no equilíbrio termodinâmico.

\subsubsection{Retração ou Expansão do Sólido}

No item anterior, o modelo de campo de fases foi utilizado para simular a movimentação de uma superfície (interface sólido-fase fictícia) plana em um domínio pequeno $(0,128 \mu \mathrm{m})$ e em condições unidimensionais. Foi mostrado que o equilíbrio termodinâmico local é atingido rapidamente, mas não instantaneamente, e que a velocidade da superfície decrescia e praticamente parava, porque a fração de lacunas nesse pequeno domínio tornava-se aproximadamente uniforme. No presente item, a capacidade do modelo de campo de fases bidimensional implementado em modelar os efeitos de curvatura da superfície será examinada. O campo de fração de lacunas no interior de cilindros de cobre puro e a 
movimentação de sua superfície serão obtidos pelo modelo para os casos onde esse sólido apresenta excesso ou deficiência de lacunas em relação ao equilíbrio termodinâmico na temperatura de simulação. Quatro condições foram simuladas, sendo que as duas primeiras apresentam correspondência com situações fisicamente possíveis e outras duas condições que não representam uma situação fisicamente possível, mas mostram aspectos interessantes do modelo. Em todas as situações, adotou-se um domínio bidimensional quadrado, contendo um círculo de cobre puro em seu interior, que está envolto em uma fase fictícia. Como existe simetria em relação aos eixos $x$ e $y$ de um sistema de referências posicionado ao centro do círculo, o domínio de cálculo foi de apenas um quarto do domínio completo, reduzindo significativamente o tempo total de simulação.

a) Cilindro de cobre puro à temperatura de $1000^{\circ} \mathrm{C}$

O comportamento de um cilindro de cobre puro imerso em uma fase fíctícia à temperatura de $1000^{\circ} \mathrm{C}$ foi simulado em duas condições, uma onde a fração inicial de lacunas em seu interior era de $1,96 \cdot 10^{-4}$ (excesso de lacunas), correspondendo à fração de equilíbrio de uma superfície plana a $1080{ }^{\circ} \mathrm{C}$, e outra onde a fração inicial era de $7,75 \cdot 10^{-7}$ (deficiência de lacunas), que representa a fração de equilíbrio a $600{ }^{\circ} \mathrm{C}$. Estas frações iniciais foram iguais às utilizadas nas simulações unidimensionais do item anterior, porém agora o sólido inicial é um cilindro com raio de $64 \mu \mathrm{m}$, igual ao raio dos fios de cobre utilizados por Alexander e Balluffi [ALEXANDER, BALLUFFI, 1957]. A temperatura de simulação de $1000{ }^{\circ} \mathrm{C}$ também foi aquela empregada por esses autores em seus experimentos de sinterização de fios de cobre. As condições de simulação e os parâmetros numéricos empregados estão apresentados na Tabela 27.

A Figura 63 mostra no instante inicial $(t=0)$ o campo de fração molar de lacunas, o campo da variável de fase, que indica a localização das fases e da superfície $(\phi=0,5)$, a curvatura local em relação ao raio inicial do cilindro $(r / a)$ e a malha adaptativa construída para a simulação. Nota-se claramente a maior densidade de volumes da malha na região da superfície, como objetivado. A Figura 64 mostra um detalhe do refino da malha na região da interface, sobreposto ao campo da variável de fase. Deve-se lembrar que durante a simulação a malha é reexaminada constantemente e reajustada automaticamente segundo a metodologia descrita no item 4.3.5.1 para a nova localização da superfície; portanto, o número de volumes pode ser alterado durante a simulação. A Figura 65(a) destaca a curvatura local ao longo da 
região da interface difusa, calculada como descrito no item 4.3.5.1. Tanto os valores de raio de curvatura como as coordenadas $x$ e $y$ foram adimensionalizadas pelo raio do grão cilíndrico (a) para facilitar a leitura. Nota-se que a curvatura local $\frac{r}{a} \approx 1$ ao longo de toda a circunferência, apresentando consistência com o raio do cilindro. Porém, observa-se também que na região onde a normal ao contorno faz um ângulo de $\sim 45^{\circ}$ com o eixo horizontal (Figura 65(b)), os valores de curvatura mostram uma certa discrepância nas bordas da interface difusa, mas está correto no centro da espessura, onde $\phi=0,5$. Essa discrepância é provavelmente causada pelos erros de arredondamento e truncamento no cálculo das derivadas utilizadas para obtenção da curvatura, um efeito muitas vezes denominado de anisotropia da malha numérica.

Tabela 26: Parâmetros das simulações de cilindros com excesso ou deficiência de lacunas $\left(a=64 \cdot 10^{-6} \mathrm{~m}\right)$.

\begin{tabular}{lcc}
\hline \multicolumn{1}{c}{ Variável } & Símbolo & Valor \\
\hline Tensão superficial & $\gamma_{s}$ & $1,72 \mathrm{~J} \cdot \mathrm{m}^{-2}$ \\
\hline Densidade molar de sítios & $\rho_{m}^{S}$ & $1,41 \cdot 10^{5} \mathrm{mols} \cdot \mathrm{m}^{-3}$ \\
\hline Coeficiente de difusão de lacunas no sólido & $D_{v}^{S}$ & $1,67 \cdot 10^{-9} \mathrm{~m}^{2} \cdot \mathrm{s}^{-1}$ \\
\hline Temperatura & $T$ & $1000{ }^{\circ} \mathrm{C}$ \\
\hline Tamanho do domínio & $L_{x} \mathrm{x} L_{y}$ & $70,4 \cdot 10^{-6} \times 70,4 \cdot 10^{-6} \mathrm{~m}$ \\
\hline Raio do grão cilíndrico & $a$ & $64 \cdot 10^{-6} \mathrm{~m}$ \\
\hline Fração inicial de lacunas no sólido $(\boldsymbol{s})$ & $X_{v, t=0}^{S}$ & $1,96 \cdot 10^{-4} \mathrm{ou}^{\prime}, 75 \cdot 10^{-7}$ \\
\hline Fração inicial de lacunas na fase fictícia $\left(\boldsymbol{g}^{\prime}\right)$ & $X_{v, t=0}^{g^{\prime}}$ & 0,9906 \\
\hline \hline Número de nós da malha raiz & $\mathrm{N}_{\mathrm{x}} \mathrm{x} \mathrm{N}_{\mathrm{y}}$ & $80 \times 80$ \\
\hline Nível máximo de subdivisão da malha & $\mathrm{N}$ & 5 \\
\hline Número total de volumes na malha $(\boldsymbol{t}=0)$ & $\mathrm{N}_{\mathrm{T}}$ & 508588 \\
\hline Passo de tempo & $\Delta t$ & $10^{-4} \mathrm{~s}$ \\
\hline Espessura da interface difusa & $\delta$ & $1,4 \cdot 10^{-6} \mathrm{~m}$ \\
\hline Mobilidade da variável de fase & $M_{\varnothing}$ & $0,137 \mathrm{~J}^{-1} \cdot \mathrm{s}^{-1}$ \\
\hline
\end{tabular}




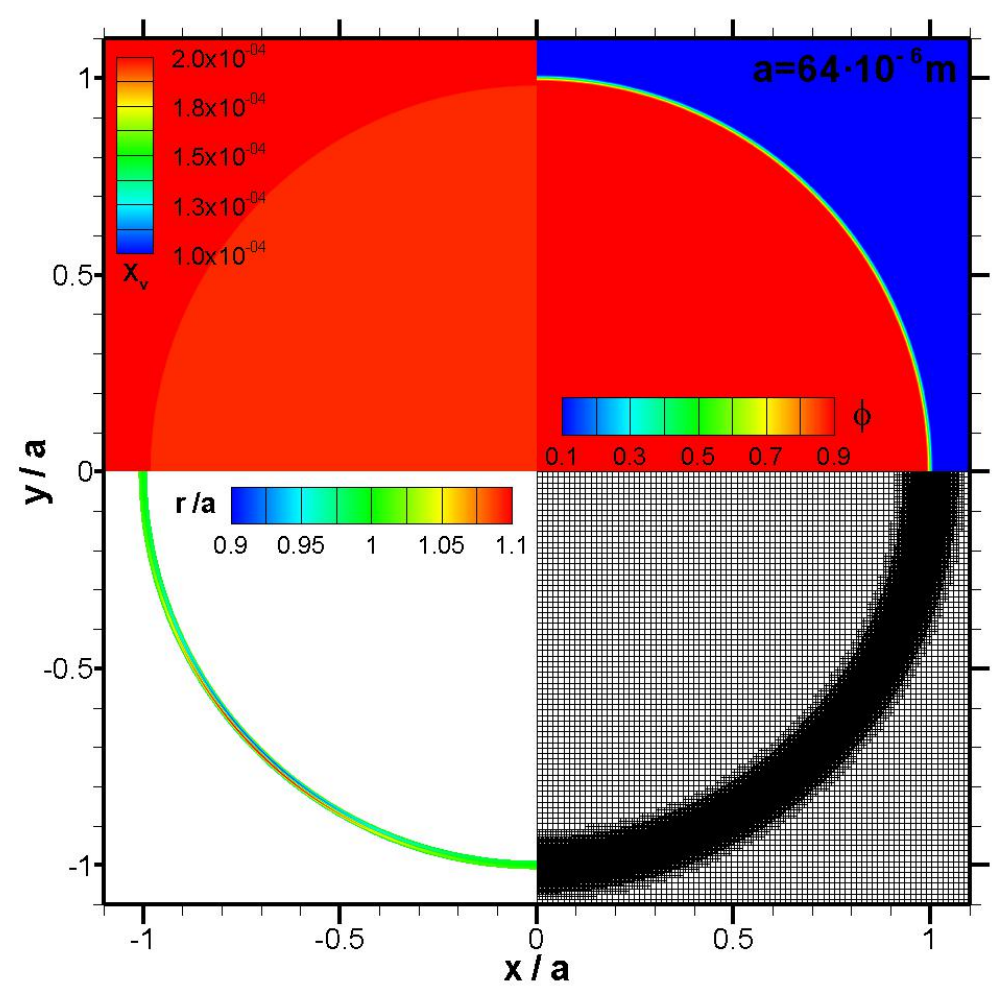

Figura 63: Campos de variável de fase $(\phi)$, fração molar de lacunas $\left(X_{v}\right)$ e curvatura local $(r / a)$, além de uma visão da malha numérica utilizada para : $a=64 \cdot 10^{-6} \mathrm{~m}, X_{v, s}=1,96 \cdot 10^{-4}$ e $T=1000{ }^{\circ} \mathrm{C}(t=0)$.

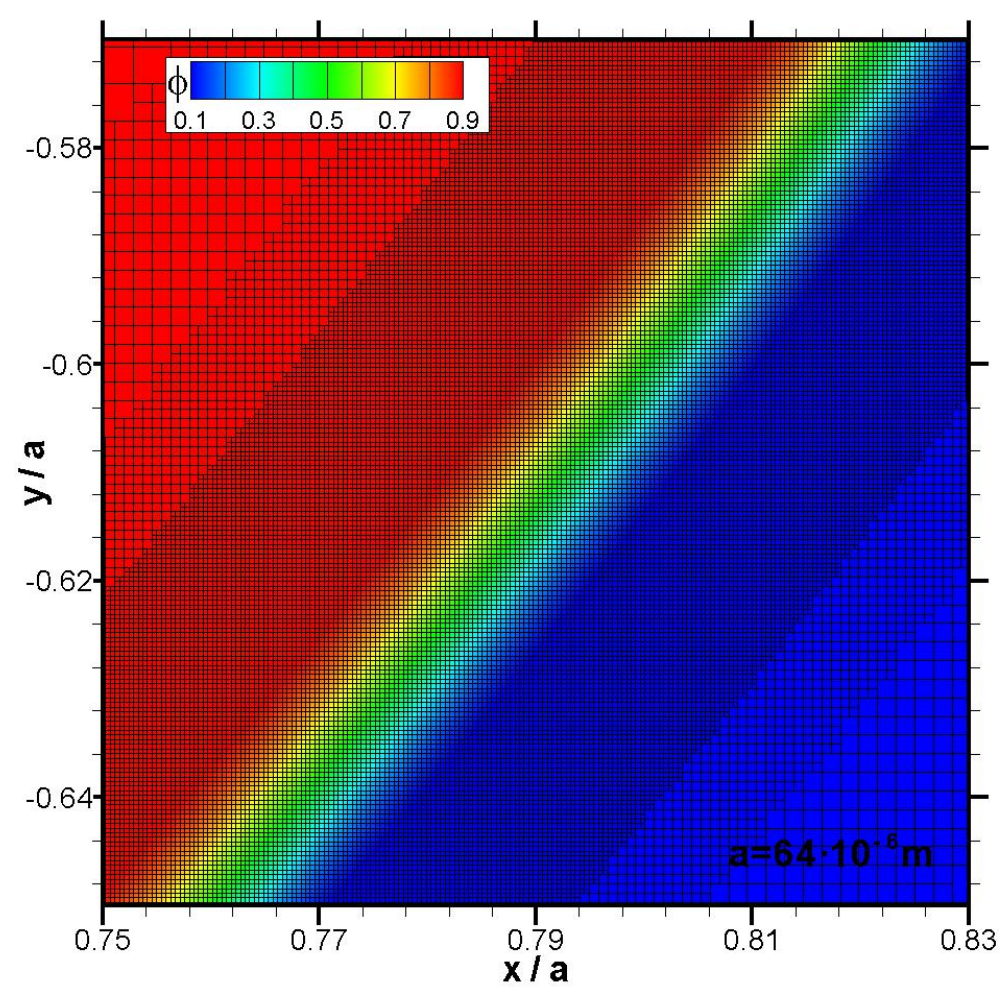

Figura 64: Detalhe da malha numérica na região da interface sobreposta ao campo de variável de fase $(\phi)$ para: $a$ $=64 \cdot 10^{-6} \mathrm{~m}, X_{v, S}=1,96 \cdot 10^{-4} \mathrm{e} T=1000^{\circ} \mathrm{C}(t=0)$. 
(a)
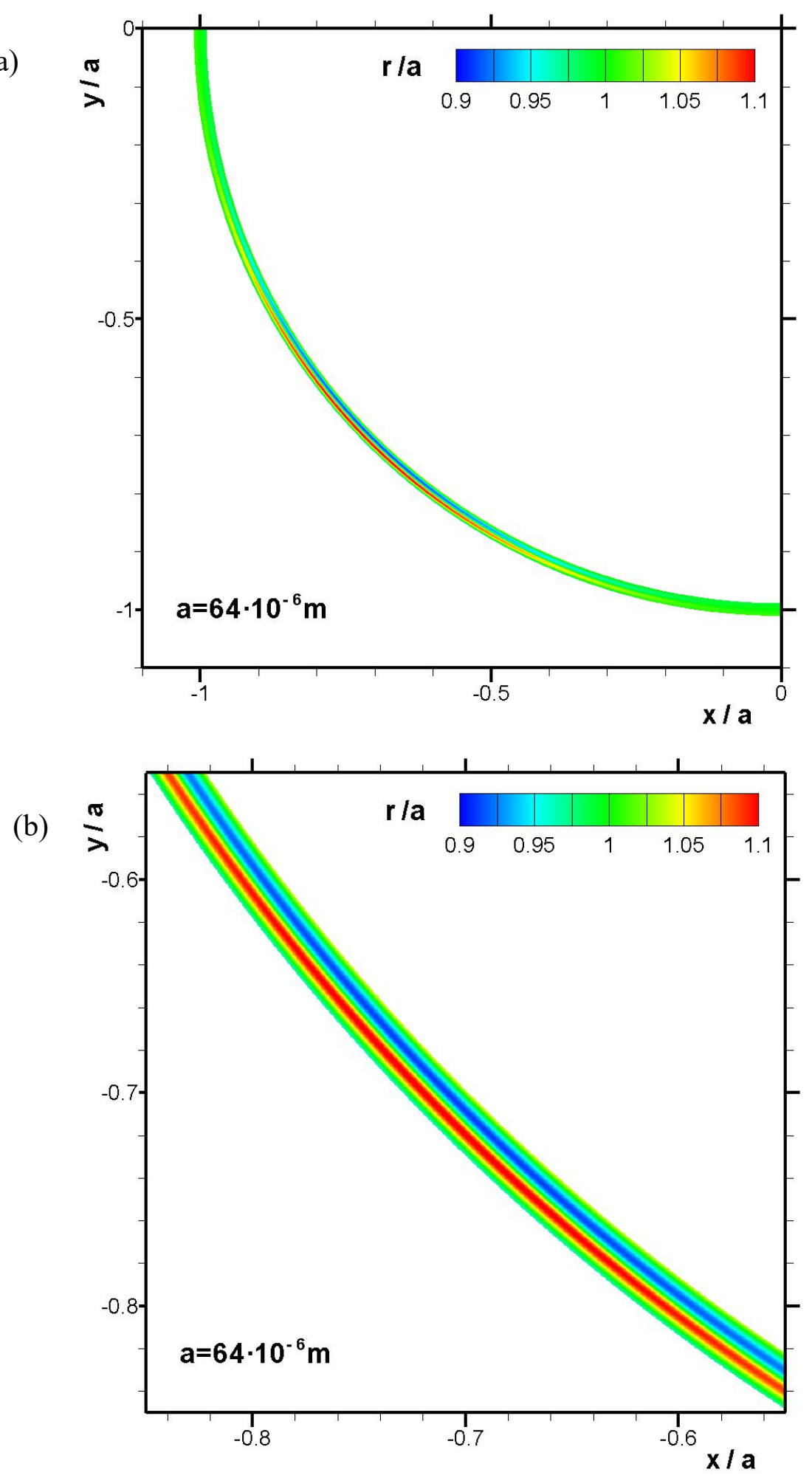

Figura 65: Campo de curvatura local $(r / a)$ para $a=64 \cdot 10^{-6} \mathrm{~m}, X_{v, s}=1,96 \cdot 10^{-4} \mathrm{e} T=1000{ }^{\circ} \mathrm{C}(t=0)$ : (a) visão completa da interface difusa e (b) detalhe na região onde a interface está a $45^{\circ}$ em relação ao eixo $x$.

A Figura 66(a) e a Figura 66(b) mostram, respectivamente, o campo de fração de lacunas inicial $(t=0)$ e após $0,5 \mathrm{~s}$. A movimentação da superfície, apesar de ter ocorrido, foi 
imperceptível neste período de tempo, mas a fração de lacunas diminuiu significativamente no interior do fio de cobre. Os perfis de fração de lacunas e variável de fase através da superfície podem ser vistos em detalhes na Figura 67(a) e (b). O efeito da malha adaptativa pode ser notado pela maior densidade de pontos, que correspondem aos nós dos volumes da malha, na região da interface sólido-fase fictícia difusa. Nota-se que, no sólido próximo à superfície em $t=0,5 \mathrm{~s}$, a fração praticamente atingiu o valor de equilíbrio $\left(\approx 1,04 \times 10^{-4}\right)$ para o raio de curvatura do cilindro, que é praticamente igual ao equilíbrio em uma interface plana. No entanto, a fração aumenta em direção ao centro do cilindro, ocasionando um fluxo de lacunas do centro para a superfície do cilindro e, portanto, um fluxo de átomos de cobre da superfície para o centro, resultando em uma imperceptível retração.

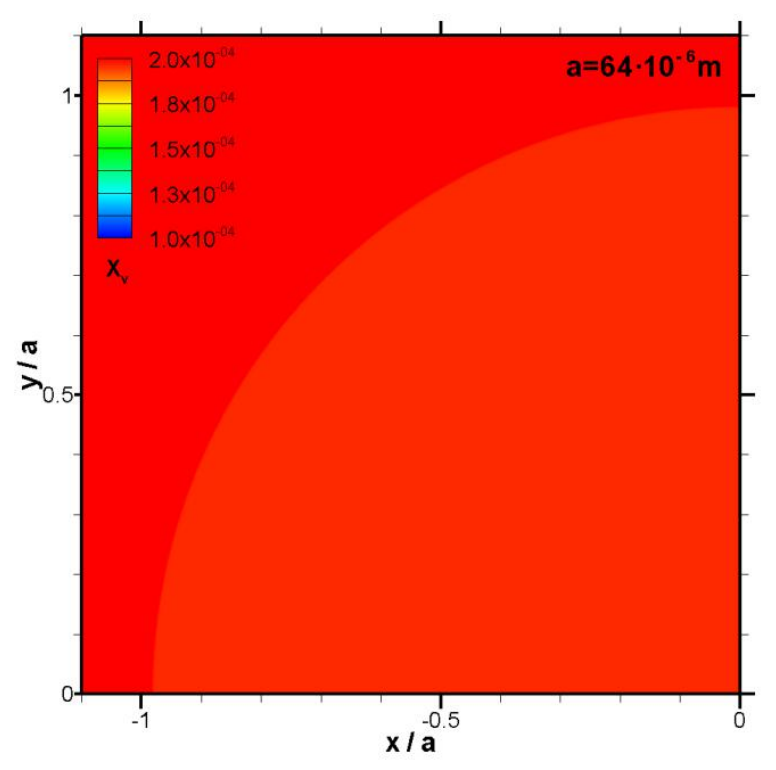

(a)

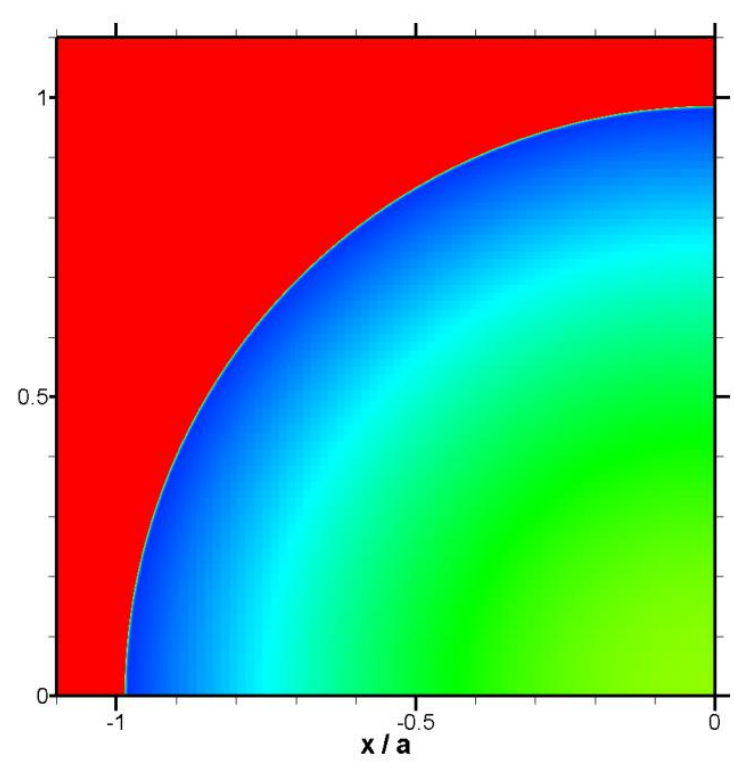

(b)

Figura 66: Campo de fração molar de lacunas $\left(X_{v}\right)$ para $a=64 \cdot 10^{-4}, X_{v, s}=1,96 \cdot 10^{-4}$ e $T=1000{ }^{\circ} \mathrm{C}$ : (a) $t=0$; (b) $t$ $=0,5 \mathrm{~s}$. 
(a)

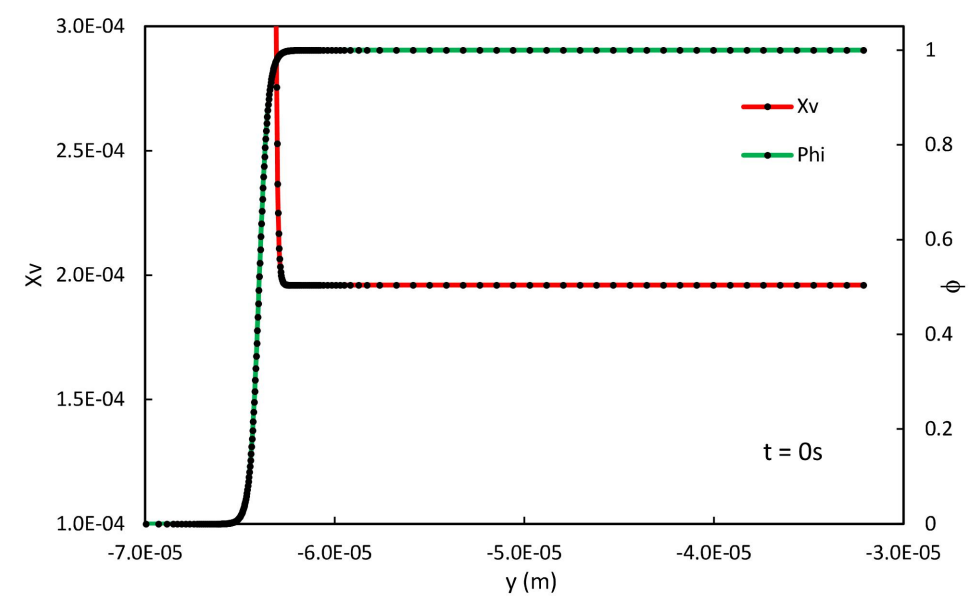

(b)

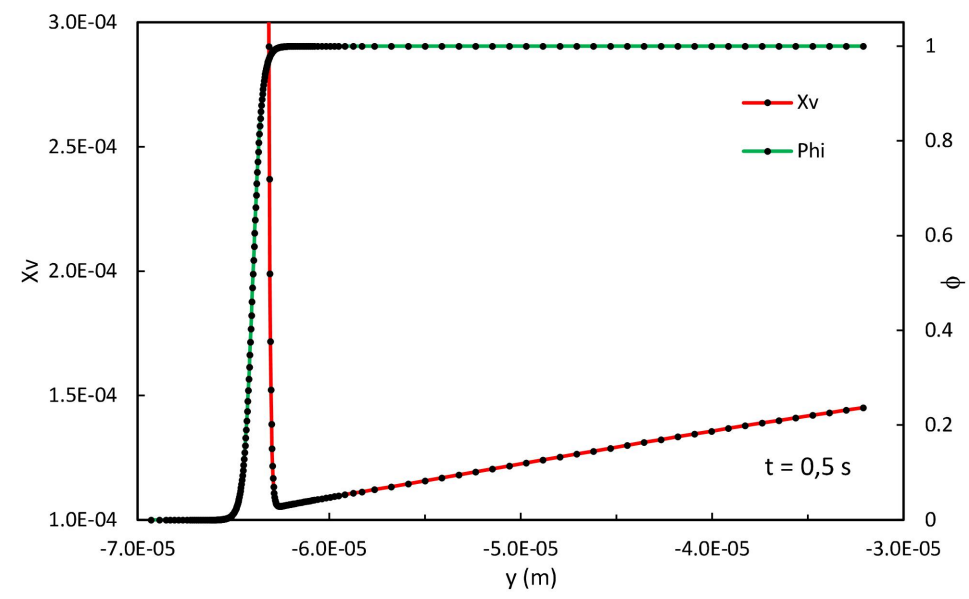

Figura 67 - Perfil da variável de fase $(\phi)$ e de fração molar de lacunas $\left(X_{v}\right)$ ao longo de $y$ para $x=0$ e para $a=$ $64 \cdot 10^{-4}, X_{v, s}=1,96 \cdot 10^{-4} \mathrm{e} T=1000{ }^{\circ} \mathrm{C}$ : (a) $t=0$; (b) $t=0,5 \mathrm{~s}$.

No segundo caso, onde o fio de cobre apresentou uma deficiência de lacunas em relação ao equilíbrio $\left(\approx 1,04 \times 10^{-4}\right)$, a Figura 68(a) e a Figura 68(b) mostram, respectivamente, o campo de fração de lacunas inicial e após $0,5 \mathrm{~s}$. Novamente não houve uma movimentação significativa da superfície, mas agora houve uma absorção de lacunas geradas nessa superfície, como objetivado na construção do modelo. Existe um fluxo de lacunas da superfície para o centro do cilindro, movido pelo gradiente de fração molar mostrado na Figura 69(b). Junto à superfície, a fração molar no sólido inicial de 7,7·10 (Figura 69(a)) aumentou para o valor de equilíbrio $\left(\approx 1,04 \times 10^{-4}\right)$ na temperatura de simulação. O fluxo de lacunas da superfície para o interior do cilindro causou uma expansão do fio de cobre, mas que foi imperceptível nessas condições fisicamente viáveis. No próximo subitem, as condições serão alteradas para realçar o movimento da superfície do fio de cobre. 


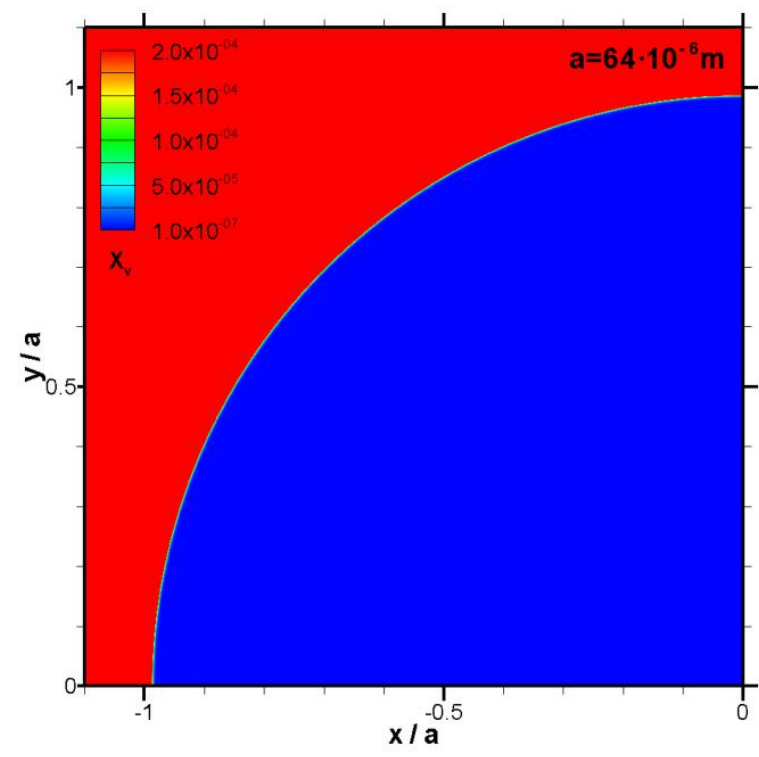

(a)

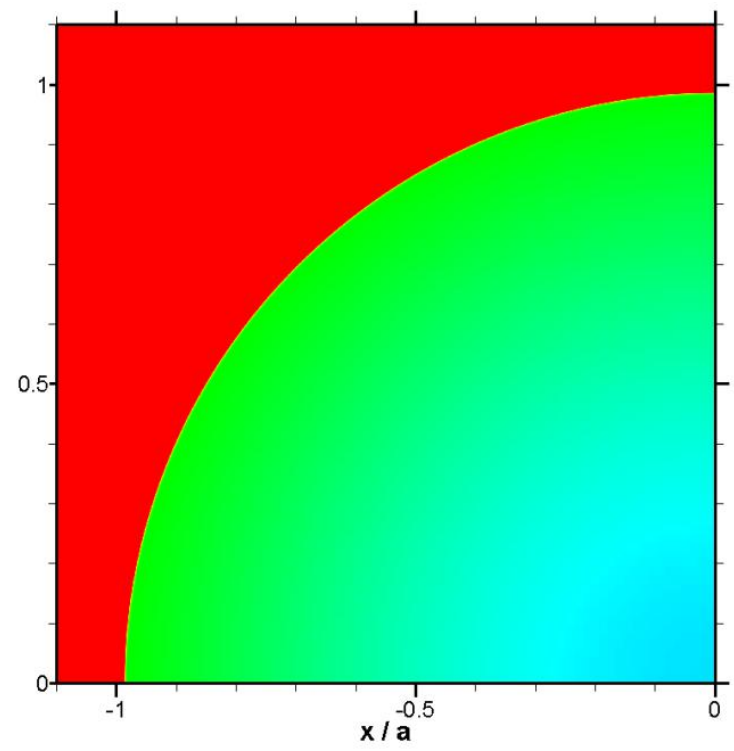

(b)

Figura 68: Campo de fração molar de lacunas $\left(X_{v}\right)$ para $a=64 \cdot 10^{-4}, X_{v, s}=7,75 \cdot 10^{-7}$ e $T=1000^{\circ} \mathrm{C}$ : (a) $t=0$; (b) $t$ $=0,5 \mathrm{~s}$.

(a)

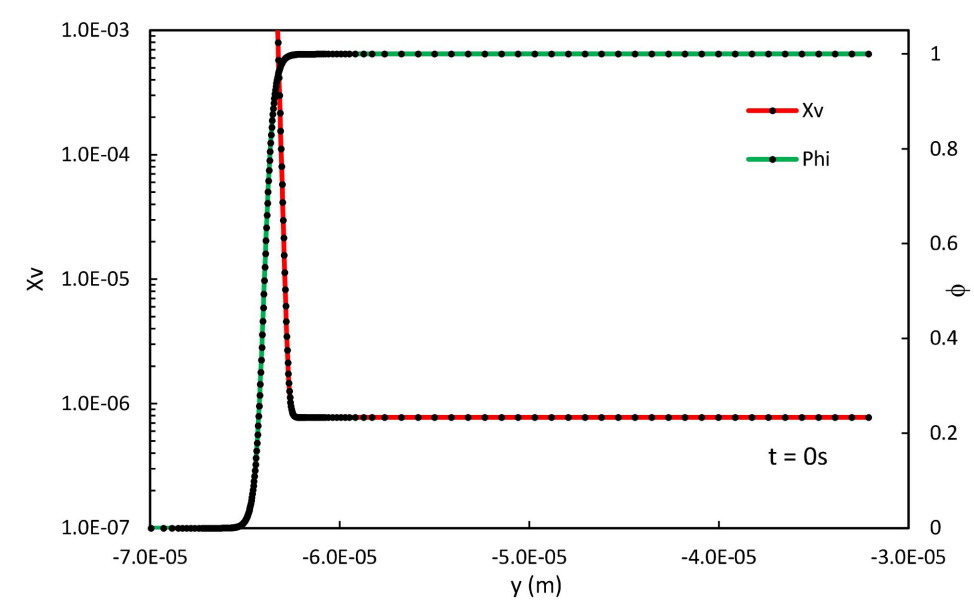

(b)

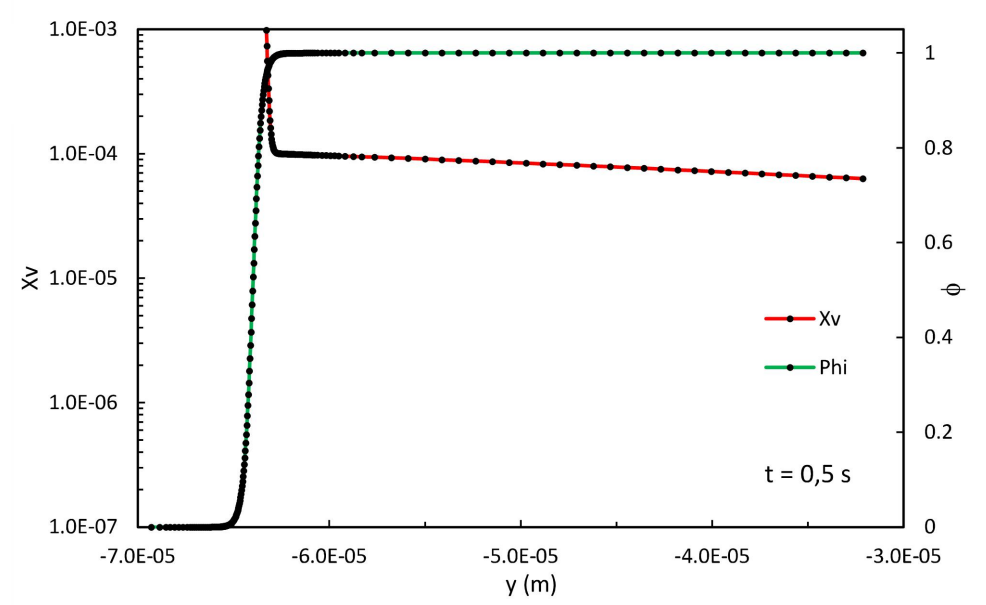

Figura 69: Perfil da variável de fase $(\phi)$ e de fração molar de lacunas $\left(X_{v}\right)$ ao longo de $y$ para $x=0$ e para $a=$ $64 \cdot 10^{-4}, X_{v, s}=7,75 \cdot 10^{-7} \mathrm{e} T=1000{ }^{\circ} \mathrm{C}$ : (a) $t=0$; (b) $t=0,5 \mathrm{~s}$. 
b) Cilindros de cobre puro à temperatura de $4000{ }^{\circ} \mathrm{C}$

A capacidade do modelo implementado em mostrar o efeito de curvatura sobre a fração molar de lacunas, assim como os efeitos de retração ou expansão devido à eliminação ou absorção de lacunas, não foi possível de ser mostrado claramente nas condições de simulação do caso anterior. Com o objetivo de mostrar estes efeitos, duas simulações em condições que não são possíveis fisicamente foram conduzidas. A temperatura de simulação foi de $4000{ }^{\circ} \mathrm{C}$, muito acima do ponto de fusão do cobre puro $\left(1084{ }^{\circ} \mathrm{C}\right)$, e o raio inicial do cilindro de cobre foi de $0,96 \cdot 10^{-7} \mathrm{~m}$, um pouco menor do que $10^{-7} \mathrm{~m}$, que foi mostrado na Figura 56(b) como o valor acima do qual praticamente não há efeito de curvatura. Em cada uma das duas simulações foram adotadas duas diferentes frações molares de lacunas no interior do cilindro sólido no instante inicial $\left(X_{v, s}\right)$, a saber, 0,4 ou $10^{-7}$. As condições e parâmetros empregados nas simulações estão apresentados na Tabela 27.

Tabela 27: Parâmetros das simulações de cilindros com excesso ou deficiência de lacunas $\left(a=0,96 \cdot 10^{-7} \mathrm{~m}\right)$.

\begin{tabular}{lcc}
\hline \multicolumn{1}{c}{ Variável } & Símbolo & Valor \\
\hline Tensão superficial & $\gamma_{s}$ & $1,72 \mathrm{~J} \cdot \mathrm{m}^{-2}$ \\
\hline Densidade molar de sítios & $\rho_{m}^{s}$ & $1,41 \cdot 10^{5} \mathrm{mols} \cdot \mathrm{m}^{-3}$ \\
\hline Coeficiente de difusão de lacunas no sólido & $D_{v}^{s}$ & $1,67 \cdot 10^{-9} \mathrm{~m}^{2} \cdot \mathrm{s}^{-1}$ \\
\hline Temperatura & $T$ & $4000^{\circ} \mathrm{C}$ \\
\hline Tamanho do domínio & $L_{x} \times L_{y}$ & $1,28 \cdot 10^{-7} \times 1,28 \cdot 10^{-7} \mathrm{~m}$ \\
\hline Raio do grão cilíndrico & $a$ & $0,96 \cdot 10^{-7} \mathrm{~m}$ \\
\hline Fração inicial de lacunas no sólido & $X_{v, t=0}^{s}$ & $0,4{\mathrm{ou} 10^{-7}}^{\prime}$ \\
\hline Fração inicial de lacunas na fase fictícia $\left(\boldsymbol{g}^{\prime}\right)$ & $X_{v, t=0}^{g^{\prime}}$ & 0,9906 \\
\hline \hline Número de nós da malha raiz & $\mathrm{N}_{\mathrm{x}} \mathrm{x} \mathrm{\textrm {N } _ { \mathrm { y } }}$ & $80 \times 80$ \\
\hline Nível máximo de subdivisão da malha & $\mathrm{N}$ & 5 \\
\hline Número total de volumes na malha $(\boldsymbol{t}=0)$ & $\mathrm{N}_{\mathrm{T}}$ & 338107 \\
\hline Passo de tempo & $\Delta t$ & $2,5 \cdot 10^{-10} \mathrm{~s}$ \\
\hline Espessura da interface difusa & $\delta$ & $2 \cdot 10^{-9} \mathrm{~m}$ \\
\hline Mobilidade da variável de fase & $M_{\varnothing}$ & $0,04 \mathrm{~J}^{-1} \cdot \mathrm{s}^{-1}$ \\
\hline
\end{tabular}

A condição inicial para o caso $X_{v, s}=0,4$ está ilustrada na Figura 70(a), sendo que o campo de fração molar de lacunas está no quadrante superior esquerdo. A Figura 70(b) apresenta o resultado da simulação para $t=6,1 \cdot 10^{-6} \mathrm{~s}$, onde se nota claramente a perda de lacunas pelo sólido e a retração do cilindro com a diminuição de seu raio. Logo, o modelo está consistente 
com o comportamento físico esperado, ou seja, uma perda de lacunas deve ocasionar uma diminuição do volume de sólido. A malha adaptativa foi adjustada corretamente para estar sempre refinada na região da interface difusa e foi capaz de proporcionar o cálculo correto do raio de curvatura local do cilindro de $r / a \approx 0,8$ (quadrante inferior esquerdo), indicado também pela coordenada do intercepto da interface com os eixos.

(a)

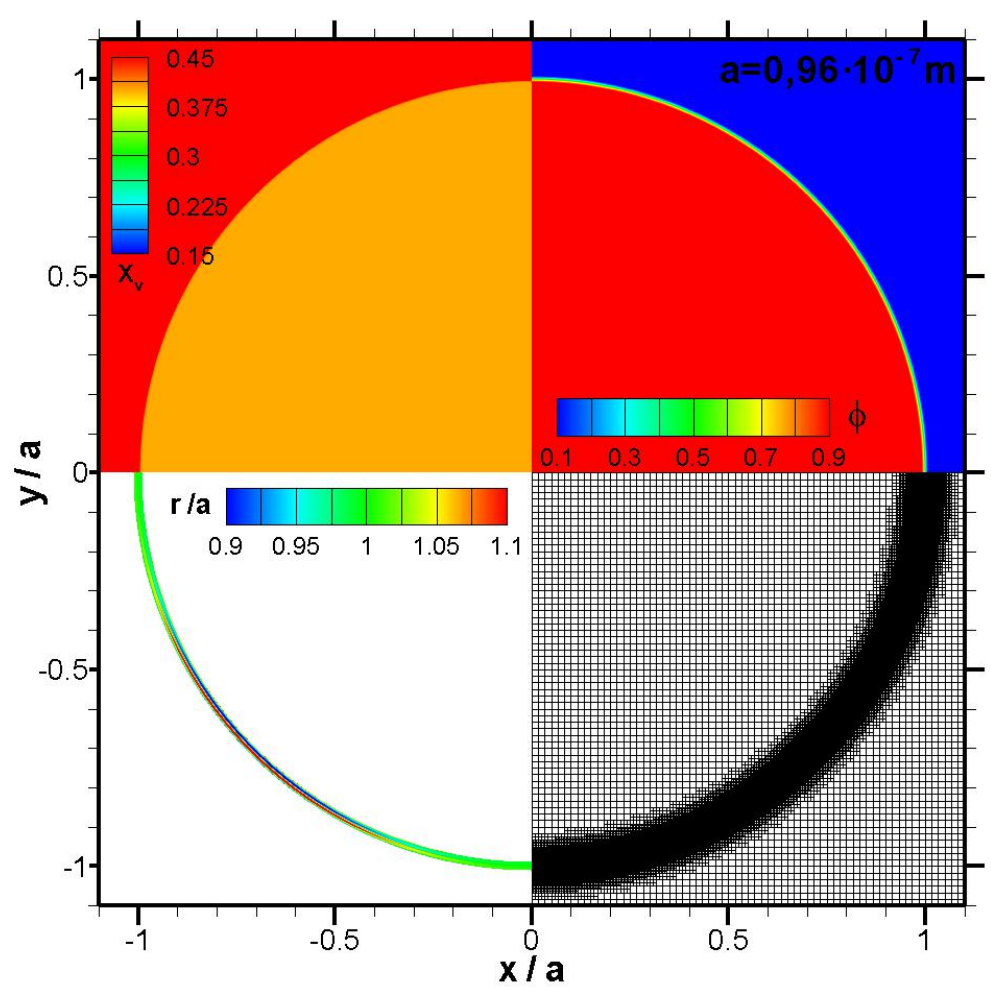


(b)
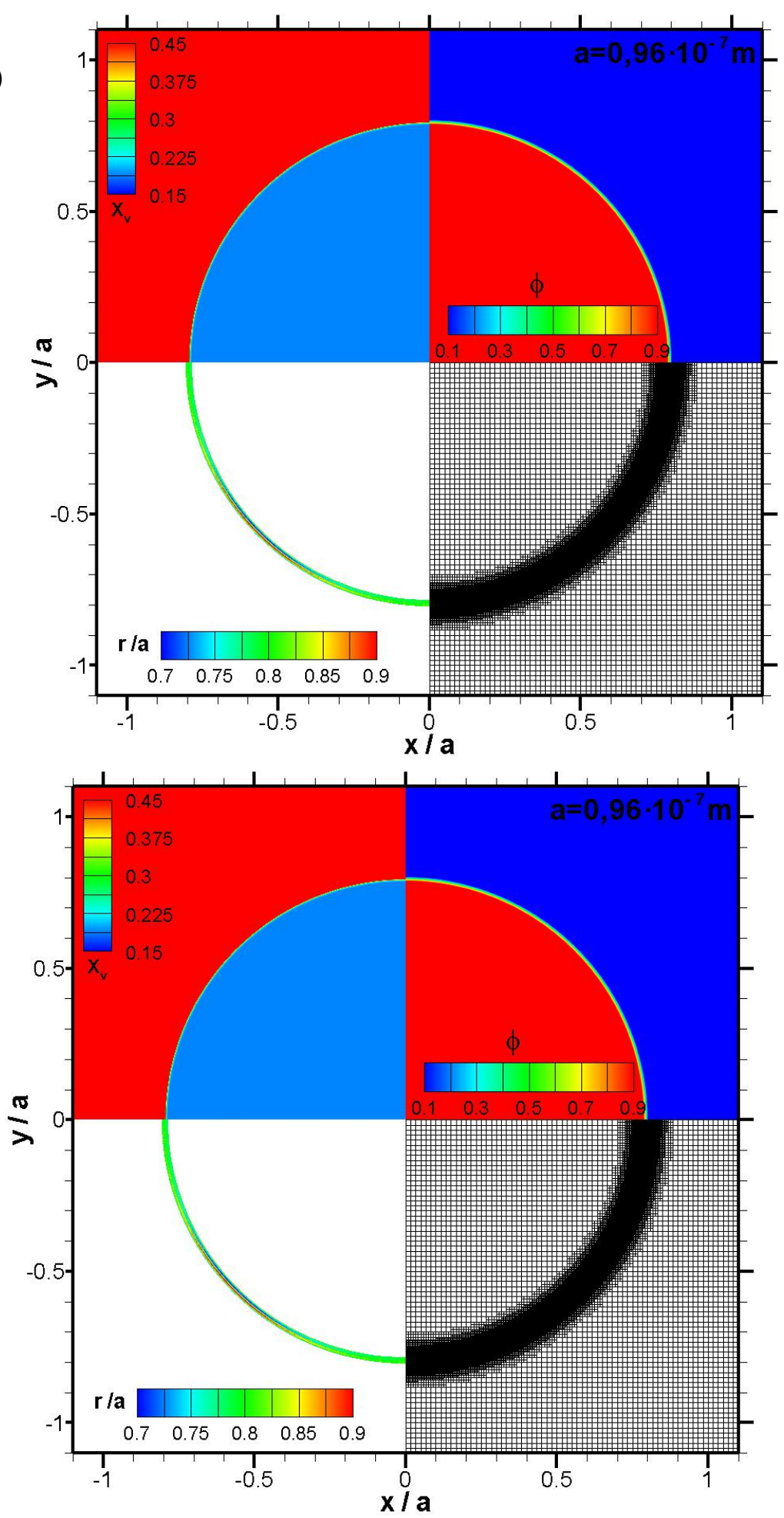

Figura 70: Campos de variável de fase $(\phi)$, fração molar de lacunas $\left(X_{v}\right)$ e curvatura local $(r / a)$, além de uma visão da malha numérica utilizada para: $a=0,96 \cdot 10^{-7}, X_{v, S}=0,4 \mathrm{e} T=4000^{\circ} \mathrm{C}:$ (a) $t=0$; (b) $t=6,1 \cdot 10^{-6} \mathrm{~s}$.

Uma comparação entre os campos de fração de lacunas no instante inicial e para $t=$ $6,1 \cdot 10^{-6} \mathrm{~s}$ está apresentada na Figura 71 . Os perfis de fração de lacunas ao longo do eixo $y$ no sentido descendente atravessando a superfície do cilindro também estão mostrados na Figura 
72. Uma comparação entre a Figura 72(a) e (b) mostra o deslocamento da interface e mostra o decréscimo de $X_{v}$ de 0,4 para 0,19 , que é o valor de equilíbrio termodinâmico para a temperatura de $4000{ }^{\circ} \mathrm{C}$ e raio de curvatura $r / a \approx 0,8$. Nota-se uma composição uniforme, indicando que o equilíbrio termodinâmico global foi aproximadamente atingido. Outra indicação do equilíbrio é o decréscimo da velocidade da interface para aproximadamente zero, como mostrado na Figura 73(a). Na Figura 73(b) observa-se que a fração molar de lacunas no sólido próximo à interface $(\phi=0,995)$ atinge rapidamente o valor de equilíbrio, garantindo o equilíbrio termodinâmico local (junto à interface) na maior parte da simulação.
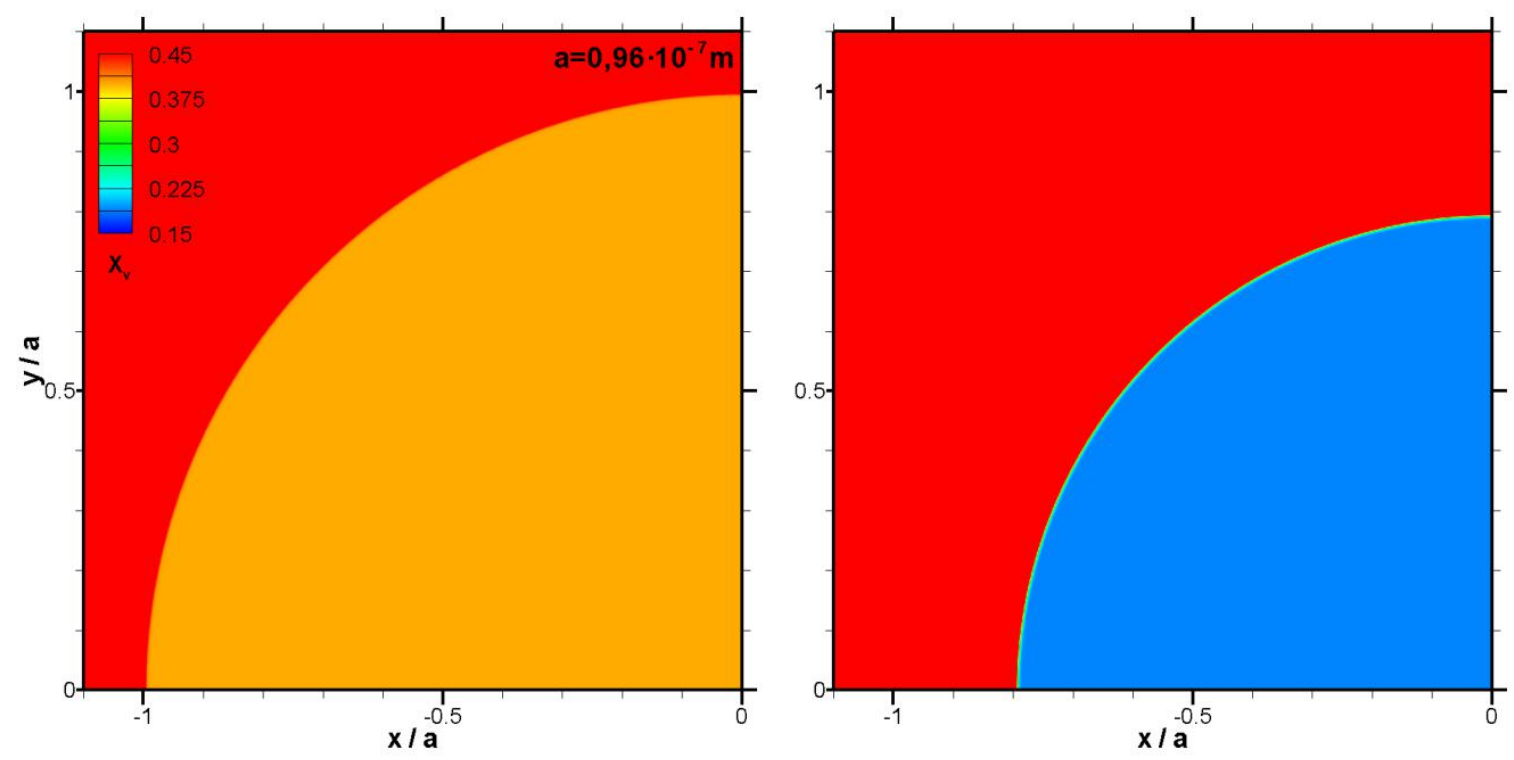

Figura 71 - Campo de fração molar de lacunas $\left(X_{v}\right)$ para $a=0,96 \cdot 10^{-7}, X_{v, s}=0,4$ e $T=4000^{\circ} \mathrm{C}$ : (a) $t=0$; (b) $t=$ $6,1 \cdot 10^{-6} \mathrm{~s}$.

(a)

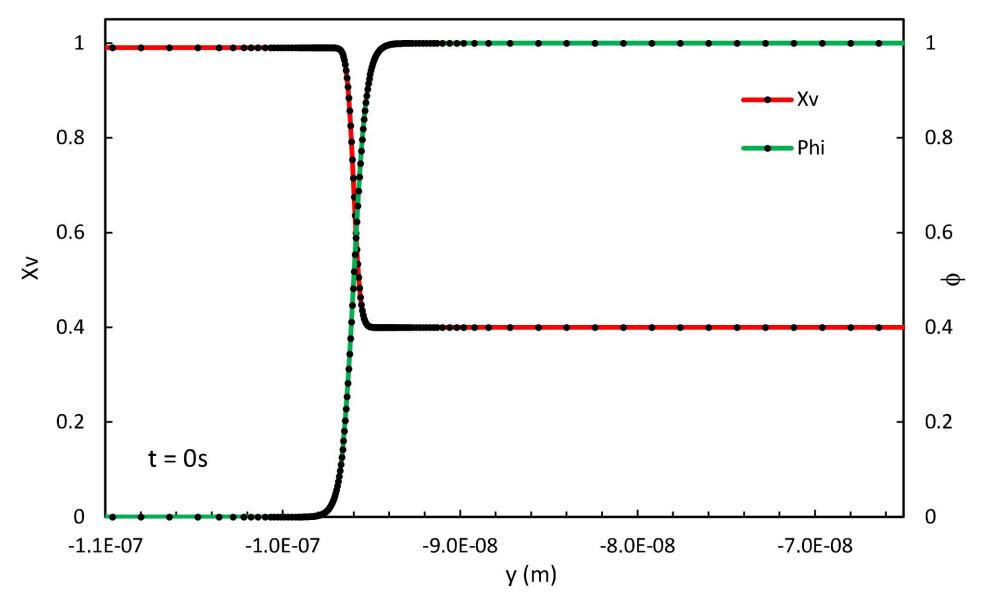


(b)

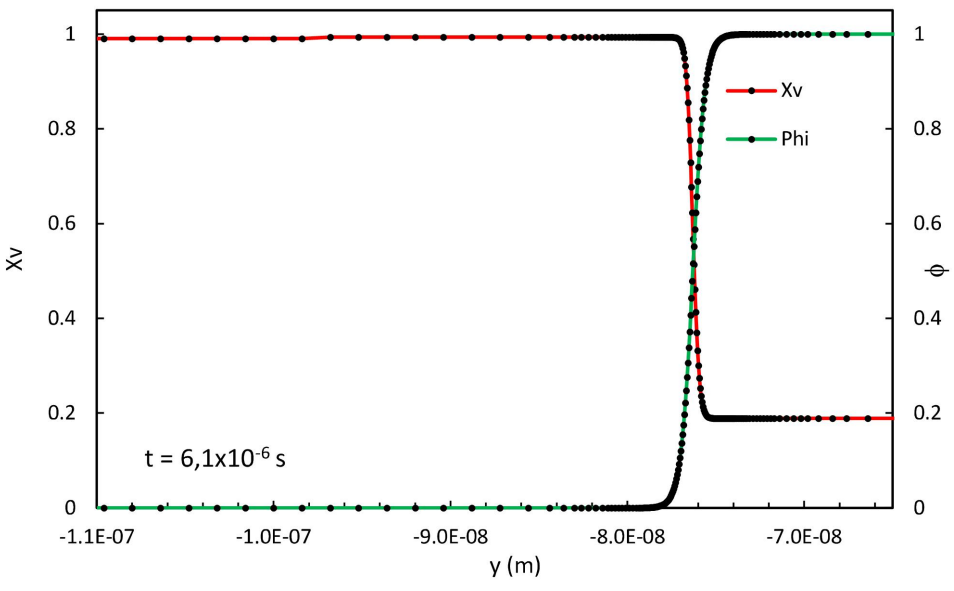

Figura 72: Perfil da variável de fase $(\phi)$ e de fração molar de lacunas $\left(X_{v}\right)$ ao longo de $y$ para $x=0$ e para $a=$ $0,96 \cdot 10^{-7}, X_{v, s}=0,4$ e $T=4000^{\circ} \mathrm{C}$ : (a) $t=0$; (b) $t=6,1 \cdot 10^{-6} \mathrm{~s}$.

(a)

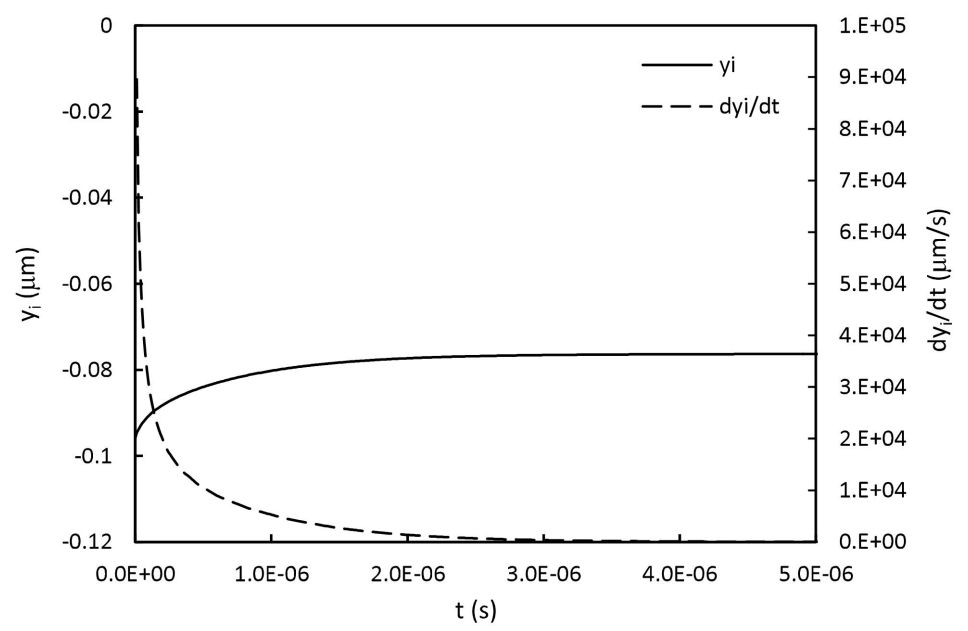




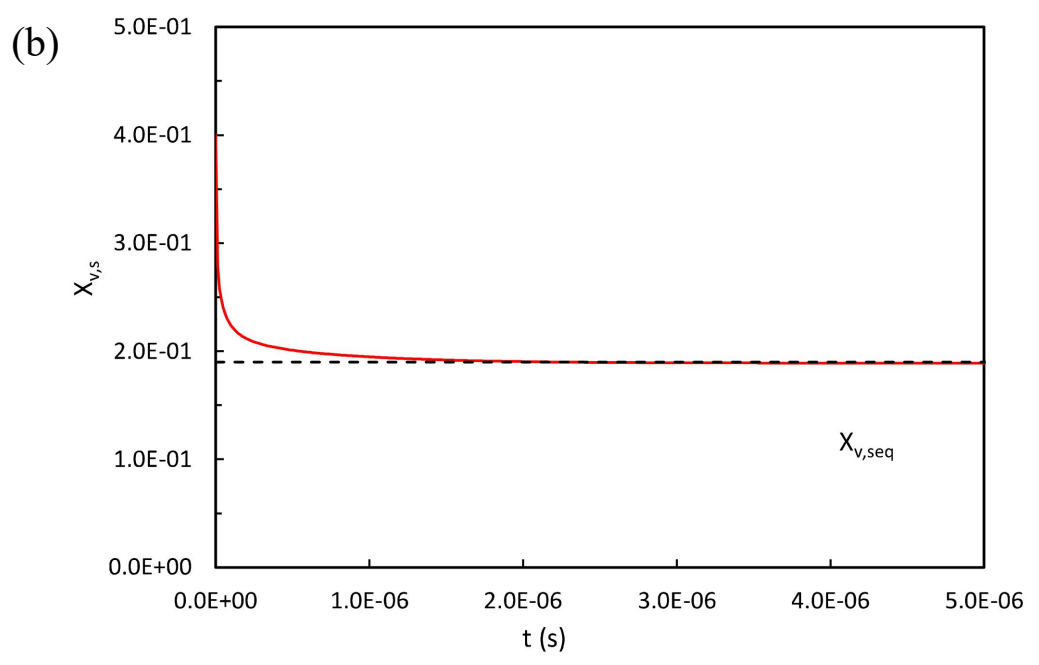

Figura 73: Parâmetros da superfície (interface sólido-fase fictícia) em função do tempo: (a) posição $\left(y_{i}\right)$ e velocidade $\left(d y_{i} / d t\right)$ da interface; (b) fração de lacunas no sólido junto à interface $\left(X_{v, s}\right)$, onde $X_{v, s e q}$ corresponde à fração no equilíbrio termodinâmico.

$\mathrm{Na}$ segunda simulação tem-se uma fração inicial de lacunas no sólido igual a $10^{-7}$, representando uma deficiência em relação à fração de equilíbrio. A Figura 74(a) mostra esta condição inicial e a Figura 74(b) mostra o resultado da simulação para $t=6,1 \cdot 10^{-6} \mathrm{~s}$, onde se observa a ocorrência da absorção de lacunas e o aumento do raio (expansão) do cilindro, como seria esperado fisicamente. A curvatura local indicada no quadrante inferior esquerdo da Figura 74(b) e mostrada em maior detalhe na Figura 75 varia ao longo da interface, sendo maior junto aos eixos $x$ e $y$, diminuindo na região intermediária, sugerindo a formação de uma ponta nesta região. Esta distorção pode estar sendo causada pela anisotropia da malha numérica e não deve ser um efeito da proximidade do contorno do domínio, já que o transporte na região externa ao cilindro (fase fictícia) é nulo. 
(a)

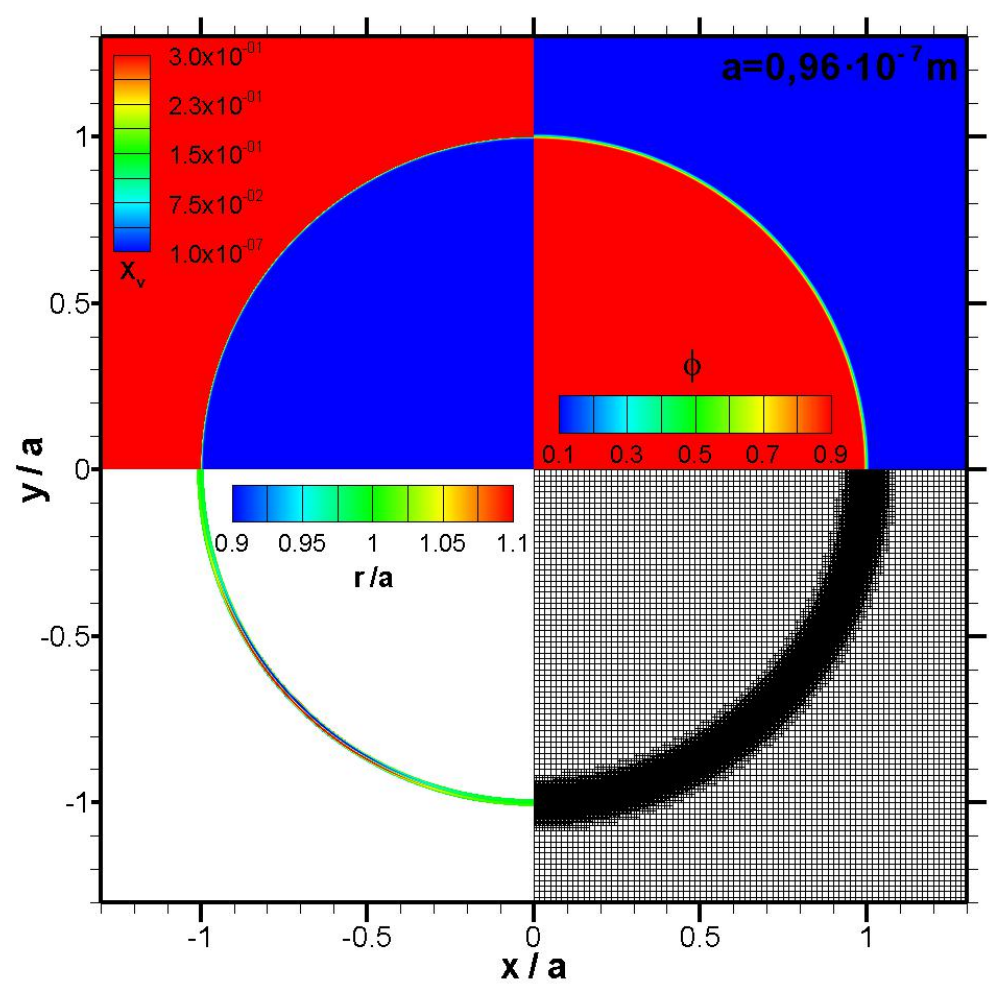

(b)

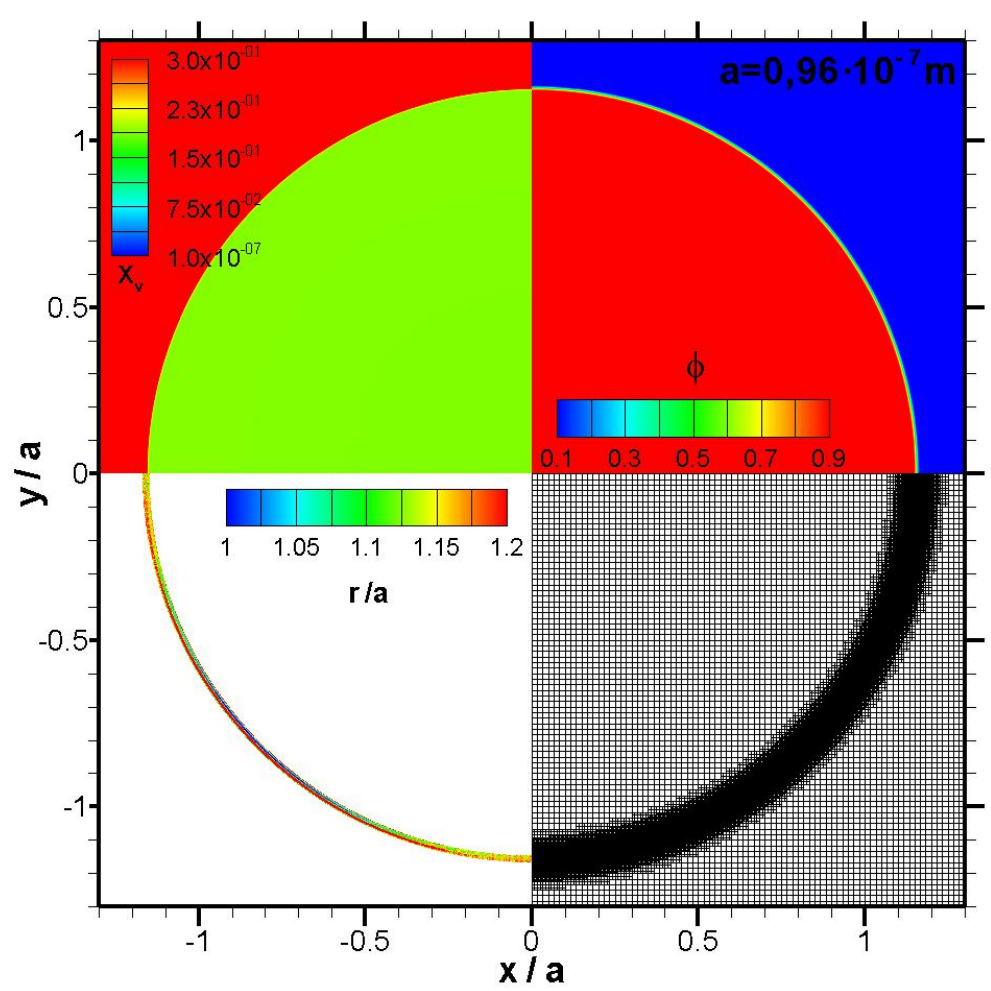

Figura 74 - Campos de variável de fase $(\phi)$, fração molar de lacunas $\left(X_{v}\right)$ e curvatura local $(r / a)$, além de uma visão da malha numérica utilizada para: $a=0,96 \cdot 10^{-7}, X_{v, s}=10^{-7} \mathrm{e} T=4000^{\circ} \mathrm{C}:$ (a) $t=0$; (b) $t=6,1 \cdot 10^{-6} \mathrm{~s}$. 


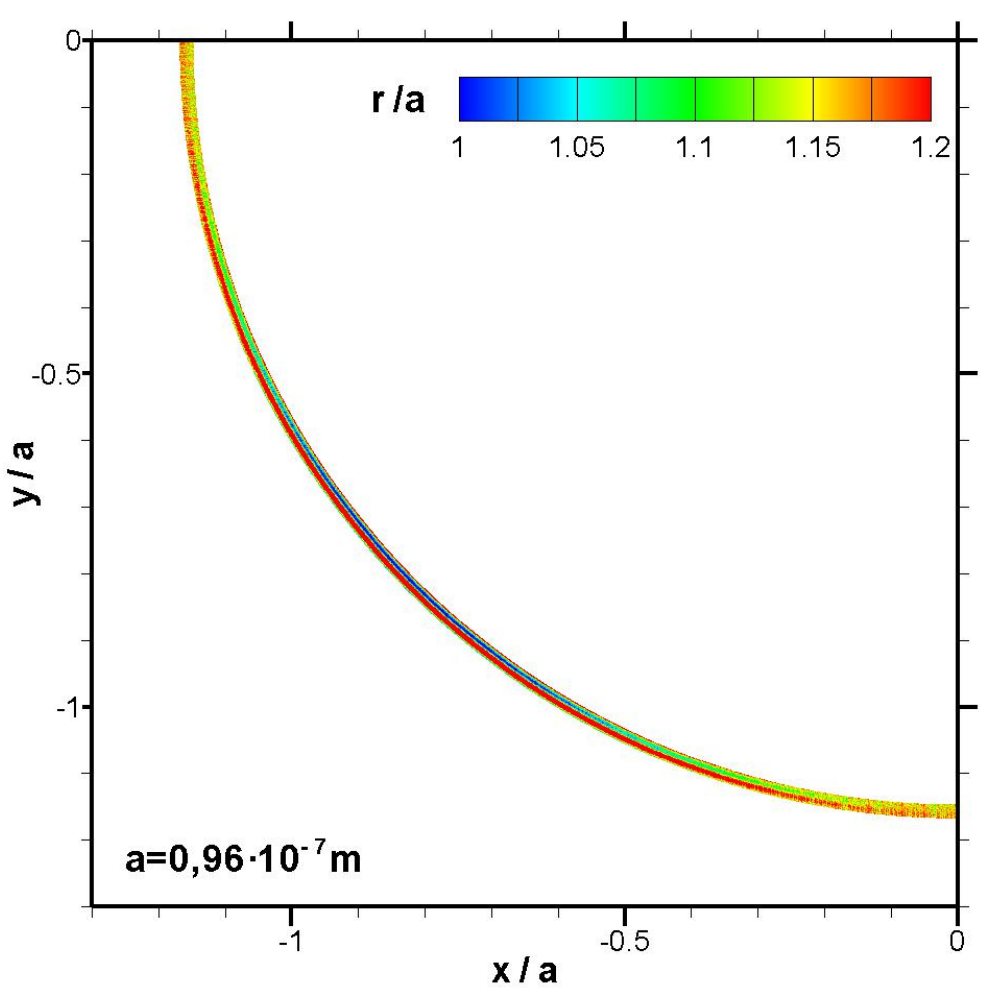

Figura 75 - Campo de curvatura local $(r / a)$ para $a=0,96 \cdot 10^{-7}, X_{v, s}=10^{-7}$ e $T=4000^{\circ} \mathrm{C}$ em $t=6,1 \cdot 10^{-6} \mathrm{~s}$.

Os detalhes da movimentação da interface sólido-fase fictícia e dos perfis de fração de lacunas ao longo do eixo $y$, através da região da interface, estão apresentados na Figura 76, mostrando o aumento de $X_{v}$ de $10^{-7}$ até aproximadamente 0,19 , que representa o equilíbrio termodinâmico. Na Figura 77(a) tem-se o comportamento típico de uma redução da velocidade da interface até aproximadamente zero à medida que o sólido absorve lacunas e atinge o equilíbrio e a Figura 77(b) indica que a fração de lacunas do sólido adjacente à interface atinge o equilíbrio local rapidamente.

Os resultados apresentados neste item mostraram que o modelo de campo de fases é capaz de simular corretamente o processo de absorção e eliminação de lacunas de forma consistente com a termodinâmica e de indicar o aumento e diminuição de volume do sólido decorrente das variações da quantidade de lacunas existentes em seu interior. 
(a)

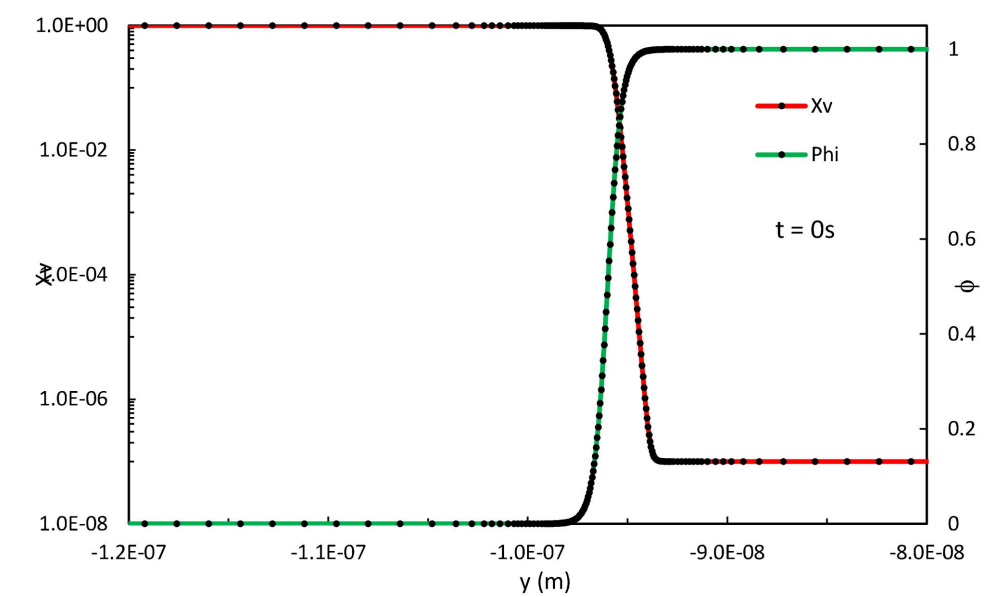

(b)

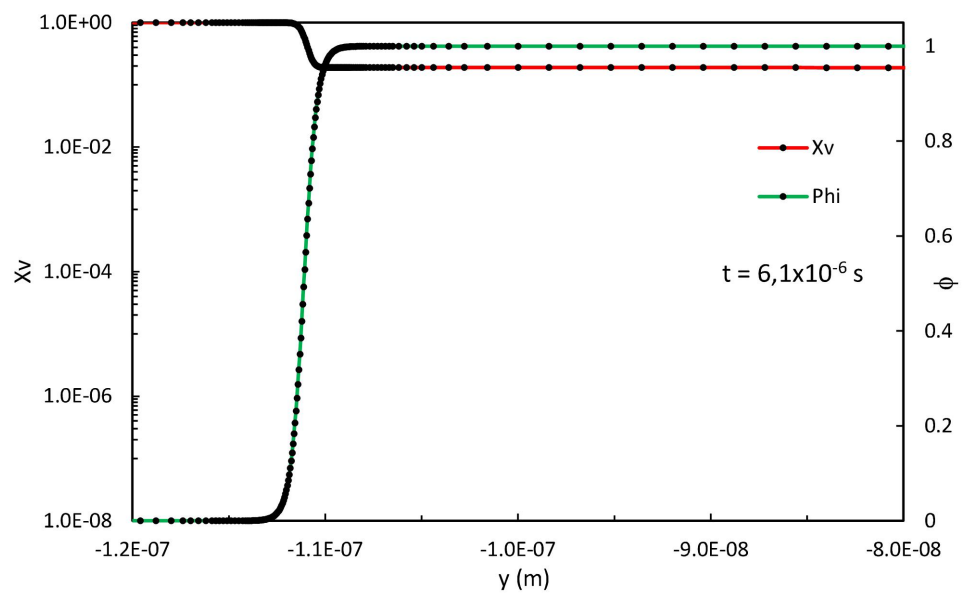

Figura 76 - Perfil da variável de fase $(\phi)$ e de fração molar de lacunas $\left(X_{v}\right)$ ao longo de $y$ para $x=0$ e para $a=$ $0,96 \cdot 10^{-7}, X_{v, S}=10^{-7}$ e $T=4000^{\circ} \mathrm{C}$ : (a) $t=0$; (b) $t=6,1 \cdot 10^{-6} \mathrm{~s}$.

(a)

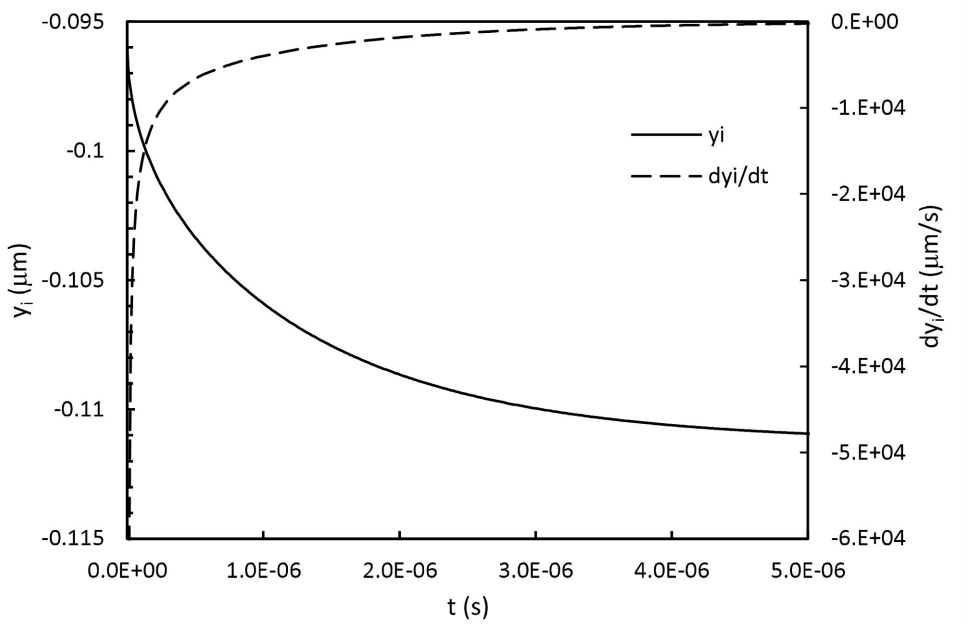




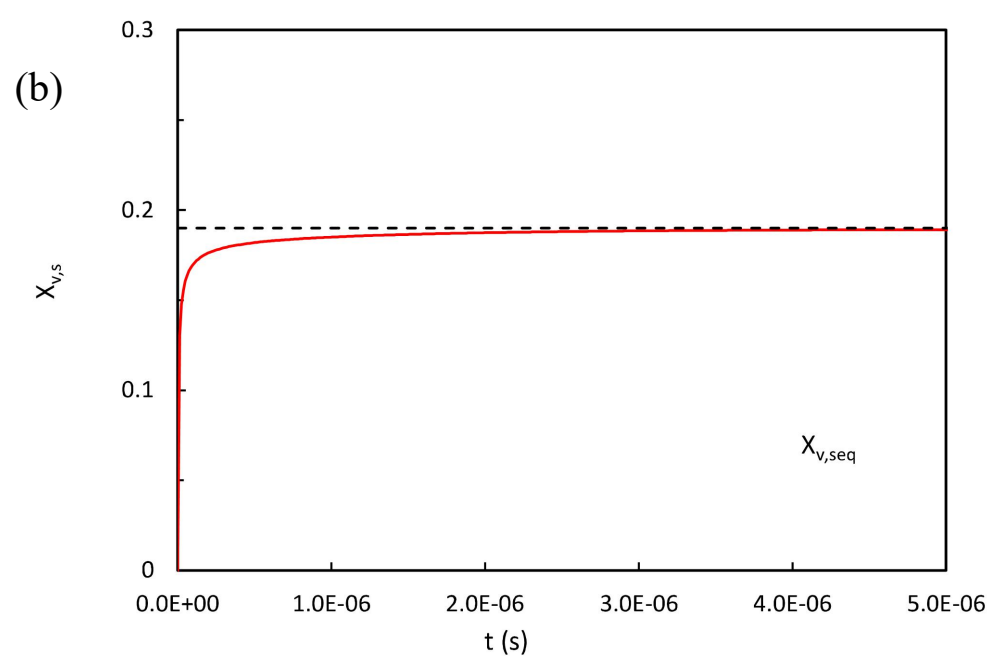

Figura 77 - Parâmetros da superfície (interface sólido-fase fictícia) em função do tempo: (a) posição $\left(y_{i}\right)$ e velocidade $\left(d y_{i} / d t\right)$ da interface; (b) fração de lacunas no sólido junto à interface $\left(X_{v, s}\right)$, onde $X_{v, \text { seq }}$ corresponde à fração no equilíbrio termodinâmico.

\subsubsection{Crescimento ou Eliminação de Poro}

No item anterior, a transferência de massa e a decorrente movimentação da superfície de um sólido cilíndrico devido às alterações na sua quantidade de lacunas foi simulada pelo modelo de campo de fases. Neste item, estes fenômenos serão também simulados, mas agora na presença de um poro no interior da fase sólida. Uma diferença fundamental em relação ao caso do cilindro sólido é que o poro tem um raio de curvatura de sinal oposto e, neste caso, a termodinâmica mostra (Figura 56) que uma diminuição do raio causa um aumento na fração de equilíbrio de lacunas. Duas simulações foram conduzidas em condições semelhantes às utilizadas no caso (b) do item anterior (5.3.3), ou seja, uma temperatura de $4000{ }^{\circ} \mathrm{C}$ e um poro cilíndrico de raio $0,96 \cdot 10^{-7} \mathrm{~m}$ inserido no cobre puro sólido com duas diferentes frações de lacunas iniciais, a saber, 0,4 ou $10^{-7}$. As condições empregadas nas duas simulações estão apresentadas na Tabela 28. Como mencionado no item anterior, apesar dessas condições não serem fisicamente realistas, elas servem para mostrar de forma mais evidente a capacidade do modelo implementado em simular os fenômenos envolvidos. 
Tabela 28: Parâmetros das simulações de poros onde o sólido apresenta excesso ou deficiência de lacunas.

\begin{tabular}{lcc}
\hline \multicolumn{1}{c}{ Variável } & Símbolo & Valor \\
\hline Tensão superficial & $\gamma_{s}$ & $1,72 \mathrm{~J} \cdot \mathrm{m}^{-2}$ \\
\hline Densidade molar de sítios & $\rho_{m}^{s}$ & $1,41 \cdot 10^{5} \mathrm{mols} \cdot \mathrm{m}^{-3}$ \\
\hline Coeficiente de difusão de lacunas no sólido & $D_{v}^{s}$ & $1,67 \cdot 10^{-9} \mathrm{~m}^{2} \cdot \mathrm{s}^{-1}$ \\
\hline Temperatura & $T$ & $4000^{\circ} \mathrm{C}$ \\
\hline Tamanho do domínio & $L_{x} \times L_{y}$ & $1,28 \cdot 10^{-7} \times 1,28 \cdot 10^{-7} \mathrm{~m}$ \\
\hline Raio do poro cilíndrico & $a$ & $0,96 \cdot 10^{-7} \mathrm{~m}$ \\
\hline Fração inicial de lacunas no sólido & $X_{v, t=0}^{s}$ & $0,4 \mathrm{ou} 10^{-7}$ \\
\hline Fração inicial de lacunas na fase fictícia $\left(\boldsymbol{g}^{\prime}\right)$ & $X_{v, t=0}^{g^{\prime}}$ & 0,9906 \\
\hline \hline Número de nós da malha raiz & $\mathrm{N}_{\mathrm{x}} \mathrm{x} \mathrm{N}_{\mathrm{y}}$ & $80 \times 80$ \\
\hline Nível máximo de subdivisão da malha & $\mathrm{N}$ & 5 \\
\hline Número total de volumes na malha $(\boldsymbol{t}=0)$ & $\mathrm{N}_{\mathrm{T}}$ & 338107 \\
\hline Passo de tempo & $\Delta t$ & $2,5 \cdot 10^{-10} \mathrm{~s}$ \\
\hline Espessura da interface difusa & $\delta$ & $2 \cdot 10^{-9} \mathrm{~m}$ \\
\hline Mobilidade da variável de fase & $M_{\varnothing}$ & $0,04 \mathrm{~J}^{-1} \cdot \mathrm{s}^{-1}$ \\
\hline
\end{tabular}

A Figura 78(a) e (b) apresentam o estado inicial da simulação, onde a fração de lacunas no sólido externo ao poro está em excesso $\left(X_{v}=0,4\right)$, e o resultado após $6,1 \cdot 10^{-6} \mathrm{~s}$, mostrando que o sólido perdeu lacunas e resultou em um aumento no tamanho do poro, como esperado. Nota-se que o raio de curvatura local calculado com base no campo de $\phi$ (quadrante inferior esquerdo) agora é negativo e foi modificado do valor inicial $r / a=-1$ após o crescimento do poro. Nota-se claramente uma distorção de forma, onde $r / a$ é maior em módulo do que o valor inicial no cruzamento com os eixos coordenados e menor na região intermediária. Esta distorção pode estar relacionada á anisotropia da malha, mas provavelmente o maior causador da distorção é a diferença de proximidade ao contorno do domínio. Nas regiões da interface mais próximas desse contorno, mais rapidamente ocorre a dimuição da fração de lacunas, resultando em um decréscimo mais rápido da velocidade local de movimentação da interface. As alterações de raio de curvatura podem ser vistos em maior detalhe na Figura 79. 
(a)
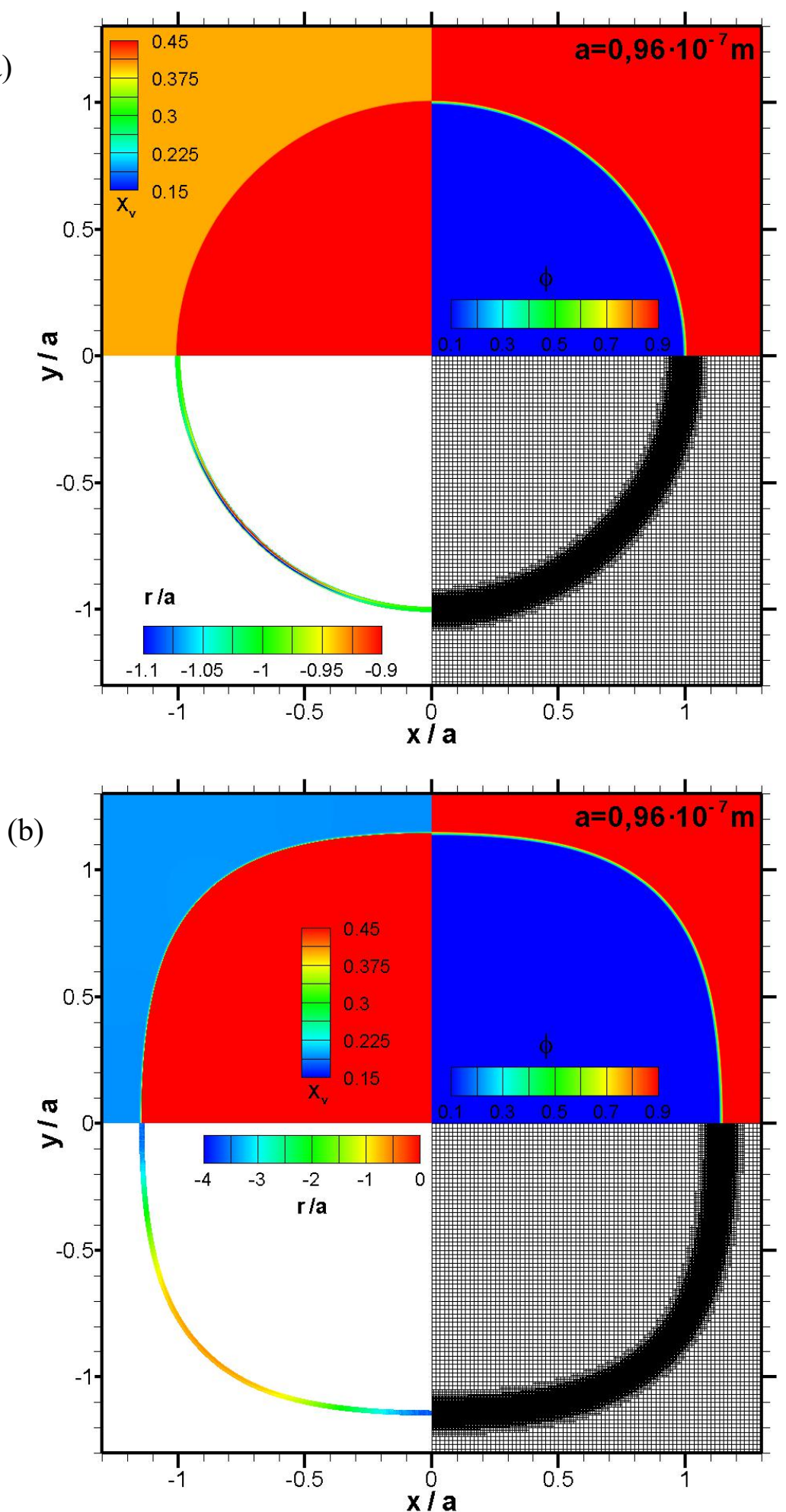

Figura 78 - Campos de variável de fase $(\phi)$, fração molar de lacunas $\left(X_{v}\right)$ e curvatura local $(r / a)$, além de uma visão da malha numérica utilizada para: $a=0,96 \cdot 10^{-7}, X_{v, s}=0,4 \mathrm{e} T=4000^{\circ} \mathrm{C}$ : (a) $t=0$; (b) $t=6,1 \cdot 10^{-6} \mathrm{~s}$. 
(a)

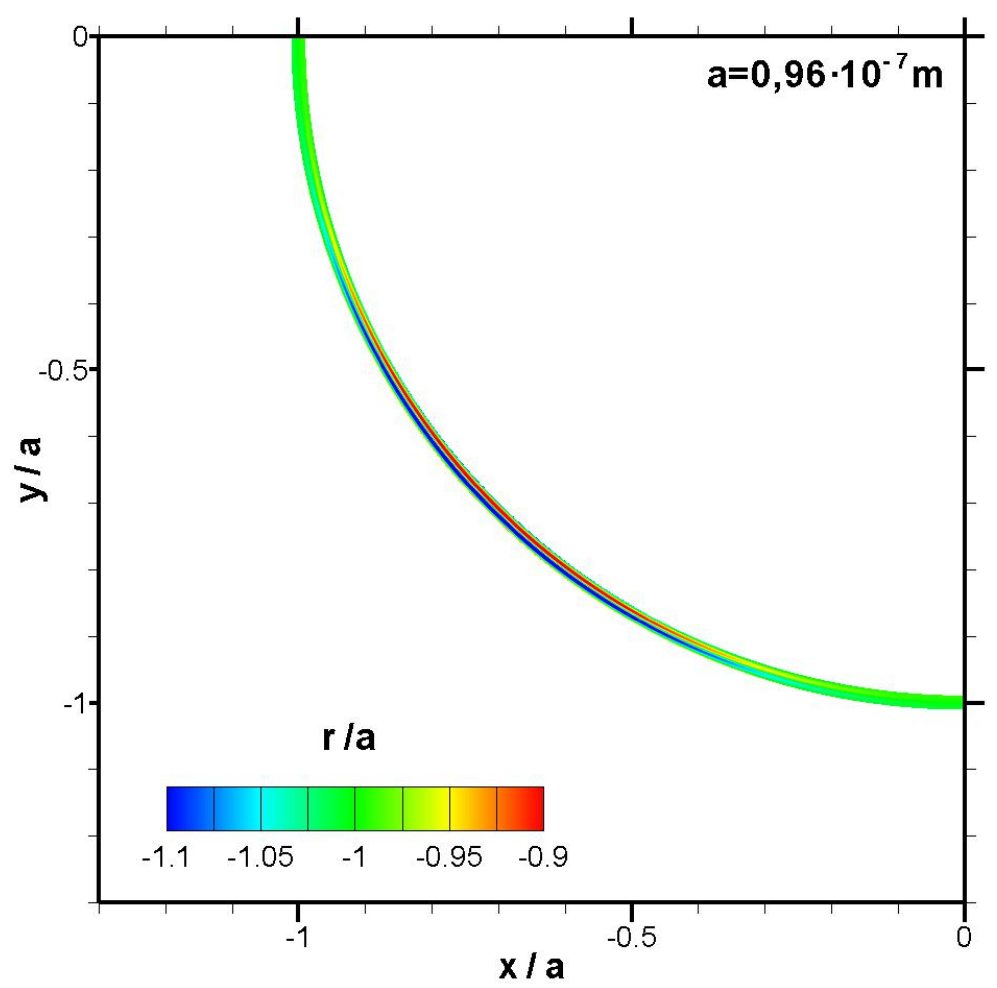

(b)

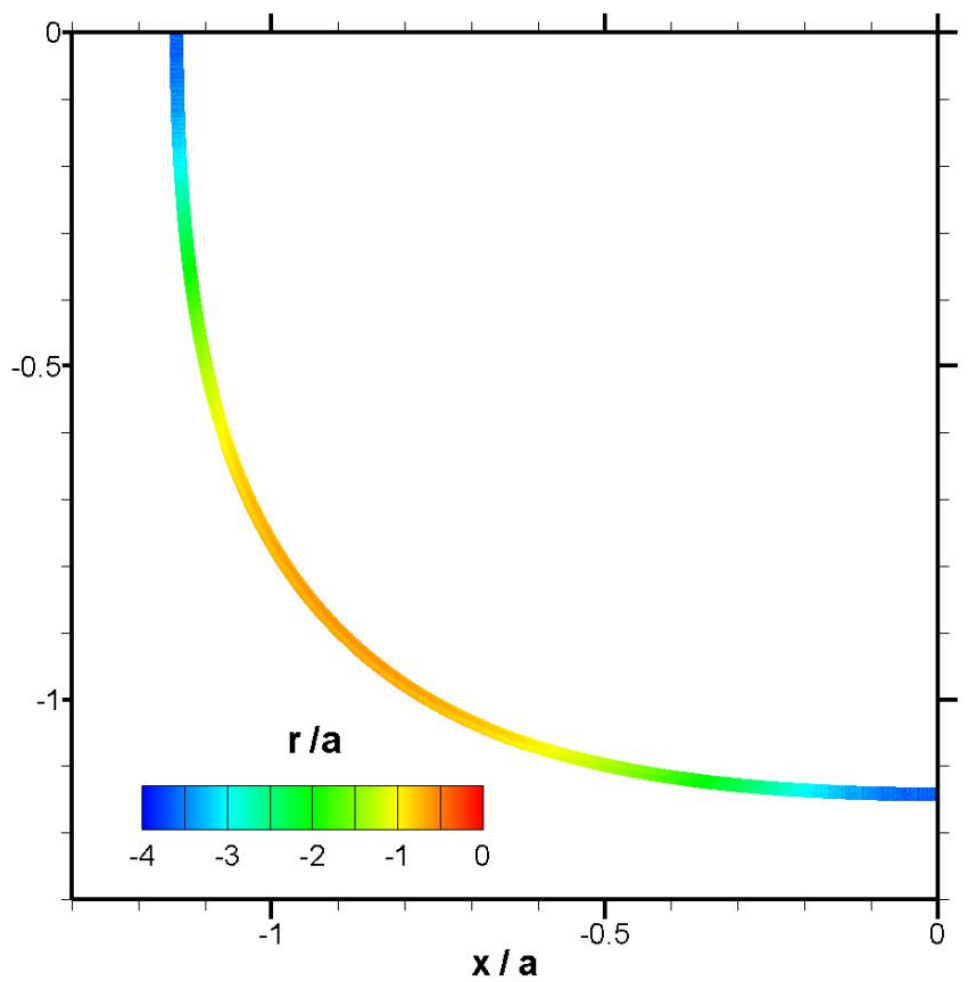

Figura 79 - Campo de curvatura local $(r / a)$ para $a=0,96 \cdot 10^{-7}, X_{v, S}=0,4$ e $T=4000^{\circ} \mathrm{C}$ : (a) $t=0$; (b) $t=6,1 \cdot 10^{-6} \mathrm{~s}$.

A Figura 80(a) e (b) ilustram as alterações nos perfis de fração de lacunas ao longo do eixo $y$, mostrando a redução da fração no sólido de 0,4 para o valor de equilíbrio termodinâmico para o raio de curvatura local $(r / a \approx-3,5)$, igual à 0,192 . Este valor foi 
rapidamente atingido no sólido junto à interface, como ilustra a Figura 81(b). A Figura 81(a) mostra novamente o comportamento típico onde a velocidade de movimentação é elevada no início da simulação, reduzindo-se à medida que a fração de lacunas no sólido se aproximada do valor de equilíbrio termodinâmico.

(a)

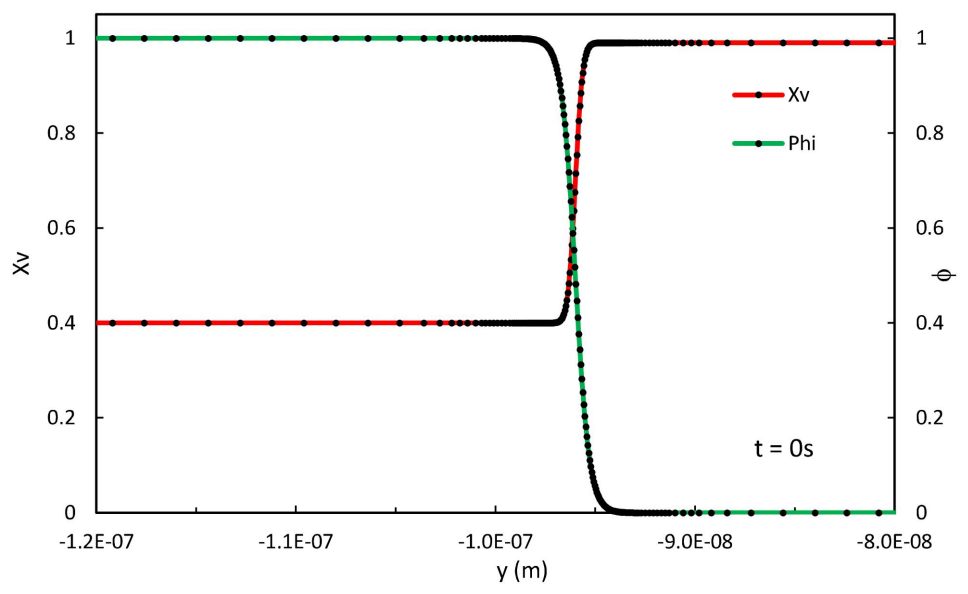

(b)

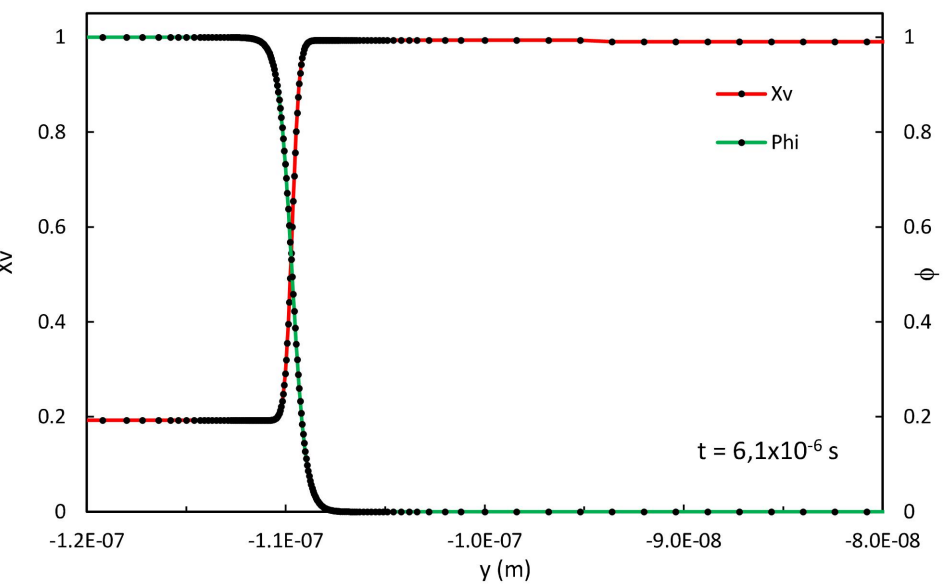

Figura 80: Perfil da variável de fase $(\phi)$ e de fração molar de lacunas $\left(X_{v}\right)$ ao longo de $y$ para $x=0$ e para $a=$ $0,96 \cdot 10^{-7}, X_{v, s}=0,4$ e $T=4000{ }^{\circ} \mathrm{C}$ : (a) $t=0$; (b) $t=6,1 \cdot 10^{-6} \mathrm{~s}$. 
(a)

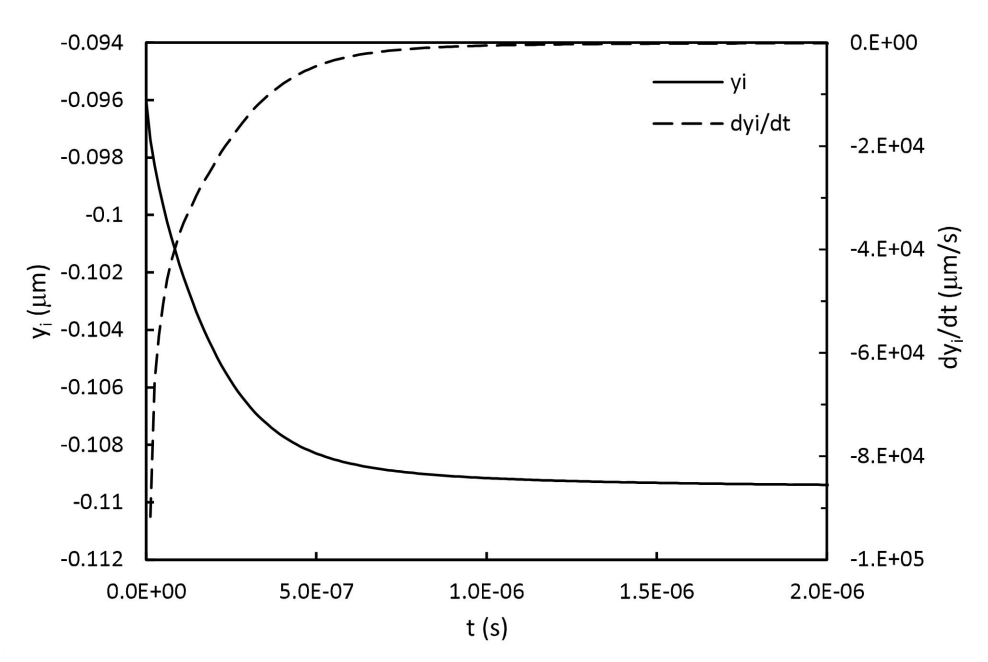

(b)

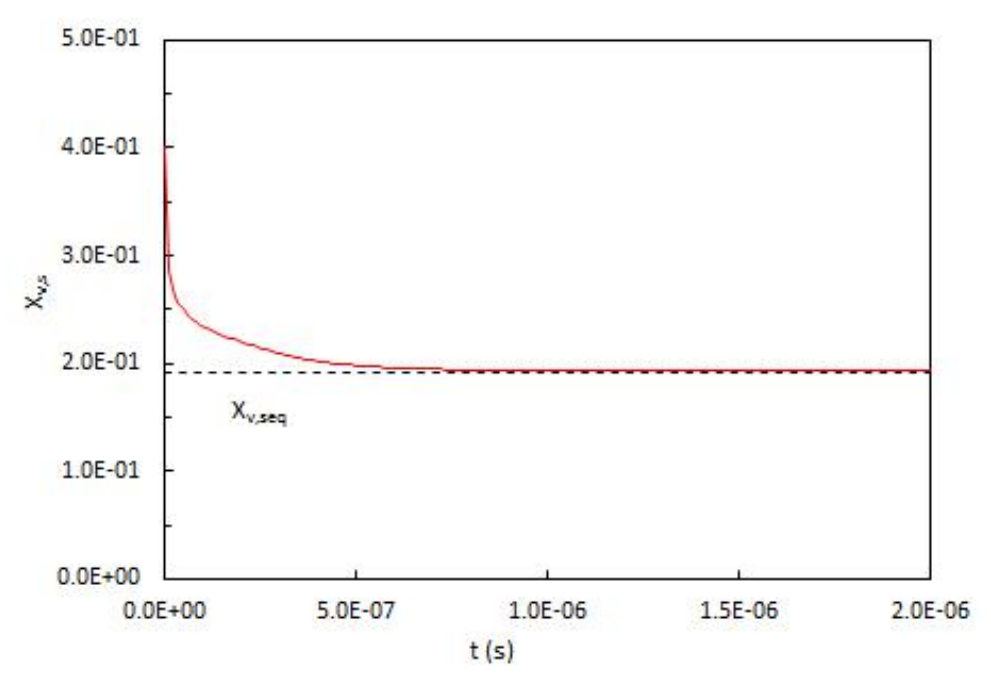

Figura 81 - Parâmetros da superfície (interface sólido-fase fictícia) em função do tempo: (a) posição $\left(y_{i}\right) \mathrm{e}$ velocidade $\left(d y_{i} / d t\right)$ da interface; (b) fração de lacunas no sólido junto à interface $\left(X_{v, s}\right)$, onde $X_{v, \text { seq }}$ corresponde à fração no equilíbrio termodinâmico.

A condição inicial utilizada na segunda simulação do comportamento do poro, onde o sólido apresenta uma deficiência de lacunas $\left(X_{v}=10^{-7}\right)$ e o resultado fornecido pelo modelo após $6,1 \cdot 10^{-6} \mathrm{~s}$ estão apresentados na Figura 82(a) e (b), respectivamente. Nota-se a absorção de lacunas pelo sólido a partir da região da interface com o poro. Como resultado, houve uma diminuição do poro, o que é esperado fisicamente devido ao aumento de volume sofrido pelo sólido. Como na simulação anterior, também se observa uma distorção na forma do poro em relação ao círculo inicial (Figura 83): nota-se agora que na região onde a interface cruza os eixos coordenados (Figura 83(b)) o raio de curvatura é menor do que na região intermediária, ao contrário do observado no caso do crescimento do poro. Este comportamento está consistente com o efeito do contorno do domínio sobre o transporte de lacunas no sólido: 
quando a interface está mais próxima do contorno do domínio, sua velocidade é menor decorrente de uma elevação mais rápida na quantidade de lacunas nesta região.

(a)

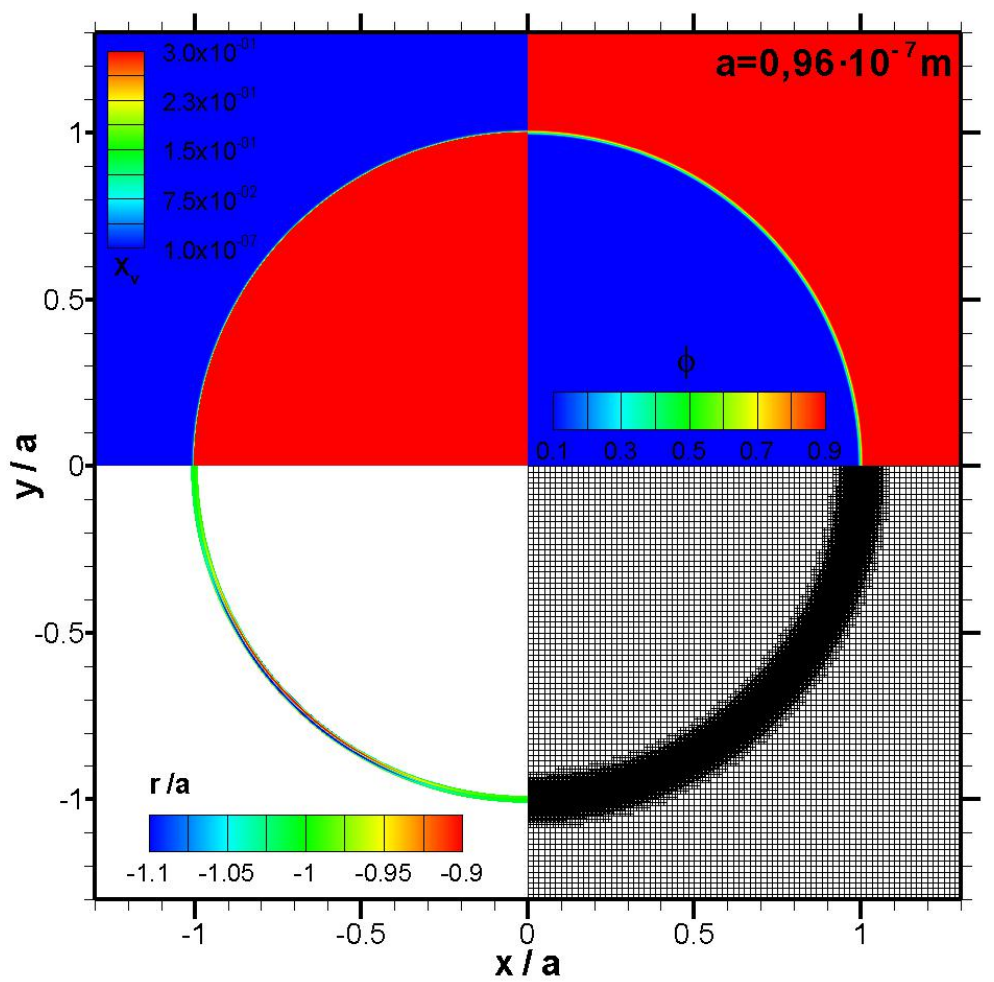

(b)

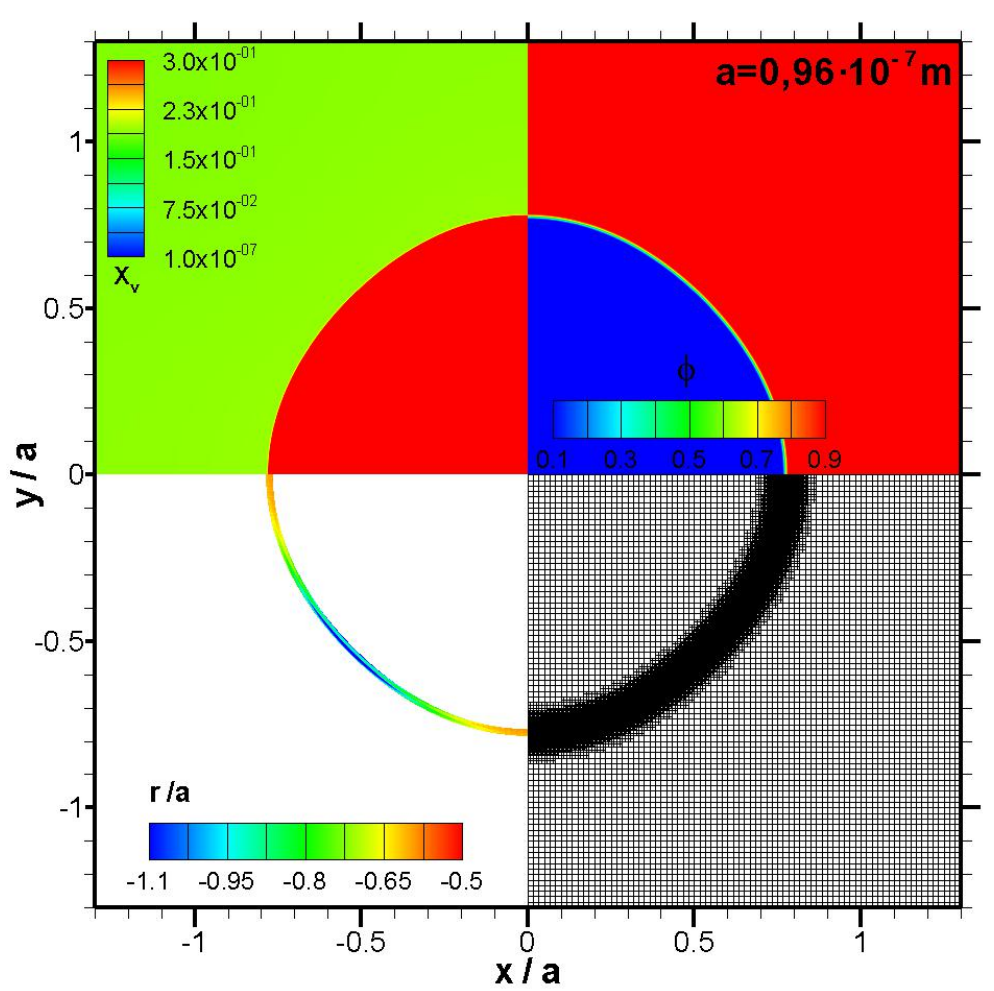

Figura 82 - Campos de variável de fase $(\phi)$, fração molar de lacunas $\left(X_{v}\right)$ e curvatura local $(r / a)$, além de uma visão da malha numérica utilizada para: $a=0,96 \cdot 10^{-7}, X_{v, S}=10^{-7} \mathrm{e} T=4000^{\circ} \mathrm{C}:$ (a) $t=0$; (b) $t=6,1 \cdot 10^{-6} \mathrm{~s}$. 
(a)

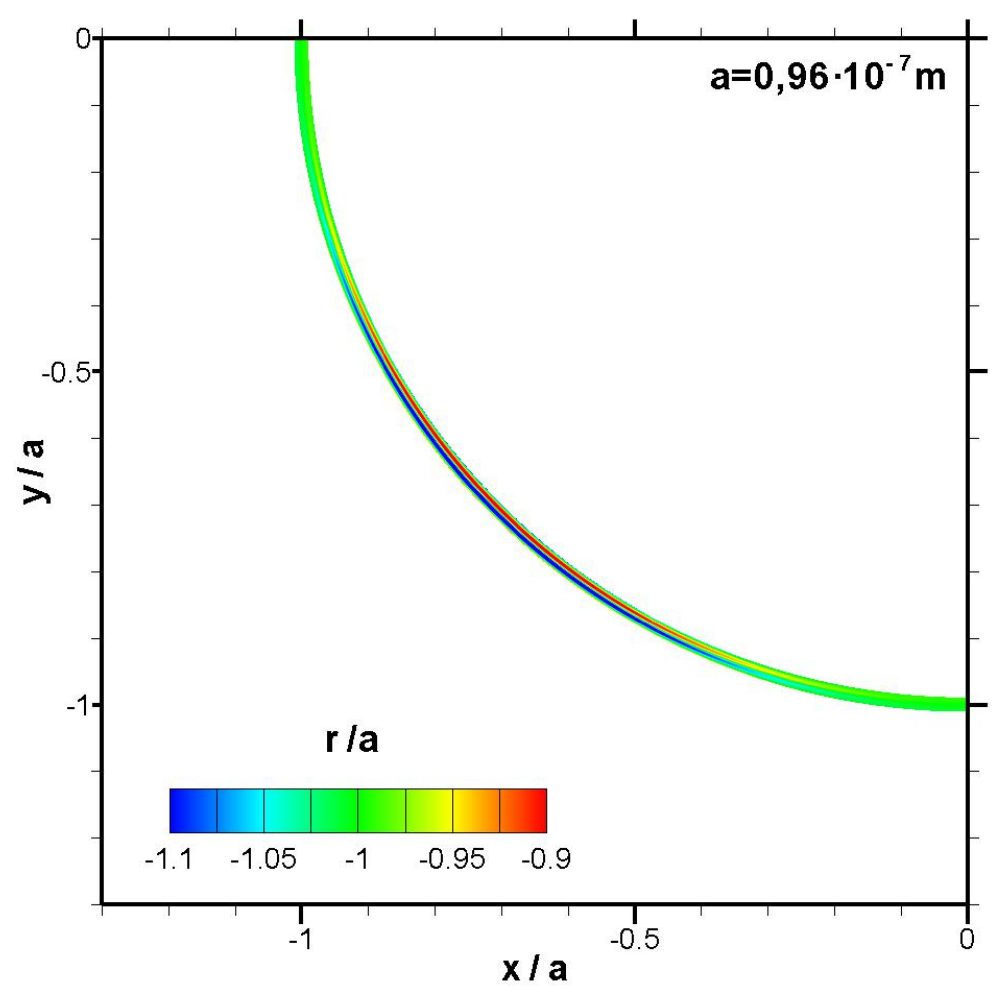

(b)

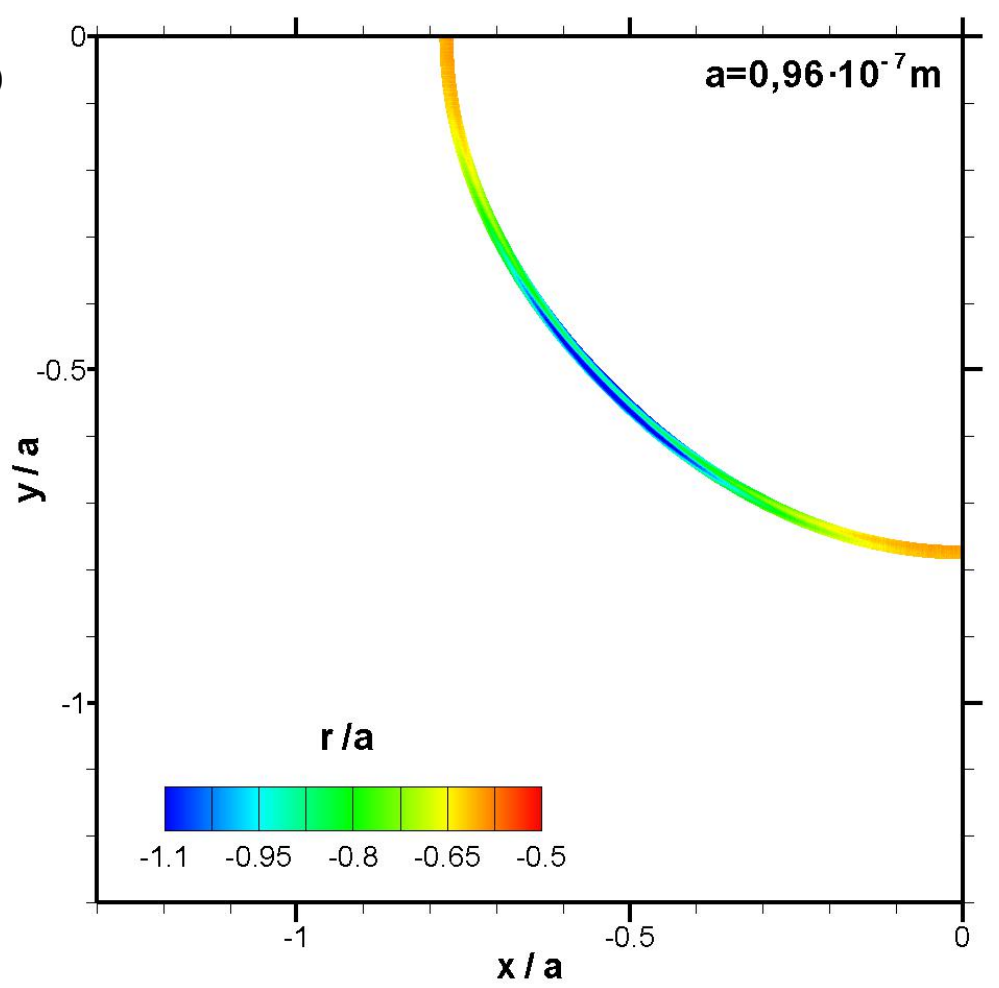

Figura 83 - Campo de curvatura local $(r / a)$ para $a=0,96 \cdot 10^{-7}, X_{v, s}=10^{-7}$ e $T=4000{ }^{\circ} \mathrm{C}$ : (a) $t=0$; (b) $t=6,1 \cdot 10^{-6} \mathrm{~s}$.

A Figura 84 e Figura 85 mostram comportamentos análogos aos observados anteriormente tanto no perfil de fração de lacunas (Figura 84) e na velocidade da interface (Figura 85(a)) como na fração de lacunas no sólido adjacente á interface (Figura 85(b)). 
(a)

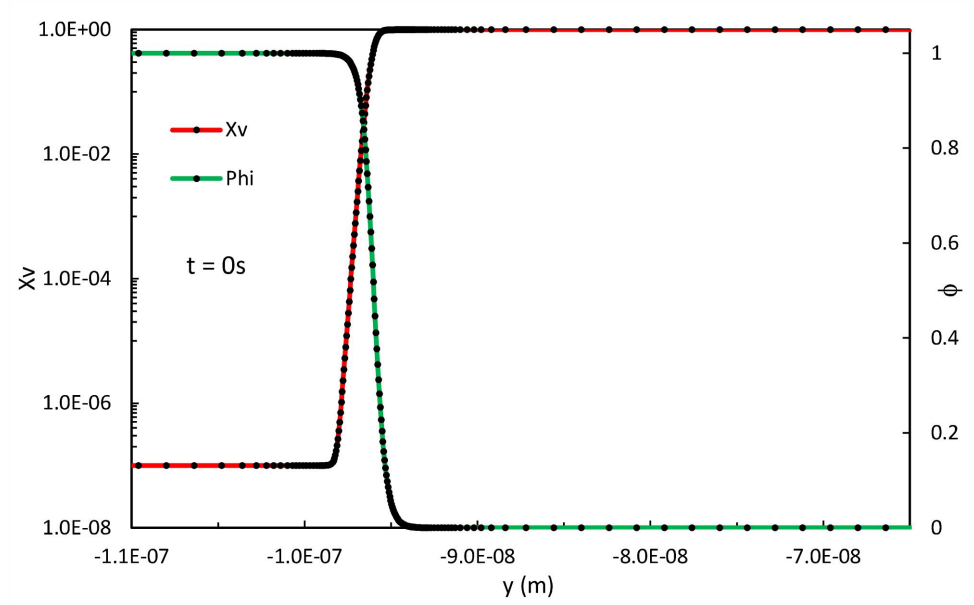

(b)

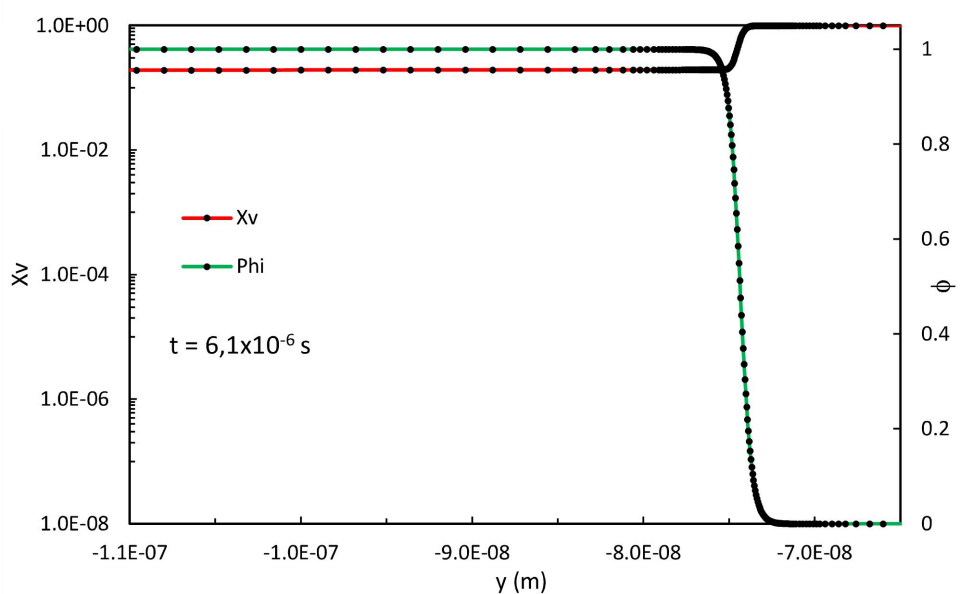

Figura 84 - Perfil da variável de fase $(\phi)$ e de fração molar de lacunas $\left(X_{v}\right)$ ao longo de $y$ para $x=0$ e para $a=$ $0,96 \cdot 10^{-7}, X_{v, S}=10^{-7} \mathrm{e} T=4000^{\circ} \mathrm{C}$ : (a) $t=0$; (b) $t=6,1 \cdot 10^{-6} \mathrm{~s}$.

(a)

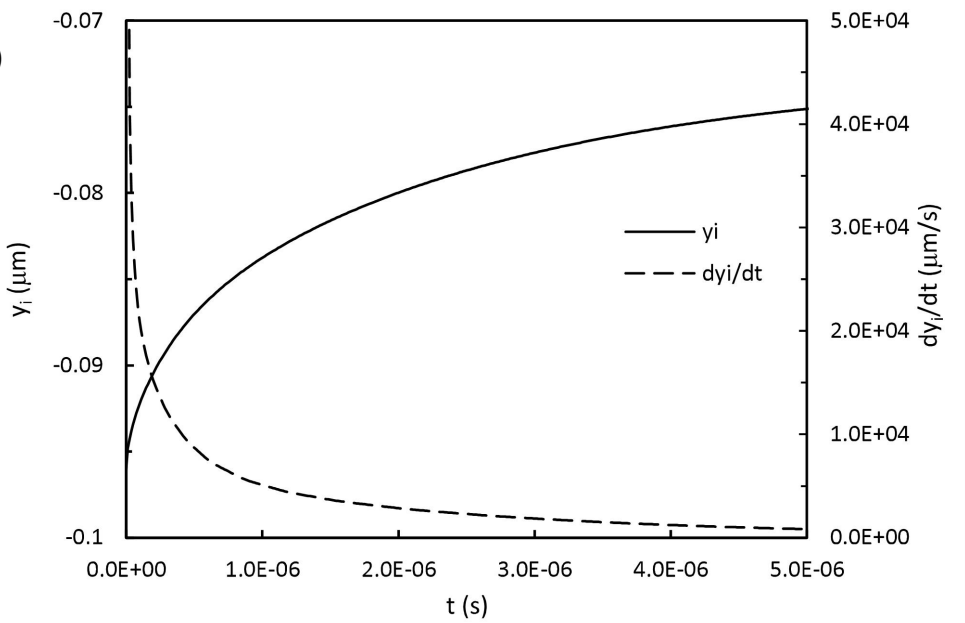




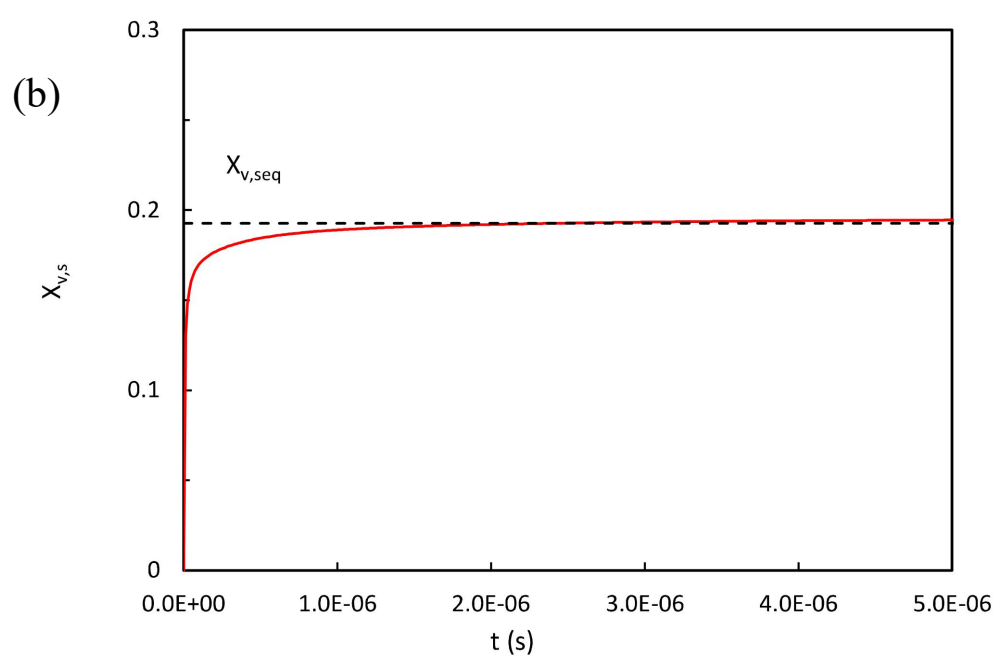

Figura 85 - Parâmetros da superfície (interface sólido-fase fictícia) em função do tempo: (a) posição $\left(y_{i}\right)$ e velocidade $\left(d y_{i} / d t\right)$ da interface; (b) fração de lacunas no sólido junto à interface $\left(X_{v, s}\right)$, onde $X_{v, \text { seq }}$ corresponde à fração no equilíbrio termodinâmico.

\subsubsection{Formação do Pescoço na Sinterização}

Nas simulações anteriores, foram examinados diversos fenômenos relacionados com os efeitos de curvatura e de transporte de lacunas em cilindros de sólido (curvatura positiva) ou poros cilíndricos (curvatura negativa) quando há um excesso ou deficiência de lacunas no interior do sólido em relação à fração de equilíbrio. Nas condições de simulação adotadas, o modelo de campo de fases foi capaz de simular corretamente os mecanismos fundamentais. Neste item, a formação de um pescoço no contato entre dois cilindros sólidos, que é o problema da sinterização de cilindros descrito no item 4.3.4, será simulado. Os fenômenos examinados nas simulações anteriores ocorrem de forma combinada no problema da formação do pescoço, onde se tem raios de curvatura negativos na região do pescoço, sendo equivalente a um poro, e raios positivos na região do cilindro, resultando na eliminação ou absorção de lacunas em diferentes trechos da superfície (interface sólido-fase fictícia).

Devido a limitações numéricas já mencionadas, serão simulados apenas os instantes iniciais da formação do pescoço durante o início da sinterização de cilindros sólidos enfileirados (Figura 19). Foram utilizadas as condições dos experimentos de sinterização de fios de cobre reportados por Alexander e Balluffi [ALEXANDER, BALLUFFI, 1957]: fios (cilindros) de cobre puro com raio de $64 \mu \mathrm{m}$ e sinterizados à temperatura de $1000{ }^{\circ} \mathrm{C}$. A fração inicial de lacunas adotada no interior do cilindro sólido foi de $1,04 \cdot 10^{-4}$, que é o valor de equilíbrio na temperatura de $1000{ }^{\circ} \mathrm{C}$. Portanto, considerou-se que os cilindros foram 
expostos separadamente a $1000{ }^{\circ} \mathrm{C}$ até a quantidade de lacunas em seu interior atingir o equilíbrio termodinâmico para posteriormente serem colocados em contato.

Os parâmetros empregados na simulação estão apresentados na Tabela 29. Adotou-se um domínio quadrado de dimensões $L_{x} x L_{y}=1,28 \cdot 10^{-7} \times 1,28 \cdot 10^{-7} \mathrm{~m}$, compreendendo apenas um quarto de uma pequena área no contato entre os cilindros, como ilustrado na Figura 19(a), (b) e (c). Este domínio foi discretizado por uma malha raíz contendo 160 x 160 volumes, subdivididos até no máximo 5 vezes na região da interface sólido-fase fictícia difusa. O refino da malha foi necessário para que os campos de $X_{v}$ e $\phi$ variassem suavemente na região da interface difusa, que deve apresentar uma espessura cerca de uma ordem de grandeza menor do que o menor raio de curvatura da interface. Deve-se lembrar que o raio de curvatura do pescoço é inicialmente zero, ou seja, a malha deve ser muito refinada para que na região do pescoço seja modelada sem o aparecimento de erros numéricos grosseiros.

Apesar do domínio de cálculo ser relativamente pequeno, a malha numérica consistiu de 644620 volumes. Um domínio de cálculo com lados duas vezes maior, que ainda seria considerado pequeno em comparação ao domínio completo, envolvendo um quarto do grão $\left(64 \cdot 10^{-6} \times 64 \cdot 10^{-6} \mathrm{~m}\right)$, poderia aumentar o número total de volumes de 2 a 3 vezes, consumindo maior memória RAM e causando um impacto significativo nos tempos de processamento.

Foi utilizado um passo de tempo numérico de $2,5 \cdot 10^{-11} \mathrm{~s}$, que é um valor bastante reduzido quando comparado ao tempo total estimado para o estágio I da sinterização $\left(22 \cdot 10^{3} \mathrm{~s}\right.$ $\mathrm{ou} \approx 6 \mathrm{hs}$ ) segundo o mecanismo de difusão de lacunas pelo reticulado sólido. Esse passo de tempo reduzido foi necessário para evitar instabilidades numéricas, pois a velocidade de movimentação da interface na região do pescoço nos instantes iniciais é relativamente elevada $\mathrm{e}$, na realidade, tende ao infinito para $t=0$ segundo os modelos matemáticos analíticos. Uma solução seria a utilização de uma programação de aumento de passo de tempo no decorrer da simulação, combinado a um aumento de tamanho do domínio. Estes artifícios não foram implementados no presente trabalho. Portanto, a simulação contemplou apenas um pequeno domínio, durante um pequeno período de tempo onde o fluxo de lacunas originárias na superfície do pescoço não havia atingido os contornos do domínio. 
Tabela 29: Parâmetros adotados na simulação de formação de pescoço entre cilindros de cobre puro.

\begin{tabular}{lcc}
\hline \multicolumn{1}{c}{ Variável } & Símbolo & Valor \\
\hline Tensão superficial & $\gamma_{s}$ & $1,72 \mathrm{~J} \cdot \mathrm{m}^{-2}$ \\
\hline Densidade molar de sítios & $\rho_{m}^{S}$ & $1,41 \cdot 10^{5} \mathrm{mols} \cdot \mathrm{m}^{-3}$ \\
\hline Coeficiente de difusão de lacunas no sólido & $D_{v}^{S}$ & $1,67 \cdot 10^{-9} \mathrm{~m}^{2} \cdot \mathrm{s}^{-1}$ \\
\hline Temperatura & $T$ & $1000{ }^{\circ} \mathrm{C}$ \\
\hline Tamanho do domínio & $L_{x} \times L_{y}$ & $1,28 \cdot 10^{-7} \times 1,28 \cdot 10^{-7} \mathrm{~m}$ \\
\hline Raio do grão cilíndrico & $a$ & $64 \cdot 10^{-6} \mathrm{~m}$ \\
\hline Fração inicial de lacunas no sólido & $X_{v, t=0}^{s}$ & $1,04 \cdot 10^{-4}$ \\
\hline Fração inicial de lacunas na fase fictícia $\left(\boldsymbol{g}^{\prime}\right)$ & $X_{v, t=0}^{g^{\prime}}$ & 0,9906 \\
\hline \hline Número de nós da malha raiz & $\mathrm{N}_{\mathrm{x}} \mathrm{x} \mathrm{N}_{\mathrm{y}}$ & $160 \times 160$ \\
\hline Nível máximo de subdivisão da malha & $\mathrm{N}$ & 7 \\
\hline Número total de volumes na malha $(\boldsymbol{t}=0)$ & $\mathrm{N}_{\mathrm{T}}$ & 644620 \\
\hline Passo de tempo & $\Delta t$ & $2,5 \cdot 10^{-11} \mathrm{~s}$ \\
\hline Espessura da interface difusa & $\delta$ & $10^{-10} \mathrm{~m}$ \\
\hline Mobilidade da variável de fase & $M_{\varnothing}$ & $0,01 \mathrm{~J}^{-1} \cdot \mathrm{s}^{-1}$ \\
\hline
\end{tabular}

Uma visão completa da malha numérica e do campo da variável de fase definidos no início da simulação está apresentada na Figura 86(a). A parte refinada, onde está a interface sólido-fase fictícia não é possível de ser vista nesta figura, portanto a Figura 86(b) e Figura 86(c) mostram uma ampliação do canto inferior esquerdo e inferior direito, respectivamente. Uma comparação da Figura 86(b) e da Figura 86(c) mostra a inclinação da interface, que representa a superfície do grão (Figura 19(c)). 
(a)
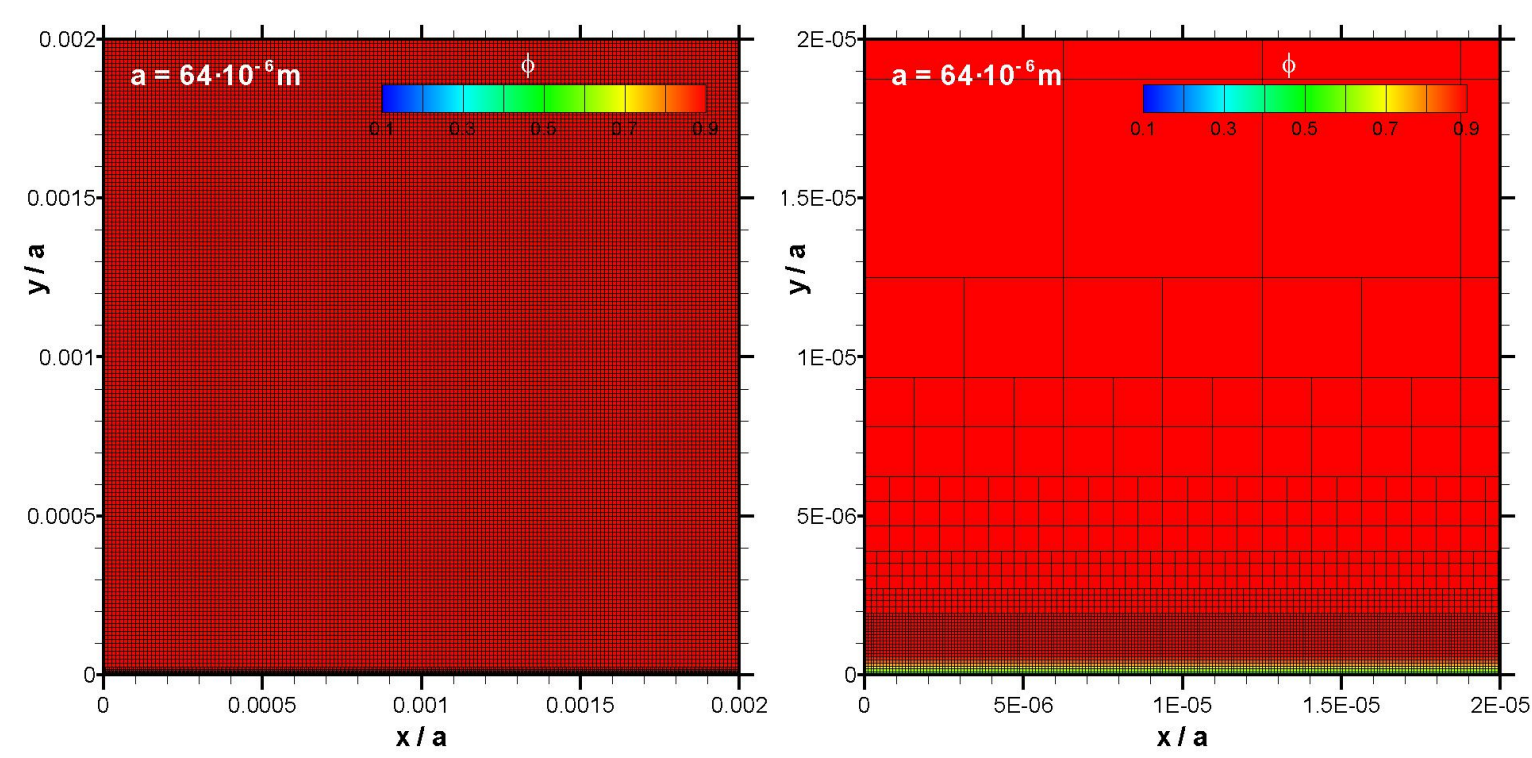

(c)

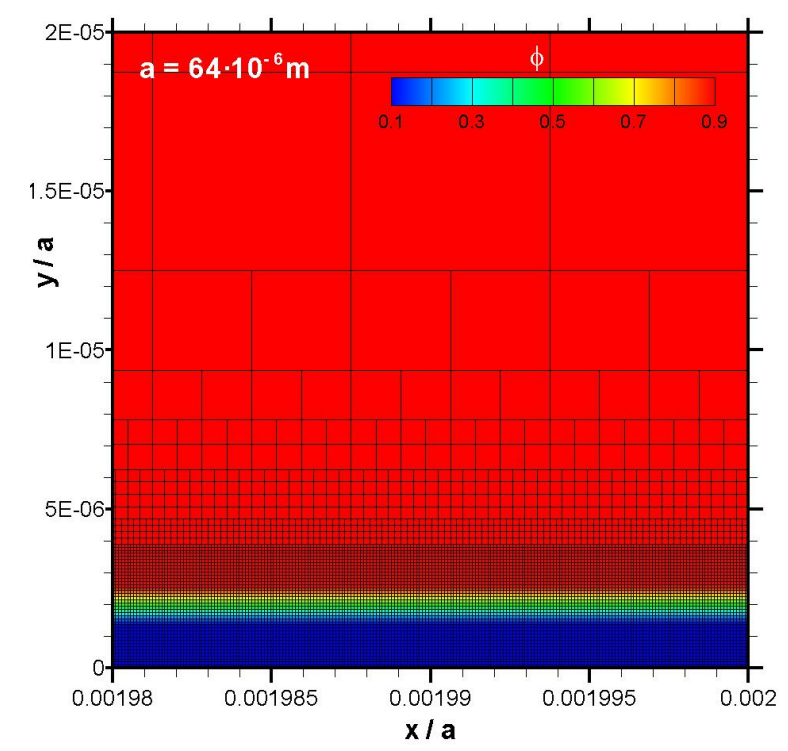

Figura 86 - Malha adaptativa sobreposta ao campo da variável de fase definidos no instante inicial: (a) visão do domínio completo; (b) detalhe do refino da malha no canto inferior esquerdo, próximo ao contato inicial com o cilindro inferior e (c) detalhe da malha no canto inferior direito, mostrando a região da fase fictícia.

A Figura 87 apresenta os campos de fração molar de lacunas obtidos na simulação em três instantes de tempo diferentes, separados por intervalos de tempo de uma ordem de grandeza. Um primeiro aspecto importante, que será detalhado adiante, é a formação automática do pescoço a partir de uma condição inicial onde existia apenas a superfície do cilindro tocando o contorno do domínio inferior, no qual uma condição de contorno de simetria foi imposta para os dois campos solucionados $\left(\phi\right.$ e $\left.X_{v}\right)$. Na Figura 87, à direita, uma seta branca indica a posição do pescoço, que não é possível de ser visto na escala de tamanho da Figura, que mostra o domínio de cálculo completo. No entanto, observa-se que este pescoço causa uma elevação de várias vezes a fração de lacunas inicial a distâncias 
significativas, resultado do processo de difusão. O movimento inicial do pesoço é relativamente rápido e, durante $1,2 \cdot 10^{-8} \mathrm{~s}$ (Figura $87(\mathrm{a})$ ), ele se deslocou muito mais do que deste instante até $1,2 \cdot 10^{-6} \mathrm{~s}$ (Figura $87(\mathrm{c})$ ). Como o raio de curvatura inicial do pescoço é inicialmente muito reduzido, a fração de lacunas ao redor de sua superfície é relativamente elevada, deixando uma trilha de lacunas durante o seu deslocamento, causando o aumento significativo da fração de lacunas observado na Figura 87(a). Este aumento é resultado do fluxo de lacunas originárias na superfície do pescoço, na direção do interior e da superfície do cilindro. Com o passar do tempo, nos instantes $1,2 \cdot 10^{-7} \mathrm{~s}$ (Figura 87(b)) e $1,2 \cdot 10^{-6} \mathrm{~s}$ (Figura 87(c)), o raio de curvatura se reduz e também o fluxo de lacunas. Logo, existe tempo para uma dissipação das lacunas para o interior do sólido, resultando em uma clara diminuição de sua fração molar.

(a)
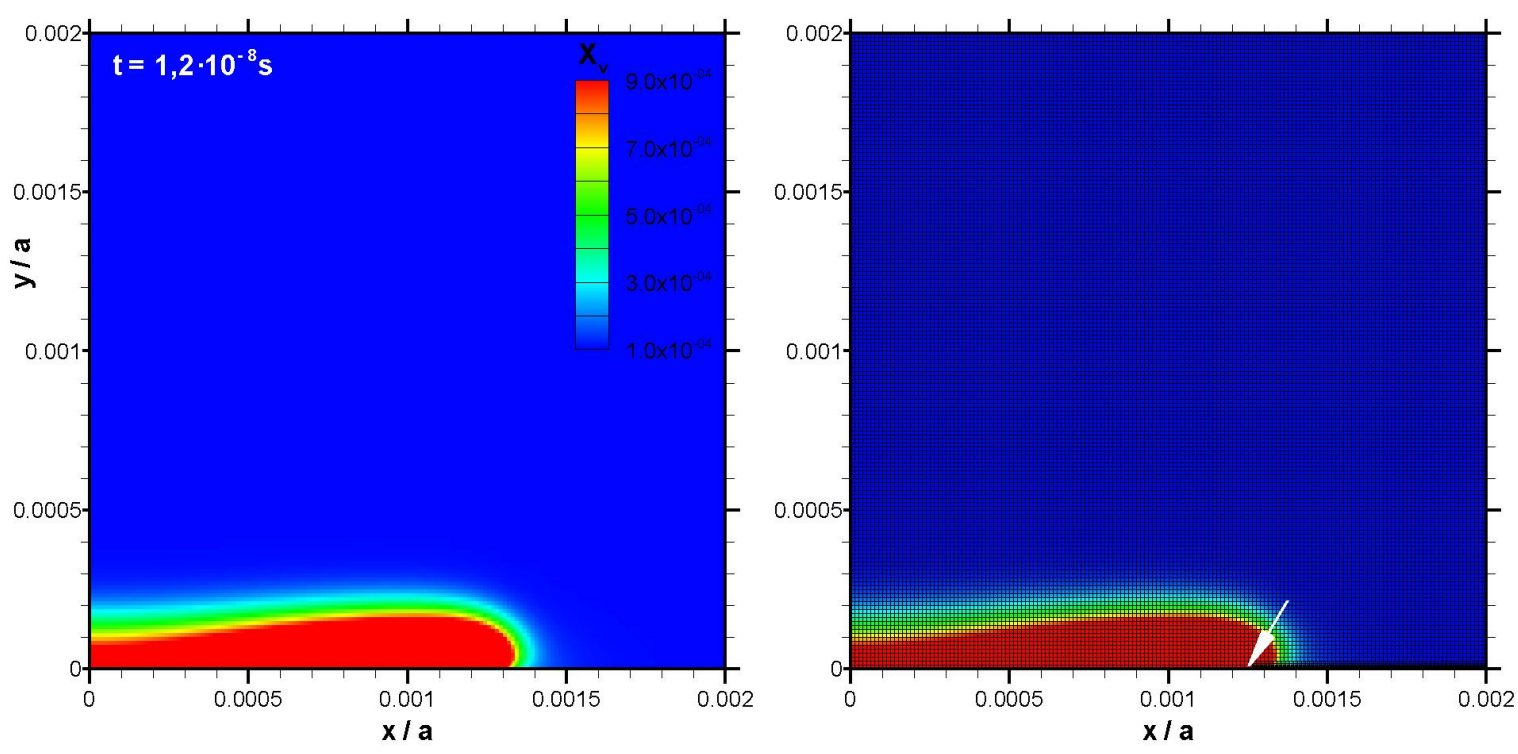

(b)
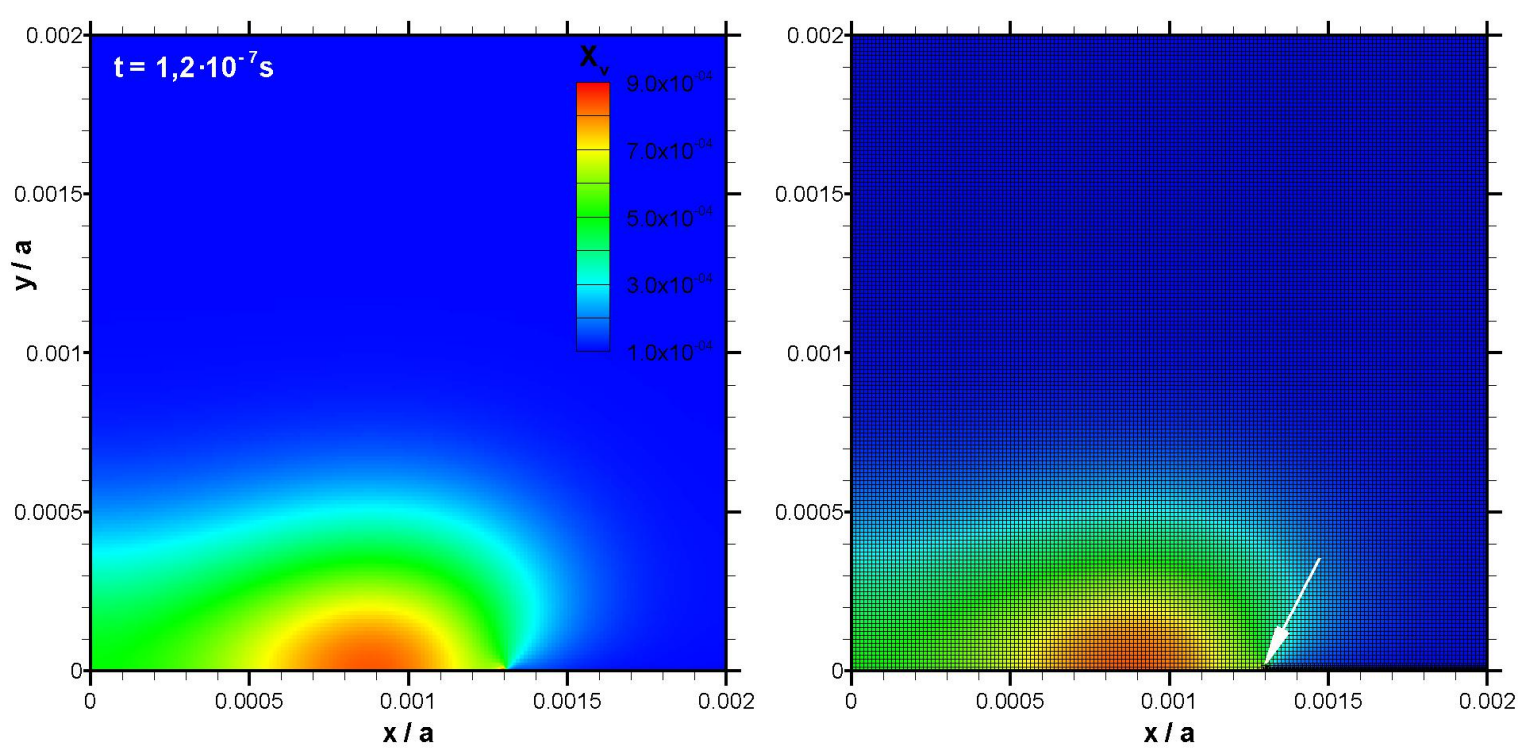
(c)
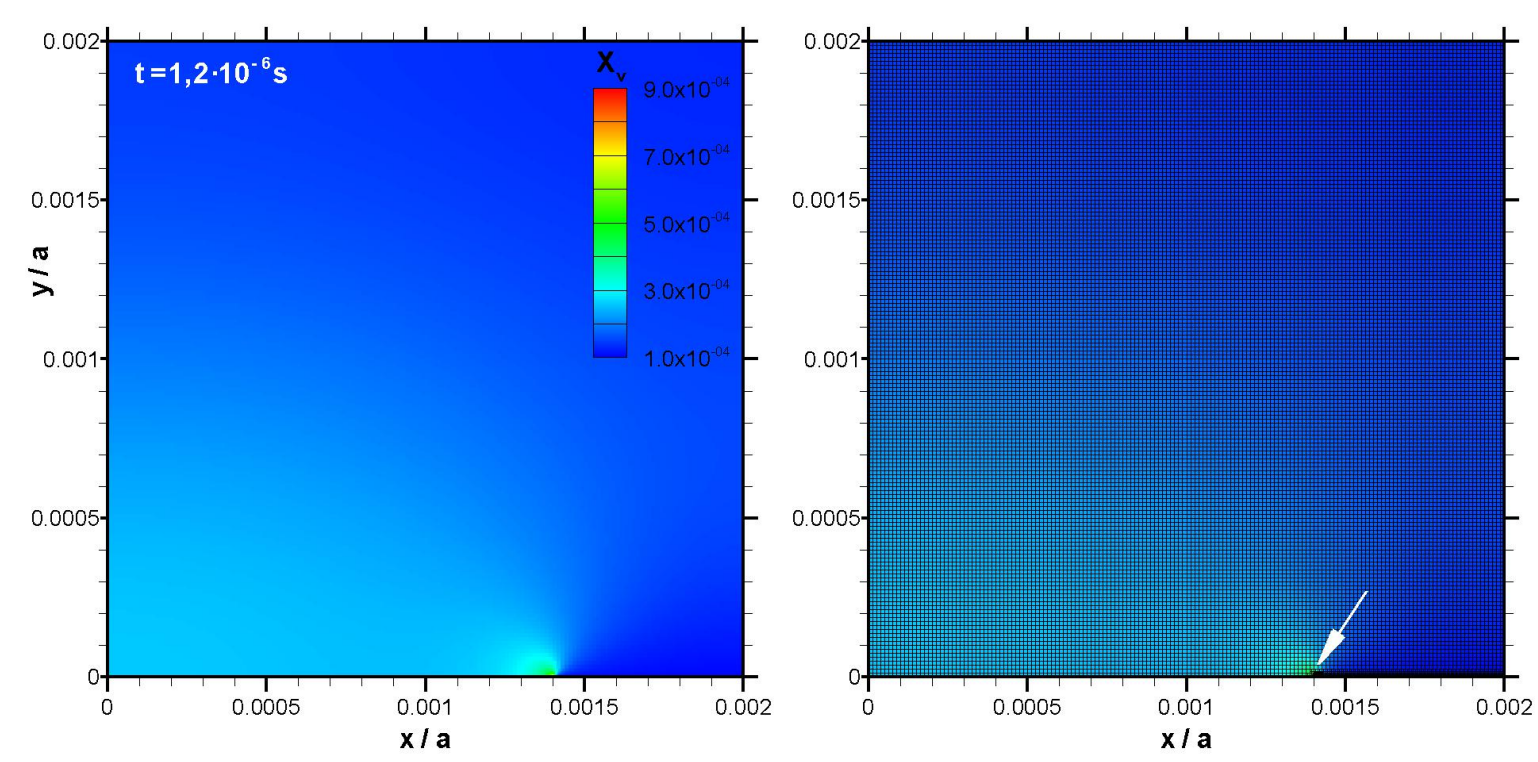

Figura 87 - Campo de fração molar de lacunas (à esquerda) e esse mesmo campo sobreposto à malha numérica (à direita) para: (a) $t=1,2 \cdot 10^{-8}$; (b) $t=1,2 \cdot 10^{-7}$; (a) $t=1,2 \cdot 10^{-6}$. A seta na Figura à direita indica a posição do pescoço, a partir do qual a malha esta refinada (região mais escura próxima ao contorno inferior).

Detalhes do campo de fração molar de lacunas e da variável de fase na região do pescoço estão apresentados na Figura 88. No primeiro instante apresentado (Figura 88(a)), observa-se que a fração molar próxima à superfície do pescoço atinge valores de $\approx 5 \cdot 10^{-3}$, cerca de 50 vezes a fração inicial. Posteriormente (Figura 88(b) e (c)), com o aumento (em módulo) do raio de curvatura do pescoço, esta fração sofre redução até $\approx 7 \cdot 10^{-4}$. Nota-se que a fração de lacunas decresce até aproximadamente o valor inicial quando se caminha ao longo da superfície do pescoço, na direção da superfície do cilindro. Este comportamento é esperado fisicamente, já que o raio de curvatura local é negativo no pescoço e tem valor máximo (em módulo) onde esse intercepta o contorno inferior do domínio. Ao se caminhar na direção da superfície do grão o módulo do raio de curvatura local aumenta, torna-se positivo (ponto de inflexão) e passa a aumentar. Esse comportamento pode ser observado na curvatura local calculada a partir do campo de $\phi$ para os instantes $t=1,2 \cdot 10^{-7}$ e $1,2 \cdot 10^{-6} \mathrm{~s}$, apresentada na Figura 89. Não foi possível calcular a curvatura relativa ao pescoço no primeiro instante $\left(1,2 \cdot 10^{-8} \mathrm{~s}\right)$, ilustrado na Figura $88(\mathrm{a})$, pois o vão entre o sólido e a fase fictícia não era suficiente para se ter uma fase completamente gasosa. Esta pode ser uma indicação de que os resultados referentes a este instante apresentam erros numéricos significativos e devem ser tratados apenas qualitativamente. 
(a)

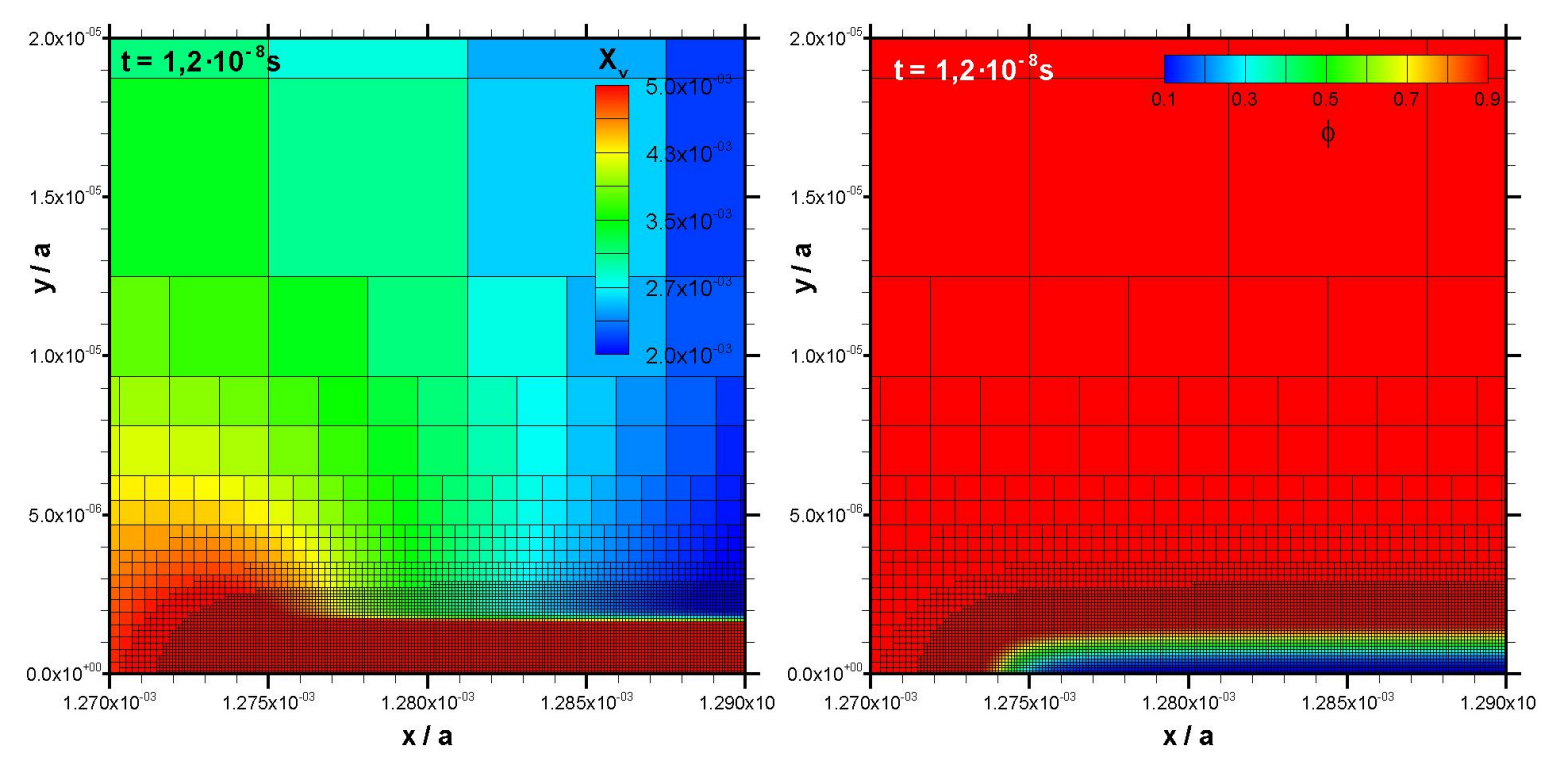

(b)
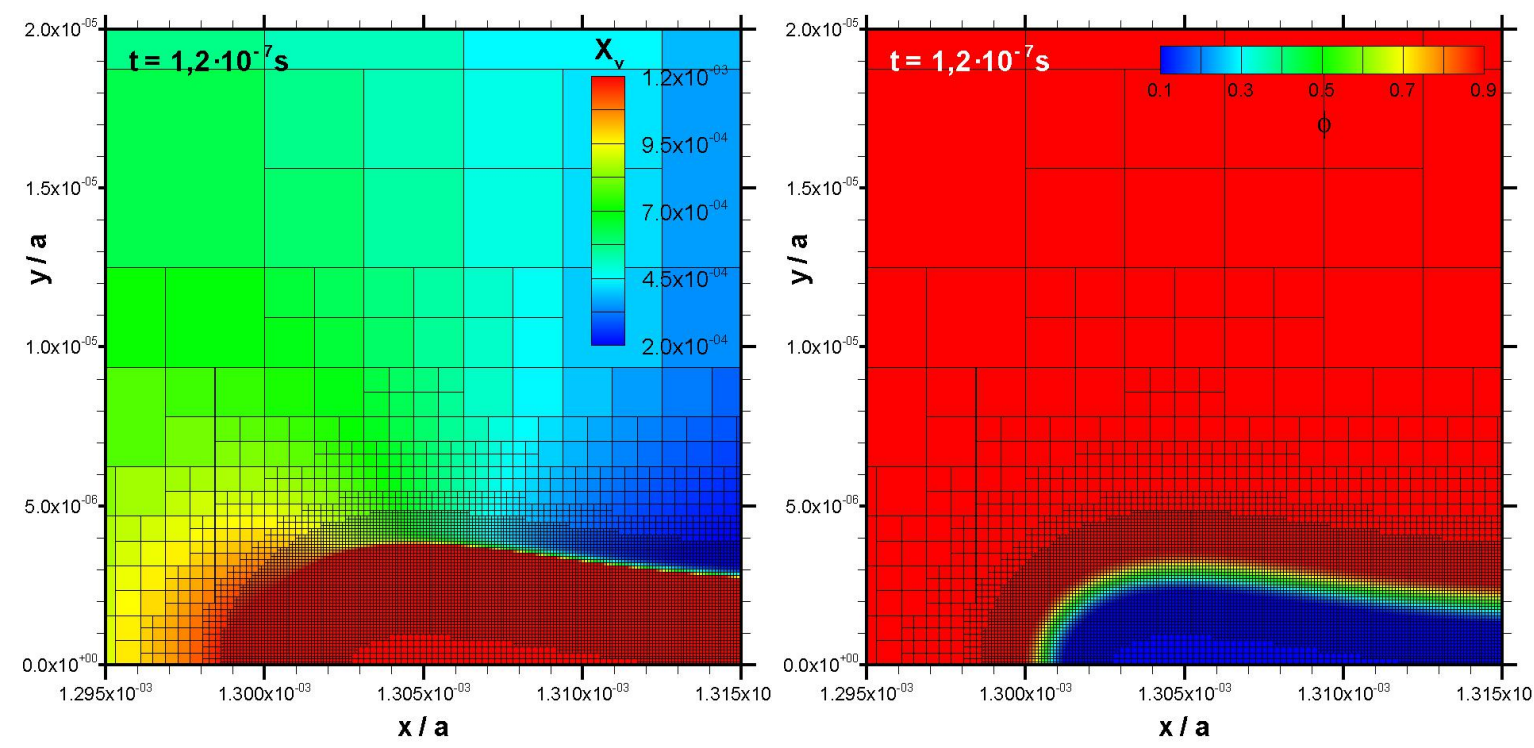
(c)

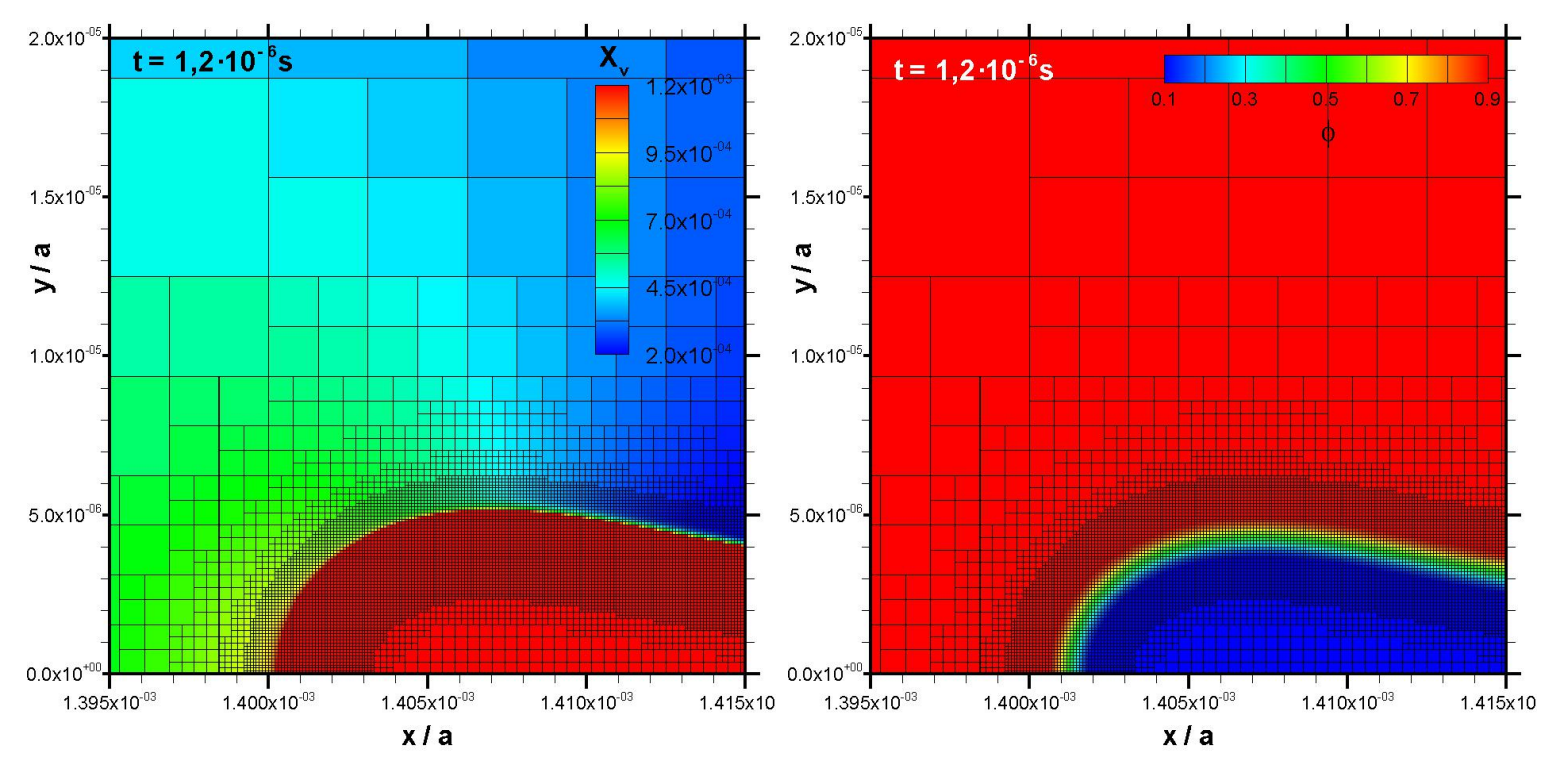

Figura 88 - Detalhe do campo de fração molar de lacunas (à esquerda) e da variável de fase (à direita) sobrepostos à malha numérica na região do pescoço para: (a) $t=1,2 \cdot 10^{-8}$; (b) $t=1,2 \cdot 10^{-7}$; (a) $t=1,2 \cdot 10^{-6}$.

(a)
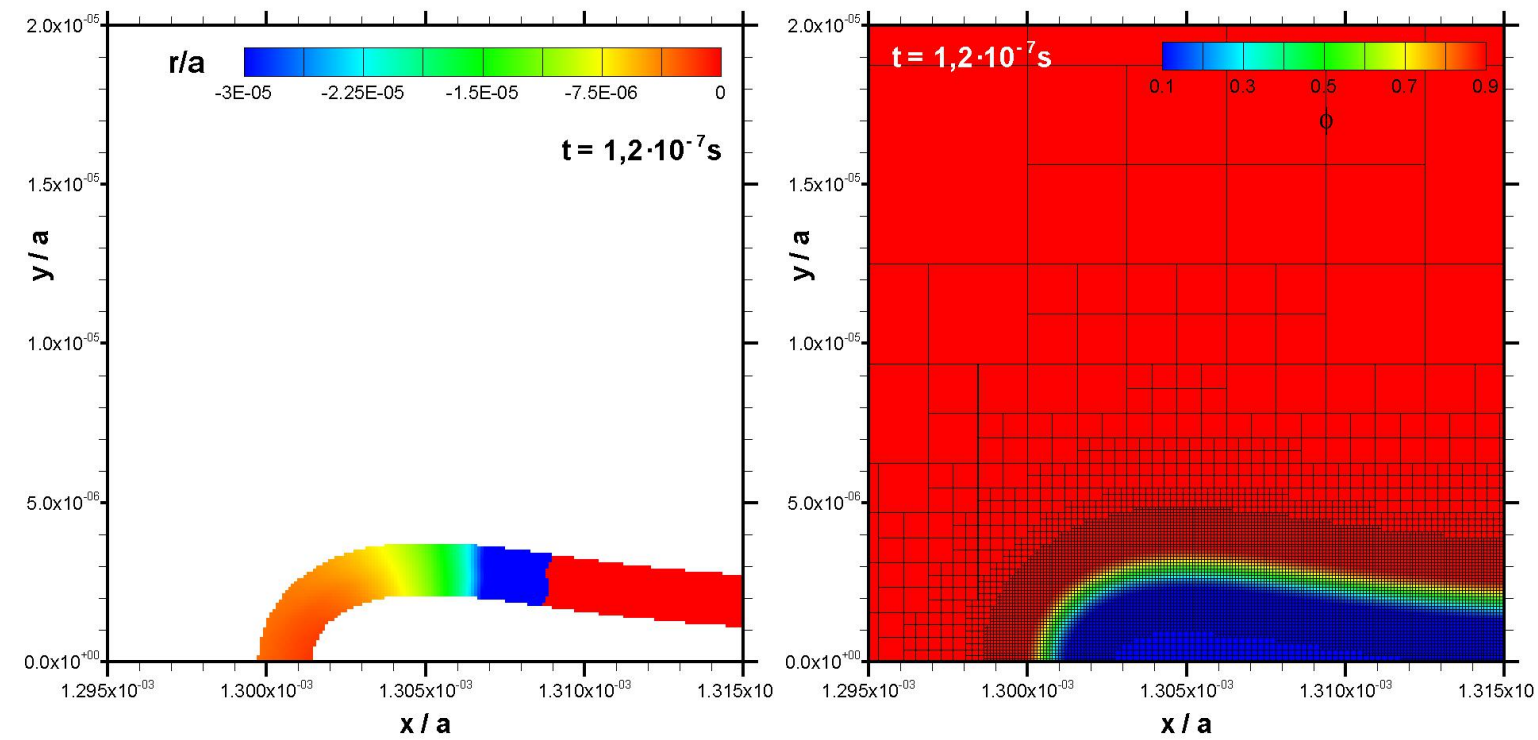


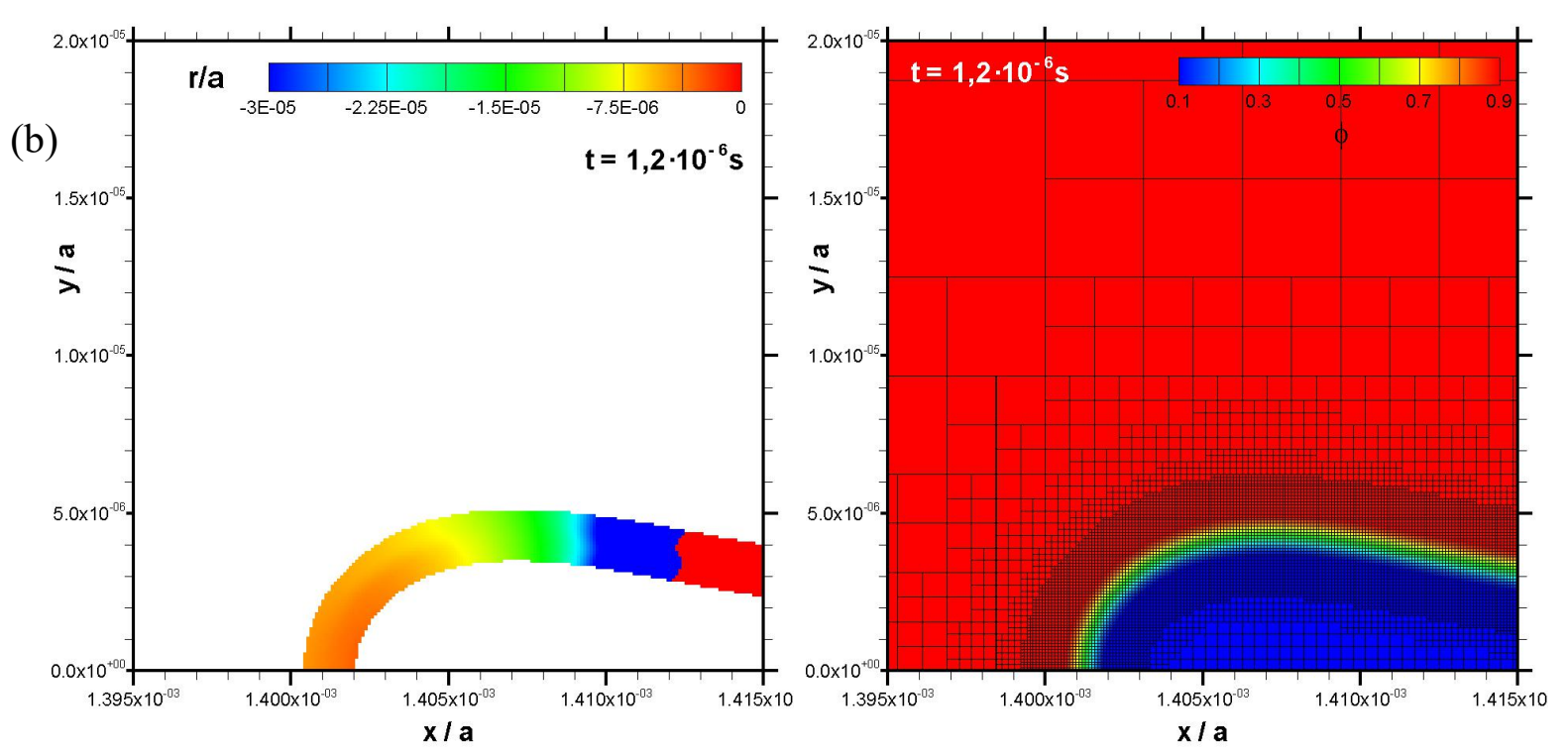

Figura 89 - Detalhe da curvatura local (à esquerda) da interface sólido-fase fictícia difusa e do campo de variável de fase (à direita) na região do pescoço para: (a) $t=1,2 \cdot 10^{-7} \mathrm{e}$ (b) $t=1,2 \cdot 10^{-6}$.

A Figura 90(a) apresenta a posição onde a interface do pescoço intercepta o eixo $x$ em função do tempo, mostrando um deslocamento inicial relativamente rápido até o instante $10^{-8}$ $\mathrm{s}$, reduzindo a velocidade posteriormente, também indicada nessa Figura $\left(d x_{i} / d t\right)$. Mesmo após redução, a velocidade continua elevada $(\approx 1 \mathrm{~cm} / \mathrm{s})$ para um domínio de lados tão pequenos $\left(1,28 \cdot 10^{-7} \mathrm{~m}\right)$. Esta elevada velocidade provavelmente requer o passo de tempo relativamente pequeno utilizado na simulação, pois na região do pescoço os campos de $X_{v}$ e $\phi$ se alteram rapidamente para acompanhar a movimentação da interface. A posição do pescoço $\left(x_{i, \text { mod }}\right)$ foi também calculada utilizando o modelo analítico que considera a difusão de lacunas no interior do reticulado sólido (Equação (46)) e também está apresentada na Figura 90(a), mostrando valores menores do que os calculados pelo modelo do campo de fase $\left(x_{i}\right)$.

A Figura 90(b) apresenta o raio de curvatura da interface onde o pescoço intercepta o eixo $x$, indicando valores (em módulo) relativamente reduzidos, que aumentam à medida que o pescoço cresce. Uma relação geométrica muito utilizada na região do pescoço $\left(r_{\text {mod }}=\right.$ $\left.x_{i, \text { mod }}^{2} / 2 a\right)$ foi empregada para o cálculo do raio de curvatura, fornecendo valores sempre menores do que os calculados pelo modelo de campo de fase. Note que mesmo após os instantes iniciais, o raio de curvatura do pescoço ainda é da ordem de $2 \cdot 10^{-10} \mathrm{~m}$ e que a espessura adotada para a interface difusa foi apenas metade deste valor $\left(\delta=10^{-10} \mathrm{~m}\right.$ ), não sendo suficiente para resolver o menor raio de curvatura nesta região. No entanto, como mostrado na Figura 89(b), existem trechos do pescoço onde o raio de curvatura atinge valores da ordem de $10^{-9} \mathrm{~m}\left(|r / a| \approx 1,5 \cdot 10^{-5}\right)$, que pode ser resolvido pela espessura de interface 
adotada. Na Figura 90(b) também estão apresentados a fração molar de lacunas no sólido adjacente ao pescoço no intercepto com o eixo $x$, ou seja, $X_{v, s}$ e, bem como o valor de equilíbrio termodinâmico sob o efeito da curvatura $r$ obtida neste local. Os valores obtidos pelo modelo de campo de fase são cerca de uma ordem de grandeza menor que aquele que deveria existir no equilíbrio termodinâmico local. Esta discrepância pode ser causada por diversos fatores, como a velocidade da interface relativamente elevada, aumentando a dificuldade desta região em elevar a fração inicial $\left(1,04 \cdot 10^{-4}\right)$, ou ainda uma espessura de interface difusa que não é suficientemente fina para modelar o raio de curvatura nesta região. Estes possíveis efeitos não foram investigados no presente trabalho.

(a)

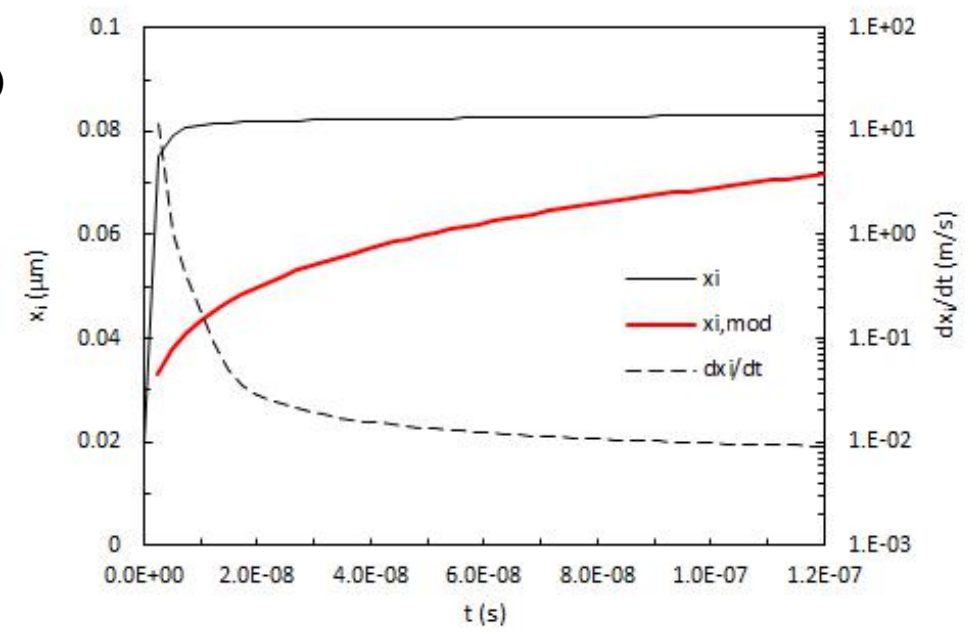

(b)

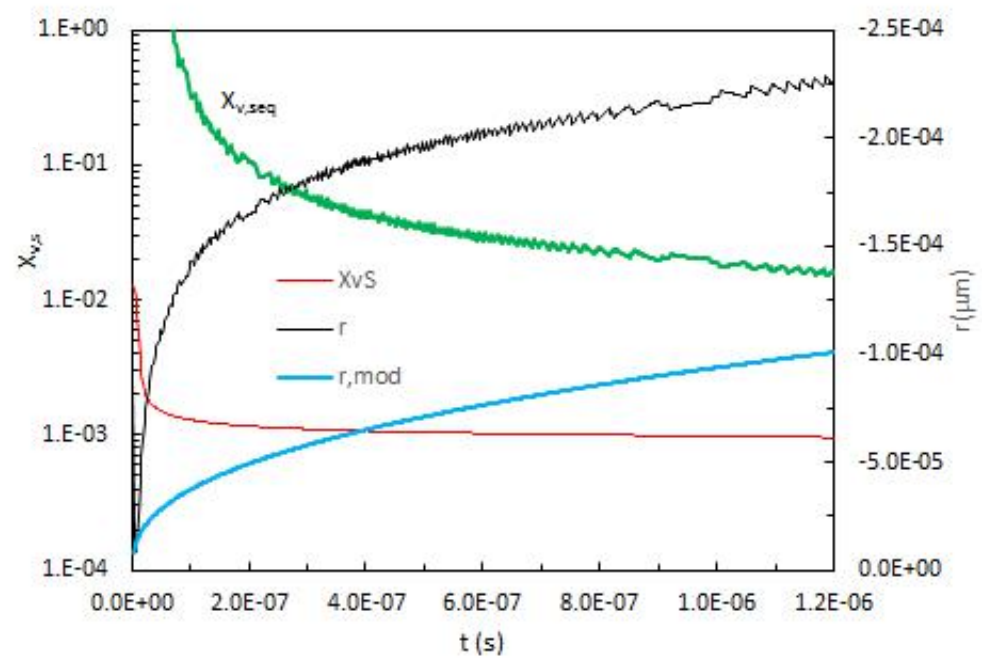

Figura 90: Parâmetros da superfície (interface sólido-fase fictícia) no intercepto do pescoço com o eixo $x$ em função do tempo: (a) posição do pescoço calculado pelo modelo de campo de fase $\left(x_{i}\right)$ e pelo modelo analítico que considera o mecanismo de difusão de lacunas pelo reticulado $\left(x_{i, \text { mod }}\right)$, além da velocidade $d x_{i} / d t$; (b) raio de curvatura calculado pelo modelo de campo de fase $(r)$ e pela relação geométrica $r_{m o d}=x_{i, m o d}^{2} / 2 a$, além da fração de lacunas no sólido adjacente à interface do pescoço obtido pelo modelo do campo de fases $\left(X_{v, s}\right) \mathrm{e}$ calculado pelo equilíbrio termodinâmico para o raio de curvatura $r\left(X_{v, \text { seq }}\right)$. 
Finalmente, a Figura 91 apresenta os perfis de fração molar de lacunas e da variável de fase ao longo do eixo $x$, atravessando a interface sólido-fase fíctícia do pescoço, no instante final de simulação $\left(t=1,2 \cdot 10^{-6} \mathrm{~s}\right)$. Nota-se o comportamento qualitativo esperado, onde a fração de lacunas é maior no sólido junto à interface, decaindo com a distância. Esta diferença causa um fluxo de lacunas a partir do pescoço e na direção do interior do sólido.

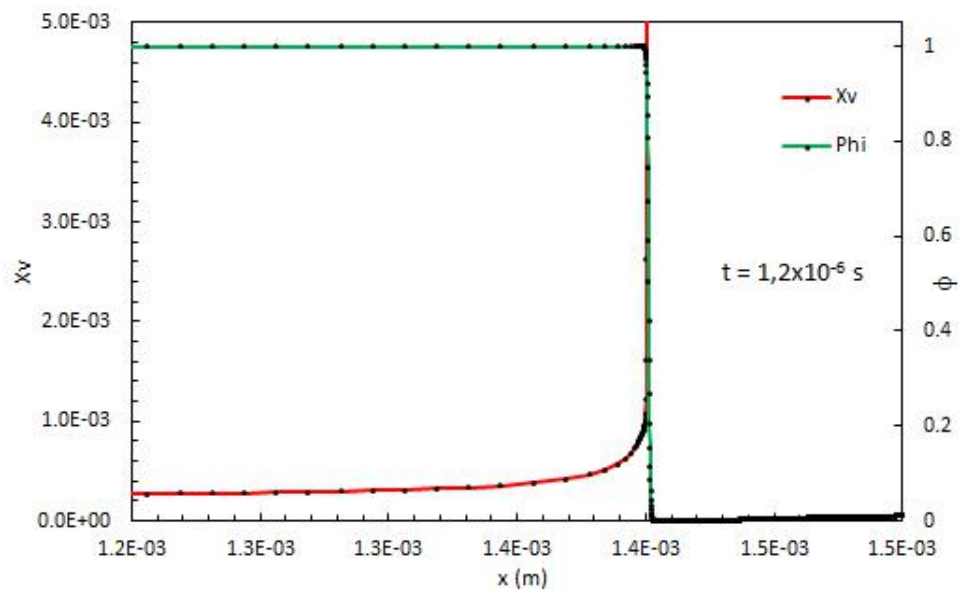

Figura 91 - Perfil da variável de fase $(\phi)$ e da fração molar de lacunas $\left(X_{v}\right)$ ao longo do eixo $x$ para $y=0$ atravessando a superfície (interface sólido-fase fictícia) para $t=1,2 \cdot 10^{-6} \mathrm{~s}$. 


\section{CONCLUSÕES}

Conclui-se que os modelos analíticos são representações aproximadas do processo de sinterização, estes apresentam muitas limitações porém explicam de uma forma geral como são os mecanismos que regem a sinterização. O uso destes modelos requer dados de entrada consistentes e precisos, além de bem definidas as formas geométricas que representarão o pescoço e das quais serão calculadas as áreas, os volumes e os raios, minimizando assim as incertezas do método.

Os modelos analíticos quando agrupados na descrição do modelo/mecanismo combinado conseguem reproduzir, na maioria das vezes, de maneira satisfatória os dados experimentais, isso reforça a tese de que não existe apenas um mecanismo atuando isoladamente, mas há sim um sistema cooperativo e simultâneo entre os mesmos que vai alterando com o decorrer do processo de sinterização. O mecanismo combinado desenvolvido no presente trabalho apresentou-se adequado mesmo com o emprego de parâmetros geométricos exclusivos de mecanismos não densificantes.

A análise estatística permitiu compreender melhor e identificar qual o mecanismo dominante para cada um dos artigos analisados. Verificou-se que por vezes a analise estatística não rejeita um determinado mecanismo, porém o erro relativo associado ao mesmo é muito elevado, isso porque o tamanho da amostra foi pequeno. Nestas situações é muito importante analisar o erro relativo e o erro do modelo. Para amostras maiores, a análise estatística é muito precisa. Vale ressaltar que não se deve excluir as análises gráficas ou via expoente do tempo, elas complementam e dão suporte os resultados estatísticos.

Observou-se que o mecanismo dominante está diretamente relacionado com a conFiguração do sistema analisado, por exemplo: se são esferas ou cilindros, se são apenas dois átomos em contato, ou um aglomerado de partículas, etc. Por isso não é possível generalizar qual o mecanismo dominante para o cobre puro, faz-se necessária uma avaliação criteriosa e independente em cada situação.

Um modelo bidimensional baseado no método do campo de fase foi proposto e implementado para simular alguns mecanismos importantes que ocorrem durante o estágio I da sinterização de metais puros. As equações do modelo de campo de fases foram definidas após uma criteriosa análise termodinâmica das energias livres. Todas as simulações foram realizadas empregando valores de entrada para as propriedades do cobre puro obtidas de 
modo independente da sinterização, possibilitando uma representação mais realista do processo e de suas análises.

As simulações realizadas em condições unidimensionais considerando uma superfície (interface sólido-fase fictícia) plana indicam que o modelo é capaz de impor as condições de equilíbrio termodinâmico local no sólido adjacente à interface e de movimentar a interface no sentido correto, dependendo do sentido do fluxo de lacunas. Ao ser utilizado para simular o transporte de lacunas em sólidos ou poros cilíndricos sob condições bidimensionais, o modelo automaticamente impõe a fração de lacunas de equilíbrio sob o efeito do raio de curvatura, seja esse positivo ou negativo. Esta fração imposta próxima à superfície do sólido resulta em um fluxo que causa a expansão ou retração do sólido/poro cilíndrico, fenômeno que foi corretamente reproduzido pelo modelo implementado. Finalmente, quando o modelo de campo de fases foi utilizado para simular a formação de um pescoço que ocorre no contato entre dois cilindros de cobre puro durante a sinterização, observou-se um comportamento qualitativo completamente consistente com o comportamento físico esperado. Entretanto, para que os fenômenos sejam reproduzidos corretamente de forma quantitativa, foram encontradas diversas dificuldades numéricas relacionadas as malhas com um número excessivo de volumes e à necessidade de passos de tempo muito pequenos quando comparados com o tempo total do estágio I da sinterização. Para resolver o problema do longo tempo de simulação, foi feita a paralelização do código fonte na placa de vídeo, enquanto que na questão da malha foi adotado o método de malha adaptativa sendo esta refinada junto e próximo a interface e mais grosseira no entorno.

Sugestões para trabalhos futuros:

- rever a malha adaptativa adotada;

- aplicar um método de tempo adaptativo criteriosamente fundamentado e especificado;

- expandir a análise estatística para outros metais com estrutura cristalina CFC, comparando os resultados com o do cobre. 


\section{REFERÊNCIAS}

ACHARI, K.M.R.; RAMACHANDER, R.B. A study of diffusion mechanisms in sintering by shrinkage measurements. Bull. Mater. Sci., v.9, n.2, junho 1987, p. 97-101.

AHMED K.; TONKS, M.; ZHANG, Y.; BINER, B.; EL-AZAB, A. Particle-grain boundary interactions: A phase field study. Computational Materials Science 134:25, 2017.

AIZAWA, K.; MOTOMURA, K.; KIMURA, S.; KADOWAKI, R.; FAN, J.R. Constant time neighbor finding in quadtrees: An experimental result. In: Third International Symposium on Communications, Control and Signal Processing (ISCCSP 2008), Malta, 2008. Proceedings, Piscataway (NJ-USA), IEEE, p. 505-510.

ALEXANDER, B.H.; BALLUFFI, R.W. The mechanism of sintering of copper. Acta Metallurgica, v. 5, p. 666-677, nov 1957.

ALLEN, S.M.; CAHN, J.W. A microscopic theory for antiphase boundary motion and its application to antiphase domain coarsening. Acta Metallurgica, v. 27, p. 1085-1095.

ASHBY, M.F. A first report on sintering diagrams. Acta Metallurgica, v. 22, p. 275289, mar 1974.

ASP, M.; AGREN, J. Phase-field simulation of sintering and related phenomena - a vacancy diffusion approach. Acta Materialia, v. 54, n. 5, p. 1241-1248, 2006.

BADALASSI, V.E.; CENICEROS, H.D.; BANERJEE, S.. Computation of multiphase systems with phase field models, J. Comput. Phys., 190 (2003), 371-397.

BEERE, W. The second stage sintering kinetics of powder compacts. Acta Metallurgica $23(1), 139-145,1975$.

BISWAS,S.; SCHWEN, D.; WANG, H.; OKUNIEWSKI, M.; TOMAR, V. Phase field modeling of sintering: role of grain orientation and anisotropic properties. Computational materials science, 148, pp. 307-319, 2018.

BIRD, R.B.; STEWART, W.E.; LIGHTFOOT, E.N. Transport phenomena. 2nd New York, J. Wiley, 2002. 
BLAKELY, J.M.; MYKURA, H. Surface self diffusion and surface energy measurements on platinum by multiple scratch method. Acta Metallurgica, v 10, n 5, p. 565-572, mai 1962.

BOETTINGER, W.J.; WARREN, J.A. The phase-field method: simulation of alloy dendritic solidification during recalescence. Mettalurgical and Materials Transactions A, v. 27A, p. 657-668, march/1996.

BOETTINGER, W.J.; WARREN, J.A.; BECKERMANN, C.; KARMA, A. Phase-field simulation of solidification. Annual Review of Materials Research, v. 32, n. p. 163-194, 2002.

BRAKKE, K.A. The Surface Evolver. Experimental Mathematics, v.1, n. 2, 1992.

BUTRYMOWICZ, D.B.; MANNING, J.R.; READ, M.E. Diffucion in copper and copper alloys. Part I. Volume and Surface Self-Diffusion in Copper. Journal of Physical and Chemical Reference Data, v 2, 3, 643, 1973

CAHN, J.W.; HILLIARD, J.E. Free energy of a nonuniform system .1. Interfacial free energy. Journal of Chemical Physics, v. 28, n. 2, p. 258-267, 1958.

CAHN, J.W.; HILLIARD, J.E. Spinodal decomposition - reprise. Acta Metallurgica, v. 19, n. 2, p. 151-161, 1971.

CASTRO, R.H.R. On the thermodynamic stability of nanocrystalline ceramics. Materials Letters, 96, p. 45-56, 2013

CHEN, I-W.; HASSOLD, G.N.; SROLOVITZ, D.J. Computer simulation of final-stage sintering: II, influence of initial pore size. Journal of the American Ceramic Society, 73 (10), p. 2865-2872, 1990.

CHEN, L.Q. Phase-field models for microstructure evolution. Annual Review of Materials Research, v. 32, n. p. 113-140, 2002.

COBLE, R.L. Initial sintering of alumina and hematite. J. Am. Ceram. Soc., 41, 55, 1958. 
COBLE, R.L. Sintering Crystalline Solids. Journal of Applied Physics, 32 (5), p. $787-$ $792,1961$.

COBLE, R.L. Sintering Crystalline Solids II. Experimental Test of Diffusion Models in Power Compacts. Journal of Applied Physics, 32 (5), p. 793-799, 1961.

COBLE, R.L. Effects of particle-size distribution in initial-stage sintering. Journal of the American Ceramic Society. V 56, n 9, p. 461-466, 1973.

COLEMAN, S.C.; BEERÉ, W.B. The sintering of open and closed porosity in $\mathrm{UO}_{2}$. Philos. Mag. 31, pp. 1403-1413, 1975.

CHU, M.-Y.; RAHAMAN, M.N.; JONGHE, L.C. de; BROOK, R.J. Effect of heating rate on sintering and coarsening. Journal of the American Ceramic Society, 74, 1217, 1991.

CHNG, H.N.; PAN, J. Sintering of particles of different sizes. Acta Materiallia, v 55, n 3, pp. 813-824, fev 2007.

DEHOFF, R.T. Thermodynamics in materials science. 2nd ed., Boca Raton, CRC/Taylor \& Francis, 2006.

DEMIRDŽIĆ, I. On the discretization of the diffusion term in finite-volume continuum mechanics. Numerical Heat Transfer, Part B: Fundamentals, v. 68, n. 1, p. 1-10, 2015.

DENG, J. A phase field model of sintering with direction-dependent diffusion. Materials Transactions, v 53, n 2, p. 385-389, 2012.

DEVEREUX, O.F. Topics in metallurgical thermodynamics. New York, Wiley, 1983.

DING, L., DAVIDCHACK, R.L., PAN, J. A molecular dynamics study of sintering between nanoparticles. Computational Materials Science 45 (2), pp. 247-256, 2009.

DINSDALE, A.T. Sgte data for pure elements. Calphad-Computer Coupling of Phase Diagrams and Thermochemistry, v. 15, n. 4, p. 317-425, 1991.

ECHEBARRIA, B.; FOLCH, R.; KARMA, A.; PLAPP, M. Quantitative phase-field model of alloy solidification. Physical Review E, v. 70, n. 6, p. -, 2004. 
ELLIOT, C.M.; FRENCH, D.A. Numerical Studies of the Cahn-Hilliard Equation For Phase Separation. IMA Journal of Applied Mathematics, v. 38, p. 97-128, 1987.

EXNER, H.E.; ARZT, E. Sintering Processes. Sintering Key Papers, pp 157-184, 1990.

EXNER, H.E.; BROSS, P. Material transport rate and stree distribuition during grain boundary diffusion driven by surface tension. Acta Metallurgica, 27, pp. 1007-1012, 1979.

FAN,D.; CHEN, L.-Q. Computer simulation of grain growth using a continuum field model. Acta Materialia, v. 45, n. 2, p. 611-622, 1997.

FAN, D.; GENG, C.; CHEN, L.-Q. Computer simulation of topological evolution in 2D grain growth using continuum diffusive-interface field model. Acta Materialia, v. 45, n. 3, p. 1115-1126, 1997.

FERZIGER, J.H.; PERIC, M. Computational methods for fluid dynamics. 3rd ed., New York, Springer, 2002.

FISHER,J.C. Calculation of Diffusion Penetration Curves for Surface and Grain Boundary Diffusion. Journal of Applied Physics, 22 (74), 1951.

FREDRIKSSON, H.; EMI, T. Effect of vacancies and alloying ordering on the thermodynamics during solidification processing. Materials Transactions Jim, v. 39, n. 2, p. 292-301, 1998.

FRENKEL, J. Viscous flow of crystalline bodies under the action of surface tension. J. Phys. (Moscow), 5, 385, 1945.

GERALD, C.F.; WHEATLEY, P.O. Applied numerical analysis. 7th ed., Boston, Pearson/Addison-Wesley, 2004.

GERMAN, R. M. Fundamentals of Sintering In: Engineered Materials Handbook, v. 4. Ceramics and Glasses. ASM International. Metals Park, Ohio, p. 261-269, 1991.

GERMAN, R.M. Sintering: theory and practice. Wiley-Interscience, 1 ed, 568 pag., jan 1996.

GERMAN, R.M. History of sintering: empirical phase. Powder Metallurgy, v 56, n 2, p. 117-123, 2013. 
GIBBS, J.W. The collected works of J. Willard Gibbs. New Haven,, Yale Univ. Press, 1948.

GOUVÊA, D. Influência das energia de superfícies e interfaces na densificação durante a sinterização - um modelo geométrico. Cerâmica, 50, p. 81-88, 2004.

GOUVÊA, D.; CASTRO, R.H.R. Sintering: The role of interface energies. Applied Surface Science, 217 (1-4), p. 194-201, 2003.

GUAN, P.-W.; LIU, Z.-K. A physical model of thermal vacancies within the calphad approach. Scripta Materialia, v. 133, n. p. 5-8, 2017.

HARROWELL, P. R.; OXTOBY, D. W. On the interaction between order and a moving interface: Dynamical disordering and anisotropic growth rates. Department of Chemistry and James Frank Institute, University of Chicago, Chicago, Illinois, 1986.

HASSOLD, G.N.; CHEN, I-W.; SROLOVITZ, D.J. Computer simulation of final-stage sintering: I, model, kinetics, and microstructure. Journal of the American Ceramic Society, 73 (10), p. 2857-2864, 1990.

HWANG, K.S.; GERMAN, R.M. in Sintering and heterogeneous catalysis, ed. G.C. Kuczynski et al., pp. 34-47, New York Plenum, 1984.

HELANDER, T. Some applications of CALPHAD techniques to diffusion reactions in gradient materials. Tese de doutorado, Suécia, 1999. Disponível em: http://www.divaportal.org/smash/get/diva2:8539/FULLTEXT01.pdf

HERRING, C. Effect of change of scale on sintering phenomena. J. Appl. Phys., 21, $301,1950$.

HERRING, C. Diffusional viscosity of a polycrystaline solid. Jounal of Applied Physics, v 21, n 5, p. 437-445, mai 1950.

JANSSENS, K.G.F.; RAABE, D.; KOZESCHNIK, E.; MIODOWNIK, M.A.; NESTLER, B. Computational Materials Engineering: An Introduction to Microstructure Evolution. Elsevier, 2007. 
JASAK, H. Error analysis and estimation for the finite volume method with applications to fluid flows. London, 1996. 394 p. Tese Imperial College of Science and Technology.

JOHNSON, D.L. New method of obtaining volume, grain boundary, and surface diffusion coefficients from sintering data. J. Appl. Phys., 40, 192, 1969.

JOHNSON, D.L.; CUTLER, I.B. Diffusion sintering I. Initial stage sintering models and their application to shrinkage of power compacts. J. Am. Ceram. Soc., 46, 541, 1963.

JOHNSON, D.L. A general model for the intermediate stage of sintering. Journal of the American Ceramic Society, v 53, 10, pp. 574-577, out 1970.

JONGHE, L.C. de; RAHAMAN, M.N. Sintering of Ceramics. Handbook of Advanced Ceramics, Elsevier, 2003.

KANG, S-J. L. Sintering: Densification, Grain Growth and Microstructure. Butterworth-Heinemann, 2005.

KANG, S.-J.L.; JUNG, Y.-I. Sintering kinetics at final stage sintering: model calculation and map construction. Acta Mater., 52, p. 4373-4378, 2004.

KATTNER, U.R. The CALPHAD method and its role in material and process development. Tecnol. Metal. Mater. São Paulo, v 13, n 1, p. 3-15, jan/mar 2016.

KATTNER, U.R.; CAMPBELL, C.E. Modelling of thermodynamics and diffusion in multicomponent systems. Materials Science and Technology, v 25, n 4, 2009.

KAZARYAN, A.; WANG, Y.; PATTON, B.R. Generalized phase field approach for computer simulation of sintering: incorporation of rigid-body motion. Scripta Materialia, v. 41, n. 5, p. 487-492, 1999.

KELLET, B.J.; LANGE, F.F. Thermodynamics of densification: I, sintering of simple particle arrays, equilibrium conFigurations, pore stability, and shrinkage. J. Am. Ceram. Soc., 75 [5], p.725-734, 1989.

KERNIGHAM, B.W. The c Programming Language. Englewood Cliffs, Prentice-Hall, 1978. 
KIM, S.G. A phase-field model with antitrapping current for multicomponent alloys with arbitrary thermodynamic properties. Acta Materialia, v. 55, n. 13, p. 4391-4399, 2007.

KIM, S.G.; KIM, W.T.; SUZUKI, T. Interfacial compositions of solid and liquid in a phase-field model with finite interface thickness for isothermal solidification in binary alloys. Physical Review E, v. 58, n. 3, p. 3316-3323, 1998.

KIM, S.G.; KIM, W.T.; SUZUKI, T. Phase-field model for binary alloys. Physical Review E, v. 60, n. 6, p. 7186-7197, 1999.

KING, R.T.; MULLINS, W.W. Theory of the decay of a surface scratch to flatness. Acta Metallurgica, v 10, n 6, p. 601-606, jun 1962.

KINGERY, W.D.; BERG, M. Study of the initial stage of sintering solids by viscous flow, evaporation-condensation, and self-difusion. J. Appl. Phys., 26, 1205, 1955.

KINGERY, W.D.; BOWEN, H.K.; UHLMANN, D.R. Introduction to ceramics. Cambridge, Massachusetts, John Wiley \& Sons, 2a edição, 1976.

KRILL III, C.E.; CHEN, L.-Q. Computer simulation of 3-D grain growth using phasefield model. Acta Materialia, 50, p. 3057-3073, 2002.

KUCZYNSKI, G.C. Self-diffusion in sintering of metallic particles. J. Metals, 1, p. 169-178, 1949.

KUCZYNSKI, G.C. Statistical theory of sintering. Z. Metalkunde, 67, 606, 1976.

KUMAR, V.; FANG, Z.Z.; FIFE, P.C. Phase field simulations of grain growth during sintering of two unequal-sized particles. Materials Science and Engineering A, 528, p. 254$259,2010$.

KUMAR, V. Simulations and modeling of unequal sized particles sintering. Tese de Doutorado, Universidad de Utah, EUA, mai 2011.

LAN, C.W.; LIU, C.C.; HSU, C.M. An adaptive finite volume method for incompressible heat flow problems in solidification. Journal of Computational Physics, v. 178, n. 2, p. 464-497, 2002 b. 
LAN, C.W.; HSU, C.M.; LIU, C.C. Efficient adaptive phase field simulation of dendritic growth in a forced flow at low supercooling. Journal of Crystal Growth, v. 241, n. 3, p. 379-386, 2002a.

LANGE, F.F. Densification of powder compacts: An unfinished story. Journal of European Ceramic Society, 28, p. 1509-1516, 2008.

LEE, W.E.; RAINFORTH, W.M. Ceramic Microstructures. Kluwer Academic Publishers, 1994.

LEE, S.-M.; KANG, S.-J. L. Evaluation of densification mechanisms of liquid phase sintering, Z. Metallkd., 92, 669-74, 2001.

LIU, Z.-K. First-principles calculations and CALPHAD modeling of thermodynamics. Journal of phase equilibria and diffusion, v 30, n 5, p. 517-534, 2009.

LIU, L.L.; GAO, F.; LI, B.; HU, G.X. Phase-field simulation of process in sintering ceramics. Advanced Materials Research, v 154-155, p. 1674-1679, out 2011.

LOGINOVA, I. Phase-field modeling of diffusion controlled phase transformations. Technical reports from Royal Institute of Technology, Department of Mechanics, Stockholm - Sweden, 2003.

MACEDO, Z. S. Sinterização a laser e caracterização física dos compostos Bi4Ti3O12 e Bi4Ge3O12. 2003, 219f. Tese (Doutorado em Ciências), Instituto de Física de São Carlos-USP, São Carlos, SP, 2003.44, p. 3-15, 2012.

MALISKA, C.R. Transferência de calor e mecânica dos fluidos computacional. Rio de Janeiro, Livros Técnicos e Científicos Editora S.A., 1995.

McDONALD, S.A.; HOLZNER, C.; LAURIDSEN, E.M.; REISCHIG, P; MERKLE, A.P.; WITHERS, P.J. Microstructural evolution during sintering of copper particles studied by laboratory diffraction contrast tomography (LabDCT). Scientific Report, v. 7, 1, p.5251, 2017

MILLETT, P.C.; EL-AZAB, A.; ROKKAM, S.; TONKS, M.; WOLF, D. Phase-field simulation of irradiated metals part I: Void kinetics. Computational Materials Science, v. 50, n. 3, p. 949-959, 2011 a. 
MILlETT, P.C.; EL-AZAB, A.; WOLF, D. Phase-field simulation of irradiated metals part II: Gas bubble kinetics. Computational Materials Science, v. 50, n. 3, p. 960 $970,2011 b$.

MILLETT, P.C.; ROKKAM, S.; EL-AZAB, A.; TONKS, M.; WOLF, D. Void nucleation and growth in irradiated polycrystalline metals: A phase-field model. Modelling and Simulation in Materials Science and Engineering, v. 17, n. 6, p. 2009.

MOELANS, N.; BLANPAIN, B.; WOLLANTS, P. An introduction to phase-field modeling of microstructure evolution. Computer Coupling of Phase Diagrams and Thermochemistry, 32, p. 268-294, 2008.

MORIYOSHI, Y.; KAMATSU, W. Kinetics of sintering at a constant rate of heating. Millennial Special-Leading papers on ceramics in the $20^{\text {th }}$ century: the best of JCerSJ, v. 79, n 10, pp. 370-376, 1971.

MULLINS, W.W. Theory of thermal grooving. Journal of Applied Physics, v 23, n 3, p. 333-339, 1957.

MULLINS, W.W.; SHEWMON, P.G. The kinectics of grain boundary grooving in copper. Acta Metallurgica, v 7, n 3, p. 163-170, 1959.

NAVROTSKY, A. Energetics of Oxide Nanoparticles. International Journal of Quantum Chemistry, v. 190, p. 2647-2657, 2009.

NICHOLS, F.A.; MULLINS, W.W. Morphology changes of a surface of revolution due to capillarity-induced surface diffusion. Journal of applied physics, 36(6), pp. 1826-1835, jul 1965.

NICHOLS, F.A. Theory of sintering of wires by surface diffusion. Acta Metallurgica, v. 16 , january 1968.

NIKOLIC, Z.S. Three-dimensional Computer Simulation of Grain Coarseaning during Sintering. Science of Sintering. Science of Sintering, 44, p. 3-15, 2012.

NÓS, R.L.; CENICEROS, H.D.; ROMA, A.M. Simulação tridimensional adaptativa da separação das fases de uma mistura bifásixa usando a Equação de Cahn-Hiiliard. TEMA(São Carlos), v. 13, n. 1, jan./abr 2012. 
OLEVSKY, E.A. Theory of sintering: from discrete to continuous. Materials Science and Engineering R23, p. 41-100, 1998.

OLEVSKY, E.A.; TIKARE, V.; GARINO, T. Multi-scale study of sintering: a review. The american ceramic society, v 89, n 6, pp. 1914-1922, jun 2006.

PADILHA, A.F. Materiais de Engenharia. Editora HEMUS, 2000.

PAN, J. Modelling sintering at different length scales. International Materials Reviews, 48, 69-85, 2003.

PATANKAR, S.V. Numerical heat transfer and fluid flow. New York, Hemisphere Pub. Corp., 1980.

PERAZOLLI, L.A. Sinterização de óxido de zinco em diferentes atmosferas. Tese de Doutorado, UFSCar, São Carlos -SP, 1996.

PINES, B.Ya. J. Techn. Physics, 16, 737, 1946

PORTER, D.A.; EASTERLING, K.E. Phase transformations in metals and alloys. 2nd ed., London ; New York, Chapman \& Hall, 1992.

PRANATIS, A.L.; SEIGEL, L. Sintering of wire compacts. Powder Metallurgy. Proceedings of an International Conference held in New York, Edited by Werner Leszynski, p. 53-73, jun 13-17, 1960.

PROVATAS, N.; ELDER, K. Phase-Field Methods in Materials Science and Engineering. Wiley-VCH, 2010.

RAHAMAN, M.N. Ceramic processing and sintering. CRC Press, 2 ed, 875 p., 2003.

RAHAMAN, M.N. Sintering of Ceramics. CRC Press, 2007.

REDLICH, O.; KISTER, A.T. Algebraic representation of thermodynamic properties and the classification of solutions. Industrial and Engineering Chemistry, v 40, n 2, p.345348, Feb 1948.

RISTIC, M.M.; MILOSEVIC, S.D. Frenkel's theory of sintering. Science of Sintering, 38(1), pp. 7-11, jan 2006. 
RISTIC, M.M.; NIKOLIC, M.V. Sixty years of the theory of B.Ya. Pines. Science of Sintering, 38, pp. 201-202, 2006.

RHINES, F.N.; DEHOFF, R.T. Channel network decay in sintering. in Sintering and Heterogeneous Catalysis, Mater. Sci. Res. vol. 16, Kuczynski, G.C.; Miller, A.E.; Sargent, G.A., Eds, Plenum Press, New York, p. 49, 1984.

RICHERSON, D.W. Modern Ceramic Engineering. Marcel Dekker Inc., 1992.

ROSENHAIN, W.; EWEN, D.Intercrystalline cohesion in metals. J Inst Metals 8:149_ $173,1912$.

ROWLINSON, J.S. Translation of. J.D. Van der waals, the thermodynamic theory of capillarity under the hypothesis of a continuous variation of density. Journal of Statistical Physics, v. 20, n. 2, p. 197-244, 1979.

SAMET, H. Applications of spatial data structures: Computer graphics, image processing, and GIS. Reading, Mass., Addison-Wesley, 1990.

SAMET, H. Neighbor finding techniques for images represented by quadtrees. Computer Graphics and Image Processing, v. 18, n. 1, p. 37-57, 1982.

SAMET, H. The quadtree and related hierarchical data-structures. Computing Surveys, v. 16, n. 2, p. 187-260, 1984.

SHALER, A.J.; WULFF, J. On he rate of sintering of metal powers. Phys. Rev. 73, 926, abr 1948.

SHAW, N.J. Densification and coursening during solid state sintering of ceramic: a review of the models I: densification. Power Mettal. Intern, 21 (3), p. 16-21, 1989a.

SHEWMON, P.G. Diffusion in solids. 2nd ed., Warrendale, Pa., Minerals Metals \& Materials Society, 1989.

SHI, J.L. Solid state sintering of ceramics: Pore microstructures models, densification equations and applications. Journal of Material Science, v. 34, p. 3801-3812, 1999.

SHI, J.L. et al Sintering behavior of fully agglomerated zirconia compacts. Journal of the American Ceramic Society, 1991, 74 (5), p. 994-997. 
SHIMOSAKA, A.; UEDA, Y.; SHIRAKAWA, Y.; HIDAKA, J. Sintering Mechanism of Two Spheres Forming a Homogeneous Solid Solubility Neck. KONA, n. 21, 2003.

SHINAGAWA, K. Simulation of grain growth and sintering process by combined phase-field/discrete-element method. Acta Materialia, v 66, p. 360-369, mar 2014.

SILVA, A.G.P.; ALVES JR., C. Teoria de sinterização por fase sólida; uma análise crítica de sua aplicação. Cerâmica, v.44, n.289, São Paulo, set/out 1998.

SILVA, M.F. Estudo de Sinterização do Sistema Policristalino $\mathrm{Bi}_{12} \mathrm{TiO}_{20}$. Dissertação de Mestrado, UFS, São Cristóvão, 2009.

SLATTERY, J.C. Advanced transport phenomena. Cambridge, UK, Cambridge University Press, 1999.

STEINBACH, I. Phase-field models in materials science. Modelling and Simulation in Materials Science and Engineering, v. 17, n. 7, p. 31, 2009.

SUWA, Y. Phase-field simulation of grain growth. Nippon Steel Technical Report, $\mathrm{n}$ 102, p. 19-24, jan 2013.

SWINKELS, F.B.; ASHBY, M.F. A second report on sintering diagrams. Acta Metallurgica, v 29, n 2, p 259-281, feb 1981.

TEBCHERANI, S.M. Estudo da Cinética de sinterização do sistema SnO2-MnO2 obtido via precursores poliméricos. (Tese de Doutorado), UNESP, Araraquara, SP, 2001.

TIKKANEN, M.H.; MAKIPIRTTI, S.A. A new phenomenological sintering equation. Int. J. Powder Metall., 1, 15, 1965.

USKOKOVIC, D; EXNER, H.E. The kinetics of contact formation during sintering by diffusion mechanisms. Reprinted from Science of Sintering, v 9, n 3, p. 265-303, 1977.

WAKAI,F. Modeling and simulation of elementary processes in ideal sintering. Journal of American Ceramic Socciety, v89, 5, p.1471-1484, 2006.

WAKAI, F.; BRAKKE, K.A. Mechanics of sintering for coupled grain boundary and surface diffusion. Acta Materialia, 59, p. 5379-5387, 2011. 
WANG, J.D.; RAJ, R. Estimation of the activation energies for boundary diffusion from rate-controlled sintering of pure alumina, and alumina doped with zirconia or titania, Journal of the American Ceramic Society 73, 1172-1175, 1990.

WANG, Y.U. Computer modeling and simulation of solid-state sintering: A phase field approach. Acta Materialia, v 54, n 4, p. 953-961, fev 2006

WHEELER, A.A.; BOETTINGER, W.J.; MCFADDEN, G.B. Phase-field model for isothermal phase-transitions in binary-alloys. Physical Review A, v. 45, n. 10, p. 7424$7439,1992$.

WHEELER, A.A.; BOETTINGER, W.J.; MCFADDEN, G.B. Phase-field model of solute trapping during solidification. Physical Review E, v. 47, n. 3, p. 1893-1909, 1993.

WILSON, T.L.; SHEWMON, P.G. The role of interfacial diffusion in the sintering of copper. Transactions of the Metallurgical Society of AIME, v. 236, p. 48-57, january 1966.

WODO, O.; GANAPATHYSUBRAMANIAN, B. Computationally efficient solution to the Cahn-Hilliard equation: adaptive implicit time schemes, mesh sensitivity analysis and the 3D isoperimetric problem, J. Comput. Phys., 230 (2011), 6037-6060.

WOOLFREY, J.L.; BANNISTER, M.J. Nonisothermal techniques for studying initialstage sintering. J. Am. Ceram. Soc., v.55 [8], p.390-394, 1972.

YOUNG, W.S.; CUTLER, I.B. Initial sintering with constant rates of heating. Journal of the American Ceramic society, v 53, 12, pp. 659-663, dez 1970.

ZENG, P., ZAJAC, S., CLAPP, P.C., RIFKIN, J.A. Nanoparticle sintering simulations. Materials Science and Engineering A 252 (2), 301-306, 1998.

ZHANG, R.; CHEN, Z.; FANG, W.; QU, X. Thermodynamic consistent phase field method for sintering process with multiphase powders. Transactions of nonferous metals society of china, v 24, n 3, p. 783-789, mar 2014.

ZHAO, J.; HARMER, M.P. Sintering kinetics for a model final-stage microstructure: A study of $\mathrm{Al}_{2} \mathrm{O}_{3}$. Phil. Mag. Lett., 63, p. 7-14, 1991. 